Silke Schmidt

(Re-)Framing the Arab/Muslim 
To my parents

Silke Schmidt (Dr.) studied American Studies, Political Science, and Communication Studies in Germany and the U.S. Her research focuses on Arab American Studies, Culture and Economics, and Gender. 
SilKe SCHMIDT

\section{(Re-)Framing the Arab/Muslim}

Mediating Orientalism in Contemporary Arab American Life Writing

[transcript] 
Dissertation an der Philipps-Universität Marburg, 20I2.

An electronic version of this book is freely available, thanks to the support
of libraries working with Knowledge Unlatched. KU is a collaborative ini-
tiative designed to make high quality books Open Access for the public
good.

\section{(c) $(1)(9)$}

This work is licensed under the

Creative Commons Attribution-NonCommercial-NoDerivs 3.0 (BY-NC-ND).

which means that the text may be used for non-commercial purposes, provided credit is given to the author. For details go to

http://creativecommons.org/licenses/by-nc-nd/3.0/.

\section{Bibliographic information published by the Deutsche Nationalbibliothek}

The Deutsche Nationalbibliothek lists this publication in the Deutsche Nationalbibliografie; detailed bibliographic data are available in the Internet at http://dnb.d-nb.de

All rights reserved. No part of this book may be reprinted or reproduced or utilized in any form or by any electronic, mechanical, or other means, now known or hereafter invented, including photocopying and recording, or in any information storage or retrieval system, without permission in writing from the publisher.

(C) 20I4 transcript Verlag, Bielefeld

Cover layout: Kordula Röckenhaus, Bielefeld

Printed by Majuskel Medienproduktion GmbH, Wetzlar

Print-ISBN 978-3-8376-2915-6

PDF-ISBN 978-3-8394-2915-0 


\section{Acknowledgements}

Any work of writing is not just the work of the writer. Writing is a solitary activity; it takes time; it requires endurance, and it constantly raises doubts - doubts about writing itself, doubts about scholarship, and doubts about life in its entirety. If the writer manages to overcome these obstacles, then the latter become part of the work itself, woven into the network of arguments, making them even stronger and more forceful in expression. This overcoming of challenges, however, cannot be done in solitude. It requires an entire web of love, friendship, and advice.

I was gifted to meet people in the academy who combined intellectual power with human empathy, scholarly support and critical encouragement. Above all, my advisors Carmen Birkle and Nicole Waller are the ones who have accompanied my entire academic development - from the first seminar paper to the completion of the dissertation. Furthermore, Alfred Hornung contributed to my academic advancement by opening windows of opportunity. All of these scholarly role models never tried to impose their own academic goals on me. They never restricted me in any way. They always encouraged me to follow my intuition and to have trust and faith in my intellectual capabilities. Most importantly, they never allowed academic ambition to interfere with cordiality. For all this and for being the people they are, I want to express my deepest gratitude.

Since a large portion of this work was conducted during my stay as a visiting scholar at the University of Michigan, Ann Arbor, in the fall of 2011 and winter 2012, a series of scholars in the United States contributed to the completion of it. Above all, Nadine Naber at the Department of American Culture became my leading advisor. She is one of the most outstanding figures in the field of Arab American Studies with an excellent international reputation. Her expertise and quick apprehension, her interdisciplinary openness, as well as her clear analytical thinking were an immense benefit to my work progress. Her big smile, charisma and lifeconfirming attitude in all situations served as major motivation. Ever since we met for the first time, it has been an absolute privilege and honor to work with Nadine.

Further scholars at the University of Michigan and across the United States also deserve my special appreciation. Partly, these scholars already supported the work 
on my M.A. thesis in 2009 and have meanwhile become important mentors. Without their open-mindedness and their unlimited willingness to share their insights, I would never have been able to enter the field of research in the first place. The first ones to mention are Lisa Suhair Majaj and Suad Joseph. From our first encounters, they both met me with genuine frankness and support. Above all, they were the ones making my truly inspiring and life-changing time as a visiting scholar in the U.S. possible. Furthermore, I would also like to devote a special thanks to my Arabic professor and Arab American literary scholar Carol Bardenstein. One of the most important things she taught me is how powerful the word معلش is and how many meanings it has. Her teaching skills as well as her capability to smile and encourage at times when life displays its darkest sides are absolutely exemplary.

In addition, I would like to extend my gratitude to the range of interview partners who altogether showed not the slightest signs of reservations when asked to contribute to my work. Among them are Evelyn Alsultany and Sidonie Smith. Their insights and scholarly expertise meant a great benefit to the conciseness of my argument. The exchange with them and their intriguing critical minds are truly inspiring. This also holds true for the contribution made by one of the earliest and most influential scholars in the field of Arab American Studies and media research, Jack Shaheen, whom I had the privilege to meet at the 2012 Suleiman Conference in Dearborn. His encouragement of young scholars to walk novel paths should count as model for the dialogue between different generations of researchers.

In addition to the outstanding individuals who supported my path as a Ph.D. student, I would also like to express my thanks to major institutional beneficiaries; namely the German Academic Exchange Service (DAAD) and the German National Academic Foundation (Studienstiftung). The DAAD repeatedly supported me throughout my entire university studies and allowed me to develop my professional and personal abilities in remarkable ways via several short- and long-term stays abroad. The acceptance as a fellow of the Studienstiftung in 2011 meant an overwhelming honor to me. The financial support of the foundation allowed me to fully concentrate on my dissertation for two consecutive years. In addition, the ideational support continues to substantially further my professional orientation.

Since academic support is only part of the reason why this work could be completed, the other part of my gratitude and appreciation is directed to people who with their advice, friendship and love helped me become the person I am today. Among them are Shaunene and Sherrill Edwards, Asher Amir, Martin Kaiser, Tatiana Cossentino, Marwan Kreidie, Mary Bejian, Katja Kurz, Kerstin Vogel, Helga Juli, Petra Wacker, Stefan Weinz, and Uwe Weissflog. A special thanks also goes to Susanne de Broglie who in a very critical phase of my dissertation provided professional support in a way that let me see the light at the end of the tunnel and who made me realize that "ramoner cerveau" does not lead to personal liberation. 


\section{Contents}

Preface | 11

1. Introduction | 13

2. Life Writing Theory: Constructing Life, Claiming Authenticity | 47

2.1 Reconstructing the Construction of Self: Autobiographical Theory Today | 48

2.2 Media Framing Theory | 96

2.3 Framing Lives: A Mediated

Theory of Life Writing | 120

3. The Framed Arab/Muslim: Mediated Orientalism | 137

3.1 The Ideological Frame: Orientalism | 137

3.2 The Political Frame: Everlasting War on Terror | 152

3.3 The Issue Frames: Race, Religion, and Gender | 170

4. (Re-)Framing the Afghan Fundamentalist in West of Kabul, East of New York | 191

4.1 Journalistic Agency between East and West $\left(\mathrm{V}_{1}\right) \mid 192$

4.2 Reframing the Muslim Fundamentalist $\left(\mathrm{V}_{2}\right.$ and $\left.\mathrm{V}_{3}\right) \mid 204$

4.3 Reception: The (Re-)Framed Muslim Fundamentalist and His Audience $\left(\mathrm{V}_{4}\right) \mid 240$

5. (Re-)Framing the Egyptian Belly Dancer in Letters from Cairo | 259

5.1 Scholarly Agency $\left(\mathrm{V}_{1}\right) \mid 259$

5.2 Reframing the Egyptian Belly Dancer $\left(\mathrm{V}_{2}\right.$ and $\left.\mathrm{V}_{3}\right) \mid 271$

5.3 Reception: The (Re-)Framed Egyptian Belly Dancer and Her Audience $\left(\mathrm{V}_{4}\right) \mid 305$

6. (Re-)Framing the Iraqi Terrorist in Howling in Mesopotamia | 317 
6.1 Legal Agency $\left(\mathrm{V}_{1}\right) \mid 318$

6.2 Reframing the Iraqi Terrorist $\left(\mathrm{V}_{2}\right.$ and $\left.\mathrm{V}_{3}\right) \mid 325$

6.3 Reception: The (Re-)Framed Iraqi Terrorist and His Audience $\left(\mathrm{V}_{4}\right) \mid 357$

7. (Re-)Mediating Orientalism | 373

7.1 The (Re-)Framed Arab/Muslim | 374

7.2 Mediated Orientalism | 380

8. Conclusion | 401

Bibliography | 419

\section{INDEX OF GRAPHS}

Graph 1: Media Framing on the Basis of Cognitive Schemata | 107

Graph 2: Reframed Theory of Production and Reception | 134

Graph 3: Frame Levels in Historical Perspective | 187

Graph 4: Multi-Level Framing Model | 189

Graph 5: Frame Model of West of Kabul, East of New York | 237

Graph 6: Frame Model of Letters from Cairo | 303

Graph 7: Frame Model of Howling in Mesopotamia | 356

Graph 8: Model of (Re-)Framed Arab/Muslim American Identity in Mediated Orientalism | 393

\section{INDEX OF TABLES}

Table 1: Functional Comparison of Literary versus Journalistic Framing | 124 Table 2: Binary Vocabulary of Orientalism | 147

Table 3: Frame Resonance Matrix of West of Kabul, East of New York | 257

Table 4: Frame Resonance Matrix of Letters from Cairo | 315

Table 5: Frame Resonance Matrix of Howling in Mesopotamia | 372

Table 6: Comparative Frame Matrix | 375 


\section{INDEX OF IMAGES}

Image 1: "David with the Head of Goliath" | 115

Image 2: "Israeli David and Goliath" | 158

Image 3: "There Is Nothing 'Other' about Us" | 174

Image 4: Women Protestors in the Arab Spring | 184

Image 5: Book Cover of West of Kabul, East of New York | 241

Image 6: Audiobook Cover West of Kabul, East of New York

vs. Press Photo 9/11 | 243

Image 7: Belly Dancers in the Past and Present | 279

Image 8: Book Cover of Letters from Cairo (back and front) | 308

Image 9: Television Is Our World | 339

Image 10: Book Cover of Howling in Mesopotamia | 359

Image 11: The Media World as Market of Ideas | 410 



\section{Preface}

Is it daring to think only in black and white colors? Can border drawing go on in a globalized world where borders are said to have disappeared? Is this ethnocentric? Is it Orientalist? Is it merely human? The following pages pose a challenge upon the reader. They require him to explore the deep roots of thinking - daily practices, long-standing judgements, the foundation of belief. This is particularly difficult for the postcolonial critic. He/she will face words such as truth, authenticity, and binary thinking. For him/her, these words do not actually exist because they are mere constructs - concepts the human mind has brought into existence and which the scholar can erase. For the world of readers outside the academy, however, these words cannot easily be dispelled because they do carry meaning. They are crucial parts of life and of identity.

Only the one who is willing to leave behind the ideology of postcolonialism and constructivism to a certain extent, in order to make room for contact with the real world of cultural discourse and materialist practice, will be able to allow for this insight. Only the literary scholar who is willing to look at literature from a new perspective will be able to see new possibilities of literary impact. Above all, life is lived in the real world and books about life reflect this. How they do this is not only a matter of artistic creation and critical investigation - it is a matter of strategy, logical insight, and political interest.

After all, life writing is a matter of power, just like life itself, especially for those without agency, is a constant struggle for power. How significantly life writing impacts life in the real world above all becomes a matter of comparison. Comparison helps highlight black and white, but it can also reveal the brightness of the black and the blackness of the white. Comparison therefore is not a matter of hierarchies, it is a matter of information and knowledge. Knowledge is transmitted in books and where else could it have a greater impact than in the books of life called autobiographies? 



\section{Introduction}

We've learned a lot since 9/11 about places like Kandahar and Fallujah and Guantanamo Bay, about al-Qaeda and the Middle East, and about ourselves. What have you learned since 9/11? Our phone number is 800-989-8255. Email us, talk@npr.org. You can also join the conversation at our website. Go to npr.org, and click on TALK OF THE NATION. (Chertoff et al.)

The year 2011 witnessed the tenth anniversary of the most cruel terrorist attacks the U.S. has ever faced. Months before the commemoration day, TV broadcasts, radio shows and panel discussions across the nation called attention to the attacks themselves, their immediate consequences and their present-day impact. Prominent politicians, journalists, as well as average Americans shared their memories and insights on how $9 / 11^{1}$ changed the country. There was a lot of grief and pain in these reports. Most importantly, however, this discourse did not focus on terrorism only. Instead, the question was one of information seeking and knowledge gain. "What have you learned since 9/11?" the talk-show host Neal Conan asked his audience. An e-mail by a listener in Chapel Hill provided an answer that summarized what others had expressed before: "I've come to realize just how fundamentally 9/11 altered our national consciousness, our world view and our sense of ourselves and others" (Brandon qtd. in Chertoff et al.).

1 The author is aware that the abbreviation 9/11 without the use of quotation marks appears problematic because it supposedly reifies the dominant American narrative on this series of events. While this is an important aspect to acknowledge, this study still uses the unmarked spelling of $9 / 11$ to also account for the fact that various disciplines, e.g., Media Studies, also use the abbreviation in different contexts without stressing a particular interpretative lens. 
The question of learning about "ourselves and others" turned out to be the most challenging one in the aftermath of $9 / 11$ because Americans for the first time in their history had to realize that the very limits between self and other, between us versus them, could get blurred. Not only did they discover cruel and bloody terrorism on the day of the attacks. 9/11 also constituted "the day on which Americans discovered the Arab world," as the Arab American author and literary scholar Gregory Orfalea provokingly stated (224). All of a sudden, one of America's previously forgotten minorities - Arab Americans - stood in the spotlight. For many centuries, Arabs had been living in the United States mostly unnoticed by the public. They counted as the "Most Invisible of the Invisibles" among America's minorities, as the Arab American writer Joanna Kadi strikingly put it (qtd. in FaddaConrey, "Arab American Literature" 187; Salaita, "Ethnic Identity" 148). Exactly these Americans now constituted the most visible subjects and objects of national discourse. After all, the terrorists who hijacked the planes that crashed into the World Trade Center were Arabs from the Middle East. The public and political attention, however, quickly shifted to Arabs living within the borders of the United States. Consequently, they became major targets of racial profiling, ethnic discrimination, and human rights violations (Salaita, "Ethnic Identity" 152). Along with political decisions made by the Bush administration, the media started to spread a "discourse of fear and hatred," intentionally labeling Arabs and Muslims as enemies (Bakalian and Bozorgmehr 150). Binary rhetoric ruled the public and political agenda; "either with us or against us" was the credo initiated by the president (qtd. in Fadda-Conrey, "Racially White" 171). ${ }^{2}$ There were only "good Arabs or Muslims" and "bad Muslisms" and nothing in-between (Naber, Introduction 3). This demonizing of Arabs and Arab Americans and those who were mistaken as such quickly turned into the new reality of America's public discourse.

No matter how fundamental the impact of 9/11 was for America and the world, it was also "The Day that Didn't Change Everything," as James Zogby provokingly puts it (11). Above all, the day revealed a general lack of knowledge about Muslims, Arabs, and Arab Americans and many unanswered questions which had existed long before the attacks. Who are these Arabs? What role do they play in the United States? Are they all terrorists, as popular sentiment seemed to suggest? What resulted from the attacks therefore was not only a literal war carried out in the battlefields of Afghanistan. It also caused what James Zogby calls "Knowledge

2 This binary rhetoric is usually depicted to have affected mostly those targeted by the axis theory. This one-sided approach, however, conceals the fact that the 'us versus them' language also led to another internal division among the American population at large. The pressure to take sides in the war on terror thus led to a form of "imperative patriotism" that saw any dissent with government decisions as inherently unpatriotic and treacherous (Salaita, "Ethnic Identity” 154). 
Wars" against misinformation and unanswered questions (41). The actors that are generally considered to have been the winners in this war of information are the media. Actors who have mostly been forgotten when the question of "what have we learned from 9/11' is posed, can be found in the realm of literature. Both actor groups are usually treated as separate domains.

It is the intention of this book to shed light on the complex yet highly enlightening relationship between the media, literary production, and public discourse. Knowledge gain linked to the strategic framing of information on Arabs living inside and outside U.S. borders is seen as the key to analyzing the trajectories of Arabs' and Muslims' public image. Interdisciplinarity thus forms the core pillar of this book, which seeks to make a theoretical as well as an analytical contribution to American Studies as a field that has the capacity to accommodate approaches and research concerns from various disciplines. Theory and methods development at the intersection of Media and Literary Studies will be given just as much room as the application of a newly developed framing approach in the analysis of contemporary Arab American life writing. This study has therefore been written in a way that multiple audiences in the academy and beyond can hopefully derive valuable findings; above all for American Studies scholars who are open to the methodological incorporation of social science approaches, for Media Studies scholars who embrace the value of non-quantitative research methods, and for all those concerned with Postcolonial Studies and Orientalism in various other disciplines. In addition, this study wants to practice the very topic it explores, namely the mediation of Arab and Muslim lives as examined through multiple frames. This reflects the larger aim of the book to contribute to the status of Arab American Studies by tracing the past and present of Arabs and Muslims in the diaspora - groups that as yet have not been written into the multicultural history of the U.S.

\section{Arabs in America - The History of the Invisibles}

When speaking of Arab identity, it needs to be clarified from the outset that the term Arab serves as a "label" (Shakir, Bint Arab 1) rather than as a coherent description of an ethnic origin (Salaita, "Ethnic Identity" 157). As Yvonne Haddad states: "It is clear that the word Arab has meant different things to different Arab groups in this country" (79). "Arab" constitutes a pan-ethnic term that includes geographically, socially, and culturally diverse groups (Ajrouch, "Gender, Race" 377; Hassan and Knopf-Newman 11; Hopkins and Ibrahim 1; Ashmore, Deaux, and McLaughlin-Volpe 80). For those who self-identify as Arab, defining criteria are 
the use of the Arabic language ${ }^{3}$ as well as a national origin in one of the countries of the Arab League ${ }^{4}$ (Naber, Introduction 5). Furthermore, a common confusion concerns the terms Arab $^{5}$ and Muslim. Whereas Muslim refers to anyone who adheres to Islamic belief, Arab is a more general ethnic category that does not include religious affiliation (Haddad 65). Suad Joseph identifies three types of commong misperceptions about Arab identity: 1) all people who live in Arab nations are considered Arabs, whether or not they identify with their ethnic roots, 2) the entire Middle East $^{6}$ is perceived as Arabic, and 3) Arabs are conflated with Islam (260). ${ }^{7}$

Clearly defining Arab identity becomes even more confusing if one considers the interdisciplinary dimension of Arab American Studies where the differentiation between Arab and Muslim identities varies according to the discipline and the national scholarly background. In Europe, for example, Middle Eastern Studies are often located within the Social Sciences with focus areas in politilal science, ethnography, geography, and linguistics. Social science scholars tend to follow official criteria of national and ethnic identification, such as home country in the Arab League, to delineate Arabs and Muslims. By contrast, Arab and Middle Eastern Studies Departments have a more hermeneutical tradition and focus more on Cultural and Literary Studies, particularly in the U.S. Accordingly, they tend to approach the study of Arab identity from a more inclusive perspective when it comes to categorization. While eschewing the reductionist confusion of Muslim and Arab identity, Arab American Studies scholars also investigate literature and other cultural material created by Muslims living in or originating from non-Arab countries in the Middle East, such as Iran and Afghanistan.

3 Considering the large variety of local and regional dialects found in the Arabic language, these linguistic and national "unifiers" are highly "vague;" yet, they serve the purpose of analytical categorization (Hopkins and Ibrahim 6).

4 The Arab League is composed of 22 countries located in the "Old World," surrounded byAsia, Africa, and Europe. This conglomerate of nations constitutes the so-called "Arab homeland" for Arab immigrants living in the diaspora (Hopkins and Ibrahim 3).

5 Despite the confusion of Arabs and Muslims, Michael Suleiman finds alternations in the naming of Arabs, e.g., "Arabians." He interprets this "changeability of the name" as an indicator of the "absence of a definite and enduring identity" (Introduction 2).

6 As Sunaina Maira and Magid Shihade point out, the Middle East as supposedly neutral geographical description also represents a "colonial construction of space," for it is always defined relative to what is seen as the center of the world map (129).

7 A common term used to refer to Arabs living in the U.S. is "Arab community" (Saliba 307). The unifying function of this umbrella term, however, obscures the internal heterogeneity among Arabs, which is why the concept will only be used in this text when specific commonalities justify its significance. 
In order to prevent scientific reductionism and avoid confusion, the term "Arab" will be used throughout the present study to refer to members of the Arab diaspora who trace their origin back to one of the countries of the Arab League. The term "Muslim" is used to denote religious identity affiliation. These definitions leave space for aspects of self-affiliation, as Muslim and Arab identity characteristics can be assumed to overlap to varying degrees. ${ }^{8}$ Literature produced by Arab Americans as well as works produced by Muslims originating from non-Arab countries in the Middle East, e.g. Iran, will be considered to be part of 'Arab American Literature' as an umbrella category frequently used in U.S. academic institutions. This practice prevents the complication of needing to separate Muslim from Arab American literature is by no means a homogeneous categorization.

The history of Arab life in the U.S. is as diverse as the term "Arab." The genealogy of Arab immigration to the New World dates back to the end of the $19^{\text {th }}$ century. The first wave of immigrants reached the shores of the "land of opportunity" in the 1870 s (Suleiman, Introduction 6). At the time, most of them were workers from Lebanon who came for economic purposes and in search of more favorable living conditions (Suleiman, Introduction 1). They considered themselves sojourners with no intention of spending their entire lifetime in the U.S. (Haddad 62). The majority sought to help their families in "the old country" by means of the prosperity pursued in America (Suleiman, Introduction 6). Until the 1930s, about 130,000 Arabs had thus started a life in the New World.

The second wave of immigration lasted until the beginning of World War I. During this period, mostly Syrians from well-educated families settled in the U.S. with the intention to find a permanent home there. This also affected their cultural attitude. Whereas former immigrants had mostly retained their cultural and national identity, second-wave immigrants due to their different immigration goals, were much more inclined to adapt to their host culture and leave behind their Arab cultural ties. This had the effect that by World War II, many Arab Americans could not be distinguished from their host society anymore (Suleiman, Introduction 8-9). Coherence could also be found with respect to religion. Up to the 1950 s, $90 \%$ of Arabs were of Christian descent (Haddad 63).

With the third wave of immigration, this relative homogeneity in immigrant demographics changed again. Recent immigration spanning from the post-World War II period up to the present has been marked by an even more decisive degree of diversity; in terms of religious background, national origin, demographic structure, and immigration motivation. Arabs from various nations continue to settle in the

8 Due to the conflation of the terms Arab and Muslim in mainstream literature, quotations will be used which differ from this rule. Explanations will be provided to clarify whether the given quotation is based on different criteria for defining the terms Arab and Muslim (Haddad, Smith, and Moore 26). 
U.S. Despite economic reasons, which have always counted as a major pull factor for immigration, political conflicts and religious prosecution in the recent past have served as major reasons for Arabs from several nations to seek a home in the U.S. (Suleiman, Introduction 2). This has also altered the cultural attitude of the various immigrant generations. In the 1980s and 90s in particular, Arabs became more politically active and founded cultural and church organizations (Haddad 76). Contrary to the pioneer generation of the $19^{\text {th }}$ century, Arab Americans of the later era have been especially eager to rediscover and retain Arab culture and language by rejecting the "melting pot approach" (Suleiman, Introduction 8-9).

Current estimates of the Arab American population in the U.S. range from 3 to 3.5 million (Tehranian 166; "Demographics"). ${ }^{9}$ The states with the largest Arab American population are California, New York, and Michigan, where about two thirds live in metropolitan areas. With $32 \%$, the largest ratio is of Lebanese ancestry. Of this total, more than $80 \%$ are U.S. citizens ("Demographics"). What distinguishes Arab Americans from other immigrant groups is their fairly high level of education and their related socio-economic status. About $45 \%$ of Arab Americans hold a bachelor's degree compared to only $27 \%$ of Americans at large. Similar figures can be found when looking at higher levels of education. Here, $18 \%$ hold post-graduate degrees whereas only $10 \%$ in the average population reach this education level (Samhan; Kayyali 71). As a result, Arab Americans are facing lower than average unemployment and relatively high income. Due to this continuous development and to steady immigration flows, Arab Americans today count as "growing, wealthy and professional" (Samhan). ${ }^{10}$ Scholars therefore predict Arab Americans will constitute “America's Next Top Minority” (Ta 155).

9 The figures are based on the 2010 data of the U.S. Census Bureau. Despite verified methods of data collection, the figures still count as estimates due to the fact that the U.S. Census identifies only a portion of the Arab population through the question "ancestry." The Arab American Institute consequently assumes an undercount factor of 3. Reasons for the undercount, among others, include limits of the ancestry question and the lack of distinction between race and ethnicity, high levels of out-marriage among later immigrant generations and misunderstandings of survey questions ("Demographics"). Despite these difficulties in determining the exact size of the Arab population, the recent data show a growing trend in pan-ethnic identity affiliation with many respondents self-identifying as "Arabs" or of "Arab origin" (Samhan).

10 A Time Magazine article by Bobby Ghosh under the heading "Arab-Americans: Detroit's Unlikely Saviors" explores the economic force behind thriving businesses owned by Arab Americans. They now count as possible rescuers of cities with degenerate economies, such as the former auto industry hub Detroit. This underlines the relatively unusual status Arab Americans occupy within the landscape of ethnic minorities in the U.S. since the former usually count as those needing economic support rather than providing it. 
When looking at these figures and the highly unique features of Arab Americans as an ethnic minority, it is quite surprising to learn about the relative historical and social invisibility they have been facing in the overall cultural landscape of the U.S. The American historian William Leuchtenberg has even called Arabs "a people who have lived outside of history" (qtd. in Suleiman, Introduction 1). In contrast to other minority groups, Arabs have thus never officially become part of the multicultural history of America (Saliba 307). Recent opinion polls on the awareness of Arab Americans as part of U.S. culture and history tend to confirm this image. A clear division among non-ethnic ${ }^{11}$ Americans and Arab Americans and Muslims manifests social and cultural cleavages. In a poll conducted by Time magazine in 2010, 62\% of American respondents stated that they did not personally know any Muslim Americans (Altman). Learning about Arabs and Muslims from the respective 'other' therefore hardly takes place, as these figures indicate. Learning about Arabs through other channels is common practice but still does not fill all knowledge shortages. Only 29\% of the American respondents in a 2010 poll therefore stated they "knew enough" about Arabs and Muslim countries, whereas $60 \%$ were in favor of learning more ("American Views" 4). ${ }^{12}$

A very different picture emerges when it comes to the question of what Americans seem to know about Arabs. The investigation of this question reveals a series of "knowledge tales" rather than fact-based information (Cainkar 163). As an

11 The term non-ethnic is pragmatically used here in order to demarcate Americans categorized as ethnic minorities and the mainstream American population without multi-ethnic background. This should not downplay the fact that the term 'non-ethnic,' despite its frequent usage by Cultural Studies scholars (see Shakir, "Mother's Milk" 44; Fadda-Conrey, "Arab American Literature" 204; Sollors xiv), is otherwise based on a tautology for a definition of self also entails ethnic origin as core factor (Hall, "New Ethnicities" 443). Hence, non-ethnic identity by definition cannot exist. Spivak once provocatively pointed to this finding by asking, "who is the nonethnic American?" ("Acting Bits" 788).

12 Interestingly, with respect to the question of knowledge about Islam as opposed to knowledge about Arabs, the figures are considerably higher. The number of respondents stating they knew enough about "Muslims and Islam" ranges around 36\% with $49 \%$ stating they would like to learn more ("American Views" 4). This points to the fact that Islam is a more widely-discussed issue in public U.S. discourse than Arab and Arab American culture and ethnicity. It remains questionable, howevever, in how far respondents in the poll were able to differentiate between Arab ethnicity and Muslim religious identity.

13 Louise Cainkar in her study on the situation of Arab Americans post 9/11 entitled Homeland Insecurity defines knowledge tales as "discourses in which the speaker asserts informed knowledge about Arabs and/or Muslims using information gleaned from American popular culture [...]" (163). The function of tales as sources of human knowledge has been a key concept in studies on the history of knowledge and ideas (Stark 310). 
opinion poll from September 2011 reveals, one in three Americans believes that Muslim Americans are more sympathetic than Americans to terrorists. 55\% say they at least know someone who holds negative prejudices against Muslims (Condon). Even though these figures have slightly dropped in the latter half of the past decade, widespread anti-Arab and anti-Muslim sentiment persists (cf. Montopoli, "Poll"; Bayoumi 3). Verbal harassment such as e-mails sent to Arabs in the professional environment bearing the subject "Dear Terrorist" 14 (Elias) are only examples of the public inclination toward open racism which emerged post 9/11 (Salaita, "Ethnic Identity" 159; see Chapter 3.3).

Overall, this burst of hostility paired with lasting half-knowledge about Arabs constitutes a major factor for the emergence of a lasting "backlash" 15 in the struggle of Arab Americans to claim their position in the multi-cultural landscape of America (James Zogby 15; Bakalian and Bozorgmehr 14; Naber, "Look, Mohammed" 278). Moustafa Bayoumi thus concludes that Arabs and Muslim Americans now constitute the "new problem" of American society (2). He thus takes up the question "How does it feel to be a problem?" which W.E.B. Du Bois' in The Souls of Black Folk asked more than a century ago (qtd. in Bayoumi 3; Du Bois 11). Contrary to the notion of many, however, the problem for Arab Americans did not start on 9/11 - it reaches back to a century-old history of stereotyping and emergent "Super Myths" ${ }^{\text {16 }}$ on Arab identity in the context of Orientalism (James Zogby 57).

14 In an interview with USA Today conducted in the fall of 2006, a 28-year-old Muslim software engineer who was born and raised in the U.S. reported having received an internal e-mail from a co-worker with the opening line "Dear Terrorist." The e-mail was directly related to a current event a few days earlier, where a train bombing in India had killed more than 200 people and Muslim fundamentalists had been held responsible (Elias). This exemplary story gives a vivid picture of the daily discrimination faced by Muslims and Arabs living in the U.S.

15 As Anny Bakalian and Mehdi Bozorgmehr point out, "backlash" is used like a household term by authors in various different fields, particularly feminism, to express the reversal of positive integration developments in the Arab American population, whereby it often lacks further conceptualization (14). Despite its negative connotation, however, the effect of suffering backlash has also proven to be a key factor in political mobilization and integration (Bakalian and Bozorgmehr 14; James Zogby 33).

16 James Zogby, who counts as one of the best-known public opinion researchers on Arab American relations, clearly propagates the idea that the lack of knowledge on Arab Americans can only be solved by detailed public opinion research. As he explains in Arab Voices, "[w]e poll Arab opinion, let Arabs speak for themselves, and then listen to what their voices tell us about their political concerns [...]" (67). As his brother John in addition formulates in The Way We'll Be on the significance of polling: "We are prognosticators, of course [...]. But as I conceive of this work, we are equally priests and philoso- 


\section{Uncovering the Frame: Orientalism and Public Discourse}

When Edward Said passed away after a long battle with cancer in September 2003, the New York Times cited his words by describing him as "a man who lived two quite separate lives," i.e., the one of an American university professor and acknowledged intellectual and, at the same time, the life of a "fierce proponent of the Palestinian cause" (Bernstein). The two works which gained Said most of his fame in both worlds, namely in academia and political activism, were Orientalism (1978) and its sequel Culture and Imperialism (1993). In addition, Said's international acclaim was and still is largely based on his active participation in public social discourse, as numerous appearances in the media document (Shereen 114; Marrouchi, Edward Said 210). What tends to be forgotten, however, is that Said also greatly contributed to academic subject areas not directly related to the fields of politics and literature. One of the most important fields in this respect is Media Studies where Said's theoretical framework of Orientalism set lasting, though mostly unacknowledged, theoretical milestones.

Said's object of investigation in Orientalism was the origin of the "mysterious Orient" (Said qtd. in Tehranian 105). What today counts as common knowledge for students in many different academic disciplines related to the study of culture and history was, at the time of the book's publication, groundbreaking. Said in his historical inquiry revealed imperial and colonialist power mechanisms underlying the multitude of Orientalist myths and the supposed inferiority of Eastern ${ }^{17}$ civilizations. Drawing on Foucault's contention that knowledge is power (Varisco 255), Said analyzed in how far the discourse of the West established an image of the Orient as backward, barbaric, and inherently inferior. Middle Easterners thus became caught in the process of othering without the agency of defining their own identity. For the following study, it is crucial to underline how central the concepts of binary thinking and its relation to imperial discourse have been in shaping contrasting worldviews. In Orientalism and even more extensively in subsequent theoretical writings, Said conceived of the term discourse in a much more far-reaching but at the same time differentiated manner than previous scholars, including various cultural and social realms as well as different actors in his model. In his view, lit-

phers trying to make sense out of the always confusing human condition" (x). This assumption of letting Arabs speak through data represents an interesting complement to the literary perspective where the idea of letting different voices speak usually takes place through narrative means.

17 Due to the central but problematic significance of binary vocabulary such as East and West, Orient and Occident as markers of Orientalist discourse, these expressions will be spelled in italics throughout this work, unless they appear in the context of citations marked by respective quotation marks. 
erature and popular culture contributed as much to the prevalence of Orientalist myths as did political figures and scholars.

The centrality of discourse as dynamic social concept became even more elaborate in the publication Covering Islam: How the Media and the Experts Determine How We See the Rest of the World which succeeded Orientalism in 1981. As the title already indicates, Said here devoted particular attention to the role of the media in shaping public discourse. His method again relied on a historical but also literary analysis of Western media representations of Islam and the Middle East which demonstrated in how far a number of recurring stereotypes have come to dominate the global view of Arabs. The title of the book thus works as a pun pointing to the fact that the "covering" of Islam in the media works toward "covering up" Islam as a universal concept (iii). Said thus also revealed the trajectories through which a "quasi-objective representation of the East" led to the evocation of Islam as a religion and culture inherently inferior to the West (Covering 24-25). He placed this finding in the larger context of Orientalism as an "interpretative project" carried out by the West to exert power over the East (Covering 155).

When reading Said's analysis of the entanglement between media stereotypes and the image of Arabs around the globe, the timelessness of his study becomes apparent. He investigated the effects of media discourse on politics and social constellations long before the media revolution fully unfolded ${ }^{18}$ with the widespread use of the internet and the manifestation of "mass-mediated culture" (Shohat and Stam 10). This also went along with a truly interdisciplinary approach to discourse analysis which combined actors from various different social realms. As emphasized by the subtitle "How the Media and the Experts Determine How We See the Rest of the World," Said did not limit his critique of reductionism and universalist stereotypes to the media itself but rather extended it to all those who enjoy a wide credibility in the public eye (Covering viii). The term "experts" thus includes public opinion leaders, ${ }^{19}$ such as journalists, and outspoken intellectuals inside and outside the academy (Said, Covering x; McQuail 308-09). To Said, all of these actors contributed to the social reality that the "media's Islam, the Western scholar's Islam are all acts of will and interpretation that take place in history and can only be dealt

18 Visionary scientists in the field of communication research emphasized, however, as early as in the 1960s, the outstanding meaning of the media for society. In 1964, Walter Lippman in had already described the media as the central force "upon which the human race depends to hold it together. Mass communication is rapidly becoming, if it is not already, the main framework of the web of social life [...]" (qtd. in Fortner 190). Given the early moment of these insights into the cultural significance of the media, it is quite surprising that the actual inclusion of the media society in the research agenda of cultural and literary critics has only taken place fairly recently at the end of the $20^{\text {th }}$ century.

19 For further details on the concept of opinion leadership see Chapter 2.3. 
with in history as acts of will and interpretation" (Covering 45). This very inclusive definition of the actors functioning in the media environment also points to Said's broad conceptual understanding of the media. This especially refers to the intersection between Literary Studies and news media production since both rely on the practice of "storytelling" (Covering 49). Storytelling and narration, however, are only some of the structural and functional similarities combining Literary and Media Studies, as Said demonstrated. Eventually, the media-theoretical findings can count as core elements of Said's larger theoretical contribution to Cultural Studies with its increasing interest in media culture and production.

This interdisciplinary orientation of Said with a particular emphasis on media inquiry becomes particularly obvious when analyzing the vocabulary Said used in his discourse analysis of Orientalism as universal ideological concept. Said did not adhere to the usual terminology employed by former generations of historians, philosophers, and literary scholars. Rather, his overall register is shaped by a very clear analytical and less aesthetic perspective. The most striking term with respect to Said's ultimate contribution to media theory is found in his usage of the concept of 'frames.' Said explicitly discussed stereotypical media representations of Arabs as "organizational frameworks" which exceed the mere factual content of information and ultimately evoke particular interpretations on the part of Western audiences (Covering 62). In an interview entitled "In the Shadow of the West" conducted in 1986, Said specified his notion of framing by stating that "everything can be and is objectively itemized, framed, formed [...]" (Interview with Crary and Mariani 45). In another instance, Said describes these frames as forming "thematic clusters" at the basis of media reporting (Said, "Scholars, Media" 295), naming Muslim fundamentalism and the Israeli-Palestinian conflict as prominent examples of this effect. In addition, Said in the same interview also revealed what to him constituted the core mechanism underlying this process of framing, namely the function of selectivity. As he asserts, "there is never anything neutral about it [media reporting]: the entire process represents choice and selectivity, exclusions and inclusions, and things of that sort that are highly sophisticated" (Interview with Crary and Mariani 295). Said here, seemingly unintentionally, identifies the core elements of what would later become known as framing theory in media research. The concern about interpretative frameworks, the observation of "communities of interpretation," and the social effect of media representations on the real-life world all bear testimony to this interdisciplinary link (Covering 9). To Said, framing was the fundamental taxonomy steering the complex links between knowledge gain, media representation, and public opinion management.

At the time of Said's study, no one could estimate how astute his insights with respect to the future impact of the global media would become. Currently, one of the central theoretical frameworks for the analysis of news coverage, framing gained prominence at the end of the 1980s especially, and its analytical tools and 
the scope of its empirical investigations in the field of Media Studies have been continuously refined and expanded ever since. Especially in the case of long-term political conflicts, such as the Cold War, but also in connection with major current events in the Middle East, framing has been instrumental in explaining how media reporting shapes the opinion of the audience. This also holds true for one of the most important and globally mediatized key events, namely, 9/11 and its aftermath. As popular culture scholar Jeff Birkenstein and his colleagues formulate with respect to the significance of a larger narrative frame for the perception of the incident: "Without a story, we are, as many of us were after September 11, intensely vulnerable to those people who are ready to take advantage of the chaos of their own ends. As soon as we have a narrative that offers a perspective on the shocking events, we become reoriented, and the world begins to make sense again" (Birkenstein, Froula and Randell 1). ${ }^{20}$

Said in Orientalism and to an even more focused degree in Covering Islam showed that the media and all actors taking part in mediated discourse offered just that story. This also raised the question of alternatives. Who could compete with the communication and interpretation monopoly represented by the media? As a selfproclaimed public intellectual and political activist (Covering $\mathrm{x}$ ), Said himself took up the challenge and used his work to initiate a counter-movement to the previous Orientalist practice by providing alternative knowledge ${ }^{21}$ about the Middle East, Arabs, and Muslims. ${ }^{22}$ He thus contributed to upending the previous framework of

20 In addition to written media content which stands at the center of this study, it must be pointed out that narrative creation by today's media largely takes place in a visual format (Orfalea 218). This particularly impacts the reception process of respective media content if particularly emotional events are covered, such as the traumatic footage surrounding the 9/11 attacks or the torture scandal of Abu Ghraib in 2004 (Whitlock 194; also see Chapter 6.2). As a number of studies in media effects research demonstrate, visual representations are processed very differently from written information (McQuail 348). Since the following analysis focuses on written life narratives and compares them to the effects achieved by other print media, the role of visuals will mostly be disregarded.

21 This view is in line with a more general definition proposed by Said according to which knowledge is not based on "the recitation of facts" but needs to be constantly challenged anew (Covering 160). Due to the scholar's constant involvement in knowledge production, Said thus also refined the role of the professional intellectual to include the duty of battling stereotypes by providing alternative knowledge (Covering 24).

22 Moustapha Marrouchi describes Said as a "strategic intellectual," thus implicitly suggesting that Said always paired his intellectual insight with political interest ("Counternarratives" 256). Despite the admiration which this unified embodiment of politics and scholarship expresses, it also constitutes one of the major strains of criticism applied to Said. Derogatively, critics call this the "Said phenomenon," suggesting that Said pursues his 
cultural misrepresentation in public media. Despite his activist vigor, however, Said still doubted the effectiveness of his means to counter the all-subsuming reductionism used to "demonize and dehumanize a whole culture" (Covering xxxv). As the further dissemination of Orientalist stereotypes in the media would demonstrate in subsequent decades, Said's outlook would prove to be true.

\section{The "TV-Arab" and Other Mediated Stereotypes}

In contrast to the fairly recent visibility of Arabs in the American cultural landscape, the image of the Arab in U.S. media and popular culture has been highly publicized for many decades. The first to thoroughly analyze the phenomenon with a particular focus on the spread of television was the mass-communication researcher Jack Shaheen. In his book with the laconic title The TV Arab published in 1984, he investigated the origin of public stereotypes surrounding the Arab as "cultural Other" (Shaheen, Arab and Muslim Stereotyping 1). As he declared, his research was based on "eight years of television viewing" (TV Arab 4). Shaheen analyzed a total of more than 100 entertainment programs, including documentaries, cartoons, and other independent formats adding up to a total of 200 episodes relating to Arabs. His investigation started out with the assumption that "[t]elevision tends to perpetuate four basic myths about Arabs: they are all fabulously wealthy; they are barbaric and uncultured; they are sex maniacs with a penchant for white slavery; and they revel in acts of terrorism," as he states in one of the opening chapters entitled "In Search of the Arabs" (TV Arab 4). Shaheen's thorough analysis suggests that this thesis is solid: In entertainment programs and supposedly enlightening documentaries alike, Shaheen spotted greedy oil sheikhs, dagger-dragging bearded terrorists and "belly-dancing harem girls" (Naber, Introduction 4). As he concludes at the end of the book: "The stereotype remains omnipresent" (TV Arab 113).

Despite Shaheen's rather discouraging research results with respect to the legacy of Orientalist stereotyping, it must be pointed out that he showed a more optimistic outlook as to whether the trend could be halted. Two findings derived from his analysis are of particular importance for current research. The first one is that Shaheen did not attribute the contorted depiction of Arabs in the popular media merely to bad intentions or some colonialist endeavor carried out by a whitemainstream monopoly. Instead, Shaheen saw the root of constantly (re-)emerging stereotypes in the lack of knowledge on the part of the media themselves and in the

"intellectual mission" with an alsmost religious verve in order to proselytize (Marrouchi, "Counternarratives" 209). Marrouchi does not fail to highlight, though, that exactly this practical involvement separates Said's concept of discourse from that of Foucault who limited his influence to theoeretical activism (Marrouchi, Edward Said 233). 
public (TV Arab 4). Ultimately, and this can count as the second innovative contention he makes, Shaheen did not regard the media as merely the source of Arab stereotyping but also as a potential interlocutor for changing these stereotypes. As he states with respect to the role of documentaries and other informative programs, "the main objective of the television documentary is to inform and to enlighten - to provide viewers with facts, questions and points of view that make us a more knowledgeable people" (TV Arab 112). This larger focus on knowledge acquisition through media consumption governs the chapter "Dispelling a Stereotype," in which he further delineates ways the media, through detailed and balanced information procurement, can use their powerful potential to draw an alternative frame around the Arab (TV Arab 126).

Following Shaheen's pioneering investigation of the role of television in creating stereotypes of the Arab, a multitude of further studies in the field of mass media research followed in his footsteps. The methodologies and range of these studies expanded with the proceeding revolution of the mass media, such as the evolution of the internet and the respective advance of mass communication research itself in the 1990s (McQuail 39). When looking at the enormous number of studies containing the terms 'Arabs, Muslims, Media and Stereotypes' in their titles, one is overwhelmed by the allure the issue seems to cast over researchers. ${ }^{23}$ Gregory Orfalea in this context ironically remarks that the analysis "of American popular culture's stereotyping of the Arab has become something of a cottage industry; there is no lack of material on this subject" (8; Pulcini 35). Some of the more recent publications on the shelves of academic libraries include Pens and Swords: How the American Mainstream Media Report the Israeli-Palestinian Conflict (2008) by Marda Dunsky, Shaheen's Guilty: Hollywood's Verdict on Arabs after 9/11 (2008) and his most recent work Reel Bad Arabs: How Hollywood Vilifies a People (2009). The titles of these studies already indicate that the bottom-line conclusion of media stereotyping has not changed considerably. ${ }^{24}$ Recent movie releases thus often

23 A January 2012 search of the popular academic database JSTOR using the terms "Arab, Media, Stereotype," yielded 980 hits with the oldest result dating back to the year 1882 . An even larger wave of studies and reports on the relation between mediated stereotypes and Arabs can be found when searching popular search engines like Google. Here, the same search terms lead to more than 1.2 million results. This overwhelming number of academic and non-academic resources points to the general social significance of the issue of Arab stereotyping.

24 Recent studies of Hollywood's tendency to denigrate Arabs provide compelling support for Shaheen's results. As James Zogby explicates, a 2008 study on American movies found that in pre-9/11 movie releases, only 12 portrayals of Arabs out of a total of 900 were positive. This picture did not change dramatically in the post-9/11 era. As the study 
recycle former blockbusters, such as Aladdin, 1001 Arabian Nights, and The Mummy with Arabs appearing as "airborne fanatics" (Little 11).

The earlier interest in analyzing the skewed media image of Arabs with a particular focus on the entertainment sector has meanwhile taken a more political turn. The events of $9 / 11$ as well as former cases of terrorism connected to the Middle East conflict marked decisive incisions to trigger this shifting research attention. Following 9/11, most empirical analyses in Media Studies therefore have explored the installation of the "War on Terrorism" (WOT) ${ }^{25}$ as a major frame of interpretation and source of stereotypical images of Arabs (Kern, Just, and Norris 292; Salaita, "Ethnic Identity" 152). These analyses mostly focus on news media items from television and newspaper outlets. In addition, comparative studies and crosscountry analyses have been pursued. These studies provide sufficient evidence that the WOT has especially dominated the global media coverage of Arabs since the 9/11 attacks (Kern, Just, and Norris 298). At the same time, they also confirm that this image of the Arab as bearded terrorist was prominent long before the attacks of 9/11 (Wöhlert 21). Hardly any report on Arabs or events in the Middle East therefore fails to refer to terrorism and the construction of fear caused by the alleged Muslim enemy (Fritsch-El Alaoui 14; Altheide, "News Media” 658). Randa Kayyali in this respect talks about a post-9/11 "media frenzy" and "cacophony" which was driven by the representation of Arabs and Muslims by non-Muslims (144). Gillian Whitlock even uses the dramatic term of an "epic war between the worlds since 9/11" (125). As Nadine Naber concludes, the image of the Muslim terrorist has steadily come to replace earlier more romanticized images of the "rich oil sheikh and belly-dancing harem girls" (Introduction 4). ${ }^{26}$

The increased visibility of Arabs in the media following 9/11, however, did not only awaken scientists in the field of communication research to explore the con-

further records, since the attacks 200 Arab characters have been created in new movie releases. Less than $30 \%$ of them showed positive features (40).

25 All further references to the War on Terror will be abbreviated by WOT.

26 The media scholar Evelyn Alsultany points to the social normative dimension of stereotypes. In an interview with the author she explains: "We live in an era in which stereotypes are no longer socially acceptable. But this does not mean they have disappeared. In the case of Arabs and Muslims, the stereotype of the terrorist is still common." While the Muslim terrorist still counts as the most vivid image many non-Arabs have in mind, new stereotypes have come to emerge. Alsultany observes that "new kinds of representations have also become common - for example the patriotic or victimized Arab American after 9/11. These are certainly improvements but they are also new limiting types of portrayals." This finding highlights the more general trajectory that stereotypes can hardly be grasped based on universal value-criteria but rather in connection with particular characteristics, such as a limited view on a certain social group (see Chapter 2.2). 
nection between the media and Arab identity. ${ }^{27}$ Especially in the fields of Literary and Cultural Studies, the impact of the mass media on manifesting stereotypes also gained widespread attention. Hardly any publication or review of Arab American literature nowadays lacks references to media stereotypes about Arabs, even if the literary or cultural object under scrutiny has no connection to the media world. No matter if dealing with poetry, feminist issues, or ethnic identity negotiation in Arab American novels - the Hollywood Arab and negative stereotypes surrounding him/her usually provide the starting point and major research motivation of the vast majority of analyses found in the field (see Banerjee, "Arab Americans"28). Similar to respective studies in media research, ${ }^{29}$ analyses conducted in the field of Cultural Studies mostly focus on media effects and share major conclusions. Almost ex-

27 Sadly though correctly, scholars in the fields of Literary Studies and American Cultural Studies also mostly belong to the group who only discovered their research interest in Arabs after the events of 9/11 (Salaita, "Ethnic Identity" 148). This finding by Steven Salaita counters his somewhat glorification of scholarship and its real-life impact expressed in the following statement: "Many of us also promote the semi-idealized notion that scholarship shapes events just as much is it is shaped by them" ("Ethnic Identity" 148). The impact of $9 / 11$ and the wave of studies that followed show that scholarship is more reactive to events than proactive.

28 A recent essay by Mita Banerjee in the American Studies Journal of 2008 entitled "Arab Americans in Literature and the Media" demonstrates the close link between media and literature in today's Literary Studies. Critically speaking, however, this pairing of literature and media both neglects and creates certain methodological and analytical differences between the two fields in suggesting a cultural impact on the part of the media which the respective studies do not empirically prove.

29 For the sake of differentiation and contrasting, this study uses the terms Communication/Media Studies to refer to the mostly empirical field of media research. The terms Literary and Cultural Studies in turn are used as umbrella terms for the hermeneutical analysis of texts and other cultural materials. This is not to deny that Literary Studies in the past two decades have undergone a tremendous transition to include a more societyoriented discussion of literature (Bissell 156; also see Chapter 2.1). Although Cultural Studies serves as an umbrella term or "metatheory" which is highly contested, its major preoccupation is seen in investigating the interrelation between culture and ideology (Kellner 139). At the basis is a historicist approach, meaning that concepts and methods are regarded as originating in a specific historical and social context (Kellner 141). This also facilitates an opening towards various cultural and media formats other than written texts. The logic of differentiation in the present study thus primarily rests on the different methodologies prevailing in the respective field. Whereas mass communication mostly locates itself in the sciences, which are characterized by the empirical method (Slingerland 224), the humanities employ hermeneutical methods (Slingerland 226). 
clusively, they suggest that the high mediatization of Arabs creates a predominantly negative image of this group which in turn steers public opinion and consequently impacts the identity negotiation and self-definition of Arab Americans themselves.

From a methodological viewpoint, it must be noted that real interdisciplinary links to media research are missing, although the media nowadays constitute such a well-favored topic in the field of Cultural and Literary Studies (Gray 25). The two spheres of the humanities and the social sciences thus remain largely distinct. ${ }^{30}$ On the one hand, this leads to the result that efforts to incorporate theories and methods from communications research and to consult empirical data from quantitative studies are hardly undertaken in Literary Studies. On the other hand, communication research with its empirical focus on quantitative data collection has not paid attention to the more hermeneutical insights provided by cultural and literary scholars. This particularly concerns the question of how media images impact ethnic and multi-ethnic identity negotiation. ${ }^{31}$ The interdisciplinary door opened by Said's investigation in Covering Islam has thus not been pushed further and the dominance of public media presentations remains mostly unchallenged in filling the mental blanks in the research agenda (Cainkar 160). In his study on Arab Americans and their racial history, John Tehranian summarizes this status quo as follows: "Through the consumption of media, individuals who have had no personal experience with Middle Easterners receive and internalize a clichéd image of the group as a whole. The tabula rasa has now disappeared, replaced with a flawed maquette of the quintessential Middle Easterner who resides in the minds of many" (105). Outside the realm of scholarship, it is Arab American writers of the contemporary period who have set out to challenge this frame of the mediated TV Arab.

30 As Ann Gray in Pertti Alasuutari's 1999 edition Rethinking the Media Audience noticed, there were only a handful of major studies in the field of communication research which were frequently cited in Cultural Studies (24). Despite the continuous inclusion of media research in Cultural and Literary Studies since that time, this situation has not changed much, whereby the growing differentiation tendency of academic subjects has also brought about an even stricter division of methodologies.

31 The most prominent exception is provided by Ella Shohat and Robert Stam who with their book Unthinking Eurocentrism count as pioneers in linking Ethnic, Cultural, and Media Studies. Despite this interdisciplinary move, however, their theoretical framework is clearly located in the field of Cultural Studies with a thematic focus in the media area. 


\section{"Tilting the Frame:"32 Arab American Life Writing Today}

Given the turbulent political circumstances surrounding Arab identity and the bleak picture emerging from the way in which Arabs and Arab Americans are framed and thus constrained in raising their own voice, it is certainly surprising to read a seemingly contradictory statement by the journalist Jonathan Curiel. In a newspaper article on Arab arts from 2003 he states: "There has never been a better time to be Arabic" (D-1). ${ }^{33}$ Focusing specifically on the area of Arab American literary production in the post-9/11 era, however, suggests that this assertion indeed proves true. Writers in this period have become especially active in carrying out Said's urging to define themselves through literary expression instead of tacitly bowing to the constant definition by others. Gregory Orfalea identifies a "publishing renaissance" in the field of Arab American literature (186), which supports the assumption that the tragedy of $9 / 11$ and the backlash it caused for Arabs also marked a unique moment to break the cycle of perpetuated humiliation in public discourse.

The current influence of Arab American literature, i.e., English-language writing produced by Arabs living in the U.S. (Majaj, "Arab-American Literature Today" 128,134$)$, must be seen within the broader literary tradition of the Middle East. ${ }^{34}$ Stemming from a traditionally rich culture of storytelling and performative arts, Arab American writing enabled immigrants to express their identity by means of literature (Majaj, "Arab-American Literature Today" 132; Ludescher 93). The categorization into literary periods roughly reflects the immigration history of Arabs, with the first era dating back to the late nineteenth century (Majaj, "Arab American Literature: Origins"). These writers participated in the so-called "Mahjar" movement, whereby Mahjar in translation means "place of immigration" (Ludesch-

32 The subheading is a reference to Steinberg's article "Tilting the Frame: Considerations and Collective Action Framing from a Discursive Turn" (1998).

33 Despite this positive outlook with respect to the number of literary productions by Arab Americans in recent years, no Arab American writers to date have succeeded in winning a major American literary prize (Orfalea 223). Obviously, it is highly questionable that the reason lies in a lack of literary quality. Rather, the scant attention paid to Arab American works in contrast to the literature of other ethnic groups, especially by African Americans, seems to at least partly account for this fact.

34 Arab American literature in this study is clearly separated from Arabic literature based on the criterion of language, not on authorship. Although Carol Bardenstein, among others, argues that it is "artificial to maintain these rigid boundaries" ("Beyond Univocal Baklava" 164; Vinson 84) the distinction is essential when taking a comprehensive approach to the study of Arab American literature with a particular focus on the respective audiences that are targeted. Language here obviously constitutes a major criterion deciding over who can actually read the respective texts. 
er 95). ${ }^{35}$ This also points to the thematic focus of immigrant identity negotiation at the time. The best-known authors of this period are Ameen Rihani and the poet Khalil Gibran (W. Hassan, Immigrant Narratives 61; Majaj, "Arab-American Literature: Origins"). ${ }^{36}$ Writers at this birth hour of Arab American literature already conceived of themselves as "cultural middlemen" between East and West (Ludescher 97). Their goal was to contribute to the larger body of ethnic literature.

The second generation of writers moved away from the strong focus on immigrant experience displayed by its predecessors. Instead, they turned to more overarching identity themes of the modern period (Ludescher 102). A "defining moment in the history of Arab American literature" in the late 1980s was the publication of the influential anthology Grape Leaves: A Century of Arab-American Poetry (1988), which for the first time explicitly centered on and highlighted English literature written by Arab Americans as opposed to literature written mostly in Arabic. A second prestigious anthology then soon followed with Food for Our Grandmothers: Writings by Arab American and Arab Canadian Feminists in 1994 (Ludescher 103). As the title suggests, the editors here specifically addressed the contribution of Arab women writers in North America. Both collections featured the status of Arab American literature as a genre in its own right and aimed at granting the latter a place in the pantheon of multi-ethnic writing in America.

The named compilations not only fulfilled a collective function by bringing awareness to Arab American writing through means of cultural documentation, in addition, they also served as lasting inspiration for the current group of young authors to continue the literary tradition (Ludescher 104; Hartman, "Grandmothers" 170-71). ${ }^{37}$ This third generation of Arab American writers, among them many women such as Diana Abu-Jaber, Laila Halaby, Laila Ahmed, and Lisa Suhair Majaj, has significantly contributed to the thematic and methodological variety found in contemporary Arab American fiction writing. The engagement with political conflict in the Arab world has fostered this development and served as major motivation for these authors to face the question of "write or be written" (Majaj, "Arab-American Literature: Origins"). ${ }^{38}$ Despite the central issue of identity negotiation in the context of political and social conflict (Suleiman, Introduction 11),

35 The Mahjar movement also included non-Arab diasporic artists (Ludescher 95).

36 Ameen Rihani's influential work The Book of Khalid was published in 1911, Khalil Gibran's masterpiece The Prophet in 1923 (W. Hassan, Immigrant Narratives 50).

37 There is quite a wide diversity of opinions when it comes to determining the exact genesis of Arab American literature. Tanyss Ludescher even adds a fourth period to the list which he labels "The Newest Generation," referring to the youngest group of artists who have emerged after Abu-Jaber and her contemporaries (105).

38 Pulcini reads this wave-like reaction to oppression in the form of increased literary production as a sign of "New Pride" following the media mistreatment (39). 
however, a more specific definition of what constitutes Arab American literature remains challenged. Whereas some today categorize it merely as part of ethnic and diaspora writing ${ }^{39}$ (Majaj, "Arab American Literature Today" 126; Kayyali 125), others regard the "schism between 'Arab' and 'American"” as unique defining feature, delineating Arab American literature from other ethnic literatures (Majaj, "Arab American Literature Today" 128). ${ }^{40}$

These mostly thematic debates on the question of genre definition conceal the larger variety of different literary formats found in Arab American writing. Here, the novel as "the great book of life" clearly dominates the picture (Lawrence qtd. in Orfalea 189). ${ }^{41}$ In addition, poetry has been a popular means of expression as well; starting with the early poems of Ameen Rihani and encompassing the recent prose poetry of Mohja Kahf and others (W. Hassan, Immigrant Narratives 227). The dominance of these two genres is reflected in the scholarly attention devoted to Arab American literature. The former largely focuses on the analysis of fiction writing, thus excluding further important formats which also make up an essential part of contemporary Arab American writing (W. Hassan, Immigrant Narratives 38). This, in turn, is reflected in the critical attention devoted to Arab American works. The strong focus on fiction writing, particularly in the case of the novel, tends to override an important discussion of Arab American autobiographies of the contemporary period. ${ }^{42}$

Contrary to the long-standing assumption that autobiography represents a fundamentally Western genre due to its focus on the individual and its neglect of communal ties with the latter counting as the hallmark of Eastern civilizations, Arabic literature looks back to a long tradition of autobiographical production (Parker ix; W. Hassan, Immigrant Narratives 78). Early examples of life writing can be found

39 Leonard argues that the case of Arabs living in the U.S. does not really constitute a proper example of diasporic identity. Her view is based on the definition of diaspora as enforced life outside one's homeland rather than a voluntary exilic status (80).

40 The notion of Arab American writing as 'just' dealing with identity struggle has brought about severe criticism by scholars arguing that "Arab life" as a thematic label is too simplified to account for an entire canon (Majaj, “Arab-American Literature Today” 134).

41 One of the earliest and, up to this point, best-known Arab American novelists is William Peter Blatty. He gained literary fame in 1971 with the publication of the bestselling novel The Exorcist. Even though Blatty thus clearly counts as Arab American, it must be noted that with the exception of his autobiographical publication Which Way to Mecca, Jack? (1960), none of his works focuses on Arab American identity or contains Arab American characters (Orfalea 185).

42 The recent publication of Wail Hassan's Immigrant Narratives provides a welcome exception to this rule. Hassan places particular emphasis on the function of life writing in the Arab American literary tradition. 
in the pre-Islamic period as early as in the $8^{\text {th }}$ century, with a multitude of works following in the $11^{\text {th }}$ and $12^{\text {th }}$ centuries (Reynolds 53). Above all, the Arabic autobiography was characterized by content and less by form (Reynolds 2). The major intention of Arab memoir was to give a historical record of one's life in order to share this knowledge with others (Reynolds 3). ${ }^{43}$ This focus on historical facts ${ }^{44}$ marks the key difference to the genealogy of autobiography in the West. As Dwight Reynolds summarizes: "Whereas western autobiography achieved its greatest popularity as a genre in tandem with its fictional counterpart, the novel, the threads of the pre-twentieth century Arabic autobiographical tradition were spun from the raw material of historical inquiry" (5). Starting in the $12^{\text {th }}$ century, political autobiographies became increasingly common (Reynolds 65).

The impact of the novel as dominant mode in fiction writing did not leave the development of the Arabic autobiography untouched. When the latter at the beginning of the $20^{\text {th }}$ century came into contact with the Western novel, a new system of classification emerged which had been unknown in the Arabic tradition up to this point: the opposition between fact and fiction (W. Hassan, Immigrant Narratives 79). The blending and factual symbiosis of autobiography and novel writing materialized in the 1920 s with the publication of the first Arabic autobiographical novel Al-Ayyam by the Egyptian intellectual and literary scholar Taha Hussein (Reynolds 10). This tradition has continued up to the present, in which women writers in particular have produced a series of works under the heading of autobiographical fiction (Orfalea 188). ${ }^{45}$ Recent anthologies, such as Post-Gibran: Anthology of Arab American Writing (1999), Sheherazade's Legacy: Arab and Arab American Women on Writing (2004), and Dinarzard's Children: An Anthology of Contemporary Arab American Fiction (2004) mirror this blending of genres in their presentation of fiction with highly autobiographical references.

43 In contrast to the Western understanding of autobiography as motivated by one's own longing to share personal experience for the purpose of self-definition, it is a convention in classical Arab life writing that authors justify their motivation by recalling that they were asked to write down their stories (Reynolds 61).

44 Eakin criticizes historians by pointing out that the writing of history itself is based on textuality. With respect to German historicism, he observes: "Facts in history are one thing; texts as facts are quite another, and Hayden White's insistence on the textuality of history has been largely ignored by practicing historians [...]" (Introduction 5).

45 It is questionable if the popular notion that contemporary Arab American writing is mostly dominated by women really is a result of their dominance in actual literary production or the result of selective appropriation. The latter assumption is hinted at by Lisa Majaj who explains that women writers get more attention by the public and by literary critics than their male colleagues due to an "American sensibility" and inclination to Orientalism as female legacy (“Arab-American Literature Today” 144). 
Contemporary autobiographies by Arab Americans which do not show any explicit relation to the realm of fiction writing can be read as an amalgam combining elements of the history of life writing in West and East. Edward Said also counts as a precursor of modern-day Arab American life writing with his well-known memoir Out of Place: A Memoir (2000). The work is commonly discussed as a prime example of "Exilic Memoirs" (W. Hassan, Narrating Identities 112), a format focusing on diasporic and specifically Arab American identity negotiation between the two worlds of East and West and the struggles linked to this "outlandish existence" (Hornung 368). The events of 9/11 then also brought about a significant change in the realm of Arab American life writing, in which autobiographical formats have continuously gained more prominence in the years that followed. ${ }^{46}$ The difficult position of Arabs in public discourse has contributed to the fact that ethnic and cultural identity negotiation more than ever before stand at the center of these accounts (Fadda-Conrey, "Racially White" 71). In contrast to earlier conceptions of autobiographical writing in the Arab tradition of historical fact-telling, the Arab American life narrative of the modern period is considered to promote identity based on "fluidity and transformation" (Fadda-Conrey, "Racially White" 77).

Based on the mixed ethnic background of Arab American writers, this identity negotiation necessarily transfers the discussion to the field of multiculturalism. Culture consequently constitutes the predominant meta-theme in the analysis of contemporary Arab American autobiography, an observation which is expressed by the labeling of Arab American life narrative as "cultural autobiography" (Reagon qtd. in Fadda-Conrey, "Racially White" 75). It must be critically remarked, though, that the term 'culture' in this context is hardly ever defined. The concept therefore gains a very vague, indeterminate, but at the same time simplistic meaning. An example of this is the debate of so-called "cookbook-memoirs," in which food and its preparation function as "essentialized cultural markers" to which Arab culture is reduced (Bardenstein, "Beyond Univocal" 210, 160). ${ }^{47}$ Culture in other instances gains a strongly political meaning, as in the case of Said's autobiography Out of Place. Further examples of this politically-oriented interpretation center on recent narratives from Palestine and personal accounts related to the practice of honor killings in countries, such as Iraq and Afghanistan (Moore-Gilbert 113, 118; Whit-

46 As Eakin rightly remarks, $9 / 11$ as a major turning point in global history not only triggered a wave of autobiographies by Arab American authors but also by writers of any nationality around the world (Living Autobiographically 122).

47 The most acknowledged example of cookbook memoirs in Arab American literature is Diana Abu-Jaber's The Language of Baklava. The book has received wide critical attention, whereby analysts indeed tend to reduce the work to its food-related title thus exluding the possibility of further themes related to the realm of cultural practice (Bardenstein, "Beyond Univocal Baklava" 175). 
lock 107). In defiance of this limited thematic scope subsumed under the heading of culture, some critics attribute the quality of circulating "intraculturally and interculturally" to Arab American autobiographies, based on their wider choice of cultural issues shared by international audiences (Whitlock 199; Bardenstein, "Beyond Univocal" 161).

When reviewing this long history of Arab autobiographical production in both the Middle East itself and in America, it becomes clear that the notion of autobiography as prototypical display of Emersonian self-reliance and Western individualism is a myth (W. Hassan, "Arab-American Autobiography" 13; Eakin, Introduction 10). The "YOU-ESS-AY" as it appears in the lyrics of Bruce Springsteen therefore can count as an inherent part of Arab American I-narration (qtd. in FaddaConrey, "Racially White" 92). With its focus on multi-ethnic identity negotiation, Arab American autobiography allows for intimate insights into the lives of Arab Americans hardly found in other literary formats. The problem remains, however, that autobiographical theory has not kept pace with the multitude of autobiographical works produced by Arab Americans and other members of ethnic minorities.

\section{Autobiography Theory in the Ethnic Borderland ${ }^{48}$}

Just like Arab and Arab American life writing itself, autobiography theory has also undergone severe shifts throughout the past decades. The interdisciplinary opening of the field to include findings derived from the areas of cognitive psychology, ${ }^{49}$ sociology, neuroscience, and neurobiology has especially contributed significantly to the advancement of autobiographical theory (Eakin, How Our Lives 50; Neisser 11). Whereas early Autobiography Studies approached the works as fact-based accounts of life, contemporary life writing analysis stands in the tradition of constructivism (W. Hassan, Immigrant Narratives 30; Neisser 10). The concept of autobiography as fact-based account has therefore almost completely been given up in favor of a model that regards life writing as narrative invention. In addition, the general role of narrative in the constitution of individual and collective identity has meanwhile gained more prominence in Literary Studies at large (Ashmore, Deaux,

48 Fadda-Conrey points out that the location of Arab American literature in the "ethnic borderland" might reinforce stereotypes (“Arab American Literature” 190). While this point certainly can count as valid, the use of her expression in the chosen subtitle seeks to emphasize the challenged status of ethnic autobiography theory at large. Arab American literature due to its generally neglected status thus finds itself constantly oscillating between theoretical innovation and the reinforcement of an ideological agenda.

49 This is not to say that cognitive psychology only benefits the subfield of autobiography theory. As Bortolussi and Dixon remind their readers, cognitive psychology is one of the major interdisciplinary links to advance Literary Studies at large (3). 
and Mc-Laughlin-Volpe 83; Ender ${ }^{50}$ 3). The self as the social conception of identity thus becomes inherently entangled with the cognitive act of remembering which is summarized by Ulric Neisser in the concept of the "remembering self" (1) based on "self-knowledge" (10). In particular, the work of John Paul Eakin and his investigation of How Our Lives Become Stories: Making Selves (1999) as well as studies with far-reaching theoretical value, e.g., Reading Autobiography: A Guide for Interpreting Life Narratives (2001) by Julia Watson and Sidonie Smith, have further expanded the analytical scope of the field. In defiance of these advances, however, hardly any autobiographical investigation pays equal attention to the two sides of authorial production and audience reception. This must be registered as one of the crucial weaknesses of contemporary life writing theory.

The transformation of Autobiographical Studies has also brought about an expansion of the definition of life writing as a genre. The category today comprises a range of different formats, such as interviews, blogs, online diaries, and other artistic forms of self-narration (Smith and Watson, Reading Autobiography 167). Due to their expression via various media channels, life narratives can thus be considered "Mediated Memories" in at least a double sense (van Dijck 1). On the one hand, the constructed nature of the narrative forms a filter which mediates the actual recollection of personal memories due to the influence of memory distortion and active literary intervention (Neisser 12). On the other hand, mediation also applies to the specific channels in which these narratives reach their audiences. The traditional written memoir in book format thus only constitutes one type of medium next to a series of electronic possibilities.

This inclusion of different media channels in the analysis of life writing has ultimately stirred an enhanced interest in the discursive context surrounding autobiographical production. This also involves a distinguished understanding of presentday political and cultural circumstances, as well as the relation between the author and these conditions and the various audiences connected to them. Ethnic autobiographies here constitute one major field of investigation. Whereas Autobiography Studies have been popular since the 1960s, attention to ethnic life writing only gained prominence in the course of the 1980s and 1990s (Payne xi; Eakin, Introduction 6). ${ }^{51}$ Especially the emergence of Postcolonial Studies and the over-

50 Ender in her ground-breaking cognitive study of autobiography in Architexts of Memory calls the autobiographic writer "the rememberer," arguing that the human ability to record experiences of the past is the foundation of human individuality (3).

51 One reason for this has been seen in the legacy of Autobiography Studies in the Western scientific tradition and its major focus on Enlightenment individualism. The latter commonly assumed one of the major motivations for the rise of the autobiographical genre in the first place (Eakin, How Our Lives 43). Western literary scholarship in consequence continued to dominate the field. This prominent dichotomy with the tendency to valorize 
coming of the "death of the subject" in structuralism fostered the need to explore the autobiographical writings of ethnic groups formerly excluded from the literary canon (Eakin, Fictions 275; Angus 237; Leitch 73). This accompanied the definition of ethnic life writing as a distinct genre and triggered a growing concern for an advanced theory of ethnic life writing (Eakin, Introduction 9; Boelhower 138). With respect to the ethnic, political, and media dimensions of life writing, the work of Bart Moore-Gilbert is particularly noteworthy due to its urge to include media discourse in the postcolonial analysis of autobiography (128).

The inclusion of ethnic autobiography with its larger focus on political and social implications has also endowed the analysis of the wider spectrum of autobiographical writing with new meaning. In light of the colonialist past faced by many ethnic writers, the "self-defining function" of life writing has become an even more important point of investigation than in previous times (Fivush qtd. in Eakin, How Our Lives 111). Narrative and identity thus become inherently linked, which in turn grants autobiography itself a more prominent status in society (Eakin, How Our Lives 100). The collective "we-experience" therefore cannot be differentiated from the "I-narrative" and vice versa (Eakin, How Our Lives 75). Gillian Whitlock puts this finding into very poetic words:

We are born into webs of narrative, micronarratives of familial life and macronarratives of collective identity, codes of established narratives that define our capacities to weave individuel life stories. From this point of view, autobiographical narrative emerges as a risky dialogic act [...]. The 'unofficial' public sphere of literary, cultural, religious, and artistic movements are vital to political contestation and opinion formation; from this it follows that autobiographical narrative is an agent in complex global dialogues and encounters and a way of thinking through the interdependencies of conceptions of the self and other. (11)

Autobiographical writing in this sense clearly gives up the burden of "crushing objecthood," as Moore-Gilbert remarks (128). Instead, life writing steps out of the merely literary realm and becomes a tool for "strategic intervention" in public discourse which pursues overtly political objectives (Golley, Introduction xxx; MooreGilbert 128).

In the case of Arab American life writing and the critical attention devoted to it, the hallmark of ethnic autobiography, however, has also led to questionable consequences. Similar to the argument applied to Arab American novels which constantly face the criticism of stoically focusing on identity negotiation, analyses of Arab

Western over Eastern autobiography research still prevails among contemporary theorists. Even Eakin, who otherwise is very concerned about ethnocentrism, continually contrasts modes of Western and Eastern autobiography scholarship, thus unintentionally evoking stereotypes (Introduction 10; Eakin, Fictions 224; also see Chapter 3.1). 
American autobiographies - if conducted at all - almost exclusively stress the aspect of ethnic identity negotiation as a response to Western stereotypes. Similarly, the methods applied by literary scholars are largely situated along "ethnic theoretical tropes" (Fadda-Conrey, "Racially White" 135). Waill Hassan derives two constraints related to this overemphasis on ethnicity, putting forward the "thesis that Arab-American autobiography is constrained, for better or for worse, by two unspoken requirements: first, that it constructs a selfhood that is intelligible in light of American paradigms of subjectivity, and second, that it addresses Western ideas about Arabs, Muslims, Middle Easterners" (10). What often follows from this narrow critical scope is that critics categorize Arab American life narratives as ethnic counter-narratives without providing sufficient textual evidence for this claim.

This tacit treatment of Arab American autobiography as simply one example of ethnic literature points to a more wide-ranging problem of reductionism in the critical discussion of Arab American literature in the academy. The strong focus on ethnicity neglects a multitude of other themes which might go unrecognized because they are completely unrelated to the theme of ethnicity. Furthermore, the label 'Arab' as an ethnic category does not account for some of the specificities which Arab Americans in contrast to other ethnic minorities face. One of these particularities is the high degree of hetereogeneity existing among Arabs on a global level and on the level of Arab American relations. In addition, the fact that Arabs play a much more important role in the national and global media discourse is a specificity which further differentiates Arab Americans from other ethnic groups. All these shortcomings, at least in part, result from the reductionist labeling of Arab American autobiography as broadly ethnic. From an institutional viewpoint, this reveals a larger shortcoming with respect to the lack of differentiated ethnic Literary Studies.

\section{Getting (Dis-)Oriented ${ }^{52}$ Postcolonial Studies and Arab American 'Non-Studies'}

There is a popular Arabic saying which states that every "Arabic word has a basic meaning, a second meaning which is the exact opposite of the first, a third meaning which refers to either a camel or horse, and a fourth meaning that is so obscene that

52 The heading is a modification of the heading "Getting Oriented," used by Holly Edwards in her essay "A Million and One Nights: Orientalism in America, 1870-1930" (18). Edwards here traces the history of Orientalism with an emphasis on American travel accounts and cultural representations such as paintings and other art work. 
you'll have to look it up for yourself" (R. Allen).$^{53}$ A statement like this in today's post-Saidian world can hardly be surpassed in its Orientalist verve. Above all, it was the major aim of Said's Orientalism to reveal the ethnocentric mindset behind literary and cultural practices like this one to expose their derogatory nature. His model of Orientalism, however, did not remain limited to the study of the Middle East. Rather, Orientalism came to serve as the platform for the emergence of a much larger project undertaken to analyze the history of colonization - namely Postcolonial Studies (Fritsch-Alaoui 21; Maira and Shihade 130). Nevertheless, with respect to the study of Arab American autobiographies, the crucial role of Orientalism in Postcolonial Studies has also brought about severe disadvantages. One of the most obvious of these shortcomings is that Arab American Studies still do not exist as a separate discipline. ${ }^{54}$

Although the increased media presence of Arab Americans as well as their rising literary engagement has led to a "hyper-visibility" in the public perception, this trend has not yet extended to the realm of academia (Fadda-Conrey, "Racially White" 174).$^{55}$ Critics thus rightfully lament the consistent absence of Arab Americans in the Cultural and Ethnic Studies canon (Fadda-Conrey, "Racially White" 175), ${ }^{56}$ particularly within the literary branch of American Studies. ${ }^{57}$ The study of

53 The proverb has been attributed to the Yale professor of Arabic Franz Rosenthal. As the allusion to camels suggests, Rosenthal despite his academic acclaim counts as fierce Orientalist in contemporary Arab American circles (Bardenstein, Personal interview).

54 Orientalism's influence as obstacle to Arab American Studies, however, should not be read in the vein of the polemical critique by the overtly Orientalist writer Martin Kramer. In his book Ivory Towers on Sand: The Failure of Middle Eastern Studies in America, he basically holds Said responsible for the long-lasting legacy of Middle Eastern Studies, which focuses merely on the victimization of Palestine (37).

55 This statement establishes a dividing line btetween the two spheres of literary production and academic analysis. Nevertheless, this should not superimpose the complex interjectories which combine both realms, since scholarly attention attributed to a certain body of works is eventually reflected in literary production in turn. As Orfalea points out in this context, "acceptance in academia has a direct impact on publishing, and vice versa. The two worlds for a literary writer are inextricably bound" (221).

56 This is associated with an inherent lack of Arab American scholars in the academy. Very often, the outward racism and ethnic stereotyping found in the public media also falls on fertile ground in the ivory tower, where the political warfare in the Middle East is carried out in an intellectual microcosm. The acclaimed literary scholar and political activist Gregory Orfalea gives a personal example of this practice. Not only were some of his fictional works rejected by publishers due to an explicit objection to his Arab American background but, in the academic setting, an inherent fear existed that a Palestinian might cause political friction. Orfalea consequently was denied a tenure-track position by a Jew- 
Arab American literature can at best be considered a niche. Only a few scholars, mostly located in the U.S., count as experts pursuing this particular research specialization. ${ }^{58}$ Additional research interest exists among scholars in the social sciences, such as ethnography, anthropology, political science, and sociology. Just as the acknowledgement of Arab American literature as a distinct genre within the broader category of ethnic literature therefore remains contested, so too is the study of Arab American identity defined as a subtopic (Salaita, "Sand Niggers" 440). Arab American Studies as a separate field has therefore not been established on a large scale. Even after more than two decades of scholarly efforts to promote Arab American Studies, the field can nevertheless only be considered as "emerging" and not as established (Hassan and Knopf-Newman 4). ${ }^{59}$

ish board member on the basis of his putative anti-Semitism (221). This incident reveals larger links to the role of Zionism in the U.S. and the suppression of critical voices (Maira and Shihade 133; also see Chapter 3.2).

57 The situation looks different when considering Iranian American literature. Here, there is a broader choice of studies available, dealing with highly-differentiated topics, such as feminist issues, human rights and native informant theory (Darznik, "Perils" 55). Unfortunately, however, this welcome analytical attention to literature by authors who have not previously been included in the canon of ethnic American literature is diminished by the troublesome finding that Iranian literature is often perceived and discussed under the label 'Arab American.' Since Iran, however, is not an Arab state, this practice again points to a lasting lack of knowledge on the part of Western scholars concerning the cultural history of the East. Even scholars who aim to correct this fallacy of cultural homogenization sometimes neglect this analytical difference. One example is Whitlock's Soft Weapons in which the author devotes a good portion of her work to the discussion of contemporary Iranian literature without clearly delineating it from Arab American literature (see 102).

58 Arab American Studies programs are currently offered only at U.S. universities. Publications by non-American scholars that explicitly focus on Arab American issues are therefore rare. An exception is the recent edition of Arab American Literature and Culture (2011), edited by Alfred Hornung and Martina Kohl. From the perspective of U.S. scholars in the field of Arab American Cultural Studies, however, these contributions are scarcely visible. Evelyn Alsultany therefore sees the general interest in Arabs on the rise in Cultural Studies departments around the globe. Yet, this research mainly focuses on Arabs as minority groups living in other European and non-European countries. An example here is the study of the Turkish minority in Germany that has become more visible even to international scholars (Alsultany, Personal interview).

59 There are recent debates on solving the problem of institutionalization by integrating the field into Asian American Studies. Proponents of this move usually justify their claim not on the basis of geographical proximity but on shared historical experiences with colonialism. Without entering this debate, it nevertheless needs to be noticed that the exchange of 
This underdeveloped state of Arab American Studies is particularly astonishing in post-9/11 times. Even the increased and explicit demand for detailed knowledge of the Arab world and on Arab Americans has not transferred to the academy in such a way that institutionalization is widespread. Ironically, the impact of the terrorist attacks has caused many in the field to have a slightly more favorable outlook. Overall, optimists such as Steven Salaita claim that the expanded interest in Arabs and Muslims post 9/11 has contributed somewhat to the further advancement of the field ("Ethnic Identity" 148). To such scholars, the multitude of academic and non-academic books "countering the negative stereotyping" related to Orientalism is an indicator of this development (Fadda-Conrey, "Racially White" 174). Others, however, interpret this result in opposite terms. For them, the focus on counter-discourses represents the essential obstacle to a brighter and more visible future in Arab American Studies.

These split opinions on the state and prospects of Arab American Studies can be read as the unintended consequence of the very entanglement of Orientalism as a founding principle of Postcolonial Studies and the role of Arab American literature therein. Whereas Orientalism, on the one hand, allowed Arab American authors and critics alike to find their own voice, its very omnipotence, on the other hand, has come to restrict the field. Hardly any publication can be found without explicit references to Orientalism. Nadine Naber, as one of the most critical voices within the field of Arab American Studies, highlights this point in her book Arab America: Gender, Cultural Politics, and Activism. Naber presents the thesis that most research on Arab Americans suffers from its focus on countering Orientalist images of the Arab as "uncivilized" and "backward" ("New Texts"). In other words, writing against Orientalism continues to reinforce the prevalence of the concept while in addition preventing new approaches from flourishing. Consequently, the question is not only how to tell the Arab American story without reinforcing Orientalist stereotypes, as Carol Fadda-Conrey correctly remarks ("Racially White" 130). In addition, the crucial question is how to counter Orientalism while constantly reinvoking it.

In order to advance and sustainably develop Arab American Studies, the field therefore needs to break away from its Orientalist legacy by means of developing new methodologies. Only such a move allows for novel approaches to investigating the multiplicity of themes and works produced by Arab Americans without becoming stuck in the circular taxonomy of Orientalism and its various theoretical successors (see Chapter 3.1). Arab American literary scholar Carol Bardenstein summarizes this need for scholarly innovation in the following way: "It is time for new

arguments once again has an Orientalist connotation since integration is perceived by some to be a form of colonialism (Maira and Shihade 119). Others see the merging of both fields as powerful "way to resist empire oppression" (Maira and Shihade 137). 
theoretical concepts - Orientalism has become overused and overquoted" (Personal interview). As a possible solution Naber proposes a "de-Orientalizing theory" ("New Texts Out"). It is one of the crucial concerns of this book to contribute to this endeavor by demonstrating the value of autobiographical writing in (re-)framing the Arab in public discourse.

\section{(Re-)Framing the Arab: Research Design and Method}

This review of the position of Arabs in America as an ethnic minority, of their literary contribution, and of the theoretical instruments underlying the analysis of Arab American life writing brings to light a central finding that will set the stage for what follows on the pages to come. Unlike any other ethnic group, the identity of Arab Americans continues to be impacted by interpretive frames established and maintained by the media discourse, also in terms of their understandings of themselves as a group. Historically, the most dominant frame has been Orientalism which is responsible for a mostly negative image of the Arab as public stereotype. Recently, the WOT frame has added an additional layer to this trajectory. Although the heightened interest in Arabs in the wake of the WOT has fostered academic research on Arab American identity and literature, the theoretical means underlying this research tend to be limited in their capacity to open up novel research paths.

This shortcoming particularly applies to the interdisciplinary link between literature and media research. While there is no shortage of studies documenting the role of Orientalist stereotypes in both fields, a synergy of their research results is lacking, which might advance methodology development beyond Orientalism. Communication Studies as part of the social sciences and Literary Studies as part of the humanities continue to operate apart from one another. A slight bridging of this cleavage has recently been achieved in the field of autobiographical research with the extended definition of the genre of life writing to include various media formats beyond the traditional self-narrative. Journalistic autobiographies in a broader sense have thus come to be read as literary texts by cultural scholars. Literary autobiographies, in contrast, have not been read as journalistic texts through the theoretical and methodological lens of Media Studies.

This study seeks to target these shortcomings by engaging in a truly interdisciplinary ${ }^{60}$ project at the border of Media and Literary Studies while integrating find-

60 The topic of interdisciplinary method will play a detailed role for the theoretical merging of framing theory and literary analysis (see Chapter 2.3) For the purpose of clarification, it must at this point already be highlighted that interdisciplinarity is not to be understood merely as thematic synergy as often done in fields, such as film studies and historical investigations. Rather, interdisciplinarity in this study explicitly seeks to achieve a conver- 
ings from the philosophy of science, cognitive psychology, anthropology, and political science. It argues that autobiographies have the capacity to (re-)frame the public image of Arabs by actively engaging in media discourse. Usually treated as separate from the media sphere, the literary sphere is perceived to be an inherent part of mass media discourse. Due to their status as non-fiction, autobiographies occupy a specific position in affecting the media audience. Effects that are found to apply in the case of news media content are thus assumed to appear as equally often in the case of life writing.

"Every cultural product frames," Sidonie Smith declares concerning the relationship between cultural production and reception (Personal interview). It remains unclear how this effect is achieved and which role autobiography plays in the process. The theory of media framing allows for the analysis of these trajectories by revealing in how far autobiographies either, reflect, alter, or replace existing media frames. More than simply aiming at a uni-directional theory transfer of the framing model from Media to Literary Studies, this study seeks to demonstrate the multidirectional value of such an interdisciplinary move. The goal therefore is to further develop and refine framing theory to the extent that it contributes novel research insights to the advancement of autobiographical theory at large and possibly also to the field of Communication Studies. What lies at the core of this endeavor is the deep conviction that literature will not make an impact on the real world beyond disciplinary and institutional borders if it continues to be read and defined merely in the realm of Literary Studies. This especially holds true for the genre of life writing which is constantly claimed to embody "the healing and bridging power of literature" (Fadda-Conrey, "Racially White" 173) while the exact means to heal and bridge remain hidden in the darkness of ethnic autobiography scholarship and its obsession with fighting Orientalism.

Instead of adding another study to the plethora of descriptive analyses concerned with Orientalist stereotypes on Arabs in the media and their deconstruction in counter-narratives, this study practices what critics have long been preaching (cf. Fadda-Conrey, "Racially White" 67), namely, to open up a truly innovative reading of Arab American autobiography and thus "redefine boundaries of autobiographical writing" (Vinson 93). This approach accepts stereotypes as an empirical given and explores the specific trajectories through which they are constituted and received by the public to ultimately find alternative answers to the question of how literature can make an impact on changing them. ${ }^{61}$ Ultimately, this study raises the provoca-

gence of Literary Studies with the empirical sciences as opposed to the idea of literary analysis as merely "human science" (Bortolussi and Dixon 2).

61 From a communication-centered viewpoint, this approach situates the work at the intersection of cultural and media research that Alasuutari terms "cultural media research" (1). This disciplinary delineation allows for the inclusion of reception research. 
tive claim that the answer to (re-)framing the Arab does not lie in countering Orientalism. Instead, it demonstrates in how far mediated Orientalism can actually serve as an effective analytical concept to alter the collective image of Arab American identity in the public.

After a recapitulation of the current status of research on Arab American autobiographies and its pitfalls in today's mass media world, Chapter 2 establishes the theoretical link between autobiography theory and media framing research. Following some essential remarks on definitions, it explores the conceptual similarities between autobiographical texts and news-media content. Since framing theory in Media Studies has a very particular and empirically-based meaning, which often contradicts the vague use of the term in Literary Studies, the chapter outlines the theoretical credentials of framing theory as they are important for the discussion of literary texts. The last section of the chapter merges the two theoretical realms and points to a comprehensive model of framing as a theory for the analysis of life writing. It provides a unique instrument for the comprehensive study of literature by including the two sides of a text's production and reception.

Chapter 3 highlights the significance of the framing model for the particular situation of Arab Americans. Based on a meta-study of previous framing analyses on the representation of Arabs and Arab Americans in the news media of the last decade, predominant frames surrounding Arab American identity and the public perception of Arabs are identified. Crucial attention is devoted to the delineation of Orientalism as a founding concept in Postcolonial Studies as opposed to its conceptual and ideological significance as a media frame. With respect to the different frame levels, the political frame of the WOT is explored in detail and so are further issue frames relevant for the framed media representation of Arabs, such as religion and gender. These findings are then transferred back to the larger theoretical level in order to arrive at a more detailed framing model applicable to the analysis of Arab American life writing in the contemporary period.

Chapter 4 is the first of three analytical chapters which provide an in-depth analysis of Arab American life narratives published in the contemporary period after 9/11. The first is Tamim Ansary's West of Kabul, East of New York: An Afghan American Story (2003). The memoir describes Ansary's struggle between the worlds of Afghanistan and America and depicts his return to the Middle East as a journalist. The second memoir discussed in Chapter 5 is Letters from Cairo (2007) by Pauline Kaldas. The epistolary memoir provides a multi-layered record of the author's temporary return to her Egyptian homeland. The last and most recent memoir to be discussed in Chapter 6 is Howling in Mesopotamia: An IraqiAmerican Memoir (2008) by Haider Ala Hamoudi. In his life narrative, the Iraqi American author reflects on his two-year stay in Baghdad and his efforts to participate in rebuilding the country. 
All autobiographies are analyzed based on the comprehensive framing approach as theory of production and reception developed in the previous chapters. An indepth close-reading analysis identifies dominant textual frames of interpretation found in each individual work. Regarding the production process of the works, authorial frames are identified based on biographical as well as textual evidence. Concerning reception, dominant audience frames are identified on the basis of a close-reading of journalistic and general audience reviews. These texts are taken from various media sources, such as interviews and reviews on the part of the audience. Each analytical chapter concludes with a comparative overview of the different frames thus identified in order to reveal in how far the theoretical assumptions underlying the effectiveness of framing actually stand the analytical test.

Chapter 7 provides a symbiosis of the preceding theoretical and analytical sections. Based on a comparative integration of the framing patterns identified in the text analysis, detailed conclusions about the form and usefulness of framing as analytical tool are drawn. Particular attention is paid here to the function of Orientalism as political and academic ideology in contrast to a renewed understanding of Orientalism as a cognitive and analytical meta-frame. A focus of the chapter rests on integrating approaches from contemporary philosophy to explain the role of comparativism and binary thinking in current media and academic discourse.

The Conclusion summarizes all findings and relates them back to the present state of Autobiography Studies in the academy. This leads over to a broader discussion of the role of ethnic autobiography and of life writing in the contemporary media context and of its impact in the marketplace. Eventually, this points to the mostly neglected capacity of autobiography as active element of the mass-media discourse, which in turn poses new research challenges to the academy. 



\section{Life Writing Theory: Constructing Life, Claiming Authenticity}

"Science is built up of facts, as a house is built of stones; but an accumulation of facts is no more a science than a heap of stones is a house." This is how the French philosopher of science Henry Poincaré expressed his ideas on Science and Hypothesis in the $19^{\text {th }}$ century (73). Now, imagine a beautiful house built on solid ground with firm texture and a beautiful facade. Everything is in harmony, for decades nothing changes. Then, slowly, the ground underneath the house begins to shift. A crack starts widening. Then, completely unexpectedly, an earthquake hits. The entire house falls apart, though, the different parts are still recognizable.

This fictional scenario reflects what happened to the theory of life writing in the past two decades. For a long time, there existed two neatly separated worlds - the world of fiction and the world of autobiography. One was built on imagination and one on truth. At first gradually and then at excelled speed, social constructivists took away the solid base of the house by arguing that truth is just a fable. Consequently, neither autobiography can be built on truth, nor can the two worlds be as neatly divided as before. But that was not the last earthquake in the evolution of autobiographical theory. Meanwhile, a media revolution has altered practically all fields of society and scholarship, including the field of Literary Studies. The discursive surroundings of literature have been altered considerably. Culture has turned away from reading to blogging, twittering, and skyping. Two things have not changed, however: 1) there are again two separate worlds, this time constituted by the literary and the media sphere; 2) the question of truth remains one of the major dividers between both spheres. 


\subsection{Reconstructing the Construction of Self: AUTOBIOGRAPHICAL THEORY TODAY}

\section{Positioning the Self in the Genealogy of a Field}

There are many things in life which at first seem very simple but then turn out to be quite complicated. Above all, literature belongs to the former kind, since it requires excessive imagination, creativity, and work to bundle one's words and thoughts to put them on paper. The genre of life writing thereby traditionally counted as one of the more facile tasks among literarians. What could be easier than writing about oneself as opposed to inventing the world of others? As it turns out, however, writing the self does not exclude the process of invention - the invention of the self and the invention of the other. This poses considerable challenges to the the writer and to the scholar of life writing. As Gregory Orfalea summarizes, "this writing life is no easy row to hoe" (225). The genealogy of the field of autobiography theory reflects this finding. It demonstrates that the writing about life writing is not an easy row to how, either. The problem already starts with defining the subject matter.

Autobiography very basically defined is "the story of one's life written by himself" (Spender qtd. in Smith and Watson, Reading Autobiography 2). The Greek term literally means "self life writing" (Smith and Watson, Reading Autobiography 1). ${ }^{1}$ The French theorist Philippe Lejeune in the 1980s added a more expansive definition by declaring that autobiography is a "retrospective narrative in prose that someone makes of his own existence [...]" (qtd. in Smith and Watson, Reading Autobiography 2). What combines most definitions formulated by autobiography researchers in recent periods is that the term serves as a genre description used for written autobiographical accounts in contradistinction to fictional genres, such as novels (de Man 919).

Autobiographical writing is a century-old phenomenon reaching back to the early records of Christianity, the diaries of famous leaders in China, and the memoirs of European philosophers. Ancient rulers and public figures wrote down their lives in order to share their insights and leave a legacy to their successors with their accounts serving as historical documents (Smith and Watson, Reading Autobiography 10). The most famous and often-cited examples include St. Augustine's Confessions $^{2}$ written in $397 \mathrm{AD}$ and Jean Jacques Rousseau's autobiographical

1 The term is derived from the literal translation of "autos" in Greek meaning "self," "bios" as "life" and "graphe" for "writing" (Smith and Watson, Reading Autobiography 1).

2 The prominence of the title 'confessions' already reveals the testimonial nature of autobiography. Personal insights here are inherently related to the act of revealing one's in- 
records published in 1782 under the same title (de Man 172). In the field of American Studies, Hector St. John de Crevecoeur's Letters from an American Farmer (1784) and The Autobiography of Benjamin Franklin (1791) count as prime examples of New World life writing (Smith and Watson, Reading Autobiography 53). As these examples demonstrate, traditional autobiography was mostly understood as a form of historical documentation.

With the emergence of Autobiography Studies in the 1960s and its further development, the very definition of the subject matter and the meaning of autobiography as literary category have undergone enormous transformations toward a more inclusive understanding of life writing (Moore-Gilbert 128). Autobiography today thus serves as an umbrella term for different forms of life writing, including written and non-written accounts (Smith and Watson, Reading Autobiography 2). As an expansive term, autobiography is divided into several genres, such as memoir, diary writing, and poetry (Eakin, How Our Lives 99-100). In addition, autobiographical representation in different media, such as film, as well as new media formats like online diaries and blogs, are included in the term autobiography (Smith and Watson, Reading Autobiography 73).

This study follows the definition of autobiography as inclusive category positioned under the original term of life writing. ${ }^{3}$ The terms life writing and autobiographical writing will thus be used synonymously, whereby autobiography is used as an overarching category of various sub-genres, such as epistolary autobiography and memoir. In contrast to authors using autobiography and memoir interchangeably to refer to life writing, this analysis will treat both as separate forms (Smith and Watson, Reading Autobiography 3). This understanding is in line with the definition of memoir as "a form of self-reflective writing that is personal, often controversial, and a meditation about the place of self in history" (Whitlock 20). Memoir therefore puts specific emphasis on the historical and cultural circumstances surrounding the writing of self. The accentuated status of memoir is derived from its emphasis on authenticity and immediacy (Whitlock 133). Complementary to the assumption that autobiography merely serves a "self-defining function," the given understanding of memoir also suggests that the writing of self always involves the writing of society at large (Fivush qtd. in Eakin, How Our Lives 111).

nermost thoughts about life and history. This particular function of truthful testimony would remain one of the most important characteristics of life writing up to the present.

3 Whereas life writing only comprises written accounts of self-narration, "life narrative," in contradistinction, includes various media formats and other forms of self-representation, e.g., performance (Smith and Watson, Reading Autobiography 4). Sidonie Smith doubts the lasting relevance of traditional definitions of autobiography, due to the fact that newer forms of life narrative increasingly represent hybrids of these forms (Personal interview). 
The aspect of self in relation to history and its surroundings already poses the first challenges to the study of life writing. Autobiography as 'self life writing' sets an explicit focus on the individual writer, thus, excluding outside circumstances. The extended definition of memoir softens these borders between self and other, between individual and collective. Traditionally this exclusive focus on the individual was the major reason why autobiography came to be known as exclusively "Western" genre (Smith and Watson, Reading Autobiography 4). This localization is not only based on the geographic division of the world and the legacy of Western ethnocentrism in the development of scholarship but also on political grounds. The "ideology of egalitarian individualism" thus incorporates the intention to tell one's story as an extension of the "rights to life, liberty, and the pursuit of happiness" (Eakin, "Breaking Rules" 113). This view pits "Western individualism" against "Eastern connectivity" as collective and monolythic identity markers located in a particular societal order (Joseph 263; W. Hassan, "Arab-American Autobiography" 11). ${ }^{4}$ The category of self has therefore always implicitly been understood in contradistinction to collective social surroundings.

Meanwhile, with the further development of life writing studies and the influence of interdisciplinary autobiography research, the field has moved away from "prescribed definitions" of self- and other-writing (Arida 4). Especially with the increased importance of "narrative identity" in the theory of identity, the self today is not seen as separated and exclusive category anymore, bound to individuallistic

4 Especially the empirical investigations by Ronalt Inglehart based on the World Value Survey have demonstrated that the strict separation between individualistic versus collective societies is not supported by empirical data since they reveal significant value correspondences between Eastern and Western societies. This especially refers to the spread of postmodern values found in East and West (Modernization 267). Values therefore largely remain a function of modernization processes (Inglehart, "Evolutionary Modernization"). Respective polls conducted by James Zogby have revealed a similar value coherence between Americans and Arab Americans (85).

5 The concept of narrative identity in sociology combines the idea of identity as social construction with the realm of identity politics (Somers 607). This notion is closely linked to the ideas expressed by Eakin in Living Autobiographically and former works. Here, he describes narration in the form of life writing as "identity activity" (78). Autobiography therefore does not only convey "metaphors of self "but rather, it "is a metaphor of self" (Living Autobiographically 78). Consequently, life writing does not represent a genre to Eakin but a lifelong process of identity formation" ("Breaking Rules" 114). What is most interesting about this logic of identity as narrative is that Eakin demonstrates how people who, due to brain damage or other serious illnesses, have been deprived of writing a truthful account of their lives also become "un-selved" as a consequence of their storytelling incabability ("Breaking Rules" 121). 
societies (Somers 607). Rather, the concept of 'self' today is perceived in a way that the "extended self is the self of memory and anticipation," as Eakin states (Fictions 122). Not only does the adjective 'extended' imply the notion that self always exceeds the individual level, it also introduces a temporal dimension by referring to past and future concepts of the self. This renewed understanding of self also goes along with a redefinition of individualism and subjectivity on a societal level, as based on a "relational model of identity (Eakin, How Our Lives 57). ${ }^{6}$ Whereas personal identity sets one apart from others, the personal narrative is thought to include the dimension of collective history and identity (Ashmore, Deaux, and McLaughlin-Volpe 83; W. Hassan, "Arab-American Autobiography” 23). In short, self-writing therefore always also represents a form of other-writing.

This reformed positioning of the self in autobiographical production and the corresponding notion that self and other complement each other on an individual and societal level necessarily brings about an extended analytical scope which is by far larger than the previous focus on the individual author. Whereas the concentration on the self as more or less autonomous narrator did not exclude but to a certain extent limited the historical and political range of investigation, the notion of the extended self brought about the need to analyze the exact relationship between self and other, between autobiography and society. In order to grasp the dynamics of this relation, autobiography theory needs to operate with concepts and terms which reach beyond the field of Literary and Cultural Studies. The philosophy of science provides this theoretical toolkit. Its theoretical indespensability, however, has mostly been neglected by autobiography scholars.

\section{The Real Self in the Philosophy of Science: Key Terms}

\footnotetext{
"The important thing in science is not so much to obtain new facts as to discover new ways of thinking about them" (Bragg qtd. in Rowan 205).
}

The location of Autobiographical Studies in the field of the humanities fosters a standard vocabulary, immanent assumptions, and tacit beliefs. This theoretical repertoire is part of a wider web of terms and concepts found in the field of Cultural Studies. Scholars, especially in Literary Studies, have developed the habit of adopting this standardized modus operandi. Partly, this is a result of professionalism and expertise. Partly, and this is the flipside of the former advantage, the practice of always building on the given while rarely questioning its usefulness within a dy-

6 Eakin in his definition of self-writing bases his insights on Antoni Damasio's evolutionary approach by not only regarding the self as extended but as an emotional state "embedded in the physiological process necessary for survival" (Fictions 126). 
namic social world stands in the way of novel discoveries. This especially applies to inderdisciplinary research projects. The unreflected appropriation of terms from other fields here leads literary scholars into a conceptual trap. Avoiding this pitfall requires to rethink the established meaning of key terms from the perspective of the philosophy of science.

Autobiography has traditionally been seen as a historical and thus factual form of documentation. The central assumption was that it represented truth. The concept of truth is rooted in philosophical realism (Hilfer 55). Realist epistemology assumes that there exists a common truth that can be objectively ${ }^{7}$ grasped, as if looking through an "unmediated "window" (Barker, Sage Dictionary 173). Truth, in turn, is defined as "the property (as of a statement) of being in accord with fact or reality" ("Truth," def. 3a). According to the correspondence theory of truth in the philosophy of science, "a statement is true if it corresponds to the facts" or "if it corresponds with some actual state-of-affairs in the world" (Hospers 9). The major criterion for truth therefore is "correspondence with reality" (Hospers 9). Although the critical mind at once identifies the tautological nature of this definition since truth and reality obviously presuppose each other, this view is in line with the popular notion of truth as "accurate information" (Christians 23 ). ${ }^{8}$

Despite the somewhat circular logic of the definition, truth as fact-based builds the cornerstone of realist thought which by far transcends the confines of academic investigation. The term realism is thus applied much more broadly to any view explicitly embracing the idea that truth consists in a relation to reality, i.e., that truth is a relational property involving a characteristic relation (to be specified) to some portion of reality (to be specified). In literary realism, truth is evoked through very detailed descriptions of events, sceneries, ${ }^{9}$ or objects, as well as by means of historical references and the reflection of social and political circumstances (Padley 127; Childs and Fowler 198). ${ }^{10}$ The overall aim is to "show things as they really are" (Lovell qtd. in Baldwin et al. 61). This also reveals the connection between literary realism and cultural materialism in the sense that "text and context" cannot be sepa-

7 In the empirical sciences, objectivity is defined as intersubjective verifiability (Kunczik and Zipfel, 283; Barker, Cultural Studies 490).

8 The first formulation of this definition of truth as correspondence to reality in the philosophy of science was advocated by Bertrand Russell and George Moore early in the $20^{\text {th }}$ century. Both count as pioneers of analytical philosophy and opponents of idealism.

9 These very detailed descriptions are known as "mnemonic presentations" which describe modes of learning that support memory. In literary history, the works of Marcel Proust and Virginia Woolf count as most prominent examples of this very detailed style of writing which aims at evoking the impression of truth in the reader (Ender 7).

10 In the Arab autobiographical tradition, historical accurateness was the major motivation and source of justification for autobiographical writing (Reynolds 68). 
rated (Padley 152). Especially in the social sciences which Media Studies is part of, realism remains the crucial concept for defining the larger research purpose.

The function of realism as the foundation of particular scientific aims points to the larger context of knowledge acquisition and scholarly methods. The definition of the central concept of knowledge as such has traditionally posed the most striking challenge to the quest for knowledge pursued in philosophy. As the American philosopher of science John Hospers remarks: "We all have many beliefs; but how can we be sure that the beliefs are true? What we want is not merely belief but knowledge. We want to be able to be certain. But about what things can we be certain?" (Hospers 18). The key to the answer lies in the relation of knowledge and truth. According to realist thought, there are three requirements which cause the formation of knowledge: 1) a statement must be true, which is the objective component of knowledge as in the definition of truth (Hospers 20). 2) There must be a belief that the statement is true, which represents the subjective component of knowledge (Hospers 21). ${ }^{11}$ 3) There must be good evidence for believing that a statement is true (Hospers 21-22). The question then remains which sources human beings have at their disposal to make this judgement. The answer provided by the philosophy of science immediately leads to the realm of autobiography.

The most important sources of knowledge for human beings are memory (Hospers 41), reason (Hospers 44), and oral testimony (Hospers 46). ${ }^{12}$ Eventually, all three resources overlap with the definition of autobiography. This constitutes the essential link between the overarching concepts related to realism and truth provided by the philosophy of science and the credentials of autobiography research in Literary Studies. Especially the third source of knowledge, oral testimony, ${ }^{13}$ is a central concept for the study of life writing. As Hospers remarks, it is a fundamental human reflex to believe in the truth of oral testimonies by others, unless there is sufficient reason to doubt (Hospers 46). In Literary Studies, this belief in the validity of a testimony is referred to as authenticity. The adjective authentic in its broa-

11 Hospers provides an illuminating example to underline the relationship between truth as rational criterion and the belief in truth: "[S]he realizes her husband is dead and still cannot believe it" (Hospers 21).

12 Sensual perception is another important source of knowledge (Hospers 41). In Autobiography Studies, this aspect comes into play when defining sensual perception as emotional perception.

13 This use of the term testimony in the field of the philosophy of science directly points to the genre of testimony in life writing. The etymology of the term defines it as "firsthand authentification of a fact" ("Testimony", def. 2a). In literature, testimony derives its major "source of legitimacy" from its supposed truth (Whitlock 119). Furthermore, in the realm of the larger media market, testimony also counts as a "'soft' genre of news" transported by journalists on predominantly humanitarian issues (Whitlock 73). 
dest terms is defined as "worthy of acceptance or belief as conforming to or based on fact" ("Authenticity," def. 2a). Furthermore, authenticity in a philosophical sense also has another meaning with particular refererence to the individual. Authenticity here is understood as being "true to oneself" in the form of an ethical imperative (Taylor qtd. in Huggan 157). ${ }^{14}$ Both defining elements, the belief in the truthfulness of an account as well as the maxim of being true to oneself are of utmost importance for the study of autobiography.

With respect to the significance of authenticity in life writing research, the close connection of the concept to the idea of authority adds another layer to the entanglement between terms derived from the philosophy of science and their significance in contemporary research. Authenticity and authority share common etymological roots. In Literary Studies, the more politically charged term of authority is mostly replaced by the concept of agency. The latter is defined as sense of ownership and the ability "to make a difference" (Barker, Cultural Studies 474). Agency thus counts as the major source of action for an individual and lies at the very core of the first-person narrative perspective (Burr 20; Eakin, "What Are We Reading" 127). ${ }^{15}$ The term has therefore gained particular prominence in the context of ethnic life writing research, where agency and the lack thereof constitute major themes and motivations for writing.

When reviewing the original definitions of truth, authenticity, and agency, as derived from the philosophy of science, one notices their immanent dependency on each other. It ultimately remains a chicken-or-egg problem to determine which one is the basis for which. On the one hand, truth as the correspondence to facts becomes a necessary requirement for authenticity. On the other hand, only authentic

14 Especially in the contemporary debate on new media life writing, e.g., the writing of blogs and online diaries, the term authenticity has experienced a revival, since it constitutes one of the most praised, but also one of the most challenging disadvantages of new media. On the one hand, the instant publication of material online as well as the immediacy created by personal pictures, movies and voice recordings seems to underscore claims of authenticity which would hardly be attained by earlier forms of life narrative. In addition, possible censors or "gatekeepers" who control the flow of information in the traditional print market are absent from the self-controlled web (Whitlock 37; John Zogby 87). On the other hand, this provides many options for manipulation and privacy violations. Authenticity as objectively traceable truth can therefore not be claimed or ensured. This has given way to the notion of a "virtual public," where facts for the proof of authenticity are practicallt absent (Whitlock 42).

15 In opposition to highly political conceptions of agency, which dominate the contemporary debate in Cultural Studies, it is a revealing fact to note that more empiricallyoriented literary scholars conceive of agency as a power emerging from mostly cognitive capabilities of an individual (Burr 20). 
representations are perceived as true. Finally, the more authority writers either represent from the beginning or establish in their writing, the more agency they gain and the more credibility the reader infers. ${ }^{16}$ Central to this group of interrelated concepts and their obvious entanglement with the realm of oral and written testimony studied in autobiography research is not the underlying question of causality but their relation to the overall function of knowledge transmission. Consequently, knowledge with all its definitorial preliminaries stands at the basis of life writing. To express this relation between individual insight and truthful storytelling, autobiography theory scholars in the field of life writing research often use the term "subjective truth" " which "signals to the reader an intended fidelity to history and memory" and "gestures of sincerity, authenticity and trust [...]" (Whitlock 12). The authentic $^{18}$ writer is thus assumed to have knowledge of certain facts which the reader cannot gain otherwise.

The crucial importance of knowledge as major aim of scholarship and knowledge transmission as function of autobiography points to a larger problem at the core of the scientific enterprise; namely the issue of normativity. Normativity can be defined as the sum of statements "specifying how a person is, or persons of particular sort are, expected to behave in given circumstances - expected, in the first instance, by the person that utters the norm" (qtd. in Opp 10714). It is this "oughtness" that constitutes the most challenging dimension to the aim of objective scientific enquiry because its definition requires a human being (Opp 10714). Hence, other crucial values of scientific investigation, such as intersubjectivity and objectivity, are in danger of being violated due to the subjective influence on normative standards. Truth thus represents the ultimate aim of supposedly value-free science, yet, exactly because it does so, truth also represents a scientific value in

16 Whitlock obviously sees authority as inherently reactionary when using the term "oppositional authority" to refer to authors of life narratives (Whitlock 31). Although the expression underlines the power of opposition in gaining authority, it obliterates the constitutional element of authority as immanent in the subject itself.

17 This is not to conceal the fact, however, that the term "subjective truth" is a tautology since truth is defined as correspondence to facts which need to be revealed based on objective methods (Hospers 13). Nevertheless, the fierce inclination of scholars to employ the concept of truth even in relation with subjectivity emphasizes the lasting importance of truth in the production and reception of autobiographical writing.

18 In life narratives, authors often try to underscore the authenticity of their accounts by integrating pictures and other visual and written material to lend their works what Bart Moore-Gilbert calls "documentary 'authority" (120). An example is constituted by Edward Said who provides many photos in his memoir Out of Place. Whereas the pictures themselves exclusively depict close family members, the captions put these images into the larger political and historical context of Egypt (n. pag.). 
and of itself (Thiel 10712). This dilemma ties in with the core objective of science as a "purposeful enterprise, established for the benefit of mankind" (Thiel 10711).

In the course of history, scientists under the influence of different philosophical and political currents have dealt with this dilemma of scientific investigation as inherently value-laden. The most popular and at the same time radical view was presented by Max Weber who promoted the view of a strictly "value-free social science" as opposed to normative social and political commitment (Thiel 10713). It is not the intention of this study to continue or interfere with this ideological debate. There is no doubt that the question of normativity by far exceeds the limits of autobiographical study. For the proposed theoretical and analytical aim it is nevertheless fundamental to clarify the meaning of normativity since it constitutes a major criterion impacting the way in which scholars in Literary Studies approach life writing. In contrast to conceiving of normativity mainly as the inclination to employ science for an overall-normative goal, this study defines normativity as the tendency to judge scientific method not according to its explanatory scope and power but rather according to normative, e.g. socially and politically desirable, ideals related to the respective research aim. Obviously, this view does not challenge the argument that science itself in the end is a value-laden endeavor. Of even more importance for the given study, however, is the definition of normativity when it comes to the comparison of research methodology and the criteria applied by scholars from different fields to evaluate these methods.

As these definitorial preliminaries of the theory of science suggest, key terms such as truth, objectivity, and authenticity have been constitutive for the formation of Autobiographical Studies. Most of them have their origin in philosophical realism. The original definition of the given concepts in the philosophy of science and their ultimate relationship to the function and study of autobiography, however, has not been coherently explored so far. This weakness seems to be less a result of the lack of interest by literary scholars than the result of an ideological development which replaced the real self of autobiographical production with the idea of a constructed self established in the humanities.

\section{The Constructed Self in Autobiography Theory}

As the genealogy of autobiographical theory suggests, the initial approach to autobiography was one that regarded life writing as fact-based documentation of individual lives. The notion was that "life produces the autobiography as an act produces its consequences [...]" (de Man 172). This cause and effect logic, however, has not survived the history of autobiographical research. The most radical change to the perception of autobiographies as lived experience came about with the emer- 
gence of constructivism. This was the theoretical earthquake that swept the formely constructed mansion of Autobiographical Studies in an unprecedented way.

Philosophical constructionism was initiated by Jacques Derrida in the 1960s and reached its climax in the 1980s (Childs and Fowler 48). Constructivism represents a "metatheory" which encompasses several different schools ${ }^{19}$ of thought and which impacted many different fields in the academy (Spivey 34). The basic characteristic of all these approaches is an anti-essentialist approach to analysis which rejects the validity of "grand narratives" for explaining phenomena and denies the existence of stable referents of words as well as the existence of innate traits of individuals ${ }^{20}$ (Burr 13; Barker, Cultural Studies 479, 485; de Zepetnek 2; Childs and Fowler $73^{21}$ ). Constructivism therefore puts "an emphasis on the generative, organizational, and selective nature of human perception, understanding, and memory [...]" (Spivey 34). This also alters the view of the individual agent and the reliance on memory. Constructivists therefore regard people as "constructive agents" in the sense that they "view the phenomenon of interest (meaning or knowledge) as built instead of passively 'received' [...]" (Spivey 34). The act of communication also becomes a means to "individual sense construction" (Donges, Leonarz, and Meier, my translation, 105).

This short overview demonstrates in how far constructivism stands in fundamental opposition to the core pillars of realism. Especially when it comes to the concepts of truth and objectivity, constructivism functions in a radical way. Since reality only represents a human construct, it cannot be objectively grasped. Consequently, truth as the foundation of knowledge and the depiction of the real world become obsolete if all knowledge is a matter of construction and subjective experience (de Zepetnek 6). On the one hand, this allows for a democratization of thought for no argument can gain hegemony on the basis of truth. It was particularly this

19 Among the best-known variants of social constructivism are radical constructivism and Russian constructivism. The latter is often referred to as forerunner of constructivism, although it has little to do with constructivism as methodological term (de Zepetnek 5).

20 This also explains the close relationship of essentialism to the concept of authenticity in Cultural Studies. Here, authenticity is also perceived as the genuine quality of a scientific category. These categories count as authentic due to an "immaculate" quality which cannot be explained (Barker, Cultural Studies 474).

21 With respect to the logic behind definitions of essentialism, some authors commit errors. Peter Childs and Roger Fowler, for example, explain that essentialism is "based on the belief that all individuals, or groups of individuals, possess certain fundamental, innate traits" (73). From this supposition they then conclude "essentialism treats identity as fixed, permanent and stable" (73). Although so-called essentialist representations of identity might evoke this impression, the conclusion of a static identity does not logically derive from the fact that certain innate and unexplained features rule human identity. 
anti-essentialist stance which accounted for the far-ranging popularity of constructivism after the historical dominance of philosophical ideas that denied any multiplicity of ideas and approaches (Burr 13). This seeming liberation, on the other hand, also caused the major "disillusionment" of constructivism (Burr 14). The abandoning of the concept of "ultimate truth" not only did away with any material basis of discourse, it also dramatically impacted the notion of agency in a twofold and seemingly contradictory way. While the individual subject in constructivism is endowed with the unlimited agency to constantly (re-)invent identity, the individual at the same time becomes the "product" of this construction undertaken by itself and by others (Burr 14). Since there is no possibility to compare these constructions with truthful referents, a cycle of relativism emerges in which different constructions of the social world can only be evaluated in relation to each other (Burr 81).

This tendency to infinite relativism has caused major criticism in the academy which can be summarized under the label "realism/relativism debate" (Burr 100). While constructivism with its underlying logic of relativism represents a critique of realism's reliance on essentialism, radical constructivists have in turn been targeted for their essentialist defense of absolute relativism as superior concept (Burr 1998, 15) - a tautology par excellence. Inspite of this theoretical weakness, constructivism nevertheless succeeded unlike any other scientific paradigm. ${ }^{22}$ In the humanities, realism therefore hardly plays a role in contemporary discourse. Especially in Literary Studies, realism can count as a neglected concept which is denied any theoretical value. Adherents of constructivism and poststructuralism therefore perceive of realism's essentialist and reductionist tendency as "politically conservative and authoritarian" (Barker, Sage Dictionary 173). Tony Hilfer in his highly critical investigation of the present status of Literary Studies entitled The New Hegemony in Literary Studies: Contradictions in Theory calls this hostility toward realism "Discourse Radicalism." As he states: "A curious aspect of Theory is its condemnation of an entire mode of literature, realism, not for what given realists say but as inherently conservative and oppressive in its form. Realism has become the straight white male of literary forms" $(55) .^{23}$

22 The term paradigm here is used with specific reference to Kuhn's The Structure of Scientific Revolutions. Kuhn traces the history of science as a series of wave-like theoretical shifts, whereby a paradigm shift to Kuhn relies on its acceptance by the respective scientific community, not on logical superiority (94). A similar argument can be made for the dominance of constructivism despite some methodological flaws of the approach.

23 Hilfer does not generally denigrate the advances made by constructivist criticism in comparison to traditional realist thought. "I am not arguing that reality or realist literature is self-evident," he therefore states before adding that realism "is the straw man Theory sets in opposition to its own antirealism. Reality, like the moral truth it quests after, is 
This fierce condemnation of realism in Literary and Cultural Studies also is reflected in the subfield of life writing theory. The extreme position of constructivists and postmodernists denies any notion of autobiography as truth-related. This stance is underlined by Eakin who quotes William Maxwell from The Liars' Club to emphasize the significant role memory distortion and cognitive creation play in selfnarration. As Eakin cites; "in talking about the past we lie with every breath we draw" ("What Are We Reading" 125). The Arab American autobiography researcher Waill Hassan follows this claim by reminding his readers that "there is no such thing as 'life as lived' to be referred to" ("Arab-American Autobiography" 8). Whitlock argues in a similar vein when summarizing the status quo of Autobiographical Studies: "It is now a given in autobiogeraphy criticism that the 'I' of autobiography and memoir has never been anything but virtual",24 (1). All of these comments on the status of autobiography research in the contemporary period stand in the tradition of radical discourse analysis. Due to the preoccupation with constructivism in any possible field, Hilfer polemically makes the point that discourse analysis today "deconstructs" everything, "from advertisements to wrestling" (55).

The recent interdisciplinary opening of autobiography research indeed provides additional evidence for the constructivists' claim that life writing cannot count as fact-telling. Major contributions in this context were made by scholars in the fields of cognitive psychology and neurology. Both areas have undergone major advancements in the last two decades (Eakin, "What Are We Reading" 121). ${ }^{25}$ Overall, scientists in these fields have refined the assumption that memory cannot be conceived of as "'library or a storehouse of information"” but as a "continuous activity" of reconstructing (Ender 5). Ender strikingly illustrates this point by stating that "no one can remember what I remember" (12).

While these findings seem to be in line with the constructivist claim that all memory is subjective and life writing therefore must count as invented, the inclusion of findings from Cognitive Studies brought about a more nuanced image. By shedding light on the detailed processes of remembering, scientists in these fields

elusive" (64). This urge is a forceful reminder to not exclude realism from the theoretical picture without insisting on any kind of theoretical hegemony.

24 "Virtual" here assumes the double meaning of constructed reality in traditional written autobiography as well as in the modern-day representation of self in different technologybased media.

25 The most well-known neuroscientist Antonio Damasio demonstrates this point in the following statement: "Multiple individuals confronted with the same body or brain can make the same observations of that body or brain, but no comparable direct third-person observation is possible for anyone's mind. The body and its brain are public, exposed, and unequivocally objective entities. The mind is a private, hidden, internally, unequivocally subjective entity" (qtd. in Ender 15). 
operate with terms borrowed from realist and constructivist vocabulary. The initial assumption is that there are indeed "facts" about life that form the basis of life narrative (Perrett). Due to the influence of subjective memory and the limited capacity of the brain to recall life facts, the literary reproduction of life in autobiography inevidently counts as construction. Instead of regarding this as a mere constraint, cognitive scientists acknowledge the positive side of the process. Ender quotes the psychiatrist Jean Delay: "Our memory is like a diary that writes itself" (3). Ultimately, this finding transfers part of individual agency to the cognitive apparatus. Reconstructing subjective memory and turning this memory into narrative thus turns into an artistic process that accounts for the beauty of the art of memory ${ }^{26}$ writing. Ender in this context uses the analogy of architecture in describing narratives of memory as "brilliant works of architecture born from the depths of our minds" that mark the uniqueness of the individual "rememberer" (13).

Scholars in Cultural and Literary Studies have widely adopted this more balanced view caused by the interdisciplinary opening of the field. Eakin concedes that memory itself is detailed and fact-related, yet the act of recording it is based on construction (How Our Lives 107). This acknowledgement of the importance of facts and of the unavoidable cognitive process of construction eases the normatively charged debate between realists and constructivists. A middle-position between both strains, namely "limited constructivism," assumes that (re-)constructing life in autobiography is not merely but also a matter of bad intention and will as it is a complex interplay of cognitive restraint and subjective agency (Hart 324).

This synopsis of autobiography research as a field highlights the significant paradigm shifts which have occurred since the 1960s. Whereas truth, objectivity, and facts used to represent the hallmarks of life writing during the dominance of realist thought, constructivism and its theoretical successors have mostly dispelled these terms from contemporary research. Although Cognitive Studies slightly contributed to the re-emergence of these concepts, life writing per se is not regarded to be an effigy of any material or historical reality (de Zepetnek 3). In summary, the real self as the starting point of autobiography research has come to be replaced by the constructed self dominating present-day scholarship. This focus on the self as active creation brings attention to the larger context in which this construction takes place. Commonly, this context is subsumed under the term discourse.

26 Edward Said also used the expression "art of memory" ("Invention, Memory" 179). To him, however, this quality of art as construction had a rather negative connotation due to the danger of distortion. 


\section{Discourse and Its Discontents}

The concept of discourse forms one of the most influential catch words in Cultural Studies and in the field of life writing research. Hardly any publication lacks terms such as discursive structures, discursive constraints, "discursive transformations" (Silberstein qtd. in Whitlock 133), "discursive intervention" (W. Hassan, "ArabAmerican Autobiography" 8) "discursive grid of globalization" (Whitlock 123), and "discursive strategy" (Salgado 204) [emphasis added]. Whitlock even describes discourse as the ultimate "catalyst" for autobiography (78). On the one hand, this focus on discourse again underlines the utmost importance of constructivist thought which favors discursive over materialist structures in the creation of life writing (Eakin, How Our Lives 62). On the other hand, the concept due to its inflationary usage causes severe discontents to the critical scholar working at the intersection of Literary and Media Studies, since the term mostly goes undefined. This leaves one with the impression that scholarly discourse itself forms the very discourse determining the production and reception of autobiography. The question then remains: What exactly does this discourse consist of in today's world?

The term discourse represents a cross-disiplinary category (Bortolussi and Dixon 2). The etymology of the term defines it as "a mode of organizing knowledge, ideas, or experience that is rooted in language and its concrete contexts [...]" ("Discourse," def. 5). The analysis of discourse furthermore encompasses "the study of linguistic relations and structures in discourse" ("Discourse Analysis"). In Literary and Cultural Studies, discourse theory has mostly been shaped by the philosophical ideas of Michel Foucault who advocated the idea that discourse unites language and practice (Barker, Cultural Studies 478). Discourse analysis in Cultural Studies therefore has a strong "textual orientation" that goes along with a focus on linguistic methods (Barker and Galasinski 62). In line with the constructivist notion of the social world as discursive invention, "objects of knowledge" are thus understood to be defined through linguistic means (Barker, Cultural Studies, 478; Gamson qtd. in B. Scheufele 41). Jürgen Habermas in addition stressed the idea of discourse as constant questioning of general truth claims based on logical argumentation (qtd. in B. Scheufele 41).

As to the specific objects of discourse found in the social world, the communication scholar Bertram Scheufele points out that it usually evolves around socially relevant topics, e.g., abortion, anti-semitism, racism, to name only a few dominant examples from our time (42). To figure out which issues dominate social discourse, communication scholars, as opposed to literary scholars who often employ linguistics means, rely on public opinion data. Public opinion is defined as a view held by a significant share of a society and measured by public opinion polls (McQuail 
565). ${ }^{27}$ Public opinion formation is seen as a process in which attitudes and norms are formed based on the selective acceptance or denial of certain frames of interpretation (Chong and Druckman 120). The term opinion itself not only carries normative but also cognitive meaning. As Denis McQuail emphasizes: "It is as much cognitive as evaluative" (516).

The cognitive component of discourse points to the crucial significance of "knowledge" in discourse analysis. As in the case of life writing in its original definition as truthful account, knowledge as the core pillar of discourse demonstrates the close links to the criteria of truth and authenticity. The given definitions of discourse in the fields of Cultural and Media Studies stress the exchange of logical and rational argumentation in contrast to the mere exchange of personal opinion, emotions or views. Following the chain of logical argumentation, knowledge transmission and acquisition require the existence of truth, which in turn is facilitated through the process of discourse. Since knowledge in discourse is not defined in individual but in collective terms (B. Scheufele 42), discourse analysis always requires the analysis of more than one actor. When transferred to the realm of literature, the writer thus functions as individual agent in influencing collective opinion formation while at the same time being constrained or at least affected by the discourse surrounding him (Golley, Reading 184).

The question of the role of the individual actor in discourse also correlates with the issue of power. Since discourse per definition implies the idea of conflicting arguments, discourse is based on the exchange of these arguments. As the postcolonial scholar Bill Ashcroft and his colleagues state, "discourse comes into being in a structure of counter-discursive practices" (Ashcroft, Griffiths, and Tiffin 167). This ultimately incorporates the idea of "dominance" in the very definition of discourse. It suggests a dualism between hegemony and alterity, between public and individual. $^{28}$ The dynamics of this discourse, i.e., the mutual exchange of conflicting ideas,

27 The concept of the "public" is similarly challenged in Communication Studies as is the term "mass" in Cultural Studies. The public generally is assumed to consist of free citizens in a society or some geographically defined space. It is thus heavily embedded in the concept of democracy resting on an "informed public opinion" (Fortner 190; McQuail 565). Based on this normative stance, the term "public" often bears a negative connotation since the degree to which public opinion can be trusted is being doubted due to the influence of manipulative tools, such as the mass media (Fortner 188). This reveals the ethnocentric origin of the concept.

28 The most influential theory to explain how public opinion comes to dominate was provided by the pioneer communication scholar Elisabeth Noelle. In the 1970s, she formulated her hypothesis of the Spiral of Silence (McQuail 519; Kunczik and Zipfel 375). According to this assumption, people are endowed with a quasi-statistical sense of constantly comparing their own views with what they think is the public opinion of the majority. 
thus necessarily brings about a redefining of power constellations. Although this finding sounds familiar to anybody working in the field of Postcolonial Studies, where the struggle for power constitutes the major concern of analysis, this logical investigation of knowledge as a formative element of discourse seeks to underscore a more general finding. For knowledge is the only means to impact dominant discourse and dominance can only be overthrown by power, the idea of knowledge as power is inherent in the very concept of discourse itself, despite any considerations of political and ethnic struggles for agency. Power therefore is not an end in itself but can be viewed as a constitutive and even positive force in discourse. As Foucault mentions, "it traverses and produces things, it induces pleasure, forms knowledge, produces discourse (Interview 62). ${ }^{29}$

Another crucial aspect for the analysis of discourse in its contemporary surroundings which emerges from the given definition is that participation in discourse with the goal of knowledge alternation is not an accidental event but an instrumen$\operatorname{tal}^{30}$ process (Bhabha, Location 103). In other words, every actor participating in discourse is assumed to pursue a discursive strategy based on rational argumentation to achieve the ultimate goal of persuasion. ${ }^{31}$ The term 'strategy' originated in military jargon. It is defined as "a careful plan or method" and as "the art of devising or employing plans or stratagems toward a goal" ("Strategy," defs. 2a, b). Strategy development and its application are thus never of an accidental nature. This idea of intentionality links the term to the definition of discourse and its rational

The media are the primary source for this assessment. Whenever individuals think they hold a minority view, their "fear of isolation" prevents them from expressing a diverging opinion (McQuail 568). The result is a "spiraling" effect which causes the preconceived dominant opinion to become even stronger. Although there is manifoldevidence that this assumption holds true, the Spiral of Silence still remains hypothetical because its formulation is very broad and can hardly be tested in detail (McQuail 520; Allen et al. 267). The media coverage of $9 / 11$ and the reinforcement of anti-Muslim sentiment without counter-representations, however, can be read as incidents of this spiraling effect.

29 The logic of this definition actually stands in contrast to previous definitions by Foucault and other theoreticians who argued that power is a necessary preliminary for entering discourse. This raises the question of whether power is an effect of discourse or an inherent preliminary (Foucault, Interview 52).

30 Instrumentalization also implies the aspect of mobilization which Smith and Watson describe as one of the goals of autobiographical discourse by politicians (Smith and Watson, Reading Autobiography x).

31 This finding also highlights the importance of authorial intent and will. Even though these concepts have lost much of their meaning in recent literary scholarship, the question of "will" remains central, as Said also underlines. To him, intention can never be completely "domesticated by the system" (qtd. in El-Haj 548). 
focus. As Homi Bhabha in his critique of Edward Said explains, discourse represents a "median category" 32 which is always linked to the categories of power and knowledge, thus, turning discourse into a "strategic response to an urgent need at a given historical moment” (Location 105).

When conceiving of life writing as discursive intervention - as contemporary scholarship in the post-constructivist era does - one can therefore not exclude questions of intentionality. Since persuasion and intentionality traditionally evoke suspicions of manipulation, the question of intentionality has become extremely unfavorable in contemporary literary scholarship (Leitch 26). The term strategy in general carries a negative connotation and evokes notions of instrumentalization, manipulation, and "indoctrination" 33 (Whitlock 152). This negative assessment of strategy especially in the literary field points to a larger problem of normativity. ${ }^{34}$

On the one hand, this neglect to explore authorial intentions is linked with the high degree of text-orientation prevailing in Literary Studies. Anything not explicitly written in a text, therefore, can hardly be proven by intra-textual means. On the other hand, this practice leaves the question of actual authorial strategies acting beyond the immediate linguistic level unexplored. This often leads to a somewhat self-enforced distancing of literary scholars from the political and social background of the respective authors. In the case of fictional writing, this imposed neutralization is justifiable since author and characters are distinct. In autobiographical writing, however, where the author is his/her own protagonist, the scholarly convention to purposefully disregard possible strategies to influence the public perception of autobiographical discourse leaves a considerable part of autobiographical production unexplored.

32 The term "median category" was actually used by Said in Orientalism. However, Said himself also endowed the term with a cognitive function, meaning that Orientalism helps mediate and structure information (Orientalism 58). This use of the term is hardly acknowledged by contemporary scholars, although it strongly supports the function of Orientalism as cognitive model beyond normative evaluations.

33 Statements like these point to an inherent weakness of Literary Studies to provide empirical evidence for axiomatic claims. Whitlock, for example, who constantly refers to the audience in her work, neither provides a close-reading analysis of the texts discussed nor does she mention figures or other data underscoring her hypothesis that "indoctrination" and other negative influences on readers actually occur (see Whitlock 152).

34 This skepticism toward framing as instrumentalization, of course, is not limited to the literary field but has also accompanied media research ever since its beginnings. The focus here primarily rests on the role of media in a democracy and its function to inform citizens to make proper decisions in deliberation processes (Chong and Druckman 120; also see Chapter 2.2). 
When looking at these shortcomings in contemporary autobiographical theory and its love-affair with discourse, discourse causes discontent. This discontent to a large extent is rooted in a very exclusionary and unworldly ${ }^{35}$ approach taken by literary theorists. Contemporary life writing theory thus suffers from a fundamental gap between theory and practice. Discourse remains the central catch word in respective publications. Its incremental elements of truth, authenticity, and objectivity, however, have been banned from the theoretical landscape due to the constructivist emphasis on anti-essentialism. This obsession with discourse under questionable theoretical prefixes has been brought to an even more paradoxical level when looking at a particular sub-genre of autobiography theory: ethnic autobiography.

\section{Ethnic Autobiography Lost in Counter-Discourse}

Life narrative in the context of discourse analysis inherently entails the notion of power relations. These power relations are particularly important when investigating the life narratives of those who, for a long time, lacked the agency necessary to take part in global literary discourse. Ethnic Autobiography Studies seek to reveal the mechanisms through which this identity negotiation takes place. When taking a closer look at the discursive strategies employed by ethnic life narrative, however, one wonders if the field does not lose itself in a never-ending cycle of countering the very preliminaries of its existence.

The field of ethnic autobiography ${ }^{36}$ research is a fairly new area in life writing research which only gained prominence in the 1980s and 90s (Eakin, Introduction

35 The positive variant of the term stands largely in the tradition of Said for whom worldliness was a central concept - both in his academic and activist work, and in his conception of literature (Shereen 111). To Said, the "text does not live outside the world," which corresponds to the rather pragmatic and highly political way in which he interpreted texts (Shereen 109). As he furthermore states in his work The World, the Text and the Critic: "The point is that texts have ways of existing that even in their most rarefied form are always enmeshed in circumstance, time, place, and society - in short, they are in the world, and hence worldly" (35).

36 Some authors refer to ethnic autobiographies as "auto-ethnography" (Whitlock 62). Autoethnography is defined as the "writing about the personal and its relationship to culture" (Ellis 37). As genre of life narrative, it reveals "different layers of concsciousness" (Ellis 37). The term is mostly used in the fields of anthropology, media, and performance studies (Ellis 12, 214). For postcolonial scholars, autoethnography is characterized as specifically political project (Pratt 49). Although the adoption of the concept by literary scholars signals methodological and interdisciplinary advancement, the present study will mostly neglect the theoretical differences between both concepts for autobiography is generally assumed to have ethnographic and political implications. 
6). Under the influence of postcolonialism, the strongly ethnocentric viewpoint that saw autobiography as merely "Western" genre was given up (Eakin, How Our Lives 43). Scholars of life writing as well as researchers interested in the fields of Ethnic and Postcolonial Studies thus increasingly paid attention to the life accounts produced by those formerly excluded from the autobiographical landscape.

What distinguishes the study of ethnic life writing from the one of autobiographies produced by non-ethnic authors is the political dimension inherent in the definition of ethnic identity. Social power constellations and notions of hegemony on the collective level are thus immediately linked to the (self-)conception of individuals. ${ }^{37}$ Since ethnic writing emerged as product of the political liberation following the overcoming of colonialism, the study of ethnic autobiography naturally transcends the realm of the literary by incorporating the political and socio-cultural circumstances of literary production (Moore-Gilbert 112; Golley, Reading 183). With respect to the individual subject of ethnic autobiography, the memories sketched ethnic writers thus take the form of "politics of memory" in which political facts and historical experiences, such as the experience of colonial oppression, are written and read through the lens of "ethnic interpretation" (Boelhowever 136). Autobiography therefore becomes a tool of cultural and intercultural learning which shapes "dialogues across cultures" (Whitlock 2). Whitlock states: "We encounter each other and ourselves in narrative." By referring to Seyla Benhabib, she then adds that "the notion of the constant creation and re-creation of identity and difference is useful for thinking about this as a dynamic process: 'I can become aware of the otherness of others, those aspects of their identity that make them concrete others to me, only through their own narratives"' (14).

In the context of social discourse theory, this characterization suggests that ethnic life writing by nature is reactive to the dominant discourse of the Western colonizer. ${ }^{38}$ The term "counter-discourse" represents this overall-discursive strategy employed by ethnic authors which allows for a "discursive intervention" otherwise unattainable (Golley, Reading 15-16). Whitlock underlines the strategic nature of this "talking back" discourse by highlighting that "autobiographical acts [...] bring into view processes of othering ${ }^{39}$ and self-fashioning" (Whitlock 13; Arida 4). The

37 Ian Haney-López, a specialist in the study of legal constructions of race, summarizes this aspect by explaining that "inferiority is a predicate for superiority, and vice versa" (22).

38 In the case of Palestinian life writing, counter-discourse often takes the specific form of "counter-Americanism" (Moore-Gilbert 114).

39 The constant emphasis on counter-discourse, however, logically represents a reaction to a dominant discourse. This underlines the critique applied by Homi Bhabha who insists that counter-discourse, just like colonial discourse, requires difference in order to perform "othering" (Location 96). The constant reinforcement of discursive opponents in counter- 
postcolonial scholar Brinda Mehta, when specifically referring to Arab American life narratives, combines the arguments provided by memory research, constructivism, and discourse theory in arguing that "counternarrative" serves the function of subverting stereotypes whereby "memory provides an important point of motivation to reconstruct the past as a means of transforming the present" (4). Carol FaddaConrey, also writing on the role of counter-narrative in relation to Arab Americans, points to the historical significance of autobiographical (re-)construction by referring to it as a document of "counterhistory" ("Racially White" 136). ${ }^{40}$ Autobiographical production by ethnic writers thus becomes a tool for the "politics of remembering," which is central not only for the self-definition of individuals, but for the collective identity formation of societies (Smith and Watson, Reading Autobiography 25). The first problem related to this notion, however, is that strategy in the case of ethnic autobiography has only been limited to the notion of counterdiscourse by means of producing "counterstories" (Lindemann Nelson 69).

This strong focus on ethnic life writing as counter-discursive mode evades a shortcoming found in other areas of autobiography research in which discursive strategies are often entirely neglected. ${ }^{41}$ Counter-discourse as practically the only definitorial feature of ethnic life writing, however, also has its major downsides. This particularly becomes obvious when integrating the credentials of discourse theory - a theoretical move which scholars have so far avoided. As the definition of discourse and its relation to autobiographical writing indicate, the mutual exchange of counter-arguments is constitutive of any form of discourse. Discourse in and of itself therefore implies the idea of counter-discourse. The "discursive imperative" 42 of ethnic life-writing therefore truly is a counter-discursive imperative because all

discourse illustrates this practice. Anthony Appiah thus warns that postcolonial scholars get lost in a mere "otherness machine" (qtd. in Fritsch-El Alaoui 22).

40 W. Hassan describes the challenging of dominant discourse with the simultaneous constitution of one's own discourse as "double-operation" ("Arab American" 9). In contrast to the permanent insistence on counter-discourse as oppositional practice found in other authors, Hassan's view highlights the interdependency between discourse and counterdiscourse without this confrontative element. Whitlock makes a similar claim when referring to a "double agency of life narrative" that can either facilitate or distort dialogue across cultures and underlying power relations (22).

41 The specific use of ethnic memory and cultural practice for the (re-)gaining of agency was underscored by Bhabha in his conception of "cultures of survival" ("Postcolonial" 190). The idea emphasizes that culture and cultural production at large have a strategic function for ethnic minorities.

42 Smith and Watson developed the term in the context of women's autobiographies and feminist theory. Here, similar trajectories with respect to identity politics and claims of agency can be found as in the case of ethnic life narrative (De/Colonizing xvii). 
discourse is from the beginning assumed to represent a reaction to the power of existing arguments (Smith and Watson qtd. in Huggan 161).

What distinguishes ethnic counter-discourse from other discursive strategies, though, is the special authenticity devoted to the writer. Graham Huggan in his study The Exotic Other introduces the term "cultural authenticity" to refer to this preliminary of ethnic counter-discourse (157). ${ }^{43}$ In other words, the ethnic writer is assumed to present a cultural perspective $\mathrm{e}^{44}$ that the audience is not familiar with and therefore cannot experience itself (Huggan 155). Due to the once more reactive character of this type of authenticity, Huggan refers to it as "counter-authenticity" (Huggan 162). ${ }^{45}$ Claims of authenticity and agency therefore constitute the narrative power of ethnic life narrative in the public (Whitlock 113). ${ }^{46}$ Overall, this trajectory

43 Cultural authenticity is usually seen in a political context in ethnic life writing. Especially recent Arab American autobiographies, however, focus less on politics and more on the expression of cultural customs and family tradition. An example of this shift is the food memoir which introduces a new "site of authenticity," as Bardenstein argues ("Beyond Univocal Balava" 161). Critics, however, argue that the focus on cultural representations, especially in the case of food memoirs, is essentialist due to the fact that food serves as an "ethnic marker" (Bardenstein, "Beyond Univocal Balava" 167). Bardenstein counters this critique by pointing to the "decomplexifying effects" of food memoirs. "Many people dismiss food memoirs as anecdotal, nostalgic, and apolitical," she states. In fact, however, "food is an easy vehicle" to transport more complex political and social realities to the public, she explains (Personal interview).

44 The notion of perspectivity is crucial for the entire body of exilic and diasporic literature. Writers derive their authenticity not merely from their particular cultural knowledge but also from their geographical location (Varisco 283). Alfred Hornung in his discussion of Said's memoir Out of Place terms this "extraterritorial” existence, a state in which people live outside their original cultural sphere and constantly face identity challenges (368). An alternative term used by Lisa Lau and Lisa Mendes to refer to the importance of location is "positionalities" (4). The theme of exile therefore constitutes one of the major theoretical underpinnings in the discussion of diaspora life narratives - both, as severe trauma and as "powerful force" to see things from a different perspective (Whitlock 182).

45 Naber in her discussion of the binary logic underlying the discourse about Arabs in America coins this authority "re-authenticity" ("Arab San Francisco" 264). In contrast to the prefix 'counter-,' Naber's formulation underlines the reactionary and less confrontative nature of authenticity in ethnic writing.

46 In light of the aforementioned theoretical explanations, this is not limited to ethnic life narrative. As Whitlock states with respect to the range of life writing, "across contemporary life narrative, the hybrid and the syncretic always coincide with identifications that pursue authentic, continuous, and homogenous self-identities [...]" (11). 
underscores the well-known credo of speaking "truth to power" as the ultimate aim of postcolonial expression (Whitlock 119). ${ }^{47}$

This entanglement of ethnic identity and cultural authenticity raises another inherent crux which has evolved around ethnic literary production ever since its emergence. As Cultural Studies expert Caren Kaplan explains, "the burden of ethnic autobiographical writing is to participate in at least two different registers at all times [...]" (qtd. in Huggan 156). This points to the challenged status of authenticity in ethnic life writing. On the one hand, ethnic autobiography derives its right of existence from the authenticity of ethnic, i.e., cultural identity. On the other hand, authenticity is something to be granted by the readers who function as "legitimizing agents" ethnic and cultural background - which is the rule per definitionem ${ }^{49}$ - then, ethnic life narrative has to meet certain expectations and communicative rules demanded by the target audience in order to be understood and conceived of as authentic. Cultural authenticity thus assumes the meaning of "cultural legitimacy" (Whitlock 20). The two definitions of authenticity ${ }^{50}$ as 'being true to oneself' and 'being true to others' by sticking to the facts thus collide. ${ }^{51}$ In addition, authenticity here experiences another complication since members of one's own ethnic group also have

47 The strategy of speaking truth to power is closely linked to Said's elaborations on knowledge and power and his ideational forefather Foucault. As Said expressed with respect to the media and the Middle East conflict, this concept is always in danger of misuse ( $\mathrm{Cov}$ ering Islam 134). As far as his own belief in the success of counter-narrative is concerned, critics share different views. On the one hand, Said due to his political activist stance saw the solution to the East/West conflict in counternarrative (Marrouchi "Counternarratives" 219). On the other hand, following the skepticism of Foucault concerning the success of narrative resistance, Said saw Arabs as "passive" and unlikely to be able to change their lot (Aboul-Ela, "Is there an Arab" 730).

48 Huggan discusses the role of readers as "legitimizing agents" largely with respect to the position of autobiographies as commodities in the marketplace. As he also points out, content and authenticity are not the only factors accounting for the successful promotion of a book, but also supposedly minor aspects like cover, design etc. (164).

49 If ethnic life writing is principally defined in relation to non-ethnic literature, then those defining it as ethnic consequently must be of non-ethnic origin.

50 With respect to the original definition of authenticity, defined as the transmission of knowledge, the solidarity imperative in ethnic life writing fosters a form of cultural authenticity (compare Huggan 175).

51 Orfalea in his memoir shares a striking confirmation of this importance of authenticity and authorial credibility in the context of Arab stereotypes and the marketplace. One of his novels never got published because, as he recalls, "I was of Arab background, I couldn't get it right [...]. I was, de facto, an unreliable narrator" (222). 
certain prescribed notions of what truthful representation means to them which the individual writer might violate. Overall, this complex meaning of authenticity in ethnic life writing and the lack thereof poses the severest challenge to the genre at large. Graham Huggan observes this difficulty in one of his subchapters under the ironic heading "Ethnic Autobiography and the Cult of Authenticity" (155).

Recent postcolonial criticism has targeted the problematic role of authenticity in ethnic life writing based on its immanent quest for fighting essentialism (Barker, Cultural Studies 488). Due to the need of ethnic life writing to meet the demands of its non-ethnic audiences, authors are accused of reinforcing essentialist notions of culture and ethnic identity. Essentialism in this vein maintains its negative connotation. This only slightly changed with the introduction of the concept of "strategic essentialism," as developed by Spivak (Morton, Gayatri Spivak 125). According to Spivak, cultural reductionism can be turned into a political strategy if it allows a group to speak up with a unified voice strong enough to influence mainstream discourse in order to subvert ethnic identity stereotypes ${ }^{52}$ (Barker, Cultural Studies 488; Naber 2002, 275). ${ }^{53}$ Spivak defines her theory as the "strategic use of an essence as a mobilizing slogan or masterword [...]" (qtd. in Morton, Gayatri Spivak 126). Elizabeth Eide in her analysis of Spivak's approach furthermore explains that strategic essentialism "entails that members of groups, while being highly differentiated internally, may engage in an essentializing and to some extent a standardizing of their public image, thus advancing their group identity in a simplified, collectivized way to achieve certain objectives" (76). The otherwise highly negative con-

52 Whitlock in her discussion of the commodification of ethnic life writing states that "there is an immediate and autobiographical appeal to a public that is gendered, classed and given permission to read [...]" (95). According to her, this audience mostly comprises a female middle-class audience (96). Although this underlines Whitlock's general critique of cooptation, the problem remains that Whitlock presents no data to justify her claim. This points to the fact that there are not only Western stereotypes about Eastern writers but also stereotypes about the Western audience.

53 Particularly contemporary Arab American women writers are often subjected to the critique of cultural essentialism. An author who is frequently attacked in this context is Leila Ahmed whose fictional and scholarly works are said to manifest essentialist representations of Arab identity (Vinson 86). Ahmed is thus accused of representing a prime example of "internalized colonialism" (Attar qtd. in Vinson 83). Defendants of Ahmed's writing, however, argue that stereotypes are only taken up in order to be subverted (W. Hassan, “Arab-American” 19-20). This debate underlines the general importance of cultural authenticity in ethnic life writing. Edward Said recognized this by positioning himself as an "inauthentic American" (Fadda-Conrey, "Racially White" 145). 
cept of essentialism is thus turned into a positive force based on its pragmatic and political usage (Eide 76; Lau and Mendes 6). ${ }^{54}$

With respect to the significance of the concept for contemporary autobiographical criticism, it can be noted that strategic essentialism is hardly granted any theoretical value. The idea of using the reductionist mechanics of essentialism for strategic purposes is therefore still regarded to confirm rather than subvert the negative side effects of reductionism. Due to the wave of criticism originating inside the postcolonial field, Spivak herself meanwhile does not uphold her theory anymore (Interview 35). ${ }^{55}$ For the current study, however, the role of strategic essentialism in contemporary discourse at large is less important than the theoretical potential of the concept which indeed needs to be highlighted. What has not been acknowledged so far, due to the highly normative tendency in Postcolonial Studies to argue against anything that might evoke essentialist tendencies, is the cognitive component of Spivak's use of essentialism. In regard to the media-oriented approach to the study of public discourse, it must be noted that strategic essentialism - independent of its specific political aims - functions on the basis of complexity reduction. Messages encoded strategically as unified and thus essentialized, according to the definitorial preliminaries of public discourse, indeed promise to have higher chances of impacting public opinion than heterogeneous and thus more complex arguments.

This scepticism toward any novel theoretical approach challenging the fierce rejection of essentialism in post-constructivist times highlights the larger concerns around the danger of cooptation prevailing in the analysis of ethnic life writing (Whitlock 121). Recently, this debate has been carried out with specific attention to the role of so-called "native informants" (Huddart 138). The term native informant originally derived from the study of colonial life circumstances in which some of those formerly colonized adopted the structure of oppression a way that they employed cultural insider information to support this system (Arida 2; Huddart 122). In postcolonial times, the concept has been applied to diaspora writers who supposedly use their exilic residential position outside their countries of origin to re-essentialize their homelands. This critique has particularly been applied to Arab writers living in the United States and Europe who, due to their often very privileged socio-

54 An example of strategic essentialism in the context of Arab American identity representation is the conscious emphasis on religious identity traits used to turn around stereotypes about Muslims (Eide 69).

55 Critics often forget to account for the specific circumstances under which Spivak developed the concept. Originally, she did not theorize strategic essentialism with respect to ethnicity but as part of her engagement with class-struggle and Marxism (Spivak, In Other Worlds 205). The underlying assumption here is that the "personal is political" in order to trigger "positivist essentialism" (Spivak, "Interview" 35; In Other Worlds 205). 
economic and intellectual status, have been accused of denigrating the Orient from a Western perspective (Banerjee, "Between the Burqa" 301; Whitlock 181). ${ }^{56}$

Meanwhile, the critique of native informants in the context of Arab American writing and its legacy of Orientalism has led to the development of new theoretical models beyond the ones of essentialism and cooptation. The most popular one in contemporary life writing research is Lisa Lau's theorization of "Re-Orientalism" intended to serve as a critique of contemporary "postcolonial cultural production" (Lau and Mendes 3). ${ }^{57}$ Lau defines Re-Orientalism in the following terms:

$[\mathrm{N}] \mathrm{o}$ longer an Orientalism propagated by Occidentals, but ironically enough, by Orientals, albeit by diasporic writers. This process, which is here termed Re-Orientalism, dominates and, to a significant extent, distorts the representation of the Orient [...]. The [argument] begins by analyzing and establishing the dominant positionality of diasporic [...] women writers relative to their non-diasporic counterparts in the genre. (Lau, "Re-Orientalism" 571)

Re-Orientalism consequently locates the agent of Oriental discourse in the Occident, at least geographically, but names the formerly orientalized subjects as sources of Orientalism. By acting as native informants, Arab writers thus abuse their superior position to further underline the inferior image of the East (Lau and Mendes 4). ${ }^{58}$ For the purpose of discussing present-day ethnic autobiography research in the context of discourse theory, it is important to highlight the particular meaning of the prefix "re" in the model. As Lau's definition suggests, this prefix does not so much refer to a changed notion of the actual practice of Orientalism itself, which she still sees as distorted representation of the East. Rather, the "re"

56 The feminist and postcolonial thinker Trinh T. Minhha has largely contributed to elaborations on the concept of the native informant. Minhha sees the native informant as the person who translates foreign culture for the outsider in a way that the cultural insider still does not represent himself in his own voice (Khan 2022). This role of the native informant is also applied to the scholar who is suppodedly turned into a "third-world native informant (re-)producing the voice of alterity" while living and writing in the "West" (Khan 2023). Contemporary criticism often targets this counter-knowledge production by scholarly native informants since most ethnic writers live in the West (Banerjee, "Between the Burqa" 322; Fritsch-el-Alaoui 26; Whitlock 181).

57 Although the term is often used synonymously with other reconceptualizations of Orientalism, it is to be strictly separated from both "Neo-Orientalism" and "Post-Orientalism" (see Chapter 3.2).

58 This argument appears in a more negative light when considering that the demand for these so-called re-Orientalist works comes from Western scholars and activists who use the authenticity and insights provided by ethnic writers to pursue their own cause within the realm of the global human rights discourse (Banerjee, "Between the Burqa" 309). 
assumes a temporal meaning in that it signals a re-emergence or repetition of classical Orientalism in the contemporary period. This re-formulated model still focuses on the core issue of power relations between East and West, whereby the former remains the target of oppression. Adherents of Re-Orientalism thus see a neocolonialist practice at work which substantiates a "new hegemony" (Banerjee, "Between the Burqa" 323). The only but certainly crucial conceptual difference between this renewal of Orientalism and its older version is that it is maintained by Orientals themselves. In other words, Re-Orientalism thus marks the culmination of the vicious cycle of counter-discourse surrounding ethnic life narrative which now not only aims to counter original colonialist structures but also the counter-reaction to these structures in the literature of the formerly colonized.

This detailed look at the development of ethnic autobiography research demonstrates that the field continues to focus on the aspect of counter-discourse as major narrative strategy of ethnic writers. This reactive nature has gained yet another theoretical twist with Lau's concept of Re-Orientalism. In sum, these findings confirm the nature of ethnic life-writing as an ambivalent genre. On the one hand, ethnic autobiography is conceived of as powerful tool against colonialism. On the other hand, its very strength can turn against it if former instruments of oppression become the means of cooptation. Whitlock in her comprehensive and innovative study on contemporary ethnic life writing visualizes this image in the metaphor of the "soft weapon." As she explains: "Autobiography circulates as a 'soft weapon.' It can personalize and humanize categories of people whose experiences are frequently unseen and unheard." Yet, as she furthermore explains, the power of autobiography as a 'weapon' is limited by the adjective 'soft' which accounts for the fact that "ethnic autobiography is easily co-opted into propaganda" (3). ${ }^{59}$

The preoccupation of ethnic autobiography with counter-discourse has several implications for the larger field of life writing studies. In general, the exploration of ethnic narrative in postcolonial criticism has considerably contributed to the theoretical expansion of autobiography research (Eakin, How Our Lives 9; Boelhower 138). With its emphasis on autobiography as means to gaining agency, this vein of research highlights the political function of life narrative beyond the literary sphere. This "politization of ethnicity" consequently calls attention to the study of life narrative along larger social trajectories (Kayyali 61). While this expanded research scope meets the initial intention of Cultural Studies which seek to look at literature within the context of actual social circumstances, the omnipresent debate on coun-

59 Whitlock later in the book provides an almost economic definition of the term "soft weapon" by describing it as "the carefully coordinated management of information across a variety of contemporary media" (54). She relates this to "public opinion management" (54). From a communications perspective, this definition shows close links to agenda setting theory which intersects with framing (see Chapter 5.2). 
ter-discourse also causes severe limitations to the further development of autobiography research. This constraint can mostly be attributed to the fact that postcolonialism continues to perceive of (counter-)discourse along the lines of power relations. Counter-discourse as the ultimate strategy of the "subaltern" speaking back has become an axiom in postcolonial scholarship (Huddart 131). As is the nature of axiomatic knowledge, it hardly ever gets questioned and/or substantiated by textual evidence. Furthermore, new ways of thinking about autobiographical discourse are suppressed due to the ideological dominance of the counter-discourse approach.

Two major shortcomings derive from the present status of ethnic autobiography lost in counter-discourse. Firstly, since counter-discourse can only exist in reaction to discourse, the detailed analysis of discursive structures surrounding the autobiographical work inevitably needs to be included in life writing research. Secondly, if ethnic life narrative is assumed to be such a powerful tool in the intervention in discourse, there is no justifiable reason why this effect should not apply to the general body of autobiographical production. Targeting both issues requires what scholars in the humanities have successfully avoided so far - a "reflexive approach" (Kayyali175) to discourse analysis which accounts for the real-life circumstances accompanying autobiographical production and reception. Here, the question of truth is central to understanding why autobiography matters far beyond counterdiscursive lines established by constructivists in the academy.

\section{The Truth Is: Truth Still Matters in Autobiography}

It must have come as a huge surprise for scholars in Literary Studies when, with the publication of president Obama's memoir in the middle of the election campaign in 2007, debates around the "truth" and the "uses" and "abuses" of autobiography erupted in the public (S. Smith, "Autobiographacal Discourse" viii). This lively discourse taking place in various social realms and the media above all underlined that to the average reader, it does indeed make a difference if he/she thinks he/she is "buying truth" (Whitlock 112) but in the end gets nothing but a hoax ${ }^{60}$ (Whitlock

60 Intensive emotional reactions by the readership usually follow the uncovering of a hoax. Whitlock describes the trajectories underlying this as "contracts" which bind readers, publishers and writers alike (110). Despite constructivist claims to the opposite, the autobiographical pact imagined by Lejeune therefore has not lost its relevance. Smith and Watson highlight this importance with respect to ethical considerations in avant-garde life narrative. As they underline, the "autobiographical pact implies that writers seek to maintain a sincere and responsible relationship to their audiences and to the ethical imperatives of that relationship" ("Rumpled Bed" 10-11). The intense response to untruth uncovered in a hoax narrative serves as striking evidence for this argument (Smith, Personal interview). The hoax, despite its negative reception, though, can also serve an intentional 
127). The postmodern autobiography researcher in the ivory tower probably shakes his head over this superficial confusion. To him, it is out of the question that any autobiography is nothing but a hoax, since memoir, just like any other literary production, is constructed. Issues of truth and reality are out of the question - to the scholar. The audience obviously has a different approach to the matter. Truth here plays a key role in determining what counts as autobiography and what does not.

The principle differentiation of life writing from other literary genres is based on the division between fact and fiction (Ender 12). Whereby the classification into factual writing obviously entails the idea of truth telling, fictional writing evokes notions of imaginative construction. The first acclaimed theoretician to further develop this basic categorization was Philippe Lejeune. With his theory of the "autobiographical pact," he set the theoretical basis for generations of autobiography researchers. Lejeune in his theory assumes that the reader of autobiography enters into a contract-like relationship with the author, thus expressing the willingness to read the work as personal account of historical facts (Lejeune 19-20; Smith and Watson, Reading Autobiography 11, 207). As Eakin summarizes, the pact is defined as "a contract between author and reader in which the autobiographer explicitly commits himself or herself not to some impossible historical exactitude but rather to the sincere effort to come to terms with and to understand his or her own life" (Foreword xi). ${ }^{61}$ Lejeune thus clearly proposes a dividing line between autobiographical writing and works of fiction as far as the relation between reader and work is concerned. ${ }^{62}$ This conception of autobiography as a genre therefore shifts the defining agency away from the text itself toward the audience. The reader becomes the "judge" to verify the authenticity of the writer (de Man 174). He/she decides what counts as fiction and what counts as autobiography.

This differentiation between fact and fiction as defining genre criterion obviously faced a challenge with the emergence of constructivist thought and its re-

function by speaking "untruth in the interest of power" (Whitlock 122). The most prominent example in the Middle Eastern context is Norma Khouri's memoir Honor Lost (2003), which supposedly describes the honor killing of the author's best friend but was later revealed to be a hoax (Whitlock 109).

61 What tends to be forgotten is that Lejeune based his theory of the autobiographical pact on a linguistic study of autobiography, thus arguing that the pact between autobiographer and reader largely depends on the use of the first-person pronoun (Lejeune, Tomarken, and Tomarken 27).

62 In order to differentiate between fictional and non-fictional writing, Lejeune also introduced terms such as "phantasmal pact" (Lejeune, Tomarken, and Tomarken 29) and "novelistic pact" to refer to autobiographical novels. According to him, all these different formats caused different effects in the audience. The choice of terms underlines how much Lejeune emphasized the idea of the pact (Lejeune, Tomarken, and Tomarken 42). 
jection of objective reality. The need for genre definition as such, however, remained important. While some argued in favor of upholding the dichotomy between fact and fiction, others did not see a reason why genre classification could be based on these blurred terms. An outstanding figure in this debate was Paul de Man at the end of the 1970s. De Man did not favor the discussion on autobiography as a separate genre in contrast to fictional writing. The reason for this was not so much his opposition to the idea of life writing as constructed. Rather, de Man was critical of genre classification in a more far-reaching sense. To him, any genre ascription enforces a particular historical function onto the work of literature. This universal classification, according to de Man, stands in fundamental opposition to the subjective memory of the narrator (921). ${ }^{63}$ De Man thus concedes that any analysis might evolve into "an endless discussion between a reading of the novel as fiction and a reading of the same novel as autobiography" (921). Instead of escaping this vicious cycle, de Man arrives at a more nuanced conclusion. As he eventually infers, the differentiation between fiction and autobiography to him is not an "either/or polarity" but "undecidable" (921). At the same time, however, de Man suspects that the question of genre remains relevant. This is not so much a matter of theory to him but a "figure of reading or of understanding that occurs, to some degree, in all texts" (921). ${ }^{64}$ The "autobiographical moment" according to de Man then is created by the subject reading and defining the text, as the text defines the reader (921).

As a bottom-line to both of these explorations, autobiography maintains its somewhat indefinite status caused by the notion that it cannot fully be categorized as either fact or fiction. Contemporary life writing research shares this view. As the Egyptian feminist and literary scholar Nawal al Sadaawi states: "Fiction and facts are inseparable. Personal stories resist vague and generalized abstractions. They maintain the urgency, the intensity, the richness and vividness of the concrete" (qtd. in Arida 1). The dichotomous distinction between fact and fiction has thus taken the shape of an etymological question which allows for autobiography to take multiple positions on a "continuum" (Ender 12; Culler 36).

63 This notion of the function and effect of genre definitions marks the center of genre theory. Adherents of pragmatism argue that a specific genre ascription exactly achieves the function which de Man was afraid of, namely, the dominance of genre over critical interpretation. Vincent Leitch elaborates that "[i]n its desire to gain interpretative power over individual texts, it [genre] knowingly sacrifices critical scope, narrowly constructing the scenario of criticism and explicitly putting the author, milieu, and text in positions of subordination to the will and strategy of the ambitious critic-exegete who defines in order to explicate/exploit generic discourse" (74).

64 Despite de Man's admiration for Lejeune's focus on the reader in autobiographical analysis, the former still described the autobiographical pact as "stubborn" because it represented a mere presupposition to him which lacked "evidence" (174). 
In light of this seeming consensus on the indeterminability of genre ascription, it has to be highlighted that this view represents an academic and therefore theoretical consensus. The reader is mostly left out of the picture. To him/her, the constructivist view that truth does not exist is highly unlikely to be decisive. Both Lejeune and de Man hinted at this when calling attention to the fact that autobiography itself only emerges in relation to the reading experience. The importance of truth in autobiography therefore cannot merely be overthrown by the constructivist move to exclude the term from its vocabulary. Since the defining moment of autobiography depends on the reader, his/her expectation to read truth when entering the autobiographical pact is not only a detached or sentimental "desire [...] promised by the autobiographical pact" but a constitutional part of life writing (Whitlock 111).

This lasting significance of the autobiographical pact draws attention to the readership. For a pact by definition constitutes a contractual relationship between two parties, however, the author's notion of truth also needs to be considered. Again, the theoretic consensus that the distinction between fact and fiction does not matter cannot simply be claimed to be a consensus existing among authors as well. As it turns out, writers indeed care about the classification of their works as either factual or fictional. A statement by Orfalea strikingly underlines this: "As for the Truth. I confess. I seek it. I'm drawn by writers who seek it" (234). On the part of the writer, this aim to represent and find truth in literature reflects a larger trust in writing as human expression. Literary production thus becomes a means and an end in itself, similar to an experiment in the natural sciences, bringing to light new discoveries (Orfalea 231). Often, this leads to a curious blending of the awareness of artistic creation while still holding on to the ultimate goal of truthful depiction which is elevated to something beyond realism itself:

Consider: There is no human instrument, not the fastest laptop - not even a legion of cameras - that can record life as it happens. Life itself is a tragedy because in its very enactment it is dying; each second dies to give life to the next [...]. But art and literature especially - has the ability to distill, to choose if you will, the representative moments, distancing, combining, bending the real to a greater capital-R Real which transcends time. [...] You are creating new life. You are giving life itself - and not the least, your life - a second chance. (Orfalea 235)

As this quotation suggests, writing and particularly the writing of one's life, gains a unique status in which truth and reality - despite the awareness of construction remain key intentions of writers. Distortion and mimicry are not seen as opposites but merely contribute to the creation of an even more elevated reality that is not labeled as fiction.

Additional confirmation for this longing to define the undefinable, to read and write truth, can be found when walking through book stores or by scanning the catalogues of presses. One finds that autobiographies in many cases are found under 
the category "nonfiction" (Whitlock 111). This longing of the readership to consume autobiography as non-fictional work also became obvious in the aftermath of 9/11. All of a sudden, there arose an immense demand for non-fiction works out of the need to gain authentic insights into the personal, political, and cultural circumstances accompanying the tragedy (Whitlock 111). A "memoir boom" and the publication of other non-fictional works tried to meet the need for information expressed by the audience (Whitlock 117).

This elaboration on the genre debate in post-constructivist times leads to a simple but far-reaching finding: truth still matters in autobiography. When seeking information on particular events or life circumstances, readers seek facts not fiction, and they turn to autobiographies. The autobiographical pact, long declared dead by literary theorists (Smith and Watson, Reading Autobiography 200), therefore has not lost its relevance when taking a wholistic and less text-centered approach to the study of life writing. The criterion of truth thus continues to be the guiding principle of autobiographical production and reception. Eakin in this context infers that autobiographical writing is "rule-governed" ("Breaking Rules" 114). As he explains: "Telling the truth - this is surely the most familiar of the rules we associate with autobiographical discourse" ("Breaking Rules" 115). ${ }^{65}$ This finding highlights the lasting importance of truth which Foucault expresses in more detailed terms:

Truth is a thing of this world: it is produced only by virtue of multiple forms of constraint. And it induces regular effects of power. Each society has its regime of truth, its 'general politics' of truth: that is, the types of discourse which it accepts and makes function as true [...] the status of those who are charged with saying what counts as true. (Interview 72) ${ }^{66}$

Truth as based on factual narrative, as these words strikingly underpin, is not merely a theoretical abstract which can easily be deconstructed out of the autobiographical picture. Instead, truth represents the overarching concept linking central theoretical elements of life writing theory to the larger social realm. The key terms of truth, discourse, and power cannot be analyzed separately from each other, nei-

65 Similar to Whitlock's thoughts on the hoax, Eakin notices that the important criterion of truthful storytelling in life writing becomes most visible when it is broken ("Breaking Rules" 113). Eakin investigates this phenomenon in a comparative analysis of I, Rigoberta Menchú and Wilkomirski's Fragments ("Breaking Rules" 116). Both works have been considerably successful in the literary market place despite the fact that or even because their authors "stretched the truth" ("Breaking Rules" 113).

66 Bill Ashcroft and his colleagues in following Foucault make an even more universal claim in favor of the inseparabability of truth and power: "Truth is what counts as true within the system of rules for a particular discourse; power is that which annexes, determines, and verifies truth. Truth is never outside power [...]" (165). 
ther can any of them be removed from the theoretical debate shaped by an ideological battle between realists and constructivists.

This obvious gap between the importance of truth as perceived by literary theorists and the importance of the concept on the part of autobiography writers and readers has indeed become the subject of criticism, particularly among critics of social constructivism. Vivien Burr therefore calls for a more pragmatic ${ }^{67}$ approach in the academy and urges scholars to not lose themselves in arguments about the nature of reality but rather focus on "the construction of accounts and what they achieve" (Potter qtd. in Burr 21). Obviously, this calls for a detailed study of the audience. So far, this aspect has been mostly neglected by life writing researchers.

\section{“Audience Matters" - But How?}

In her analysis of autobiographical writings by scholars, Margaret Willard-Traub arrives at a seemingly evident but often forgotten finding: "Audience Matters" ("Scholarly Autobiography" 196). Although this insight should count as general principle for any literary scholar in the age of Cultural Studies, the gap between autobiographical practice and literary theory shows that the audience has not played a vital role in autobiographical research so far. The field is still dominated by textcentered analyses and Cultural Studies' initial promise to read 'texts in context' often steps into the background. Contemporary autobiography research thus suffers from a lack of reception research. One reason for this might be that some literary scholars show a lasting distaste for anything that counts as supposedly 'unliterary.'

In Literary Studies beyond high school level, there are two questions which count as inherently disqualifying for anybody pretending to engage in serious scholarship. The first one is: What does the author want to say in this text? The second one is: What does the reader think the author wants to say? Especially for constructivists, these questions are only important to the extent that their answers reveal the constructive nature of the readers' imagination. For audience studies, however, these questions are crucial. The first theoretical movement that focused on the audience more than on the text was reader-response criticism (Bortolussi and

67 In the highly abstract intellectual debate on constructivism and the latter's denial of the real world, pragmatism has almost been lost along the discursive spectrum. Pragmatism, nevertheless, is crucial for the concept of truth, since it assumes that questions of truth and action are inseparable. The approach therefore shares a somewhat anti-essentialist view of truth, yet, links it to a very practical call for social change. This differentiates pragmatism from more theoretical debates of poststructuralism (Barker and Galasinski 16). The role of theory is thus not undervalued in general, but the local adaptation of theory aims to describe the world in normative ways for the purpose of intervention based on human agency (Barker and Galasinski 17). 
Dixon 2). The movement emerged in the 1960s in the course of the succeeding interdisciplinary opening of the humanities. Reader-response criticism posed a direct challenge to New Criticism which assumed that the meaning of a text only lies in the text itself (Cruz 1; Iser 134). In contrast to other methods of literary analysis, reader-response criticism does not stand for one specific approach. Rather, the term has come to serve as a label for a plethora of different approaches to study the effects of texts on readers (Powell 16). All of these approaches share the common focus on the act of reading as central to the creation of meaning (Iser 5). The impact of the text itself is thus an issue of debate. Some reader-response critics deny any importance of the text and completely focus on psychoanalytical models of meaning creation and the personality of the reader (Powell 17; Iser 45). Others conceive of reading as a dialectical process where neither the reader nor the text should be given absolute preference in exploring how meaning is created (Powell 18). ${ }^{68}$

Independent from the debates on different versions of reader-response criticism, the movement certainly filled a gap in the theoretical landscape by drawing attention to literary interpretations from the audience. This very benefit, however, also turned into the major point of critique of reader-reponse criticism. Whereas interpretation constitutes an essential element in a post-realist world in which the 'real' always depends on the subject defining it, the complete shifting of the regime of interpretation from the text to the audience came to be perceived of as "hermeneutical anarchy" (Powell 17). Since there is no fixed meaning according to which the reader's reception of a text can be evaluated, everything becomes a matter of interpretation. Critics thus claim that reader-response research can only collect and explore these interpretations while providing no structured means to decipher the underlying "interpretative strategies" of readers (Cruz and Lewis 6; Leitch 116). ${ }^{69}$

Following the emergence of reader-response criticism in the field of literature, a theoretical milestone in the development of reception theory was set by Stuart Hall at the intersection between Cultural and Media Studies. In his 1973 essay "Encoding/Decoding" Hall turned around all previous assumptions about the nature of texts and the process of media communication. Whereas former approaches saw communication as inherently linear, meaning that information travels from the media to the audience where it is passively received, Hall established the idea of communication as a multi-directional process ("Encoding/Decoding" 163; McQuail

68 Others argue that dominance on the part of the reader can never be written out of the equation of response studies since it does not mainly depend on interpretation but on market sales figures (Whitlock 97; Darznik "Veiled Bestsellers" 6).

69 Stanley Fish with his theory of "interpretive communities" meanwhile has altered this view. He explicates that specific collectives of readers share common reading strategies to the extent that meaning creation overlaps and can be distinguished (Powell 17; Bortolussi and Dixon 8; Cruz 6). 
64; Gray 27). At the center of this approach stands the "active audience," which does not only receive media content passively but actively processes and reproduces information in public discourse (Gray 25; Davis 62). Hall's approach to look at communication from the perspective of the audience introduced a new mindset to discourse studies (Logan 54). Pertti Alasuutari in his overview of the different phases of reception research in Cultural Studies subsumes, Hall's model marked "the birth of reception studies" (2). ${ }^{70}$ As the title of his work reveals, he paid particular attention to the elements of "encoding" and "decoding" as "determinate moments," as he states (164). Hall hereby refers back to an earlier model developed by Philip Elliott which introduced the idea that the audience serves both as "source" and "receiver" of a message in a discursive context (Hall, "Encoding/Decoding" 165). The sequence of encoding and decoding then follows the logic that information becomes encoded in communicative structures that become part of public discourse. The messages received in this discourse are then decoded by the audience, actively processed and again encoded to form elements of "frameworks of knowledge" in discourse (Hall, "Encoding/Decoding" 165). Hall thus also sheds light on the relation between reality and construction, between language and code:

Discursive 'knowledge' is the product not of the transparent representation of the 'real' in language but of the articulation of language on real relations and conditions. Thus there is no intelligible discourse without the operation of a code. Iconic signs are therefore coded signs too [...]. Naturalism and 'realism' - the apparent fidelity of the representation to the thing or concept represented - is the result, the effect, of a certain articulation of language on the 'real.' It is the result of a discursive practice. (“Encoding/Decoding” 165)

Especially with respect to the theoretical underpinnings of discourse and their significance for present-day media discourse, it is noteworthy that Hall's model already entails the idea of interpretative power. Hall in this context mentions "preferred meanings" which emerge due to the fact that certain reading strategies are preferred over others ("Encoding/Decoding" 169). Similar to the debates surrounding reader-response criticism in Literary Studies, Hall distinguished three different scenarios regarding the impact of the reader on the process of encoding/decoding. One scenario sees a hegemonic dominance on the part of discourse in which the reader fully acts within the given code. The second scenario focuses on negotiation whereby the reader partly adapts to but also partly opposes existing codes. The third reading practice is characterized entirely by oppositional decoding. Here, the reader

70 Without impairing Hall's lasting impact on the field, it needs to be added that "reception studies" as a subfield had already existed in communication research in the 1940s with prominent models developed by George Gerbner, Harold Lasswell, as well as by Claude Shannon and Warren Weaver (Alasuutari 3). 
intentionally interprets the message in a contradictory way (Hall, "Encoding/Decoding" 171-73). All three positions together account for the "politics of signification" within Hall's model of "encoding/decoding” (173).

The language used by Hall already indicates that his model not only made an immense contribution to the realm of literary reception studies. Instead of focusing on linguistic or deconstructivist terminology, Hall employed terms taken from various disciplines. The central significance of "code" underlines this practice. Due to this encompassing approach, Hall set the interdisciplinary basis for communication analysis in a broader disciplinary setting. Hall himself, nevertheless, limited the theoretical relevance of his approach. To him, "Encoding/Decoding" was not a "grand model" but an approach " which has to be worked with and developed and changed," as he once stated (Hall qtd. in Davis).

Instead of following this urge by stepping into the footsteps left by Hall and others, autobiography theory continued to neglect the readership as major source of knowledge. One of the earliest critics of this weakness was de Man. In his short essay "Autobiography as De-Facement" published in 1979, he identified the shortcoming of what was then contemporary autobiography theory. He introduces the essay by calling theories of autobiography not only "false" and "far-fetched" but also "aberrant" and "confining" because in his view, it presupposed assumptions about discourse which were "problematic," as he put it (919). Another well-known critic who argued in a similar vein almost two decades later was David Morley. He identified an increasing gap between reality and theory, between Literary Studies and society. Morley thus urged scholars to engage in "new audience research." Its purpose, however, was not to get lost in the practice of decoding and encoding but to return to methodological pragmatism and epistemological realism (122).

The target of the critique uttered by de Man and Morley was the incremental gap between the theory and practice of autobiography. As Sidonie Smith and Julia Watson in their overview of Autobiography Studies remark, audience research in life writing studies is severely underdeveloped (Reading Autobiography 92). Contemporary autobiographical theory therefore disregards the interdisciplinary groundwork laid by earlier theorists and mostly relies on literary approaches to reading. Since the latter continue to be dominated by the constructivist conviction that discursive reality does not exist, neither the author as initiator of discourse, nor the readers as active participants in autobiographical discourse are sufficiently accounted for. The focus remains on the text itself. This goes along with a simultaneous ignorance of many exterior factors influencing autobiographical production. When reading autobiography within the actual discursive network of the $21^{\text {st }}$ century, a theoretical approach is needed that combines all three elements of life writing; namely, the author, the text, and the audience. A theory of production and reception fulfills this promise. 


\section{Getting Practical: A Theory of Production and Reception}

If there is any quote which students of the humanities and of the social sciences are highly likely to share in the course of their studies, it is one by Kurt Lewin. The famous Polish American psychologist who shaped the interdisciplinary use of psychological theory in various fields is constantly quoted for his finding that " $[\mathrm{t}] \mathrm{here}$ is nothing so practical as a good theory" (qtd. in Goethals 7). As the shortcomings with respect to autobiography's tendency to lose itself in abstract discussions of the discursive while disregarding the analytical basis to actually explore discourse reveals, the field is in need of a theoretical uplift. This is particularly important since autobiography is more than just a literary object which finds itself in dialogue with itself but with the world at large. As Whitlock explains: "The 'unofficial' public sphere of literary, cultural, religious, and artistic movements are vital to political contestation and opinion formation; from this it follows that autobiographical narrative is an agent in complex global dialogues and encounters and a way of thinking through the interdependencies of conceptions of the self and other" (11). This finding expands the theoretical horizon even further and leads to a wholistic theory of "production and reception," which, however, does not disregard practical relevance (Golley, Reading 183). The starting point is to acknowledge the global market of life writing.

One of the few scholarly consenses in Cultural Studies is the finding that formerly separated cultures due to the influence of modernization and migration have moved closer together, at least in a virtual sense (Whitlock 13). This phenomenon is commonly summarized under the heading of globalization. ${ }^{71}$ Globalization has originally been discussed as an economic phenomenon based on the assumption that the mingling of cultures is mostly the consequence of the flow of material goods (Guarnizo and Smith 3). This development has particularly influenced the book market on an international level. In this "massively globalized" world, books circulate beyond cultural and national borders (Whitlcock 5; Damrosch, What Is 110). Amazon and Co. make it possible to read almost any book in any language within a few days after only one mouse click. The national or even local audience

71 Globalization is highly contested in the field of Literary Studies and is denigrated as "flawed concept" (Whitlock 8; Fluck 73). Authors who draw attention to texts as cultural commodities are therefore often criticized. An example of this is Whitlock's critique of Arjun Appadurai (72). She shows a strong tendency to reduce Appadurai's argument only to the negative sides of commodification. A less ideological reading of Appadurai reveals that he in fact provides one of the most nuanced approaches to the integration of globalization in Cultural Studies. This also goes along with a very detailed analysis of the concept of the commodity (Appadurai 7). 
of former times is thus replaced by a "transnational reception environment",72 (Vinson 79). This particularly applies to ethnic autobiographies which are gaining more prominence. As Whitlock states, life narrative thus represents an "exotic" commodity in a world of mobile texts" (Whitlock 4).

As the vocabulary used in the context of an ever-expanding globalization of the book market indicates, autobiographies are increasingly seen as "objects" of a mass market of popular culture that is ruled by "consumer capitalism" (Naficy qtd. in Whitlock 183). Life writing therefore does not only find itself "in transit" with respect to the crossing of national borders but also regarding the very definition of the genre (Whitlock 8). The latter thus turns into a "material genre" (Willard-Traub, "Rhetorics" 512). These changed dynamics of the market of autobiographical production and the definition of autobiography as commodity has ultimately forced autobiographical scholarship to reposition itself. Sidonie Smith and Julia Watson in an essay entitled "The Rumpled Bed of Autobiography", "74 take up this challenge by posing the following question:

To what extent does our theorizing itself need to be remade by contemporary practice at these 'rumpled' sites of the experimental, so that we may take account of changing autobiographeraudience relations, shifting limits of personal disclosure, and the changing technologies of self that revise how we understand the autobiographical? (13)

As these lines emphasize, the changed nature of autobiography in a globalized world also brings about a different analytical perspective based on a changed notion of literary functions and roles (Whitlock 14). Whitlock's response to this movement suggests an analytical shift toward the audience because "what readers do with texts, and how texts circulate as commodities, must become vital components of autobiography criticism," as she explains (Whitlock 13). Cultural and Literary Studies despite their obvious interdisciplinary shyness to integrate approaches from

72 The increasing importance of the transnational approach is not only limited to the study of literature and media audiences. It also reflects the dynamics of literary production in an ethnic context. As Carol Bardenstein explains, "formerly, there were mostly unidirectional immigrant narratives. Today, the demographics are changing. People are not settled in one place. The distinctions of cultural identity are not clear-cut. I therefore find the transnational approach more fruitful" (Personal interview).

73 The term exotic has a long history, both in the dissemination of Orientalist images of the East in historical representations and travel narratives and in the academic discussion thereof. Ethnic autobiography is thus suspected to arouse an "exotic appeal" that is targeted toward "the consumer as an enlightened, sympathetic, and politically correct individual [...]" (Whitlock 15).

74 The article explores the "Rumpled Bed" as a recurring theme in avant-garde life writing. 
the sciences - not to mention economics - have finally acknowledged this economic development. ${ }^{75}$ The market of books is increasingly seen as "culture industry" which is supported by readers as consumers in "capitalist systems of production and consumption" (Whitlock 15).

Given the fact that the audience to a large extent has been neglected in Autobiographical Studies, this inclusion of market trajectories certainly represents a welcome step toward developing the field. Despite this broad embracing of the audience, however, not much advancement can be noticed. One reason for this stagnation is of a methodological nature. Viewing the reader as consumer and thus essential part of the book market indeed emphasizes the reader's role. The problem remains, however, that Autobiography Studies lack the methodology to study consumer behavior beyond Amazon sales figures (Whitlock 16). The link between textual means of analyses and market data evaluation is missing.

The other reason for the lasting disregard of a more market-centered approach to the autobiographical audience is a normative one. The view of the reader as "market reader" is inherently linked to the highly detested notion of power and cultural decline in an era of commodification (Waring qtd. in Huggan 165). While it is not so much the traditional notion of colonial power based on cultural dominance which accounts for this normative condemnation, the economic force exerted by the consumer is still thought to maintain colonial power trajectories. The fear of "cooption" (Muecke qtd. in Huggan 160) and appropriation combined with the impossibility of autonomy is thus reawakened in a market world where the Western reader has the legitimizing power to judge cultural authenticity (Huggan 164; Bissell 194). ${ }^{76}$ Globalization, according to post-Marxist critics arguing in this vein, therefore brings along another threat of colonialism. Whitlock identifies this phenomenon in the context of Arab American life writing post 9/11: "Narratives from Afghanistan circulate in the war on terror as commodities that become part of a debate about the politics of intervention and resistance. What does the flood of life narratives make available to the metropolitan West: spaces for dialogue and exchange, or a reemergence of the stereotypical and mythic East?" (53).

The latter critique of commodification as new form of colonialism certainly is justified given the long and often oblique means through which colonialism repre-

75 Although Whitlock does not see many positive side-effects emerge from popular culture books in the mass market, she nevertheless acknowledges that these works can make a cultural impact if new audiences are reached without cooptation. As an example, she mentions Mahmoodi's Not Without My Daughter (102).

76 The discussion of the market and its impact on Literary Studies has given new momentum to the debates on native informants (Banerjee, "Between the Burqa" 322; Fritsch-elAlaoui 26; Huggan 156). Authenticity, as Huggan thus concludes, also turns into a myth in this market situation (Huggan 166). 
sented economic exploitation as means of cultural oppression. What remains questionable, however, is whether this historical legacy also justifies the highly normative and less analytical move to condemn the concept of life writing as commodity. This harsh denigration of the market audience disregards the opportunities emerging from this new and rather economics-based perspective. Commodification here provides the essential basis for life narratives to reach larger audiences (Whitlock 18). The aspect of economic commodification therefore represents a requirement for autobiography to become part of public discourse in the first place, not some additional cultural burden underlining the decline of culture.

Literary scholars therefore err in reducing the meaning of memoir as commodity $^{77}$ merely to the aspect of money. This reductionism disregards the underlying potential which the market - not only in monetary but especially in conceptual terms - opens up for a more comprehensive study of life writing. Nawar Al-Hassan Golley in this context calls for a theory of "production and reception" (Reading 183). The key to establishing such an approach lies in accepting that "multinational publishing enterprises, mass media, and migrant audiences" represent the real environment for autobiographic discourse (Whitlock 4). If autobiographical writing is accepted as part of this globalized market environment based on its entity as cultural and material good, it also becomes clear that life writing today not only represents a literary tool but a discursive medium that competes with other media in a global market.

\section{Life Writing as Mediated Memory}

"Can we ever distinguish between fact and fiction in autobiography, any more than we can in our media?" Waïl Hassan quotes from Ihab Hassan's Rumors of Change ("Arab-American Autobiography" 12-13). With this question, he points to the most pressing issues facing contemporary autobiography theory today. One is the lasting struggle over genre divisions separating fact and fiction, whereby Hassan's question already reveals an answer to this. Obviously, the genre classification based on fact or fiction becomes obsolete if the two cannot be separated (W. Hassan, "ArabAmerican Autobiography" 8). Most important about Hassan's argument, here, is the link he creates to the media sphere. Despite focusing on the impact of autobiography as a commodity in the market place, Hassan builds the bridge to seeing and reading life narrative in an even larger context. This context is not only one of glo-

77 Based on the etymology of the word, commodity historically stands for any natural or economic good. Its value is not merely measured in financial terms but also based on its general capacity to bring about benefits. The one-sided reduction of the term to monetary aspects is therefore misleading, especially since "exploitation" and the loss of value are only some possible effects linked to commodity trade ("Commodity," def. 5). 
bal money making and advanced means of technological invention but the one of mass communication. Autobiography here comes into play as mediated memory.

When linking the keywords of media and autobiography, one wonders if there really remain any new findings to be explored. After all, autobiography research, just like Literary and Cultural Studies at large, has integrated the media age into the curriculum. Hardly any conference, book, or article centers on written literary works only anymore. Rather, videos, movies, computer games, and other media are analyzed alongside and in comparison to each other. Especially digital forms of life writing therefore comprise an expanding field of investigation. This also underlines the fact that the definition of life writing as such has undergone another expansion. It now explicitly includes online sources and digital writing (Smith and Watson, Reading Autobiography 4). New technologies are thus seen to open up new textual forms for the transmission of life narratives (Whitlock 18). This in turn also alters the notion of the social world in which these narratives are created. Smith and Watson thus see a "time of simulated realities - on television, in everyday life, and in the virtual reality of cyberspace" ("Rumpled Bed" 10).

When scrutinizing this seemingly interdisciplinary approach to the study of life writing in the context of the media revolution, one aspect is quite remarkable but hardly ever noticed: the debate in the context of new media in literary Autobiographical Studies almost exclusively has the meaning of "new media"78 and/or "digital media" (Whitlock 18; Smith and Watson, Reading Autobiography 189). Only non-traditional formats and mixed-media ${ }^{79}$ modes of life writing are devoted increased attention, especially when it comes to their impact on different audiences (Smith and Watson, Reading Autobiography 286). The continuing debates on the uses and abuses of social networking sites as forms of new-media life writing but also scholarly investigations of alternative life representations, e.g., in the form of "avant-garde" digital artwork, represent some examples of the expanded analytical scope brought about by the new media age (Smith and Watson, Reading Autobiography 183). The significance of the concept of media as such therefore has undoubtedly gained prominence in the study of life writing.

The obvious excitement of literary scholars when it comes to the exploration of alternative forms of life writing should probably cause equal excitement on the part of the media scholar. If looked upon from a critical perspective, however, Literary

78 A definition in contrast to traditional media underlines the main features of new media, i.e., the facilitation of "many-to-many conversations," the simultaneity of distribution and reception of cultural objects and instant global connectivity (McQuail 138).

79 Mixed-media representations may combine old and new media formats at the same time. An example is a video (i.e., old media) posted on the personal site of a user on a social networking platform (i.e., new media) (Kunczik and Zipfel 56; Smith and Watson, Reading Autobiography 183). 
and Cultural Studies' flirtation with (new) media is puzzling. Why does a 3-Dmovie depicting the life of a famous character or an emotional blog entry of a teenager all of a sudden tempt the literary scholar to consider the larger context of mediated discourse? Are only new media real media? Have books been deleted from the list of media? Hardly so. As a closer look at the concept of media reveals that autobiography as a medium existed long before facebook and twitter triggered the media debate in Autobiography Studies.

A medium is generally defined as "a means of effecting or conveying something" ("Medium," def. 2a). More specifically, a mass medium is "a medium of communication (as newspapers, radio, or television) that is designed to reach the mass of the people" ("Mass Medium"). ${ }^{80}$ Single individuals in this collective are referred to as "recipients" (my translation, Kunczik and Zipfel 55). Today, the term mass media has mostly become used in the specific context of even more advanced technologies which make communication possible with an increasingly global audience (McQuail 55). Furthermore, the term mass media also covers institutional aspects as characterized by the following attributes: 1) the production and distribution of symbolic content, 2) operation in the "public sphere," 3) participation (either as sender or receiver) is voluntary (McQuail 58). Following these criteria, the terms mass communication and mass media are not to be equated since mass communication constitutes a process which takes place through the means of mass media as major actors shaping this process. In result, relationships between the media and their audiences emerge. In contrast to interpersonal communication where this relationship is immediate, the relationship between mass media and audience counts as "mediated" (McQuail 55; Gray 33). The activity of mediating thus refers to the process of conveying information as an intermediary agent ("Mediate," def. 2a). Mediation, ${ }^{81}$ mostly used as a noun, however, also has a second meaning: an "intervention between conflicting parties to promote reconciliation, settlement, or com-

80 Similar to the theoretical debates on the concept of the "public" in popular culture research, the term "mass" in the field of Communication Studies remains contested. The term signifies an undefined but large number of people assumed to share certain characteristics and react to media stimuli in a similar way. This homogenization therefore does not allow for any differentiation on the individual level (McQuail 560).

81 Mediation is not equal to the term "mediatization." Whereas mediation describes the use of media to communicate information in a rather neutral sense, mediatization aims at the instrumental use of media to achieve a maximum affective impact on the audience. It often goes along with distorted representations of events to fulfill the "media logic," i.e., specific rules and values which are seen to constitute effective media coverage (McQuail 563; Kunczik and Zipfel 87). 
promise ("Mediation"). ${ }^{82}$ In other words, while mediation refers to the process of conveying context through media use, mediation can become an intention of this mediation process with the goal of reconciliating diverging views or concepts.

Although the given definitions hardly play a role in the writings of the majority of Cultural Studies scholars working on (new) media life writing, they are nevertheless central to the interdisciplinary study of life writing in the media context. Especially the double-meaning of mediation is of immediate relevance for the following analysis. The given definitions in sum point to two simple but conceptually crucial findings. The first one is that books - no matter if fictional or non-fictional - represent print media, ${ }^{83}$ just like other journalistic formats, such as magazines and newspapers (McQuail 25). ${ }^{84}$ The second relevant finding connected to this is that a medium "is not just an applied technology for transmitting certain symbolic content," as McQuail points out. Instead, it represents "a set of social relations" (136).

Both of these findings are hardly ever acknowledged by literary scholars who unjustifiably draw a conceptual line between books and media, between autobiographies and new media life writing. There is no reason to assume that traditional print media are not media anymore, simply because new media have now complemented the range of media options available. In addition, the categorization into mass media does not depend on intrinsic qualities of the respective medium but on the audience it seeks to attract. Written autobiography as a means to impact dominant discourse, i.e., the discourse ruled by the mass of the people in a given society, therefore represents a medium. This medium competes with other media formats of life writing but also with other media at large. ${ }^{85}$ This "plurality of media" accounts for the fact that every autobiography exists in a "situational relationship" with the media environment establishing public discourse (Angus 247). Hence, there is no justified reason for claiming that life writing on the one hand represents a discursive means, as scholars of autobiography have constantly claimed, while at the same time limiting their analysis either to the literary realm or to the study of new media.

82 McQuail points out that the concept of mediation as a form of reality intervention by the media represents a metaphor in the shape of a "window," "mirror" or "filter" (83).

83 Many decades before the media revolution, de Man already established the link between life writing and Media Studies when describing the role of the autobiographical writer as someone who employs the "resources of his medium" (172).

84 As major characteristics of the book as medium, McQuail mentions so-called "[m]edium" and "[i]nstitutional aspects" (McQuail 27). Among the medium aspects are criteria such as multiple copy distribution and individual authorship. The institutional aspects include the book as commodity, market distribution, and the freedom of publication.

85 The emergence of life narratives in various media formats has come to be subsumed under the heading "automediality" (Smith and Watson, Reading Autobiography 168). 
When conceiving of life writing as medium in social discourse, the question of mediation also becomes important. In the past, scholars in the field have experimented with the concept of "mediated memories" in the context of the "Digital Age" (van Dijck). When recalling the quality of mediation as a process, however, this single-minded understanding of autobiography does not suffice. Instead, mediation in the case of autobiography as part of media discourse actually takes place in at least five different ways: 1) Personal memory is stored under specific historical and discursive circumstances which are themselves ruled by mediated discourse (Golley, Reading 184). 2) The recollection and reconstruction of this memory is influenced by the discursive surroundings in the instance of memorizing (Eakin, How Our Lives 106). 3) The (re-)construction of these memories intentionally or unintentionally mediates, i.e., alters, the content based on complex processes of cognition. 4) The goal of this mediation can itself be mediation, i.e., the reconciliation of diverging discursive arguments. 5) Life narrative is mediated to the audience in the form of different media representations.

These logical inferences from the definition of media and media discourse altogether illustrate the nature of life writing as mediated memory. Obviously, the artificial division between old and new media life writing does not shed any light on these complex trajectories. Eventually, this also explains why life writing has not been analyzed as part of the larger social and political media discourse. Doing so not only requires a conceptual but a methodological basis. The traditional text interpretation practiced in the humanities here meets its limits.

\section{From Literary Interpretation to Interdisciplinary Analysis}

Moreover, as the bonds of discourse are loosened, the mind will be freed from the constraints those bonds imposed, and the person thus freed will move toward "the full development of all human faculties" [Ryan 490], leaving behind the narrowness of vision that befalls those who remain tied to the confining perspectives of the ideologically frozen divisions of intellectual labor. (Fish 101)

Interdisciplinarity remains one of the most important catch words of contemporary scholarship. In fact, it has come to represent a "movement" in and of itself, as the American anthropologist George Marcus states with respect to the expansion of Cultural Studies as a field (174). ${ }^{86}$ Everybody therefore has to work 'interdisciplinarily' in order to be acknowledged, so it seems. This often gains the shape of being interdisciplinary "for the sake of being so" (Gibson and McHoul 25). Stanley Fish once put the matter into even more polemic terms when speaking of the "gospel of interdisciplinary study" in his essay "Being Interdisciplinary Is So Very Hard to

86 Marcus mostly discusses interdisciplinarity in the context of anthropology (175). 
Do" (106). ${ }^{87}$ The latter thesis especially gains confirmation when looking at contemporary Autobiography Studies. The field offers a particularly fruitful terrain for interdisciplinarity. As Whitlock remarks: "Life narrative is not disciplined, and in particular it is not contained by the Literary or the literary [...]" (193). ${ }^{88}$ This transcendence of the (L-/l-)iterary is facilitated by life writing's long inclination for interdisciplinary discourse analysis. The views of what discourse and interdisciplinarity here really mean, though, vary considerably, as has already been demonstrated. When taking interdisciplinarity seriously for the sake of actually expanding the analytical instrumentarium, one finds that more is needed than the losening of the definition of the literary. Rather, a methodological bridge between hermeneutics and empiricism is essential.

Interdisciplinarity is defined as "involving two or more academic, scientific, or artistic disciplines" ("Interdisciplinarity"). ${ }^{89}$ In Literary Studies in particular, this disciplinary border-crossing takes various forms. The most common practice of interdisciplinarity is the integration of terms and concepts from other fields (Paulson 49). Furthermore, interdisciplinarity is also used in the sense of intertextuality, ${ }^{90}$ i.e., a comparative approach to different texts as sign systems (S. J. Schmidt, "Literary Studies" 4). In addition, the cross-disciplinary cooperation of designated

87 Fish based his critique on the assumption that interdisciplinarity was inspired by Marxism and deconstructionism. He essentially argues that the way in which interdisciplinarity is practiced often ends up in anti-professionalism, whereby different fields "colonize" others for selfish ends (99). Due to these lasting difficulties, even young and innovative scholars nowadaysstill criticize the lack of true interdisciplinarity. This especially refers to the link between Literary and Cultural Studies. In short, "more interaction is needed between media scholars and researchers in literary studies," Alsultany acknowledges (Personal interview).

88 Whitlock here refers to the work of Ken Gelder who introduced the differentiation between the "literary" and the "Literary." The "Literary" to him signifies an explicitly artistic orientation of popular fiction (14).

89 As Stanley Fish in his polemic and thought-provoking essay points out, the term interdisciplinarity, defined as the crossing of disciplinary borders, is a tautology because disciplinary realms are to a large extent arbitrarily "compartmentalized" (100) and the product of "political construction" (109). According to Fish, these artificial borders bring about "divisions of knowledge, in a sort of segregated disciplinary discourse" (103). Fish even goes so far as to label these divisions "disciplinary ghettos" (100).

90 Intertextuality has its roots in structuralism and is interested in the connection between different sign systems in the process of meaning creation. Texts of all kinds, including visual, virtual, and oral material, are assumed to depend on each other based on common codes (Childs and Fowler 121). Thereby, the exact border between texts as containers of other texts and as separate entities can hardly be drawn (Barker and Galasinski 68). 
experts from various fields on common objects of study is also referred to as interdisciplinarity (Campbell 132).

In the realm of Autobiography Studies, interdisciplinarity is embraced by popular culture research (Kellner 140). In contrast to Cultural Studies at large, popular culture research pays particular attention to the cultural artifacts that previously counted as "trivial" (Jensen 97). This includes texts and meanings produced for and by popular audiences. ${ }^{91}$ Popular culture research therefore combines Media and Literary Studies by approaching culture as mass-mediated phenomenon (Jensen 91). It also has a political connotation in its longing to disentangle the struggle over meaning in society and the constitution of "citizen publics" (S. Smith, "Autobiographical Discourse" xix; Barker, Cultural Studies 485). Whitlock defines the "popular" in autobiography research as "distinguished by the whole apparatus of production, distribution, advertising, promotion, and consumption" (94). ${ }^{92}$

This overview of research efforts beyond the traditional confines of literature in Autobiography Studies might evoke the impression that there is no shortage of interdisciplinarity. This view appears in a different light when looking at the specific nature of joint projects. Uniquely transdisciplinary publications are hard to find. Almost exclusively, cooperation takes place within the confines of the humanities, whereby literary scholars often work with scholars in film studies, comparative literature, history, and linguistics. A welcome exception is the recent integration of

91 Contrary to the clear delineation between writer and reader, production and reception, popular culture definitions of autobiography include the reader as producer of literature.

92 This definition of the "popular" is in line with a theory of production and reception that spans the whole life cycle of literature. The negative evaluation of commercialism, however, reveals that the field of popular culture is still highly contested in the academy. Even though institutionalized since the 1980s, proponents of the "'hard' sciences" still judge the objects of popular culture research as "trash" (Jensen 97). In order to adhere to some theoretical space of their own, researchers in popular culture are therefore hesitant to openly equate popular culture with "mass-mediated culture" in order to emphasize the authenticity of genuine culture in society (Jensen 91). In general, it is a characteristic of Cultural Studies to work against the division between high and low culture (Kellner 140; Alsultany, Personal interview). This also marked the major separation between the Marxist tradition of the Frankfurt School and the British vein of Cultural Studies, whereby the former emphasized low culture to resist high culture class pressure (Kellner 141). In addition, contemporary scholars emphasize that Cultural Studies pay tribute to the fact that various forms of cultural production must be analyzed alongside each other. As Evelyn Alsultany notes: "One goal of Cultural Studies is to make sense of texts, and media is a primary text in U.S. culture" (Personal interview). 
concepts from cognitive science, neurobiology, psychonarratology, ${ }^{93}$ and neurophilosophy (Eakin, Living Autobiographically 124; Bortolussi and Dixon 3-4; Smith and Watson, Reading Autobiography 210; Dixon 5; de Zepetnek 6).

Overall, this view of interdisciplinarity that mostly limits itself to the realm of the humanities raises the question of interdisciplinary method. In the case of interdisciplinary cooperation among Cultural Studies scholars, the methods applied are highly similar since scholars in the humanities continue to rely on the method of interpretation. In cases where the sciences are indeed considered and the inderdisciplinary border to the social sciences transgressed, as in the case of cognitive science research, interdisciplinarity mostly involves the inclusion of findings from these fields, not the integration and active application of methods. Although this practice does exceed the boundaries of one's discipline as far as the object of research is concerned, it remains questionable whether the exclusion of interdisciplinary method really counts as interdisciplinary practice. Stanley Fish raises a thoughtprovoking question in this resepect: "[D]oes the practice of importing into one's practice the machinery of other practices operate to relax the constraints of one's own practice" (Fish 107)? In quoting Stearn, Fish demonstrates the logic of this trajectory by using the example of historians: "What has happened is that social historians have borrowed topics, concepts and vocabulary [...] but they have then cast them in an essentially historical frame [...]" (qtd. in Fish 107). Jacques Derrida once described this type of limited interdisciplinarity as "outward," meaning that it is rooted in existing academic disciplines and practices and does not create something genuinely new (qtd. in Campbell 132). The contemporary critic Hilfer puts this neglect of true interdisciplinary theory in even harsher words: "Theory is calcifying to blindness as its discourse approaches a point of scholarly entropy where 'texts' are endlessly 'interrogated' by application of a set grid of predictable and unexamined assumptions" (xi).

Both, the practice of autobiographical research to stay close to its own methodology and the tendency to only import but not apply established concepts from the sciences, confirms this tendency toward a certain pseudo-interdisciplinarity. Literary Studies thus employ hermeneutics ${ }^{94}$ and close reading as their major means

93 Psychonarratology is one of the most recent interdisciplinary offsprings in the study of literature. Based on cognitive science, psychonarratology almost exclusively rests on empirical methods to understand the reception process of readers. Adherents praise it as the future path to discourse analysis (Bartolussi 24).

94 Siegfried Schmidt does not neglect that today's hermeneutics differ from the methods employed before the 1960s because they are more theory-oriented and rely on "analytic philosophy" (3). Still, the belief in intuition as major source of interpretation remains the driving force in Literary Studies. This view stands in fundamental opposition to the harsh rejection of master narratives which otherwise dominates the field. 
of analysis (S. J. Schmidt, "Literary Studies" 4; Childs and Fowler 103). Very often, these hermeneutically-derived interpretations take the shape of highly subjective and often purely descriptive accounts (Miall 24). Autobiography Studies as part of the humanities still center on "Verstehen" in the sense of "interpretative understanding" rather than on scientific procedure (Slingerland 226). The term analysis thus continues to be a synonym for interpretation. As Chris Barker and Dariusz Galasiński point out, "[a]nalysis is interpretative: the process is laden with researchers' attitudes and beliefs," which consequently brings about a high degree of "arbitrariness" (64). Steven de Zepetnek adds that this is an inherent weakness in Literary and Cultural Studies (1). Some consequently question the existence of any method in Literary Studies at all (3).

The latter critique is mostly applied by scholars who observe an inherent resistance to any type of empiricism in Cultural Studies (de Zepetnek 1). ${ }^{95}$ The empirical method is based on observation, i.e., the collection of data under reduced terms of complexity. These data in turn are used for the testing and modification of theories and models (S. J. Schmidt, "Logic of Observation" 304). The underlying assumption is that "empirical knowledge is functional knowledge," which means that it seeks to explain the construction of this knowledge through the means of observation (S. J. Schmidt, "Logic of Observation" 309). ${ }^{96}$ As compared to merely text-based analysis, empirically-minded scientists presuppose that meaning indeed is not inherent to the text itself, as especially structuralists argued. Not the product of literary creation and analysis therefore is the focal point of attention, but the process through which meaning is created, i.e., the process of interpretation based on a systemic and logical methodology (S. J. Schmidt, "Logic of Observation" 309). The underlying philosophical root of the empirical method can thus be found in realism whereby ideas and general concepts are judged according to "how well they explain particularities" and not by the particularities of a text or social phenomenon themselves (Hilfer 66).

The empirical procedure thus takes into account what Lejeune and de Man already hinted at in the constructivist era - the fact that autobiography and its effects

95 Slingerland attributes this resistance to empirical inquiry to "postmodern skepticism" (221). Without denying that objectivism poses many problems due to essentialist notions of truth, he still sees an urgent need for more empirical inquiry. This explanation highlights that the friction between scholars in the humanities and in the sciences partly rests on a misunderstanding. Obviously, both reject ultimate truth claims and the notion of absolute objectivity, yet, they still adhere to very different means of analysis.

96 When including the larger context of Orientalism surrounding this work, it must be pointed out that the empirical method still counts as prime example of Western rationalism which in turn contributes to the high "prestige of science" found in Europe and the United States (Slingerland 221). 
rely on a mode of reading as activity. ${ }^{97}$ In the academy, this strain of thought was taken up and theorized under the heading empirical Literary Studies which emerged in the 1980s as "collateral to [radical] constructivism (de Zepetnek 2). Empirical Literary Studies ${ }^{98}$ directly challenge the omnipresence of "axiomatic" assumptions in favor of empirical enquiry (Miall 12). Based on the notion that literature is a social phenomenon, empirical Literary Studies rely on the meta-theoretical basis of analytical philosophy and Karl Popper's critical rationalism (S. J. Schmidt, "Literary Studies" 3). There are four analytical core pillars in empirical Literary Studies: 1) the production, 2) the distribution, 3) the reception, and 4) the post-processing of literary texts. Post-processing describes the process of referring to literary texts in relation to other media offers. This means that the literary text ${ }^{99}$ is necessarily embedded in social processes operating under social, cultural, political, and economic conditions of the respective society" (S. J. Schmidt, "Literary Studies" 3).

These general principles of empirical Literary Studies strikingly highlight an earlier finding, namely that any text must be studied by taking into account its production and reception (S. J. Schmidt, "Literary Studies" 4). Instead of just calling for such a comprehensive approach, empirical Literary Studies also provide the respective methodology. By setting a primary focus on the processing of literature by the audience, empirical Literary Studies form the so far lacking link between text and audience. The essential basis is rooted in realism since processes of reading despite the subjective construction that takes place in individual cases - are seen as "real acts" which can be investigated through empirical observation (Miall 2). ${ }^{100}$ This methodology provides the tools for studying autobiography in a larger frame-

97 Interestingly, de Man in his critique already made a far-sighted statement on interdisciplinarity. "Empirically as well as theoretically, autobiography lends itself poorly to generic definition," he claimed (920).

98 Schmidt counts as one of the founders of Empirical Literary Studies (ELS). Although the approach fostered an analytical shift in Literary Studies because it moved away from the literary text to "the literary system" as object of investigation ("Literary Studies" 3), it must be underlined that the impact of ELS by far has not been overwhelming. Especially in the German academic landscape, traditional scholars are still "hostile" to the approach (Schmidt, "Literary Studies" 6). After the 1990s, hardly any publications or critical discussions on the topic can be found.

99 Due to the social embeddedness of literary works, empirical literary scholars have a different notion of texts. They therefore prefer the term "literary phenomenon" (S. J. Schmidt, "Literary Studies" 4).

100 Although Smith and Watson do not count as representatives of ELS, they call for the application of "case studies for advancing the auto/biographical method" (Reading Autobiography xxiii). This underlines an obvious longing of the field to move beyond traditional literary reading practices. 
work in which the processing of literature and its effects are investigated in comparison to other media for the purpose of "Delimiting the Literary" (Miall 33) instead of further emphasizing the "literariness" of autobiography (Miall 93).

This journey through the development of life writing studies demonstrates that the construction of self has occupied scholars from various theoretical angles throughout the decades. Especially the ideological war between realists and constructivists, the connected genre debates over fact and fiction, and a certain degree of methodological insularity have so far prevented scholars from developing an innovative methodology to comprehensively explore the constructed self and its real audiences. Especially "the healing and bridging power of literature" is thus continuously claimed as major function of autobiography but never actually verified by evidence on audience effects (Fadda-Conrey, "Racially White" 173). For the one keeping "at least one eye on the larger conditions" (Fish 108), it thus becomes obvious that axiomatic thinking about the role of autobiography in society does not equal scientific analysis. In other words, if autobiography indeed stirs a "transformative dialogue," (Fadda-Conrey, "Racially White" 194) all parties involved in this dialogue have to be accounted for in the study of life writing. In a world in which discourse does not take place in the private sphere of the home anymore but in the media environment, this dialogue becomes a complex trialogue between literature, the public, and the media. The question "how can memoir claim a distinctive place among the various news media in these times?" is therefore of limited relevance (Whitlock 137). Instead, accepting that memoir, due to its unique structural features, is already part of the news media marks its distinctive place in the field of literature. The question linked to this is not "what" autobiographical discourse in general does but "how"101 it affects public discourse (de Zepetnek 7). This requires an analysis of life writing in the context of mediated discourse. Media Studies and the theory of framing provide the analytical toolkit to carry out this "impossible necessity" (Huggan 175).

\subsection{Media Framing Theory}

The way we see other people depends on the window on which we look at the world, what we see through it, when, under what lights and shadows, and, especially, in what larger setting, for whatever the many varieties of individual experience, each one's outlook is perhaps most

101 De Zepetnek uses a similar logic in his interdisciplinary framework of "comparative cultural studies" as a medium path between hermeneutical and ELS. He devotes major attention to meaning creation as "process" and on the importance of methodology in literary analysis (7). 
heavily influenced by the larger political, economic and cultural facts of the relationship at the given time. (Isaacs qtd. in Shaheen, Arab and Muslim Stereotyping 29)

It is hardly a surprise to read these lines in the work of Jack Shaheen, the man who devoted almost his entire research to exploring the stereotypical representation of Arabs in the media. The "window" that every human being looks through counts as one of the most important concepts in contemporary media research and even in scholarship as a whole. Obviously, science today is equally interested in exploring some form of objective empirical reality as well as the different subjective realities people perceive (McQuail 86). These different ways of looking at the world are often described by means of metaphor. Shaheen uses the one of the "window" to express the fact that perceived reality not only depends on a particular perspective but also on limitation. The other most common metaphor to describe this selective and somewhat bordered view of the world is the one of the frame. Nearly all realms of social life can be clustered by imagining them in frames - be it the political, economic, or cultural sphere. In contrast to the 1960s, when autobiographical research made striking contributions, these frames today all act under the command of the media world. Autobiographies and their readerships are no exception to this rule. The theory of media framing investigates this phenomenon by shedding light on the question of how frames act in the construction and perception of reality.

\section{Defining Frames and Framing}

Framing first became prominent in the field of sociology. In his publication Frame Analysis: An Essay on the Organization of Human Experience (1974), the Canadian sociologist Erwin Goffman developed framing as an approach ${ }^{102}$ which explains how human behavior and interaction are structured by different frames (Frame Analysis 21). ${ }^{103}$ Nowadays, framing counts as one of the most prominent theories in

102 There are debates whether framing merely represents an approach, a model, or whether it fully meets the criteria of a theory. Most scholars use the term "model" to refer to framing based on the psychological mechanism underlying the concept (Chong and Druckman 115). The present study, however, will treat framing as a theory, since additional indicators underlining the explanatory capacity of framing will be added.

103 The book can be understood as a continuation and further theorization of Goffman's seminal work The Presentation of Self in Everyday Life (1959) in which he employed the analogy of the theater in order to compare acting on stage and everyday identity performance (124). Goffman's groundbreaking finding that human experience includes performative elements can count as inspirational thought for many contemporary theoreticians who have transferred the finding of performed identity to fields such as feminism, ethnicity, and gender studies (Smith and Watson, Reading Autobiography 43). 
the fields of communication, psychology, sociology, and linguistics (Dahinden 22; Druckman 1041). Frames also constantly appear in Literary Studies where concepts such as "frame narrative," "frame story," the framing of dialogue (Whitlock 75), "frames of reference" (Butler qtd. in Whitlock 191) and "frames of individual and collective responses" (Golley, Introduction xxxi) are used in very different contexts. In addition, a frame not only constitutes a scientific term but a widespread metaphor in common parlance (Entman, "Framing" 52; Slingerland 172). Due to this "omnipresence" of frames, the communication scholar Robert Entman has come to call frames "fractures" because the definition of the concept comprises so many diverse particles (Entman, "Framing" 51). While some of the uses in different fields overlap, they differ in others. When employing framing as an interdisciplinary approach to the study of autobiography in the media context, is it thus crucial to underline how the concept is used in Communication Studies. ${ }^{104}$

The media researchers Dennis Chong and James Druckman introduce the basic idea of framing in the following terms: "The major premise of framing theory is that an issue can be viewed from a variety of perspectives" (104). David Altheide describes a frame as "a border around a picture, that separates it from the wall [...]" ("News Media" 651). This illustrates that information is always presented in a specific context, which in turn evokes particular mechanisms of processing this information (Dahinden 67). The most commonly used definition summarizing these preliminaries is the one introduced by Entman who understands framing as "selecting aspects of a perceived reality and make them more salient ${ }^{105}$ in a communicating text, in such a way as to promote a particular problem definition, causal interpretation, moral evaluation, and/or treatment recommendation for the item described" (Entman, Projections 52). In complementation to framing as an activity, frames as the products of this activity are defined as interpretation patterns ${ }^{106}$ that help structure and process new information efficiently (B. Scheufele 46). Framing research has predominantly centered on the analysis of news media. This, however, should not conceal the fact that framing also takes place in the case of fictional media content (McQuail 374).

As to the relevant actors of framing, the mass media are assumed to create frames by providing the public with information. The way in which this media

104 The contemporary use of the term, even within the confines of Communication Studies, highly differs from the original definition of framing by Goffman (Dahinden 3).

105 Salience is defined as "making a piece of information more noticeable, meaningful, or memorable to audiences" (Entman, "Framing" 53). The concept is central in media effects studies and seeks to explain how the degree of coverage on a topic impacts the way in which this content is processed by the audience (Kunczik and Zipfel 355-56).

106 Scheufele differentiates between "interpretation patterns," "discourse patterns," and frames as "passepartout terms" (my translation, 40). 
content is perceived by the audience accounts for specific social problem definitions dominating public opinion (Altheide, "News Media" 650). Media frames with their capacity to impact public opinion are not assumed to be the only sources of framing in public discourse, yet they have proven to be substantial ones (Norris, Kern, and Just 13). This emphasizes that frames are not only defined by what they include, but naturally also by what they omit. Issues and interpretation patterns which do not appear in the definition of social problems dominating the media coverage therefore also alter the nature and extent of the problems that do gain public importance (Entman, "Framing" 54).

The most prominent example of a frame in Communication Studies, which for decades ruled the media reporting on a global level, was the so-called "Cold War frame" (Entman, "Framing" 52). Particularly in the U.S. coverage of news but also in many other countries, this meant that events that had no direct relation to the Cold War between Russia and the capitalist countries of the West were nevertheless represented as taking place in the context of this ideological warfare. ${ }^{107}$ As this example demonstrates, framing has the potential to impact political ${ }^{108}$ and social decision-making processes on a national and even global level. This has become the major target of criticism due to the possibility of abuse (Whitney, Sumpter, and McQuail 405). Chong and Druckman summarize the logic of the argument in the following terms: "If opinions can be arbitrarily manipulated by how issues are framed, there can be no legitimate representation of public interests" (104). Despite these politically-linked concerns, framing can also be seen in more "neutral" terms when regarding the cognitive benefit of the practice as a social learning process (Chong and Druckman 120). The media thus foster "cognitive development" and encourage life-long learning (Logan 54).

As to the multiplicity and dynamics of framing, Chong and Druckman state that frames "occur when (often small) changes in the presentation of an issue or an event produce (sometimes large) changes of opinion" (104). These changes largely

107 The Cold War plays a decisive political but also theoretical role in several discplines. The literary scholar Margaret Somers calls the struggle between capitalism and communism "metanarrative" (619). Mignolo also mentions the Cold War as an era which "redrew the map of the early modern/colonial world and displaced the colonial difference from the dichotomy between Occident and Orient to North and South" (34).

108 The effect of political framing counts as a driving motivation for the development of framing research. The first to prove direct relations between framed media reports based on the use of symbolic language and their impact on political views was Shanto Iyengar in the mid-1990s (Allen et al. 267). The original interest in this sub-field of public opinion research points to the legacy of World War II and its impact on Communication Studies. A driving urge was to reveal mechanisms of "political instrumentalization" and its effect on war-sentiments and patriotism (Kern, Just, and Norris 292). 
rest on the use of symbolic language or imagery (Allen et al. 267). The most prominent framing processes analyzed in Media Studies focus on visual and verbal framing. These two must be conceptually separated since they evoke different effects (Barnett and Reynolds 90; Coleman 239). ${ }^{109}$ Frames have proven to be stable over time (D. Scheufele 104), yet they are not static. Instead, they depend on constant repetition and reinforcement. If existing frames fail to be stable, "frame-shifting" occurs (Slingerland 172) and issues are "reframed" (Allen et al. 282). ${ }^{110}$

The most important external factors contributing to the replacement of a media frame is the occurrence of so-called "key events" (McQuail 317). In contrast to pseudo events ${ }^{111}$ as products of mediatization without much real-world importance, key events are real events which end up as big, mostly global, news. The reason for this is their immensity, their unexpectedness and their dramatic nature. Often, the coverage of key events quickly accelerates to unexpected levels. This is due to the fact that these events contribute to the creation of prototypes. Journalists are thus prone or "primed" to interpret similar events within the explanation pattern. Due to the self-reinforcing mechanisms of the global media market, this leads to a disproportionately high amount of coverage (Johnson-Cartee 287). Key events have such a large impact on the global media landscape and on public opinion that they ultimately alter or replace previous media frames (Ruigrok and van Atteveldt 74). This especially holds true for violent conflicts, wars, and natural disasters (Bennett 31 ). The most prominent example of a key event is 9/11. In the more recent past, the swine flu epidemic of 2009 constitutes another important example of a key event which ruled the global media coverage for weeks (McQuail 317).

The audience is thus often confronted with various competing frames at a time (Chong and Druckman 112). ${ }^{112}$ As experimental research indicates, recipients, when faced with this challenge, usually prefer the alternative that is consistent with their

109 This definition shows common features with the concepts of paratextuality or epitextuality in Literary Studies. Whitlock defines epitexts as "the messages located outside of the book that nevertheless signal its presence: media interviews, reviews, articles, readings, and private communications such as letters and diaries" (61).

110 Media production studies differentiate between "routine phases" and "orientation phases" (Scheufele 104). While frames remain relatively stable during routine phases, orientation phases give way to new frames.

111 A pseudo or "media event" is characterized by the purpose to receive media attention without necessarily having any real-world importance. Media events are particularly ascribed to television reporting. Examples include special celebrations, state visits, and national celebrations (McQuail 563).

112 Although a certain degree of coherence can usually be found when comparing different frames, one pressing question in current framing scholarship is why certain frames become stronger than others (Norris, Kern, and Just 11; Chong and Druckman 116). 
values or principles. "In short, being exposed to opposing sides of an argument increases consistency among decisions taken on specific policies and underlying principles" (Chong and Druckman 112). This demonstrates that the replacement of an existing frame depends on specific conditions, including pre-existing values and the relative strength of the opposition frame. ${ }^{113}$ As this definition based on the notion of "perceived reality" underlines, framing shares certain credentials with the constructivist $^{114}$ school of thought (Dahinden 73; D. Scheufele 104). Reality is thus assumed to be of a subjective nature. The degree to which framing impacts the individual, however, varies according to the degree of media consumption and other personal predispositions. ${ }^{115}$

This relation to personal identity aspects influencing individual framing effects in the audience highlights the close entanglement of framing research with the field of psychology, with the latter providing essential contributions to the study of framing. Both disciplines commonly understand themselves as parts of the social sciences which rely on empirical research methods. Three interrelated fields of investigation in psychology are of crucial importance for communication scholars: 1) knowledge units and their networking, 2) information processing, 3) psychological framing effects (B. Scheufele 13). Based on this sub-division, scientists in Media Studies - particularly in effects studies and media psychology - investigate the framing phenomenon and its effects as a multi-faceted and quite complex process

113 In general, strong predispositions, such as special personal values towards issues, have been found to limit the impact of frames by increasing the resistance to contrasting information (Chong and Cruckman 111). The strength of the opposition frame determines how far one is pulled away from an existing frame (Chong and Druckman 114). These findings that derived from experimental research are in line with the predictions made by cognitive dissonance theory as it will be discussed in more detail with respect to the changing of stereotypes (see "Of Scripts, Sparrows, and Stereotypes" in this chapter).

114 A more detailed categorization divides framing into a critical, constructivist, and cognitive paradigm, whereby the construction of mental models counts as defining feature of the cognitive approach (Ruigrok and van Atteveldt 71).

115 With respect to its capacity to shape the reality perception of the audience, framing shows strong commonalities with cultivation theory as developed by George Gerbner. The theory holds that, depending on the degree of media consumption, media content, and other personal characteristics, recipients tend to conflate the media world with the real world (McQuail 497). This leads to the thesis that especially increased television exposure "cultivates viewers" (Tehranian 105). The most prominent studies on this phenomenon have been conducted in the context of crime statistics. Viewers who display high news media and other crime-related media consumption generally overerstimate the real occurrence of crimes (McQuail 498). This example also demonstrates a major difference to framing research with the former being much more effect-oriented. 
(Chong and Druckman 110). This complexity is rooted in the fact that framing accompanies the entire communication process. As already suggested by the division of psychology into different research areas, frames can be identified in at least three locations: 1) on the part of the communicator, i.e., the journalist or the media in total, 2) the text or alternative media content, 3) the receiver of the message, i.e., the audience as reader, listener, or viewer (Entman, "Framing" 52).

When reviewing this short introduction to framing, the seemingly unlimited potential of the approach unfolds. Due to its close entanglement with the field of psychology and its relevance for very different stages of the communication process, framing provides seemingly limitless options for possible applications in a variety of fields (Barnett and Reynolds 47). Media Studies have come to occupy a specific function for the further development of framing theory due to their lasting efforts to synthesize and integrate the different theoretical and disciplinary strains (Entman, "Framing" 51). A central contribution in this respect has been the further theorization of schema theory which provides a crucial element for the interdisciplinary application of framing in Literary Studies.

\section{Mapping Schemata}

الحمـار يتعلــــم حـنى، التكــــــ The previous line expresses an old Arabic proverb which translates into "by repetition, even the donkey learns" (Merskin 164). This focus on learning as based on mere repetition, although true, only represents one aspect of learning processes. Another crucial component of learning is categorization based on so-called schemata. These schemata are responsible for the fact that even the reader who might not be able to read Arabic still recognizes the printed letters as Arabic by means of distinction from European or other sign systems stored in his/her memory. Schema theory constitutes a crucial element of cognitive psychology, and it has also come to account for the close link to framing research in Media Studies (D. Scheufele 103). Since framing is a cognitive process, schemata are assumed to constitute the conceptual basis of the theory. What complicates this interdisciplinary synergy is the fact that both concepts, i.e., frames and schemata, appear in both disciplines and often take on different meanings. ${ }^{116}$

116 While the degree to which communication scholars include psychological schema theory in their frameworks varies, it is largely acknowledged that schemata lie at the core of cognitive framing. Some communication researchers therefore use the terms frames and schemata synonymously, whereby framing tends to be used more interdisciplinarily (Dahinden 35). The focus on schemata marks a more psychology- and sociology-oriented approach. This emphasized the large potential for a theoretical synthesis (Dahinden 92-93). 
In cognitive psychology, frames are defined as "cognitive structures of organized prior knowledge, abstracted from experience with specific instances [...]." Their relationship to schemata is established based on the fact that "schemas guide the processing of new information and the retrieval of stored information" (Fiske and Linville qtd. in Dahinden 30). This general definition of the relationship between frames and schemata already reveals a hierarchical order, whereby schemata serve as overarching structures. An even more detailed exploration of the concept of schemata reveals the following:

In essence, a schema is a cognitive structure. This mental image represents a commonsense model of life situations that an individual has experienced directly or vicariously. Schemata contain information about the substantive elements usually encountered in the situation and the interaction of these elements. They are used to integrate new information into established mental images and to retrieve information. (Graber qtd. in Dahinden 90)

Psychological definitions also recognize the larger cognitive environment of schemata referred to as "stimulus domain." As the cognitive psychologists Shelley Taylor and Jennifer Crocker elaborate: "The schema contains general knowledge about a domain, including a specification of the relations among its attributes, as well as specific examples or instances" (qtd. in B. Scheufele 13).

These definitions already point to a close relationship between the concept of framing and the one of metaphor used in Literary Studies. The first to recognize this link in Autobiography Studies was John Eakin. In his work Fictions in Autobiography he explicitly establishes the connection between scientific research on schemata and life writing in stating that "the dominant trope of autobiography is metaphor" (187). This opens up an interwoven net of interdisciplinarity ranging back to Aristotle who defined metaphor as a figure of speech "giving the thing a name that belongs to something else; the transferrence being either from genus to species, or from species to genus [...]" (qtd. in Lakoff and Johnson 384). This logic of replacing a phenomenon by an orverarching image gave way to the modern understanding of "conceptual metaphor" whereby "Categories are Containers," as George Lakoff and Mark Johnson summarize (382). Based on these philosophical foundations, Urs Dahinden points to the most important characteristic of metaphor with respect to the use of the concept in framing theory; namely its dynamic quality. As he states, metaphors are "'nomadic,' that is taken up by interacting with various discourses over time, thereby showing their malleability both actively and passively" (79-80). From this he derives that the term "frame" itself constitutes a metaphor (Dahinden 79). ${ }^{117}$

117 Dahinden in his conception of metaphor stresses the significance of models and theories which travel from different scientific to "everyday discourses and vice versa" (79). 
This relationship between the terms frames, schemata, and metaphors as used in different fields of the academy - despite slightly different uses in each field - points to the most important function of frames as "mental images" (Graber qtd. in Dahinden 90). As the psychological contribution of schema theory suggests, these mental images are inherent to human thinking and learning. Schemata are the most basic means for people to process and structure information (Dahinden 92). This process takes place more or less unconsciously since schemata are activiated automatically whenever new information needs to be stored (Dahinden 60; D. Scheufele 106; Dixon 3). This cognitive function in turn is related to the act of communication. McQuail highlights this characteristic by emphasizing the support function of schemata: "A schema is an aid to communication and understanding, because it provides some wider context and sense-making" (567). Despite this very general function, Bertram Scheufele identifies the following specific functions of schemata in the context of communication research: 1) the structuring of experience, 2) the support of information acquisition, 3) abstractions of object classes, 4) the facilitation of interpretation, 5) the extension of existing schemata based on new information, 6) the categorization of existing schemata as well as 7) the expectation of particular values (14-15).

Based on the finding that schemata come into play at different stages of the communication processes, these functions must be further explored with respect to the actors involved. At one end of the communication process, the senders, i.e., the media as operated by journalists, represent "schematic experts" (B. Scheufele 17). Because of their constant exposure to dominant schemata in public discourse and their distribution of information, they are able to activate and employ very elaborated and interrelated schemata. Activation thus depends on the availability of background knowledge stored in the form of schemata in long-term memory (B. Scheufele 26). ${ }^{118}$ Schemata thus allow for the structured presentation of otherwise isolated events (McQuail 567). This demonstrates why schema-based media fra-

118 Information activation is the focus of priming research in cognitive psychology and Media Studies. Priming is often mentioned in close connection to framing. Priming, however, has a much more nuanced cognitive focus in that it explains the specific nature of different activation processes. The approach states that the more a specific scheme is enforced and reactivated, i.e., primed, the faster incoming information is categorized and interpreted according to this schema (Allen et al. 266-67; Scheufele 26; Semetko 361). Chong and Druckman even see a conceptual confusion in the simultaneous use of priming and framing. As they clarify, "priming may be thought of as a procedure that increases the accessibility of some category or construct in memory" (115). To them, an increase in the accessibility of information is not equal to a rise of salience concerning an issue. As these findings highlight, priming does contribute to the explanatory potential of framing, yet the two approaches need to be delineated. 
ming is a crucial part of the modern media routine. Schema-oriented processing of information thus allows journalists to structure and order high amounts of information under time and economic pressure. Only schematizing therefore enables them to quickly adapt to very dynamic and constantly changing discourse situations (B. Scheufele 17; Whitney, Sumpter, and McQuail 406). Due to this function of journalists to administer information by reproducing and creating schema-based frames, media terminology refers to them as "gatekeepers" (Dahinden 64). ${ }^{119}$

At the other end of the communication process, recipients of media messages process the information delivered to them within the frames created by the media. The cognitive function of schemata here is equal to the one of journalists. Yet, the degree of influence on pre-established frames is different. If audience members are not actively involved in the communication process, as holds true for the majority of traditional media ${ }^{120}$, they have relatively little power to shape the creation of new schemata. They are thus less autonomous ${ }^{121}$ when compared to journalists (Entman, "Framing" 56). Schema-based information processing on the part of the audience takes place both as a bottom-up and top-down process. Bottom-up means that information is extracted from the text or respective piece of mediated information and then categorized into an existing schema. Sometimes, this can lead to the creation of a new schema in the cognitive apparatus. Top-down processing, in constrast,

119 The term gatekeeper was first established by David M. White in the 1950s. It refers to individuals in the mass media market who have the authority to decide in favor of or against the publication of units of information. Gatekeepers can be found on different hierarchical levels, whereby they accompany the entire process of news media production (Kunczik and Zipfel 242). Gatekeeper research meanwhile constitutes a subfield of media research of its own (Kunczik and Zipfel 241; Dahinden 64). From the perspective of a literary scholar, the concept of the gatekeeper obviously represents a similarly evident metaphor as the term framing.

120 Low interactivity is still the major characteristic of old media, such as television, radio, and print. What communication scholars are most interested in when it comes to the question of audience involvement is not the issue of autonomy as such but the analysis of gratifications derived by the audience. These differ from the ones of new media consumption (Kunczik and Zipfel 350).

121 The question of autonomy, however, should not be confused with the larger concept of the active audience. Audience members are always assumed to actively process information. This processing naturally takes place based on individual predispositions so that no 1:1-relationship between incoming information and information output can be assumed. The question of audience autonomy is linked to the ideological and more normatively-oriented debate on the social struggle over meaning and definitions of social reality, as they are particularly prominent in Postcolonial Studies (Gamson et al. 385). 
means that incoming information is already processed and at times filtered, based on pre-existing information stored in schemata (D. Scheufele 23).

This actor-specific explanation of the function of schemata clarifies the connection between schemata and frames. Whereas some authors use these terms interchangeably, this study follows the approach chosen by Dietram and Bertram Scheufele. Cognitive frames are thus understood to consist of different interlinked schemata (110-11). Both audience members and journalists develop these cognitive frames when being exposed to information. Media frames, in turn, are the result of the media's framing of events in a particular way. These media frames activate a set of schemata on the part of the audience. Since the audience receives the information provided by the media based on pre-established cognitive frames, framed media representations can either meet these mental maps or consist of "frame-discrepant information" (Scheufele and Scheufele 112). In any case, it is most likely that media frames and pre-existing audience frames concerning an issue do not overlap completely, meaning that the media only activate parts of the schemata related to a cognitive audience frame. ${ }^{122}$ The degree to which audience frames and media frames overlap can be assumed to be rather high since some frames are more applicable to the activation of certain schemata than others. ${ }^{123}$ Scheufele and Scheufele mention the example of the operation "Iraqi Freedom" to demonstrate this effect. The mere terminology is likely to activate an audience schema linked to freedom rather than one related to economy or others (114). The degree to which the presented media frame shapes the cognitive frame of the audience is referred to as "frame adoption" (Scheufele and Scheufele 113). The following graph gives an overview of the interrelationship of cognitive schemata, frames, and their activation by media content.

122 Besides the schemata which are immediately activated by media framing, so-called "spreading activation" causes further schemata to be triggered, which show no immediate connection with the media frame provided. Spreading activation sets in because schemata all are interconnected. This means that information stored in neighboring schema are also affected without immediate stimuli (Scheufele and Scheufele 117).

123 The logic of this correspondence is in line with Stewart Hall's Encoding/Decoding model, though, empirical Media Studies use different parameters to explain the relationship between frame creation by the media and audience adoption. 


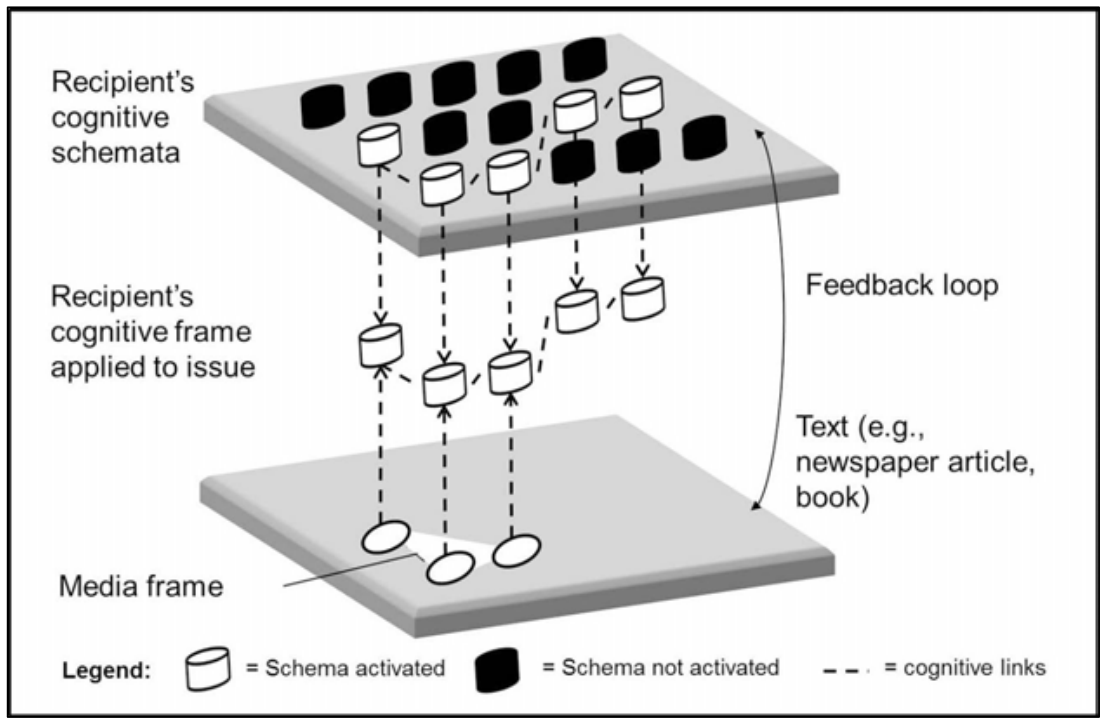

Source: Adaptation of wood board figure developed by Scheufele and Scheufele (118). The graph shows how pre-existing cognitive frames on the part of the recipient impact the processing of new media content. Media frames usually activate a limited number of audience schemata only. The total number and structure of activated audience schemata accounts for the cognitive frame applied to a specific issue.

When looking at the separation between the media as creators of frames and the audience as recipients of frames, it needs to be highlighted that this seemingly clear-cut division is a simplification for the purpose of model building. In an interrelated and reflexive media world, audience members quickly take the place of journalists and vice versa. The same logic applies to the recognition of "journalists as audiences" (D. Scheufele 117). Due to their professional environment, journalists also constitute their own audience, meaning that they are exposed to the frames created by their colleagues and social discourse at large (B. Scheufele 17; Dahinden 59). ${ }^{124}$ This notion might seem self-evident in light of today's assumption of the 'active audience.' Since framing, however, is constantly criticized due to the possibility of undermining audience autonomy based on frame manipulation, it needs to

124 This role switching between sender and receiver on the part of journalists is a major research focus of news-selection studies in the field of communication. Framing here again comes into play at different stages of the news selection process itself. The influences of journalistic media frames on the media's selection of news are commonly referred to as "reciprocal effects" (Ruigrok and Atteveldt 71; Kunczik and Zipfel 271). 
be clarified that the audience as active participant in the framing of social discourse is explicitly included in the model. Media frames that become part of social discourse are thus assumed to be influenced by the audience before becoming part of media discourse. This trajectory can be imagined as a "feedback loop" from social discourse to journalistic framing and back (see graph 1). ${ }^{125}$

This overview of schema theory and its importance to media framing provides the key to understanding how individual audience members process media content and how the media and audience are involved in public discourse creation. Furthermore, the significance of framing and schema theory sheds further light on the importance of a cognitive approach to reception studies. Here, the process of media consumption for the purpose of knowledge gain remains at the center of attention. Knowledge, however, as stored in cognitive schemata, cannot be separated from affective concerns, since incoming information is always subjected to evaluation. This is where stereotypes enter the picture. Linking schema theory with scripts and sparrows reveals that stereotypes are not as bad as their image.

\section{Of Scripts, Sparrows, and Stereotypes}

Whenever the term stereotype comes up, negative associations follow. Especially in the West, where individualism and one's differentiation from the rest of society are highly valued (Lakoff and Johnson 305), stereotypes are considered backward and discriminating. For researchers taking a cognitive approach to the study of stereotypes, this conclusion is premature. When exploring the function of stereotypes as part of the cognitive apparatus, stereotypes turn out to be necessary and even helpful tools. Could the negative image of stereotypes in fact be a stereotype itself?

Schemata have shown to be very abstract concepts since they already contain clusters of interrelated information stored in the brain. On the lower-level of everyday-information processing, these schemata can be broken down into categories. Categories are clearly defined cognitive patterns which contain particular attributes (Scheufele and Scheufele 127). Every category has a border to another one, based on a particular set of attributes. An object occurring in the context of newlyacquired information is attributed to a certain category if it shows all - or at least

125 Some media researchers try to emphasize the difference between framing processes and their actors by referring to "frame building," which takes place in social discourse, and "frame setting," which is done by the media (Scheufele and Scheufele 112-13). For the purpose of simplification, the present study mostly neglects this terminological difference and uses the terms frame creation, building, and frame setting interchangeably while mentioning the respective actors involved. 
the majority - of the given attributes. ${ }^{126}$ At the center of each category, one finds a so-called "prototype" representing the ideal object within the given category, while objects differing from this prototype are stored in the periphery after being compared to the attribute pattern of the prototype (B. Scheufele 18). The most prominent example of a prototype in communication literature is the one of the sparrow. It represents an object which belongs to the category of birds. This category is characterized by attributes such as "can fly, has feathers, lives in trees, eats worms (Scheufele 19). To demonstrate the function of categorization based on prototypes in the context of Arab Americans, one can imagine the keyword Arab as a category containing prototypical elements such as Muslim, violent, terrorist, veiled, etc.

This example highlights the link between prototypes and stereotypes which requires particular attention in an interdisciplinary setting. In general, stereotypes are defined as simplified representations that reduce individuals to exaggerated and mostly negative character traits. Stereotyping thus becomes a means of power exertion (Barker, Cultural Studies 488). Once an individual is defined as a social outsider on the basis of meeting a set of stereotypes, he finds himself in "symbolic exile," often even denied the most fundamental trait of "having humanity" (Merskin 161). From a cognitive-psychological viewpoint, stereotypes are cognitive schemata which are linked to belief systems about social groups (Dixon 3). While one schema refers to one object, the constructed reality of the individual is made up of the interplay between different objects and bundles of schemata which together account for certain expectations regarding the behavior or causal relationships of other objects or people (B. Scheufele 97). A person or an object is thus categorized into a stereotypical category the more features correspond to the respective prototype (Hewstone 338). ${ }^{127}$ These schematic expectations toward prototypical objects account for the fact that information contrasting the information previously stored is ignored. This interplay between cognitive information processing and affective evaluation characterizes the emergence and maintenance of stereotypes (Cainkar 163). ${ }^{128}$ The

126 Many definitions of categories require all attributes of an object to meet the respective criteria of a category. Since this is hardly the case in reality, however, such definitions must count as overly reductionist (Scheufele, Frames 18 ).

127 This process of categorization is known as the "goodness of fit principle" (Dixon 4; Hewstone 338). The goodness of fit principle reflects to which the degree expected traits or characteristics of an object or a person correspond to the actual features observed. This juxtaposition of expected versus experienced reality influences the way in which an object is categorized (Hewston 338).

128 The cognitive mechanism behind the sustainability of stereotypes is analyzed in Communication Studies by use of the media-psychological approach of cognitive dissonance. The theory goes back to the social psychologist Leon Festinger and holds that media users prefer media content that is in line with preexisting attitudes and beliefs. 
most important cause giving way to the emergence of stereotypes is the lack of personal experience and knowledge regarding members of social groups and objects (Merskin 161). Prototypical information is thus used to fill these information gaps (Dahinden 20).

When adding the dimension of time to this cognitive interplay, stereotypical action sequences are established which are called scripts. A script is defined as "a coherent sequence of events expected by the individual, involving him either as a participant or as an observer" (Abelson qtd. in B. Scheufele 20). Cognitive scripts not only influence the production or reception of media content itself but also the way in which this information is processed by memory. This also applies to information about the self. Here, so-called "self-scripts" which represent "cognitive generalizations about self" impact the way in which autobiographical memory is constructed through scripts (Perrett). The best-known example of a script from everyday life is the "supermarket frame" developed by Umberto Eco. According to this example, the supermarket forms a "deterministic environment" (Lewis 23) that denotes a particular cause of events related to certain objects found in the supermarket (Eco 21). The notion of place is thus already connected to a series of activities and objects which are found in the given setting. As Eco remarks: "In this sense a frame is already an inchoative text or a condensed story [...]" (21). ${ }^{129}$ Again, when transferring this general example to the Arab American case, there could be a script ${ }^{130}$ attached to the object of Arab causing other individuals to suspect criminal

Content that contradicts this information tends to be avoided in order to prevent cognitive dissonance. The finding suggests that individuals have an internal need to remain in a state of value and attitude coherence. According to Elbow, who employs the concept in Literary Studies, a large range of human thinking, feeling, and behavior can be explained by cognitive dissonance. As he explains, "the organism seems to want somehow to find some kind of harmony or unity" (54). While Communication Studies share this assumption, newer public opinion research has revealed that in ambivalent situations, individuals are found to tolerate a certain a level of dissonance (McQuail 551).

129 The example of a university lecture helps illustrate the influence of time and sequencing on scripts. When thinking of the word 'lecture,' individuals who are familiar with the concept immediately associate a certain chain of events with it, e.g., the professor enters the room, the students take out their books, the professor talks, the students ask questions at the end (Scheufele, Frames 20). This demonstrates the script-like character of mental schemata.

130 This psychological use of the term shares many characteristics with the understanding of scripts in popular culture. Scripts usually occur in the context of film studies. Researchers in "auteur studies" reveal how screenwriters dictate the sequences of scenes, cuts, and other essential elements of movies (Schatz and Perren 507). In cognitive studies, this directive function of the screenwriter is fulfilled by cognitive schemata. 
behavior, religious fundamentalism, or the suppression of women in every-day life. These examples emphasize that scripts do not just stand for certain prototypical characteristics but for a sequence of events linked to these attributes.

This synthesis of key concepts in cognitive science sheds a very different light on the process of stereotyping than Cultural Studies usually convey. Whereas the simple term of the stereotype usually evokes immediate reflexes of opposition, framing theory demonstrates that stereotypes, by nature, are part of human cognition. Stereotypes as cognitive prototypes and related scripts are unavoidable and thus a natural part of human thinking. ${ }^{131}$ The question whether stereotypes can somehow be prevented or abolished therefore obviously does not make much sense. The question of how existing stereotypes can be altered and new ones established, however, is one that is of equal interest to scholars in Cultural and Media Studies. Whereas the former, however, invest much energy in calling for counter-discourse to achieve this effect, framing theory provides a less ideological and more empirical explanation for the alternation of sterotypes and their possible reframing.

\section{Cracking the Frame: Reframing Stereotypes}

When calling for the replacement of stereotypes, scholars in Cultural Studies oftentimes use terms such as the "redefinition" and "reinvention of identity" ("ArabAmerican Autobiography" 31). Furthermore, they link this with the idea of "new public narratives" (Somers 630). As to the cognitive processes underlying this discourse, Cultural and Literary Studies, however, have not provided sufficient analytical means to explain how stereotypes can be changed beyond the axiom of counter-discourse. Framing theory and its explanation of the origin of stereotypes in mental schemata and scripts fills this gap. It provides answers to the question of how "Cracks in the Frame" can cause alternative stereotypes (Steinberg 847). The necessary requirement for such a shift in the mental mindmap is persuasion.

Persuasion has been a key term in Communication Studies ever since public opinion research emerged in the first half of the $20^{\text {th }}$ century (Cruz and Lewis 7; Chong and Druckman 103). Especially early media theories in the 1970s stood heavily under the influence of so-called propaganda ${ }^{132}$ studies as a legacy of the

131 The activation of stereotypes not only serves the purpose of protecting mental resources because stereotypical information gets processed faster, stereotypes also serve a very literal function of protection as a result of human evolution. Based on stereotypical judgements about people and situations, individuals are able to avoid or quickly escape situations that might harm their lives.

132 Propaganda refers to the "product of deliberate attempts to influence collective behavior and opinion by the use of multiple means of communication in ways that are systematic or one-sided" (McQuail 564). Based on this definition, which suggests intentional mis- 
Second World War and the media machine employed by Nazi Germany. Mass media at the time were assumed to exert almost unlimited power over the audience (McQuail 51). With the adoption of the active audience concept, these concerns about manipulative persuasion started to cease. According to the status of presentday empirical findings, persuasion still plays an important role in media effects research but the focus rests less on normative generalizations than on exploring the specific circumstances under which this effect takes place. With respect to the intentional constitution of frames and their impact on stereotypes, persuasion also remains of importance because it underlines the impact of frames on different levels of media processing. In the context of cognitive framing, persuasion is defined as a "learned predisposition to think, feel and behave toward a person (or object) in a particular way" (Allport qtd. Dahinden 95). This delineated view of framing as effects model points to two further requirements needed to achieve persuasion; namely, the affective as well as the behavioral component.

As to the affective dimension, persuasion only occurs if the emotional level is touched. Furthermore, framing causes attitudinal ${ }^{133}$ changes toward certains objects or people. Both prerequisites need to be met in order for frames to become reflected in the audience (Dahinden 83). Scheufele summarizes this interrelation beyond the cognitive dimension by referring to framing as "two-step-model." As he explains, "media frames steer thoughts of recipients into a certain direction and thereby affect emotions and opinions" (my translation, 79). Media frames thus affect the mediumand long-term affective predispositions of the audience (Dahinden 87). ${ }^{134}$ Examples

information, propaganda usually has a very negative connotation (McQuail 565). This view of media affects is highly normative (McQuail 15).

133 Attitude in empirical studies is calculated by using the following formula: Attitude $=\sum$ $v_{i} * w_{i}$, where vi is the evaluation of the object on attribute $i$, and wi is the salience weight $\left(\sum \mathrm{w}_{\mathrm{i}}=1\right)$ associated with that attribute. The attitude toward an object thus equals the weighted sum of a series of evaluative beliefs about that object. This highlights the importance of prior information for the evaluation of new information and the possible neglect of incoming information based on established cognitive schemata.

134 This dimension also constitutes a core difference to the theory of agenda setting, which is often associated with framing (Dearing and Rogers 71). Agenda setting is defined as the capability of the media to influence the public agenda based on the salience and frequency of certain topics in the news coverage (Semetko 360). In contrast to framing, agenda setting has mostly been found to impact the affective dimension of the audience on a short-term scale (Dahinden 87). Currently, the scholarly debate focuses on socalled second-level agenda setting, which is researched in connection to "associative framing." Both approaches are based on psychological priming processes (Ruigrok and van Atteveldt 71; McCombs 87). Although these very detailed theoretical differentia- 
of this persuasive effect of media framing have been found in numerous empirical studies. In the case of the Iranian Contra Affair, for example, a topic which has been widely researched, emotional representations of the issue clearly affected the attitude of the audience toward the delivery of weapons to the Middle East (B. Scheufele 78). Another prominent example is the shooting of a Korean plane by the Soviets in 1983. Comparative studies contrasted this event with the shooting of an Iranian civil plane by U.S. forces in 1988. Both incidents caused huge losses of civilian lives. The tone, vocabulary, and problem definitions used by the media, however, varied considerably. Whereas the former event was presented as a human tragedy, the Iranian case was depicted as a military accident (McQuail 379). This difference in framing caused different emotional reactions in the audience. In the case of Korea, humanitarian ${ }^{135}$ concerns outweighted strategic or military evaluations. The opposite was true for the Iranian incident where emotional attachment was lacking (Druckman 1047; Jasperson and El-Kikhia 120).

It is at this intersection of the affective ${ }^{136}$ and the cognitive where the logic behind prototypes and their ultimate role as stereotypes in social discourse unfolds. What is commonly referred to as negative stereotype therefore must be seen as a negative evaluation of a prototype which is stored and categorized in memory in such a way that associated attributes lead to a negative evaluation. Additional information provided by the media or other sources can then either change the connotation of these existing attributes or account for a different categorization of the

tions might sound confusing to the literary scholar, they point to the overall relevance of framing in the landscape of empirical discourse analysis.

135 Humanitarianism has been found to be another meta-frame in the coverage of international news events (Dahinden 187). Empirical studies on the coverage of the IsraeliPalestinian conflict, for example, reveal that a "humanitarian frame" sometimes replaces the common "terrorist frame" that still dominates the media (Scheufele and Scheufele 117). As Scheufele and Scheufele demonstrate, the representation of violent incidents in the Gaza strip with a focus on the humanitarian concerns of Palestinians leads to very different audience evaluations of the respective events than the coverage within a terrorist frame (117). Parallel to this increasing interest in the topic of humanitarianism on the part of communication research, human rights research has also gained significantly more attention in the field of Literary and Cultural Studies in recent years (Whitlock 76-77).

136 Some communication scholars refer to the specific impact of framing on the evaluation of objects as "attribute framing" (B. Scheufele 34). The dependent variable here is not connected to the actual behavior resulting from information processing (goal framing) but on the evaluation of the object itself. An example is the discussion of beef either within an economics frame or within the frame of the organic food movement (B. Scheufele 34). 
prototype. What changes is the context in which the object is seen, not the object itself. In other words, when speaking of changing or replacing stereotypes, it is not the stereotype as such that can be replaced or altered. Rather, the emergence of a new prototype might eventually replace the old stereotype based on different context information.

This cognitive approach to the study of stereotypes ultimately reveals why "counter-stereotypical" representations do little to stop stereotypes from operating (Dixon 4). Empirical studies have shown that counter-representations usually lack the link to the original object stored in memory to an extent that the stereotype remains untouched. Successfully changing or replacing existing stereotypes therefore requires alternative representations linked to the stereotypical object that still show a clear relation to the original stereotype. Simply replacing an existing frame with a new one therefore does not automatically lead to the eruption of stereotypes (Chong and Druckman 114). ${ }^{137}$ In the Arab American context, this means that in order to change the image of the Arab oil sheikh or the belly-dancing harem girl, alternative representations of Arabs cannot completely ignore former stereotypes. Instead, they have to trigger positive evaluations on the basis of new and more detailed information. This discursive process, then, is not one of opposition but one of complementation, discursive contest, and multiplicity. ${ }^{138}$

The media, as assumed by Jack Shaheen already (see Chapter 1), indeed are major actors to achieve this end by providing alternative information concerning popular stereotypes (Dixon 5). They trigger processes of "[d]ehabituation" (Miall 17) and "defamiliarization" (Miall 53; Boelhower ${ }^{139}$ 134). ${ }^{140}$ This in turn allows the

137 Dixon provides research results on racial groups. He shows that the confrontation with people who completely disconfirm the stereotype will lead to the categorization of the individual in either a different or a new category but it will not alter the stereotype of the present category. Therefore, in order to be effective, the alternative to the stereotype must still show a correlation to the existing schema (Dixon 4).

138 This is in line with the concept of "Discursive Rivalries," as developed by Gary Fine in the field of sociology. Instead of the purely dichotomous view of counter-discourse, discursive rivalries imply the plurality of discourses that stand in equal competition to each other (Cainkar 154).

139 Boelhower also acknowledges that defamiliarization plays a crucial role in the "strategy of reconstruction" in autobiography. Instead of basing this argument on a cognitivepsychological basis, Boelhower defines defamiliarization in terms of geographic and metaphorical space, whereby the growing distance between "actual self and place" achieves the effect thus described (134).

140 So far, this process of defamiliarization has been attributed to fictional writing mostly due to the artistic and stylistic devices of the writer. Novel images can thus be created that escape everyday reality (Miall 17). While framing provides the cognitive explana- 
media consumer to place the objects and members of social groups "Beyond the Schema Given," as the interdisciplinary literary scholar David Miall entitles his subchapter (53). Framing can therefore either trigger a new "mental model" or it can reinforce old ones (Ruigrok and van Atteveldt 71). The reflexive nature of the process turns framing into a constant alternation between framing and being framed, between reframing and being reframed (Angus 234). This finding will later play a crucial role in demonstrating the capacity of autobiographies to (re-)frame stereotypes. Just like stereotypes function on different levels of the mind, frames also operate on several levels.

\section{David versus Goliath: Frame Levels and Issue Frames}

\section{Image 1: "David with the Head of Goliath"}

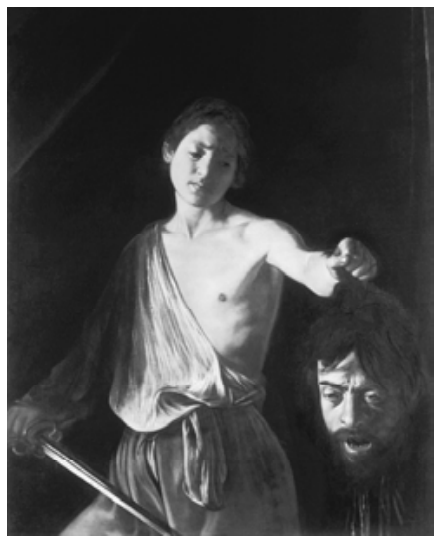

Source: Reprint of Caravaggio painting from 1606 (Graham-Dixon xvii).

If there is one image which communication researchers, literary theorists, and journalists alike are equally familiar with, it is the one of David versus Goliath. The biblical story represents the struggle of the young David against the giant Goliath bringing about the ultimate fall of the giant. The fight in a larger sense depicts an "allusive metaphor" of the fight of the underdog versus the superpower with the essential tension emerging from the hope that the underdog still has a chance to win (Lennon 68). ${ }^{141}$ As communication researchers have revealed, David versus Goliath is not just a popular metaphor but one of the most prominent media frames.

As all previous examples of media frames have demonstrated, frames appear in all possible contexts. In order to arrive at a more structured understanding of frames as opposed to mere topics, an additional conceptual classification between frame levels and issue frames is essential. The example of David and Goliath counts as well-researched in this respect and helps demonstrate how frames act on different

tion for this effect in a non-fiction context, this is not to deny that other formats of media representation can achieve the same effect. This highlights the universal value of the theory for several sub-fields of Cultural Studies.

141 Lennon in his study Allusions in the Press reveals the David versus Goliath motif to appear particularly often in the economic context of company mergers and acquisitions in German newspapers (68). 
cognitive levels. As meta-studies of the use of the David and Goliath metaphor revealed, the image counts as the most popular frame used across various different media and subject areas (Dahinden 14) ${ }^{142}$ It represents a "conflict frame" that evokes the effect of polarization on the part of the audience. Conflict frames are generally characterized by the opposition of different interests of two or more social powers whose relationships to each other can take various shapes. All conflict frames share the common feature of revolving around questions of power as central concern (Dahinden 107; D. Scheufele 113). The vocabulary accompanying the David versus Goliath frame usually centers on the terms "us" versus "them," whereby the "them," i.e., the coverage of the oppositional party, dominates. The frame is independent of thematic content. It can be used in all possible contexts, e.g., in sports, politics, or social struggles (Dahinden 186). This universal applicability of the dialectic points to the nature of the David versus Goliath frame as meta-frame which acts superordinate to different issues.

The example of the David and Goliath frame highlights that frames occur on various levels of abstraction which are categorized according to different selection criteria and cognitive hierarchies (Dahinden 186; Allen et al. 266-67). On the metalevel one finds so-called "basis-frames" (Goffman qtd. in Dahinden 107). ${ }^{143}$ These basis frames represent cognitive schemata which reflect "inter-categorical hierarchies" which have cognitive priority in categorization processes (my translation, B. Scheufele 19). Besides the conflict frame, morality and ethics have also been found to function as basis frames (Dahinden 106-07). A particular incident of these higher-level frames is the so-called "personalization frame" (my translation, Dahinden 107). ${ }^{144}$ The personalization frame represents a meta-frame that puts personal expe-

142 In addition to the metaphor of David and Goliath, researchers also often use the concept of the Manichaean dualism that goes back to the medieval adherents of the Persian religious leader Manes and the conception of the world as struggle between good and evil (Exoo 29). Calvin Exoo identifies this Manechaean binary as a historical characteristic of U.S. media coverage, which especially became visible in the post-9/11 period. This is not to deny that the origins of the Manichean binary already date back to the Puritan ideology of good versus evil in U.S. history.

143 Authors use various terms to account for the existence of different frame levels. This study adopts the rather clear-cut terminological differentiation between higher-level and lower-level frames used by Dahinden whose work is also highly interdisciplinary (107).

144 This categorization into basis frames by Dahinden only represents one example of meta-analytical frame analysis. Other studies by researchers who use a similar terminology arrive at different results and models, e.g., concerning the number of basis frames and the respective terminology. David Altheide, for example, speaks of a "problem frame" and describes it in terms similar to the "conflict frame" sketched by Dahiden ("News Media" 648). 
rience to the forefront of information processing. Single, topic-related incidents operating on lower levels of abstraction are presented as more or less typical examples of the larger frame (Dahinden 108). All of these meta-frames constitute "ideological frames" in that they are related to issues of moral or political conflict, as the example of David and Goliath again illustrates (Bakalian and Bozorgmehr 185).

On the lower level of abstraction, micro-frames, so-called "issue" or "thematic frames,"145 operate (Allen et al. 266-267; Chong and Druckman 107). Nel Ruigrok and Wouter van Atteveldt define issue framing "as a process of selecting and emphasizing certain aspects of an issue on the basis of which the audience can evaluate the issue described or the protagonists associated with the issues" (70). Issue frames comprise smaller units of categorization by relying on a very theme-specific interpretation (B. Scheufele 72). ${ }^{146}$ Issue frames, such as terrorism, have shown to be highly contingent between the media and the audience (D. Scheufele 112).

The distinction between higher-level ideological frames and lower-level issueframes allows for a more differentiated understanding of the cognitive levels involved in the categorization of information on the part of the audience. As to the relation between macro- and micro-frames, it can be stated that their construction takes place interactively with more than one frame operating at a time (D. Scheufele 106). From a conceptual perspective, frames can therefore be imagined to act on a vertical axis represented by higher- or meta-level frames and lower-level issue frames. This also accounts for the differentiation between a "discursive level" and a "textual level" of framing (Scheufele and Scheufele 111). In addition, the delineation of different issue frames takes place on a horizontal ${ }^{147}$ framing axis. This obviously poses an analytical challenge to framing research because different frame levels need to be distinguished. The question thus remains how communication research actually identifies frames?

145 Since the definition of what exactly constitutes a theme is quite challenged in Communication Studies (Dahinden 75), this study will use the term issue frame to emphasize the cognitive principles underlying issue categorization in contrast to the term theme used in Literary Studies. Issues are further differentiated in contradistinction to "events," whereby an event counts as one element of a larger issue (Dahinden 76).

146 This specific focus on an issue without including detailed context information to Justin Lewis serves as a confirmation for the thesis that news is inherently "ahistorical" (31).

147 Scheufele and Scheufele also base their framing model on a horizontal and vertical framing matrix to account for different "schema hierarchies" (117). On the horizontal level, they use the term "arenas" to refer to different social realms such as politics and society (111). This somewhat equals the definition of issue frames in this study. 


\section{Identifying Frames: Media, Text, Audience}

“'Taking a photograph,' the teacher says, 'is above all centering in a frame. So you have to learn framing, and that means learning how to see everything through a little square in that frame and hot to choose the best angle of attack" (Babin and Iannone 57). This episode on framing as a photographic practice that must be learned also represents the position researchers must take in order to study media frames in society. The development of respective research tools also involves a long methodological learning process. Communication departments around the world now focus on empirical research methods, particularly when it comes to framing studies (Tankard 97). ${ }^{148}$ The identification of frames, however, is complicated by the fact that frames not only occur on different conceptual levels but also in three distinct elements of the communication process; namely, the media, the text, and the audience.

The largest amount of empirical framing research has focused on frames as audience effects (Whitney, Sumpter, and McQuail 399). This strand of research analyzes frames both as dependent and independent variables ${ }^{149}$ (D. Scheufele 107; Whitney, Sumpter, and McQuail 399; Scheufele and Scheufele 113). This hints at the question of causality which poses a challenge to empirical framing research. Media frames can be assumed to function - rather mono-causally - as the origins of audience frames. When considering the interrelationship between the media as active and its participation in public discourse, the audience can also be seen as source of framing. This, in turn, would reverse the definition of the independent and dependent variable under scrutiny, meaning that media frames as the outcome of discursive framing are dependent variables. Since this introduces a degree of complexity which standard means of analysis can hardly master, most studies focus on the study of audience frames as effects, which has proven to be valid. This causal relationship, however, can never be simply presupposed but must be shown by correlation (Dahinden 304-05). ${ }^{150}$ Put in simpler terms, the identification of a frame in a given text does not guarantee that this frame is also reflected in the audience

148 The communication scholar James Tankard praises the contribution of framing research to discourse analysis because, to him, framing offers an alternative to "the old 'objectivity and bias' paradigm" (95).

149 The dependant variable in Media Studies is defined as the effect of a media stimulus, whereas the stimulus itself is the independent variable. If both variables stand in a causal relationship to each other, one speaks of internal validity (Kunczik and Zipfel 23).

150 The status quo of framing research in regard to the question of causality is that media frames are necessary variables for the establishment of audience frames but not sufficient ones since other discursive frames of different origins also interact (Dahinden 305). 
reading the text (Entman, "Framing" 53). Neither can a single text be considered the only cause of an audience frame.

The definition of frames as either independent or dependent variable consequently depends on the specific research objects at the basis of the investigation; namely, journalists, texts/media content, or the audience. In the case of journalists as sources of frames, interviews are used to reveal the specific motives and means behind the production of media content (B. Scheufele 49). On the other end of the communication process, audience frames are usually explored by means of questionnaires, interviews, and long-term data collection to account for frame shifts (B. Scheufele 60). From a methodological viewpoint, the most detailed research is conducted on frames found in texts or other media content (Dahinden 60). Frames here are analyzed by means of comprehensive content and cluster analyses (B. Scheufele 56). In contradistinction to text analyses in Literary Studies, where the term analysis mostly relies on interpretation, content analysis in empirical Media Studies implies a strict methodological design. ${ }^{151}$ This usually involves the choice of sample content, the formation of analytical categories and the encoding of the text according to these categories. Frames are then identified inductively to arrive at a coding scheme (Chong and Druckman 107). The frequency at which these units occur is then counted. The result of this reveals the existence of certain media frames (B. Scheufele 55; McQuail 363). Quantitative content analysis is a very established means of frame analysis. The major advantage of this method is the fairly high degree of reliability (McQuail 363). Its biggest weakness, however, is the risk of imposing interpretation systems on the content based on a certain categorization instead of inferring frames from content only (McQuail 354).

Due to some of these methodological constraints connected to quantitative frame analyses, researchers are now trying to apply mixed methods to the study of frames (McQuail 365). The major goal here is to complement quantitative data collection with more qualitative means of interpretation in order to grasp text information which pure content analysis cannot register (Entman, "Framing" 57). This more hermeneutical focus inevitably relies more on single and rather detailed case studies than on the analysis of a large number of texts. Since this, in turn, runs counter to some of the hallmarks of empirical research, including reliability and validity, communication scholars so far have not been in favor of integrating these qualitative approaches into their designs (B. Scheufele 57-58). Man continue to

151 In more specific terms, content analysis represents a qualitative-inductive approach, since it derives its theoretical conclusions on the basis of data collection (Dahinden 203; Donges, Leonarz, and Meier 135). Deductive quantitative analysis, in contrast, proceeds from theory to data collection (Dahinden 205). Inductive-quantitative analysis, as additional variant, represents the methodological synthesis of the two generic approaches but counts as less common in the empirical practice (Dahinden 206). 
denigrate hermeneutics as "myriad of contradictory theories and insights" which do not promise much potential in terms of knowledge gain (Bortolussi and Dixon 8).

It is at this methodological intersection where the weaknesses but also the strength of framing analysis fully unfold and give way to the creation of something new. Whereas autobiographical text analysis suffers from the lack of the empirical method, empirical scholars in the field of communication theory seek to integrate more qualitative tools into their methods. Robert Entman in this context makes the following claim: "We (communication researchers) should identify our mission as bringing together insights and theories that would otherwise remain scattered in other disciplines" (qtd. in Dahinden 319). The first step toward achieving this interdisciplinary goal is the realization that literary scholars and communication researchers, after all, work on the same cultural material. Above all, they analyze the impact mediated discourse has on the lives of individuals, thus turning them into mediated lives. The framing approach ultimately provides the basis for developing a mediated theory of life writing to explore these lives in more detail.

\subsection{Framing Lives: A Mediated Theory of LIFE WRITING}

I assert that continued growth is essential to the rational and empirical character of scientific knowledge; that, if science ceases to grow it must lose that character. It is the way of its growth which makes science rational and empirical; the way, that is, in which scientists discriminate between available theories and choose the better one or $[\ldots]$ the way they give reasons for rejecting all the available theories [...]. (Popper 7)

Autobiography theory with its focus on close-reading and framing theory in Media Studies are both count as sophisticated in their own fields, athough they suffer from individual shortcomings that limit their explanatory power. As is the case with many theories in the academy, both fields continue to live separate lives. Autobiography Studies have not incorporated methodologies from Media Studies so far, and Media Studies have mostly ignored cultural material other than news when testing the interdisciplinary value of framing. In order to carry out Popper's claim above, one needs to acknowledge that framing counts among the "available theories" which have the capacity to benefit the growth of knowledge in Literary and Media Studies. As Popper also acknowledges, it is the "empirical character of scientific knowledge" which accounts for its continuous growth. This empirical nature of knowledge contribution has so far been missing from the methodological instrumentarium of life writing studies. A new way of reading autobiographies marks the 
first step to developing a (re-)mediated theory of life writing which does not reject "all the available theories" but chooses "the better one" to arrive at new insights.

\section{From Media Frames to Mediated Lives: Life-Reading the Journalistic Way}

The comparative approach to the methodologies used in the fields of Literary and Media Studies already demonstrates the theoretical synergies which emerge for the application of framing in life writing research. So far this move has been prevented mostly by the dominant view in Autobiography Studies that life narratives are located "outside the frames sustained by the media networks [...]" (Whitlock 153). The only exception to this rule is found in the case of journalistic memoir. Here, the boundary between the media and the literary market is blurred because non-literary writers, i.e., journalists, engage in life writing. By taking a closer look at the professional roles of journalists and literary writers, however, one finds that memoir takes the shape of journalism even outside the genre of journalistic memoir.

Journalistic memoir constitutes a sub-genre of memoir which focuses on the narration of important events related to the life of the journalist (Winslow 34). This highlights that the definition of the genre is not only linked to the personal life of the respective writer but to his profession specifically. ${ }^{152}$ Journalistic memoirs flourished in the $20^{\text {th }}$ century during the era of realism. In the United States, socalled "muckraking" accounts by journalists helped reveal social and political ills (Hartsock 144). In the recent period, journalistic memoir has experienced another upswing in the form of war narratives, especially with respect to journalistic autobiographies reporting on the Middle East conflict. As Whitlock in her chapter "Embedded: Memoir and Correspondents" suggests, journalists have thus become "witnesses in the war on terror" (132). The war in Iraq provides the latest example of a violent conflict that caused a major wave of journalistic life narratives (Whitlock 131). Whitlock in this context refers to journalists as "authorized witnesses of the war in Iraq [...]" (132).

This notion of journalists as "authorized witnesses" points to the exceptional professional status of journalists as authors of life narratives. Their accounts are commonly assumed to reveal even more "accurate" and "immediate" information than former ways of reporting (Whitlock 133). In addition to the finding that auto-

152 This definition needs to be clearly separated from life narratives by famous personalities who often use the support of journalists, e.g., by means of interviews, to write their autobiographies. Also, the adjective 'journalistic' is sometimes applied to highlight a report-like style of writing in memoir (Winslow 34). Both forms are not journalistic life narratives that are included in the given definition, since the latter requires the journalist as narrator of his/her own biography. 
biography as a genre enjoys an exposed status with respect to truthful and authentic narration, this demonstrates that journalistic life writers are characterized by an even larger degree of "discursive authority" (Whitlock 149). ${ }^{153}$ On the one hand, this authority is rooted in the ethical self-commitment to truthful reporting (Christians 22-23). On the other hand, journalists, especially in the case of war reporting, act as cultural and social outsiders in foreign countries. Due to their immediate access to foreign events, however, their status equals the one of exiles in ethnic life writing in that they act in "transnational contact zones" (Whitlock 148). Due to this elevated authorial agency, the journalist as memoirist gains additional "moral and ethical accountability" (Whitlock 156). This parallel to ethnic life writing corresponds to the market dynamics of journalistic life narrative. The works usually aim at reaching a domestic audience (Whitlock 143). ${ }^{154}$ Here, they circulate as "traveling nonfiction" (Whitlock 148). This again underlines the blurred genre lines between life writing and news reporting, between literary and media discourse.

This practical blending of life narrative and journalism has not brought about an analytical rapprochement between the two fields of literature and media research so far. The discussion of journalistic life narratives in Literary Studies demonstrates this separation once more. Journalists are acknowledged as life writers by literary scholars. Their professional authenticity and the truth of their accounts are presupposed almost self-evidently. Discussions of the fictional nature of life writing here mostly step into the background. Most importantly, however, literary means of interpretation dominate the respective analyses, not media theories which would require interdisciplinary exchange. The British novelist Graham Greene once established a rather sarcastic explanation for this lasting disciplinary demarcation on the basis of the division between fact and fiction: "A petty reason perhaps why novelists more and more try to keep a distance from journalists is that novelists are trying to write the truth and journalists are trying to write fiction" (qtd. in Andrews 261).

153 Critics often see this trend in a negative or even cynical way by claiming that the "war on terror has created a new market for the production of celebrity journalism [...]" (Whitlock 140).

154 This obviously refers to "Western journalists" only, i.e., non-Arabs and non-Muslims narrating their experiences in the Middle East (Whitlock 134). To Whitlock, these accounts therefore still tell "an American story," no matter how close authors get to the respective events abroad (Whitlock 145). This reveals a lasting ethnocentric bias when it comes to the analysis of journalistic life writing at large. American journalists are thus tacitly imagined to be of American, i.e., non-ethnic, descent. The possibility that journalists with mixed ethnic backgrounds engage in war coverage is thus completely ruled out. In the context of the Iraq War, this has led to the critique that narratives are "gendered" and "nationalized" (Whitlcok 142). 
Although this comment sheds light on the present state-of-affairs in life writing studies, it does not account for the structural similarities between life writing and journalistic writing as non-fiction. The example of journalistic memoirs in addition reveals further commonalities with respect to the professional roles of autobiographical writers in media discourse. The following overview systematizes these structural and role-relatd commonalities by connecting the respective terminologies used in the fields of Literary and Media Studies:

- Autobiographers as journalists, journalists as authors: Authors of autobiographies are producers and receivers of public discourse. As such, they have an equal capacity to establish and alter frames circulating in the public like journalists.

- Autobiographies as media, media as texts: Autobiographies as print media share many characteristics with other mass media content, specifically with news media formats. The most important one is their common classification as non-fiction despite their constructed nature as influenced by the practice of framing. Autobiographies thus mediate life stories and sometimes also engage in the mediation of political or social conflict.

- Autobiography readers as media consumers, consumers as audience: Readers of autobiographies buy and consume autobiographical works like they consume other non-fiction media content. Since genre-related expectations steer the cognitive processing of media information, readers of life writing as media consumers experience the same framing effects.

This systematic overview of the professional roles fulfilled by journalists and by writers of autobiographies allows one to fully uncover the potential which framing as theory of life writing presents. Such a theoretical move goes far beyond the discussion of journalistic life narrative in Literary Studies, although this genre transgression provides additional evidence why the content-based similarities between journalistic and literary writing should ultimately lead to a theoretical synthesis as well. Yet, analyzing texts produced by journalists as autobiographies is not the same as treating autobiographies produced by literary writers as journalistic texts. ${ }^{155}$ This conceptual move allows one to fully explore and comprehend the impact of life writing on mediated discourse. The following table highlights the overlapping functions and effects of framing in life narratives and journalistic writing.

155 The terminology is chosen based on the limited scope of this study that focuses solely on written life narratives and therefore only includes equivalent print media formats. 
Table 1: Functional Comparison of Literary versus Journalistic Framing

\begin{tabular}{|c|c|c|c|}
\hline Role/Object & Literary Sphere & Function & Media Sphere \\
\hline Author & Autobiographer & $\begin{array}{l}\text { Reception of surrounding } \\
\text { media frames } \\
\text { Replication and/or alternation } \\
\text { of frames } \\
\text { Establishment of new frames }\end{array}$ & Journalist \\
\hline Text & Autobiography & Mediation of frames & Article, news piece \\
\hline Reader & $\begin{array}{l}\text { Media audience } \\
\text { (fiction/non-fiction) }\end{array}$ & $\begin{array}{l}\text { Reception of frames } \\
\text { Transformation of frames into } \\
\text { public opinion } \\
\text { Replication and/or alternation } \\
\text { of frames }\end{array}$ & $\begin{array}{l}\text { Media audience } \\
\text { (fiction/non-fiction) }\end{array}$ \\
\hline
\end{tabular}

The table demonstrates in how far the role of journalists equals the one of literary writers of autobiography and vice versa when it comes to their potential to frame public discourse. This capacity not only relies on the narrative authority accredited to both groups of writers but also on the particular status their texts occupy as nonfictional works. It is this perception of literary identity narration as "public" discourse which opens up a new angle to the study of literature at large (Somerss 617).

Whitlock in her study on contemporary ethnic life writing makes the striking observation that the "transits of life narrative remain a breaking story [...]" (187). Although she uses this journalistic vocabulary as a figure of speech to emphasize the topicality of life writing research, the previous structural and functional similarities between the literary and journalistic sphere confirm the literal significance of this statement providing the essential preliminaries for reading life writing through the media lens. Yet, the fact that authors of autobiographies can frame public discourse does not mean that the possibilities of framing are limitless. Particular requirements therefore need to be met in order to (re-)frame mediated lives.

\section{"Who Can Frame?" The Agents of Framing}

The possibilities of framing public discourse on the part of journalists are not unlimited and the same holds true for the writer of life narrative. This issue of the framing limits not only points to questions of how framing takes place but also to the question of who exactly has the means to frame. As communication scholars have revealed, there are specific characteristics which determine the effectiveness of framing on the part of the writer. The issue of "Who Can Frame?" therefore 
requires a more specific actor analysis (Druckman 1041). This takes one to related aspects of technique and style which also raises the question of what can frame?

Empirical studies agree that framing can only be achieved by so-called "elite actors" (Chong and Druckman 117). Journalists naturally enjoy an elite status in influencing public opinion due to their function as gatekeepers of the news. Outside this journalistic environment, so-called "opinion leaders" 156 represent this elite (McQuail 476). The theory of opinion leadership assumes a two-step flow of communication in which public opinion leaders, who enjoy the trust of other audience members, function as mediators by passing on and evaluating perceived media content. Their status therefore not so much relies on monetary wealth or other material means but on the capacity to impact public opinion based on their social status. Popular examples of opinion leaders are politicians, scientists, and intellectuals (Chong and Druckman 117).

Whenever media theorists enumerate groups of opinion leaders it generally tends to be forgotten, though, that authors of literature also count as significant opinion leaders who have the same - if not a larger variety - of means at their disposal to impact public opinion through their writing. ${ }^{157}$ This especially refers to the authors of life narrative. Whitlock emphasizes their special status among intellectuals by stating that the "memoir is traditionally the prerogative of the literate elite" (132). Although this notion of a literate and thus also literary elite itself represents an umbrella category which can include elite actors from various social realms, their status is linked to their intellectual and thus cognitive potential. This finding derived from present-day communication theory reveals a close relation to life writing research as it was put forward by early theorists such as de Man. He already regarded the intellectual contribution of life writers and their focus on fact-telling as

156 The concept of opinion leadership also suggests that audience members who do not count as "leaders" are categorized as "followers" (McQuail 473). This categorization is not static, however, because it is issue-dependent. In addition, some audience members cannot clearly be assigned to any of these two categories, which also points to the fact that the two-step flow of communication underlying the concept of opinion leadership is rather a multi-step process in which different inviduals negotiate between media content and public opinion (McQuail 472-73).

157 Said is usually granted an exceptional position with respect to opinion leadership for he made "no pretense of professional authority" (Shereen 124). As far as Said's belief in the practical value of scientific knowledge and his focus on amateurism are concerned, this finding receives evidence. However, as Said's own life narrative reveals, he was extremely aware of the influence he enjoyed as public intellectual and used this status to underscore his authorial agency (S. Schmidt, "(Re-)Framing as Political Project" 10). The critic Paul Armstrong is therefore convinced that both authority and authenticity constituted core pillars of Said's persona and nurtured his political ideals (98). 
crucial for their discursive impact. According to de Man, writers of autobiography "are obsessed by the need to move from cognition to resolution and to action, from speculative to political and legal authority" (174). This summarizes a common understanding of opinion leadership in Media and Life Writing Studies, whereby cognitive capabilities and factual information provide the basis of authority on the part of the writer. This authority in turn accounts for the credibility granted by the audience and ultimately sets the stage for possible framing effects.

This criterion of opinion leadership also points to the enormous importance of the truth criterion again. As was the case for truth as a criterion for the division of different literary genres ${ }^{158}$ into fiction and non-fiction, truth in a larger sense also severely influences media framing. Truth here is more strictly defined as the credibility devoted to the source by the audience (Druckman 1042). As experimental research shows, the degree of credibility devoted to the source, which in turn is based on the authority of the author, has an enormous impact on framing. The more credible the source in the eye of the audience, the more likely it is that the audience adopts a particular frame (Druckman 1054). ${ }^{159}$ Credibility is specifically linked to the importance of personal experience. Again, this accounts for both realms - journalism and literature. Leila Buck highlights this connection between autobiographical storytelling and reporting: "Personal storytelling is doubly powerful because the skeptic is confronted with not just a real person, but an eyewitness - someone who can say "not only did this really happen - it happened to me" (22). This again emphasizes the severe importance the aspects of truth and persuasion have in the fields of literature and communication research (Angus 244).

This characteristic of credibility based on personal and professional experience is closely linked to the criterion of analytical distance. This distance can either be created by geographical or cognitive separation from the object studied. The con-

158 Genre is a major criterion determining how media content is cognitively processed by the audience. Different genre expectations thus attract different frames. These frames also impact the subjective gratifications gained from media consumption (Willems qtd. in Dahinden 81; Miall 92; Bortolussi and Dixon 21).

159 In contrast to the vast majority of studies on framing that are based on content analyses in combination with audience surveys, Druckman conducted an experimental study to test the impact of source credibility. It consisted of two groups of university students who were given texts on the topic of government spending on the poor. One text framed the issue as government expenditure issue while the other focused on humanitarianism. The varying degrees of credibility of the two sources severely impacted the adoption of the respective frames on the part of the readers (1047). Experimental research designs are usually very time- and cost-intensive, yet, they have the advantage of revealing causal relationships between variables which other methods lack, since intervening variables can be controlled (Kunczik and Zipfel 23). 
cept of location thus becomes linked to knowledge acquisition and distribution, underlining that "knowledge and voice are always located in time and space and social power [...]" (Barker, Cultural Studies 485). Location consequently functions on two fronts. With respect to an inward effect of location, inner distance to an object or subject is perceived to aid self-reflection. This inner distance is an effect of the geographic distance to the object or culture studied, whereby additional analytical perspectives emerge. Both aspects are reflected in writing since the "organization of a text in 'spatial' terms reflects a shift of location" (Moore-Gilbert 126). As the debate on native informants in the context of ethnic life writing revealed, "ethnic framing" presents a particular case for the credibility criterion based on geographic distance (Boelhower 137). Here, authority not only refers to cultural insider knowledge but also to geographic ${ }^{160}$ location. Where the subaltern speaks is thus equally important as who the subaltern is. The "authentic insider" of ethnic life narratives therefore combines geographical, analytical, and cultural distance (Vinson 88). This in turn increases the potential of ethnic life narrative to frame.

This list of criteria sheds light on the question of who can frame. Although opinion leadership, authenticity, credibility, and analytical distance are not sufficient criteria to guarantee the impact of framing on the audience, they constitute necessary requirements to achieve this effect. This rather one-sided actor-analysis with a focus on the characteristics of authors, however, should not conceal the fact that the audience as active participant in mediated disourse already impacts the very production process of life narratives. After all, frames are always "chosen with the audience in mind" (Chong and Druckman 117). This applies to journalists in the case of news framing, and it similarly plays a role for authors of life narratives. This audience-orientation on the part of the writer directly points to the means employed to frame lives in autobiography.

\section{What Can Frame? Framing and Stereotypes of Strategy}

[A] utobiography as a medium for revealing the self to an 'other' also transforms the genre into a means for influencing the other through a textual portrayal of the self. Such a view of

160 Said defines geography as "a socially constructed and manifested sense of place [...]" ("Invention, Memory" 180). In addition, geography according to him cannot be separated from ideas of power and domination ("Invention, Memory" 181). Interestingly, constructivist thought here enters the definition in a twofold way since geography itself counts as "constructed" while this construction then gives way to the similarly constructed idea of "place" as a subjective feeling rather than an actual location. 
the transformative power of narrative is consistent with the view Hilde Lindemann Nelson ${ }^{161}$ proposes in Damaged Identities: Narrative Repair. (Vinson 88)

This reflection on the potency of life writing by Pauline Vinson in her exploration of Arab women's autobiographies once more underlines the extra-literary significance of the genre in shaping society at large. Framing and its cognitive underpinnings provide a starting point for grasping the psychological mechanisms accompanying this process. The use of the term "means" in this passage, however, reveals a very specific trajectory. It implies that "influencing the other" is not an arbitrary task, nor is it accidental. Rather, influence implies the idea of intentionality which is achieved via the use of authorial strategy. This significance of strategy becomes the key factor in the transformation of framing into a theory of writing and reading life narratives. As Margaret Somers in this respect remarks, "getting heard requires new theories" (610). "Strategies of Framing" allow for this effect to ultimately (re-)frame lives and also autobiography theory (Chong and Druckman 117).

The use of framing as strategy reverts back to the idea of discourse as intentional and purpose-driven activity to produce meaning (see Chapter 2.1). With respect to framing as explicit discursive strategy in literature, however, no theory has been formulated so far. The only research area which explores framing as strategic device is found in mobilization studies. Framing here constitutes a powerful instrument of activists for mobilization purposes (Bakalian and Bozorgmehr 185). It "refers to the interactive, collective ways that movement actors assign meanings to their activities in the conduct of social movement activism" (Buechler qtd. in Bakalian and Bozorgmehr 25). In sum, framing provides the "know-how" for mobilization (Steinberg 849). Frames and their resonance in public discourse thus determine the nature and extent of individual and collective action (Hackett and Zhao 297). In contrast to the notion of framing as manipulation, this strategic function of framing highlights the positive aspect of framing as a means to gain agency (Steinberg 849). ${ }^{162}$ Analyses that focus on framing as strategy therefore mostly are found in the context of social and civil rights movements (Bakalian and Bozorgmehr 21). Framing here functions in a double sense with social activist framing and media

161 The title of Hilde Lindemann Nelson's work Damaged Identities: Narrative Repair underlines the almost therapeutical relationship to identity theory that narration is granted in contemporary life narrative research. Nelson as a philosophy professor has made considerable contributions to the field of bioethics by exploring the construction of narrative identity and its impact on the self and society.

162 This also implies that collective action rather than individual agency is assumed to have the capacity of altering social frames through discourse (Steinberg 857). 
framing overlapping. ${ }^{163}$ This intertwinement of political mobilization and framing as media strategy can be summarized as "mediated action" (Steinberg 853).

The technique through which framing as mediated action in life narratives becomes a strategy is inherent in the text itself. Life writing simultaneously employs affective and cognitive registers. The personal and often intimate details of individual lives naturally appeal not only to the rational perception of the reader but also to the affective dimension. It is this "emotional and aesthetic value" which impacts how images of the other and images of the self become entangled in the experience of life narratives (Whitlock 200). ${ }^{164}$ Emotional depictions evoke vital images in the mind of the reader who becomes sucked up by the strain of events and is thus even more susceptible to adopt the frame he/she is presented with (Coleman 252). Whitlock describes this composite of emotions and events in almost addictive terms: "These lives have the power to pull readers into an aporia of reading and looking: the gap between allegro and lento, when reading and seeing are halted - in a productive pause. Here the wounding implications of image and word in flesh and emotion can make the reader wince, and yet [...] we must continue to read on" (201). Similar effects are achieved by the mass media coverage on highly controversial and often ethical issues such as the death penalty, religious rights, and abortion (Tankard 96).

This potential of life writing as strategic political instrument is usually highlighted with respect to ethnic life narratives and the discourse on cultural difference. Here, the use of framing as strategy supports the function of autobiography to "thematize" (W. Hassan, "Arab-American Autobiography" 10). Other postcolonial scholars even regard this "instrumental use of autobiographical forms for concrete political objectives" as defining criterion of postcolonial writing at large (MooreGilbert 128). This well-established acknowledgement of ethnic life writing as strategic, however, brings to light two essential problems which severely limit the study of autobiographical strategy. The first one is a very limited and often mistaken categorization of ethnic life writing as inherently political and thus strategic while the bulk of autobiographical writing is treated as rather unpolitical and thus unstrategic. The task of exploring strategies of writing therefore is pushed into the background. Not only does this lead to a shortage of analyses on the strategic use of life narrative at large, it also denigrates non-ethnic life writing to the status of the per-

163 Bakalian and Bozorgmehr base their research findings not on literary or documentary research but on interviews conducted with activists (25).

164 Whitlock, based on her critique of autobiography as commodity, labels this emotional dimension of life narrative "politics of affect" (Whitlock 123). To her, this is the result of reiterating certain stereotypical images, such as the one of the exotic woman. Her choice of words in this context again underlines how much politics and emotions are intertwined in the analytical approaches of contemporary life writing research. 
sonal while only the ethnic seems to be political. The second problem is linked to the definition of strategy in the context of ethnic life writing in a narrower sense. As has already been demonstrated, ethnic life writing scholarship has colonized itself to an extent that counter-discourse seems to be the only answer to postcolonial discursive means. Not only does this distort the concept of discourse, it also limits the enormous strategic potential of life narratives to only one single strategy.

Both problems have so far prevented scholars from unveiling and studying alternative strategies of life writing beyond the realm of ethnic life writing and beyond the realm of counter-discourse. Consequently, framing as based on media and cognitive theory has not been discussed as a strategy for writing and/or reading life narrative so far. Especially the explanatory power of life writing with respect to the cognitive underpinnings of stereotyping demonstrates the potential of framing as a strategy of writing and as a strategy of reading. Framing theory thus strikingly destroys the most powerful myth in postcolonial Autobiography Studies, namely the assumption that the "production of counter-polemics" provides the answer to existing stereotypes (Orfalea 189).

The assumption of counter-discourse as only powerful strategy to change stereotypes thus turns out to be one of the most powerful stereotypes in life writing theory at large. One of the harshest critics of such a narrow-mindedness on the basis of a normative understanding of stereotypes is Homi Bhabha. In The Location of Culture one of the chapters bears the revealing title "The Other Question: Stereotype, Discrimination and the Discourse of Colonialism" (95). Bhabha here severely criticizes the normative bias of postcolonial scholarship in the study of stereotypes:

My reading of colonial discourse suggests that the point of intervention should shift from the ready recognition of images as positive or negative, to an understanding of the processes of subjectification made possible (or plausible) through stereotypical discourse. To judge the stereotyped image on the basis of a prior political normativity is to dismiss it, not to displace it, which is only possible by engaging with its effectivity [...]. (Location 95)

Bhabha in this passage demonstrates a luminous and quite uncommon standpoint by looking at the study of stereotypes beyond common (mis-)conceptualizations. He thereby acknowledges that stereotypes are the results of an ambivalent discourse which is much more complex than the dialectical and "assertive" notion postcolonial scholarship suggests (Said qtd. in Heffernan 21). ${ }^{165}$

165 Bhabha later in the book sketches his well-known idea of the stereotype as "fetish" (Location 105). He describes a fetish in similar terms as the concept of metaphor by stating that both replace the actual subjects they describe and provide access to identity (Heffernan 22). 
Framing with its focus on cognitive and affective mechanisms of public discourse and stereotyping by far exceeds this simplified and normative model criticized by Bhabha. It provides both writers and analysts of autobiography with the theoretical underpinnings of modern-day public discourse and the distribution of knowledge therein (Tankard 96). Ultimately, this knowledge can help (re-)frame the public stereotype of the "bad Arab" (Orfalea 168). It only does so, however, if framing is employed not only as a strategy of writing autobiography, but also as a strategy of reading it.

\section{(Re-)Framing as Empirical Theory of Reading Autobiography}

As the normative debate on the creation of stereotypes in Cultural Studies reflects, framing as a strategy of writing and reading autobiography requires a mind change away from normativity toward the inclusion of empirical findings from the fields of Media Studies and cognitive science. This also calls for a methodology that combines the analytical advantages of Media and Literary Studies while limiting their weaknesses. Surprisingly, scholars in the fields of Media Studies in this context complain about similar shortcomings as their colleagues in literary study departments. As Justin Lewis polemically remarks, there are only two types of media research; the first one is "literary and speculative" and the second is "political and power oriented" (19). A theory of (re-)framing allows for the literary and the political reading of life narrative while combining these readings with the analytical strengths of empirical Media Studies. This leads to a coherent analytical framework consisting of specific predefined analytical steps and a number of variables to be identified in order to test the explanatory value of the theory.

Such an empirically oriented model of analysis provides a very specific understanding of framing that differs from the conventional use of the term in Literary Studies. Many authors mention framing without ever defining it or without even providing a close-reading analysis of the texts discussed (see Whitlock 139). Gillian Whitlock in her study on Arab and Muslim life writing, for example, uses the term 'frame' throughout her entire work in very different contexts. She speaks of a "rhetorical frame" which is constituted in life narratives and the use of memoir to "alter the frame" (Whitlock 139). Furthermore, a "literary frame" (Whitlock 153) and "frames of reference" are functioning as intertexts (Whitlock 158). This omnipresence of framing vocabulary is not an exception, though. Other authors in autobiography research use the concept with similar frequency. Waill Hassan, for example, focuses on the historical "frame" in his discussion of Leila Ahmed's memoir ("Arab-American Autobiography" 18) and concludes that the theme of connectedness "frames" her autobiography (W. Hassan, "Arab-American Autobiography" 
20). Sidonie Smith ${ }^{166}$ and Julia Watson in their study of avant-garde autobiographical art also repetitively employ the concept of the "frame" to explain the narrative set-up of the texts discussed ("Rumpled Bed" 6). In addition, scholars focusing on political functions of autobiographies also favor the term framing to describe the way in which literature can impact public discourse. This particularly applies to scholars working on feminist theory (Whitlock 89). ${ }^{167}$

The acknowledgement of framing as a strategy of writing based on the theoretical elements of framing in Media Studies already eliminates this vague and inflationary use of the concept. Framing as authorial strategy, however, only becomes visible if framing is embraced also as a theory of reading and writing. Such a move can account for what scholars in the field of autobiography have been calling for, namely, "one of strategic auto/biographism" to fully grasp "lived experience" ("Discourse in the Theatre" $\mathrm{xx}$ ). In order to be able to speak of a theory of writing and reading, of production and reception, analysts need to be able to identify the frames interacting in mediated life writing. This requires more than the universal use of framing vocabulary or inductive inferrences without sufficient textual proof. A thorough text analysis is therefore needed that relies on a defined set of variables according to which the existence and effectivity of frames can be identified. Based on the given trajectories of necessary requirements for the existence of framing, the following variables (V) will serve this function in the literary analysis:

- $\quad V_{1}$ : Claims of Truth and Authenticity - Since the credibility of the source is a key factor for the successful implementation of frames, authors employing framing as their strategy must underline their authenticity. For authenticity can be linked to several identity traits, e.g., profession, cultural experience, or ethnic identity, all textual or visual ${ }^{168}$ references to these characteristics can count as means to achieve credibility on the part of the reader.

166 Sidonie Smith in an interview with the author strongly underlines the rather universal application of the concept of framing in Cultural Studies at large. "Everything can frame," she highlights. According to Smith, autobiographies do not necessarily have a privileged status to achieve this effect in public discourse. The use of framing for the analysis of autobiography certainly does not deny this assumption that any cultural material has the capacity to frame. Still, the specific use of framing as rooted in media theory requires the comparability of different cultural material based on structural similarities such as non-fiction content.

167 The most-frequently cited example in the context of Orientalist literature is the use of a frame story told by the narrator Sheherazade in 1001 Arabian Nights (Whitlock 89).

168 Again, when calling attention to the different cognitive effects by information provided either in visual or textual format, visual material will be recognized if it plays a very 
- $\quad V_{2}$ : Structure/Form - Frames can be identified on various levels, i.e., on more abstract ideological as well as on more focused issue levels. Higherlevel frames can be identified by paying particular attention to the structure and general format of a work. This can include structural elements such as title, chapter divisions, headlines, and subheadlines, as well as individual insertions which interrupt the body of the text (e.g., diary entries, pictures, etc.). All these structural devices can be assumed to create a particular reading scheme which functions as an umbrella frame encompassing several issues on the lower level.

- $V_{3}$ : Language - This criterion obviously constitutes an umbrella criterion since all of the afore-mentioned variables also rely on textual evidence linked to the use of language. Language as separate variable, however, seeks to specifically identify the creation of different issue frames. The use of recurring key terms and vocabulary linked to specific issues counts as strongest indicator to prove the existence of these issue frames. ${ }^{169}$

- $V_{4}$ : Reception - The final variable seeks to grasp textual frames as they are adopted by the audience. Audience here explicitly includes the realm of “"everyday' readers" and professional audiences, such as literary critics and journalists (Douglas 156). The analysis therefore includes reviews published in literary journals and magazines, as well as newspaper reviews and electronic reviews published on commercial book selling sites, special interest platforms, and bookclubs. ${ }^{170}$ This analysis of audience frames also extends to the larger setting of the marketplace. Whenever available, sales data and oth-

dominant role. It nevertheless has to be pointed out that the comparability between visual and print media needs to be assured.

169 Since this vocabulary-based analysis does not equal quantitative content analysis which relies on coding (Scheufele and Scheufele 127), it certainly involves subjective interpretation. While this can count as an inherent weakness of the analysis, it also accounts for its strength since it values literary interpretation as complementary to content analysis in order to arrive at a more nuanced understanding of framing mechanisms.

170 As Kate Douglas rightly points out, reviews play an increasingly important role for literary scholars and the publishing industry since they often serve as the only early indicators of how a book is received by the audience. Reviews today are mostly published online, not only by professional reviewers but also by the reading public. Some analysts have started to pay attention to online reviews, among them John Eakin ("Breaking Rules" 118) and Gillian Whitlock (Whitlock 14). Predominantly, however, these authors only provide tentative snapshots of these audience evaluations which therefore do not contribute to a thorough analytical approach to audience studies. So far, there are no coherent studies on online reviews in Autobiographical Studies (Douglas 156). 
er commercial indicators, e.g., the marketing of the respective books with respect to particular target audiences, will be included in this variable.

As can be noted, $V_{1}$ explicitly targets possible gatekeeping efforts by writers to establish a frame (Production). $V_{2}$ and $V_{3}$ focus on the text-immanent instruments used to constitute frames (Text). $\mathrm{V}_{4}$ seeks to grasp if and in how far the frames identified in the text are adopted by the readership (Reception). This methodology therefore does assume a causal relationship proceeding from text to audience with textual frames representing the independent variable. This reflects the original intention of this study to reveal the effects of autobiographical writing on public discourse and not the reverse. This logic does not seek to neglect, however, that these effects are "culturally resonant" and therefore likely to become part of authorial frames at a later point (Bakalian and Bozorgmehr 19). ${ }^{171}$ As the description of the given variables already indicates, certain variables might sometimes be difficult to delineate since means of textual representation often overlap. It is, however, the guideline for the analysis to adhere to this analytical methodology as strictly as possible to identify the dominant ${ }^{172}$ frames operating in the chosen autobiographies.

\section{Graph 2: Reframed Theory of Production and Reception}

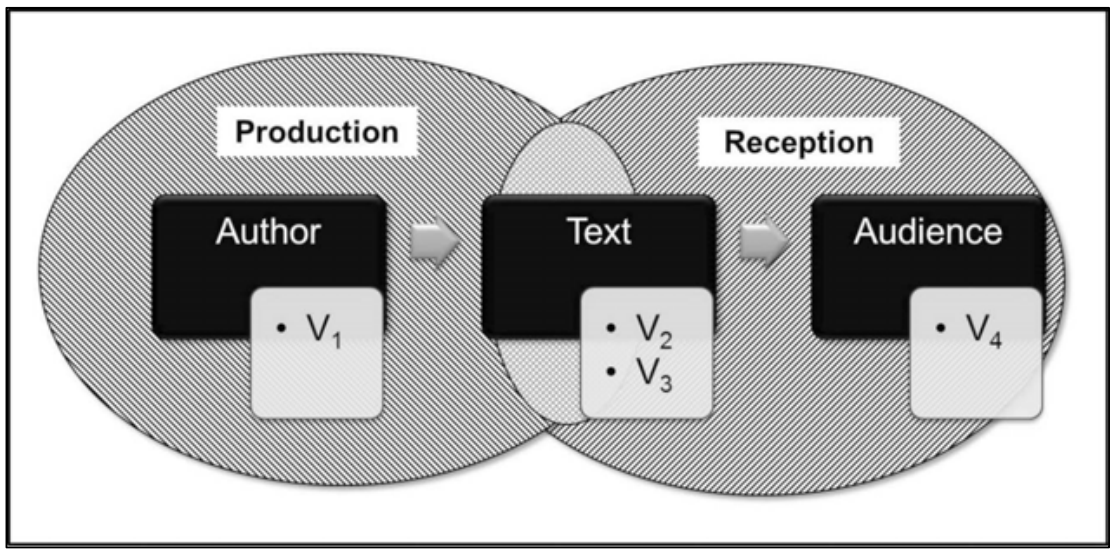

171 To a certain extent, these reciprocal effects are already implied in $\mathrm{V}_{1}$ based on the assumption that authenticity claims by the authors are already a reaction to dominant frames circulating in the public.

172 This suggests that the aim of the analysis is not total integrity. The goal is to identify and analyze the establishment and effects of major frames found in the given works. This does not rule out the existence of additional frames functioning in the works which the present analytical model cannot capture. 
Ansgar Nünning and Manfred Jahn once stated that the "main advantage of models is that they are unbeatable didactic tools" (qtd. in Schulz 7). The given model of framing as a theory of writing and reading autobiography fulfills this function in several ways. By including the production process and other situational circumstances surrounding the text in the analysis, the scholar is forced to leave the narrow view of the literary sphere to engage in true "discourse studies" (Alasuutari 12). Different from the conventional use of the term, this requires an embracing of the entire "media culture" as the discursive environment of life writing (Alasutaari 9). This environment, in turn, must not be regarded merely as the place of identity politics, but as the place where knowledge is constantly produced and reproduced, framed and reframed. Ultimately, (re-)framing as theory of writing and reading life narrative becomes a "public knowledge project" (Alasutaari 17). This knowledge project must eventually start where stereotypes take their origin; namely, with the media coverage creating the framed Arab. 



\section{The Framed Arab/Muslim: Mediated Orientalism}

When Said established the bridge between Orientalism as literary creation and the impact of the media in Covering Islam, there was not yet much of an empirical basis to support his claim. Instead, he trusted the "hermeneutically trained mind" to think critically and act against labels like Arab and Muslim (Said, Covering Islam 165). Any contemporary analysis which seeks to investigate the impact of mediated Orientalism on the real world needs to start with a detailed status-quo analysis of what this real world looks like. When acknowledging the complexity of Orientalism, a mere counting of stereotypes does not suffice for this task. When seeking to gain a more differentiated picture of how the mediated image of Arabs is framed, a close analysis of Orientalism and the empirical data provided by Media Studies reveals that Orientalism is a multi-layered concept. This complexity is also reflected on the various levels and layers through which Orientalism is mediated.

\subsection{The Ideological Frame: Orientalism}

\section{Defining What Defines the Orient(al)}

Edward Said in Orientalism does not provide a single and universally applicable definition of his theory. Rather, the work in its entirety due to its mostly "historical method" serves as a demonstration of how many facets have accompanied and thus created Orientalism throughout the centuries (El-Haj 550). This has not prevented scholars of Orientalism from creating their own definitions of what Said missed or intentionally refused to define. Differentiating between the said and the "Unsaid" in Said therefore brings illuminating insights into the vast desert of definitions circulating in the literature (Varisco 1). While Said did not provide a concise definition of Orientalism, the following passage provides one of the most comprehensive summaries found in his work: 
Orientalism as a Western style for dominating, restructuring, and having authority over the Orient. I have found it useful here to employ Michel Foucault's notion of a discourse [...] to identify Orientalism. My contention is that without examining Orientalism as a discourse one cannot possibly understand the enormously systematic discipline by which European culture was able to manage - and even produce - the Orient politically, sociologically, militarily, ideologically, scientifically, and imaginatively during the post-Enlightenment period. (Orientalism 3)

This passage demonstrates Said's conception of Orientalism in very broad terms. Although he mentions Foucault as theoretical source for his argument (Varisco 254), his inclusion of various discursive realms in society exceeds the narrower definition of Foucauldian discourse as semiotic system. ${ }^{1}$ Discourse to Said refers to the "bounded area of social knowledge" (Ashcroft, Griffiths, and Tiffin 165). With respect to art, this obviously implies all kinds of cultural production. Only later in the book does Said specify the linkages between Orientalism, discourse, and the role of literature:

Not only is the Orient accommodated to the moral exigencies of Western Christianity; it is also circumscribed by a series of attitudes and judgements that send the Western mind, not first to Oriental sources for correction and verification, but rather to other Orientalist works. The Orientalist stage, as I have been calling it, becomes a system of moral and epistemological rigor. As a discipline representing institutionalized Western knowledge of the Orient, Orientalism thus comes to exert a three-way force, on the Orient, on the Orientalist, and on the Western 'consumer' of Orientalism. (Orientalism 67)

Critics in the postcolonial era have exhaustingly written on the implications these and other descriptions have for the struggle of power in a postcolonial world. ${ }^{2}$ Un-

1 Carol Bardenstein provides a clear-cut analytical positioning of Orientalism as a theoretical specification but also limitation of Foucouldian discourse theory. "Said's Orientalism was based on Foucault's concept of discourse," she explains. "The latter was not related to any specific cultural material. Said then provided a case study of the Western production of knowledge on the Middle East and pointed out the operations behind it [...]" (Personal interview). According to Bardenstein, this also sheds light on another aspect of Orientalism, i.e., the common assumption that it is only exercised by Westerners. "Said is not saying that only 'Westerners' do that [Orientalize], i.e., construct partial and schematic versions of the more complex reality around them. It is in the nature of human perception," Bardenstein clarifies (Personal interview).

2 While most scholars apply Orientalism as an overarching concept to analyze the representation of various different ethnic groups in the postcolonial era, some reduce Orientalism specifically to the Middle East. Stephen Salaita, for example, discusses Orientalism 
fortunately, this has caused them to largely overtress one part of Said's argument while neglecting many others. In other words, critics using Said's short summaries of Orientalism often end up misusing the concept since they focus on Orientalism merely as a theory and not as an approach. An important hint to this necessary delineation is marked by the fact that Said presents various and sometimes contradicting characteristics, such as social circumstances, situational aspects, and actors, which account for Orientalism. The ethnologist Nadia El-Haj points to this multiplicity in arguing that Said presents at least three overlapping definitions of Orientalism in addition to the one given above: 1) The first one deals with the Orientalist as "anyone who teaches, writes about, or researches the Orient" (Said, Orientalism 2). 2) The second definition is one of Orientalism as "a style of thought based upon an ontological and epistemological distinction made between 'the Orient' and (most of the time) 'the Occident"” (Said, Orientalism 2). 3) Another definition sees Orientalism as a "corporate institution for dealing with the Orient - dealing with it by making statements about it, authorizing views of it, describing it, by teaching it, settling it, and ruling over it: in short, Orientalism as a Western style for dominating, restructuring and having authority over the Orient" (Said Orientalism 3).

When juxtaposing these three overlapping, yet, distinct descriptions of Orientalism, the full theoretical potential of the concept unfolds. This differentiation targets the Orientalist as actor, Orientalism as binary thought construct (Yeğenoğlu, Colonial Fantasies 22), and Orientalism as an institution of hegemony. Due to the heavy focus of today'a adherents of postcolonialism on the latter aspect of hegemonic dominance, this distinct theoretical delineation is hardly ever recognized. The first component of Orientalism refers specifically to Orientalism as an active intellectual practice. This underlines the overarching conception of Orientalism as based on knowledge construction; yet, it personalizes the construction of this knowledge. "Knowledge of the Orient, because generated out of strength, in a sense creates the Orient, the Oriental, and his world," Said writes in Orientalism (40). The focus therefore rests on the individual actor in discourse who creates this knowledge, not on a collective hegemonic power. Even though Said here already links the idea of knowledge with power by using the term "strength," the passage does not heavily rely on a normative concept of instrumentalization. Rather, anyone engaged in knowledge production about the Orient practices Orientalism. ${ }^{3}$ In more neutral

in the context of "anti-Arab racism" (qtd. in Cainkar 87). This demonstrates how broadly but at the same time narrowly Orientalism is being perceived in post-Saidian times.

3 In the context of Orientalism as a field of study, Esra Sandikcioglu differentiates between "Western scholars" and "nonprofessional Orientalists," whereby both contribute to the creation of Orientalism by means of fictional and non-fictional accounts. This stressing of professionialism is particularly interesting in light of the fact that Said himself stood for, what he called, "amateurism" (Varisco 280). 
terms, Orientalism, according to this separate definitorial element, describes an area of study. ${ }^{4}$

The second definition of Orientalism as constructed in opposition to Occidentalism underlines the binary nature of the concept (Lau and Mendes 5). A vast amount of studies have dealt mostly with the disadvantages of this binary approach, particularly with respect to the constitution of counter-discourse. Walter Mignolo conceives of Occidentalism as "the visible face in the building of the modern world, whereas subaltern knowledges are its darker side, the colonial side of modernity" (20). In addition, according to Mignolo, Occidentalism represents "the overarching metaphor of the modern/colonial world system imaginary" (23). Although this example of post-Saidian Orientalist theory sounds convincing, Said himself did not engage in defining Occidentalism in these competitive terms. In fact, he did not define Occidentalism at all, even though critics later accused him of advocating Occidentalism or "reverse Orientalism" as major strategy (El-Haj 541). This reductionist approach that pits Occidentalism against Orientalism as essentialist categories does not meet the complexity of Orientalist discourse exemplified by Said (El-Haj 542). He obviously described the two concepts as binary oppositions but did not evaluate this binary structure itself. In other words, Said's definition is much more in line with the finding that Orientalism and Occidentalism constitute two separate categories or schemata which are divided by their individual characteristics. This depiction of the relationship between Orientalism and Occidentalism therefore is one of distinction, not one of opposition or political antagonism. Said's conclusion, which often tends to be overlooked by scholars, confirms this finding: "I hope to have shown my reader that the answer to Orientalism is not Occidentalism" (Orientalism 328).

A similar distortion of Orientalism as it was re- and often mis-defined by later scholars can be detected in the case of the third element of Orientalism, i.e., its institutional nature. ${ }^{5}$ Said indeed specifies Orientalism as an institution in hegemon-

4 This definition of Orientalism is the reason why, up to the present day, many academic departments and other scientific institutions connected to the study of the Middle East contain references to Orientalism in their institutional descriptions. Orientalism here merely defines a geographic and cultural region that marks the field of investigation without any intention to misrepresent this object of study.

5 It is interesting to note that Said here uses the term "institution" in the sense that political science defines it. Institution in the realm of international relations refers to "social environments" which emerge as the result of socialization processes (Johnston 488). This underlines Said's interdisciplinary interest and use of terminology. Critics today, however, mostly read the term in a very literal sense and argue that Orientalism works beyond institutions based on "banal" encounter, meaning that inviduals and not organizations spread Orientalist thought (Haldrup, Koefoed, and Simonsen 176). 
ic terms whereby the East is dominated by the West. Most scholars here merely center on the aspect of power while neglecting the importance of the concept of discourse as formative element of Orientalism. As Said states, "the Oriental is contained and represented by dominating frameworks" (Orientalism 40). Said's use of the term "frameworks" here is particularly noteworthy, especially with respect to the fact that he uses the plural. ${ }^{6}$ This underlines that, far from the reductionist stance of Said's critics and adherents alike, he did not think of Orientalism only as one dominant framework but as the interaction of multiple frameworks. This also sheds light on the meaning of authority and power in his work, which is usually overemphasized and simplified to black-and-white-thinking (Ta 160). ${ }^{7}$ If Orientalism first and foremost means discourse, and if the definition of discourse, in turn, requires the idea of dominance, Orientalism naturally implies this feature. The mere existence of discursive dominance therefore does not reveal anything about the specific power relationships within this discourse neither does it answer if these relationships are fixed or dynamic.

This close look at Orientalism as multi-faceted concept above all demonstrates that the concept as envisioned by Said was not merely the binary power conglomerate which many critics today see as the essence of Saidian theory. While this reductionist treatment of Orientalism has already been acknowleged by critics, these thinkers still do not provide alternative analyses of Said's conception of Orientalism. The previous differentiation fills this gap by demonstrating that Orientalism includes the Orientalist actor, Orientalist practice, and Orientalist discourse. While some of these elements are linked to questions of power, their common denominator - despite normative considerations - is their ultimate goal of knowledge production and dissemination. This significance of knowledge is at the center of any discourse. Said's work therefore has to be read as a theory and partly critique of knowledge production in general, not merely as theory of knowledge instrumentalization by the West alone. "If the knowledge of Orientalism has any meaning," he thus states, "it is in being a reminder of the seductive degradation of knowledge, of any knowledge, anywhere, at any time" (Said, Orientalism 40).

This differentiated view of Orientalism as it was formulated by Said reveals the complexity of the concept. Said in Orientalism did reveal the various constitutive

6 Said in another instance also named some of the most important frames of Orientalism, e.g., the Middle East conflict and earlier political crises. Only much later would empirical studies show that these frames are indeed highly relevant ones in the public identity construction of Arabs and Muslims (Covering Islam xxiii).

7 Although Ta acknowledges that the relations between "East" and "West" have significantly changed in the past decade, she nevertheless perceives of Orientalism as a mere form of "domination" (160). This is characteristic of most critics in the field who overstress the element of power in Said's work. 
elements of discourse which define the Oriental in the public. These diverse elements also need to be accounted for when tracing the trajectories of contemporary Orientalist discourse in the media age. This requires a translation of these crucial elements into variables which, based on a coherent methodology, have the capacity to signal the existence of Orientalism as frame of interpretation. Furthermore, such an analysis needs to reveal which role Orientalism plays in the interrelated network of frames surrounding the Arab/Muslim. The significance of binary thinking as constitutive element provides the key to unfolding the overarching function of the Orientalist frame.

\section{Ideo-Logics of Orientalism}

Samuel Huntington in his critique of ethnocentrism in the sciences reminds his audience that the "West won the world not by superiority of its ideas or values or religion but rather by its superiority in applying organized violence. Westerners often forget this fact, non-Westerners never do" (qtd. in Whitlock 26). Although one can as well argue that the superior status of the West is a consequence of all of the given factors rather than an either/or question, Huntington's statement points to several characteristics that are crucial to the logic of Orientalism. The most important one is the resulting division into a Western and non-Western world. This highlights the importance of binary thinking in Orientalism. The other reference which Huntington provides refers to the importance of value dominance. Both aspects reveal the logics of Orientalism, which in turn account for the ideological component of the frame.

The etymological origin of a binary describes something "made of or based on two things or parts" ("Binary"). A term which is often used synonymously is the one of dualism. While also describing something which consists of two fundamental elements, a dualism encompasses a more far-reaching philosophical scope. The concept thus describes the "doctrine that the universe is under the dominion of two opposing principles one of which is good and the other evil" ("Dualism," def. 3a). The most commonly recited dualism in Western philosophy is the so-called "mindbody dualism" which propagates the detachment of rational thinking and kinaesthetics, or the separation between soul ("Geist") and "brain" (Verstand) (Slingerland 25; Huddart 59). A third term which is closely linked to the previous two is the one of dichotomy, i.e., "a division into two especially mutually exclusive or contradictory groups or entities [...]" ("Dichotomy," def. 1).

The importance of binaries within Orientalist thought is best summarized by a "contrapuntal perspective" in colonial discourse analysis (Armstrong 115; Bayoumi and Rubin xxviii). This concept implies the simultaneous consideration of two opposing positions at a time (Aboul-Ela, "Is there an Arab" 735; Varisco 290). The 
most constitutive binary in Orientalism is seen in the opposition of Orient and Occident which leads to a division of "Occidental and Oriental cultures" (Whitlock 99). Occidentalism thus represents the "antidote" to Orientalism (Ning 64). As this use of the term "antidote" suggests, binaries in Orientalism are not merely seen in neutral terms as mere oppositions based on difference. Rather, the dualism is inherently linked to value judgements and opposing belief systems.

Values constitute a crucial part of human life. Accordingly, the definition of what exactly counts as value is rather vague. As the sociologist Rudolf Rezsohazy states, "[e]verything social actors appreciate, appraise, wish to obtain, recommend, set up or propose as an ideal, can be considered as a value" (16153). Values consequently comprise several dimensions: 1) they are attached to certain objects which are either appreciated or declined; 2) values are inherently linked to judgements about these objects; 3 ) values become norms when they regulate behavior in a larger-scale social setting; 4) value holders are required to propagate values either individually or collectively. Since the emotional and moral nature of values depends on acceptance, the concept of values also immanently implies the idea of "countervalues" (Rezsohazy 16153). This highlights the importance of a substantial binary within the concept of values itself.

When investigating the significance of the two concepts of binaries and values for the concept of Orientalism, it becomes clear that binaries are always linked to value judgements. This goes along with the notion that value opposition includes hierarchies. The example of "master and slave," as employed by Hegel, wraps this thought into a striking metaphor (Mignolo 67). The two formative elements of a binary are thus not seen to stand in juxtaposition to each other but in contrast, whereby one is superior to the other. Power imbalance originating in language is thus assumed to inadvertently lead to conflict exceeding the linguistic ${ }^{8}$ realm where "conflict is no longer conceived as a contamination of the linguistic but as its properly defining function" (Terdiman qtd. in Ashcroft, Griffiths, and Tiffin 167). The divisions of East and West and Orient versus Occident are thus primarily the products of value separation based on particular values which are thought to be Western or Eastern in nature (Norris and Inglehart 205). ${ }^{9}$ This indivisible association of binaries as causes for hierarchies and conflicts has ultimately found its mani-

8 The normative notion of binaries is also reflected in the linguistic theory of signs as brought forth by Ferdinand de Saussure. A dualism here is conceived of as "binary opposition" (Ashcroft, Griffiths, and Tiffin 167).

9 Pippa Norris and Ronald Inglehart in their differentiated analysis of Orientalist representation in the media rightly point out that the values by themselves were neither of Western nor of Eastern origin. As they explicate, "[i]ndividually almost none of these factors was unique to the West. The combination of them was, however, and this is what gave the West its distinctive quality" (Norris and Inglehart 205). 
festation in the social sciences with the "clash of civilizations" thesis developed by Samuel Huntington in his seminal work The Clash of Civilizations and the Remaking of World Order (1996). Here, the struggle of "politics of ethnicity" and the struggle of superpowers is assumed to lead to an insoluble confrontation (Huntington 28; Norris, "Public Opinion" 205; Naber, "Introduction 38). ${ }^{10}$

When looking at the core characteristics of Orientalism as binary and valueladen concept through the lens of framing theory, it becomes clear that Orientalism is not limited to any specific cognitive frame level impacting the way in which Arabs and Muslims are represented in public discourse. Rather, Orientalism constitutes an overarching "belief-system" and thus an ideology ${ }^{11}$ (Steinberg 847-48). ${ }^{12}$ Ideology can be defined as "the social (general and abstract) representations shared by members of a group and used by them to accomplish everyday social practices [...]" (Barker and Galasinski 65-66). ${ }^{13}$ This underlines the instrumentalist function of ideology that is also connected to the central importance of the concept of truth. As Chris Barker explains, ideology involves "binding and justifying ideas" to support universal truth claims on the part of a dominant power while ignoring the fact

10 The clash of civilizations thesis counts as one of the best-known concepts in interdisciplinary cultural scholarship, though, severe differences exist with respect to its interpretation. The major debate dividing the humanities and the sciences is on the question whether the "clash" is mostly caused by value differences or by a global economic divide (Norris and Inglehart 206). Norris and Inglehart thus provocatively conclude that the clash of civilizations has also brought about a "clash of scholarship" (222).

11 The concept of ideology is commonly used in opposition to science and truth. What Chris Barker and Dariusz Galasiński rightly call attention to in this division is that science itself represents a "mode of thinking" that bears characteristics of ideology (66). Hilfer exposes this ideological quality of contemporary literary theory by pointing to the fact that the field continues to be ruled by a limited number of theoretical thinkers establishing a theoretical hegemony: "Theory is full of airpockets. It seems odd that a discourse that so professes skepticism, suspicion, and, above all, diversity, has authorized, after searching through all twentieth-century thought, only one political scientist, one philosopher, one 'historian,' and one psychologist: the discursive law firm of Althusser, Derrida, Foucault, and Lacan [...]" (19-20).

12 Said characterized Orientalism as an ideology, although he did not explore the theory of ideology in further detail. Even without this explicit thematization of ideology, Said nevertheless described Orientalism as a "closed system" which is entirely "self-containing" and "self-reinforcing" (Orientalism 70). All these characteristics are also essential to the definition of ideology.

13 The nature of ideology as functional also again reverberates back to the theory of discourse. Discourse, based on its strategic use, is thus always ideological in a sense that ideology is produced through discourse (Barker, Cultural Studies 482). 
that this truth is in fact historically and culturally specific (Cultural Studies 482; Foucault, Interview 61). An important feature of ideology is that its logics work through cognitive and normative measures to achieve political ends. "Historically, a combination of (mis)information has worked to construct an enemy image in the popular imagination that has an important function in the maintenance of political power or hegemony through ideology (Merskin 158).

When ordering this quality of Orientalism within the model of framing, Orientalism constitutes a "master frame" on the upper level of the vertical framing axis (Steinberg 846). It therefore occupies an influential role in affecting lower-level issue frames. In order to detect how this ideological frame operates in mediated discourse, the focus needs to shift to the dimension of language (Sandikcioglu). The binary of Orient/Occident here only constitutes one example of a broad register of terms that Orientalism as ideological frame is based on.

\section{The Language of Binary Thinking}

Altogether an internally structured archive is built up from the literature that belongs to these experiences [Orientalism]. Out of this comes a restricted number of typical encapsulations: the journey, the history, the fable, the stereotype, the polemical confrontation. These are the lenses through which the Orient is experienced, and they shape the language, perception, and form of the encounter between East and West. (Said, Orientalism 58)

Said in this passage again employs a metaphor to demonstrate the workings of Orientalism as a master frame. ${ }^{14}$ Orientalism on the ideological level gives way to further "lenses" shaping the vision of the Middle East. Nevertheless, the stories which make up this vision are products of language, and it is in the realm of language where Said locates the severe impact of Orientalism. Two sets of vocabulary and their respective connotations thus form the frame of Orientalism: binary thinking and inferiority/superiority connected to the binary.

When studying the way in which binary thinking is reflected in today's discourse, the opposition of Orient versus Occident only represents one vocabulary pair on the highest level of Orientalist discourse. Another very prominent binary is the terminology of East versus West. Said himself summarized the omni-presence of both terms as "over-all identity of something called 'the East' and something else called 'the West", (Orientalism 257). Whereas East and West, on the one hand, underline the geographic nature of the global divide, several other constructions

14 Despite acknowledging the importance of this passage to Said's argument, Homi Bhabha describes it as "underveloped" and "forgotten" (Location 104). This critique does not apply to the critical reception of the passage but to Said directly. Bhabha thus employs the passage to build up his own argument of reading stereotypes as "fetish" (Location 106). 
involving this binary terminology have evolved. A popular practice is the contrasting of "Western and non-Western" cultures (Shohat and Stam 14). In addition, the terms West and East are also frequently applied to the individuals living in the respective cultures; meaning that Americans or Europeans are simply referred to as "Westerners" (Whitlock 26). As Armstrong analyzes, the ideological nature of this dichotomy not only emphasizes the awareness of conflict, but it often leads to a polarization in which "the Oriental becomes more Oriental, the Westerner more Western [...]" (113). A prominent term in this respect, which draws particular attention to the normative superiority of the West, is reflected in the use of the adjective "Westernized" (Tehranian 102). ${ }^{15}$

As Said demonstrated at length, the binary oppositions of Orient/Occident and East/West, are the products of a plethora of "myths and fantasies" created through language (Williams qtd. in Shohat and Stam 13). The real-world implications of these fables are reflected in the power dichotomy between East and West. This ideological impact has given rise to another prominent binary, namely, the opposition of $u s$ and them. Assigning who occupies which position obviously depends on the position of the one defining (Sandikcioglu). The history of colonialism and the emergence of science as Western project have ensured that the role division has become universal ideology. It was the West, i.e., "we," aiming to bring civilization to the East, i.e., "them" (Shohat and Stam 3).

This further division into $u s$ and them as linked to the idea of civilization reiterates the ideological nature of Orientalism. Civilization as Western concept finds its contrast in the idea of barbarism. This reinvokes the implicit reliance of values on countervalues which ultimately find expression in the language of binaries. Further binary pairs can therefore be detected in this repertoire of terms which circulate in the public discourse on Arabs and Muslisms. These terms can be categorized according to different social realms. The following table gives an overview of these categories and respective binary vocabulary:

15 As Raynold Williams points out, the geographical origin of the division between East and West is a fiction in itself due to its relativity. The Middle East from the perspective of China represents Western Asia (333). Shohat and Stam therefore label this complication "The Myth of the West" in one of their subchapter headings (13). 
Table 2: Binary Vocabulary of Orientalism

\begin{tabular}{|l|l|l|}
\hline Orientalism & Occident & Orient \\
\hline Agent & American/European & Arab/Middle Easterner \\
\hline Location & West & Them \\
\hline Rere & White & East \\
\hline Ideology & Enlightenment & There \\
\hline Social Order & Democracy & Black \\
\hline Secularism & Eastern Thought \\
\hline Economic Order & Rule of Law & Totalitarianism \\
\hline Religion & Capitalism & Religious Authority \\
\hline Orientalism & Occident & An Eye for an Eye \\
\hline Other collective & Progress & "Camel Trade" \\
\hline values & Civilization & Islam \\
\hline Power & Orient \\
\hline Maturity & Backwardness \\
\hline Rationality & Barbarism \\
\hline Stability & Wodesty & Immaturity \\
\hline & Meakness \\
\hline & Emotionality \\
\hline & Instability \\
\hline
\end{tabular}

Source: Table by the author based on Sandikcioglu (also see Norris and Inglehart 205; Mignolo 19; Ta 161; Shohat and Stam 2-3; Wöhlert 2).

The ascription of these terms to different categories is not exclusive since some of them also bear characteristics of other categories. Such is the case, for example, with secularism versus religious authority. Depending on the respective theoretical focus, this binary could as well be grouped under the category of "Religion." The order of the categories entails a hierarchy in itself with the first two categories, namely, "Agents" and "Location," being the most inclusive ones. This division overspans the lower-level binary pairs. Most notable here is the significance of the ideology of enlightenment and the associated collective value of rational thought. Both values hint at the normative dimension of Orientalism at large and at the affective component of the binary vocabulary upholding it. Every component of the binaries therefore is linked to a specific value-connotation with positive or strong 
being linked to the West and negative or weak ones with the East. ${ }^{16}$ Since the Ar$\mathrm{ab} /$ Muslim within Orientalist history has become the object of this dichotomization rather than the "creator of discourse," he/she represents the stereotypical other in the normative binary structure (Aboul-Ela, "Is there an Arab" 737).

\section{Empirical Evidence of Mediated Orientalism}

One year after the Arab Spring swept the Middle East, headlines such as the following are daily news. "Bias in West's Response to Arab Spring" (Associated Press). These articles repetitively pit "Western governments" against "Arab autocratic rulers" (Associated Press, "Bias"). Symptomatic about these articles is not so much their specific content but the way in which these articles make use of binary vocabulary in order to convey this content. The term "West" is hardly ever accompanied by long explanations. Instead, this foundational element of binary discourse has found its way into the heads of the readers throughout history in a way that the different connotations of the term are established and need no further clarification. While this example highlights the general impression that Orientalist binaries in fact pervade the contemporary media discourse on Arabs and Muslims, empirical Media Studies have made increasing efforts to document and analyze the specific way in which Arabs, Muslims, and Arab Americans Muslims are represented. What differentiates these studies conducted in the field of Communication Studies from hermeneutical investigations carried out in the field of literary studies is the capacity to provide empirical evidence Orientalist framing as well as for the impact of this frame on the media public throughout several phases of its constitution

The first phase of empirical studies on Orientalism in the press dates back to the 1980s. At the time, empirical methods in Communication Studies such as content analysis became increasingly sophisticated. In addition, events in the Middle East fostered the heigthened interest in the relation between the image of Arabs and Muslims and their mediated representation. Following key events like the Oil Crisis in 1973 and the Iranian Hostage Crisis in 1979, studies with a theoretical focus on framing started to be conducted more frequently. ${ }^{17}$ The results of these early ${ }^{18}$ ex-

16 Certainly, this value-connotation is not inherent to the terms themselves but already a consequence of their evaluative use in Orientalist discourse.

17 This went along with a rising interest in the depiction of ethnic minorities in the mass media at large, which has remained stable ever since (Wöhlert 26). This attention to ethnic minority representations in Media Studies also triggered a more nuanced understanding of different ethnic groups. In the U.S., for example, research on ethnic minority coverage for a long time was dominated by African Americans, Hispanics, and Asians in former times (Wöhlert 28). 
aminations underline Orientalism as overarching ideological frame for the depiction of Arabs. Orientalism here specifically functioned through "de-contextualization and de-historization" (Cherkaoui 110). Keywords which frequently occur in codebooks of the respective analyses include "Orient versus Occident" (Wöhlert 31) as well as the contrasting of civilization versus barbarism (Wöhlert 2). These binaries are often accompanied by the " "us-and-them' dichotomy" (Cainkar 85). The normative charging of these binaries was achieved by references to the Arab as "evil" (Cainkar 289) and "violent" (Wöhlert 28). These results speak a clear language as to how the use of Orientalist terminology fostered the production of Orientalism as ideological master frame (Steuter 259).

The second major wave of studies on Arab stereotypes occurred in the aftermath of the Gulf War. ${ }^{19}$ The tendency to present Arabs and Muslims within the Orientalist frame peaked during this period (Cherkaoui 125). Orientalism was used to sketch the image of the Arab as enemy, ${ }^{20}$ not only in a political but cultural and moral sense. The basic technique to achieve this effect rested on polarization. The language of binaries thus played the most important role to activate and maintain stereotypical schemata (Sandikcioglu). Most obvious in the coverage of the Gulf War was the lack of background information on the conflict. Rather, the coverage was structured within an "Iraq and US" grid with a very limited thematic focus on diplomatic and military affairs (Iyengar and Simon 180). These findings underline the operation of the Orientalist frame as an ideology. Esra Sandikcioglu, based on

18 Some of the studies conducted in the 1980s and 1990s also included media material which reached further back than Shaheen's investigation of The TV Arab (Ghareeb 4). The dates of the studies therefore do not necessarily reflect the media representation at the time of publication. An example is Laurance Michalak's comparative study on popular culture films showing Arabs of the 1940s and the 1960s. His conclusion regarding the development of Orientalist stereotyping in the media is sobering. As he states, "the Arab world had changed but the Arab stereotype had not" (qtd. in Cainkar 89).

19 Especially the second Gulf War plays an important role in Communication Studies since it represents the first war of modern history which was completely covered by the media to the degree that the media themselves became the story of the war (P. Taylor 15). It is thus also referred to as the first major "media war" in history (P. Taylor 104). A similar turning point in war reporting was identified in the U.S. invasion of Iraq in 2003. This was the first time when so-called "embedded journalists" reported directly from the war front, a concept which became severely challenged afterwards (Lewis et al. 2).

20 Debra Merskin in her article "The Construction of Enemies" explores the rhetorical and strategic mechanisms underlying the creation of enemies. An important finding is that enemies compose an essential part of hegemonic politics to serve political mobilization and distract from internal difficulties. Contrary to the assumption that enemies are a negative component in the relations of nations, she thus notes: "Nations 'need' enemies" (159). 
an in-depth analysis of metaphors used to taper the East/West binary, identifies "Orientalism as the "ideology' behind the metaphorical Gulf War [...]."

Empirical studies on Arabs and Muslims in the media again soared in the period following 9/11 (Wöhlert 29). The tradition to frame the Arab/Muslim in the media by drawing on Orientalist ideology thus experienced another upflift in the early years of the new millennium. Respective content analyses indicated that the coverage at this time did not differ much from previous periods. The key terms used to manifest the binary between East and West naturally stood under the influence of the terrorist threat. Reports predominantly employed terms such as safety, security, peace, and progress in order to contrast them with war and backwardness in the Middle East. As Michael Ryan in a content analysis of 104 editorials published in ten major newspapers observes, 75 contained strongly one-sided stories in order to gain support for the War of the "West" against the "barbaric East" (363; Tehranian 101). Ryan describes this use of Orientalist vocabulary as a "singular narrative" which characterized the coverage. Similar results have been found for other media formats such as TV and radio news (Nacos and Torres-Reyna 150).

With respect to the range of the Orientalist frame, the majority of studies focus on the role of U.S. media. On a domestic level, their framing efforts stressed the propagation of Enlightenment thought ${ }^{21}$ to foster "national collectivity" (Wöhlert 42; Naber, "Look, Mohammed" 278). This gave way to a renewed sense of "American Orientalism" (Cherkaoui 85$){ }^{22}$ Evidence of Orientalist framing post-9/11 and before, however, is by far not limited to the U.S. Similar results with respect to the lasting use of Orientalist binaries have been found in news studies on European countries. Respective comparative studies revealed similar frame patterns in countries like Germany and Britain (Wöhlert 16).

Overall, the vast amount of studies conducted on the framing of Arabs and Muslims in public discourse provides overwhelming evidence for Orientalism as ideological media frame. In order to reveal in how far this frame actually transfers to the wider media audience, public opinion data need to be consulted. Not surprisingly, these studies mirror the Orientalist bias. Early opinion polls conducted in 1981 show that the American audience in particular used the adjectives "barbaric," "cruel," "treacherous," "warlike," and "bloodthirsty" to refer to Arabs (Cainkar 88). The

21 Slingerland critically illuminates that "Western culture" ultimately treats Enlightenment thought and the focus on science virtually like a "religion" by endowing it with superb prestige (221). In light of the fact that this emphasis on science above all is used as secular advantage of the "West" in order to create a distance to the religiously dominated "East," this comment is quite ironical.

22 Cherkaoui identifies American Orientalism as sub-form of Orientalism as a century-old phenomenon which reaches back to the depiction of the Arab as "barbarian Oriental" in 19th-century literature, such as Susanna Rowson's Slaves in Algiers (89). 
dominance of this binary language has remained fairly stable throughout the past decades. Particularly noteworthy is the affective impact of the frame. Negative depictions thus lead to an overall lack of skepticism toward Arabs and Arab countries. Gallup polls in 2006 showed that $51 \%$ of respondents thought that countries in the Middle East cannot be trusted (Wöhlert 1). Again, this impact of the ideological frame proves to be a transnational phenomenon. Opinion polls conducted in European countries show similar results. In the German GFE ${ }^{23}$ Survey carried out in 2005, 70\% of respondents stated that "Muslim culture does not fit into the Western world" (Wöhlert 1). The latest Pew Global Attitudes Survey documents similar results concerning the culture clash between East and West. Especially in France and Germany, $62 \%$ and $61 \%$ of the respondents state that the relations with Mus$\lim ^{24}$ countries are bad, followed by $48 \%$ in the U.S. ("Common Concerns").

These empirical findings on the constitution of Orientalism as meta-frame and its impact on public opinion underscore not only its relevance but its ideological nature. The Orientalist attitudes prevailing in the various media publics inside and outside the U.S. reflect the value hierarchy associated with Orientalist binaries. Certain values therefore continue to have a positive and thus Western connotation while others evoke negative associations in connection to the East. This valueattribution in turn shapes the image that Western audiences have of the Middle East not only as geographic and cultural entity, but also of Arabs and Arab Americans as individual representatives of these cultures. "Arabness" in its broadest conception therefore gains a negative connotation (Cainkar 85).

This overview of empirical studies conducted on the media framing of Arabs confirms the hypothesis established by Said more than three decades ago. "In the system of knowledge about the Orient," he wrote in Orientalism, "the Orient is less a place than a topos, a set of references, a congeries of characteristics [...]. Direct observation or circumstantial description of the Orient are the fictions presented by writing on the Orient [...]" (177). Empirical Media Studies have meanwhile found concise instruments of observation to reveal these "fictions" in the writing on the Orient. In contrast to case studies and hermeneutical analyses on stereotypes in Literary and Cultural Studies, the empirical framing studies in combination with public opinion data reveal that Orientalism is not "an artificial opposition between the East and the West," as Wang Ning suggests (65). Rather, despite its constructed nature, Orientalism represents the empirical reality of past and present media discourse and the perceived reality of the majority of media consumers around the

23 GFE stands for "group-focused enmity" (Wöhlert 1). The survey is conducted annually to record shifts of collective social attitudes.

24 The report uses the terminology "Muslim" to refer to respondents in predominantly Muslim Arab countries ("Common Concerns" 4). A further differentiation between Mus$\lim$ Arabs and Arabs is not provided. 
world. Consequently, Orientalism maintains the status of an ideology which reigns "civilization and culture" (Said, Orientalism 2). It is this encompassing nature which marks its status as a meta-frame. As it is the nature of a meta-frame, Orientalism therefore also leaves its marks on lower-level schemata.

\subsection{The Political Frame: Everlasting War ON TERROR}

Orientalism as an overarching ideological framework surrounding the representation of Arabs and Muslims has been a century-old phenomenon (Mignolo 67). Within this meta-frame, further frames have formed which affect "the stereotypical ideas and images regarding the Orient which the West has still not been able to give up and probably never will" (Sandikcioglu). The distinction between Arabs in general and images of Arabs living in the West is however difficult to draw. The lack of personal experience with Arabs in the diaspora in daily life and the high degree of mediatization on Arabs and the Middle East gives way to multiple layers of frames surrounding the stereotype. The most important influence is of a political nature. Theodore Pulcini points out, "one must remember that the voice of Arab Americans is muffled or magnified as a result of political developments in the Middle East. Perhaps no other American ethnic group is so affected by political and military events abroad" (51). This impact of foreign political events on the domestic view of Arabs in America contributes to the maintenance of a political frame which is marked by one key term: terror. A series of military conflicts in the Middle East gave way to the emergence of this frame.

The first key event that became the subject of high mediatization in the Arab World was the 1967 Arab-Israeli War. The occupation of East Jerusalem and Gaza by the Israeli military received intense media coverage around the world, particularly in the U.S. (Ghareeb 6; Palmer 144). The Six-Day-War and the corresponding U.S. policy decisions were the prime news in all major news outlets in the U.S., and they significantly shaped the way in which the global but especially the American public saw the Middle East (Cainkar 84). As Allen Palmer in his study on various media representations of Arabs during the conflict displays, a series of stereotypes which still circulate today originated in this period. Political cartoons, for example, depicted violent Arabs rooted in ancient Islamic practice and Arab oil sheikhs ${ }^{25}$

25 This image of the rich oil sheikh, that had already shaped early 19th-century travel accounts, later experienced another upswing during the 1973 Oil Crisis (Shaheen, TV Arab 15). Even public agencies did not refrain from employing severe racism against Arabs at the time. The example of bumper stickers distributed by the Department of Energy 
(146). Altogether, the War of 1967 marks the most crucial event in the media framing of Arabs. It gave way to the "Western version" of a narrative focusing on "Arabs as aggressors" (Cainkar 84). This in turn also severely shaped the selfimage of Arabs around the world. Louise Cainkar therefore calls it the "Arab American awakening" (84) and attributes this effect to the racialized and inferior depiction which Arabs during the time had to endure (87). The key event which today is mostly referred to by mentioning the year 1967 and the "mediated events" which accompanied it thus had a long-term impact on the depiction of Arabs in succeeding decades (Fritsch-El Alaoui 138-39). It marked the turning point from which onwards the image of Arabs and Muslims as enemies established the norm in mediated discourse (Naber, "Arab San Francisco" 11). ${ }^{26}$ Above all, it immensely heightened the political awareness of Arabs and Muslims around the world (Aruri 33).

The second major historical moment in the media framing history of Arabs was the Gulf War. The war was the first war of the modern mass media world which was covered in detail around the clock. Upon the moment when Iraq invaded $\mathrm{Ku}$ wait in August 1990, the eyes of the American public could watch every move (Khadduri and Ghareeb 3). ${ }^{27}$ Ever since, numerous studies have shown that the vast majority of reporting during the Gulf War employed Orientalist framing (Wöhlert 32). Sandikcioglu unfolds the argument that "this culture-specific cognitive model helped frame the debate about the Gulf crisis by conceptualizing Iraq as the incarnation of the Orient [...] which has been symptomatic of the age-old relationship between the Orient and the West." This Orientalist framing of the war was linked to the manifestation of existing stereotypes of the Arab as backward and violent (Cainkar 90). In result, Arabs found themselves facing severe identity struggles. On the one hand, the real war taking place in the Middle East fired back at the intercultural home front of America. Those who combined Arab and American identity in their biographies therefore faced an identity split. On the other hand, the military war was accompanied by a media war which brought to light the construction of

demonstrates this. It contained the slogan: "The Faster You Drive, The Richer They Get. ... Driving 75 is Sheik; Driving 55 is Chic" (Naber, "Arab San Francisco" 12).

26 In the context of Arab American autobiographies, Said is one of the most outspoken figures showing how much the war of 1967 impacted the life and image of Arabs around the world (Hornung 371). "The Question of Palestine" and its right of existence would become a life-long theme in all his writings (Stein 317). Nadia El-Haj even interprets this immense devotion to the cause of Palestine as an "over-identification" with political purposes and sees it as Said's major legacy (549).

27 Khadduri and Ghareeb even speak of an "American and British media campaign" which directed Saddam Husein to make several public statements critical of U.S. foreign policy in the Middle East (87). This underlines the almost theatrical function mediatization and media framing can gain at times. 
"identity" and "counter-identity" between East and West (Sandikcioglu). Both aspects severely affected not only the public image of Arabs and Muslims but their self-image. The Gulf War thus "pitted their Arab and American identities against one another" (Hatem 376). Ideals of multi-culturalism and hybrid identity became unattainable. A radio commentator at the time summarized this lasting impact on binary framing in the following words: "In war there are no hyphenated Americans, just Americans and non-Americans" (qtd. in Hatem 373). ${ }^{28}$

Numerous other events could be added to the long list of military conflicts which shook the Middle East in the past decades. No other events, however, were so constitutive of the media framing of Arabs than the two wars (Wöhlert 19). As meta-analyses in Media Studies conducted on the 1967 War and the Gulf War indicate, the media framing on these events differed from the Orientalism previously in place. Certainly, Orientalist binaries provided the overall-structure of the coverage which again highlights Orientalism's ideological and far-reaching impact. Furthermore, the media coverage of the wars added another layer to the framed representation of Arabs. From now on, Arabs were not only seen within the framework of the exotic other anymore. Rather, political conflict and war as "crisis-laden negative events" started to dominate the characterization (Wöhlert 34).

With respect to the scope of this political conflict frame, it is crucial to emphasize that both key events obviously took place in the Middle East. From the perspective of the American media audience and the one of Arabs living in the diaspora, the Middle East represents foreign ground. The high degree of mediaitization, however, transcended any cultural or geographic boundaries. Framing processes triggered by events in the Middle East and framed representations of Arabs living there were transformed into international frames surrounding the image of the $A r$ ab/Muslim as global prototype. Arab self- and other-definitions in the U.S. and around the world therefore rely on media frames that are in no way related to Arabs in the diaspora. This impact of international frames on national and personal identity definition gives way to the diffentiation between the "external Arab" (Wöhlert

28 Even though Iranian literature is not a particular focus of this work, it must be mentioned that this framed depiction of the Gulf War had severe consequences for the relation between the U.S. and Iran. While many Iranian intellectuals at the time made their new home in America and continue to do so up to the present, the negative reports fostered the notion that "Americans are haunted by Iran" (Whitlock 163). This lasting fear of Iranian politics might be an underlying reason for the prevailing interest in Iranian literature which often exceeds the one in Arab and Arab American literature (Whitlock 171). The rise of Iranian literature in the U.S., however, was also clearly influenced by the political event of the Iranian revolution (Whitlock 161). 
34) and "internal Arabs and Muslims" (Wöhlert 18). ${ }^{29}$ Both images are inherently interwoven and dominate the cognitive frames Americans have of Arabs, as well as the ones Arab Americans have of themselves. Evelyn Alsultany highlights this inseparability: "The image of Arabs cannot really be separated from the one of Arab Americans. The stereotypes of Arabs inform perceptions and experiences of Arab Americans" (Personal interview).

The major impact of military key events in the Middle East obviously had a sustaining impact on the framing history of Arabs (Wöhlert 29). Under the heavy influence of Orientalism, the political conflict frame therefore took the shape of a lower-level frame in and of itself. It is largely due to the significance of violent political events that images of the internal and external Arab can hardly be delineated (Aboul-Ela, "Edward Said's Out of Place" 15). This political framing of Arabs, however, is not only a consequence of single key events in the political arena. Rather, ongoing political unrest has further contributed to the lasting association of Arabs with political unrest. The Israeli-Palestianian conflict represents the major ongoing political trouble spot in this respect. As it turns out, the media framing surrounding the conflict is shaped as a well-known biblical metaphor.

\section{Israel in Palestine: David versus Goliath in the Holy Land}

Much of the problem comes from the stark reality that Palestinian politics are essentially Arab politics, whereas the U.S. and Western Europe inhabit a totally different world, in which, for example, the media, the academy, and the research institutes, churches, professional associations, and labor unions of civil society play almost as important a role as the central government in political society. (Said, Question of Palestine xxvii)

Said in these lines hints at yet another layer of the political frame surrounding the image of the Arab worldwide. The earlier wars in the region, particularly the one of 1967 , only marked the beginning of a long conflict-laden political history. Today, this series of conflicts is referred to as "Middle East conflict" (Nacos and TorresReyna 147). At the heart of this conflict remains the struggle over Palestine. This supposedly Middle Eastern conflict, however, is not restrained to this geographic location. Rather, the Middle East here, due to the involvement of Europe and the U.S., takes the shape of a political metaphor depicting the cultural war between East and West as struggle between David and Goliath.

29 Wöhlert's differentiation between the internal and external Arab stands out among the wide range of studies conducted on the media representation of Arabs. The large majority of these studies do not explore in detail in how far the coverage of foreign political events must always be read in connection to the self-perception of Arabs living in the diaspora. 
What is now commonly referred to as the Middle East conflict originated with a series of key events following the 1967 War. Among them are the Yom Kippur War of 1973, Israel's invasion of Lebanon in 1982, the two intifadas, the war in Lebanon 2006, and the failed diplomatic attempts to negotiate peace agreements ("Timeline"). Almost every day, new incidents could be added to this list. What all of these events have in common is their high degree of media coverage. Romy Wöhlert found that before 9/11, 33.3\% of all print media articles on the Middle East focused on the Israel-Palestine conflict (92). This result is in line with earlier studies that document the significant dominance of Arab-Israeli relations in the general coverage on the Middle East (Ghareeb 4). This omnipresence of the Israeli-Palestinian conflict therefore largely contributed to the emergence of the political conflict frame surrounding Arabs and Muslims. In fact, this specific conflict has become the epitome of political violence in the entire region.

The almost symbolic significance of the Israeli-Palestinian conflict, however, is not only a consequence of high mediatization as such. Rather, the way in which this media coverage has been characterized reflects a larger power trajectory linked to the image of Israel and Palestine. The key concept which gave way to this notion is Zionism. The term Zionism reaches back to the early days of the foundation of Israel in the Holy Land. It was meant as a "philosophy of Jewish empowerment" (Bouzid 4). Despite the colonial origins of the struggle of the Jewish people to found a state, the concept largely had a religious connotation of improvement and uplift. Meanwhile, Zionism has lost most of its positive resonance. Following the continued settlement efforts of Israelis and countless violent clashes, Zionism today mostly indicates the aggressive expansion policy of Israel (Bouzid 46).

Zionism has therefore turned from a religious to a highly political and ideological concept. Ideology here not only refers to Palestinian-Israeli relations as such, but to the larger power trajectories on an international level. Based on the political involvement of the U.S. and Europe in the Middle East, two major fronts have emerged: the U.S. and parts of Europe as the Western supporters of Jewish policy and Palestine as the Arab opponent on the other. This power division of the world with the U.S. as leading hegemon supporting Israel versus Palestine and its weaker Arab partners reflects former colonial relations. The image which emerges from this political conflict is a familiar one: the conflict between David and Goliath.

The media coverage of this binary opposition reflects this ideological battle in a way that pro-Israel sentiment has largely been fostered by the media and in the realm of academia, as critics and Arab Americans have long claimed (Aoudé 145). Zionism here again marks the key word to describe the ideological dimension of this "imbalance" (Ghareeb 4). Muslim students at the University of California in 
their magazine $\mathrm{Al} \mathrm{Kalima}{ }^{30}$ present their view on the relation between Zionism and media representations with drastic words:

Zionism has been a thorn in the side of the lovers of justice, peace and oppressed peoples around the world. Zionist-controlled Western media gives us a picture of 'Israel' that makes it seem democratic, just and fair [...]. The reality of the situation is that Zionists have been oppressing, torturing, and killing and ethnically-cleansing Christians, Muslims, blacks and whites [...]. (Naber, “Arab San Francisco" 188)

Studies on the framing of the Middle East conflict have repetitively revealed that this pro-Israeli sentiment which is supposedly spread by the media is not only a subjective feeling on the part of Arabs or a "media conspiracy theory" (Ghareeb 21). The news coverage about the Middle East in U.S. media indeed has been found to be biased throughout the past decades. Studies focusing on the use of language in news reports reveal "classic Zionist rhetorics" and "racist defenses of the Jewish state" (Stein 318). ${ }^{31}$ Further studies on the images drawn of Arabs and Muslims in the context of the Israeli-Palestinian conflict underscore this "pro-Israeli bias" (Naber, "Arab San Francisco" 190). Major news media thus seem to have adopted a commandment which continues to rule U.S. foreign policy. It states that "thou shalt not criticize Israel [...]" (Aruri 34). Although this favorable media stance toward Israel has slightly changed after $9 / 11^{32}$ and the public discussion of unjustified

30 Literally translated, 'al kalimah' means 'the word.' The student magazine is an example of how the identity definition of Arabs and Muslims is linked to the realm of politics. As the editors state in their self-description: "We strive to shift from the stereotypical, apathetic, and insular college experience, and instead move towards gaining a deeper understanding of not only community and domestic issues, but also of international topics as well. By questioning societal norms and expectations, we make it Alkalima's goal to bring back serious intellectual dialogue about the critical issues that students find important, necessary, and impactful" (Alkalima). This intention highlights the value attributed to media publications to convey knowledge about Arab Americans and thus change deceived perceptions.

31 Rebecca Stein identifies particular images and locations which incorporate and display what she calls a "Zionist fantasy" (325). One of these places is the café which, while representing a location of bourgeois intellectual exchange, also constitutes a major target of bombing attacks. Stein terms this "café discourse" which permeates the media (321).

32 Brigitte Nacos and Oscar Torres-Reyna analyzed media biases in the coverage of Muslim and Arab Americans before and after 9/11. As they demonstrate, the amount of positive and supportive reports actually increased in the six-month period after $9 / 11$ whereas negative coverage declined (148). 
violence exerted by Israel against Palestine, the conflict between Palestine and Israel remains intertwined with global power relations (Wöhlert 19). ${ }^{33}$

\section{Image 2: "Israeli David and Goliath"}

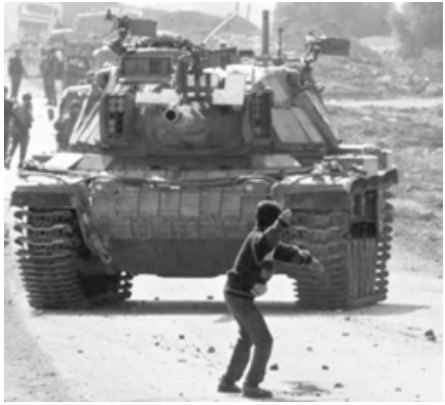

Source: A young Palestinian boy throwing rocks at an Israeli tank (Wrong). ${ }^{34}$

The overall relevance of the Israeli-Palestinian conflict in the media thus exceeds the boundaries of the conflict as a news issue itself. Due to the involvement of the U.S. in support of Israeli politics, the conflict continues to reflect postcolonial trajectories (Stein 331). Zionism hereby seems "to enjoy a near monopoly" in the coverage (Aruri 34) ${ }^{35}$ while Muslims and Arabs are struggling to find their own voice in the depiction of the conflict (Nacos and Torres-Reyna 143). The increasing critique of this bias has hardly changed this empirical finding (Stein 317). Read within the hierarchy of frames surrounding the construction of Arab identity worldwide, the Middle East conflict thus contributes considerably to the maintenance of a political conflict frame

33 A series of publications taking a critical stance toward Israel and the influence of Jews on U.S. foreign policy have started to bring the pro-Israeli stance of the U.S. government to critical attention. The most-often cited work is The Israel Lobby by John Mearsheimer and Stephen Walt. Even though the authors count as experts in the field of international relations and foreign policy, a huge portion of their work is devoted to the influence of the media in fostering the cause of Zionism and pro-Israel support. As they state in their subchapter entitled "The Media Is the Message" based on McLuhan's influential thesis: "This claim [pro-Israeli media bias] might sound to some like the old anti-Semitic accusation that 'Jews control the media.' It is anything but' (169).

34 N. T. Wrong is the acronym of an anonymous blogger who specializes on the Middle East. In the text accompanying the picture, the author explains: "It's not only sticks and stones that hurt our bones. The 'David and Goliath' metaphor has provided a powerful lens through which to view the Israeli-Arab conflict. Moreover, the metaphor has helped determine the way in which the Israeli-Arab conflict has developed in the real world." This double-metaphor of David and Goliath as "lens" again powerfully underlines the framing effect of the image.

35 The notion of a Zionist bias in U.S. culture, media, and society severely supported the political awareness of Arab Americans. This also led to the foundation of several organizations at the interface of academia and political activism, such as the AAUG (Association of Arab-American University Graduates) (Aruri 34). 
around the identity definition of Arabs and Muslims in the U.S. and in other diaspora countries (Wiegand 236; Wöhlert 93). With the events of 9/11, this political frame shaped by Zionism gained yet another twist.

\section{The War on Terror Frame}

Although terrorism had already accompanied the political framing of Arabs within the Zionist framework of the Israeli-Palestinian conflict, September 11 as most significant key event of the past decades changed the discursive climate considerably. Rebecca Stein critically summarizes the rhetoric of the media landscape following the terrorist attacks: "What one witnessed was a polyphonic discursive sphere in which the language of Zionist coloniality and Palestinian terror competed for space and audibility within the mainstream media in relatively unprecedented ways" (318). ${ }^{36}$ The previous dominance of Zionism in the binary discourse on the the Middle East did not become replaced. Rather, Zionism became incorpoared into a more inclusive frame that became known as the war on terror.

Today, even those who were still in their early childhood when the twin towers collapsed are only too familiar with the word terrorism. ${ }^{37}$ In historical terms, though, terrorism is quite a novel invention of society. The use of the word "terrorist" to refer to politically violent anarchists only became widespread in Europe at the end of the $19^{\text {th }}$ century (Cherkaoui 30 ). Since then, only a few scholars in the field of Cultural Studies have undertaken the attempt to define the concept before using it. One of them is Pippa Norris who describes terrorism as "the systematic use of coercive intimidation against civilians for political goals" (6). According to this definition, terrorism is identified by "the techniques, targets, and goals" it pursues. Norris adds, "all these attributes are regarded as necessary and sufficient for an act to qualify as terrorism. 'Terrorists' are those who employ the methods of terrorism"

36 With respect to the impact of the 9/11 attacks on media history, not only the magnitude of the event itself was unprecedented but the way in which it was covered. In the words of communication scholar François Debrix, it was the " 'first terrorist attack' in real time" (2). Debrix here refers to the fact that, by the time the second plane crashed into the towers, CNN had already started its live coverage.

37 Reports from young-generation Arab and Muslim Americans illustrate the paradox that, although they did not consciously experience the terrorist attacks due to their young age, they still become the victims of hostilities resulting from 9/11 (Chertoff et al.). The fact that many of those committing these hostilities also were in their kindergarten years when the attacks happened, underlines this as an example of inherited discrimination without immediate experience as motivation. 
(6). ${ }^{38}$ In the context of present-day international politics, the term terrorism experienced a notable upswing after the 1967 War (Cherkaoui 101). In the following decades, international key events, such as the hostage crisis at the 1972 Olympics, the Lockerbie bombing and violent acts by the IRA and ETA in Spain, continued to boost the use of terrorist vocabulary (Kern, Just, and Norris 285). In addition, the Palestinian resistance to Jewish settlements also has come to be read through the lens of terrorism.

The real upswing of terrorism as dominant media frame thus occurred following the 9/11 attacks (Kern, Just and Norris 290; Ruigrok and van Atteveldt 74). Due to the magnitude of the event, its effect on the role of the U.S. as world hegemon, and the feeling of vulnerability, the familiar connotation of the general terrorist frame did not meet the discourse needs of the public anymore (Ryan 363). In line with the theoretical assumptions explaining frame shifts, 9/11 thus triggered the emergence of a new frame. Following President Bush's declaration of the "war on terrorism," the media quickly took up the terminology and adjusted it to the media logic (Barnett and Reynolds 55; Naber, "Look, Mohammed" 267). ${ }^{39}$ As quantitative and qualitative analyses on major U.S. news outlets suggest, the "War on Terrorism" frame quickly became the major news frame in the aftermath of the attacks (Altheide, "Fear, Terrorism" 11; Cherkaoui 103; Barnett and Reynolds 4). Even minor political incidents which did not show a clear relation to $9 / 11$ or terrorism at large came to be presented and interpreted within this "domestic cultural filter" (Weimann and Winn qtd. in Ruigrok and van Atteveldt 73). ${ }^{40}$ Research on the CNN coverage right after the attacks shows that the WOT as dominant mode of interpretation was clearly drawn toward military responses and the justification to secure unity (Ruigrok and van Atteveldt 73). In addition, the spread of nationalist sentiment ${ }^{41}$ and one-sided media reports sought to push a nationalist agenda (Rajagopal 76). This went along with an affective bias to evoke feelings of fear in the audience

38 On the basis of this definition, all U.S. military acts following the September 11 attacks show sufficient criteria to count as terrorism. This finding confirms the perception of Arabs who have come to regard U.S. policy decisions in the aftermath of the attacks as "counter-terrorism" (Lyon 20).

39 Barnett and Reynolds conceptualize the WOT as separate dominant frame surrounding Arab American identity definition. In the present study, however, the WOT is regarded as part of a more comprehensive political frame within the multi-level frame model.

40 Ruigrok and van Atteveldt refer to the WOT as "post-cold war frame" (68). This is in line with other studies arguing that the WOT replaced the Cold War as dominant global media frame (Norris, Kern, and Just, Introduction 15). This serves as evidence for the capacity of major key events to replace long-standing cognitive frames in public discourse.

41 Some authors refer to the renewed sense of nationalism after $9 / 11$ and the resulting measures of racial profiling as "neo-nationalism" (Ta 143). 
to justify political measures against terrorism (Altheide, "Fear, Terrorism" 12). While counter-voices in favor of alternative schemata to interpret the political events were strategically silenced, designated experts focusing on terrorism manifested the WOT as dominant cognitive frame (Cherkaoui 109). This was reflected in the frequent use of vocabulary directly linked to the WOT, such as terrorism, terrorist, war, attacks, etc. (Cherkaoui 130).

While many studies have focused primarily on the role of the WOT in the U.S., international comparisons with European countries reveal that terrorism became a global media frame (Ruigrok and van Atteveldt 84; Wöhlert 105). Despite the common significance of the WOT across nations, there are also differences as to how the WOT frame was fabricated according to the specific demands of domestic audiences. Affective elements of the media frame constitution therefore vary. A comparative study by Nel Ruigrok and Wouter van Atteveldt under the title "Global Angling with a Local Angle: How U.S., British, and Dutch Newspapers Frame Global and Local Terrorist Attacks" (2007) devotes particular attention to these local nuances. The analysis of four different terrorist events in the U.S. and Europe demonstrates that the coverage of these events is either localized or globalized, meaning that either very specific local circumstances are related to the explanation of terrorism or far-reaching global aspects (80). In the majority of cases under investigation, local angling dominated the picture. This also held true for the coverage accompanying the commemoration of the attacks. "Stories were framed, angled, geared and worded to suit the emotional and cognitive framework of audiences at home," Ruigrok and van Atteveldt conclude (73). This "domestication" of news based on the WOT frame according to domestic and even local needs was also confirmed by further studies (Ruigrok and van Atteveldt 73; Kern, Just, and Norris 293). All these empirical results emphasize the impact of the WOT frame on lowerlevel national and even local news framing, whereby "national worldviews derived from the international system greatly shape the interpretation and framing of the causes of the terrorist attacks" (Barnett and Reynolds 48).

In order to demonstrate that the WOT frame of interpretation, in fact, was a media fabrication and not merely the result of real-world political developments, the framing dynamics need to be read in comparison to the actual occurrence of terrorist incidents (Kern, Just, and Norris 281). Obviously, terrorism as phenomenon of political violence did not originate in 2001, yet with the introduction of the WOT, the terrorist frame gained a different quality (Allen et al. 257). This change can be read from the background of a long-term development. Beginning in the 1980s, the number of actual terrorist attacks decreased on an international level (Kern, Just, and Norris 282). Whereas figures record an average of 437 incidents per year in the 1970s, the 1980s first witnessed a slight increase, with the absolute figures then falling again in the 1990s to 383 incidents per year (Kern, Just, and Norris 286). The coverage of these events in the media for the most part reflects this real-world 
development (Kern, Just, and Norris 290). The tremendous rise of the terrorism frame in the years after $9 / 11$ stands in complete opposite to this trend. An example from the print media is provided by the New York Times coverage. Whereas the number of articles referring to Arabs, Muslims, Islam, and terrorism ranged at 37 in the period from September 2000 to March 2001, the number increased to 376 from September 2001 to March 2002 (Nacos 139). This means an overall increase by more than $1,000 \%$. Whereby the actual number of terrorist incidents worldwide continued to decline at this time, the WOT experienced its unprecedented upswing in a way which does not reflect the actual development of global terrorism (Kern, Just, and Norris 289; "Global Conflict Trends"). ${ }^{42}$ As Pippa Norris and her colleagues in their study on the news framing of the war on terror conclude, it was not terrorism itself that changed its nature after $9 / 11$, it was the public perception of it (Norris, Kern, and Just 4).

Altogether, these findings on the WOT media frame underline the importance of political events for the public framing of Arabs and Muslims. The WOT changed the nature of this political conflict frame in way that it now incorporates many political concepts which had already ruled the public discourse on Arabs in previous times. Consequently, the Israeli-Palestinian conflict and Zionism are not seen separately from the terrorist framework anymore. The global dominance of the WOT frame further complicates the framed identity definition of Arabs and Arab Americans. Although the rhetoric of "wanted: dead or alive" originally referred to Arabs living in the Middle East, it is now inherently linked to the way in which Arabs living in the diaspora are seen by the public (Merskin 157). This trajectory has especially fostered the conflation of the internal with the external Arab in the eye of the American public. Even worse, the Arab is not merely Arab or Muslim anymore, he/she has become the incarnation of a stereotypical terrorist.

\section{The Framed Internal/External Terrorist}

Hardly hours had passed after the attacks of September 11 until the U.S. government publicly voiced what the media had been speculating before: Arabs "did it" (Nacos 6). The WOT frame that emerged afterwards targeted Arabs as the enemies of the world. The omnipresence of this frame consequently affected all Arabs and

42 Due to the different data used by authors analyzing the relation between real-world terrorism and the WOT frame, it is difficult to provide an exact comparison of the dynamics. Whereas some studies reveal a sharp increase in global terrorist attacks in the years after 2001 , others identify a steady decline. The reason for these divergences must be seen in different definitions of international terrorist attacks and varying means of data collection. All studies, however, agree on the finding that the absolute number of terrorist incidents post-9/11 is below the one in the 1980s ("Global Conflict Trends"). 
Muslims in the United States and elsewhere, not just those who "did it." Debra Merskin summarizes this development in the following equation according to which the media presented "all Muslims as Arab and all Arabs as terrorists" (158). This simplified notion of Arabs and Muslims provides a glimpse at the strong impact the WOT media frame had on public discourse. A range of public opinion data confirm that the WOT frame turned into a powerful cognitive frame in the audience (Panagopoulos 608). The distinction between Arab terrorists and Arab American citizens has been lost since then.

Obviously, the impact of the WOT frame on public discourse not only depended on the frequency of the coverage but on the particular set up of the frame. Content analyses of news media representations of Arabs and Muslims post 9/11 confirm the dominance of previous Orientalist stereotypes within the political frame. In addition to these pre-existing stereotypes, the Arab in times of the WOT became increasingly depicted as politically oppressive and dictatorial (Cainkar 85). This contributed to the manifestation of the image of Arabs as "bloodthirsty terrorists" (James Zogby qtd. in Cainkar 86). Moreoever, the conflation of religious and political interpretations became reflected in the emphasis on Islamic fundamentalism. The most prominent stereotype which combined all negative characteristics spread within the WOT frame was the one of Arabs as "Bearded Terrorists" (Naber, "Look, Mohammed" 295). This bearded terrorist personified all negative evocations linked to the WOT frame and came to serve as universal emblem of the evil Arab (Tehranian 103; Cainkar 89). As Merskin metaphorically explains, "the 'Face of Terror' is not only that of Osama bin Laden and Saddam Hussein but also all persons of Arab descent, evoking the simulacrum of all Middle Eastern-looking men as the face of terrorism" (158).

When comparing this media-created image of the Arab as terrorist with the cognitive frames circulating in the audience, the effectiveness of the WOT frame becomes apparent. The specific stereotype of the Arab terrorist fell on fruitful ground for it had been an essential element of the framing of Arabs since the Gulf War. Negative views of Arabs and approval ratings of the war could thus directly be traced to the media framing of the Operation Desert Storm ${ }^{43}$ (Allen et al. 257-58). ${ }^{44}$

43 Operation Desert Storm is the term of the military strike conducted in the first Gulf War. The term is frequently used to highlight the difference to the Iraq War of 2003. The latter is also referred to as second Gulf War (Lewis et al. 27).

44 The analyses of the severe impact of media framing during the first Gulf War also reveal striking mechanisms of "reframing." The coverage of the war was severely shaped by technological and military vocabulary. This register was actively changed, however, when the U.S. accidentally bombed a baby milk factory. The coverage then started to be presented within a humanitarian frame (Allen et al. 282). Officials also promoted that the factory had actually been a bomb factory. As research results by Amy Jasperson and 
This time, the stereotypical images conveyed by the WOT frame had a similar but even stronger cultural impact on Americans and their view of Arabs and Muslims as terrorists (Kern, Just, and Norris 293). A figure which strikingly underlines this immediate impact of terrorist framing on public opinion is provided by a Gallup survey. Before the attacks, terrorism was not considered to be a pressing issue. Immediately after $9 / 11$, however, the percentage of respondents stating that terrorism was the "most important problem facing the nation" skyrocketed to $49 \%$. Even by spring 2003, this number remained five times higher than in pre-WOT times (Kern, Just, and Norris 290). Surveys conducted on the views of the American public on Arabs and Muslims also confirm the dominance of the terrorist frame. A poll conducted in September 2002 revealed that 33\% of the respondents declared that Arab Americans are "sympathetic to terrorists," a figure which doubled when compared to $18 \%$ in October 2001 (Panagopouluos 613). Later surveys show the continuation of this trend. In a poll conducted by USA Today in July 2006, 34\% of the respondents believed that American Muslims tend to sympathize with AlQaeda (Wöhlert 2). Again, international comparisons show that this strong adoption of the terrorist frame by the media audience was not an American phenomenon only. ${ }^{45}$

What tends to be forgotten with respect to the constitution of the Arab-asterrorist stereotype in the media audience is the effect the WOT frame had on the self-definition of Muslims, Arabs, and Arab Americans. The available data speak a clear language in this context. Arabs living in the shadow of the WOT frame developed an urgent need to display a collective "Arab identity" to oppose public stereotypes (James Zogby 75). In some cases, this longing led to an increased focus on religion. Nadine Naber expresses this indivisibility of global international and national images in the self-definition of Arabs in the chapter heading: "Muslim First at the Intersections of the 'Global,' the 'National,' and the 'Local"' ("Arab San Francisco" 184). ${ }^{46}$ The difficulty of this aim to constitute individual and collective

Mansour El-Kikhia show, however, this humanitarian frame was an exception during the Gulf War. The authors attribute this to the lack of direct access to respective scenes. Attrocities depicted on U.S. television therefore all focused on violence committed by Iraqis. Al Jazeera nevertheless offered the American public an alternative angle and also showed humanitarian violations committed by U.S. military personnel (120).

45 Cross-national evidence from Europe confirms this pattern with Muslims being considerably more often associated with terrorism than before 9/11 (Ruigrok and van Atteveldt 84). The most recent figures published by the Pew Research Center in 2011 confirm the lasting cross-national impact of the WOT frame. The characteristics of being "violent" (50\%) and "fanatical" (58\%) still are at the top of the list when it comes to "Western" views of "Muslims" ("Common Concerns" 4).

46 Naber investigates the impact of global stereotypes of Arabs on the self-definition of Arabs/Muslims in the San Francisco Bay area. Her research is based on in-depth inter- 
identity beyond terrorism is reflected in the figures documenting the rise of psychological illnesses among Arab Americans who cannot master the cleavage between Arab American self- and American other-definitions. According to a 2006 survey, about $50 \%$ of respondents showed symptoms of depression whith could be related to the public discrimination they experiencd in post 9/11-times (Elias). A number of oral and written reports document the longing of Arab Americans to define themselves in opposition to the public media frame and its seeming inescapability. ${ }^{47}$

The empirical data on the reflection of the WOT frame in American public opinion underlines the strong impact media framing has on public discourse (Wöhlert 2). This applies to the American public as well as to the global media public alike. The framing of the Arabs/Muslim as terrorist has become the most dominant stereotype. As Lisa Suhair Majaj puts it, "Arab today mutually means the same as terrorist" ("Arab-Americans and Race" 327). Most important for the maintenance of this guiding mental schema is the conflation of the internal and external Arab. Media depictions of terrorists in Iraq, Afghanistan, or Palestine therefore immediately revert back to the way in which Arab Americans are seen. ${ }^{48}$ In other words, the internal Arab American as an effect of mediated discourse is converted into the external Arab terrorist. ${ }^{49}$ It can thus be derived that the terrorist forms the central cognitive stereotype of the WOT schema. When integrating this finding into the

views. One of the major findings of the study is that, in reaction to media images, many respondents identify as Muslim first and Arab second ("Arab San Francisco" 209).

47 In comparison to the multitude of studies conducted on the perception of the Arab as 'other,' the small number of advanced empirical studies on the self-perception of Arabs reflects the lack of scholarly interest with respect to the study of Arab Americans as distinct and culturally heterogenous group. Before 9/11, hardly any specific data could be found on intra-Arab American demographics. Only after 9/11 did the Pew Research Center develop a specific survey to track this group (Wöhlert 25).

48 The impact on foreign news events on the self-definition of Arab Americans is further complicated by the fact that Arab Americans to a large extent have access to satellite TV and are thus exposed to news frames created by Middle Eastern media. As a survey on transnational communications conducted by Mark Tessler in 2003 suggests, about $50 \%$ of Arab Americans in the greater Detroit area watched Arab satellite TV. The degree to which these transnational sources of information are used varies amongst different immigrant generations, whereby those born in the United States are less inclined to access foreign media content than the parent generation born abroad.

49 Lisa Suhair Majaj when asked about the separation of Arab and Arab American literature at a reading in November 2011 confirmed this notion: "Since our identity is so much influenced by political events taking place abroad, I do not think one can draw a clear line" (“Geographies"). 
overall framing model of Arab identity definition, the stereotype of the internal/external terrorist endows the political frame with renewed Orientalist meaning.

\section{The War on Terrorism Frame as (Neo-)Orientalism}

Hardly any other words are more prominently associated with the presidency of George W. Bush than his "monologue" delivered following the terrorist attacks. His announcement "you're either with us or with the terrorists," came to represent the guideline for all policy decisions in the remainder of his time in office (Aoudé 147). This triggered an "American Jihad" which is still being fought in the battlefields of Iraq and Afghanistan (Ta 151). ${ }^{50}$ The actual military war surrounding the WOT, however, is only one consequence of Bush's binary division of the world into terrorists and anti-terrorists. Bush's statement also opened up a more far-reaching ideological war between the West and the East. The binary nature of the WOT therefore also gave way to a renewed version of Orientalism. ${ }^{51}$

Due to the prominence of binary language and familiar stereotypes, the significance of Orientalism for the WOT frame is apparent. "The deeply embedded interpretive frameworks of Orientalism, exoticism, and neoprimitivism that produce the East for Euro-American consumption have hardened in idological support of the war on terror [...]," Whitlock explicates (49). This direct relationship between present-day WOT discourse and century-old Orientalist binaries underscores the persistence of the Orientalist framework. Just like the Orientalism Said referred to, Orientalist discourse today is characterized by normative credentials, meaning that the West as morally superior is pitted against the inferior East (Altheide, "Fear, Terrorism" 11). ${ }^{52}$ This inferiority continues to be framed by "narratives emphasiz-

50 What tends to be forgotten in the debates on the U.S. military intervention in the Middle East after 9/11 is the fact that about 3,500 Arab Americans serve in the U.S. military. Some of them have been deployed to fight the war on terror abroad. Even though this number represents less than $1 \%$ of the overall Arab American population, this situation causes a severe double-bind for the identity definition of these soldiers (Ta 151).

51 The Orientalist legacy accompanying the WOT was not a new phenomenon in the context of U.S. foreign policy. Already in the case of the Gulf War, framing studies revealed that Orientalism was constitutive of the interpretative schemata provided by the media. Esra Sandikcioglu explicitly links this relation to the cognitive underpinnings of framing theory. "The argument is that this culture-specific cognitive model helped frame the debate about the Gulf crisis by conceptualizing Iraq as the incarnation of the Orient and thereby justify a specific political and military approach to the conflict which has been symptomatic of the age-old relationship between the Orient and the West."

52 Rigid claims of moral superiority are especially remarkable after such incidents as Abu Ghraib where American soldiers were presented as acting like barbarians. One can there- 
ing the primitivism of Arab and Muslim societies" (Whitlock 109). Another familiar characteristic of the WOT as Orientalist frame is that the "Orient" continues to be represented instead of representing itself. This underlines the maintenance of familiar global power relations between the former colonizers and their subaltern inferiors (Dabashi xi). In sum, Orientalism within the WOT frame remains a "problem of generalization and totalisation" (Lau, "Re-Orientalism" 571). The global media discourse thus continues to be ruled by the "binary, polarized logic of Orientalism" (Salgado 210) and the confrontation between "East and West, insider and outsider" (Salgado 201). When thinking back of Jack Shaheen's early TV studies, one can conclude that the Orientalism conveyed in the WOT frame is nothing but "Civilization versus Barbarism” Episode II (Wöhlert).

When taking a more detailed look at the characteristics of Orientalism within the WOT frame, however, this equalization of traditional Orientalism with the Orientalism observed post 9/11 appears premature. What distinguishes both ideologies is the particular rationale used to explain the division of the world. Whereas the former model of Orientalism mostly relied on a general ethnocentric valuesuperiority of the West, this superiority today relies on a different explanation pattern which is commonly referred to as "neo-Orientalism." 53 The concept emerged fairly recently based on discursive analyses following the 9/11 period (Tuastad 91; Maira 319). Just like traditional Orientalism, neo-Orientalism relies on the image of the Arab as barbaric other. What differentiates the "new barbarism" thesis from the old one, however, is its specific reference to political and partly economic and religious ${ }^{54}$ circumstances (Tuastad 591; Naber, "Arab San Francisco" 1). ${ }^{55}$ The core

fore agree that a severe paradox between public image and public behavior exists. Whitlock even predicts that this gap will ultimately bring about the end of the Orientalist legacy. As she states, "[u]ltimately the extremes of Occidentalism - the self-construction of the West in and through its constructions of the other - reach a point of excess where the oppositions they construct collapse in disarray" (31).

53 Neo-Orientalism is to be strictly separated from other variants of Orientalism which were developed in the recent period, such as re-Orientalism (El-Haj 544; Banerjee 301). Many of these concepts derive their theoretical contribution from the assumption that Orientalism is now practiced and sustained by different actors, such as members of the diaspora themselves. Neo-Orientalism, in contrast, does not focus on actors in the first place but on the justification of Orientalism (also see Chapter 3.1).

54 Lynn Ta, for example, provides an alternative definition of neo-Orientalism. She describes it as ruled by the ideal of redefining Islam and of categorizing Arabs into good and bad Muslims (162). Other authors focus on the racial aspect of neo-Orientalism, such as Minoo Moallem who terms it "neo-racist" and Naber who sees the depiction of white superiority as major trait ("Arab San Francisco" 17). Although these religious and racial 
assumption of this neocolonialist frame is that Arabs and Muslims are barbaric and backward not simply because they are barbaric and backward by nature but because they are unable to implement or actively resist democratization (Sadowski ${ }^{56}$ 14; Tuastad 595). Obviously, this logic does not solely rely on normative essentialism since inferiority is not primarily seen as an immanent human trait. Still, the concept involves essentialism and ethnocentric bias since it establishes a fundamental value division between East and West. An article in Newsweek underlines this reductionist entanglement of political, economic, and religious rhetoric with Orientalism which ultimately culminates in the new barbarism thesis:

But what are we going to do about countries that are the real source of modern Islamic terrorism [...]? [...] These countries have been the fertile ground on which radical Islamic terrorism has grown. [...]. It is clear that Saudi Arabia now exports two products around the globe - oil and religious fanaticism. [...] We think of our allies in the Middle East as 'moderates.' And certainly compared with the barbarians of Al Qaeda, they are cautious, conservative rulers. But for decades now the governments in Riyadh and Cairo have resisted economic and political modernization with disastrous results. (qtd. in Wöhlert 210)

These lines are exemplary of the discourse of neo-Orientalism within the WOT frame. The idea of allies and enemies is thus clearly linked to political, economic, and religious ideals. This is underscored by the historical role of the U.S. as patron of democracy and peace. In addition, the installation of neo-Orientalist discourse particularly served the purpose of justifying U.S. foreign policy rulings and the military intervention in the Middle East (Naber, "Arab San Francisco" 17). Critics of neo-Orientalism therefore regard it as a uniquely American phenomenon and refer to it as new "American national ideology" (Tuastad 597) and "new North American Orientalism" (Naber, "Arab San Francisco" 269). This ideology continues to be fostered by opinion leaders in politics and in the academy alike. One of the most outspoken proponents of the neo-Orientalist thesis is the scholar and writer

aspects form part of the neo-Orientalist rhetoric, religion in the vast majority of neoOrientalist criticism ranges behind the aspect of democratization and modernization.

55 Hamid Dabashi uses a similar definition for his concept of "post-Orientalism" which to him means the constitution of new knowledge and related power constellations (xiv). Since post-Orientalism has been defined differently by other authors as well, the concept will not be used synonymously with neo-Orientalism in this study (see Chapter 7).

56 Contrary to the argument that neo-Orientalism is a post-9/11 construct, the fact that authors like Yahya Sadowski already used the term "new Orientalism" in post-Gulf War years underlines that the concept is not so new after all (14). 
Daniel Pipes ${ }^{57}$ who has been proclaiming that Muslims have been unable to embrace democracy and modernization for almost two decades (Sadowski 18). Despite the characteristic American features of neo-Orientalism, this interpretive framework is not unique to U.S. public discourse. As Wöhlert in his comparative study of U.S. and German news frames finds, neo-Orientalism has become the guiding schema in European media framing as well (32). ${ }^{58}$

In summary, these findings on neo-Orientalism as guiding principle in post-9/11 media framing highlights the enduring interrelation between "Knowledge and Power in Time of Terror" (Dabashi ix). As the empirical evidence illustrates, neoOrientalism in fact differs from traditional Orientalism as overarching ideology due to its explicit political and economic rationale. This does not limit the overall message of neo-Orientalism, however, which still advocates the West's "oppressive relation to its internal and external "others"” (Shohat and Stam 3). "Orientalist stereotypes" thus continue to dominate the public media discourse with former stereotypes being replaced by the archaic and fundamentalist Arab/Muslim terrorist (Cainkar 86).

The central importance of the terrorist stereotype allows one to put together the different historical and theoretical fragments which together form the current political frame surrounding the image of Arabs and Muslims. Different political key events in the Middle East have led to the result that Arab identity definition cannot escape political framing in the public. These events were linked to certain interpretative schemata and binary concepts such as Zionism. Each phase slightly altered the explanatory logic of the political frame. At the present stage, neo-Orientalism has come to incorporate all these previous features. It contains the fundamental binary logic of traditional Orientalism and propagates the message of Eastern inferiority. Yet, due its mostly political nature, neo-Orientalism is not as far-reaching as the higher-level ideology of Orientalism which nurtures it. This is also underlined by the central stereotype of the neo-Orientalist schema. In line with the theory of framing, every interpretative schema is built around a major prototype. For neoOrientalism, this stereotype has been identified as the terrorist who evokes scripts of political violence and barbarism. This script gives way to further prominent

57 Pipes is best known for launching the site Campus Watch. It encourages students to report on and discriminate against professors who supposedly are "pro-Arabic sympathizers" (James Zogby 34). Along with Martin Kramer, Pipes is one of the most outstanding examples of how neo-Orientalist images find their origin in academic circles.

58 Wöhlert finds strong correlations between a nation's collective self-image and attitudes toward Islam. In the case of Germany, this confirms earlier research results which revealed "that this hostile stereotype [of Islam] reflects the perception on the part of the German Self that the Germans' own societal concept is the only right one and that the Islamic Other is clearly demarcated from this concept (Ates qtd. in 32). 
stereotypes that accompany the collective image of Arabs and Muslims in public discourse. All of these stereotypes are again surrounded by various media frames as guiding cognitive schemata. In contrast to the ideological frame of Orientalism and the political frame of neo-Orientalism, these schemata are found on the lower level of issue frames.

\subsection{The Issue Frames: Race, Religion, ANd Gender}

In 1963, the renowned media researcher Bernard Cohen made statements which would guide the entire discipline until the present. Cohen held that "while the media may not tell us what to think, they are stunningly successful in telling us what to think about" (qtd. in McCombs 71). ${ }^{59}$ The question of what to think about ultimately raises the question of prevalent issue frames dominating the public discourse on Arabs and Muslims. These issue frames also stand under the influence of higherlevel Orientalist framing. Yet, they provide information for the definition of Arabs in more specific thematic contexts. Again, these issue frames are predominantly built around a central stereotype as cognitive prototype which incorporates the most dominant features of the respective frame. Based on the prevalence of stereotypes such as the veiled woman or the Muslim fundamentalist, it might not come as a surprise to the reader that the most dominant issue frames found in the contemporary media coverage on Arabs are race, religion, and gender. ${ }^{60}$

\section{The Race Frame: Blackwashed and Otherized}

In his book Whitewashed, the Iranian American author John Tehranian recalls his experience on a flight in the post-9/11 era. A fellow passenger looks at him very suspiciously, until she finally starts a conversation. Among other things, Tehranian in the course of this conversation reveals that he is a lawyer. The lady, however, remains skeptical. As it turns out, this skepticism is linked to Tehranian's Arab

59 Cohen's statement emerged at an early stage of agenda-setting research. At the time, findings on the attitudinal impact caused by framing and priming were not as far advanced, which is why Cohen saw the impact of the media as limited to topic-relevance (McQuail 548). Meanwhile, framing research has indeed found methods to also prove the media's impact on what and how people think about certain issues. This does not lessen the fact that agenda setting remains a primary function of the media.

60 Naber in her study on Arab Americans in San Francisco also reveals gender, race, class, and religion as major "subdiscourses" found to impact the self-definition of the respondents in her sample ("Arab San Francisco" 266). This again underlines the severe influence of media frames on the identity definition of highly-mediatized ethnic groups. 
appearance. As the lady replies, "my brother is a lawyer and you don't look like a lawyer" (Tehranian 109). This anecdote serves as a striking example of how looking $A r a b,{ }^{61}$ which often differs from actually being Arab, has come to stir evaluations of otherness and inferiority. This observation points to the larger function of race in the discourse on Arab Americans. As the history of Arab immigration to the U.S. reveals, Arabs have undergone several stages of racial identity (mis-)definition by the U.S. government and by themselves. Part of this involved the practice of being "whitewashed," as Tehranian reminds his readers. Current findings on the racial framing of Arabs reveal the opposite movement. Arabs are thus blackwashed to a degree where they represent the ultimate stereotype of the racial other in the media and in the general public.

Race in critical race theory is defined as "a fluctuating, decentered complex of social meanings that are formed and transformed under the constant pressures of political struggle" (Haney-López 9). When it comes to outer appearance as visible marker of race, the concept is immanently relational since racial categorization relies on the difference of skin color (Haney-López 20). White identity thus presupposes non-white identity and vice versa, which accounts for the function of race as a "positive mirror" (Haney-López 21). Race therefore constitutes a key element of identity definition. It serves as an "organizing principle" to categorize individuals into different groups (Aoudé 142). This function of categorization is of legal significance as well. Here, race is defined according to specific characteristics such as racial appearance, but also geography, language, ${ }^{62}$ and religion (Majaj, "ArabAmericans and Race" 322). Since the more or less random choice of these markers determines the legal status of citizens and non-citizens, race can be seen as a "prelegal phenomenon;" a product of "coercion" and ideology (Haney-López 9-10).

The concept of race is often used synonymously with ethnicity. This equation, however, is misleading as a definition of ethnicity by Chris Barker and Dariusz Galasiński demonstrates. The authors conceive of ethnicity in Cultural Studies as the "sharing of norms, values, beliefs, cultural symbols and practices" (122). Fur-

61 John Tehranian is Iranian American and therefore not considered Arab.

62 Arab Americans frequently report incidents of discrimination because they are falsely assumed to lack English language skills. An Arab American woman born and raised in the U.S. ironically recalls: "Neighbors are surprised I can speak English without an accent. They assume I'm fresh off the boat and I just haven't assimilated yet" (91). Demographic data in fact reveals that the majority of Arab Americans does not show any deficiencies in the use of the English language but many have never learned Arabic (Kayyali 84). A new trend among the youth generation is the use of so-called "Arabish" (Kayyali 83). It is an interlanguage used to fill in language gaps in either language in everyday or online conversations. It also appears in online life writing, as the example of Salam Pax suggests (Whitlock 11). 
thermore, the primary function of ethnicity is seen in "boundary formation" between individuals who are perceived or "discursively constructed" as sharing certain cultural norms and practices (Cultural Studies 479). The concept of ethnicity therefore acknowledges the place of history, language, and culture in the construction of subjectivity and identity. It relies entirely on the perception of discourse as constructed with all knowledge therein being "contextual" (Hall, "New Ethnicities" 446). In result, ethnicity therefore also serves as "contrasting strategy" to differentiate the ethnic from the non-ethnic (Sollors xiv). ${ }^{63}$ Race and ethnicity therefore share this function of classification. In the case of ethnicity, however, classification takes place in a discursive realm, whereby race also fulfills a significant function in the legal realm.

With respect to the history of Arabs in America, race has always been a prominent issue surrounding the public discourse on Arabs and Muslims. When Congress in 1790 restricted naturalization to "white persons," race served as a "scientific rationale" (Haney-López 1-3). Arabs, however, due to their hetereogenous origins, never met the characteristics of legal and facial whiteness. Evelyn Shakir highlights this indefinite racial status in her comment that "Arab Americans come in a range of colors" (Bint Arab 113). Consequently, the racial status of Arabs could not be determined based on a simplified rationale of skin color categorization. One result of this confusion was that the decision whether Arabs were black or not became a matter of random choice. A series of court rulings known as the "prerequisite cases" marks this struggle over racial categorization (Haney-López 48; Tehranian 48). According to these cases, Syrians in 1909, 1910 and 1915 were classified as "white persons" but not in the years in-between. In other cases, courts ruled they were "Caucasian" or "Asiatic" (Haney-López 5; 48-49, Majaj, "ArabAmericans and Race" 321; Suleiman, Introduction 7). These early cases were succeeded by a multitude of further legal struggles lasting up to the present period (Majaj, "Arab-Americans and Race" 324). ${ }^{64}$ Today, Arabs are officially acknowledged as white in the catalogue of America's racial categorization. ${ }^{65}$

63 Based on the logic that the "non-ethnic" requires the ethnic in order to exist, Werner Sollors explains that this dualism gets complemented by the emergence of alternative ethnicities for self-definition (xiv).

64 In 1944, for example, the court ruled that Arabs were "white enough" to count as white. In another prominent court case decision in 1987, however, a professor was denied tenure due to being of "Arabian race" (Majaj, "Arab-Americans and Race" 325).

65 The federal Equal Opportunity Commission divides among six racial identification categories: White, Black/African American, Hispanic/Latino, American Indian/Alaska Native, Asian, Native Hawaiian/Other Pacific Islander. Middle Easterners, Turks, Kurds, and Persians are white according to this classification schema (Tehranian 37). 
This struggle over the racial classification of Arab Americans in legal terms has left severe marks on their social and racial self-definition. The question of skin color remains at the center of this debate. While the term American still serves as "synonym for white," Arab Americans continue to challenge prescribed categorizations (Haney-López 14; Majaj, "Arab-Americans and Race" 320). ${ }^{66}$ They are "not white, not black," as Majaj puts it ("Arab-American Ethnicity 324). This colorless status is also reflected in the way they are perceived by the mainstream American public. Here, they "occupy a contested and unclear space within American and cultural discourse (Majaj, "Arab-Americans and Race" 320). In turn, Arab Americans constantly face the challenge to clarify their status (Audi). Racial identity consequently becomes a matter of "choice," make (Majaj, "Arab-American Ethnicity" 323). Historically, early immigrants tended to make this choice in favor of white mainstream society. They distanced themselves from immigrants of darker complexion to become part of America's predominantly white society. Later generations, especially in the wake of the Civil Rights Movement, decided to position themselves on the opposite end of the racial spectrum by taking pride in their ethnic origins and aligning themselves with black African Americans (Majaj, "Arab-Americans and Race" 325; Haddad 79). Meanwhile, the climate of racial definitions has shifted again. In the Census of 2000, an overwhelming majority of $80 \%$ of Arabs living in the U.S. self-identified as white (Shryock 83). Partly, this expresses the longing of many Arab Americans to be fully accepted by U.S. mainstream discourse without counting as the other. In addition, this ethnic self-affiliation is the consequence of severe methodological shortcomings in the census which does not contain a racial category for Arabs and thus forces respondents to checkmark the "other" section of the survey. ${ }^{68}$

66 This also highlights the function of skin color as a metaphor. The British playwright Simon Stephens at the CDE Annual Conference 2009 in Vienna pointed to the metaphorical role race plays in the performative arts. In his keynote address entitled "Writing Black People" he explained: "Color only operates metaphorically in my plays [...]. Color itself is a metaphor. If I were really white - how frightened would you be and call the physicians to help me [...]?"

67 The idea of ethnic identity as a choice was brought forth by David Hollinger who regards ethnicity as affiliation, similar to religion and other voluntary identity choices (13; Leonard 141). His concept has become known as "postethnicity" thesis (Hollinger 116). Even though the unclear legal situation of Arabs when it comes to racial definition supports this model, the high impact of public discourse on Arabs also shows that racial and ethnic identity is severely constrained by outside factors.

68 The census currently contains more than a dozen racial categories, yet none for people of Arab descent (Manneh). Before the Census of 2010, Arab Americans in the Bay Area therefore started a campaign under the heading "Check it right; you ain't white!" encour- 


\section{Image 3: "There Is Nothing 'Other" about Us"}

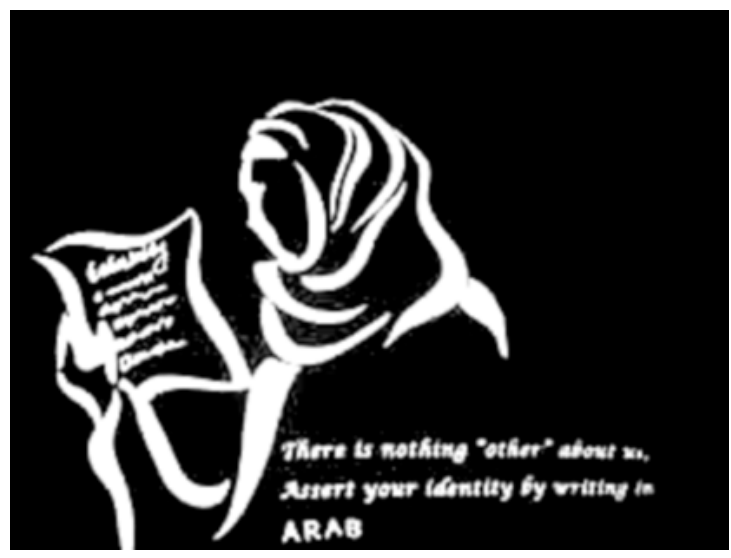

Source: Image of the custom-

made t-shirt to support a

write-in campaign in

preparation of the U.S. Census

2010 to motivate Arabs to

check the box for the ethnic

self-categorization as "other"

in the survey (Manneh)

The self-identification of many Arab Americans as white, however, differs

extremely from their public perception, particularly in the post-9/11 era. Arabs are by far not seen as mainstream white Americans. Rather, they lastingly represent the racial and mostly black other. The most important policy measure that has fostered this notion within the WOT movement is racial profiling. ${ }^{69}$ It gave the government the official permission to treat Arabs as suspects simply based on their race, i.e., black appearance (Audi; Cainkar, Homeland 129). ${ }^{70}$ This government-initiated racism in turn inflated a wave of discursive and "cultural racism" based on the logic of "othering" (Naber, "Look, Mohammed" 279). One effect of this cultural racism was the rise of hate crimes committed against Arab Americans following the 9/11attacks ("Report on Hate Crimes" 11; Audi; James Zogby 16; Merskin 172). In 2002, the FBI reported an increase in anti-Muslim ${ }^{71}$ hate crimes by $1,600 \%$ (Disha, Cavendish, and King 21). Even though these figures have slightly declined in recent years, they are still above pre-9/11 levels (Disha, Cavendish, and King 22; Bayoumi

aging Arabs to check the "other box" on the form and write down Arab (Blake). The change of the current census data might reflect the impact of these efforts.

69 According to Ghada Audi, racial profiling means "treating someone first as a 'suspect,' based solely on the false belief that a person's race, ethnicity, and/or religion alone is a sufficient predictive indicator of potential criminal behavior." This definition also stresses the intersectional overlapping of identity categories thus complicating racial profiling.

70 Most remarkable about this reaction to racial profiling is that the poem was written in 1995, long before the $9 / 11$ attacks. This shows that racial profiling, contrary to the assumption that it is a recent phenomenon, ruled the identity definition of Arabs long before the contemporary "paranoia" around national security (Alsultany, "Prime-Time" 214).

71 Since the FBI lacks the category "Arab" in its statistics, this figure only mentions antiMuslim hate crimes. In states which differentiate between Muslims and Arabs, dramatic increases in assaults against Arabs have been reported (Disha, Cavendish, and King 21). 
3). ${ }^{72}$ Outside the legal realm, the consequence of the discursive blackwashing of Arabs Americans is lasting media framing along racial lines. Representations here focus on Arabs and Muslims as black other. Connected to this are racial and ethnic stereotypes such as the dark-skinned "camel jockey" and the turban-wearing "suicide bomber" (Audi; Shakir, Bint Arab 3; Shohat and Stam 178).

The complex history of racial identity classification in the case of Arab Americans thus reveals the lasting impact skin color plays for the (self-)image of Arab Americans. Public discourse upholds the image of the Arab as black other. The media play a substantial role in the maintenance of this issue frame by representing Arabs as blacks. Overall, this confirms a poignant finding by Mustapha Bayoumi who in his study "How Does it Feel to Be a Problem"73 concludes that Arabs represent the "the new blacks" of America (Bayoumi 2; Sirin and Fine 193). ${ }^{74}$ In short, they are blackwashed via public discourse. Another essentialist tendency with equally striking stereotypes can be found with respect to the issue frame of religion.

\section{The Religious Frame: Arab Means Muslim}

Edward Said in Culture and Imperialism made a striking observation long before cultural pluralism as a concept became popular. "No one today is purely one thing," he acknowledged (336). For Arab Americans in particular, this finding is of special significance. For once, the collective term Arab itself refers to a very heterogeneous group. This stands in fundamental opposition to the homogeneity assumed by the public. For the majority of non-Arabs, Arabs are indeed "purely one thing," namely Muslim. This constant conflation of ethnic origin and religious identity again turns out to be the result of a framed media discourse in which the terms Arab and Muslim are used as meaning virtually the same (Shohat, Introduction 7; Majaj, "Arab-

72 Comparative studies on hate crimes actually revealed that while hate crimes against Muslims and Arab Americans dramatically increased in the period following 9/11, crimes motivated against other minorities, such as African Americans, Asians and Hispanics, actually declined during the corresponding period (Ahmad 105). This raises the question whether the motivation for these offenses actually derives from specific reservations against Arabs and Muslims or whether this group has simply gained more attention among homophobics who commit crimes against any minority.

73 The title plays on Du Bois's famous publication The Souls of Black Folk and underlines the similar racial position occupied by African and Arab Americans.

74 As Karen Leonard observes, racism against African Americans has become far more acknowledged than racism against Arab Americans (58). The latter tends to be tolerated and not labeled as such. Majaj therefore provocatively concludes that Arab Americans are the only ethnic group "safe to hate" in the U.S. because racism does not lead to any serious legal consequences (“Arab-American Ethnicity” 321-22). 
Americans and Race" 323). Religion thus constitutes the second issue frame which accompanies the representation of Arabs in the media.

The early history of Arabs in America already suggests that the equation of 'Arab equals Muslim' relies on a myth. Early immigrants from Syria and Lebanon were Christians who strongly distanced themselves from any non-Christian background because it would hinder their naturalization procedure (Majaj, "ArabAmericans and Race" 323). This dominance of Christians among Arab Americans remained fairly stable at around $90 \%$ up to the the 1950s (Haddad 63). After this, with more immigrants coming from predominantly Muslim countries such as Egypt, Iraq, and Jordan, this figure changed. Today, about $60 \%$ of Arab Americans are members of a Christian religion whereas about $25 \%$ are Muslim ("Demographics"). ${ }^{75}$ Throughout all immigrant periods, religion remained a very important aspect of self-definition. More than a matter of pure religious testament, Islam has become a "way of life" with a high social significance (Ajrouch, "Family and Ethnic Identity" 134). The term Islam therefore does not stand for a fixed religious tradition but reflects an "amalgam" of religious beliefs (Lambert 91). Often, religious identification gains priority over national affiliation for Arabs from various countries. ${ }^{76}$

As was the case with the ethnic issue frame, the representation of religion and Islam in the media stands in opposition to the given data on actual religious affiliation. Islam here is closely related to the discourse on terrorism (Wöhlert 30). The dominant interpretation within this issue frame is that Islam is the main reason for "aggression, and brutality, fanaticism, irrationality" as well as "medieval backwardness" (Thofern qtd. in Wöhlert 31). Based on the influence of the neoOrientalist political frame, Islam is thus mostly interpreted as "political Islam," which in turn is equated with "radical fundamentalism" (Wöhlert 32). This also includes the binary representation of the Western, i.e., Christian, world versus the

75 This trend continues whereby Islam is expected to become the most common religion in the U.S. next to Christianity (Shakir, Bint Arab 114).

76 Comparative studies have shown that severe cultural differences exist between countries of the Middle East and Europe or North America when it comes to the importance of religious identity. In the case of Jordan, for example, $65 \%$ of the respondents in a Pew research study of 2011 consider themselves Muslim first, only 24\% give priority to their nationality. These results from Arab countries confirm earlier findings by Nadine Naber in the American context ("Arab San Francisco" 209). In most European countries, the opposite holds true with religion playing a minor role behind national self-identification. This stands in contrast to the case of the U.S., a country which represents a clear exception in the context of religious self-affiliation. Here, the percentage of people who primarily identify themselves as Christians ranges at $46 \%$, which is equal to the ratio of respondents identifying as American first ("Common Concerns" 5). 
so-called "Mohammedan world" (Majaj, "Arab-Americans and Race" 323). Since the separation of church and state counts as one of the core pillars of "Western rationality" (Said, Covering Islam 9), this interpretative framework underlines the backwardness of Islam (Wöhlert 33).

At the center of this cognitive framework, one frinds a prominent stereotype which combines most of the key characteristics associated with religious framing. This stereotype rests on the dichotomy between the "good Muslim and bad Muslim" with the latter clearly dominating the picture (Bakalian and Bozorgmehr 188). In the praxis of every-day media discourse, this stereotype is framed by the representation of Arabs in connection with religious images and symbols. In addition, explanations given for social or political developments taking place either in the Middle East or among Arab Americans are rationalized based on religious arguments. This trajectory applies to news media content and popular culture entertainment alike. Meta-studies on the representation of Arabs in major newspapers and news frames confirm this interpretation pattern. Religious framing here is especially popular in combination with political topics (Wöhlert 98). These present-day representations of Arabs therefore still represent a familiar stereotype already discovered by Jack Shaheen almost three decades ago. The Arab is contextualized as Muslim fundamentalist (Arab and Muslim Stereotyping 1).

When relating these findings on media framing to the patterns in which these frames are absorbed by the media public, one finds high degrees of frame adoption (Wöhlert 31). In a Pew Researchs study from 2011, 70\% of American respondents stated that Islam is the most violent religion ("Common Concerns" 23). This is followed by figures showing that American non-Muslims see Muslims above all as fanatical (41\%), violent (45\%), and arrogant (34\%) ("Common Concerns" 26). These figures have remained at fairly high levels throughout the past years. This negative view of Islam is furthermore connected to a severe fear of Islamic extremism expressed by $69 \%$ of the respondents in the U.S. ("Common Concerns" 31). This figure stresses the close link between religious framing and political topics. ${ }^{77}$

As the theory of framing suggests, frames are most readily adopted by audience members whenever alternative information is missing and a general lack of background knowledge persists on an issue. This phenomenon becomes most obvious

77 Additional empirical data confirming the negative stance toward Islam is manifold. A 2009 poll on American opinions conducted by Zogby International, for example, found that $42 \%$ of the American respondents tended to believe that Muslims are "religious fanatics" (James Zogby 29). Another study from 2010 furthermore revealed that $46 \%$ of the respondents shared the view that "Islam teaches hate" ("American Views" 6). These and other opinion data highlight the strong negative emotions associated with Islam. 
with respect to the religious issue frame. Hardly any other stereotype ${ }^{78}$ is so much grounded on the lack of knowledge than the one of the Muslim fundamentalist. Studies exploring the knowledge about Islam among American non-Muslims reveal striking shortcomings. Respondents are hardly able to name any of the core pillars of Islam or other details concerning Muslim religious practice. Furthermore, the majority thinks that the term Islam merely stands for "submission" (Joseph 261). ${ }^{79}$ The most common answer found among respondents is that Islam is "highly different from their own" religion (Panagopoulos 611). As this response suggests, it is not detaild knowledge ${ }^{80}$ about Islam which evokes feelings of difference and opposition but the definition of Islam as different as such. The British researcher Rana Kabbani highlights the importance of this oppositional thinking for the depiction of Islam in Western popular culture:

Islam was seen as the negation of Christianity; Muhammad as an imposter, an evil sensualist, and Antichrist in alliance with the Devil. The Islamic world was seen as Anti-Europe, and was held in suspicion as such. Christian Europe had entered a confrontation with the Islamic Orient that was cultural, religious, political, and military, one that would decide from then on the very nature of the discourse between West and East. (qtd. in M. Hasan 33)

Kabbani's explanation of Islam as "negation" strongly confirms the logic of present-day assumptions about Muslim faith in public opinion. Again, the binary which is inherent in Orientalist thought also characterizes the religious framing of Arabs. Moreoever, the intertwinement of religious interpretations with other issues puts additional emphasis on the stereotype of the Muslim fundamentalist. The religious framing of the Arab in public media discourse thus accounts for the fact that

78 It is important to reiterate at this point that stereotypes are not synonymous with the concept of framing. Stereotypes as simplified representations of objects account for the emergence of cognitive schemata. The latter, in turn, are part of higher-level cognitive frames usually comprising more than one stereotype.

79 The word Islam is derived from the Arabic roots of "salima," which is associated with safety and unharmedness, and of the term "salam," meaning peace (Joseph 261). In addition, the word Muslim describes someone who fully devotes him-/herself to God, which is different from the concept of submission.

80 The lasting lack of knowledge among the general population runs counter to the rising interest in Islam and Muslims in the academy, especially in Europe. Muslims here count as the most studied immigrant group (Leonard 129). Studies on Muslim identity are characterized by thorough analytical procedures in both quantitative and qualitative works. Often, experimental and novel designs contribute to further research progress. An example is the study conducted by Selcuk Sirin and Michelle Fine who introduce identity maps in their study (xv). 
religion as an "umbrella" concept becomes more of a cultural, ethnic, and political ${ }^{81}$ marker of difference (Wiegand 237). Islam therefore gains an encompassing meaning that almost exceeds the boundaries of religion as specific issue in public discourse. $^{82}$ The journalist Anthony Weiner based on the research for his book Man Seeks God summarizes this centrality of Islam for the public debate by comparing the faith to " 800 -pound God in the room"” before adding "that everyone has an opinion on it even if they don't express it." A similar pattern can be revealed when looking at the issue frame of gender. Here, the intersection of race, religion, and womanhood culminates in the image of the veiled woman.

\section{The Gender Frame: Veiled Womanhood}

In November 2004, news of an assassination spread around the world. A man had been assassinated by what is publicly called an "Islamist" (Wöhlert 2). The man who was killed was Theo van Gough, film director and writer. Van Gogh had directed the movie Submission together with the Somali-Dutch women's rights activist and politician Ayaan Hirsi Ali, ${ }^{83}$ a short film on the abuse of Muslim women. The movie depicted the story of these women as written on the body of a nude female body wearing a see-through chador (Eyerman 1). The movie caused outrage among Muslims and Westerners alike. Finally, it also brought about the death of the director. Hardly any other example from the recent past demonstrates the centrality of gender for the framed view of Arabs better than this controversy. It highlights in a tragic way how much the veiled woman stands in the limelight of the issue frame of gender ${ }^{84}$ in the contemporary discourse on Arab and Muslim identity. ${ }^{85}$

81 The junction of religious with political matters has a long tradition in the history of social discourse studies. Political means have commonly been justified from the background of religious punishment (Merskin 161).

82 Krista Wiegand points to this overarching function of Islam as identity marker in her essay "Islam: Religion or Ethnicity" (239). The author here reveals how Islam can serve, both as unifier and as cause of ethnic conflict. An example is the movement of PanArabism in the context of Islamic revivalism (240).

83 The discourse surrounding Ayaan Hirsi Ali in the aftermath of van Gogh's death underlines some common features accompanying the authenticity and credibility granted to Muslim women in their battle for women's rights. Ali who now enjoys the status of an "international celebrity" and is often accused of using her political goals for the purpose of gaining personal fame (Eyerman 2). This debate has similar features as the ongoing struggle of ethnic writers and activists to counter the accusation of native informanthood.

84 Just like race, gender is understood as a constructed category which relies on cultural assumptions about proper behavior and social code (Barker, Cultural Studies 480). 
Ever since the first European travelers visited the East, there was one issue which pervaded the travel accounts, namely: "Eastern women" (Whitlock 100). ${ }^{86}$ Oriental women thus became the gendered symbols of the East in cultural and literary representation (M. Hasan 31). The issue of gender, however, quickly became enmeshed with the question of physical appearance. It is therefore not the Oriental woman as woman who has become the incarnation of the East from the foreign perspective but the Oriental woman as "the veiled woman" (Yeğenoğlu, "Veiled Fantasies" 554). Meanwhile, this image is attached to a series of further cultural stereotypes emerging from the depiction of the Orient in popular culture:

This [the presentation of Middle Eastern women] often includes association with the words harem, polygamy, belly dancer, sexy, uneducated, oppressed, and veiled. These images are the result of the frequent representation of Middle Eastern women in U.S. popular culture in terms of the character of the belly dancer and seductress, Cleopatra of the Nile, the harem beauty, and the veiled woman with bewitching kohl-circled eyes. (Hamilton 174)

As this passage indicates, the current associations linked to the image of the Arab woman are the products of a long history of popular culture framing which can be

85 Although women indeed constitute the center of the gendered discourse on Arab identity, the gender frame itself also includes the stereotypical depiction of men. This not only applies to the recent depictions of Arabs as mostly male terrorists but also to the historical legacy of Arabs as dark-skinned males as represented in popular culture (Merskin 158).

86 When it comes to the lasting legacy of Orientalism in depictions of the East in early American travel literature, critics tend to forget that travels by Arabs and Muslims to America have also become the subject of literary production. As the recent edition America in an Arab Mirror demonstrates, Arab travelers to the New World engaged in travel writing as early as in the 17th century, in 1668. Respective accounts continue to be produced in the present. Many of these accounts were written by journalists who focused their observations on the direct opposition between East and West. An example is the early report by Mikhail Asad Rustum of 1895 which includes a table entitled "The Contrasts Between American Western Ways and [Middle] Eastern Ways and the Differences.“ (3). The oppositions revealed by the author directly speak to the title of the edition centering on mirror images: "1. We are [Middle] Easterners," he writes, "They are American Westerners" (3). This strong focus on the division between East and West as conceptual framework for depicting the 'Other' thus also proves to be a feature of travelogues written by the 'Arab Other.' An editorial review recognizes this effect by acknowledging that the "descriptions of America differently engage and revise Arab pre-conceptions of Americans and the West. The country figures as everything from the unchanging Other, the very antithesis of the Arab self, to the seductive female, to the Other who is both praiseworthy and reprehensible" (Rev. of America in an Arab Mirror, Palgrave). 
divided into different phases and genres (Naber, Introduction 25; Shaheen, TV Arab 45). In the realm of literature, especially novels fostered the gendered framing of Arab identity. An early example of this is Margaret Mead's Sex and Temperament published in 1926 which contrasts the relationship of Western women and men with that of women in so-called " "primitive' societies" (Bahramitash 228). The "harem literature" of the mid-century then (Whitlock 14) became outnumbered by so-called "veiled bestsellers" ${ }^{87}$ that reproduce the Orientalist trope (Whitlock 93). One of the most prominent examples is Betty Mahmoody's Not without My Daughter. Published in 1991, the book mostly focuses on the struggle of a veiled woman to claim her daughter (Haddad, Smith, and Moore 29).

The depiction of Arab womanhood in the West increasingly became accompanied by a high degree of politization, particularly with respect to the feminist cause. From the early history of Orientalism, the veil created a distance (Yeğenoğlu, "Veiled Fantasies" 548) or "border" (Yeğenoğlu, "Veiled Fantasies" 557). This border separated the "Arab virgin" from the "American whore" (Naber, "Arab San Francisco" 36). The veil thus became the central symbol of early feminist discourse sloly taking a more nuanced shape at the beginning of the $20^{\text {th }}$ century (Guindi 595). Especially in the 1960s, the earlier condemnation of the Arab woman as lascivious was replaced by the image of the veiled woman as victim. This substantiated earlier notions which suggested that Arab women must be rescued from the harem (Andrea 4). The discussion of genital mutilation and forced marriage in recent decades gave additional momentum to the veil as central signifier of oppression (Shakir, Bint Arab 104; M. Hasan 43). ${ }^{88}$ Altogether, this evoked the notion that Arab women are "buried alive behind the veil" (Ahmed 154). With the further differentiation of feminist studies and the emergence of third-wave feminism, this ethnocentric view of Western feminists was slightly altered. Feminist Orientalism thus gave way to Orientalist Feminism, ${ }^{89}$ a modern approach to the liberation of

87 The term "bestseller" is highly problematic, although it is used in everyday language and by literary scholars. The problem is rooted in the varying methodologies used to determine best-selling books. Often, the position of a book on a bestseller list does not merely depend on sales figures but needs to be seen relative to other criteria, such as genre classification (Clabough).

88 The argument of women's oppression based on veiling tends to be discussed as religious legacy used to argue against Islam as submissive religion. As scholars and public critics of this theory keep pointing out, however, veiling as a religious requirement must be questioned, since there are very few references to the topic in the Qur'an (Guindi 588). Veiling here also is interpreted as a means of protection (Yamani 19).

89 Orientalist Feminism, just like its predecessor, is not without criticism. Despite claims of increased cultural relativism within third-wave feminism, the lack of detailed knowledge about the Middle East still upholds a high degree of ethnocentrism (Hamid 82). Further- 
women in the Arab world which is supposed to be more culturally relativist (Bahramitash 223). Despite these efforts to move away from ethnocentric views of feminism, the veil continues to be read as a sign of oppression within feminist discourse (Ahmed 152). ${ }^{90}$

This degree of politization and the prominence of the veiled woman in the public media discourse has experienced another uplift in the post-9/11 era in which the "timelessness of the stereotype of the Muslim woman persists" (Haddad, Smith, and Moore 26). What differentiates the gendered framing of Arabs and Muslims from the framing of other groups is the plethora of additional stereotypes connected to veiled womanhood. All of these stereotypes stand under the strong influence of the WOT. The central image therefore depicts the suppressed Arab woman as passive victim with a "veiled and beaten body" (Fadda-Conrey, "Racially White" 177; Naber, Introduction 37). In addition to the focus on victimhood, the footage encircling the coverage of Arab women in the context of U.S. military operations ${ }^{91}$ also propagates the view of the Arab woman as a threat. The stereotype connected to this notion is the "female suicide bomber" carrying explosives under her niqab (Fadda-Conrey, "Racially White" 177). Nowhere is this impression of the female suicide bomber expressed more vividly than in Mohja Khaf's poem:

No, I'm not bald under the scarf

No, I'm not from that country

where women can't drive cars

No, I would not like to defect

I'm already American (Kahf, E-mails 39)

more, the question remains whether cultural relativism in general promises to be the answer to this Orientalist legacy. Progessive feminist critics from the MiddleEast thus ask, "How far Should We Take Cultural Relativism?" (82).

90 The Orientalist legacy of feminism also remains visible apart from the concepts of Feminist Orientalism and Orientalist Feminism. As Asma Hasan points out, the very concept of feminism continues to be treated as a "Western" monopoly, since European and North American feminists remain highly skeptical of Arab feminist movements initiated in the Arab world, such as "Muslim Feminism" (74). This also leads to the fact that the multitude of non-Western feminist movements in the Middle East, such as "Islamic feminism" and secular feminism, are hardly acknowledged (Yamani 1).

91 Whitlock even goes so far as to ascribe a military propaganda function to the role of women in veiled bestsellers (105). It remains to be questioned whether the negative undertone in this critique additionally undermines the productive impact life writing can have with respect to conveying knowledge about foreign gender concepts. 
This tidbit from Khaf's autobiographical and highly political poems demonstrates a larger trajectory behind the depiction of Arab womanhood in public discourse. Discussions of Arab womanhood are strategically employed to convey an image of the Arab world which exceeds the gender topic. News media increasingly focus on gender and the prominence of veiling when dealing with far more comprehensive issues (Wöhlert 155). A New York Times report illustrates this mechanism:

Life for women here in rebel-held northern Afghanistan is not without its constraints. Some of the strict Muslim dictates rigidly enforced by the Taliban government that controls most of the country also apply here. But generally the Islam practiced here is far more permissive. [...] The women are almost always covered by a light blue cotton burkah, a veil that extends from head to ankle. They rarely speak to men in public and almost never interact with foreigners. [...] Family pressure still plays a major role in marriage, but women in larger towns generally choose their own husbands. (Wöhlert 187)

News reports like the one above underline the empirical finding that the contemporary discourse on Arab identity, particularly as it is framed in U.S. media, largely largely revolves around veiled Arab women (Wöhlert 80; Williams and Vashi 271). The gender frame thus becomes a central point of reference, not only for the definition of Arab and Muslism women, but for Arab identity as a whole. ${ }^{92}$ This finding gained additional confirmation in the coverage of the Arab Spring where the role of women as "driving force" was given particular prominence (DeLong-Bas). Starting with early reports from Tunisia, the subsuming coverage of demonstrations in the streets of Cairo, and uprisings against the dictatorship of Mohammar Ghaddafi veiled women came to represent the faces of the revolution. ${ }^{93}$

92 Another example of this gendered representation of more far-reaching political and cultural issues in the Middle East is the law in Saudi Arabia which forbids women to drive cars. This gender constraint is frequently used by Western media to presumably explain larger trajectories of oppression in the Arab world and to justify attempts to liberalize these societies (M. Hasan 49).

93 At a lecture at the University of Michigan in November 2011, the Yemeni recipient of the Nobel Peace Prize of 2011 Tawakkul Karman strongly highlighted the role women played in the Arab revolution. As she provocatively put it: "Before the revolution, women had three duties in their lives: birth, household, grave." As she furthermore explained, this status dramatically changed in and after the revolution. "In the protests, women did strategic planning, provided medical care in the camps, planned the political future." These words strikingly underline the importance granted to the political involvement of Arab women by Arab women themselves and not by Western feminists. 


\section{Image 4: Women Protestors in the Arab Spring}

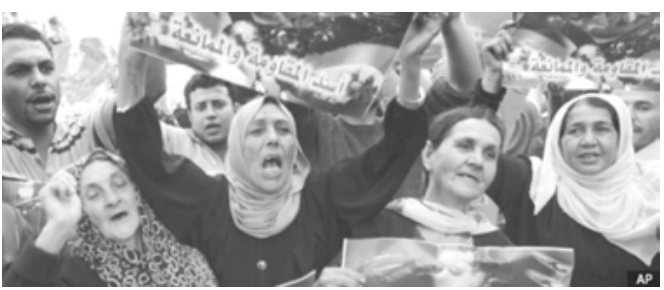

Source: Women and men protest the government after the EU extended its sanctions on Syria in November 2011 (Guest).

These images of protesting women alongside male demonstrators stand in contrast to former mediated stereotypes of Muslim women as victimized and bound to the home. Their political engagement is attached to ideas of political agency and social influence. Yet, there remains considerable doubt that this altered depiction of women as driving force behind the Arab Spring can change existing patterns of interpretation. The seemingly furious way in which the women pursue their rights is not in line with Western ideals of political deliberation. The framing of these stories of the revolution nevertheless reiterated well-known images of barbarism and chaos. While veiled women might therefore represent progress in their respective societies, to the outside media audience, this progress still seems to take place in a different world and in a different century.

This recent example of the veiled woman as political agent, but also as a lasting symbol of Orientalist framing, highglights the overall significance of the gender frame for the interpretation of the Arab world. The veil, which was originally meant to protect the woman from the view of any outsider, has come to symbolize the "barrier" between the Oriental woman and the Western gaze (Yeğenoğlu, "Veiled Fantasies" 543). The media presence of veiled women therefore matters beyond gender concerns with the veil representing "one of the most intractable signs of cultural difference [...]" (Whitlock 17). Orientalism is the legacy from which this cultural binary derives and it remains highly gendered, as the title of Mahmudul Hasan's paper "The Orientalization of Gender" suggests (26). Hasan reveals a "double Orientalization" in which the power structure of Orientalism victimizes women as colonized and gendered (31). Feminist scholars of the postcolonial era therefore claim that gender and sexual difference are genuine components of Orientalism as a theoretical concept (Yeğenoğlu, "Colonial Fantasies" 2).

When looking at the impact of the gender frame on popular culture, the figures strikingly confirm the suggested interpretative pattern. In a recent Pew ${ }^{94}$ survey on global attitudes, only $22 \%$ of Western respondents thought that Muslims were re-

94 Attitudes about the respective 'other' are based on responses given by non-Muslims in a series of Western countries, such as the U.S., Germany, Britain and France. Conceptions of "the West" are based on the responses provided by Muslims in predominantly Muslim countries ("Common Concerns" 19). 
spectful of women ("Common Concerns" 19). Despite public opinion polls, political decision-making reveals further consequences of the gender frame drawn by the media. Several European countries have become increasingly hostile to the veil. France, for example, banned the veil in public places in 2004 (M. Hasan 47). Furthermore, the omnipresence of the issue of veiling in public discourse also becomes reflected in the scholarly and literary market. Publications dealing with the veiling and unveiling of Arabs and Arab Americans count among the most written and read in the contemporary canon. As is the case with ethnic and religious stereotypes, the production of counter-images can be observed as primary theme here. This abundance of popular discourse on the covered female body confirms that the veil is “pregnant with meaning," as Leila Ahmed suggests (Whitlock 50).

This increasing prominence of veiling as product of framed discourse stands in sharp contrast to the veiled reality of Arab America. Here, the practice of veiling has actually been decreasing in the past two decades. Figures from the 1990s published in the New York Times report that about two thirds of Middle Eastern women were wearing the veil (Haddad, Smith, and Moore 31). In the years to follow, a continuous decline appeared. Data from 2011 indicate that out of one million Muslim women living in the U.S., only $48 \%$ wear headscarves (Khalid). This steady decline was interrupted only by a slight increase following the events of $9 / 11$, as many women decided to intentionally wear the hijab to publicly identify as Muslim and thus establish a counter-example to the violence of al-Qaida (Khalid). ${ }^{95}$ This also hints at the complex motivations of veiling which hardly ever get accounted for in the common media coverage (Williams and Vashi 271). Wearing hijab particularly for the young second-generation of Arab American women above all functions as a "social symbol" (Williams and Vashi 285). It fulfills various needs which do not stand in contrast to American social values, such as the need for individualism and autonomous personal identity. ${ }^{96}$ Arab American women today thus place great

95 The contrary reaction to veiling as sign of solidarity can also be found as the case of a young Arab American woman shows. The woman reports to have stopped wearing the hijab after graduating from college. In her opinion, wearing hijab has an enormous signal function which she experienced as a burden: "When you put the scarf on, you have to understand that you are representing a community," Abdelnabi says on a radio show. "And that is huge. That's a huge responsibility. And I don't know if it's for everyone" (Khalid). This experience reflects the central importance of the discourse on veiling and its impacts on the individual lives of Arab Americans.

96 A study conducted on the religious involvement of young Arab American adults in a midwestern metropolitan area reveals that wearing hijab can be a mere fashion concern used to express individuality (Williams and Vashi 284). Motivations like this, which might easily be discredited as teenage concerns, still need to be registered if engaging in 
emphasis on the hijab as symbol of individual choice and conscious religious decision-making (Williams and Vashi 284). ${ }^{97}$

As this comparison between the gendered media coverage, its impact on public discourse, and its empirical circumstances demonstrates, the gender frame turns out to be one of the most complex issue frames surrounding Arab identity. Above all, the borders to the other issue frames of religion and race are difficult to draw since the veil is seen as a cultural, religious, and racialized symbol which is not only attached to Arab womanhood but to Arab identity at large (A. Hasan 71). ${ }^{98}$ Arab American women thus feel the most intensive cultural pressure because of their mostly involuntary function as symbols of Arab collectivity. The veil functions as most prominent signifier, especially in the discourse around the WOT (Ajrouch, "Family and Ethnic Identity" 132; Hatem 379). On the one hand, the veil remains a central instrument for the Islamic movement, religious identity definition, and political emancipation (Yamani 11). On the other hand, the WOT discourse and the association of the veil with violence and terrorism, as well as the sustaining image of the oppressed woman, are major causes of anti-Islamic sentiment (Ahmed 163). This altogether culminates in the fact that Arab women in America to a heightened extent find themselves caught "Between Two Worlds" (A. Hasan 71).

\section{Linking the Frames: Ideology, Politics, and Issues}

The symbolic position of the veiled woman between two worlds leads to the larger picture of mediatic frames thus encountered. Just like the veil represents a layer surrounding perceived Arab women's identity, a series of frames surrounds the public image of Arab identity. The gender frame represents the third issue frame alongside the issue frames of race and religion. These issues have empirically proven to dominate the media framing in the post-9/11 period. Each issue frame is built around a dominant stereotype and associated keywords that trigger particular interpretative patterns of Arab identity definition on the part of the media audience. Sometimes, these schemata overlap. The same holds true for the frame structure in

serious research on Arab American gender issues. Unfortunately, these aspects tend to be obscured or neglected due to the heavy emphasis on religion in the discourse on veiling.

97 This focus on individual expression not only refers to the public representation of Muslim identity but also to a function within Arab American family structures. Particularly young women therefore report to wear hijab in order to make a commitment to their roots and separate themselves from their "Westernized parents" (Williams and Vashi 283).

98 This importance of gender roles for cultural and ethnic identity definition is shared by many Arab Americans themselves. As interview studies reveal, especially young Arab Americans place special emphasis on proper female behavior because it is an important symbol of collective ethnic identity (Ajrouch, "Family and Ethnic Identity" 131). 
which these issue frames are embedded. These higher-level frames are NeoOrientalism with a specific political connotation and Orientalism as meta-level ideological frame. From a historical perspective, these frames have developed successively in the course of the past two centuries, with the issue frames reflecting snapshots of present-day media framing.

\section{Graph 3: Frame Levels in Historical Perspective}

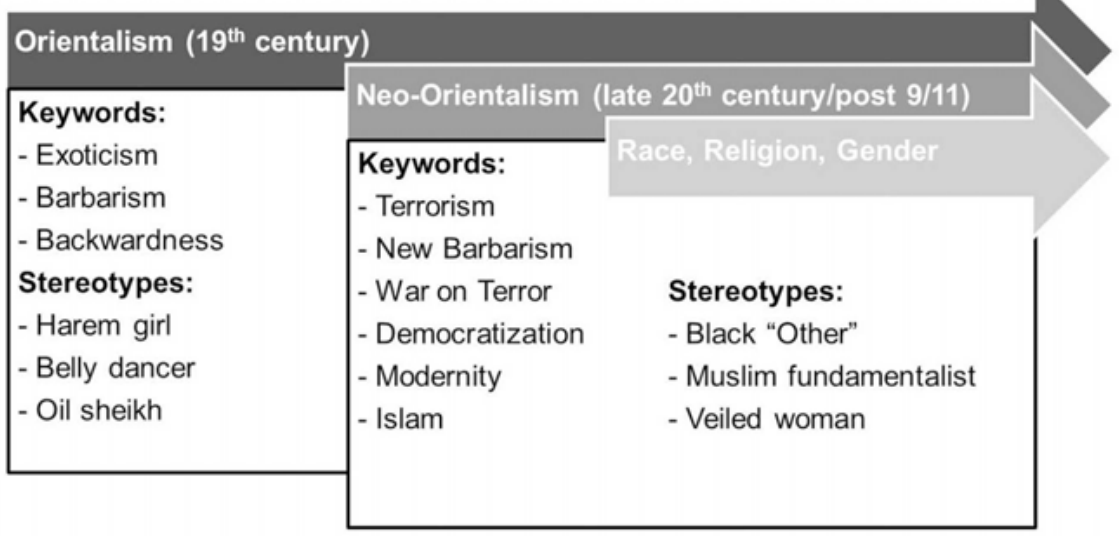

Although the model for the sake of theoretical distinction draws clear lines between the different frames, the identification of specific issue frames gets complicated by the fact that issues often overlap when the media coverage combines different thematic categories. In addition, the influence of Orientalism and Neo-Orientalism still determines the binary character of issue framing. It is therefore impossible to precisely separate each frame level. With respect to the general importance of issue framing within the embedded frame model, however, recent empirical findings suggest that the amount of information around single media events involving Arabs increases. Whereas the coverage before 2001 largely centered on "episodic framing," i.e., the coverage of single events without much background information, "thematic framing" $" 99$ has come to dominate thereafter (Nacos 148). ${ }^{100}$ Although this

99 Some authors use the term thematic frames when referring to the framing of particular events with a specific thematic focus. This definition is similar to the concept of issue frames as chosen in the present study.

100 A study on the coverage of Arab Americans in major American newspapers revealed that the ratio of episodic versus thematic framing was reversed from $60 \%$ to $30 \%$ in the period before $9 / 11$ to $39 \%$ and $49 \%$ in favor of thematic framing in the period thereafter (Nacos 148). It remains to be analyzed whether this turn toward more background in- 
trend might be welcomed since more information also promises to fill existing knowledge gaps about Arabs and Muslims, the range of issues nevertheless remains very limited. This again reflects the selective bias under the influence of the higherlevel ideological and political frames. Whereas in the pre-9/11 era, topics such as Arab culture and customs were part of the media agenda, they have received far less attention in recent times (Nacos 144).

The absence of a cultural issue frame also points to the blurred meaning the concept of culture has for the identity definition of Arabs and Muslims. As the previous overview of the most significant frames derived from framing research illustrates, Arab and Arab American identity has historically been dominated by discursive framing. Identity in this context can be best understood as cultural identity, whereby culture serves as a "mobile signifier" and is determined by public discourse rather than by nationality or ethnic origin (Barker, Cultural Studies 477). Due to the strong media presence of Arabs, social identity, i.e., the ascriptions society has of Arabs, clearly impacts the self-identity of Arabs. The additional analysis of public opinion data suggests that the latter often varies considerably from the public view (Barker, Cultural Studies 476).

When merging the given findings on the historical emergence of different frames, a hierarchical representation of their interrelation provides further insights into the dynamics ruling the discursive framing of Arab identity. The model highlights the importance of the different frame levels in respect to their cognitive complexity and magnitude. Also, this hierarchical depiction emphasizes the inversive effect of framing, whereby the ideological frame of Orientalism continues to dominate lower-level frames to varying degrees. The neo-Orientalist frame thus reflects basic characteristics of Orientalism as ideology; yet it is more limited to political circumstances. The issue frames on the lowest level of the hierarchy are in turn impacted by both outer frames. Nevertheless, with their more specific thematic focus, they also have the capacity to convey more detailed cognitive schemata.

formation in the long run leads to the emergence of additional media frames since additional cognitive interpretation patterns are constructed. 


\section{Graph 4: Multi-Level Framing Model}

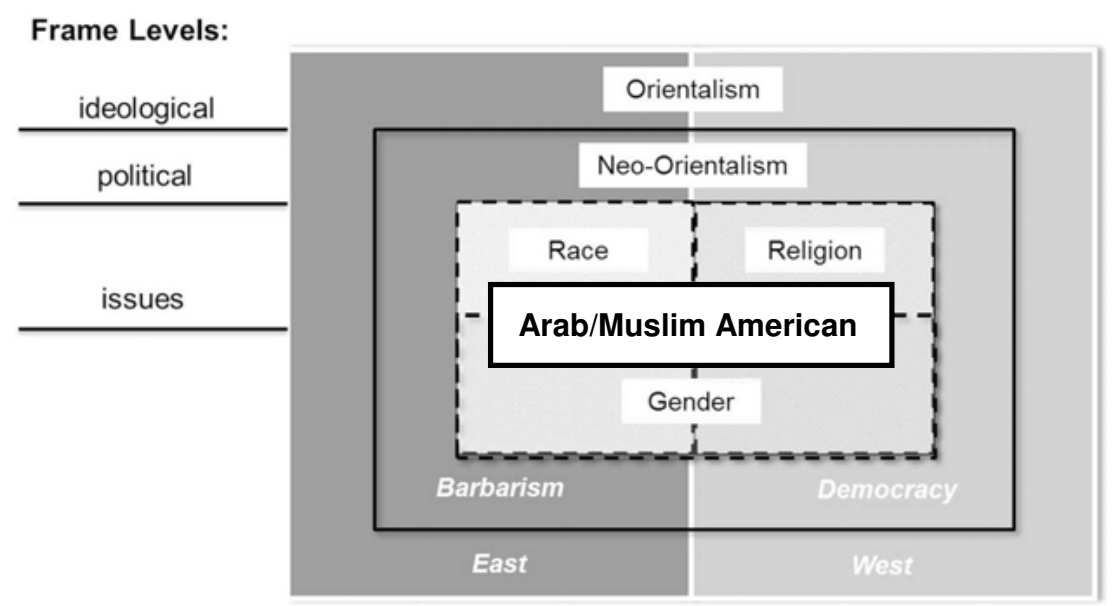

The model depicts two major findings. The first one is that all frames are ruled by dichotomies, such as East versus West, Islam versus Christianity, or veiled versus unveiled. Arab American identity ascription and self-perception remains locked in this grid of dualistic thinking. This prevents the granting of a higher degree of complexity and internal diversity for collective identity definitions, a situation that Majaj calls the "double-legacy" of Arab Americans ("Arab-Americans and Race" 332). This is linked to the second major finding of the frame analysis stating that the range of issue frames is very limited. All issues which have empirically proven to be most relevant in the present media discourse stand in the tradition of themes that have accompanied Orientalist discourse long before the mass media age.

The resulting multi-level frame model provides the discursive regime surrounding framed Arab identity. Literary production and autobiographical writing take place within this network of mediated discourse. As the critical reflection on previous periods of life writing research has shown, Arab American autobiographies have mostly been read to follow the Orientalist logic they sought to overcome. By conceiving of these life narratives as counter-narratives, critics have thus locked their own scholarly discourse in the same binary trajectory. While entirely focusing on counter-discursive means to overthrow mediated stereotypes, they have neglected the detailed analysis of the dynamics underlying this mediated discourse and its reciprocal effects. The new model of media framing as theory of life writing now allows for this more complex but also more structured analysis of autobiographical writing. It conceives of autobiography as inherent part of mass media discourse. The challenging task then remains to employ this novel methodological lens in order to find out how Arab American life writing actually functions within the complex network of media framing. 



\title{
4. (Re-)Framing the Afghan Fundamentalist in West of Kabul, East of New York
}

\author{
CONAN: This is TALK OF THE NATION. I'm \\ Neal Conan in Aspen, Colorado. We're at the As- \\ pen Ideas Festival in the Grand Ballroom of the Ho- \\ tel Jerome. Nearly 10 years after the worst terror at- \\ tacks in U.S. history, lessons continue to play out on \\ the battlefields of Afghanistan and Iraq, in the halls \\ of the Central Intelligence Agency and the FBI and \\ Congress and the White House and at dinner tables \\ across the country. (Chertoff et al.)
}

Even ten years after the attacks of $9 / 11$, there is primarily one scenario which Americans associate with Afghanistan: terrorism. Even though the plane hijackers of 9/11 did not come from Afghanistan, the country has become the epitome of evil and is regarded as the breeding ground for Muslim fundamentalism. Afghanistan is the country where America loses its beloved soldiers, more of them every day. For about 65,000 Arabs living in the U.S. today, Afghanistan is a very different place. It is their home country. They know Afghanistan in a way which CIA, FBI, and the American Congress are still struggling hard to grasp. For Afghan Americans, their home country is not only the incubator of terrorism and violence. Instead of retreating to the "dinner tables across the country" to discuss the aftermath of terrorism on public radio shows, many of them have therefore set out to tell their own stories of Afghanistan in autobiographical writing (Whitlock 51). The journalist Tamim Ansary was amongst the first to present his views. His memoir West of Kabul, East of New York was published in 2003. What the author presents here is not one of the common journalistic reports from the war front. ${ }^{1}$ Rather, it is an intimate record of

1 Whitlock puts great emphasis on autobiographies from war-struck nations. "Life narratives from Afghanistan, Iran, and Iraq are compelling and urgent, and autobiographical 
his experience in Afghanistan which combines multiple frames of interpretation to create a complex picture of Muslim American identity with the aim of intervening in the discourse on terror.

\subsection{Journalistic Agency betWeEn EASt AND WEST $\left(V_{1}\right)^{2}$}

\section{Author and Structure of West of Kabul}

"Growing up bicultural is like straddling a crack in the Earth, especially when the two cultures are as vastly disparate as America and Afghanistan. The memoir is an account of just such a life," Tamim Ansary reveals in a short biographical statement on his homepage. Ansary was born in Kabul in 1948. His father was a university professor who married an American English teacher who came to live with him in Afghanistan. Ansary describes this intercultural marriage on the opening pages of his memoir. "I was born into that world when it was virtually untouched by the West. I emphasize the word virtually. Some penetration had already occurred - my sister and I embodied it. Not only was our mother American; she was the only American woman in Kabul when she arrived there in 1945" (Ansary, West of Kabul 42). ${ }^{3}$ His mother therefore was not "any" American, but a secular feminist, something quite unknown in the traditional world of Afghanistan (WK 9). In Afghan society, she was thus considered "neither female nor male, but American" (WK 24).

This life between two cultures, between two worlds, America and Afghanistan, East and West, would also become the life of Tamim Ansary himself. After coming to the United States as a high-school student, he engaged in a career as a journalist. Ansary now lives in San Francisco as a writer, lecturer, and editor of fiction and non-fiction (Ansary, Home page). His memoir reflects this life and constant journey

acts are enmeshed and active in conflicts where lives are at risk here and now" (9). On the one hand, this extreme focus on the context of war underlines the double meaning of life narratives as "soft weapons." This also concedes life writing a new role in public discourse which has formerly been underestimated. On the other hand, however, the use of weapons as metaphors of life narrative also achieves the contrary effect by reiterating the WOT surrounding the definition of Arab identity. This reproduction of the most popular media frame severely reduces the value of Whitlock's otherwise novel approach.

2 The abbreviation in parentheses, e.g. $\mathrm{V}_{1}$, in the following subchapters of the text analysis is provided to immediately establish the connection to the analytical variables $V_{1}$ to $V_{4}$ identified in the theoretical model.

3 All further references are to the same edition, abbreviated by $W K$. 
between two worlds and two cultures. As he states: "West of Kabul is my account of the struggle to reconcile two great civilizations and to find some point in the imagination where they might meet" (Home page). After having engaged in this struggle of reconciliation in the past, Ansary today is convinced that he will only remain part of one of these worlds. In an interview conducted in September 2011 on the occasion of the tenth anniversary of the 9/11 attacks, he presented this life in one world as a conscious decision. Except for occasional visits, as he declared, "I personally don't plan to go back to Afghanistan because my life is here in the West" (Interview with Menten).

This dichotomy between two worlds could nowhere be more clearly emphasized than in the title of Ansary's memoir. West of Kabul, East of New York above all draws attention to place and opposition. Whereas in the days before 9/11, Kabul in contrast to New York counted as a forgotten village for most Americans, this situation has dramatically changed in the days of the WOT. This altered awareness of Afghanistan as the Garden of Eden for terrorists which the media have fostered also changed Ansary's conception of his memoir. As he reveals, he originally planned to focus on the questions of "bicultural identity" and the negotiation between two cultures in his book. With the event of 9/11, however, this outline underwent a revision. From then on, Ansary wanted to respond to the discourse on terrorism and its relation to "East and West," as he states retrospectively. This binary opposition therefore moved to the center of his attention (Interview with Menten). The immediate impact of $9 / 11$ as a key event that altered the structure and conceptual framework of his book emphasizes the immense relevance of mediated discourse for autobiographical production.

The importance of places, such as East and West, and the position of the individual subject therein, not only plays a dominant role in the title. It rather serves as a mental mindmap for the structure of the entire memoir. Instead of following a chronological order in his narrative, as is typical of autobiographical narration, location and the change of location turn out to form the overall structure when looking at the table of contents. The first part of the memoir following the prologue is entitled "The Lost World" (WK 13). Subsequent chapters in this section adhere to the names of places, such as "Villages and Compounds" (WK 16) and "Leaving Afghanistan" (WK 86). This geographic structure spans like a red thread through the entire book, particularly in the form of chapter titles mentioning country names, such as "Crossing Morocco" (WK 143), "Crossing Algeria" (WK 156), "Bus to Turkey" (WK 188), and "Istanbul" (WK 194). Overall, this place-focused scaffold represents a virtual map for the narrative to follow. It can be read as a direct continuation of the title and signals a high degree of narrative construction. Different from life narrative as the random recollection of various events or the chronological enlisting of key events, this very obvious geographical structure from the start draws attention to a larger frame drawn in the narrative. 
This larger frame of Ansary's narrative is contained in the chapter overview which mentions various locations turning out to be the destinations Ansary visits on his trip to the Arab world and ultimately to his own past. Travel and the literal change of location thus become intertwined with the life journey of the author. This journey, however, does not start in the past, as the common pattern of autobiography might suggest. Rather, it starts in the present of the post-9/11 world in which the autobiographer positions himself as an agent to translate between two worlds.

\section{Public Agency}

Then came September 11, 2001. The day after those airplanes brought down the twin towers, an email I wrote to a few friends went viral on the Internet, and I found myself derailed from my previous career (whatever that was) into speaking for Afghanistan and trying to interpret the Islamic world for the West - because at the time there was no one else to do it. (Ansary, Home page)

Ansary shares these lines on his personal website. ${ }^{4}$ They give a vivid impression of the day that changed his life and career as much as the one of many people around the world. This event also comes to constitute the beginning of Ansary's life narrative. He describes himself driving around in San Francisco on September 12, 2001. He listens to the radio broadcast focusing on the prominent topic of Afghanistan. A woman calls in, obviously in tears, because she does not want the U.S. to go to war. Another caller shortly thereafter makes a suggestion quite to the contrary: "Nuke that place. Those people have to learn. Put a fence around it! Cut them off from medicine! From food! Make those people starve!" he states (WK 4).

While listening to these words, Ansary imagines his grandmother in Afghanistan to be dying once again because of the public denigration of her homeland. An important thought then crosses Ansary's mind: those "people" who "have to learn," are certainly not the Afghan people. Rather, those who have to learn, by means of words and not through bombs, are the American people. Instead of calling into the radio show, which he feels "too shy for," as he admits, he decides to write

4 The personal homepage of Ansary offers comprehensive information on his literary and political engagement. The user finds detailed information on his biography, current projects, and links to current articles. Also, a schedule with upcoming public appearances is available. The site is designed in the fashion of online newspapers with various crossreferences and detailed excerpts from Ansary's work. There is also a series of comments and articles on current events referring to the Middle East and Afghanistan. The site also functions as a marketing tool for Ansary's books, whereby summaries of his works are accompanied by journalistic reviews. Overall, the homepage is highly professional and underlines Ansary's role as a public persona, political spokesperson and social activist. 
down his thoughts in an e-mail to a circle of friends ( $W K$ 5). "I poured out to them what I would have said to the public if I could have mustered the courage to call that talk show," he explains his motivation and ultimately feels better after hitting the "SEND" button (WK 5). Ansary at this point does not anticipate that the public indeed becomes his audience. "My e-mail spread like a virus throughout the United States and across the world," he later recalls (WOK 6). His e-mail in fact ended up reaching thousands of people. Even radio and TV stations cited his text. "The media seized on me as a pundit," Ansary remembers ( $W K 7)$. The e-mail is not quoted in full length in the prologue of the memoir. Ansary only provides a glimpse of the "brutal" vocabulary he used in his letter.

\section{CULT}

of IGNORANT

PSYCHOTICS.

When you think BIN LADEN, think

HITLER. (WK 7)

The full text of the letter written on September 12, 2001 is added as an attachment chapter entitled "The E-Mail" following the epilogue and preceeding the afterword of the life narrative (WK 287). "Dear Friends - I've been hearing a lot of talk about 'bombing Afghanistan back to the Stone Age,'” Ansary begins, before enumerating the various myths surrounding Afghanistan in the heated media debate right after the attacks (WK 289). From the beginning, he clarifies that the Afghanistan others only know from the news is a country which he is well familiar with and which he has remained attached to by constantly following the events there. "So I want to tell anyone who will listen how it all looks from where I'm standing," he explains (WK 289). This very position, as he underlines, is not the one of a terrorist, as the public media coverage might suggest. "I speak as one who hates the Taliban and Osama bin Laden," he thus adds before elaborating on the devastating economic and political situation the country finds itself in (WK 290). He then quickly responds to the public claims in favor of a military operation against Afghanistan:

We come now to the question of bombing Afghanistan back to the Stone Age. Trouble is, that's been done. The Soviets took care of it already. Make the Afghans suffer? They're already suffering. Level their houses? Done. Turn their schools into piles of rubble? Done. Eradicate their hospitals? Done. Destroy their infrastructure? Cut them off from medicine and healthcare? Too late. Someone already did all that. (WK 290-91)

5 Various major newspapers and TV stations still offer the text of the e-mail online, such as CNN ("Text of Ansary's E-Mail"). 
This crucial passage of the letter stands out in terms of form and poignancy. The short sentences and the anaphora of "Done" emphasize the emotional attachment and the rage which Ansary seeks to convey. This passage makes it very clear that "bombing Afghanistan" is not merely an invention of the present, nor is it merely the problem of Afghanistan itself. Rather, these lines strikingly bring Afghanistan to the forefront of the American reader's consciousness because Ansary leaves no doubt that the "Someone" who took care of the destruction leading to Afghanistan's debilitating state is the U.S. This sudden erasure of the geographic distance between the two countries appears even more drastic when Ansary flips around the direction of destruction and presents the U.S. as potential victim of its own military warfare. "What's actually on the table is Americans dying," he speculates (WK 291).

This unexpected turn to transplant a likely war in a forgotten country somewhere in the Middle East to the heart of North America becomes even more tangible for the reader when put into a global context. Ansary offers this contextualization in the fatal conclusion of his e-mail. "We're flirting with a world war between Islam and the West," he exclaims (WK 292). It is exactly this type of war that would play into the hands of Osama bin Laden, as he adds:

He [Bin Laden] really believes Islam would beat the West. It might seem ridiculous, but he figures if he can polarize the world into Islam and the West, he's got a billion soldiers. If the West wreaks a holocaust in those lands, that's a billion people with nothing left to lose; that's even better from Bin Laden's point of view. He's probably wrong - in the end the West would win, whatever that would mean - but the war would last for years and millions would die, not just theirs but ours. (WK 292)

Again, this passage is marked by the use of strong keywords which evoke lively emotions and images of war and death, such as the one of the holocaust. Particularly striking is how Ansary seeks to convince his readers that this particular war, no matter how long and dreadful, takes place under the umbrella of the larger confrontation between West and East, between America and the Middle East. This strongly highlights the significance of the geographic binary Ansary alludes to in his title. With respect to the importance of positioning oneself somewhere along the virtual pathways connecting East and West, Ansary points to the significance of different perspectives arising from different locations. It is the "point of view" that matters in speculations about life and death. What is noteworthy, however, is that Ansary in this passage clearly positions himself on the American side of the border delineating the world. When speaking of the possible victims of the war as "not just theirs but ours," he obviously includes himself as part of the American collective. Despite the agency derived from his insights as an Afghan native, the identification with the us that defines them emphasizes his American voice. 
This function as a public speaker for a political cause in the aftermath of the email becomes one of Ansary's major obligations. Yet, it is one he struggles with from the beginning. Ansary describes his rise as a public figure in the fight against anti-Afghan rhetoric in the U.S. He recalls a representative of the Northern Alliance approaching him. "You have the ear of the American media," the man tells him. "You know how to say things. We know what things must be said. Let us work together. From now on, you must be the spokesman" (WK 9). At first, Ansary does not think he is capable of fulfilling this task. "Look, I have nothing to tell people but my own small story," he replies. After a moment of hesitation, he adds: "Maybe I can help Americans see that Afghans are just human beings like anyone else. That's about all I can do." The man agrees: "That's important, too [...]," he responds (WK 10). What here appears to be a minor side effect of Ansary's spontaneous reaction to $9 / 11$, however, quickly turns out as the major focus of his existence. This transformation into a public spokesperson thus had a tremendous impact on his personal and professional life, as he later reflects. Despite his initial understatement to simply show that Afghans are "just human beings," he is very aware that the public role he plays in negotiating between two worlds is decisive. He also knows, however, that he is one of the few who have the knowledge and opportunity to do so (Ansary, Home page).

Read from the background of the e-mail, it quickly unfolds that Ansary's "small story" is of much more social and political significance than the reader might think at first. The self-positioning of Ansary in the opening lines of the memoir points to the authenticity which he seeks to claim from the very start. Although he describes the circumstances leading to his status as a public figure as more or less coincidental, this depiction leaves no doubt that he is a well-known opinion leader who managed to raise public awareness in unprecented ways. As one critic put it, the email "was powerful stuff, to be sure. And it had an impact" (Nichols). Due to this strong association with his political impact, Ansary does not evoke any expectations on the part of the reader to find a semi-fictional tale about the author's life. Rather, the integration of the e-mail in the memoir, as well as the diary-like recollection of his life in the days of 9/11, point to the overall aim of the narrative as authentic and truthful record. This record is embedded in the political and social trajectories of his time. Ansary presents seemingly familiar arguments of terrorism and fundamentalism to his audience in order to quickly reverse them and move them onto American ground by means of powerful words.

This pathbreaking role of Ansary's e-mail for his reputation as a political voice, however, should not be confused with his autobiographical intentions. As he decisively claims, the "memoir" must not be seen as a "follower" of the e-mail (Interview with Menten). Ansary here insists on using the term memoir to refer to his book to clearly separate it from his public role. His earlier announcement to tell his personal story from where he is standing puts particular stress on the fact that he 
speaks for himself in the memoir, not for a collective. Nevertheless, this emphasis on personal perspective does not limit his aim to make a larger discursive impact on the way in which Afghanistan, the Afghan people, and the Arab world at large are seen and interpreted. On the contrary, the fact that such a task requires an authentic insider view even adds to his agency as a public figure. Above all, this agency is underscored by Ansary's multi-cultural identity.

\section{Arab Afghan Authenticity}

As the subtitle of Ansary's memoir emphasizes, the story of Afghanistan conveyed on the pages hidden by the book cover is not the account of an embedded American journalist in the war in Afghanistan, neither is it the one-sided account of an Afghan spokesperson trying to draw a counter-image to the public media frenzy. As the subheading states, the reader will find "An Afghan American Story." This dual identity directly draws attention to the binary contrast between East and West as conveyed by the title. Similar to this geographic opposition, the emphasis on multicultural identity also from the beginning positions Ansary in a space in-between, which nevertheless allows the author to be in touch with both worlds (Fritsch-alAlaoui 23). Instead of focusing on this aspect of multi-ethnic identity negotiation as main subject of the life narrative, as previous research on ethnic writing might suggest (Abdelrazek 124; Majaj, "Arab-American Literature Today" 129; Hatem 382), Ansary employs ethnic hybridity ${ }^{6}$ for a larger autobiographical purpose. To him, his Arab American identity only becomes a helpful means to pursue his aim of changing the frames surrounding Afghan identity.

"For many years, my siblings and I thought we were the only Afghans in America" (WK 1). These are the opening words of Ansary's actual narrative following his highly political prologue. Right from the beginning, he draws attention to the message that an Afghan speaks based on his life experience in America. This alternation between the worlds of America and Afghanistan, between West and East, becomes a permanent narrative lens throughout the memoir. Ansary's bi-cultural

6 The concept of hybridity has become extremely popular in contemporary postcolonial research and in Cultural Studies. Hybridity according to its etymology describes an "amalgam" combining different elements which lose their individual entity and consequently form an "indistinguishable whole" (Rapport and Dawson qtd. in Abdelrazek 171; Fadda-Conrey, "Arab American Literature" 202). The concept is often used alongside the term hyphenation. Since hybridity, however, is linked to the complete erasure of borders, this conceptional equation of both terms poses severe theoretical problems (S. Schmidt, "Arabian Dance" 62). Ansary's identity struggle points to these shortages since interior borders remain prevalent, no matter how much cultural adaptation blends different ethnic predispositions. Hybridity as the disappearance of all borders is therefore hard to achieve. 
voice is based on the history of his parents, a past which endowed the children of the family with an exceptional status. His American mother met his father in Chicago, as he recalls, "where the Afghan government had sent him to acquire Western knowledge" ( $W K$ 20). With this educational task, his father continued a tradition started by one of his brothers who previously had won one of the first scholarships "to a university in the West" (WK 21). This importance of intellectual skills acquired in "the West" also gets reflected in Ansary's own life. Following the example of his uncle who "was the first Ansary and one of the first Afghans of nonroyal blood to study in the West [...]" (WK 33) and who "attended conferences in the West" (WK 34), Ansary comes to pursue a similar path.

When recalling the history of his education, Ansary at first focuses on his American identity. Especially during his childhood, this posed a cultural burden on him. Since his mother dressed the children in "American clothes," he felt quite uncomfortable in the Afghan school environment (WK 45). In addition, the difficulty of not speaking Farsi placed him as an "obvious foreigner in the class," as he painfully remembers ( $W K 52$ ). This changes when the family moves to "American Lashkargah", (WK 62), a city inhabited by many Afghan Americans - "people like us," Ansary recalls (WK 66). Here, Ansary feels secure with his American identity and the American part of Lashkargah becomes the children's "world" (WK 67). Although the young Ansary can play with his American friends and engage in teenage activities, there remains a gap between his American peers and himself.

Ansary remembers a scene at a youth clubhouse where the young boys supposedly had "sex," which to him sounded "intriguingly American" (WK 67), Ansary is not allowed to enter. "'Don't let those dirty Afghans in here!"” the boys exclaim. "I was shocked and confused," Ansary describes his reaction, "not just that he was calling Afghans dirty but that he was calling us Afghans. After all, among the Afghans, we were Americans; so if we weren't Americans, either, what were we?" (WK 67). In the memoir, this question becomes a rhetorical one and Ansary answers it by stating that the family members "remained Americans with an asterisk" (WK 67). Even the strong impact of his mother and her teaching of the American curriculum cannot change this torn identity (WK 68-69). "I always felt like an American wanna-be," Ansary utters in his reflection on life in American Lashkargah (WK 72). At least when learning how to kiss and do "teen stuff," he feels a little more American. "Such, then, was the American half of my divided life," he summarizes ( $W K 77)$.

7 Lashkargah is a city in southern Afghanistan. The name literally means "army barracks" which were installed in the region thousand years ago. In the 1950s, Lashkargah then became the headquarters of American engineers involved in irrigation development projects. The city therefore was largely built according to the American architectural model with brick houses and tree-lined streets (Grey 19). 
All these detailed recollections of a life between two identities, between two educational systems, put strong emphasis on the claim that the author knows both worlds very well. They strongly underline Ansary's bi-cultural authenticity. At the same time, however, his childhood experiences and the rejection he faced by both, Americans and Afghans, also underline that this two-sided perspective continues to be challenged. This urge to position oneself on only one end of the multi-cultural identity spectrum, though, is not only the product of outside pressure Ansary clarifies. Rather, he finds that there is an inner need to unambiguously identify onself:

Two systems. The mind cannot contain both as legitimate. Thats my testimony. When you're in the two worlds so different, your mind is forced to say that one is legitimate and the other is a crock. My mind chose the Americans [sic] ethos as legitimate. Why? Because it promised more fun? I don't know. I do know, however, that on this issue of sex, Afghanistan and I parted ways. And parting ways on this, we parted ways on everything. (WK 91-92)

These lines highlight that a life in-between "two worlds" in Ansary's case was not a durable solution. The word "testimony" here puts particular emphasis on the inner conviction Ansary expresses in this passage. Even more noteworthy, however, is the effect these lines have on the American reader. Above all, this is a turning point in the memoir where Ansary deomonstrates to the American reader that he departed from his Afghan identity. In other words, he shifted from East to West. This mental change of location is underlined by the physical relocation he recalls next when referring to his high school life in the U.S.

When the school applications arrive in the family's mail box in Afghanistan, the dream of going to America awakens in Ansary. To him, America is not just a single country, it is part of a different mindset, "that charmed otherworld, the West" (WK 93). It does not take long and he indeed finds himself at the embassy preparing for the family's emigration to this "otherworld." Since his mother never lost her American citizenship, the legal procedure is fairly easy which makes Ansary happily conclude: "We were Americans after all!" (WK 94). This "American" family thus soon returns to its origins and in Ansary this also evokes the hope that his dual identity struggle will come to an end in the U.S. "The next thing I knew, we were landing in Tehran and our journey to the West had truly begun. Soon I would be relieved of the discomforts of a divided self, free to roam the world as just one person: Tamim Ansary, American guy" (WK 97).

This emphasis on Ansary's longing to fully become and feel American certainly increases his credibility in the eyes of the American readership. He thus aims to underscore his authenticity by demonstrating that he as an Arab American not only knows about both worlds of East and West, but he is also aware of the mutual longing of these worlds to reduce the complexity of this dualism to one part - by either identifying as American or Afghan. This continuous negotiation process remains 
part of Ansary's entire life in America. What also remains fairly stable is his leaning toward the American side. This becomes particularly obvious when he describes his feelings from a later period in his life. Upon moving to San Francisco, he remembers that "my life became splendidly American" (WK 103). What exactly this means, he reveals in the sentences that follow by enumerating almost stereotypical features of American life, such as having a good job, making money, and going on plenty of dates.

Critics reading this narrative merely alongside other examples of ethnic life writing could point to the fact that the identity negotiation described by Ansary constitutes the major theme of the memoir. When applying the model of framing to the dynamics of the book, however, a different pattern starts to unfold. Ansary with his continuous emphasis on American and Afghan identity, especially at the beginning of the narrative, above all builds up multi-ethnic authenticity. This aspect continues to be reiterated throughout the book, whereby the author places strong emphasis on the binary of East and West. This indicates the strong influence of the familiar Orientalist binary for Ansary's own memory recollection. This multi-ethnic identity negotiation sets the stage for gaining further credibility on the part of the reader, which is a necessary condition for the creation of alternative frames of interpretation. Ansary's legitimacy, however, does not only rest on his multi-ethnic identity status. Rather, it is furthermore strengthened by his journalistic profession.

\section{Journalistic Agency}

West of Kabul is not only the story of a man negotiating his personal life. It is also the account of a writer finding his path in his profession as a journalist. Writing, in turn, not only constitutes an important theme in the memoir, it also allows for detailed insights into the writing process of a memoir at large. Ansary throughout the narrative pays close attention to the mediatic environment surrounding his life. Just like this life is shaped by the alternation between two worlds, the media and reality often present alternative rather than complimentary truths. Ansary's professional ability to disentangle but also participate in these mediated realities endows him with additional agency to frame his life story.

At the time of his birth, Afghanistan still lacked the means of modern mass communication. These "ancient" structures Ansary recalls were marked by the circumstance that Afghanistan had "no media except rumors, storytelling, and the word of travelers passing through" ( $W K 15$ ). Storytelling and travel become major components of Ansary's own life as a sojourner between the worlds. Instead of watching television, the relatives spend hours exchanging family stories ( $W K 27$ ). "Endlessly, we told and retold our family stories, honing them into folklore, absorbing them into the soil from which grew our greater self, the tree of which we were 
just the buds, the leaves, the branches" (WK 41). Ansary links his attachment to these stories to his reading ability. "I think I had learned to read because I had such a hunger for stories," he explains ( $W K$ 27). Every new experience and impression he encounters in real life thus becomes added to the register of stories he knows from home, e.g., tales of religious figures and of God. These accounts represent "remarkable stories of an enormous fellow who watched us from the sky," he recalls his magic childhood memories ( $W K$ 60). As he underlines, however, learning about faith to him was not the most important part of storytelling. What mattered most to him was learning as such and the related quest to get beyond storytelling. "I wanted to know what was true," he underlines (WK 60).

These childhood memories of Ansary and his deep attachment to storytelling in a world which lacked the modern means of televised entertainment demonstrate Ansary's close attention to the way in which discursive trajectories shape one's life. Throughout the narrative, storytelling thus becomes a theoretical lens through which Ansary looks at his life while sharing this perspective with the reader. In tracing the process and meaning of storytelling in his own life and in society at large, he puts particular emphasis on the cultural distinction between Afghanistan and the U.S. The importance of storytelling as a deep-rooted Afghan tradition is thus indirectly juxtaposed to the lack of such an oral culture in the U.S. At the same time, this appreciation of narration reverses the common misbelief that life narrative constitutes an inherently Western tradition ( $W K 41)$. Ansary thus displays a comprehensive concern for the genre of memoir at large, which exceeds the borders of his own life narrative. He describes this fascination with the underlying trajectories of life writing in an interview:

The role of memoir and of memory in general is something that I think is very important. It's my view that you find the meaning of your life in the arc that unfolds as you live. I am very interested in pushing this view here in America, because I think the opposite point of view has a great hold on the American imagination, which is that the past doesn't matter - you don't need to think about it; just start from here and go towards tomorrow. My view is so strongly [sic] that there is no "right here" without the past, and that remembering and finding the patterns and meaning of the past is very much not the same thing as living in the past. It's an attempt to find the meaningful pattern in what you're doing and where you are going. (Interview with Menten)

Ansary in this interview very clearly addresses the different approaches toward past and present which separate the "American imagination" from life concepts persisting in other parts of the world. On the one hand, he clearly locates himself "here in America" in this statement. As he also higlights, though, his mindset and ultimately his approach to memory writing are centered in a different cultural tradition. Read from the background of the narrative tradition he comes from, this insepara- 
bility of the past from the present in the search for meaning stands in contrast to the Western ideals of progress and constant modernization.

The detailed reflection on Eastern and Western narrative traditions also leads Ansary to dig deeper into questions related to truth and memory reconstruction. When trying to remember one of his best friends Jeff, he is only able to recollect bits and pieces. Instead of conscious and detailed memory, he finds himself "in that state of almost remembering" and adds: "I capture flickers of strange, deep, dreamlike emotions and prehistoric imagery [...]" (WK 43). Despite his obvious awareness of the fluidity and futility of human memory and narrative construction, he nevertheless believes in the ultimate truth hidden in it. The search and intensive thematization of truth finding thus constitutes an important issue in the life narrative. In addition to his journalistic quest for truthful storytelling, several incidents in his personal life cause him to engage with the issue of truth telling and memory reconstruction. A striking instance in this context occurs toward the end of his story. In a fight with his brother Riaz which ultimately leads to their irreversible separation, Ansary again is reminded of the liability of human memory. "Sometimes a bad experience acts like a flashbulb, puts a harsh glare on memory," he ponders while still adhering to his overall goal of authentic memory writing. "But I don't think I'm falsifying or exaggerating," he thus adds ( $W K 255$ ). This strong and sometimes paradoxical emphasis on the truth of memory despite its constructed nature, which has so much shaped the history of autobiography research, therefore also comes to permeate the life story of Ansary. The climax of this paradox is depicted on one of the last pages of the narrative, on which the author insists that "whatever shapeshifting my narrative has gone through, the accident of history that gave me a divided soul has always been the original fact" (WK 282).

Eventually, this interest in revealing the truth and his fascination in writing served as major motivations for Ansary to become a journalist, as he later reveals. While living as a hippie in Portland, he just "wanted to be a writer," he recalls, but ends up editing a newspaper, which ultimately leads him into the field of journalism (WK 102). Obviously, this seeming frustration with the course of his career underlines that writing is a nuanced task. Being merely a journalist and being a "writer" obviously are two different things for him. This does not stop him from plunging into his journalistic life, however, which he masters with increasing success.

This detailed tracing of his development as a professional writer demonstrates the nuanced meaning Ansary ascribes to writing and storytelling in a larger sense. This aspect gains special importance with respect to the relationship to his father who remained in Afghanistan when the family went to the U.S. Writing in this case becomes the major means of attachment between father and son. Strikingly, this bond gains further impetus only after the death of the father and during the process of mourning ( $W K$ 240). On the plane returning from his father's funeral, Ansary takes out a poem his father had once written to him and which he previously never 
paid due respect to, partly because it is written in Farsi (WK 244). When he reads it again, however, this experience gains an almost revelational dimension:

Translating my father's poem became my way of getting to know his mind. Too bad I started after he was dead. But you know what? A relationship doesn't end with death. It doesn't even stop growing. I have discovered that my father's thoughts and works and spirit permeate my life. I continue to learn more about him as I ponder his narrative and meet people who knew him. (WK 246-47)

This very emotional description of the role writing and storytelling come to play in the relationship between father and son is exemplary of the status these themes gain in the life of Ansary and hence, also in his life narrative. As a journalist, writing is his instrument to constantly get to the bottom of things, to reveal their true nature and continue to learn and teach, just like the poem made him learn about his father. Read alongside his dual ethnic identity, the detailed engagement with the power of writing underlines Ansary's ultimate aim to interfere in public discourse. His profession as a journalist allows him to do so. Armed with the legitimacy of a truthful writer, he constantly reminds his readers that he conveys more than fictional stories. Instead he reframes the public image of Afghanistan on the basis of his authentic accounts from a different world standing in sharp contrast to the media images.

\subsection{Reframing the Muslim Fundamentalist ( $\mathbf{V}_{2}$ And $\mathbf{V}_{3}$ )}

\section{The Religious Frame}

But I had grown up in the most purely Islamic society of modern times, and I had never heard of a hand being chopped off, a tongue being ripped out, or an adulterer being stoned. I wondered if I might not break into a career as a macho journalist by traveling through the Islamic world and writing the real story of Islam. (WK 108)

At the outset of his journey to the Middle East, Ansary is deeply aware of the frame surrounding the definition of the Afghan as barbaric Other and adherent of ancient rules of punishment. As Ansary reveals in these lines, these notions are closely intertwined with religious images. "In the West, indeed, most people had only the vaguest notions of Islam itself, and the papers were full of articles purporting to 'educate' the public about this religion," Ansary explains (WK 108). Consequently, he turns this shortcoming into a personal calling and decides to "educate" the public from his point of view - from the perspective of one who "had grown up" in this society. He does so under the camouflage of a supposed "macho journalist." This 
macho journalist, however, has no easier goal than revealing the "real story of Islam." Obviously, this story stands in diametrical opposition to the story of the Arab world and its religion depicted in the media. Ansary therefore does not write a newspaper article to pursue his quest. The truth he wants to unfold requires his own small story in the form of his memoir as a means to reframe the image of the Afghan fundamentalist. This story begins with a journey to his past and its religion.

Ansary introduces the issue frame of religion by drawing on his family past. "But ever since, Islam has been divided into the Shiite Muslims, who backed Ali, and the Sunni Muslims, who backed the first three khalifahs," he explains. "My family were Sunnis, as are most Afghans" (WK 51). The family, though, is all but united when it comes to the matter of faith. While the majority of family members do not seem to put great emphasis on religious practice as such, his brother Riaz represents an exception. His religious devotion continuously increases to the result that he undertakes a spiritual and literal journey to Pakistan where he converts to orthodox Islam (WK 117). This step, however, does not remain a matter of personal faith but has lasting consequences for the two brothers. Their otherwise close relationship comes to a sudden halt at a religious scene which Ansary remembers very vividly: the killing of a lamb.

Ansary visits his newly converted brother at a local halal farm in Maryland. Here, he witnesses the slaughtering of a lamb carried out by his brother who mumbles the traditional Qur'anic verses during the ritual (WK 119-20). In Ansary, the orthodoxy and fierceness with which his brother pursues his religion raises critique. He shares his doubts with Riaz and tells him that in his opinion, Islam due to its insistence on strict rules and absolute devotion does not advocate an integrative approach to humanity: "If this is what God demands," he asks Riaz, "most of humanity is going to be excluded. How can that possibly be right?" (WK 122). His brother's reply denies the fatalism perceived by Ansary: "To me, Islam points out a middle path between self-denial to the point of abuse and self-indulgent chasing after glitter and ostentation. Accepting Islam doesn't mean forsaking the world; it just changes the focus. The acts of living take on a meaning of which they are bereft in a materialist framework," Riaz explains (WK 122).

The recollection of this conversation with his brother Riaz marks a key passage in Ansary's thematic framing of the narrative. In contradistinction to merely talking about religion, as is the practice of the media and experts around the globe, Ansary lets those speak who represent this religion, in this case his brother. As a counterpole to this view, Ansary employs his own voice to raise doubts as they are often found by critics of Islam. These doubts are the popular ones ruling in the West as consequence of the intensive religious media framing of Arab and Muslim affairs. The perceived fatalism of Islam and the seemingly submissive devotion of Muslims to find higher meaning in religious practice are thus juxtaposed to the materialism and rationalism presiding in the U.S. Usually, this contrast is presented based on the 
superior view of the Western secular audience mocking the primitivism of Islam. Ansary, however, does not allow his voice to dominate the one of his brother by means of Western paternalism. Rather, the reader is given the chance to directly learn from the believer. The impact of this immediate exchange between religious insider and outsider gets highlighted by Ansary's own experience, as he starts being caught up by the way in which his brother pursues his religion. When he joins Riaz in his prayers, he starts feeling a degree of closeness and even physical tension toward the Qur' an which he had not known before. Suddenly, he even remembers verses he had learned in school. In this moment of enormous religious tension, an idea emerges in his mind concerning his trip to the Middle East: "Instead of telling people I was a writer looking for a story, I would tell them I was a lapsed Muslim looking for his roots. That might get people to open up more. I would learn a few verses from Riaz's Koran, so as to put the story across more effectively" (WK 123).

With this decision in mind and with his intention to write "the true story of Islam," Ansary endows his entire journey with a religious frame. At first, however, this religious motivation for his trip appears rather superficial. After all, Ansary consciously instrumentalizes religion and Muslim identity to pursue his journalistic interest. This attitude then quickly starts to change as soon as he finds himself in an Islamic environment. In Tangier, his first destination, Ansary walks around telling people he wants to learn about Islam to find his own religious roots. What starts out with a false pretense thus soon turns into an unexpectedly serious endeavor for Ansary as he gradually learns how much meaning these "religious roots" have in his life. Everyone he meets is willing to talk about religion and what previously seemed like a lie to himself, such as the story of his birth as a Muslim and his childhood in Afghanistan, suddenly becomes part of Ansary's present life. His past and whatever fictional pretense Ansary added to pursue his truth-telling task turn into immediate reality. "And I got my cover story out with less compunction than I had feared, because it was so close to the truth. So close that I felt my psyche leaning out of myself to hear their answers - almost as if I had a personal interest in this issue and not merely a journalist's curiosity" (WK 130).

As these lines emphasize, Ansary gets more and more drawn into the world of Islam, a religion that indeed constitutes an important part of his own past. Yet, he almost violently tries to hold on to his professional distance in his pursuit of learning and teaching about Islam in the West. Despite his increasing emotional entanglement with his religious origins, Ansary does not give up on this knowledge project. Wherever suitable, he provides information on important religious practices by means of contrasting them to Christian customs. Anyone not familiar with the Muslim faith can therefore easily learn about major differences. An example of this narrative strategy occurs in a passage in which Ansary recalls his conversation with an acquaintance from Morocco. He asks the latter about the role of religion in the Qaddafi regime. The Moroccan man pauses for a moment and then emphasizes that 
Khomeini is a Shiite. This allows Ansary to almost unnoticeably add further information on Islam. "Shiism and Sunnism are the two main branches of Islam, as I mentioned earlier, and Moroccans are Sunnis. It reminded me of a talk show I'd heard once in America, about whether Catholics could be considered Christians," he remembers ( $W K 131)$. This passage serves as another example of the way in which Ansary gives voice to the people who do not have a voice in the public media discourse. Instead of simply pointing to contrasts in their attitudes and religious beliefs, Ansary clings to his task of "teaching" by putting emphasis on detailed information. Mentioning the "talk show" he once saw concerning the challenged view of Catholics immediately points to the close connection between the media discourse on religion and the detailed religious knowledge Ansary seeks to convey. In addition, this parallel opens up a bridge of understanding to his American audience. Next to clarifying what the two branches of Islam are, he also allows his readers to identify with these different denominations by alluding to the similar debate taking place on Christianity in America. This move signals that the term Muslim offers far more complexity than is commonly assumed. Furthermore, it highlights that Muslim does not equal fundamentalist after all.

The task of erasing the image of the Muslim as monolithic other continues to occupy the author on his journey. Ansary carefully describes his observations of differences among Muslims. Some Muslims are rather "lax" in their pursuit of religious ideals but try hard to "be better," he learns (WK 131). Other Muslims Ansary meets consider themselves "true" Muslims who carefully follow the rules of their faith ( $W K$ 132). When he is invited to take part in the prayers, he accurately watches the rituals and learns about religious dress (WK 133). In doing so, he remains the interested outsider learning about a religious world which he is not familiar with in detail. When his Moroccan hosts talks about the obligation of a Muslim to guide his family in finding the "sunna of the Prophet," Ansary ingenuously asks; "is that different from the sharia?" (WK 134). "Yes," the Moroccan man replies, the "sunna is the way the Prophet lived his life. God gave us the sunna of the Prophet as an example," he explicates (WK 134). Especially the Muslisms in Europe, he then states, have turned away from this path which makes them "careless" (WK 135).

This encounter with praying Muslims marks another striking example of how Ansary makes his readership join in on a virtual trip to explore a religion which the American public in particular is not familiar with. Ansary does so in a very detailed manner by conveying much information without, however, displaying the mentality of a textbook lecture on Islam written by self-declared cultural insiders. Rather, he insists on his own outsider status and lack of knowledge of Islam, despite his childhood in a Muslim environment. He thus functions as a mediator absorbing and conveying the information he gains from others. Repeatedly, Ansary does not speak for the Muslims he meets but lets them speak by replicating their points of view in direct speech. Just like Ansary, the reader thus becomes a traveler and student while 
learning about Islam. The result of the multitude of information is a complex and multi-layered picture of Muslim identity and Islam as a whole. This complexity is mediated by Ansary and therefore easier to grasp for the reader, since he repeatedly employs the method of comparing multiple perspectives on Islam as they circulate in the public media discourse.

This contradiction between outside stereotype and insider knowledge, between media frame and the interpretative frame based on detailed knowledge, is strongly highlighted in the words uttered by one of Ansary's further acquaintances named Abdullah. "In the West," the latter states, "people picture a Muslim as a fat rich guy lolling on cushions" (WK 136). A comment like this one from a man Ansary randomly meets in the streets of Cairo provokingly presents a mirror to the face of the American audience. As the multitude of research on stereotypical representations of Arabs shows, the image Abdullah draws indeed depicts the way in which Americans and other Westerners think about Muslims. Even more important than the mirroring of this stereotypical image itself is the fact that it is uttered by someone who usually only appears as a stereotype in the public discourse. The strong voice of Abdullah thus additionally scatters the picture of the Third World barbarian who does not know about world affairs because he lacks access to modern means of mass communication. All these myths about the supposedly backward and, from the Western perspective, simple-minded Middle Easterner, are at once destroyed by the obvious awareness Abdullah displays of the global media discourse.

Ansary's own reaction to all these experiences is one of confusion. He realizes that he was at least close to counting among those imagining the Muslim as "fat rich guy lolling on cushions." The complexity of Muslim identity surprises him and it makes him feel uneasy to write his true story of Islam. Consequently, his devout attachment to the notion of absolute truth starts to shatter. The images he sees in the streets of Tunisia and Morrocco do not conform to a clear image of either the "good" or the "bad" Muslim. The Muslims he talked to did say they believed in God, yet, they also disobeyed the rules of the Qur'an by drinking or not following the prayer rituals. Ansary tries to make sense of his observations by enforcing an explanation. He then arrives at the following preliminary conclusion: "I had already decided what was true: the people had turned to Islam out of poverty and desperation" (WK 143). Again, the ideal of finding ultimate and simplified truth here becomes very obvious. Ansary, however, also becomes aware of this dilemma. He pauses upon catching himself making judgements he could have made without ever leaving the U.S. "Was I not merely trying to recast the whole situation in materialist terms," he asks himself ( $W K$ 143). As his growing self-criticism reveals, Ansary starts questioning not only the conclusions he arrives at but also the overarching thought patterns which lead to these prejudgemental conclusions. Slowly, a sense of ethnocentrism emerges based on the finding that his mostly American upbringing has taught him to prefer materialistic interpretations over the willingness to accept 
the faith of Muslims as immaterial value ( $W K$ 144). This allusion to financial desperation as source of religious fervor also strongly underlines the binary division of the world into a rich West and a poor East.

Instead of giving in to his own prejudices or giving up on his project to write the story of Islam, Ansary is eager to collect more knowledge and information. To him, this seems to be the only way to eliminate the confusion between previous frames of interpretation and the reality he faces in the Arab world. Ansary then starts reading an intellectual history of Islam by a Pakistani scholar and shares this reading process with his own readers by providing long elaborations on the history of Islam, the different religious and doctrinal disputes, and the role of religious ideology in the context of politics (WK 145-48). ${ }^{8}$ At the end of this in-depth recapitulation of Islamic history, Ansary provides his personal summary of the book:

Jews put the coming of the Messiah in the future. Christians seek individual salvation by accepting Jesus as a personal savior. Islam, however, focuses on the first Muslim community as the core religious fact. It proclaims that the truth about human history was incarnated in a historical moment, from which we'we been receding ever since. Throughout the centuries, therefore, renewal movements in Islam have tended to look backward, have tended to preach the doctrine of getting back to the way it was. (WK 149)

Contrary to providing a conclusive overview of the details of Islamic history, Ansary here provides a comparative summary of the history of all major religions. He especially highlights the major differences of these religions with respect to their understanding of salvation. Exactly by pointing to these differences, he reveals their commonalties in their longing for a state of coherence and salvation. In particular, Ansary's stressing of religious renewal movements read from the background of Islamic history completely counters the view of Islam as ancient and barbaric custom. Rather, he presents the Islamic conception of progress as a logical step following history to constantly reinvent and renew Islam in a way which his American audience can directly compare to the other religions thus enumerated.

Ansary's religious quest continues as he makes his way to Tunisia. Here, he is given a religious teaching by a molluk, a function similar to the one of a mullah, as he explains. "I will tell you about Islam," the molluk begins. "It is the law of the universe, and not just for Muslims. It is the law that establishes the reason for the

8 Ansary spends much time on explaining the role of the Mu'tazilites and their conservative influence on Islam (WK 149). The Mu'tazilite ideological school defends the notion that the teachings of God are accessible to rational thought and empirical inquiry because knowledge is derived from reason and thus functions as the ultimate authority to distinguish right from wrong (Stroumsa 289). This is particularly interesting when read in the context of Ansary's own adherence to the concept of absolute truth. 
feminine and the reason for the masculine. It is the law that describes for each its duties, for each its place" (WK 179). From Ansary's previous comments on the separation of the sexes in Islam, the reader is aware that he is not in favor of this concept. Despite this preconceived judgement, however, this religious lesson makes him consider various dimensions of Islam anew. He moves away from his intense preoccupation with the historical origins of the faith and its practices and starts pondering its social and ultimately political dimension.

After making his way to Tunisia, Algeria, and ultimately Turkey, this social dimension of Islam gains particular significance in the chapter "The True Believer" (WK 209). It opens up with Ansary walking into a bookstore in Istanbul carrying English language books. Here, he makes an unanticipated encounter with a man he describes has having "a coal black beard and shining dark eyes and a dark complexion [...]" (WK 210). He is struck when the man in "perfect English" tells him his name is Abdul Qayum (WK 210). Ansary in obvious surprise and excitement exclaims: "You're American." Abdul simply counters: "Not anymore [...], [n]ow I am a Muslim" (WK 210). Following this somewhat surprising introduction, the two then engage in an in-depth discussion of what being a Muslim means to Abdul. Amongst other things, this also involves being part of a Muslim brotherhood for Abdul. "That's how it is," he explains to Ansary, "once you become a Muslim. Everywhere you go, you find community" (WK 211). The conversation then continues to focus on the rights linked to the Muslim community, such as the freedom from tyranny and the legal code of the sharia (WK 214). Ansary tells Abdul, "that's what people have trouble with," and reminds him of the American viewpoint of religious law (WK 214). Abdul in turn proclaims that this law is "much more than a legal system." Rather, punishment and behavior correction are seen as "markers" showing the right direction to becoming a good Muslim. Ultimately, Abdul tries to convince Ansary that Islam is more than a religion, it implies the idea of a "Muslim world" based on the "social project of Islam" (WK 213). Here, a "good Muslim" above all longs to attain "quality of the heart" (WK 215).

The long conversation with Abdul opens up completely new insights into Islam for Ansary. Not only is he able to gain more information on sharia law and its definition by a Muslim himself. In addition, Ansary learns about the comprehensive influence of Islam as guideline for daily life and for the social and political realm as linked to rights and liberties. It is a very community-oriented view of Islam which Abdul depicts. All these components do not coincide with the traditional notion of sharia law eminent in the Western public, Ansary reveals in the conversation. Most important in this further session of religious teaching is the fact that Abdul represents what Ansary himself hardly believes in the beginning: an American Muslim who now considers himself Muslim and not American anymore. For Abdul, this dominance of his religious over his national and cultural identity points to the incommensurateness of both realms which rely on very different value systems. His 
emphasis on the ideal of being a "good Muslim" underscores this understanding. With respect to the effect this has on the American perspective, Abdul as American Muslim again shatters the simplified picture of the Muslim fundamentalist. Ansary's own stereotypical description of Abdul's complexion at the outset of their conversation highlights this frame. This is an Arab in a "business suit that looked expensive" who then turns out to have abandoned his American citizenship, Ansary illustrates (WK 210). Nevertheless, the outside appearance of this Muslim and his interior values do not stand in such a sharp contrast, after all, although he insists on his Muslim identity. Based on his authentic and honest depiction of Islam and the social ideals attached to it, he is able to unite pre-assumed dichotomies by showing that Islam shares many ideals with American views on nationalism, the belief in democracy, law, and justice.

Despite the decisive knowledge Ansary gains in his encounters, the conflict between his former frame of interpretation and the reality he meets exceeds his ability to cope with these binaries. After the meeting with Abdul, he tries to turn away from his religious project altogether, abandons his books, and instead turns toward reading Odyssey $^{9}$ (WK 216). His efforts of diversion, however, are not successful. Religion, as an overarching framework for looking at the countries of the Middle East he visits, continues to haunt him. The climax of the religious impact on his personal life appears in the context of his brother. The idea of Islam as "social project" thus unexpectedly turns into a very personal project, since it becomes the dividing line between him and Riaz. The clash between them occurs when Riaz sends him a book that outlines the very ideas which Abdul formerly described to him upon their meeting ( $W K$ 254). Ansary reads the Islamic project his brother imagines along political lines. The fact that Ansary has meanwhile become married to his wife Debby, who is Jewish, complicates the matter. The Palestine conflict thus turns into a conflict separating the two brothers irreversibly when Ansary discovers that the book his brother sent him contains references to literature denying the existence of "real Jews" by replacing them with "fake Jews" (WK 257). In light of Ansary's newly gained knowledge about religion and particularly Islam, these thoughts go too far. The following passage describes the conclusion he draws after intensely engaging in his religious analysis:

As I reckon it, Muslims and Jews have no serious quarrel on theological grounds. Original Islam saw Muslims, Jews, and Christians as cousins nourished by a single message. Islam accepts Christ, David, Moses, and all the Judaic prophets and patriarchs as 'messengers.' In

9 The fact that Homer's Odyssey counts as one if not the classic of high Western culture heavily underscores the contrast to the literature on Islam as Eastern philosophy, which Ansary is now seeking to escape from. 
light of this tenet, how can Muslims deny Jewish claims to a homeland in Palestine? (WK 257-58)

Since the only answer the books provide to this question is that "Israel was peopled by fake Jews, and therefore could be regarded without heresy as Satan's beachhead in the Muslim world," Ansary loses his patience with religious openness. He cannot understand how political fanaticism and nationalism can destroy the common religious grounds uniting Muslims, Christians, and Jews. His willingness to accept contrasting views in this respect reaches a dead end and he distances himself from Islam as well as from his brother ( $W K 258)$.

These passages on Islam as a social project and the latter's very personal impact on Ansary's family life open up yet another facet of the religious frame in the memoir. The topic of the Palestine conflict and its religious justification above all point to the omnipresence of the political conflict frame. Here, however, this conflict is not presented in the manner of CNN headlines standing in the tradition of a Zionist news frame which the American public is well familiar with. Instead, these ideological quarrels move to the background of perception, as Ansary is forced to reflect on the issue on a very personal level. He carefully traces the line of arguments based on the knowledge of religious history he has gained. This also leads him to a very thorough recapitulation of the meaning of knowledge and truth itself. Ansary delineates the way in which the religious "war between believers and unbelievers" is presented in the books he is reading ( $W K 259)$ :

It sounds like something only a few scattered loonies could find convincing, right? Well, I, don't know. What alarmed me was the internal coherence. Every plank supported every other plank. Once you're inside such a house, you can never get another message from the outside world. The windows are all mirrors, and the house can reshape every incoming piece of information into another beam in its own framework. (WK 258)

This passage obviously recalls the trajectories of religious fanaticism in a very metaphorical and striking way. The particular relevance of these lines, however, exceeds the issue of religion itself. Ansary here thoroughly demonstrates how obviously outlandish arguments can be presented in such a way that their logical coherence is striking. This mechanism is not restricted to the religious realm but rather depicts the logic of ideology at large. Especially to the American reader, Ansary's meta-analysis of the trajectories accompanying religious arguments provides a different explanation as to why religious fundamentalists actually deny Israel the right of existence. The focus on logic here is crucial to emphasize that these people are not backward barbarians who lack the skills of rational thinking. It is exactly the logic of the argument which turns them into followers. On an even more abstract level of interpretation, this careful delineation of ideological thought as interpreta- 
tive monopoly of the mind reads like a definition of framing at large. The dominance of one mode of interpretation, the reciprocal workings of arguments in the same logical vein, the denial of contrasting information - all these are crucial components of framing. This impression is strikingly confirmed by Ansary's choice of words when he explicitly refers to the trajectory he observes as "framework." Although this significance of ideological frameworks is analyzed in the context of religion and the issue of the Palestine conflict here, the reader also becomes aware that the underlying mechanism is of universal importance. The fact that not just "scattered loonies" can become trapped in this framework of thinking highlights that human beings, Muslims and Christians, Americans and Arabs, are susceptible to ideological thought patterns.

For Ansary, this very personal confrontation with Islam and the impact of religious framing, connected to the dangers resulting from it, underscores his decision to depart from his religious project. The omnipresence of the religious frame in public discourse, however, prevents this. In the course of Ansary's narration, religion gains an increasingly political connotation. This blurring of religious and political boundaries reaches its climax in the latter section of the memoir where the author reflects on the post-9/11 era and its impact as a key event on religious identity definition. The issue of religion is thus abruptly transplanted from the Arab world onto American soil. After his return to the U.S., Ansary recalls a scene in a New York taxi. When the Egyptian cab driver learns about his passenger's Afghan origin, he immediately calls him a "true Muslim [...]" 'You are the ones living the pure Islam,"” the man explains his conviction. "Thank God for the Taliban. Now at last, God will help us to sweep away all this filth [...]. I hate America [...]," the man adds (WK 275). The fervor with which the driver presents his views truly scares Ansary. 'I've heard other people say, 'I hate America,' but once I heard this man, I knew that none of them had ever really meant it," he explains his uneasiness (WK 275). Following this incident, Ansary has a different sense of the Taliban threat. By again emphasizing his knowledge of Islam, he recapitulates that the Taliban's themes indeed are in line with some original Islamic ideals of the first community. This finding eventually forces him to eliminate the artificial border in his mind between the Muslim World and America. "I had thought of the Taliban as terrible for Afghanistan," he concludes. "Now, suddenly, I saw them as a potential menace far beyond their borders" (WK 278).

This key concept of border-crossing puts a bracket around the religious frame of Ansary's account. At this point, he leaves the reader with the political reality of the present which he personally experiences as being threatened by Islam. In contrast to the average American media consumer, this conviction does not derive from a mental shortcut, as his thorough dealing with the issue of religion throughout the memoir underlines. Ansary's own lack of trust emerges after thoroughly sketching a complex and multi-faceted picture of Muslims living in different countries of the 
Arab world. He lets them speak to explain what they believe. Ansary's own Afghan American background allows him to present a balanced and self-reflective account of Muslim identity. His learning process about Islam as religion thus also becomes the one of the audience. The readers are given the opportunity to use the religious frame to add information to their image of the Muslim. Instead of being presented merely with a counter-story of the favorable Muslim pursuing his faith, they get a picture of Islam as religious but also social and political framework. Finally, the reality of the political world also leads Ansary to ponder the negative role religion plays in the Palestine conflict and the WOT. The fact that this religious frame shows a clear structure and thematic dramaturgy, for different aspects of religion are analyzed in an almost didactic way, speaks to the constructed nature of the account. Ansary starts with history and ends with the present political state of Islam just like a book on religious history would. History, however, not only plays a role in the religious framing of the memoir. History itself can be identified as the second dominant frame of Ansary's life account.

\section{The History Frame}

Ansary's journey from the past of Islam to its present position in the world motivates his trip to the Middle East. The history of religion, however, is only one reason for his journey. His preoccupation with the past and its relation to the present exceeds religious issues and turns into another frame of the account at large. "Traveling can erase everything except the present, and turn the present into a hallucination," Ansary notes (WK 184). Before the stage of hallucination is reached, though, the present becomes an exciting intellectual adventure for the author. This adventure is driven by Ansary's thorough exploration of the history of Afghanistan and its revelatory nature for the present state of the Western world as well.

From the very beginning of the account, Ansary embeds his personal memories in a very detailed historical framework. Most opening sentences in the chapters recall detailed descriptions of the political or historical circumstances surrounding a certain event or time period. This historical focus is introduced to the reader in the very first chapter of the book: "In 1948, when I was born, most of Afghanistan might as well have been living in Neolithic times. It was a world of walled villages, each one inhabited by a few large families, themselves linked in countless ways through intermarriages stretching into the dim historical memories of the eldest elders," Ansary writes (WK 16). Contrary to the stereotypical notion of memoir as "I narrative," Ansary here rather talks about the world which he was born into than merely about himself. The tone and the pictorial scenery he creates make the reader easily slip into the very historical era Ansary is describing. Again, this era is marked by severe differences to the present and to the cultural realm which Ansary 
and his readers live in. Most importantly, however, the author conveys information on two textual levels at the same time. The passage is not merely a description about the past as he records it, but a meta-depiction of the ways in which history in is recorded in much broader terms. In the Afghanistan of his childhood, oral narrative was the basis of historiography, as Ansary's mentioning of the "dim historical memories of the eldest elders" reveals.

This strong focus on history as another dominant frame in the narrative continues with Ansary's long descriptions of historical anecdotes he remembers from his childhood and their religious entanglement with Islam, the prophets, Byzantine, and different rulers of the Uman (WK 47-50). Amidst this endulgence in historical analysis, Ansary makes the following observation:

All of human history can be seen, can it not, as an argument between those who try to explode the existing forms and those who try to freeze things as they are. The second impulse always wins in the end, except it's never the end. The cosmic winner is always change, except change can never settle in as the permanent state. History is a river, except people can live only in lakes, so they dam the current and build villages by still waters - but the dam always breaks. (WK 50)

The author in this passage provides an insightful analysis of historiography and the power struggles involved in it. Human beings try to retain history, even "freeze" it; yet, they are never successful in doing so. History resists attempts of enforced stagnation, as he explains, and to a large extent writes itself. The language Ansary employs here is severely metaphorical. The dynamics of history are presented as inescapable, as the metaphor of water as uncontrollable natural force suggests.

The imagery of waters and dams, however, is not only used as a means of illustration. Instead, the landscape thus depicted is linked to the very economic and political history of Afghanistan. Ansary thus uses this passage to lead over to his narration of the specific history of the Helmland Valley in Afghanistan. As part of a larger development program, the U.S. in the 1960s funded an irrigation project in this area that is full of history, as Ansary explains. "About this land, certain stories were told, stories that went back a thousand years, to the days of the Ghaznavid Empire" (WK 55). This ancient history then becomes part of Ansary's family history as well. Due to his friendship to a high official in the Afghan government who comes to preside over the irrigation project, his father becomes promoted as the vice president of the Helmland Valley Authority. He gets chosen "out of the ranks of the Western-educated commoners," Ansary underlines the special significance of an education in the enlightened West again (WK 57). This promotion ultimately causes the family to move to Lashkargha which flourishes due to the number of American engineers living there. The water project, however, not only aims at building dams and straightening the river. In addition to these very practical aims, 
Ansary identifies a clear political rationale behind the development program, i.e., "to impose Western progress on the Afghan people [...]" (WK 69).

Just as the human attempt to control or even escape the trajectories of history can never be successful, the human intrusion into the natural path of the river turns out as failure. Ansary describes this sobering devolution of the project in his chapter "Unintended Consequences" (WK 83). Ultimately, these unintended consequences become the hallmark of an entire historical era in Afghanistan. As Ansary explains, the government-initiated irrigation project originally aimed at taming the Helmand River. The officials, however, designed the project without taking into consideration that further downstream, villagers had already invented their own irrigation systems which recognized the natural pattern of the river. The new system made this historical installation ineffective and the crops of the farmers failed. These Afghan peasants thus fell victim to "the law of unintended consequences," Ansary infers, "the one law in history you can really count on" (WK 83).

This episode about the failure of the American-aided irrigation project, when read alongside Ansary's earlier depictions of the dynamics of history, serves as a powerful example of the author's larger concern about the history of the East as written and influenced by the West. The water project failed because the West, as represented by American engineers, tried to impose its knowledge and technological skills onto an environment and a people which for centuries had succeeded in developing their own ways to nurture and sustain themselves. This life in harmony with nature and with history then comes to a sudden breakdown with the intervention of American technology. The irrigation project and the supposed ingenuity of American engineers thus serves as a metaphor of the well-known Orientalist reflex to convert barbarism into civilization by means of development, modernization, and ultimately Westernization. The fact that this project fails illustrates the historical irony of colonialism at large, though, Ansary makes it very clear that the reason is not the inability or unwillingness of the East to develop. Instead, as he points out, the Afghans were never informed about the details of the American project and therefore the "villages never knew why the river was flowing differently [...]" (WK 83). The reader, however, becomes well aware that the West failed by interfering with the natural cause of history and nature, by disrespecting historical systems of water supply, and by paternalizing the village people.

The episode of the development program is only one instance of the Western entanglement with Afghanistan Ansary recalls in his historical reflection. As he also depicts in his historical reflections, political interferences by the U.S. in the $20^{\text {th }}$ century were not limited to environmental development. Another sector of engagement was education, one of the key areas to impact the cultural capital and development of a country (Barker, Sage Dictionary 37). Again, the U.S. engagement in this context caused more conflict than common progress, Ansary remembers. One such instance was the foreign enforcement of co-education in Kandahar. The 
conservative religious leaders here got outraged over this non-traditional way of education. What followed was a bloody uprising against the "Westerners and the officials" in Kabul (WK 79). Yet, the West and particularly the Americans kept pressing their finger prints on the education system by "educating boys: Westernizing them, secularizing them, decultering them [...]," the author summarizes (WK 84). This also left marks on the architecture of the cities. When describing his first impression upon moving to Kabul, Ansary remembers that each of the "high schools had been built by a different Western country" (WK 90).

The traces of this historical intervention of the West in the political and social development of Afghanistan confirm the pattern Ansary reveals in the previous case of the irrigation project. The West interferes in a colonial manner that disregards whatever former structure and cultural custom was in place before. The main consequence this causes, as he emphasizes, is not only deculturation but violence and death on the part of those colonized (WK 79). The uprising against Western officials and the government thus turned out to be a "master plan" for those who did not know how to protect themselves differently against the foreign power. Ansary thus learns in the present that the past and mostly unsuccessful violent attempts of resistance could have brought the death of most Westerners in Lashkargah and also the death of Ansary's own family (WK 78). Despite the fact that Afghans here are depicted as violent perpetrators by the author, the nuanced illustration of the circumstances leading to bloodshed contradict the common image of Afghans as political tyrants. Rather, Ansary makes it very clear that the occupation of political violence is a result of the previous Western suppression without, however, euphemizing or even excusing political violence as such. The complexity of the depiction thus resists both the simplified image of the Eastern barbarian as well as the defensive view of suppressed colonized victimhood. Most importantly, Afghans within this historical framework of interpretation are not blind fundamentalists. They are described as reacting to the historical interference in their culture. Ansary once again reiterates these tragic trajectories toward the end of the chapter by calling them "Unintended consequences" (WK 84).

While the unintended consequences of the water project and America's attempts to co-educate Afghans took place within historically rather limited time frames, further colonial interferences encompassed much longer historical periods in the context of the Cold War. Ansary remembers the dynamics of this development very specifically. The unintended consequences deriving from the sum of foreign interventions by the U.S. in the region turned Afghanistan into the microcosm of the global confrontation of East and West. Instead of providing a detached episodic snapshot of the Cold War, as the common media practice tends to do, Ansary embeds his reflection on Soviet rule in his overall historical framework. He thus interprets the support for communism by young Afghan adherents in the military as an immediate result of the former education failure of the U.S. (WK 84). As he ex- 
plains, this military movement finally overthrows the monarchy in 1978 . The Soviet Union again has its own ideas of how to run the country. Education is one of them, and while the Americans fostered co-education, the Communists propagate "women's education," which again causes uproar among the tribes (WK 85). The result is characterized by violence and destruction. Ansary's summary in this case is marked by critical historical insight, linguistic verve, and a good portion of cynicism: "And so they rose up against the outside power in rage and fear, determined not to die, and as those clans and tribes fought for survival, their cells died like ants in a war that demolished Afghan culture and shredded the social fabric over the next twentythree years. Unintended consequences? You can count on them" (WK 85).

The rhetorical question Ansary poses here can be read as a hallmark of the method he employs in his entire historical framing of the memoir. He does not introduce any kind of preconceived evaluation as to who was the most fatal occupier in the country, either the U.S. or the Soviet Union. This normative stance would transfer the ideology of the Cold War to his own argumentation. Instead, Ansary, as in the case of the religious issue frame, connects singular historical events and points to overarching patterns of control and financial destruction which both occupiers forced onto the country. Calling the severe effects of these acts "unintentional consequences" at first seems to free the ones to blame from responsibility. Yet, the repetitive nature of the same destructive pattern of foreign control that Ansary reveals eventually sheds light on the very predictability of these "unintended consequences" if one is only willing to read and learn from history. Exactly this drawing of lessons from history, which he invites the reader to adopt, is something society has lacked in the past, as the metaphor of the broken dams in the water project again underlines. Instead of accepting and learning from history, humans still tend to forcefully change it. This seems particularly true for the most powerful actors, as Ansary demonstrates.

How quickly the unintended historical consequences of the Cold War can have very personal but similarly unintended effects Ansary learns in the context of his own trip to Afghanistan. As was the case with the religious lens through which Ansary observes the country, his engagement with history does not end at the level of distanced analysis. Right before Ansary starts his trip, the Iranian hostage crisis breaks out. He sees the pictures of students storming the embassy on TV (WK 112). This event continues to overshadow Ansary's trip and his planned route. On his way, he closely follows the international news which are full of violence. "Soviet tanks were crushing Afghanistan. Blood was running in the streets of Kabul [...]. American tourists had been stoned in Syria. American diplomats had been attacked in Egypt [...]" (WK 159). The climax of the conflict in Tehran is reached when Ansary finds himself on a train in Algiers. In this instance, the struggle between East and West culminates when he meets a group of soldiers on the train: 
The whole Islamic world was in an uproar. Just that weekend, Libyans had burned down the American embassy. Muslims triumphant; Western dogs, go home, Muslim power hooray; Yankee nothing: We spit on you, and what are you going to do about it? Fuck with us, we'll take more of you hostage. Yeah. We'll cut the heads off your so-called diplomats - your fuckin' spies. (164)

Due to his American background, Ansary here involuntarily becomes involved in the emotional outbreak of the Algerians, a clash motivated by the conflict between East and West, between the "whole Islamic world" and the rest. In this historical instance, however, there is hope for the suppressed underdog to win the struggle. The images of "Muslim power" and "Yankee nothing" reverse familiar power roles while the tension of this historical moment and possible overthrowing of a centuryold colonial order become almost tangible for Ansary. He explains the historical significance of the situation by taking the perspective of the formerly colonized as he alludes to the we/they dichotomy separating the world. "But this 'we' was bigger and more intense," he remembers. "For three centuries, the West had slowly been forcing the Muslim world to its knees, and not even noticing - that was the worst of it. Now at least - this year! this weekend! - Islam had risen again" (WK 165).

The given passage strikingly confirms the larger historical framework Ansary sets up in his memoir. This framework is deeply shaped by his awareness of the binary between East and West. In addition, his use of the term "Islamic world" points to the close entanglement of the historical frame with the religious focus Ansary pursues on his journey and in the narrative thereof. As is the case with the religious frame ruling the coverage of the Middle East in the media, the issues of religion, politics, and history also remain intertwined as Ansary pursues his literal and figurative life journey. History is never absent from any of his observations. Ansary constantly reads the present he encounters on his trip through the lens of the past and invites his readers to do so with him.

In sum, the reading of history as power struggle between East and West forms the dominant mode of interpretation. ${ }^{10}$ Instead of accepting this dichotomy as ideological legacy, Ansary's strategy to solve this very binary is detailed historical enquiry. Only this, the memoir suggests, can lift the veil of misinformation and mystery which turn history into a threat for the present. "To the untutored eye, history looks like a wriggling snake pit full of disparate but interwoven dramas; the Romans battling the Parthians, Columbus discovering America, the Industrial Revolution, World War II, etc.," Ansary explains (WK 256). With the framing of his own small story in larger historical terms, he actively works toward tutoring his

10 The clash with Ansary's brother can also be read as another instance of the strong reliance on historical interpretation. After all, it is the intentional misrepresentation of religious history, as Ansary perceives it, which leads him to end the relationship with Riaz. 
audience. Eventually, his reading of history as power struggle, however, does not only dominate the historical frame of Ansary's narrative. Due to its far-reaching effects, it also permeates the issue of culture to a large extent.

\section{The Culture Frame}

The dichotomy between East and West is not only an abstract concept in the literature of postcolonialism. Instead, this binary is still reflected in the daily life of people around the globe whose diverging cultural routines also account for different social structures. "Growing up bicultural" naturally involves a constant exposure, but also learning process, to get to know both sides, as Ansary is well aware of (WK 279). His trip to the Middle East sheds new light on this bicultural tightrope walk. Writing about this life between cultures allows the reader to get involved in this learning process to ultimately see both worlds through a differentiated cultural frame. As Ansary clarifies at the very outset, in the case of Afghanistan, a cultural interpreter between East and West has to start from scratch.

At the very beginning of his account, the author points to the shortcoming that the culture of Afghanistan, despite its prominent role in the WOT, has mostly remained a black box to the Western audience. In his opening chapter "Villages and Compounds," he therefore gives a detailed description of the Afghan environment and life circumstances he grew up in (WK 15). This was a world of farmers and rural life in the countryside, unchanged by modern technology, as he illustrates ( $W K$ 15). The city of Kabul was crowded with people. A postal service existed, but the mailman hardly knew individual names. Somehow, however, letters made their way to their recipients because someone might have "heard of you," Ansary notes (WK 16). "Oh not you in particular; you were just a leaf, a bud. He'd know the branch, the trunk, the tree itself: your people," he adds. This focus on the family, "your people," is also reflected in the life circumstances that accompanied Ansary's childhood. People in the countryside lived on farms whereas urban families resided in compounds together with many other family members, "surrounded by walls that divided the world into a public and a private realm," he explains ( $W K 16$ ). To the foreigner, only one of these worlds was visible. "Those who came from the West didn't even know our private universe existed, or that life inside it was warm and sweet," he continues (WK16-17).

Ansary in these lines introduces the reader to the hidden realms of Afghan life. The tone is somewhat romanticizing and nostalgic. However, the need to make the Western visitor look behind the walls of Afghan life is at least as important for the present as it was at the time of Ansary's childhood. The only major difference is that the foreign visitor to the Orient used to encounter the brick walls separating Afghan privacy only when he actually went there. Today, these walls are drawn by 
television news and public stereotypes. The spectator merely proceeds as far as the cameras and embedded journalists of the media allow him to. Although in the era described by Ansary, Afghanistan was still unaware of the technological advances taking place in other countries, there is no sense of inferiority or backwardness in his description. Rather, the author draws a very inviting picture of the culture and environment he grew up in, which is not marked by a perfect infrastructure and modern means of communication. The culture Ansary obviously treasures is dominated by people. "As far as I can tell, none of my Afghan relatives was ever alone or ever wanted to be," he explains ( $W K 17$ ). This demonstrates in how far the idea of a "group self" outweighs the importance of "individual selves" in Afghan society (WK 17). This is linked to a different concept of kinship altogether, he explains when attempting to describe his family structures. This need derives from a linguistic problem that he encounters when trying to find the right words. "Family doesn't cover it," he points out (WK 17). "Even extended family feels too small. Tribe, however, is too big. I'm inclined to hijack the term clan from anthropology," Ansary decides before admitting that the word, as he uses it, also lacks some of the formal characteristics of the textbook definition (WK 17).

With this almost scientific approach to describing his family structures, Ansary's memoir assumes traces of a college textbook on Middle Eastern culture. The differentiation between collective versus individual identity, as well as the crucial delineation between different concepts of kinship ${ }^{11}$ which in Europe and North America are all summarized by the term 'family,' reveal an intensely didactic tendency. Especially the clarification of the term "tribe" gains a demystifying function since this concept in particular has gained a negative connotation in Orientalist discourse and especially in the WOT. ${ }^{12}$ This contrasting of the specific cultural meaning of seemingly familiar terms alerts the reader to not succumb to culturally relativist practice at a very early stage of the memoir. Ansary additionally highlights this tencendy by referring to his own rootedness in Western culture. As he admits, this culture shapes the individual and his feeling of well-being:

11 In Arabic and in Farsi, there is no single word for family as such. The terms always describe specific family structures. A similar logic applies to different family relationships. General terms such as cousin or brother in law do not exist, since the terms to describe family connections already imply further specifications as to the exact lineage.

12 The negative connotation of the term tribe could again be observed in the context of the Arab Revolution. Several of the political leaders who were expelled from their state positions or countries had indeed been nepotists. In the public discourse on the events, however, these cases were largely generalized in familiar Orientalist ways. This meant that tribal culture as common feature of supposedly backward countries was denigrated as the major reason for political disorder and corruption in the Middle East (Cole). 
And that's [Afghan concept of social environment] so different from my life today, here in the West. Because I write for a living, I spend most of my waking hours alone in my basement office [...]. If I'm too much with other people I balance this with some downtime. Most of the people I know are like this. We need solitude, because when we're alone, we're free from obligations, we don't need to put on a show, and we can hear our own thoughts. (WK 17)

With the "people I know," Ansary refers to Americans in his current life who, instead of focusing on collective identity, highly value the cultural trait of individualism and increased solitude. The fact that this often leads to putting on a "show" ironically plays on a cultural stereotype of America as the nation of Broadway and Hollywood. Read from the background of Ansary's rather scientific elaborations on cultural concepts, this personal experience complements the detailed insights the author provides into Afghan culture in comparison to the one prevailing in America. One of the most crucial messages he conveys here is that the self cannot be separated from its cultural surroundings. As his own experience as trespasser between two worlds also signals, this cultural groundedness is not static since cultural needs and preferences change depending on the culture one lives in.

How important these cultural surroundings are for one's self-definition, Ansary learns on each day of his trip. Hardly a day passes without him being forcefully reminded of his deep-rooted cultural predispositions as an American - not an Afghan. One of these deeply ingrained cultural legacies is revealed in the context of money. Coming from the capitalist culture of the U.S. where anything can be bought at any time with any credit card, Ansary on his trip finds himself constantly facing money shortages. When he tries to withdraw money in Morocco, for example, the bank teller reacts helpless. He does accept traveler checks from a number of small European banks, he explains to Ansary, before enumerating all the names of these banks. To the latter's surprise and frustration, however, the "only financial institution on earth he'd [bank teller] never heard of was American Express" (WK 152). When Ansary after serious efforts finally manages to exchange some money for Algerian bills, a sign at the Algerian border warns him: "IT IS FORBIDDEN TO BRING ALGERIAN MONEY INTO ALGERIA,” it reads (WK 153). He nevertheless attempts to smuggle in some bills before discovering that he lost part of his travelers checks in Morocco, a country which he cannot reenter (WK 154). Ansary's financial struggle therefore continues. Yet, his frustration does not prevent him from clinging to the conventional materialistic pattern he knows from home: Everything has a certain price and everything is available as long as one is willing to pay for it. This logic again becomes turned upside down when he tries to proceed to Algiers on a train. Ansary repeatedly asks for a "first-class ticket" in order to escape turmoils in the economy section of the train (WK 157). He becomes more and more impatient until someone finally explains to him: "There is no first class, 
second class here. You're in socialist Algeria, brother. There is only one class here, first class, and you are in it" (WK 164).

This highly ironic way in which Ansary describes his own naiveté and cultural ethnocentrism reverses the familiar pattern of colonization. He becomes helpless and lost in a culture in which no general currency exists and nobody cares about American credit cards. The fact that "American Express" is not accepted by the bank, but several minor European credit institutions are, specifically ridicules the position of the U.S. as supposed financial hegemon. Ultimately, these incidents make Ansary aware that the materialist culture he is so used to is worth almost nothing in a cultural environment where class, at least officially, does not exist. These experiences once more demonstrate to him how much he is rooted in American culture. This awareness also comes to change the way in which Ansary interacts with others. Upon meeting another American in Algeria, he makes a striking selfobservation. According to dress and general appearance, the stranger would rather scare than attract him if they had met in the U.S., as he admits. In his present situation as a cultural stranger in a foreign country, however, the American feels like an outright ally to him. "In the United States, I would have put a great distance between me and this guy right away. Here in Algeria, he felt like my wayward brother," he explains with in a tone expressing relief and the awareness that shared cultural experience creates a bond, which is hard to explain in rational terms ( $W K 160$ ).

Ansary's changed awareness of cultural predispositions is also reflected in the criteria he applies when meeting other people. He starts assessing acquaintances in terms of cultural similarities and dissimilarities, particularly with respect to outside racial markers. An example of this is provided in his description of Hocine, a young man he meets in Tunisia. "His skin had a European pallor that suggested bicultural genes. He wore oversized glasses and a leather jacket, a striped T-shirt, khaki pants - European clothes with a Western flair," Ansary illustrates (WK 172). He then points to the sharp contrast the appearance of the man represents in comparison to the traditionally-dressed Tunisians surrounding him. Hocine's European orientation is not limited to clothing, though. "In fact, Hocine was a Euroculture groupie. He plied me with questions about the West," Ansary continues and recalls how Hocine wants to learn more about U.S. TV shows, dating culture, hamburgers, bars, and picnics (WK 173). Obviously, Ansary does not feel annoyed by the stereotypical image of the West Hocine seems to have in mind. On the contrary, he even develops admiration and closeness to the man who seems to be so attached to his own cultural homeland. The conclusion he therefore draws based on this single example is that "Tunis apparently was much more Westernized than Algeria" (WK 173). Compared to the cultural alienation he experienced in Algiers, this finding comforts him.

The encounter with the European-looking and -thinking Hocine serves as an example of Westernization in the Muslim world for Ansary. Furthermore, the situation also puts emphasis on the dynamics of cultural coping which Ansary develops in 
the course of his trip. He increasingly longs for peers who share the same cultural background. This cultural background is much more detached from the Arab customs that accompanied his childhood and which he experiences on his journey, as he comes to realize. The longing to re-establish cultural companionship also touches on the aspect of language. When Ansary tries to write after visiting Turkey, he is not able to: "I tried to write. Thousands of miles on the ground, months on the road, hundreds of conversations with Muslims, and I had not shaped a single coherent article. Without English around me, my head felt empty, as if my thoughts were only internalized visions of my conversations" (WK 208). This reflection on the perceived loss of language strikingly underlines the increasing importance Ansary attests to cultural issues. At the same time, the link between language as most important means of expression and the thoughts guiding it serves as a metaphor of postcolonial agency, whereby those who are bereft of their culture and language also lose the ability to formulate proper thoughts.

All these instances of cultural alienation demonstrate to Ansary how much he is attached to Western culture, as he experiences it. This becomes even more explicit in a conversation with his acquaintance Uger in Turkey. With Uger, he meets a man whose family history has endowed him with a similar history as his own. ${ }^{13}$ Just like Ansary's past was closely entangled with the political faith of Afghanistan, the young Turk reveals that political unrest in Turkey severely affected his family. Ansary immediately recognizes his own story in the account and acknowledges its effect on his present political consciousness. "I had many of the same elements in my psyche," he explains. "My family was part of the leading edge of rational secularism in Afghanistan. We were the Westernized ones, as Uger was in Turkish society; and then in American society, I had been a hard-core member of the radical counterculture, a leftist by any measure," (WK 197). The term counterculture here is particularly noteworthy since it carries political as well as cultural meaning. According to Ansary's conception, the "Westernized" obviously formate a counterstandpoint opposed to the culturally familiar. This common identity of the outsider and cultural Other eventually forms a common bond, as the example of his conversation with Uger suggests, and it also separates him from Arabs without the experience of Westernization. After listening to the story of Uger that concludes with the death of the latter's mother, Ansary makes a striking statement: "In America, as far as I can tell, human relationships pass out of one's life all the time," he concludes (WK 207). This observation can be read as a preliminary summary of his

13 Ansary's stay in Turkey also offers various instances in which the historical framing of the narrative becomes particularly strong. The author here provides extremely lengthy accounts of the history of the Ottoman Empire, the Atatürk regime and the position of modern Turkey ( $W K$ 196). 
cultural learning experience at large which highlights the fundamental difference between human versus material values in the Arab world.

The immense importance of cultural alienation and its impact on personal interaction, however, only strike Ansary after his return from the "Islamic world," as he calls it (WK 223). When spending time amongst Afghan students in San Francisco, he more and more gains the feeling that he does not share their cultural orientation and habits. 'I'd felt awkward among them; I'd felt like I didn't know all the secret handshakes of Afghan culture anymore. They shared references to times and places I had left behind," he explains his feeling of estrangement (WK 223). This inability to connect to his former cultural allies increases when the students ask him to join them on a committee in order to raise money for refugees from Afghanistan (WK 224). As Ansary admits, he merely joins in order to "alleviate the guilt I felt over being safe and sound in America" (WK 225). This self-declared privileged status thus clearly separates him from the current immigrants and also from the genuine cause the other Afghan students are seeking. During his involvement, further committees start forming and tensions arise between them based on cultural hostilities boiling in their homeland. Ansary consequently loses his feeling of cultural bonding as well as his patience and recedes from his committee position. "I lost faith in my ability to work on any project with other Afghans," he laments. "They operated by rules I could not decipher" (WK 237).

Ansary's multifaceted experience of being both, a stranger in the "Arab World" as well as estranged to his own countrymen in America, makes him reflect on the larger trajectories of culture and migration in a very complex manner throughout the narrative. His final reflection on the issue of culture mirrors the difficulties that have accompanied Ansary's bicultural origins throughout his life and journey. He thus suspects that his losing track of Afghan culture results from the fact that almost all his family members came to America. "My Afghanistan came here," he summarizes (WK 264). At first, the family tried to import Afghan culture to America. Yet, the pull of acculturation in the new homeland left its marks on their identity. "I think all of us Afghans tried at first to establish here a sense of those private family villages we grew up with, but in America, you can't keep out what's public. You watch TV, you go to work, you make friends there, you have no walls around your house, and you live next to strangers" (WK 265). Ansary at this stage has obviously learned that the immediate transfer of one culture to another country, of one place to another, cannot be successful. The place cultural migrants long to adhere to cannot be created in the new country of residence. Rather, the distorting dynamics of memory transform the very memories of the homeland which thus gets transformed into a "mythical place, that didn't exist, that couldn't exist in America" (WK 265).

The cultural lessons Ansary draws from his journey remind him of the binary framework dividing Afghan and American culture. Being a good father, a "good citizen," successful at work and making friends - these are his "preoccupations as 
an American," Ansary notes (WK 266). Being a good host and caring about kinship, these are the "preoccupations of an Afghan," he contrasts (WK 266). This makes him return to his theoretical elaborations on the different definitions of kinship once more. As Ansary explains, many of the latter values stem from the institution of an "extended-extended-extended family" which does not even know an equivalent term in American culture (WK 266). Keeping up with both facets, however, is hardly possible. Although the relatives who came to America and brought their culture with them "had to fit into the clockwork schedules of America," he metaphorically notes (WK 267). From this reflection, Ansary infers an equation in which the gain of one cultural component requires the loss of another. "My American self makes me a little less Afghan," he ponders and suspects this to be the major reason why he was drawn to the American side of the cultural spectrum. Here, the loss can be limited, it seems. "It was more that being an Afghan among Americans made me no less American. After all, most Americans are something else, as well. America's characteristic flavor is made of the otherness we all bring to this stew" (WK 281).

The theory of cultural gain and loss Ansary lays out here provides a powerful summary of the cultural frame he offers his audience. This frame designs a nuanced map of cultural experience based on theoretical as well as personal insights. He constantly contrasts the cultural realms of East and West by focusing on their values and benefits, not merely on their shortcomings. Especially the above-cited summary he provides toward the end of his account appears like a remarkable reiteration of the century-old ideal of America as a melting pot, where every individual, no matter from which background, becomes amalgamated into the "stew" of multiculturalism and individualism. Ansary presents this image in a positive light without succumbing to naiveté, stereotyping, or blind idealization. The personal struggles he describes and the loss going along with multi-cultural identity negotiation in America endow his elaboration with much realism. The pressure to choose a defined cultural identity gains a compulsive component that separates Ansary's version of the melting pot from reductionist images (WK 282). His own life story and the multiple stories he depicts therein serve as empirical evidence for this complex cultural framework between bi- and multi-polarity.

Overall, the cultural frame Ansary designs for his American audience again relies on techniques of interpretation similar to the previous frames of religion and history. The detailed information he is able to provide allows the reader to gain insights into Muslim and American cultures which are hard to attain otherwise. Above all, this leads to the effect that cultural complexity as a seemingly familiar concept gains new meaning. This nuanced approach stands in sharp contrast to the concept of culture as a mere symbol of separation, as it is conveyed by the media. Ansary seems well aware that his two-sided analysis of Muslim and American identity remains an exception in the public discourse on Afghanistan in which lasting stereotypes prevail. As he reminds his readers at the very end of his account, 
"Americans seem to think of Afghans as bearded gunmen who live for war, but actually, for Afghans, generosity far outweighs military prowess" (WK 266). Obviously, this reinforces the significance culture plays in the maintenance of media stereotypes. Simply reminding his readers of the existence of these stereotypes does not suffice for Ansary, though. Instead, he designs an alternative media frame in his own narrative by revealing the very dynamics the media employ for their discursive hegemony on Muslims.

\section{The Media Frame}

The Afghan as bearded gunman is the most pervasive stereotype constructed by the media's framing of the WOT. Due to Ansary's status as a public voice in the context of 9/11, which the reader learns about at the very beginning of the narrative, the political frame remains visible in the reconstruction of Ansary's memories. Based on his journalistic agency, the author does not make any efforts to merely deny or counter the stereotypes he and his audience are very aware of. Rather, he addresses the media and their practices as a dominant issue in his entire narrative. Eventually, this leads to the effect that the media's perspective on the Middle East also becomes a lens through which Ansary reflects on his own experiences. Instead of merely reproducing the media's practices, Ansary engages in a thorough analysis of media framing. This task accompanies him from the very beginning of his journalistic journey to the Muslim world.

Right before Ansary leaves for his trip, he introduces the reader to the news coverage prevailing at the time of his departure. It mostly centers on the Soviet conflict played out on Afghan soil (WK 124). These are the TV images left in Ansary's mind when he finally takes off to his first destination Morocco. As he gets closer to the region where these images are captured, a different reality starts unfolding. Right after his arrival in Tangier, he walks around in the city and is instantly reminded of how much the global media coverage has come to shape the worldview of the audience - not only in the U.S. but in the Arab world as well. Young people ask the obvious stranger where he is from. Upon telling them that he is from the United States, he is met with a very revealing reaction. As he recalls, "they cheerfully mimed shooting pistols and said, 'Bang bang! Cowboys!" (WK 126). When Ansary reminds them that this image rather reflects Texas but the comes from San Francisco, they have more bangs to distribute. "Bang bang! Karl Malden! The Streets of San Francisco," they reply (WK 127).

This episode in the medina of Tangier gives Ansary a first taste of how he is seen by the Muslims whom he would like to interview about Islam and religion. Not only do they immediately associate Americans with guns, they also reveal the source of this knowledge by relating to a Hollywood classic. This at once reminds 
Ansary and his readers that Morocco is not some backward country where access to a TV set counts as an exception. This encounter ironically underlines that the West's media culture has penetrated the world to such an extent that Hollywood is everywhere. The global impact of the media culture, however, is only one aspect hinted at in this scene. Another ironic move with a highly political connotation is the reversal of the gunned villain as central mediated stereotype. The Moroccans are imitating something they think is typically American: namely, guns and violence. How strong this conviction is, Ansary learns in his failed attempts to convince them of a different reality. The image the Moroccans have of Americans is highly resistant against counter-arguments, and there seems to be no room for complex differentiations between different types of Americans living in different states. For them, the Moroccans he meets, there exists one universal American and this American likes playing with guns. The obvious irony behind this strong adherence to a mediated stereotype is that the roles are reversed. In the tradition of Orientalist discourse, it has always been the West who engaged in essentializing the East by reducing the Arab to the image of the violent barbarian. The notion that the very same process might be taking place on the part of the Arab/Muslim was mostly ruled out by the fact that the Orient counted as backward and thus unable to conceive of the world at large. In this instance, however, the direction of Orientalism is reversed with the Orientals mocking the violent American cowboy. This demolishes the image of the Other as misinformed outsider of the world. Furthermore, it sends a crucial first signal to the reader of the memoir by suggesting that the media practice of essentializing is not a Western monopoly.

The binary mode of thinking and the importance of the political frame around Arab identity definition become even more emphasized in the further course of Ansary's encounter with the young Moroccans. Because of the political relevance at the time, their conversation turns to the Cold War conflict. When Ansary reveals that he was born in Afghanistan, they again take out their virtual pistols. "Russians! Bang bang! Muslims support Afghanistan!" (WK 127). Obviously, they are informed about world news and besides that, they know who is with us or against us, as their reaction demonstrates. The $U s$ that is implied in their determined taking of sides is the Arab/Muslim world. The most important characteristic of this perspective, as they clarify, is the belief in "One God, not two" (WK 127). Therefore, it does not really matter to them if Ansary is from Afghanistan, Iraq, or some other country in the Middle East. As long as he believes in one God, he is part of their world and this world is fighting the suppression of the Afghans by Russia. The simplistic manner in which the young Moroccans express their worldview here underlines the reductionist nature of the Orientalist division of the world at large. Ansary does not ridicule them. Rather, it becomes obvious that this simplified binary logic infuses the Cold War conflict. How essentialized this logic really is becomes even more visible in another conversation Ansary recalls with a man he 
interviews about Islam in Morocco. "The Iranians and the Afghans - they are the front line now, in the battle for the honor of Islam," the man explains to him (WK 131). When Ansary interjects that both fight on "opposite sides, of course," the man refuses to listen and insists that both "are brothers" (WK 131-32). "But Iran is battling the United States. The Afghans are battling the Soviet Communists. Those are opposite sides," Ansary attempts to explain (WK 132). "Soviets, Americans - same thing," is the Moroccan's conclusion (WK 132).

This vivid description of the Middle East as stage of the Cold War emphasizes the important meaning political events have always had for the perception of the region by others and by Arabs and Muslims themselves. As revealed by the empirical framing studies, this political frame of the Cold War has meanwhile come to be replaced by the WOT, yet, the far-reaching impact of this political framing has not changed. Although at the time of Ansary's journey, 9/11 was still unthought of, the impact of this key event and the effect it had on global media framing obviously also plays a role in his depiction of the Cold War. The extreme essentialist mindset he finds in the men who insist on their preconceived black-and-white-logic constitutes the core of the binary media framing of the WOT. The same held true for the Cold War. Just like the Moroccan does not differentiate between Soviets and Americans because to him, all Americans employ force to pursue their interests, the Middle Easterner today represents the other end of the axis of evil because all Middle Easterners are terrorists. Although Ansary in these instances does not immediately address the media as major agents in this binary framing, his depiction leaves little doubt that the people he talks to derived their knowledge from the media - be it Hollywood or CNN. The practice of the Moroccan Muslims to constantly refer to the binary division of the world underlines the universality of the media frame. Moreoever, the negative comments Ansary's acquaintances drop make the reader aware that the image of Americans is highly problematic.

This confrontation with negative images of America receives further confirmation when Ansary finds himself on a train to Algeria. Stereotypes here boarded the train long before Ansary does so. Not only do the soldiers he meets not care about the American obsession with capitalism, they also do not take his aim of learning about Islam seriously. The soldiers then ask him if he eats pig meat. "We don't eat pig meat," they emphasize (WK 166). "I'm a Muslim, too," he tells them. "But you lived in America! They eat pig meat," they point out, before they go on speculating about Americans supposedly eating "horse testicles" and "snake meat" (WK 166). "Traveler," they finally address him, "you have seen these places. Tell us: Do Americans eat excrement?" (WK 166). Their real interest in the truth behind these rumors is rather limited. Before Ansary can give an answer to their questions, a debate erupts about whether he should be thrown off the train. "You're not going to throw a Muslim off your train," Ansary tries to intervene. Since his Muslim identity 
is challenged by the soldiers, this argument does not count much. Eventually, the conflict ceases, yet, the Algerians' mistrust in his Muslim identity prevails.

This confrontation on the train marks another key scene in which the American in Ansary is confronted with severe mediated stereotypes about Americans. Most striking about this depiction and the way in which the Muslim soldiers treat Ansary is the high degree of humiliation and ridicule they inflict on him. According to their normative framework, an American eating pork and other things which they regard as excrement represents the lowest step of civilization. The basis for their judgement is rooted in their Muslim faith, which, as Ansary in his religious framework demonstrates, is linked to several social and cultural conventions. Since American rules are not in line with their rules as Muslims, the fact that Ansary considers himself an American Muslim does not change much. As in the case of Ansary's bookstore acquaintance, the two identities seem to be mutually exclusive. This incongruous binary is highlightd by the emphasis Ansary puts on their statement that "They," in italics, "eat pig meat." Contrary to the Orientalist definition of they as the Middle East, the respective reference here clearly refers to the Americans as cultural and moral Others. This reversal of the dominant discursive trope strikingly holds the mirror to the American media audience which this time is put into the position of the inferior and uncivilized pig eater.

The moral vilification of Americans by Muslims obviously is the result of mediated stereotypes they have in their minds. Ansary's reflection on these stereotypes does not remain at the level of merely dealing with the consequences of these images. Rather, he also explores how these stereotypes get produced by the media. This ultimately takes him to reveal the framing mechanisms underlying journalistic work. As in the case of all other conceptual frames Ansary builds up, he does not choose a one-sided approach to his media analysis. From the beginning, he focuses on the difficult bridge between the media as unique source of information and the media as distortion module of reality. His trip provides striking examples of both functions. The news he sees on TV and in foreign-language papers are his only contact to the outside world since the time of internet and e-mail communication was still in the distant future in the 1980s, as he reminds the reader (WK 138). Yet, Ansary does not travel as a mere recipient of this information. As a "macho journalist" he also observes his surroundings through the lens of an information provider. An example of this dual role is given when Ansary gets into an in-depth discussion with his acquaintance Uger in Turkey. The latter engages him in an eight-hour long information session on the social and political struggles of Turkey. Ansary describes his reaction as follows: "He had me sitting up. Hey, maybe this could be my story. Turkey sounded like an explosion waiting to happen - about to be overrun by neo-Nazis or Muslim fundamentalists. Events had moved too fast for me in the Islam story, but with Turkey, I would be ahead of the news" (WK 192). 
The picture Ansary draws of his extreme excitement based on the information he gains from Uger leaves the reader with an ambiguous picture of journalists. Ansary indeed seems to be interested in the information he gains. His urge to get "ahead of the news," however, also sheds negative light on his personal quest and on the role of journalists in general. The relevance and content of the information does not seem to matter as much as the fact that the "story" is important and interesting enough to let him take the lead in the hunt for sensational news reports. Journalists working with this motivation do not seem to care much about truthful accounts but stories which sell, as Ansary's depiction suggests. The problem remains that he is not talking about any profession in this case. Ansary is talking about his profession and therefore also about his own normative struggles as a journalist. The gap between sensationalism and truthful storytelling thus comes to be the source of a severe identity conflict that starts to dominate his memoir. Especially as the distance between his original professional quest and his personal life starts eroding in the course of his journey, he increasingly tries to build up an artificial professional distance to the events.

These efforts of separating himself from the negative traits of journalists turn out to be rather unsuccessful. Ansary's bicultural identity struggle and his oscillation between "macho journalist" and a Muslim in search of his roots reach a climax in the chapter "Embassy" (WK 201). Ansary wants to travel from Turkey to Pakistan, which means he has to go through Iran in the middle of the hostage crisis. When he hears that Americans are not likely to safely make their way through, he goes to the embassy in Turkey to find out about the conditions. There, he meets a group of Iranian students and starts speaking to them in Farsi, "which I spoke with a convincing Afghan accent," he underlines (WK 203). This conversation then unexpectedly forces Ansary to give up any professional pretense. When he shares his real longing to explore his cultural roots, his connection to the Afghan homeland and the story of his left-behind father, an emotional barrier breaks. This is when he realizes that his journalistic endeavor has only been a farce. "All this time, I had thought I was pretending to be on a personal quest in order to pursue my real goal of bagging a story. Now I realized I was pretending to be a journalist in order to pursue my real goal of exploring my roots, nailing down my identity. From Morocco to Istanbul, I had been telling the truth," he confesses to himself and to the reader (WK 203). This revelation brings tears into the eyes of his Iranian soul-mates who immediately identify with the issues of "exile and the homeland" (WK 203). When the Afghan students treat him as one of their kind, Ansary's professional posture fully collapses. "This is Tamim Ansary, our brother Afghan," they embrace him in their circle, "long lost in the wilderness of the West, now returning to his home [...]" (WK 203).

This incident for Ansary marks a true turning point, not only for his further trip but for his identity negotiation. It emphasizes that he cannot keep up with the pro- 
fessional and sensational nature of journalistic story-seeking anymore. Clearly, these are the characteristics that he marks as important determinants for being a successful reporter. What distinguishes him from the journalist, though, is his insistence on honesty and "truth." This focus on authentic recording thus remains a prominent theme throughout the memoir. While it discredits journalism as seeking stories but not truth, Ansary's own credibility is underlined by this statement. The neglect of truthful reporting, however, is only one of the ethical violations Ansary reveals as inherent to the journalistic procedure. The tendency to avoid laws and other official regulations in order to get ahead of the news is another one. Both obviously require a degree of emotional detachment and ruthlessness which Ansary cannot identify with anymore.

How severely the loss of this professional shield can turn into a severe personal burden, Ansary also learns at the embassy. After seemingly having won the Iranian's honest admiration and trust as one of their kind, he has to admit that he is traveling on an "American passport" (WK 204). This makes the face of the officer and the young men around him freeze immediately. Their heartfelt bondage instantly turns into absolute coldness and abomination. The American passport cuts off whatever shared experience might have existed only seconds ago. Ansary is denied the visa. This, in turn, completely ruins whatever journalistic façade might be left at that point. "For a true macho journalist, this would have been merely the beginning," Ansary honestly explains. "A true MJ would have found some way to sneak across the border disguised as a truck driver. But I was not a macho journalist, it turned out" (WK 205).

Although Ansary here seemingly gives up the journalistic authority he has built up from the very opening description of his persona, his withdrawal from the evils of journalism does not impede his agency. On the contrary, by revealing the often dubious and partly immoral methods of journalists, he additionally underlines his comprehensive knowledge about the mechanics of news media production. At the same time, he denies adhering to them. The emotional impact of this sudden revealation is so significant that he decides to put an end to his entire journey. He does not reach his final destination Pakistan therefore, yet, he reaches a destination in himself which he hardly thought about before: "Clearly, my trip was over. No, I didn't get a news story. All I did was learn about myself - that I was not a macho journalist, and that my soul was not on the road or in the East. The Islamic world was someone else's, not mine," he recapitulates (WK 219). Ansary then moves to San Francisco and engages in an American life that seems to be much less stressful for his identity negotiation, a "life as one unconflicted soul: Tamim Ansary, American guy," he states with relief (WK 219).

Obviously, Ansary's greatest loss, the lesson that he is not a true "macho journalist" and the fact that he is less Afghan than expected, also means the greatest gain to him. To a large extent, he turns his back to the "Islamic world" and fully 
embraces his American identity. This decision is an involuntary one since he could not escape the constant reminders of the people he met on his trip who tended to reduce him to his American identity. This retreat from his Afghan identity, though, does not make him turn away from the Middle East as prominent concern in his life. After his return, Ansary keeps following the news from the region closely, and his engagement with the role of the media in shaping America's view of the country remains as intense as ever. One day, Ansary's journalistic work takes him to meet an Afghan refugee. The school girl by the name of Na'eed tells him the story of how she protested against the Soviets in the streets of Kabul. The girl walking next to her was killed by gunfire, but she picked up her country flag and kept marching fearlessly (WK 228-29). "Here in America, her story got out to the media, and she was briefly canonized as the 'Afghan Joan of Arc,"' Ansary explains (WK 229). "She even got a photo op with President Reagan," he then adds (WK 229).

By using the example of the young refugee girl, Ansary wraps up his comprehensive analysis of the role of the media in the conflict frame surrounding the Arab world. He thereby reveals the trajectories of media framing in general and the particular cognitive lens this creates in American discourse. The way in which the U.S. reports on the Afghan resistance to Soviet rule is clearly dominated by U.S. political and idelological interests. This underlines the workings of the larger Cold War frame at the time. The fact that the refugee girl even "got a photo op" with the president endows the story with a critical connotation, once again underlining the sensationalist verve of journalists to get good footage for their stories. At the same time, Ansary here makes the reader aware of how the mere presence in the media can turn ordinary people, even if they have fulfilled inordinary deeds, into public heroes within the blink of an eye. The multi-faceted picture Ansary provides of the impact of media discourse on the public framing of the Arab/Muslim highlights the high degree of reflection which enables Ansary to address the media as major issue in his memoir. He does not only renarrate the pictures the audience is already familiar with, but explains to his audience how these pictures frame the American perception of Afghans and Muslims at large.

On the flip side of the coin, this framing effect also occurs with respect to issues going unnoticed by the public because they do not find the ear of the media. Ansary mentions the story of Massoud to demonstrate this point. The Afghan nationalist warned of further foreign invasions in the country and smuggled out video tapes "to Afghans in the West," Ansary describes Massouds story (WK 272). But "none of these tapes were ever shown on television, because the war in Afghanistan had no audience," Ansary criticizes. He identifies a similar problem of public neglect deriving from the lack of media presence in the case of the land mine problem in Afghanistan. The mines made thousands of victims in Afghanistan lose their limbs as a consequence of the Soviet war. While "the global land mine problem is widely 
publicized today," Ansary reminds his readers, “[...] back then, the issue was lost in the noise of all the other causes" (WK 273).

With these powerful examples, Ansary further underlines the immense role, the global media play in framing the world and particularly the East. As the definition of framing revealed, frames are results of both; information which is provided and information which is left out of the coverage. Ansary highlights this mechanism by pointing to the various stories which never reach the West because they do not fit into the dominant media frame of the time or simply lack the characteristics of a good story to attract the audience. The author is able to express these observations only by following a comprehensive approach to news media production and reception. He always keeps the audience in mind. This focus on media processing therefore marks another key component of Ansary's own mediatic issue framing of his narrative. By looking at his life through the mechanisms of journalistic production, he allows his readers to look beyond the news media images present in their minds. Ansary does not get tired of reminding his Western audience of these stereotypes. As he states on one of the final pages of his memoir, the "only thing most people knew about Afghans was that 'they oppress women.' Never mind that most Afghans were women. To the American public, Afghanistan equaled Taliban" (WK 273-74). Although Ansary here uses the past tense, the constant consideration of the current media discourse leaves no doubt that this framed view of Afghanistan has not changed considerably between the time of the Cold War and the present WOT.

Ansary's personal conclusion following all these detailed insights into media framing is a rather bleak one. To a certain extent, he doubts that the discursive monopoly of the media can be challenged by individual stories or cultural insider knowledge. "Undoubtedly, the media will find a better story than Afghanistan itself in the days to come, and the land of my father will again slip into obscurity," he wearily infers (WK 284). This conclusion puts brackets around the media frame Ansary creates in his narrative. Despite the hopelessness to challenge the media's monopoly in framing the public view of peoples and nations, his narrative itself provides an instrument to achieving this aim. The constant alternation between the media images of the public and the truth which Ansary seeks to unveil is the most important technique in this respect. It allows the audience to look at Afghanistan not only through the eyes of the media consumer, but through the eyes of the journalist who shares his knowledge about the creation of these images. This method of getting beyond conventional frames of interpretation also marks Ansary's personal theory of life writing. His elaborations on this theory come to serve as a testimony to life writing as (re-)framing strategy. 


\section{Reframing the Afghan Fundamentalist as Theory of Memory Writing}

The complex interplay between memory recollection and the analysis of this memory by means of overlapping issue frames suggests Ansary's conscious employment of memoir as medium. He develops a complex image of the Muslim, Muslim America, and Afghanistan. As he states in the final sentence of the epilogue: "I am a kaleidoscope of parts now - and so is Afghanistan. So is the world, when you get right down to it" (WK 285). This multi-colored potpourri of Afghan identity stands in contrast to the reductionist image of Afghanistan and the East as conveyed by the media. Memory writing, by means of employing the strategy of framing as an instrument of activism, can make a difference to changing public discourse, as Ansary's own theory of memoir suggests.

"Every memoir is full of unfinished stories, I suppose," Ansary opens his "Afterword" (WK 293). The latter ultimately reads like an instruction manual to reading his memoir and the media world surrounding it. By pointing to the incompleteness of his own narrative, Ansary also emphasizes the fact that any writing, any media content, only represents a fragment of the kaleidoscope of parts. There are always facts and events which remain excluded. This instance of complexity reduction based on selectivity obviously reflects a key characteristic of framing. Ansary even explicity mentions this term with respect to his own narrative construction. "Other stories ended outside the frame of my own narrative, and yet they are worth noting," he explains (WK 293). One of these noteworthy stories is his somewhat unfinished identity, "my own unfinished story," as he calls it (WK 294). This story, despite his rejection of Afghanistan and his attempt of "Forgetting Afghanistan" (WK 221), makes him go back to visit Kabul shortly after the publication of the book. Here, he traces the shadows of his past, visits relatives, gains a new picture of the old memories of Kabul he has in mind. Yet, even this experience does not put a definite end to his identity quest, just like there can be no endings in writing and in the writing of life stories, as he suggests: "So you never know. That's what I have concluded. Even the past can change, depending on what happens next - or at least the meaning of the past can change, which is what counts. [...] The pattern is never visible until it's over - and it's never over. Endings don't exist" (WK 300).

With this ending describing the denial of endings, Ansary leaves the reader with a seemingly paradoxical, yet, powerful piece of advice as to how to approach life and life writing. His emphasis on the changed meaning of the past resulting from different interpretive frames in his own story highlights the crucial function framing has in his narrative. As the framing analysis has revealed, the issue frame of history here gains prominence and shows the most intensive overlapping to some of the other frames. The most important indicator of this finding is the large amount of 
historical information Ansary provides throughout the narrative. He treats history as a key to understanding the past and the present, which clearly also affects the construction of other frames in the memoir. Ansary thus regards life writing as an instrument to interfere in historical discourse. He confirms this notion in an interview:

It's all very good to have official histories and dry texts taught by Harvard professors about the unfolding history of our times, but I think memoirs are the lifeblood of history. It's important to keep remembering that history, seen up close, is nothing but myriad memoirs interlocking and intertwining. So I'm adding my little bit to that tapestry. (Interview with Menten)

These words speak to the dominance of the history frame in Ansary's life narrative, and they also point to the importance Ansary devotes to history in his entire life and career as a writer. The publication of a history book in 2009 with the heading Destiny Disrupted: A History of the World through Islamic Eyes serves as additional evidence of this. The metaphorical title of the book reflects Ansary's insights into frames of interpretation. This goes along with his larger aim to facilitate alternative readings of history and of Muslim identity by providing insider information based on thorough historical analysis. ${ }^{14}$

The historical frame, however, is not the only one that receives retrospective confirmation by Ansary. He also stresses the importance of culture for the reframing of Eastern identity in the West:

In the whole first part of the book where I describe my childhood in Afghanistan, I'm speaking in my American voice about not just my Afghan self, but also the context that gave rise to that Afghan self. I feel that the culture of Afghanistan in those days before the war was something that nobody had been situated to describe in a way that could make Americans really see it. [...] I think I am using whatever voice I have to speak for not just Afghanistan, but also for a certain kind of cultural and social coherence that has passed away in a lot of places, especially in the parts of the world we now describe as the developing world. I think it is only recently that secular Western civilization, thoroughly industrialized and technology-driven, has come in contact with cultural frameworks that are much more traditional and more ancient. (Interview with Menten)

This statement testifies to the significance of the cultural frame found in the closereading analysis. Ansary in the interview carefully delineates the different issues separating the "developing world" from "Western civilization." From his viewpoint, culture and the different concepts connected to it are crucial to mutual under-

14 Ansary in the interview also announces that history will most likely remain his major focus. He therefore thinks about writing a historical novel ("Interview"). 
standing in both worls, which also drives his motivation to clarify these "cultural frameworks."

Ansary in the same interview also underlines the importance of religious issues for the collective image of Afghans and for his own identity negotiation. As someone who has spent life "between the traditional Islamic society of his youth and the secular Western culture he came to call his home," his intention remains to look at religion from "two angles," as he states (Interview with Menten). "I think that in portraying the peaceful Muslim society of my youth, I did want to bring this vision of Islam to Americans and show that this is how a lot of Muslims live and want to live. At the same time, I became aware that there was an emerging political ideology in the world that had its roots in Islam" (Interview with Menten). Ansary's achievement in the memoir is to delineate these different dimensions and to provide alternative information on Islam as religion in opposition to Islam as political ideology. The complex discussion of these issues within different frameworks allows for this separation.

When integrating the issue frames revealed in the analysis based on the variables of authorial authenticity, truth claims, and use of language, the following model emerges:

Graph 5: Frame Model of West of Kabul, East of New York

\section{Frame Levels:}

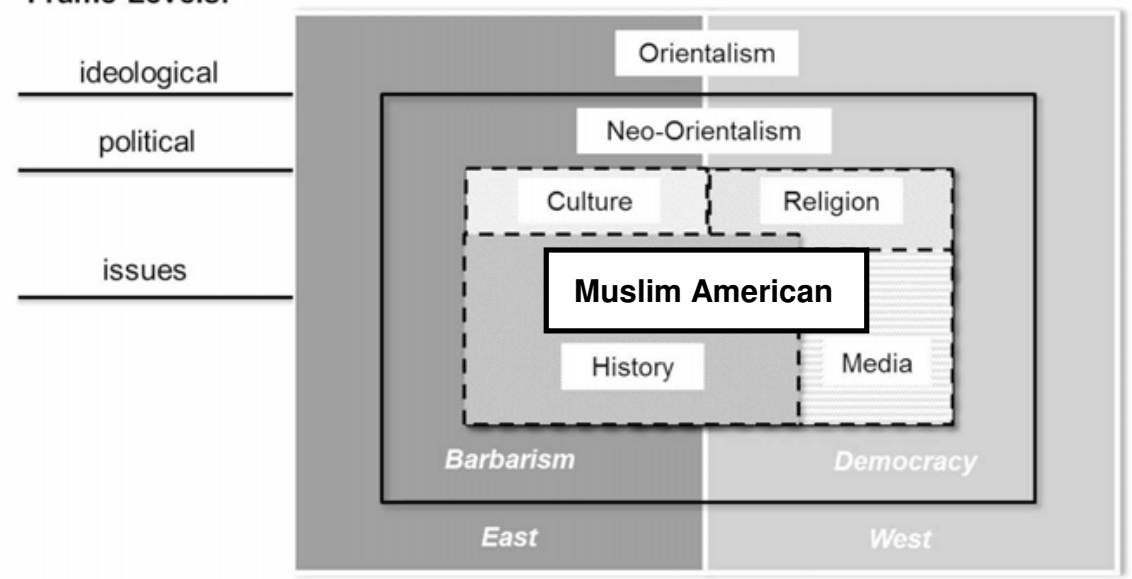

As the graph illustrates, the history frame turns out to be the most dominant one, affecting all other issue frames. Due to this focus, the reader is invited to change the existing image of Afghanistan through a historical lens. When recalling the results of the meta-analyses of media frames on the Islamic world, it becomes obvious that this historical frame offers a novel reading of Muslim identity, since history is not a 
dominant frame in the media coverage on the Middle East. This reframing gets complemented by the other issue frames installed by the author, namely: religion, culture, and the media frame. Whereas religion has been found to be a strong frame in media coverage, culture has fallen out of the picture post $9 / 11$. The memoir thus puts emphasis on an issue which is mostly absent from public discourse. The same holds true for the media frame which deserves further attention.

The very existence of the media as dominant issue in the memoir highlights the strong impact of mediated discourse on the production of memoir in contemporary times. Even more important, however, is the finding that this issue frame has never appeared in conventional empirical analyses on the coverage of the Middle East. Literary authors and empirical media scholars such as Jack Shaheen, Edward Said and many others have, of course, repeatedly addressed the media as source of misrepresentation. Ansary's thorough analysis of the self-reflexive mechanisms of framing in the media coverage, however, adds a new theoretical dimension to the issue. This novelty is especially remarkable since journalists in general tend to conceal rather than expose their own means of reporting. In Ansary's case, memoir provides the appropriate format to look behind the scenes of media framing while at the same time practicing the technique of framing to arrive at these insights.

When looking at the outer frames surrounding the issue frames in the given model, i.e., the neo-Orientalist frame linked to the WOT and the Orientalist frame marked by the vocabulary of $u s$ versus them, a surprising finding evolves. Although an Afghan American author can be assumed to counter the stereotypes linked to the respective frames, they are still omnipresent in the memoir. As the analysis on the level of issue frames has revealed, Ansary's method of contrasting is full of East/West-binaries. This vocabulary becomes the most dominant mode through which Ansary structures his past and present experiences. The same holds true for the impact of the neo-Orientalist frame and of the WOT. Although Ansary provides a series of alternative issue frames to look at the Afghan through a different lens, it cannot be denied that the political circumstances of the present severely shape the construction of the memoir. In contrast to a one-sided processing of both frames, Ansary's bicultural position and his technique of letting other voices speak allow for a two-sided view of East and West. Ansary points to this nuanced approach to binary differences at the end of his memoir when describing the focus on invidualism in American culture. "And different was an inescapable part of my identity from the start, so I gravitated to the one place where different didn't mean suspect" (WK 282).

This (re-)framing of the image of the Afghan by providing alternative frames of interpretation and by filling existing frames with more complex information should not conceal the fact that the very language of binary thinking connected to it remains highly visible. This overall dominance of East versus West vocabulary, which is already suggested in the title, thus brackets Ansary's life and his narrative. 
He summarizes this with respect to the different paths his own family members have taken and returns to the theme of positioning oneself in either East or West toward the end of his account: "My siblings and I grew up with such divided souls, and we responded in different ways," he summarizes (WK 279). His sister Rebecca "shifted almost entirely to the West," as he explains in the epilogue (WK 279). She married a man who "appreciated her American persona," and in her professional life she focuses on "Western theater" as a university professor (WK 279-80). Ansary's brother Riaz, on the other hand, "shifted to the East as thoroughly as he was able," he observes (WK 280). He has ultimately left the United States to live in the United Arab Emirates and teaches Arabic there. "Riaz' soul ended up even east of Kabul," Ansary plays on the title of the book (WK 280-81).

As to Ansary himself, his soul remains "bicultural" as he states, yet, he clearly positions himself on the American side. "I shifted my weight quite definitely over to my American foot," he metaphorically puts it (WK 281). This does not prevent him from actively engaging with the other foot. With his continued mental and physical oscillation between both worlds, Ansary uses his American agency to engage in the public discourse between both worlds. In his memoir, he definitely does not achieve this by creating a mere counter-narrative, as the theory and practice of ethnic life writing suggests. Instead, Ansary reframes the outside view of East and West with detailed insider knowledge based on his authority as a bicultural writer and public figure. At the same time, he cannot deny to be restrained by the existing frames surrounding him in the present media environment. The dichotomy between East and West therefore remains omnipresent. To Ansary, however, this is not a normative burden, as Postcolonial Literary Studies might suggest. Rather, this division of the world obviously constitutes the mental framework through which the public clusters information about the respective Other. Dichotomies therefore do not prevent the dissolving of stereotypes in this case. Instead, the stereotypes are altered on the basis of detailed information on Muslim and Afghan identity. The method of contrasting helps achieve this function of complexity creation.

Ansary obviously believes in the success of this method of reframing based on binary thinking and continues the path he has opened up with his memoir and with his e-mail. His life remains the one of a journalist, writer, and public spokesperson. All these functions allow him to (re-)frame the public discourse on Afghanistan, the Muslim world, and the East at large. The basis of this is information, not counterstereotyping. As he announces in an interview: "I'm going to continue to do what I've done in the last six to seven months, which is bring information from that part of the world to this part of the world" (Interview with Menten). 


\subsection{Reception: The (Re-)Framed Muslim Fundamentalist and His AUdience $\left(\mathrm{V}_{4}\right)$}

A framing analysis of Ansary's memoir on the basis of a theory of production and reception would be imcomplete if it ended with the discussion of the authorial and textual frames. It still remains to be explored which effects the detected frames have on the readership. More precisely, this reception-oriented analysis seeks to reveal in how far Ansary's frames resonate in the views and discursive patterns of the audience and whether this leads to a reframed notion of the Afghan Muslim. West of Kabul provides a very promising study object for such a holistic analysis since some of the frames found in the memoir are not found in the common media discourse on Afghanistan and the Middle East. A thorough investigation of the audience's reaction to the book lays the groundwork for more far-reaching findings on the usefulness of frame analysis in life writing studies. Reception, as the theoretical model suggests, comprises a multi-faceted process, which acknowledges the role of the memoir in the media environment at large. This also includes the realm of the marketplace where Ansary's book proved quite successful.

\section{West of Kabul, East of New York in the Marketplace}

One of the supposedly most decisive differences between East and West is the latter's obsession with materialism and unlimited commercial indulgence. Ansary himself admits having adopted this credo of American culture when giving in to his own "materialist" impulse on his trip. Nevertheless, no book would ever be successful outside the academic realm if nobody bought it. This simple equation of supply and demand lies at the basis of economic thought, although it does not meet the taste of many postcolonial scholars, intellectual leftists, and adherants of high culture. If Literary Studies really want to leave their anti-materialist corner and move beyond the ivory tower, the importance of economics in the reception of literature has to be accounted for. Especially in the case of Afghan life narratives, such a move indeed promises new insights into the mindset of the readership. "If we are what we consume," Whitlock in this context states, "buying life narratives from Afghanistan is a way of indicating cosmopolitan tastes, openness, sympathy, political commitment, and benevolent interest in cultural difference" (55). ${ }^{15}$ In fact, the marketing of West of Kabul seems to have appealed to all of the above sentiments.

15 Despite making detailed speculations about audience preferences and predispositions, Whitlock never reveals the sales figures of the works she discusses. 
Image 5: Book Cover of West of Kabul, East of New York

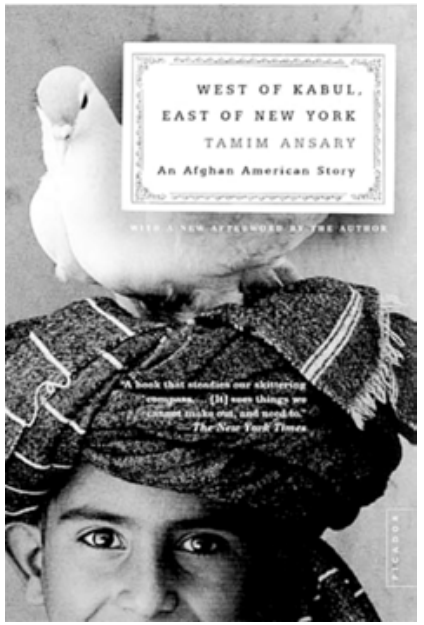

Source: Front cover of the memoir ("WK, Front Cover").

West of Kabul, East of New York was published in March 2003 by Picador. The cover of the book shows a young, supposedly Afghan, boy wearing a turban. On his head sits a white dove, the common symbol of peace. The boy is smiling shily, his eyes are shining. He clearly represents the "exotic" Other who promises to take the reader to an unknown world. The back cover first lists quotes from reviews of major newspapers, which prize the book as "Urbane, accessible, compulsively readable" (Los Angeles Times), "[s]tirring" (Santa Fe New Mexian), "delicious" (Esquire), as well as "emotional and moving" (The Times-Picayune). The blurb underneath the reviews mostly focuses on Ansary's "divided self" and his search for a united identity on his journey. It also immediately relates to the events at the World Trade Center and Ansary's e-mail which brought about his public popularity. The short text ultimately closes by regarding the e-mail as "the culmination of his lifelong struggle" whereby the memoir represents "his story." Next to the paragraph, a picture of Ansary is printed and a one-sentence bio mentioning his publication of several children's books and his authorial contributions for Encarta. ${ }^{16}$

The publication of the memoir fell roughly 1.5 years after the 9/11 attacks and in the middle of the military intervention of the U.S. in Iraq. The operation followed the previous intervention of U.S. forces in Afghanistan in October 2001. ${ }^{17}$ This immediate political involvement in the Arab world made the demand for books on the Middle East rise considerably. As the New York Times journalist Martin Arnold noticed in October 2001, ten out of 15 books on the New York Times bestseller list were related to terrorism or similar topics. "Even the Koran has become a big sell-

16 Encarta counts as one of the leading electronic encyclopedias. Ansary's contributions again emphasize his focus on historical research. Moreover, at the center of Encarta is a virtual map of the world which the user can interact with to seek information on global, regional, and local histories. Metaphorically speaking, Ansary with his focus on geography and geographic position shifting creates a similar map in his memoir.

17 In June 2011, president Obama announced the withdrawal of 30,000 troops from Afghanistan by the end of 2012. As the president declared in the fall of 2011: "After nearly 9 years, America's war in Iraq will be over" (Montopoli, "Obama Announces”). Still, about 40,000 non-combat troops are to remain in the country at the time of writing. 
er," he writes (E.3). ${ }^{18}$ Ansary's memoir obviously appeared at the peak of this period. The blurb on the book cover emphasizes this link to the WOT. The mentioning of Ansary's multi-ethnic identity, however, exceeds this political focus and appeals to a readership concerned with identity negotiation and ethnic identity conflict apart from current political quarrels. Based on these hints, the target audience of the book certainly includes American readers eager to get insights into a world they only know from television newscasts and the context of war. In addition, a larger audience of readers identifying with multi-ethnic identity negotiation, such as Afghan Americans or members of other ethnic minorities, can count as possible consumers of the narrative. Especially the emotional adjectives used in the newspaper reviews appeal to the latter aspect of personal involvement. Since the book is clearly described as memoir, readers with a general interest in life writing are also included in the potential readership.

The actual sales numbers of the memoir confirm the large target audience. About 55,000 copies of the book were sold by the end of 2011 (Ansary, "Your Questions"). This number by far exceeds the sales figures of most other Arab American narratives. ${ }^{19}$ The marketing of the book in print format was complemented by the publication of West of Kabul as audio book in March 2007 (Baskin 112). This time, the press was Blackstone Audio Inc. ${ }^{20}$ The fact that there exists an audio version points to the high commercial success of the book. So far, hardly any other contemporary memoir by a Muslim or Arab American has been transformed into an audio version. Despite the fairly long time lapse between the book publication and the launching of the audio book, the marketing material remains largely the same. The editorial reviews found on prominent sales pages offering the electronic version of West of Kabul therefore have not been replaced.

Changes have indeed occurred, however, in the case of the outer appearance of the memoir as audiobook. The front cover differs significantly from the one of the print version and lacks the high degree of personalization. The new cover is largely held in black with only a small lighter strip of sky spanning underneath the title. At the bottom, one can see the silhouette of a city under a foggy mist emerging. Surprisingly, this silhouette does not show the fragments of the bombed Kabul cityscape, as one might expect considering the gloomy atmosphere of the dark. Instead, a closer look at the picture makes one recognize the skyscrapers of New York with the Empire State Building in the center. Whereas the title therefore puts equal em-

18 Yale also purchased rights for the term "Taliban" from Taurus London (Arnold E.3).

19 Another outstanding example of an Arab American bestseller in contemporary life narrative is Lolita in Tehran by Azar Nafisi, which was also published in 2003 and remained on the New York Times bestseller list for more than 100 weeks (Nafisi, Home page).

20 No reliable sales figures could be obtained for the audio book. The press bought all rights from the author and does not report to third parties (Ansary, "Your Questions"). 
phasis on both worlds, East and West, the new edition geographically locates the memoir in the West with its prototypical image of the New York skyline. This stands in sharp contrast to the romanticized and Orientalized image of the young Afghan boy on the print version. The way in which the New York cityscape is presented under the black and dusty sky clearly evokes images of the 9/11 attacks. If any media image has burned itself into the memory of millions around the globe, it is this picture of a city that, for days, was covered under a black cloud of ashes. The scenes of people running disoriented in the streets and covered in white dust were repeated over and over again on $\mathrm{CNN}$ and other national and international broadcast stations. It comes as no surprise that the new front cover stirs these memories by what is obviously missing from the cityscape - the twin towers.

\section{Image 6: Audiobook Cover West of Kabul, East of New York vs. Press Photo 9/11}

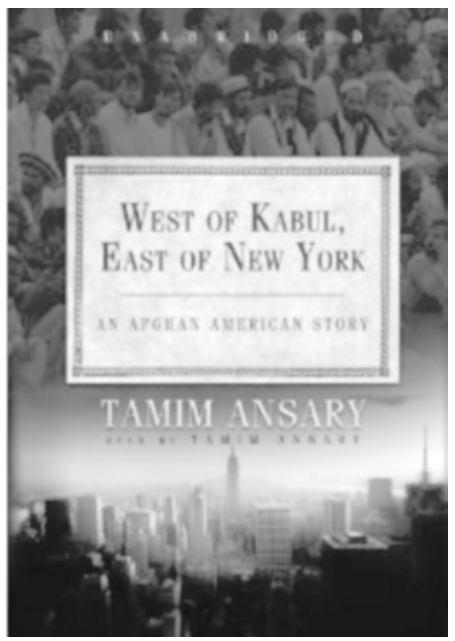

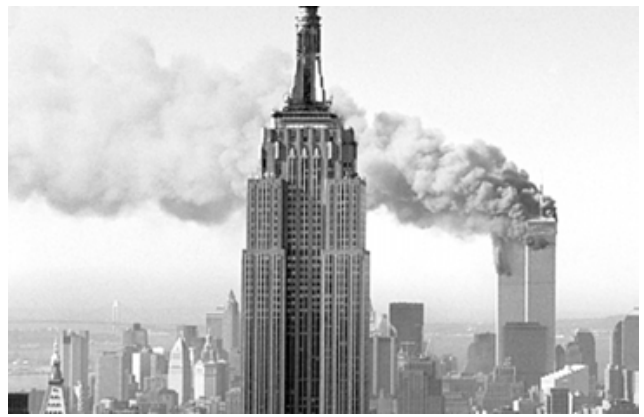

Source: The left image shows the cover of the new audiobook version (“Audiobook Cover $W K$ ”). The right image depicts a press photo taken on $9 / 11$ (Lederhandler).

Whether the different covers of the two versions are rooted in different demand patterns of the audience in dealing with the trauma of 9/11, or whether the presses merely pursue different marketing strategies, remains speculation. Clearly, however, each individual image sends a different message to the readers and listeners as to where the narrative they are about to consume might take them. Whereas the first might evoke classical ideas of Orientalism, the second one is located in the political climate of the here and now. Ansary himself was only involved in the selection of the cover of the print version. The cover of the 
audiobook was chosen by the press. Ansary himself states, he does not have any reservations regarding the motif. ${ }^{21}$

This close look at the way in which the book has become anchored in the marketplace already leads to the emergence of certain frames. Whatever the reader sees when looking at the cover already raises specific expectations as to where in his cognitive framework the memoir might be placed. It now remains to be explored in how far this expectation goes in line with the frames found underneath the cover and to what extent these frames actually become internalized and reproduced in popular discourse. A close-reading analysis of audience reviews reveals this effect of frame resonance. Both the journalistic as well as the public readership are the agents in this process.

\section{The Journalistic Audience}

Journalists who write about other journalists are rather an exception than the rule. ${ }^{22}$ Mostly, this scenario happens whenever something is not right, as in the case of journalistic scandals or war coverage. In the case of Ansary's memoir as subject of their writing, however, everything seems to be more than right. Whereas the academic world has not shown much interest in Ansary's memoir so far, the public press and notable magazines discussed his work in a very detailed and benevolent way. One reason for this heightened interest in literature from Afghanistan by feuilleton journalists, of course, was the need to satisfy the demands of the readership post 9/11. As one reviewer notes: "Americans are hungry for that personal story the human face of the country in which our government plays out its war on terrorism" (Smith Rakoff 53). Reading that "personal story" from someone who is not only Afghan American but a public media figure is even more exciting. It is therefore little wonder that most reviewers focus on the persona of Ansary first before dealing with the memoir itself. When doing so, however, it turns out that the textual issue frames indeed have a significant impact on the journalists' perception.

The majority of newspaper reviewers use Ansary's e-mail as the starting point of their discussion. As the subline of Joanna Smith Rakoff's review states, an "E-

21 Ansary explains more details on the cover photo of the print version in an e-mail to the author. "I found and supplied the boy-with-dove photo. The cover designer used only part of the photo - the original is the whole boy, with some background" ("Your Questions").

22 This simplified categorization becomes more complicated when literary writers function as reviewers for magazines and thus write about the literary work of other journalists such as Ansary. An example of this is a review of West of Kabul by the Iranian American author Gelareh Asayesh. She also published a memoir entitled Saffron Sky: A Life between Iran and America ("The Stolen Education"). It remains debatable in how far literary involvement impacts the objectivity of journalistic writing in these cases. 
Mail for Afghanistan Catapulted Him Into Celebrity" (53). The somewhat awkward preposition "for" instead of "from" here emphasizes Ansary's taking of sides with his public involvement as a public agent. He is consequently described as a "sought after media pundit, an unofficial spokesperson for the Afghan people" (Smith Rakoff 53). Other reviews confirm this exceptional status of Ansary as an author who became "famous overnight" - not so much because of his books or other journalistic works, but because of the e-mail he sent the day following the attacks (Hilton 12). Others rather ironically refer to him as a "talkshow celebrity" due to the public visibility the author gained (Seaman 1186; Baker 13). All of these comments underline what Ansary himself explicates at the outset of his account. He is not just some Afghan American writing but the Afghan American who sent the e-mail. This underlining of his authorial agency based on personal status is certainly effective, as the journalistic reviews indicate.

These praises of Ansary's public fame, however, are not based solely on the impact of his e-mail. Rather, this effect was only possible because Ansary's bicultural identity endows him with an exceptional position in the public discourse on Afghanistan. The reviews take up this larger background of "bicultural existence" as underscoring Ansary's power to influence his readership (Smith Rakoff 53). In his e-mail, he spoke "for Afghanistan with his American voice"; in his memoir, he derives his agency from the very same bicultural existence, as critics note (Asayesh, "Stepping Westward" T.15). A reviewer from The Booklist expresses this logic by using the familiar vocabulary of two worlds opposing each other: "Ansary embodies the East, the West, and the struggle between them" (Seaman 1186). Despite the fact that this also leads to severe identity conflict for Ansary, critics frequently highlight his positioning on the American side of the hyphen. They thus point to the lasting impact of his privileged upbringing in a "Western-educated family" (Smith Rakoff 53)" and the family's encounter with "the West" (Asayesh, "Stepping Westward" T.15). Some reviewers interpret this battle of the "divided self" explicitly in the context of the WOT by stating that this event has led to the result that Ansary's "American self is winning the cultural wrestling match inside his head. His goals and desires are distinctly American [...]” (Smith Rakoff 53).

These reviews with their initial focus on Ansary as a public figure and on his bicultural identity confirm the blended relationship between the literary and the media market. The previous media contribution of Ansary and the coverage about this contribution in turn become the subject of the media discussion of Ansary's memoir. This severe degree of self-referentiality as major feature of journalistic production also sets the basis for resulting framing effects and the reproduction of existing frames of interpretation. Often, the previous presence of a topic or persona in the media discourse becomes the very reason why a topic is discussed again. This is certainly the case with Ansary since it is no speculation to assume his memoir would have received much less intention had he not been the author of the e-mail. 
In addition, the agency and authenticity he is granted by the journalistic readership are clearly based on his status as relying on his occupation as a journalist and his bicultural identity. This exactly reflects the way in which Ansary positions himself at the outset of the narrative. As the reviews also suggest, the credibility derived from his ethnic background is additionally underpinned by his conscious decision to lean toward the American side of the hyphen. A reviewer from the The Washington Post takes this up by quoting Ansary's own words from before the e-mail, when he was still a "regular American guy" (Asayesh, "Stepping Westward" T.15).

These insights stating that there is someone writing who does have bicultural expertise but, nevertheless, is an American and therefore part of the West, strengthens Ansary's potential to convince his audience with his writing. The necessary condition of credibility for framing is therefore affirmed. This is also reflected in the genre classification made by the journalistic readers. His autobiography is nowhere conceived to be a fictional creation of dubious memories. Rather, Ansary's truth claims are indeed accepted by the readers. A reviewer from Publishers Weekly thus notes that the "book chronicles, with calm insight and honesty" (Rotella 55). This focus on mere facts, however, is complemented by a sense of "nostalgia," as another journalistic review states (E.2:39). Instead of nostalgia as an emotional device typical of fiction writing, the reviewer adds that that nostalgia "can be as truthful as memory [...]" (E.2:39). The choice of words here is crucial for tracing how the textual frames actually transfer to the readership. Authenticity and truth are the major criteria underlying the reception of the memoir as fact, not as fiction.

This factual approach to the memoir as chronicle with a sense of "nostalgia" furthermore points to the enormous relevance of the history frame in Ansary's memoir. "Ansary's strategy is as simple as it is rare," a reviewer from the Seattle Weekly analyzes. "He speaks of the world and its grand events entirely through the spectrum of his own experience. He doesn't lecture us on Afghan history; he tells us as he learned it, growing up among the poor but privileged half-Westernized elite of royal Kabul in the early years of the Cold War" (Downey). These lines reflect the dominance of the historical frame in Ansary's memoir. As Downey explains, this effect is only possible based on the bicultural authenticity of the author. The fact that the reviewer uses the word "strategy" when praising Ansary's writing furthermore indicates that Ansary is assumed to intentionally construct his narrative around history. In contast to the impulse of literary critics to escape questions of authorial intention, the journalistic readership obviously treats the strategic relevance of life writing not only as a given, but as a much acclaimed feature of the genre. The didactic purpose that the reviewer hints at when contrasting Ansary's strategy to the one of a university lecturer is furthermore highlighted by Downey's tartly inference that Ansary's goal is to "introduce previously immune Americans to 
how it feels to be a target of the world historical process." ${ }^{\text {,2 }}$ The New York Times reviewer Richard Eder shares this impression by introducing the work as one that "delivered us from text into context, from crisis into history [...]" (E.2:39). Other reviews mention the history frame by referring to specific aspects of Ansary's historical analysis, such as Afghanistan's struggle between tradition and modernity, the Soviet rule, and the role of the Taliban ${ }^{24}$ (Hilton 12).

Most important in the context of this resonance of the historical frame in the journalistic audience is the twofold nature of Ansary's agency that allows for this effect. Ansary is not merely accredited by critics to convey historical knowledge based on personal experience, as the theory of life writing suggests as most important feature of memoir. This personal perspective only functions in connection with his historical expertise he conveys in the form of very illustrative writing. This allows the readers to instantly engage with a time and world which is utterly opposed to the America of the here and now. As Capital Times reviewer John Nichols states in this context, "it is refreshing to read of a time and a place where, instead of television, we had genealogy." This praising of Ansary's ability to transmit historical information in a comprehensive, yet, easily accessible way is complemented by the thematic range the author covers. Nichols probably provides the most striking testimony to the role of the book as historical inquiry exactly because it is not an official chronicle or a "polemic" against imperialism but a memoir of historical significance. As he concludes, the book "belongs to the broader library in which are considered the big questions about the price of progress in this perhaps too modern world." This strong focus on Ansary's historical insights which spans like a read thread through the majority of journalistic reviews thus altogether highlights the result of the textual frame analysis and the resonance of the historical frame in the journalistic readership. ${ }^{25}$

23 Ansary himself confirmed this notion in an interview by stating that Americans have a need to learn about Afghan history but hardly are given the appropriate material for that (Interview with Menten).

24 Isabel Hilton also criticizes Ansary for his rather "medieval depiction" of the Taliban because, according to his stance, the Taliban represent the "Western (and the Soviet Union) vision of progress" (13).

25 Ansary's thematic orientation toward historical analysis has drawn even more public attention in reviews on his historical book Destiny Disrupted (2009). The study has received international attention and already been translated into several languages, among them German. Interestingly, the title in German reads "Die unbekannte Mitte der Welt: Globalgeschichte aus islamischer Sicht," which directly points to the lack of knowledge underlying the prominent history of the East as written by the West. Critics claims that the author's major strategy is to pursue "history as narrative" by telling "two histories" in order to counter Fukuyama's thesis of the end of history (Schneiders, my translation). 
A similar impact of Ansary's memoir on the audience can be detected when looking at the religious frame. The issue of religion thus represents the second focus taken up by journalistic reviewers (Rotella 55). Similar to the historical frame, religion is largely discussed under the overall umbrella of 9/11, which most critics see as the basis of Ansary's narrative (Eder E.2:39). Ansary's aim to tell the true story of Islam comes to constitute a major issue occupying the critics' perception of the memoir at large. Especially the story of Ansary's brother and his orthodox conversion to Islam entirely "east of New York" is interpreted as a prototype of Islam's encompassing social and political function (Silverman 108). Again, critics here point to the significance of Ansary's interference in the WOT discourse based on his e-mail. The critics therefore read the memoir as a similar discursive intervention to explain the real reasons behind the "holy war between Islam ${ }^{26}$ and the West" (Baker 13). Particularly, Ansary's picture of the Muslim youth and of its desperate economic situation is conceived of as highly illuminating by critics since it adds important information to the actual life circumstances surrounding religious upbringing (Asayesh, "Stepping Westward" T.15). ${ }^{27}$ The fact that Ansary himself has ultimately rejected "the Muslim world" is read to endow him with additional agency to elaborate on the issue (Asayesh, "Stepping Westward" T.15). Based on his Muslim family background, he still counts as an insider while at the same time gaining the necessary analytical distance to convey reliable information otherwise unobtainable for the American readership.

The given reflections on the importance of religion in Ansary's memoir point to a similar effect as found in the case of the historical issue frame. Religion as major interpretative lens therefore does transfer to the journalistic audience. The reviews also reveal that the religious frame, just like the historical one, is of an encompassing nature because it overlaps with other issues. A striking indication of this interrelatedness is provided by the following statement of a reviewer who claims that the book represents an "exploration of militant Islam, with a smattering of contemporary Afghan history" (Asayesh, "Stepping Westward" T.15). The issues of politics, culture, and religion are thus also reflected in a large majority of reviews. Mostly, however, their importance is mentioned with respect to their interplay with historical and religious aspects, whereby the history frame clearly dominates.

26 In regard to the journalistic reviews of Ansary's work, the terminological conflation of Islam with Eastern identity is nevertheless pervasive. Barker provides an example of this since he uses Islam as an umbrella term for the binary opposite of the "West" (Baker 13).

27 This relating of religious identity to economic circumstances can also be read as indication of a different media frame that is often applied by journalists, namely, the metaframe of economic progress. This frame has also been found to constitute a global-metaframe by Dahinden (107-08). 
Another highly illuminating result in connection with the audience resonance of the various issue frames in the memoir can be found when looking at the media frame. Here, the journalistic reviews provide an equally striking confirmation of how Ansary is able to shape the vision of his readers. This refers to questions of method and technique as well as to content. In line with the critics' perception of Ansary's work as non-fiction, as opposed to literary, fictional, or semi-fictional life construction, critics praise the clarity of his prose as "subtle and addictive" (Smith Rakoff 53). Furthermore, the "directness" of his voice is celebrated in direct connection to his ability to integrate the voice of his travel acquaintances ${ }^{28}$ (Asayesh, "Stepping Westward" T.15). The comments on the writing technique of Ansary underline the journalistic verve conveyed in the memoir. His story is therefore clearly read as the work of a reporter who expresses his insights based on fairly objective analysis, plain language, and a collection of information derived from interviews. This perception of Ansary's memoir as a work of journalism - with all the implications a journalistic media piece implies - is made explicit by another reviewer. Donna Seaman thus states that the memoir "illuminates more brightly than any news report or political analysis" (1186). This remark directly establishes the link between the memoir and its place in the larger media discourse. The New York Times reviewer even goes one step further by not only comparing the memoir to journalism but equating the two: "Such personalizing of an event is not only good journalism, but it illuminates history, too, and also is the stuff that may still capture interest long after the event" (Arnold E.3). Another confirmation of this is provided in the Seattle Weekly which contains even more powerful comparative images. As the reviewer states, the book "is one of those rare pieces of journalism Rebecca West's ${ }^{29}$ dispatches from Nuremberg come to mind, and John Hersey's Hiroshima - that don't just record history but make it" (Downey).

This comparison to a famous journalist who covered such dramatic historical events as the Nuremberg trials and the Hiroshima catastrophe strongly underlines the effect Ansary's journalistic persona has in the eyes of journalist critics. Not only do the reviewers confirm the inseparability of memoir from mediatic discourse based on similar narrative means employed. They also point to the actual - not only theorized - impact of memoir on public and "social discourse" (Asayesh, "Stepping Westward" T.15; Nichols). Obviously, this intervention is not achieved through the mere establishing of a counter-narrative, as ethnic autobiography theory has claimed. In fact, ethnicity, alterity discourse, and victimization do not appear as

28 Asayesh critiques that the conversations Ansary recalls deviate too much from his own voice and thus "read more like lectures [...]" ("Stepping Westward" T.15).

29 West is acclaimed not only for her journalistic work but for the fact she has also made outstanding contributions in the literary field (Schweizer 29). This multifaceted approach to writing is in line with Ansary's broad interests by far exceed the realm of journalism. 
frames in Ansary's story at all, neither do these themes appear in the reviews. The critics instead attest the work an almost didactic discursive function in a much larger sense than the mere focus on postcolonialism would suggest. Ansary does not engage in the normative condemnation or reversal of Orientalism. Rather, his method is based on the conveying of knowledge, i.e., cognititive and emotional information allowing the reader to develop a more complex picture of the Afghan. In effect, this leads to the emergence of a (re-)framed image of Muslims. The review in Publishers Weekly puts emphasis on the crucial function of detailed knowledge as key to changing stereotypes. Mark Rotella thus regards Ansary as an "educational writer" ${ }^{30}$ who provides orientation for the reader and conveys the complexity of Afghan by using journalistic language which is plain and easy to process (54). Another reviewer metaphorically describes this learning effect by concluding that Ansary's memoir "steadies our [the American audience's] skittering compass" (Eder 2:39). In addition to the cognitive function of framing, this also hints at the importance of positionality and the geographic oscillation between East and West, as conveyed by the memoir's title.

In sum, the audience responses in the case of journalists reflect the frames revealed in the textual analysis. This also sheds light on the usefulness of framing as analytical tool in life writing studies. The tracing of frames starting with the authorial intention of the author, proceeding to the text itself, and finally leading over to the way in which frames resonate in audience discourse reveal insights into the processing of life writing which former theoretical approaches have not covered. Furthermore, the equalization of Ansary's memoir with journalism and with other non-literary works highlights that, even though all these formats represent different genres, their reception functions according to similar trajectories. This determines the very impact of non-fiction writing on social discourse. Ansary's "advocacy rather than activism" therefore is perceived by the audience to be of equal importance in his political and literary work (Smith Rakoff 53). This also underscores the impact of life writing on social discourse at large, which also means that any effort to seclude the genre merely into the literary arena is mistaken. One critic puts this argument into a nutshell by writing that "it can reasonably be argued that any sensitivity the United States and other Western governments showed Afghan civilians was in no small part a byproduct of Ansary's efforts" (Nichols). Since the

30 This didactic orientation of Ansary's work at large, even in his memoir, is underlined by several reviews which recommend the memoir to academic libraries and as high school literature. The book is actually discussed in the section "Political Science" (Silverman 108). Ansary himself identifies with this educational purpose. On his homepage, he calls himself "Afghan American Author and Lecturer." In addition, under the rubric "My books," Ansary features West of Kabul, East of New York as "common freshman reading by colleges and universities [...]" (Home page). 
American "sensitivity" not only depends on the government but on the body of the American people, this impact - if it holds true - also needs to be reflected in the reviews provided by the larger consumer readership.

\section{The Consumer Audience}

When asked about the reaction of his readers to his memoir, Ansary recalls amiable experiences. Above all, Americans tell him that the picture he draws of himself in the book is quite "likeable." To him, as he states, it is even more important that many readers indeed treasure that he is telling "the truth" and that he "got it right" ("Interview with Menten"). This reaction by the American readership again appeals to Ansary's permanent quest to assure his own authenticity and credibility. As it turns out, this high degree of agency indeed caters to the general audience as well to the effect that the interpretative frames established in the memoir are mirrored in their reviews.

When speaking of the general readership of Ansary's memoir, the still manageable number of copies sold suggests that the data available might not be overabundant. Still, the variety of reviews found on popular selling sites and book discussion platforms indicates a comparatively high engagement of the readers with the book and an equally high need to share their views. At the time of writing, ${ }^{31} 31$ reviews could be found on Amazon as well as 392 ratings and 95 rankings $^{32}$ on Goodreads. Sometimes, the reviewers very briefly state their spontaneous reaction right after reading the book. Other reviewers are quite thorough and elaborate in offering detailed thematic reflections. The following close-reading analysis of a selection ${ }^{33}$ of these reviews offers a basis for determining if and how strongly the textual frames dominate the perception of the audience.

31 As of November 2011.

32 A review comprises a rather thorough discussion of a book which usually focuses on specific topics and often mentions textual references. Rankings or ratings, in contrast, are quick evaluations of books which are usually expressed by distributing stars on a scale from one to five. Reviews and rankings have become helpful guides for potential readers who based their purchase decision of books on other customers' views.

33 Since this study does not actually conduct a quantitative content analysis but a closereading investigation of audience reviews to identify audience frames, the limited scope of the analysis requires a selection of a certain number of texts, e.g., by excluding very short reviews or by summarizing repetitive statements. In empirical terms, this procedure certainly bears a selection and interpretation bias on the part of the author. Since the goal of this analysis is not to provide a representative and methodologically unchallangeable study but an experimental one which points to the blending of different methods, this shortcoming is not only unavoidable but necessary. 
The first aspect to notice in the reception analysis of West of Kabul is that reviews can be found in the section of non-fiction. Obviously, this corresponds to the category under which the book is listed by journalistic reviewers as well. The first responses to the book date back to the time right after the book's release and continue up to the present. Some recent reviews therefore refer to the audio version. ${ }^{34}$ The comparatively high popularity of Ansary's memoir for the wider audience, as was already the case with the media attention the author gained, can largely be traced back to the post-9/11 e-mail. Most reviewers point to the e-mail and Ansary's involvement in the public debate on Afghanistan as major point of attention before turning to the content of the memoir. This awareness of Ansary's public persona is immediately linked to the agency accredited to him. As one reader states, Ansary provides an "honest, open perspective" on the events of 9/11 in his book (Community Reviews of $W K$ ). Another reader strongly underlines that the account is above all "realistic" (Community Reviews of $W K$ ).

These statements highlight that the general readership, in line with journalistic reviewers, places great weight on the authenticity and truth of the memoir. These are the criteria that determine the credibility devoted to the author and ultimately affect the way in which the work is processed. In Ansary's case, this truth-telling capability mostly rests on his bicultural identity, "his own predicament as a man divided between two cultures," as one reviewer puts it (Community Reviews of $W K$ ). This "description of straddling the east and west divide," endows him with the insight to "accurately" convey information on both worlds, a reviewer named Dalia points points out (Community Reviews of $W K$ ). The importance of conveying cultural insider knowledge while at the same time maintaining a distanced analytical perspective is also stressed by many other reviewers. He thus counts as a "bicultural guy" (Community Reviews of $W K$ ) who allows his readers to look at the U.S. and Afghanistan "through a more balanced lens" (Community Reviews of WK).

These comments on the author's bicultural background reveal an interesting pattern which meets the theoretical assumptions of the framing model. While the majority of readers seem to be highly interested in the issue of ethnic identity negotiation as such, they do not see this as the major theme of the memoir. ${ }^{35}$ Rather, An-

34 Obviously, listening to an audio-recording and reading a print copy stand for two different ways of media consumption, connected to different processes of sensual information processing. Since the focus of the reception analysis here rests mostly on the content and structure of the work, which do not differ in both versions, reviews on the audiobook will therefore be included in the following.

35 Since many online reviewers do not reveal their full name, it is often hard to make inferences on their real identity and their ethnic background. In some cases, however, where a full name is given, it can be speculated that respective reviewers share an Arab and/or Muslim background with Ansary. 
sary's dual perspective is perceived as the major foundation of his authorial power. It endows him with the agency to provide accurate information and in turn create interpretative frameworks. Any conventional reading of the memoir in the vein of postcolonialism's reductionist focus on identity negotiation as the major end in and of itself is too short-sighted. A critical comment by one of the readers makes this lack of the classical ethnic identity struggle very clear:

After more than 100 pages, there was still no true conflict. Ansary says it was awkward - and maybe a little unpleasant - growing up Afghan-American in Afghanistan. But his childhood seems to be pretty privileged (even by American standards). His father is employed by the government, which automatically makes him wealthier than about 80 or 90 percent of the country. He obtains a certain high status among children his age without much struggle. And he seems to have good memories of his childhood. There are no racial/ethnic conflicts. He's not picked on because he's too American or too Afghan. (Christina Kristofic)

It remains debatable whether there really is "no true conflict" with respect to Ansary's multi-ethnic background. The comment nevertheless emphasizes that readers of ethnic life narratives are used to stories which are much more focused on the theme of conflict-laden ethnic identity negotiation. Other readers who self-ientify with Ansary's mixed background indeed report about an emotional bond emerging from the account. "Ansary's memoir is beautiful, heartbreaking, and honest," one of them states. This also holds true for those who come from the Western side of the cultural divide as another reviewer indicates. "He [Ansary] writes about cultural, national, political, religious, and personal identity in a way that the reader can connect to him, even if our histories are different" (Community Reviews of WK)

The latter statement not only emphasizes the emotional component of Ansary's multi-ethnic identity struggle as basis of identification. Also, the prevalent themes mentioned by the reviewer point to the cognitive effect of the narrative. History for the readers here plays the most decisive role. Most reviewers do not primarily regard the narrative as personal storytelling but as an "analysis of Afghanistan's past and present [...]" (Community Reviews of $W K$ ). The reviewer Kim adds that she found it "intriguing to learn about the rich history" of the Middle East (Community Reviews of $W K$ ) and others characterize the book as "a chronicle of Afghanistan and their [the Afghans'] turbulent history [...]" (Community Reviews of WK). This stressing of the memoir as historical account gains even more prominence among readers who seem to have much historical knowledge themselves. Some of them reflect on the book in a very detailed manner and take up specific historical elaborations provided by Ansary. “Tamim made a fairly balanced analysis of Afghanistan's 
past and present," Intikhab Amir ${ }^{36}$ writes. "His views about Pakistan are close to truth, though he misses the point that Pakistan is also a victim of Russian invasion of Afghanistan," he then criticizes (Community Reviews of WK). This reaction shows that Ansary's historical framing of his memoir fosters historical discourse on the part of the readers. In line with the autobiographical pact, credibility is the basis of this effect, which also draws the dividing line to other genres. ${ }^{37}$ The readers place West of Kabul in the category of history books and are attracted by the way in which Ansary differs from the neutral and dry way of history education they know from their schooldays. The reviewer Jenny thus states that "it's more than just a boring history read" (Community Reviews of $W K$ ). This is strikingly underlined by the comment of the following reader who describes herself as someone who is usually not a "non fiction reader but this is a biography by an Afghani-American easy to read history and background on Afghanistan and Islam [...]" (Community Reviews of $W K$ ).

All these reactions underline the resonance of the historical frame. Yet, they are also closely connected to the issue frame of religion. Again, the comments on the importance of religion read more like reviews on college textbooks than on leisure literature. "A fabulous introduction to the Muslim world, through the eyes of an Afghan emigre. Really, really good," Emily states (Community Reviews of WK). Other readers almost exclusively focus on the religious exploration provided by Ansary (Community Reviews of $W K$ ) and on specific religious information they were able to gain. Christina thanks the author for giving the "best explanation of the difference between Sunni and Shia Muslims I've ever read" (Community Reviews of $W K$ ). This also reveals more about the background of Ansary's readers. While some obviously gain their first insights into Islam from the book, others have substantial prior knowledge. The strong religious framing of Ansary's story, however, also raises critique. "The sub title of the books reads: 'An Afghan American Story," S Khalili writes and corrects "really it should read 'An Afghan American's Personal Journey through the world of Islam"' (goodreasds).

Although the high amount of religious knowledge derived from the memoir is appreciated by the majority of readers, some obviously feel annoyed by being forced to look at Ansary's life and at Afghanistan through the religious lens. This

36 Amir himself is a Pakistani journalist and writer who published numerous articles on the past and current historical situation of the Middle East and Asia and on multiculturalism.

37 The audience's inner urge to place a literary work in a specific category which de Man already recognized gains confirmation in the case of Ansary's memoir. While the large majority of readers clearly regard the work as non-fiction and historical account, others are confused about the status of the memoir. A reviewer named Kellie thus poses the following question: "This isn't a biography. It's not a work of fiction. So what is it?" (Community Reviews of $W K$ ). 
critique, however, allows for a finding that exceeds the specific issue frame of religion. Obviously, the frustration on the part of the reader is founded on a gap between his original expectation and the information acquired from the book. This in turn confirms the importance of genre classifications for the reception of life writing and ultimately for the likelihood that interpretive patterns are willingly adopted by the audience. As the example demonstrates, readers approach autobiographies with a more specific interest in learning about selected issues and not just with the intention to read the story of someone's life.

This points to the larger meaning of knowledge mediation for the purpose of intervening in and changing public discourse. The fact that autobiography as nonfictional work does have the ability to participate in mediated discourse is the most important finding in the analysis of the audience frames. Almost without exception, the readers stress the aspect of information gain with respect to different issue frames as most important benefit. Terms like "informative" (Community Reviews of $W K$ ), bringing "insight" (Community Reviews of $W K$ ), and "enlightening" frequently appear in the reviews (Community Reviews of $W K$ ). Another reviewer describes the memoir as "brow-beaten with information" (Community Reviews of $W K$ ). Overall, this vast amount of factual knowledge leaves another reader "understanding a lot of the world better" (Community Reviews of WK). A reviewer named Adres summarizes: "Every chapter feels self contained and like there is a lesson to be learned" (Community Reviews of $W K$ ). Others explicitly mention the didactic context of the book by stating: "What a great education on Afghanistan" (Community Reviews of $W K$ ). This general appreciation of the memoir as learning experience about Afghanistan is specified by others who specifically refer to certain issue frames. As another reviewer therefore states: "Finally a book that explains a culture in terms I can understand" (Community Reviews of WK).

The given reviews are remarkable when considering that a memoir is being discussed here, not a history textbook in college. Yet, the educational aspect appears to be a recurrent need voiced by the readers. It particularly occurs with references to history and religion, whereas the issue frame of culture does not resonate with equal emphasis in the audience reflections. Although not all textual frames therefore transfer to the audience to an equal extent, the reception analysis strikingly confirms the relevance of memoir as non-fictional work and medium of knowledge acquisition. The role of memoir as medium therefore automatically places the work alongside other media formats which compete in public discourse. This reference to the media is also found in the remarks by the general audience. One reviewer highlights the capacity of the work to provide an alternative image of Afghanistan due to the "power of communication" it reveals (Community Reviews of WK). An even more striking confirmation of this capacity to reframe the public discourse on Afghanistan by mediating different positions is provided by another reviewer. By taking up the geographic dualism of the book's title, the reader states that Ansary's 
narrative is a "timely mediation on the relationships between the East and the West" (Community Reviews of WK).

\section{Frame Resonance in Perspective}

Especially the latter review builds the bridge to the former analysis of the journalistic audience and reveals that the reception mechanisms of both groups overlap to a large degree. The journalistic reviews as well as the reviews of the general readership strongly support the existence of the historical issue frame as most dominant interpretation pattern, followed by the religious issue frame. Both groups place high value on cognitive information gain. This stands in contrast to the fulfillment of escapist motives or emotional pleasure, which mostly determine the consumption of fictional works. The cultural frame found in the text is somewhat more reflected by the journalistic reviewers. The same holds true for the strong emphasis on the overall political frame of the WOT, which seems to play a more dominant role for journalists. ${ }^{38}$ Both groups, however, clearly read the memoir with the political events of the present in mind. The salience of the WOT framing has certainly decreased in the recent decade, yet, the political context of the Middle East has remained conflict-laden ever since the memoir was first published.

What has not lost any salience, however, and this holds true for journalistic reviewers and the general readership alike, is the perseverance of the Orientalist framework surrounding the reception of Ansary's work. ${ }^{39}$ The vocabulary of the binary struggle between "East" and "West" is omnipresent in the majority of audience responses (see Eder E.239; Hilton 12; Rotella 55). The most noteworthy and metaphorical testimony to the transfer of this ideological frame is provided by the New York Times reviewer Richard Eder who concludes as follows: "Pointing east and west it [Ansary's memoir] signals not galactic opposites but two ends of a needle we can hold in our hand" (E.2.39). On the part of the general audience, the reviewer Janelle takes up the binary of East and West in describing her interest in

38 Certainly, the dyamic also needs to be accounted for when it comes to comparing journalistic and general audience reviews. The journalistic reviews at hand mostly stem from the period immediately following the publication of the memoir in 2003, when the impact of 9/11 was much more immediate. The reviews of the general readership, in contrast, were in part published much later, when the WOT had already lost some salience.

39 This linguistic differentiation between East and West is again the most striking characteristic appearing in reviews on Ansary's history book. Especially German reviewers focus on the aspect of ethnocentrism. They describe Ansary's book as an attempt to provide an alternative for the "Eurocentric model of history." Furthermore, they constantly reiterate terms such as "narrative of the West" and "Western science" (Interview with Güvercin, my translation). 
the book: "I read this book because Khlaed [sic] Hosseini ${ }^{40}$ mentioned it as a book Westerners should read about Afghanistan [...]" (Community Reviews of WK).

This engagement with Afghanistan as the other world which Westerners should learn about indicates the lasting significance of Orientalism as reflected in the binary vocabulary of East and West. As demonstrated in the textual frame analysis of the memoir, this ideological framing constitutes a recurrent practice by Ansary to structure and convey his experiences. The readers obviously reproduce this mental framework. It allows them to position themselves in the mental map of the world and thus gain insights into historical, religious, and cultural practices which they are not familiar with. It is most important to emphasize that this dichotomy is not used in a derogatory way in most instances, neither by Ansary nor by his readership. Rather, it serves as a tool to contrast information in a systematic way. The respective issue frames are embedded in this binary framework on the lower level of the frame hierarchy. The following graph gives a comparative overview of the different frame categories identified in the text and their resonance in the audience.

Table 3: Frame Resonance Matrix of West of Kabul, East of New York

\begin{tabular}{|c|c|c|c|c|}
\hline Frame Level & Frame & $\begin{array}{l}\text { Text } \\
\text { (Production/ } \\
\text { Medium) }\end{array}$ & $\begin{array}{l}\text { Journalistic } \\
\text { Audience } \\
\text { (Reception) }\end{array}$ & $\begin{array}{l}\text { General } \\
\text { Audience } \\
\text { (Reception) }\end{array}$ \\
\hline Ideological & Orientalism & $\cdots$ & $\cdots$ & ... \\
\hline Political & Neo-Orientalism & .. & .. & - \\
\hline \multirow[t]{4}{*}{ Issue Level } & History & $\cdots$ & $\cdots$ & $\cdots$ \\
\hline & Religion & .• & .• & .• \\
\hline & Culture & • & - & • \\
\hline & Media & •• & .. & • \\
\hline
\end{tabular}

Legend: The number of dots marks the salience of the respective frame, as based on the close-reading analysis

The table illustrates the strong correlation between the frames identified in the text and their resonance in the audience, clustered by the journalistic as well as the general reading public. The results suggest that strong frames have an equally strong effect on the reception process of the readership. This particularly holds true for the issue frames of history and religion, as well as for the overarching idological frame of Orientalism. Particularly noteworthy, again, is the resonance of the media frame in the audience. This suggests that readers are willing and able to engage

40 Khaled Hosseini is another famous Afghan American novelist who is best-known for his debut novel The Kite Runner. 
with the mechanisms underlying media production on a high level of complexity and self-reflection. This supports their ability to adopt alternative frames of interpretation and thus look at established stereotypes, such as the Muslim fundamentalist, through a different interpretative lens. It can thus be concluded that Ansary's partial reproduction of existing media frames is complemented by effective reframing efforts. It remains to be explored in how far other autobiographies succeed in this task of reframing the Arab/Muslim. 


\section{5. (Re-)Framing the Egyptian Belly Dancer in Letters from Cairo}

Proceeding from the memoir of Tamim Ansary to Letters from Cairo by Pauline Kaldas means a decisive shift in geographic and stylistic terms. Whereas Ansary already in his title hints at a country struck by war and terrorism, Kaldas sends her dispatches from Egypt, a country that, until the outbreak of the Arab Spring in 2011, counted as one of the more peaceful places in the Arab world. Tourists from all over the world spend their vacations here and especially students from the U.S. often spend one or more semesters at the American University in Cairo. Egypt lies at the heart of the Arab world with its ancient history and pharaonic past as the cradle of manhood. These images, however, have also contributed largely to Egypt representing a metaphor of the Orient at large, as conveyed by the early European travelers who explored the Nile and the pyramids. One of the most prominent Orientalist stereotypes, the one of the belly dancer, originated here. Up to the present, this stereotype dominates the public image of Egypt around the world. The insights into Egyptian life which Pauline Kaldas provides in her epistolary memoir, however, do not fit into this framework.

\subsection{SCHOLARLY AgEnCY $\left(V_{1}\right)$}

\section{Author and Structure of Letters from Cairo}

Pauline Kaldas was born in 1961 in Cairo where she spent the early years of her childhood. In 1969, the family immigrated to the United States. Kaldas explicitly relates this decision to the aftermath of the 1967 War and Egypt's defeat, which made many Egyptians look for a new place to live and raise their children (Kaldas, Letters from Cairo 3). ${ }^{1}$ Today, she works as an Assistant Professor of English and

1 All further references are to the same edition, abbreviated by $L C$. 
Creative Writing in Virginia (Kaldas, Home page). In this position, she has contributed immensely to the development of Arab American Studies as an academic discipline. ${ }^{2}$ Kaldas carried out two trips to her homeland. The first one took place from 1990 to 1993 and the second one in 2002 (LC 5). ${ }^{3}$ This second trip was motivated by the fact that her husband, who is a scholar in African American Studies, accepted a Fulbright scholarship to teach American Literature for one semester at Cairo University ( $L C$ 8). Letters from Cairo is an epistolary memoir recording the family's experience during its residency in the Middle East. ${ }^{4}$

As the title of the book indicates, Kaldas's memoir differs in many ways from the more traditional form of the memoir employed by Ansary. Kaldas presents her autobiographical reflection as an epistolary account. This format has traditionally been regarded as a bourgeois type of life writing which originated in France (Smith and Watson, Reading Autobiography 113). Especially in the $19^{\text {th }}$ century, travel memoirs often took the shape of epistolary writing. Kaldas's narrative combines both aspects. Her reflection on her visit to Egypt does have traces of a travel narrative, yet, she integrates biographical information from a much wider time frame. Letters from Cairo can thus be referred to as a "return narrative"5 (Kindinger).

2 Kaldas was involved in editing some of the major collections in Arab American Studies, such as Food for Our Grandmothers (1994), Post-Gibran Anthology of New Arab American Writing (1999) and Dinarzad's Children: An Anthology of Contemporary Arab American Fiction (2004).

3 Kaldas's oldest daughter was born during her first stay in Egypt, which is particularly relevant for her motivation to return to the country and write a memoir ( LC 5).

4 Personal information on Pauline Kaldas can also be found on her homepage. The design of her web presence differs considerably from Ansary's. It is much more artistic and contains personal poems and pictures about Kaldas and her family. In addition, a short biography is provided as well as detailed publication information. These two sections appear much more like the personal information found on department websites of universities. There are no strong marketing efforts concerning Kaldas's books despite the quotation of editorial reviews. Also, there is a link to a blog that is rather infrequently updated (Home page). Altogether, Kaldas's web presence corresponds to her public perception as a scholar and writer but lacks obvious links to realms outside the literary sphere. Kaldas consequently is not perceived as a public persona.

5 Return narratives do not constitute an established subgenre of life writing, yet. The format combines modes of traditional travel writing with the theme of postcolonial return to the homeland or to the land of the family's origin. As Evangelia Kindinger in her analysis of Greek American return narratives points out, "return" does not necessarily have to include an actual trip based on geographic movement, but can also represent the "journey paradigm" represented by second-generation immigrants in the form of mental travel (Wong 149). This clearly distinguishes the format from conventional travel writing. 
Kaldas does not stick to any traditional epistolary format, though. Her work rather reflects a large potpourri of different memory pieces, blended together in a mixture of different autobiographical formats. At the heart of the book one finds six letters to friends and relatives written during the time of her family's stay in Egypt. In addition, the book contains e-mails from her and her children, as well as drawings from her children (see 42-44) and recipes from Egypt ( $L C$ 140). A detailed table of illustrations navigates the reader to the different graphical elements ( $L C \mathrm{xi}$ ). The memoir thus reads like a diary with different memory bits and pieces put together like a mosaic. As Kaldas herself states in the opening pages about the format: "Perhaps it was also a way of bearing witness, of recording our experiences and observations at that particular time. [...] It is the collage of our journey" ( $L C 6)$.

The structure of the book reflects this diary-like format. All the material included contains a date and the order is chronological. The first chapter called "Journeys" ( $L C$ 3) provides a biographical introduction, followed by several journal entries from January 2002 and two shorter reflections on Kaldas's immigration to the U.S. Kaldas in this section explains her major motivation for going to Egypt for a second time. As she depicts, she wanted her daughters to learn about "the country of their origin not through stories and pictures, but through the reality of being physically there" ( $L C$ 5-6). The structure of the remaining chapters reflects this importance of (re-)location embedded in the diary structure. Every chapter bears the title of a particular month of their stay in Cairo. The subheadings indicate the various materials included in the chapters, such as "Journal Entries" ( $L C$ 24) or "EMails" (40). In addition, Kaldas inserts so-called "Reflections" each month, which are written under a specific theme, such as "A Sense of Place" ( $L C$ 27) or "Immigration and Return" ( $L C$ 64). As these subtitles suggest, location and the shifting of places are structural elements in the book. This reveals a parallel to Ansary's memoir. Kaldas, however, uses the different subheadings to direct the reader to distinct stylistic shifts. Her reflections clearly stand out in this respect since they are written in very clear and often critical prose. The language and their noticeable thematic focus set them apart from other material collected in the memoir. Moreover, Kaldas includes several "Snapshots," usually in the form of short poems ( LC 38).

As this mixture of different structural elements suggests, there is no dominant issue frame to be identified at first sight. Since the subheadings point to formats rather than content, no obvious thematic focus can be noticed to the exception of travel and place-shifting. The kinds of documents collected in the book overall evoke the expectation of a very personal and almost intimate account of the author in which personal and family matters outweigh historical or political elaborations. Still, this very personal framing of the memoir from the beginning strongly highlights Kaldas's authenticity. All the documents she includes serve as testimonies that she is not merely recalling past events but providing actual records of her past. Kaldas with this move prevents the reader from perceiving of the memoir as semi- 
fictional reconstruction of her life. This high degree of personal authenticity is not only linked to the format Kaldas has chosen. In addition, she supports her authorial credibility by punctuating her Arab American identity.

\section{Arab American Authenticity}

In line with many other Arab American authors of the contemporary period, Pauline Kaldas sees her writing and her identity as deeply intertwined. "In a sense, by virtue of my immigrant experience," she explains, "I was handed my subject matter [...]. Arab-American literature is an expression of the world and of experience through the eyes of someone for whom Arab-American identity is a primary lens" (Kaldas, "Quote"). In fact, this bicultural ethnic lens plays an important role in her memoir. It underlines her authority to bring back images and experiences from Egypt which differ significantly from the ones the average reader is familiar with from watching the news or Hollywood movies.

I'm home with that urge to bend and kiss the ground - but perhaps more distant this time. I feel more American at this point in my life than I have before. We adapt despite our will. It is Yasmine and Celine who have pulled me into American in a way I could never have accomplished myself. At some point we must claim things as our own. At the age of forty, I have claimed America as home and the loss of homeland is less painful. ${ }^{6}$ (LC 9)

With these words, Kaldas describes the family's arrival in Cairo. The passage illustrates a very emotional, yet, also contradictory bond to Cairo. While using the word "home" to refer to Cairo, Kaldas at the same time explicitly stresses her American identity. The way in which she describes this dual concept of belonging and the process of involuntarily adopting a culture, however, do not point to an identity conflict at first. This is reiterated in another scene at Roanoke airport. A female security guard asks her politely in Arabic to step behind a curtain for inspection, so she can maintain her privacy. Kaldas recalls her thoughts at that moment in the following passage:

And I smiled to embrace our connection, realizing that we are everywhere, and that Arab American is not a fragmented identity but one that is whole and that we create. It is an identity that becomes transformed through immigration in this new place where the need for unity is greater than the issues that divide us. [...] We bring our distinctive features with us to the United States, yet the similarities of language and cultural origin pull us toward each other to

6 Journal entries in Kaldas's book are always printed in italics to separate them from the remainder of the text. 
create an Arab American identity, enabling us to acknowledge that we belong together. (LC 9)

These lines reveal that multi-ethnicity to Kaldas at the beginning of her narrative clearly does not place a burden on her but a gift. It involves a constant cultural transformation but also the inevitable necessity of bonding with others who share the same background. The repeated use of the pronoun "we" here strikingly underlines that Kaldas considers herself as part of the collective of Arabs living in the United States, thus suggesting a certain degree of homogeneity uniting this group based on the common immigrant experience.

Despite Kaldas's obvious affiliation with this collective of Arab Americans, however, to her the gift of mixed ethnic identity is very much based on her selfidentification as an American. Kaldas describes the year of her family's immigration to the U.S. almost as a second "birth date" ( $L C 15)$. This seeming wholeness, though, starts to be disturbed very soon after she and her family settle in Cairo where she constantly gets confronted with questions about her ethnic selfunderstanding. She remembers the words of her cousin Usama who at one point asked her: "What are you? You're not Egyptian. You're not American" ( $L C 14)$. As it turns out, despite her initial praise of ethnic hybridity, this very feeling of (n)either/(n)or identity starts turning into a severe identity struggle (Majaj, "Boundaries" 82). As she admits, she has strong difficulties adjusting in Egypt and lacks a "sense of belonging." All of a sudden, her American identity becomes almost too American for her. "People know I'm Egyptian, but they sense that something isn't quite right by the way I speak and move. So I feel far more American here than I do in the States. I'm beginning to think I can only belong on a plane between both countries, suspended in flight" ( $L C 23$ ).

As these words illustrate, Kaldas's seeming identity stability starts erupting when she is confronted with the outside view of herself. Although, initially, she seems to be proud of her ability to have adapted and become American, it becomes clear that her hope of going through a smiliarly smooth process in Egypt gets disappointed. Different from her own view of herself, to the outside, her habits do not correspond to what Egyptians would consider Egyptian. Kaldas emphasizes internalized cultural habits as outside markers by explaining that it is not only the use of language which separates her from native Egyptians but also her movement and general appearance. Kaldas then adopts this view when looking at her children. As she notices how much her American identity has really come to dominate her entire life, her children display the same predisposition. When observing her children during the first weeks in Egypt, she at one point notices "how American they are" ( $L C$ 26). It is this Americanness that continues to separate her from her immediate social environment in Egypt. Somehow, she cannot attain the same feeling of belonging which she is used to from her life in the U.S. This struggle also makes her 
reflect on her first extended stay in Egypt in 1990 when she taught at the American University in Cairo. She realizes that her memory might have glorified the process of cultural adaptation while her American identity also dominated at the time. She was treated as a "foreigner," as she admits, and the fact that she did appear quite "westernized"" also led to a certain lack of respect on the part of the Egyptians ( $L C$ 32-33).

These reflections demonstrate that Kaldas, even against her will, is rather at home on the American side of the hyphen than on the Egyptian one. This also forces her to constantly change positions when looking at herself and at her Egyptian surroundings. Soon, she finds herself in a position of cultural oscillation which she already knows from her life in America. She describes herself as a "cultural and linguistic translator" who constantly has to negotiate between two worlds ( $L C 35$ ). In the U.S., as she explains, the worldview is dominated by familiar Orientalist images. "Does everyone own a camel? What's it like over there? Say something in Arabic," she remembers Americans asking her ( $L C$ 35). Kaldas consequently feels that she has no other option than to accep this role. She quotes Lisa Suhair Majaj who once wrote that "this negotiation of cultures results in a form of split vision: even as we turn one eye to our American context, the other eye is always turned toward the Middle East" ( $L C$ 37). At times, this immanent role of a cultural interpreter and translator makes her feel "at ease in my mixed identity," as she states (LC 52). At other times, Kaldas struggles with her lack of definite cultural location.

With this thorough description of her split identity, Kaldas from the beginning emphasizes her unique position and the special agency underlying the writing of her memoir. Due to her American Egyptian identity, she presents herself as being forced to always look at two worlds from two different positions, no matter whether she physically finds herself in America or in Egypt. While sometimes struggling with this impulse, this forced multi-positionality also substantiates her agency. She thus clearly evokes the expectation on the part of the reader that she is able to provide insights into both worlds, which are hard to obtain otherwise. Indirectly, this points to her ability to challenge mediated stereotypes such as the one of Egyptians as camel owners. Kaldas does not meet this malaise from an overly critical perspective, however. Rather, she demonstrates that there is an urge to learn about other cultures which drives people from both worlds to ask questions based on whatever they know or seem to know. Due to her mixed identity, she has the privilege, but also the burden, of filling respective cultural knowledge gaps. The fact that especially American readers can relate to her and trust in her ability to convey this knowledge is underlined by her dominant American self, as she constantly reiterates. This ensures her the necessary credibility and authority of an Egyptian American writer who nevertheless shares the American perspective to a high degree. These factors underlining her authorial agency in turn provide the necessary preliminaries for her to impact her readers from the very start of her narrative. 
Kaldas's intensive identification with and appreciation of American identity continues to increase in the course of the memoir. The reader is always reminded of the double perspectives he is presented with, yet, also assured that the Egyptian side does not take over. The author increasingly longs to settle in a stable life in America, thus thinking more and more about her life in the U.S. ( $L C$ 83). She feels most comfortable when spending time among American expatriates in Cairo. Still, there is an invicible line separating her from non-Arab Americans. "Is this my Americanness: the heavy breath of balancing rocks?" she rhetorically asks, thus emphasizing the burden of her constant oscillation between two identities ( $L C$ 107). Somewhere inside, however, she is convinced that the life she wants to live cannot take place anywhere else than in America. This is highlighted when she describes her efforts to convince relatives to move to the U.S. As she realizes, this urge might also be rooted in rather selfish reasons. "Perhaps I want my cousin to come only to affirm my own sense of rightness in being in America . [...] At times, I feel whole, secure, solid; at other times, the ground cracks under my feet" ( $L C 129)$.

The theme of split identity is introduced at the beginning of Kaldas's account and continues to span through the entire narrative. It is exactly the uncomfortable feeling she shares about being caught in the position of the cultural interpreter which highlights the immense responsibility linked to this role. The awareness of this responsibility punctuates her authority as an autobiographer to produce a credible and authentic account of her life experience. In addition, she always ensures that this authenticity to a large part relies on her voluntary affiliation as an American. These strategic moves to underline her authorial agency get complemented by the authentic fragments of diary entries and other material. These come to represent very personal pieces of a puzzle that forms a powerful pool of cultural knowledge. The intentionality behind this reassurance of multi-cultural authority gains striking confirmation when Kaldas reveals her thoughts on the importance of credibility and truth in the chapter "June Reflection: Authenticity and Influence" (LC 131):

As an immigrant who came here as a child, I am part of what Rubén Rumbaut called the 'oneand-a-half' generation (quoted in Firmat 1994, 4). Emigrating as children, this generation is situated between those who emigrate as adults and those who are born in America. The question of authenticity is one that plagues many of us who cannot define ourselves with a single term. (LC 131)

Kaldas in this passage approaches the key dilemma of her identity struggle in a very theoretical manner. When quoting Rumbaut's concept of the "one-and-a-half generation," she even provides the respective source as one would in a scholarly paper. This style stands in sharp contrast to the very personal memory fragments in the form of e-mails and drawings which otherwise dominate the book. The struggle experienced by the respective immigrant generation, however, is not only rooted in 
personal feelings of loss and disorientation, as she explains in these lines. Rather, her concern about "authenticity" highlights that cultural self-identification is immanently connected to the cultural definition applied by others. Linked to this is the act of communication, of mediating a torn identity that escapes simple explanations or disambiguation. This process of authenticity granted by the cultural other is thus complicated by the self-questioning of authenticity of the ones who compare themselves to earlier immigrant generations who adhered to their ethnic roots.

This evocation of authenticity and cultural credibility points to the author's concern for authorial agency in a larger context. Kaldas not only shares her doubts about her own cultural affiliation, she also shares her worries about representing this struggle on behalf of a cultural collective and in her life writing. Authenticity and truthful narration therefore clearly mark important guidelines for the production of her autobiography. Despite sharing the reader's longing to read truth rather than fiction in her life account, Kaldas also pinpoints the negative sides of authenticity as the ultimate aim of the writer. "However, the issue of authenticity can often stagnate the potential of artistic influence, which must ultimately lead to innovation rather than imitation," she warns ( $L C 133$ ). Kaldas obviously does not want to become the victim of authenticity if understood as a constraint rather than a benefit. Still, as a writer, she does not clearly align herself with other artists whose main purpose might be innovation. Her strong concerns about the issue of authenticity therefore emphasize her efforts to position herself as an author who seeks the innovation of established cultural images based on authentic memory writing.

Innovation and her rather theoretical approach to the topic of authenticity also allude to another source of Kaldas's authorial agency. In addition to being a cultural insider in the worlds of the U.S. and Egypt, she also is a member of the academic world. It is her scholarly occupation that allows her to spend time in Egypt in the first place. Scholarship, however, is more than a mere profession in her life. It constitutes a major trait of her identity and also turns into another core pillar of her efforts to underline her authorial authenticity.

\section{Scholarly Agency}

One of the very first aspects the reader learns about Kaldas and her husband T.J. is that both work as university professors. The fact that T.J. even gains a prestigious scholarship to teach in Egypt for one academic year underlines this exposed intellectual status (LC 3). ${ }^{7}$ Academic life therefore becomes the second core pillar of Kaldas's agency. It provides the ultimate ground for her efforts to change the public

7 Although the general readership might not be familiar with the benefits linked to specific academic fellowships, Kaldas makes no secret of the prestigious status associated to a Fulbright scholarship. 
image of the Arab based on the well-reflected, authentic, and knowledgable life account of a scholar.

"International Schools" ( $L C$ 31), "The American University in Cairo" ( $L C$ 32), and "Cairo University" ( $L C$ 33) - these are some of the sub-headings found in Kaldas's early chapters. These headings automatically take the reader not only to Egypt as the other world but specifically to the academic realm in which she situates herself and her family. Her academic identity that Kaldas stresses from the very beginning of the life narrative is again linked to a constant shifting of perspectives. In this case, it is not the oscillation between two different ethnic identities. Rather, the fluctuation takes place with respect to two different levels of narration. One is the actual description of her experience, the other is the simultaneous analysis of this experience. The latter is rooted in her position as a scholar and intellectual who approaches every aspect in life with a high degree of abstraction and theoretical insight. An example of this entanglement of multi-ethnicity and scholarship is provided in one of the numerous examples Kaldas recalls from her teaching experience. "While teaching about colonialism, I stumbled over my pronouns: we [...] they $[\ldots]$ us $[\ldots]$ them. I existed on both sides of the divide: the colonizer and the colonized. [...] In this case, I learned to embrace my shifting pronouns; it was the only way to articulate the complexity of my own position" ( $L C 33$ ).

This passage stresses Kaldas's authority to indeed speak from the perspective of both sides of the hyphen. In addition, this reflection exposes the intellectual angle from which Kaldas analyzes and describes her situation. The opposition between "we," "us," and "them," as well as the explicit reference to "the colonizer and the colonized," clearly reveal her knowledge of postcolonial theory to the reader. This degree of abstraction and the analytical distance linked to it clearly separate these lines from the level of mere personal storytelling. In fact, the "complexity" of multi-ethnic identity which Kaldas here explicity refers to also serves as proof of the complexity of her own thinking and thus of her intellectual capabilities. How important this intellectual identity is for her self-definition, Kaldas underlines when describing the academic surroundings in Egypt. "For me, $\mathrm{AUC}^{8}$ is the place where I have felt most at home. East and West confront each other both in the curriculum and in the lives of the students and faculty. I felt closest to my students there whose lives also encompassed Arab and Western culture. Their education, class position, and travel experiences had placed them inside and between both cultures" ( $L C 33$ ). This observation opens up the world of the academy as a microcosm of intellectual growth and multi-cultural encounter. The emotional undertone and Kaldas's emphasis on feeling "most at home" at the university demonstrate that she not only values the academy as place of intellectual advancement but as social institution where people share her mixed cultural background. Overall, this depiction grants

8 AUC is the abbreviation of the American University in Cairo. 
the university a somewhat idealistic position with the ability to smoothe the cultural confrontation between "East" and "West" which causes so much conflict outside the academic realm and in the personal life of those representing both sides.

Despite her admiration of the university as place of identity reconciliation, Kaldas is well aware that the academic worlds of "East" and "West" differ considerably. In order to expose these differences, Kaldas provides a detailed sketch of the academic landscape in Egypt and compares it to the American one. Cairo University, where she and her husband teach, is presented as a large school with more than 100,000 students, low fees, and admission practices based on strict test score results. Kaldas immediately contrasts this to AUC, where she previously taught. Here, "Western influences" are much more dominant than at Cairo University, she notes, before stressing the university's role as place of political activism and social movement ( $L C$ 33-34). The American-run AUC, in contrast, is not described by her as the center of intellectual excellence but as the epitome of academic profitmaking. This notion gains a satirical twist in her recollection of her first visit to the AUC campus. "But the first time I step on campus with its manicured lawns, tennis courts, and courtyards with fountains, I wonder if I'm still in America. The students in European clothes, young women wearing miniskirts, young men on a fashion runway in their jeans. I puzzled at how they got through the city streets dressed like that" (LC 110).

Kaldas with this very literal description of the AUC campus as a symbol of American materialism invites the non-academic reader to enter the academic world of Egypt. ${ }^{9}$ The pictures she is presented with do not at all correspond to the ones of belly-dancing harem girls and veiled women. Yet, the critical undertone of Kaldas's depiction as well as her direct comparison of AUC to the rest of the city also immediately draw attention to the fact that this academic world is not the real Egypt. Although Kaldas highly identifies with this world, she is nevertheless aware that it constitutes an artificial realm within the Middle East. The seeming cultural unity and the lack of multi-ethnic conflict at AUC therefore are in no way representative of life in Egypt at large. Kaldas's interaction with other Egyptians, however, prevents her from giving in to the illusion that this imaginary state of hybridity is real. She thus recalls a conversation with another Egyptian asking her about her workplace. When she tells the lady that she teaches at AUC, the woman simply replies: "You're not really living in Egypt" ( $L C 110)$. This negative perception of the academy as somewhat fake world with its heavy emphasis on capitalist materialism also

9 Kaldas's detailed depictions of the academic environment and campus life indeed carry traces of the traditional campus novel, which emerged during the 1950s in Britain and by now has mostly disappeared entirely (Padley 74-5). Just like its fictional counterpart, her academic life writing opens up a world to the readership that is unfamiliar to those outside the ivory tower. 
reminds the reader or the fact that these basics of American culture are not praised everywhere. In addition, the notion of value as defined in materialist terms from the perspective of the West also affects the status of Kaldas as a scholar in broader terms. "Where was I, participating in this space of Western images, gaining respect because I had lived in America?" she asks herself and the reader after describing the scene at AUC (LC 110).

Obviously, Kaldas's academic identity is marked by a similar degree of ambivalence as her multi-ethnic identity negotiation. On the one hand, she admits that the academy is the place where she feels most at home. On the other hand, she knows that the American University in Cairo is much more a miniature reservation of America than it is of Cairo, where American standards by far outweigh any Egyptian influence. The dilemma for Kaldas remains that she feels drawn to the American perspective despite the criticism and doubts she is facing. This also causes her to look at the Egyptian education system in more or less derogatory terms. When she mentions the education of her children in Cairo, she describes their school as "supposedly American run" ( $L C$ 22). The limitation of "supposedly," however, reveals her doubts that American education standards are in fact applied. As she admits, she therefore does not think her children learn a lot in the school ( $L C 22$ ). This comment additionally stresses the strong belief of Kaldas in the value of education. The way in which she applies American education standards to the evaluation of Egyptian schools, though, also exposes her outsider status and the supposed cultural superiority connected to her American upbringing and her status as an American scholar.

By explicitly connecting her Arab American identity with her role as an intellectual, Kaldas again reveals her concern for authorial authenticity and credibility. Even though the mixed reaction by other Egyptians puts the academic world in a somewhat ambivalent light, the overall emphasis on the university setting and her ability to analyze her own situation from a detached theoretical perspective highlight her efforts to appear credible in the eyes of the reader. With this distinct "positionality," Kaldas purposely evokes the image of the intellectual who "can speak truth to power" (Shereen 109). Personal storytelling based on this academic agency in memoir thus turns into "honest scholarship" which blurs the line between fact and fiction (Marrouchi, "Counternarratives" 237). This honesty, however, is not merely based on "anti-Westernism," as is most often claimed as core strategy of the postcolonial scholar (Marrouchi, Edward Said 215). Rather, the postcolonial scholar as autobiographical writer here uses scholarly authority to present alternative images of the postcolonial other undermined by personal experience and substantiated by more abstract theoretical reflections. Autobiography in this sense becomes an "intellectual adventure" (Shereen 109). Kaldas thus functions as a prototype of the intellectual envisioned by Said who urged the scholar to "act in the interest of truth and justice and fairness and honesty" (Said, "Scholars, Media" 
306). At the same time, this intellectual role is complemented by a larger social purpose. Kaldas therefore also takes on the function of a "political intellectual" by mirroring, analyzing, and possibly subverting stereotypes about the East (Marrouchi, "Counternarratives" 239). Overall, this model corresponds to the ultimate potential of the exilic intellectual envisioned by Said:

I mean that my diagnosis of the intellectual in exile derives from the social and political history of dislocation [...]. Intellectuals can [...] be divided into insiders and outsiders [...]. The pattern that sets the course for the intellectual as outsider is best exemplified by the condition of exile, the state of never being fully adjusted [...]. Exile for the intellectual in this metaphysical sense is restlessness, movement, constantly being unsettled, and unsettling others. (qtd. in Dabashi 6)

These words provide a summary of the analysis Kaldas undertakes of her own status. In her case, the outsider status fully unfolds while physically finding herself in "dislocation" in Egypt. By sharing her personal and scholarly insights about this state with the reader, she manifests her agency of "unsettling others." This notion of unsettling can be read as a synonym of reframing since it exactly describes the process of altering the mental maps of cultural outsiders. This reframing requires agency. In addition to cultural agency, professional agency strengthens the ability to make a cognitive impact on the reader. In the case of Ansary, this potential strongly relied on his journalistic persona. In the case of Letters from Cairo, the scholarly profession of Kaldas serves the same end. Her explicit efforts to reinforce her status as an intellectual in the eye of the reader thus serve as a powerful confirmation of the key role scholarly agency plays for the construction of autobiographical authority at large (Willard-Traub, "Scholarly Autobiography" 188). This finding also testifies to the lasting importance, authenticity and credibility play for the construction of the autobiographical self (Marrouchi, "Counternarratives" 231). Eventually, this strategy sets the stage for reframing the dominant stereotype of Egypt as home of the half-naked belly dancer. 


\subsection{Reframing the Egyptian Belly Dancer $\left(V_{2}\right.$ And $\left.V_{3}\right)$}

\section{The Literature Frame}

Based on her authority as an Arab American scholar, Kaldas sets out to provide her personal picture of Egypt. Her medium is her memoir in which she establishes a series of issue frames to create alternative cognitive patterns for the reader to look at Arab and Arab American identity. To Kaldas, however, the detailed engagement with specific issues can only happen if the importance of mediation at large is accounted for. The act of writing thus takes precedence over anything that follows from it. "For me the writing comes first and the subject matter comes second," she explains in a biographical statement ("Quote"). In the frame analysis of Letters from Cairo, this conviction indeed is devoted much attention. As it turns out, literary production comes to form a dominant issue frame in itself.

Kaldas from the opening pages of her memoir onwards not only positions herself and her husband as scholars but as literary scholars (LC 3). Writing and the detailed engagement with literature thus play an important role in their lives. The very format of her memoir highlights her knowledge in this field by combining different literary genres and narrative techniques. This diversity of her literary production might point to a very artistic conception of writing on her part which stands alongside her scholarly style. Yet, literature to her only liminally constitutes an act of free creative invention since much of it is predetermined by one's personal history, as she explains. "But once born, so much is imprinted on us," she reveals in one of her early journal entries upon observing her daughters deal with the cultural transition to Egyptian life ( $L C 12$ ). These words uncover the very encompassing but at the same time distinct metaphorical meaning Kaldas ascribes to writing as medium of personal expression. To her, the human being as a whole represents a text containing all the stories and experiences irreversibly carved into one's memory. This also points to the performative understanding of autobiographical production shared by Kaldas, since life writing in this sense cannot be separated from living one's life according to particular predefined trajectories.

This significance of the human being as text and as living document of partly unavoidable events gains special prominence in the context of history - both in terms of personal and political history. A powerful scene in this respect is provided in Kaldas's depiction of the family's arrival in Cairo. Right after getting off the plane, Kaldas feels the immediate and at the same time confusing impulse to kneel down and touch the ground. As she then reveals, the reflection on this impulse reminds her of the novel The Kite Runner by Khaled Hosseini. Here, one of the main characters also fills a snuffbox with dirt from Afghanistan before leaving his homeland. A similar scene, Kaldas recalls from Beirut Fragments, a book that she 
taught her college students. Beirut Fragments is a "memoir of the Lebanese Civil War," she explains. It provides a medium to teach her students about the loss of homeland and the urge to stay ( $L C 35)$.

These early references to important Arab American literary works from the contemporary period demonstrate how deeply interwoven Kaldas's life, thinking, and self-identification are with the realm of literature. Furthermore, the fact that she mostly refers to other literary works in the context of teaching foregrounds the didactic power she attributes to literary writing. Especially with respect to the aspect of migration and ethnic identity negotiation, literature seems to provide a tool to make her students look at life through a different lens. It is particularly striking that Kaldas with Beirut Fragments specifically mentions another memoir to exemplify the power of literature. Since this memoir with its focus on migration and loss shows close thematic overlaps with Kaldas's life story, the reference comes to represent a metaphor of her own autobiographical endeavor.

This didactical purpose behind teaching life and immigrant identity through the lens of literature becomes even more visible in another scene Kaldas remembers from her teaching career in the U.S., a moment when she referred to the essay collection Becoming American, written by a series of immigrant women in the U.S. In this book, she observes the following pattern of immigration and homeland:

[T]he struggle for identity is often marked by a return to homeland. These writers describe their visits to their homelands as the turning point in understanding their identity in the new world. [...] For several of the authors in Becoming American, the return to their homelands allows them to retrieve a part of themselves, making them feel whole and connected across time and distance with others. They achieve their American identity only after they have returned to their origins, finding their place within the community that propelled them into the world. (LC 65)

Clearly, this reflection on the complicated struggles of multi-ethnic identity negotiation and the importance of homeland mirror Kaldas's personal experience while at the same time underlining her scholarly agency. Despite sharing literary knowledge on the topic of ethnicity, Kaldas's elaboration on Becoming American again comes to serve as a form of self-analysis of the autobiographical work which she is about to produce. She here depicts the homecoming of immigrants to their country of origin as a real turning point in their lives. By shedding light on the impact of this experience for her students and for her readership, Kaldas also writes the story of her present life. As the protagonist of her own life narrative, she is one of those returning to their homeland. At the moment of writing, however, she is the one already reflecting on this transformational experience. The reader therefore is made aware of the significance the return to one's homeland has for Kaldas's life and for the narration of her life story in the memoir. Literature here becomes a 
means of expression as well as the subject of literary analysis for the author. It is thus transformed from a mere topic to an interpretive lens through which the reader follows Kaldas's story.

The potential of literature to facilitate the changing of perspectives continues to be highlighted throughout the account, with particular emphasis on the author's experience in the college classroom. "When I teach immigrant literature in the United States," she explains, "the focus is on the lives of those who immigrate [...]. Returning to Egypt, I saw the other side of the mirror: the effect immigration has on those who stay" ( $L C$ 65). Although Kaldas is well familiar with literary narratives of migration, the different context in which she teaches the seemingly familiar works causes her to look at the experience of migration from a different perspective. She describes this as a special challenge her husband also faces when teaching American and African American culture and literature in Egypt where students are unfamiliar with American society. This "challenges him to read the literature he teaches from a different perspective," she explains ( $L C 112$ ).

The double significance of location in a geographical and metaphorical sense becomes especially obvious in another one of her reflections entitled "Understanding Where We Are." Kaldas here illustrates how she employs literature as a tool to make her American students change their ethnocentric position. She thus aims to widen her "students' vision of the world by introducing them to a variety of literature - African American, multicultural, immigrant, African, or Arab" (LC 112). In Egypt, Kaldas is trying to achieve the same effect by means of literary reading and interpretation to make her students "see the world through other lenses," as she writes ( $L C$ 112). The chapter title "Where We Are" again emphasizes the intertwinement of physical location, interpretative positioning, and identity. The location from which one looks at the world and the location from which the world looks at oneself are both connected to the question of "Who" one is, as Kaldas demonstrates. Narration thus always depends on positionality. This trajectory is impeded in the case of migrants who have lost their original geographical and interpretative position and are thus forced to see the world from a different angle. The return to the homecountry then complicates the simultaneous taking of multiple perspectives. The literary examples that Kaldas provides, while at the same time creating another illustration of this process in her own life account, invite the reader to adopt literary narrative as the key to changing perspectives.

Kaldas, however, does not limit the definition of narrative or storytelling to immigrant literature as such. Rather, non-written stories and the narratives of everyday life have a similar meaning for her. This expanded significance of narration becomes particularly visible in her observations of life in Egypt. Here, she puts the ordinary rather than the special into the center of attention. Be it the cook, a mail deliverer, or even a cab driver, Kaldas carefully scrutinizes the people in her surroundings and shares her impressions of how they manage life ( $L C 80)$. In this 
context, she recalls the words of her husband in a letter to her friends. "T.J. always says: 'Everyone has a story.' This is certainly true in Egypt. At times I switch my gaze and turn to look at us from the outside [...] and if I were a stranger, I would wonder what our story was and how we would tell it" ( $L C$ 81). In another instance, she further highlights the overall significance of literature for one's horizon: "It is the stories and poems of others that make our world larger, that stretch our vision so we can see beyond our own experiences" ( $L C 112)$. Kaldas in these lines further explores the meaning and function of narrative for biography. As the words of her husband underline, every life is based on stories which are worth telling. This is ver much in line with the contemporary concept of identity as narrative performance. Kaldas as a literary scholar obviously is aware of this theoretical conception of life narration and shares her views on it with her audience. This more abstract exploration of autobiographical writing is complemented by her insights into positionality. Narrative, as she makes clear, is not the product of recalling objective facts. The perception of the life of others and one's own life entirely depend on the perspective from which one looks at it. ${ }^{10}$

Very unobtrusively, Kaldas in these instances teaches the reader to leave his/her ethnocentric viewpoint by promising that in result, both the creation of narrative as well as its reading broaden one's knowledge in unprecedented ways. This also refers to the political and activist impact of literature. Her thoughts on this issue are triggered by the political events taking place in Egypt, such as student protests at the university ( $L C 101)$. When talking about her experiences with teaching political literature, she highlights her efforts to fight the resignated attitude of some of her students who think of themselves "as individuals who could not counter the actions of stronger nations" ( $L C 112$ ). Kaldas here clearly advocates a postcolonial stance when it comes to the transformative function of literature in the social and political realm. This adds another dimension to the theoretical level on which she deals with the potential of literature. Not only do literary writing and reading facilitate the shifting of perspectives, they also actively interfer with the politics of one's time.

The function of narrative as an analytical and activist tool, however, is not limited to literature, neither is it bound to time. "Art, whether literary, visual, or performative, is the way we decipher our world. As recipients and creators of art, we are in constant motion, shifting our perspective of the world and our position in it," Kaldas writes ( $L C 113)$. She then links her own insights into the words of Edwidge

10 Kaldas's lasting occupation with the question of positionality is also reflected in her book Time between Places, published in 2010. The book comprises a collection of fictional short stories about Egyptian protagonists who either live in Egypt or immigrated to the U.S. Although Time between Places is a work of fiction, Kaldas here nevertheless focuses on autobiographical content. 
Danticat in the essay "AHA" travel so we can be in two places at once" ( $L C 113)$. Kaldas with this literary reference expands her insights into writing and literature to art in general. What is particularly emphasized with respect to Danticat's finding thus quoted is the importance of the time dimension. Whereas being in more than one place is not exceptional for human beings in a dynamic world reigned by transnational movement, being there "at once" and not in sequence requires the metaphor of the shadow. This image of the traveling shadow also comes to represent a metaphor of Kaldas's approach to life writing in general. Writing about the past thus has the capacity to impact the present. At the same time, the present makes one look at the past from a different perspective. This voluntary and involuntary blending of past and present lies at the heart of modern life writing theory. Kaldas as literary scholar transmits these theoretical findings by means of writing her own story. The importance of narrative tense for the telling of life stories here again occurs in the context of Kaldas's daughters. As she points out, Celine even two years after their return to the U.S. continues to tell stories from Egypt "in the present tense" ( $L C 154)$. When the parents remind their daughter of the mistake by insisting that this happened "in the past," Celine reacts with indifference. Kaldas concludes, "the past and the present: she collapses them and places them in front of her in a seamless pattern" ( $L C 154)$.

With the exploration of time as important device in narration, Kaldas complements her comprehensive depiction of the role of literature in life and life writing. The "seamless pattern" that is "placed" in front of her daughter thus functions as a metaphor of Kaldas's memoir as a whole. Not only does she share thoughts on the significance of writing with the reader, she also reveals her very own writing process. In writing her "story" in the form of memoir, she at the same time introduces her readers to the very process of the memoir's production. This multi-dimensional engagement with literature is extended by her integration of theoretical knowledge from the fields of Literary and Postcolonial Studies. She does not, however, convey this information in a textbook format. Instead, she makes this knowledge easy to absorb by packaging literary theory in small parcels of anecdotes and references to other works of literature and art.

These different narrative and theoretical elements together create a cognitive frame which allows the reader to look at the narrative from the perspective of literary production. As Kaldas reiterates, the frame of literature allows one to see the world at large in a different light. This ultimately also impacts the image Americans have of Arabs and Arab Americans. Based on the detailed depiction of migration

11 AHA stands for African-Haitian-American. The abbreviation thus stands for a "doublyhyphenated identity," which, in contrast to other models, does not focus on fragmentation but endorses inclusiveness and the value of multiple interpretive lenses deriving from an immigrant background (Mardorossian 46). 
provided within this literature issue frame, the reader is given the opportunity to share the experience in the process of reading in order to understand the Egyptian, the Egyptian American, and also him-/herself differently. This high complexity linked to the didactic potential of literature at once eliminates the stereotype of Arab culture as poor in terms of cultural production. The aspect of Arab culture in a more nuanced sense, however, forms another issue frame.

\section{The Culture Frame}

When explaining the differences between teaching in America and teaching in Egypt, Kaldas observes how her husband meets the challenge of mediating a culture to students who are not at all familiar with American society. "To see a new culture," she concludes, "requires that you position yourself in a different place" ( $L C$ 112). Kaldas and her family do so in a physical and mental sense by traveling to Egypt. The memoir documents this place shift not only in the form of memory reconstruction but by assembling various cultural testimonies. "I wonder if we smile because we're still very much an oral culture, because words are what bind us," Kaldas at one point notices ( $L C 58$ ). This hint at the different modes of storytelling as part of a cultural legacy points to the overall meaning of culture as interpretative frame. Kaldas collects various elements of cultural production in her memoir and again combines them with theoretical elaborations. The total of these particles builds a cultural frame around the memoir, which not only teaches the reader about culture on an abstract meta-textual level but also functions as cultural artifact.

Kaldas literally allows her reader to "see a new culture" by equipping her memoir with very illustrative depictions of life in Cairo. She describes the noise in the streets, the sounding voices, parked cars on the side walk, chaotic traffic and the constant mingling of the inhabitants of an overcrowded city. "Human interaction is constant here beginning the moment we step out of the building," she summarizes ( $L C$ 19). Keeping physical distance in a culture like this appears to be extremely difficult and different from her usual habits ( $L C$ 20). This sense of personal closeness and intimate human interaction is not only bound to physical space. Rather, it points to an overarching understanding of human relationships as it differentiates between life in Egypt from the one in the U.S. Kaldas emphasizes this with an anecdote in one of her journal entries. She describes how the family used to go to a pastry shop in Garden City during their first stay in Cairo. When visiting the shop again during their second visit, the man remembers the family at once, even though their last visit dates back many years. Yet, to Kaldas, this heavy emphasis on individual human relationships is symptomatic of Egyptian culture at large. "Here, if you go to the same store, you establish a relationship; a bond is formed and its 
strength holds. But in the U.S., I can go to the supermarket everyday and my presence will remain irrelevant," she explains (LC 24).

These reflections on everyday cultural experience and human encounter allow the reader to get a very vivid picture of Egyptian culture. The switching between different formats of narration, especially the short journal entries, furthermore allows the reader to take part in Kaldas's own cultural exploration. The author in this context predominantly draws on her multicultural authenticity by directly comparing Egypt and the U.S. The differences she encounters between both cultures with respect to patterns of human interaction become even more visible in retrospective. When she returns to the U.S. and moves to the South, she transfers the cultural dualism of "East" and "West" to the domestic cultural North/South divide in America. For people in the South, she notices, "human interaction was much more valued than efficiency and speed" ( $L C$ 155). This personal experience is again supplemented with her scholarly insights. "When I try to draw distinctions between Arab and Western cultures for my students," she acknowledges, "I explain how Western culture focuses on the individual while Arab culture focuses on the community [...]" (LC 64). Again, this example emphasizes how Kaldas uses both her multiethnic as well as her professional status as a scholar to convey cultural knowledge on two levels - the personal and the more abstract theoretical level. In both cases, she draws on the method of binary juxtaposition to illustrate cultural differences.

Despite close human interaction as defining characteristic of Egyptian culture, Kaldas also explores language and cultural habitus as significant cultural elements. Again, she first depicts her personal experience to make her point. When previously teaching at AUC, the use of English alongside Arabic was common, she explains. The mere use of Arabic and the lack of English-language speakers at Cairo University, in contrast, cause a dilemma for her which make her shift identities. "I've been told before that when I speak Arabic, I transform, become a different person," she recalls the observation by others ( $L C 58$ ). The transformative nature of language switching, however, is not the only dynamic element of culture that Kaldas recognizes. In addition, Kaldas recognizes a behavioral element as fundamental to cultural identity which seems visible to others but can hardly be defined by distinct cultural markers. As she learns, cultural habitus is something that changes with its surroundings. In the context of her interaction with other American expatriates, she thus observes that "twenty-five years in America allow my Egyptianness to be overlooked" (LC 107).

The given examples provide snapshots of the diverse cultural experience Kaldas has in Egypt. All of them are marked by a high degree of self-reflection. While looking at the culture of Egypt, Kaldas also looks at herself through the eyes of others. This multi-dimensional approach to cultural analysis underlines the complex image Kaldas designs of culture as a concept. This image does not at all correspond to the common notion of Middle Eastern culture as shaped by belly-dancing harem 
girls and shisha-smoking sheikhs. In contrast to this popular notion of culture as based on cultural representation, Kaldas provides an almost sociological reading of the concept by enumerating different elements that together make up a conglomerate called culture. This understanding of culture is very much in line with the anthropological definition of cultural identity, comprising elements such as cultural behavior, language, and self-identification (Barker, Cultural Studies 476). In fact, this definition of culture as cluster of different fragments reflects the potpourri format of the memoir itself. Furthermore, it points to the very complexity of cultural identity which cannot be reduced to single stereotypes. This demonstration of the complexity of Arab culture, though, would remain incomplete if it left out the most stereotypical features of Arab identity - among them are dance and food.

As in the case of all other cultural features in her account, Kaldas chooses to deal with the prominent issue of food not by writing about it but by inscribing it into her work. The author therefore includes several Egyptian recipes throughout the memoir. In contrast to food memoirs which rely heavily on the textual intertwinement of recipes and storytelling, the recipes in Kaldas's memoir do not dominate. Rather, they are integrated whenever a respective journal entry or reflection points to a particular culinary event, such as the visit of the family to a special restaurant. The recipes themselves all have a very personal and at the same time cultural meaning since they mostly represent traditional Egyptian dishes ( $L C$ 46). These detailed insights into Egpytian cuisine allow the reader to easily grasp this important part of Egyptian culture. Kaldas in these instances again functions as a cultural interpreter by explaining the different ingredients and the places where to get them in America. Cooking therefore is not presented as a mere leisure activity. Rather, Kaldas highlights the meaning of cooking as form of art which requires cultural skills that she obviously lacks, as she admits. When mentioning the example of kosharee, a mix of lentils with rice and pasta, she describes the unique blending of ingredients and the taste as a "secret" which outsiders cannot fully grasp (LC 73). This emphasizes the important and almost mystical status cooking enjoys in Egypt. Food as a simplified cultural marker of Orientalism thus comes to symbolize a much more complex element of Egyptian culture. By offering the reader authentic recipes, Kaldas continues her mixed method of providing personal, theoretical, and practical information about Egypt. Just like her more theoretical depictions on culture serve the function of facilitating understanding for the reader, the recipes provide a practical "how to" key to reading Arab cuisine in a larger context.

A similar symbolic function within the cultural issue frame can be attributed to the drawings of her daughters which Kaldas includes. Despite some self-portraits of the girls, the paintings represent different cultural scenes, such as visits to famous sites at the pyramids, cultural events the family attends, and people they meet. From a simplified analytical standpoint of postcolonialism, some of these drawings could indeed be interpreted as Orientalist. For example, there is a drawing by Celine 
Kaldas depicting a belly dancer in light dress, wearing heavy make-up and dark hair (LC 138). ${ }^{12}$ What immediately resolves this Orientalist bias is the unadulterated immediacy of the experience speaking through the painting. Just like Kaldas records her daily impressions in the written form of the journal, her children express themselves by means of drawing. The obvious naiveté of the drawings rules out any kind of intentional Orientalist distortion. At the same time, this unfiltered recording of daily cultural experience steers attention to the fact that the given scenes indeed are part of the Eyptian cultural landscape. This plain empirical finding sometimes seems to be forgotten by scholars criticizing any image of belly dancers and oil sheikhs as Orientalist. Kaldas interferes in this ideological battle exactly by not participating in any normative judgements but by presenting the images of memory in a visual format. She thus leaves the reader with his/her own interpretations.

Image 7: Belly Dancers in the Past and Present
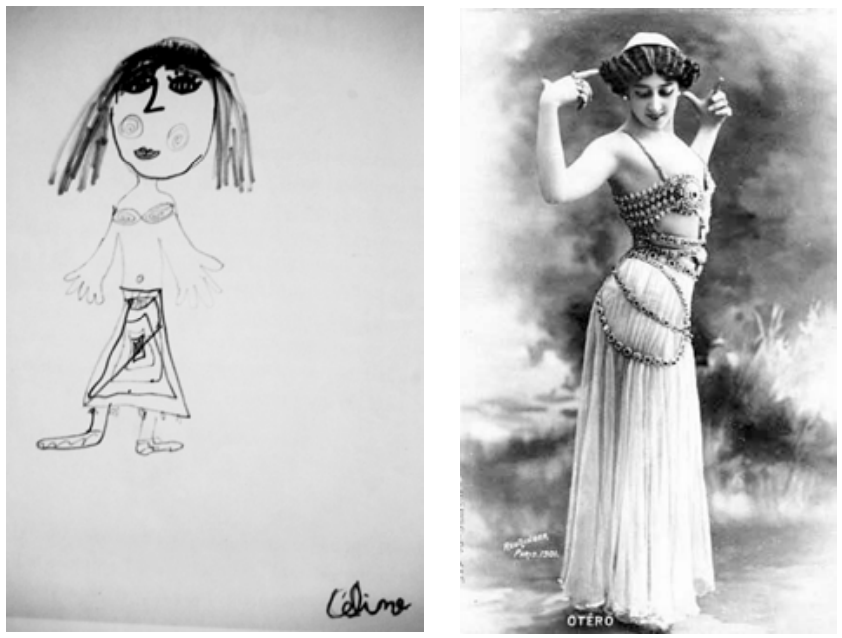

Source: On the left, "The Belly Dancer," drawn by Celine Kaldas (LC 138), on the right "La bella Otero," disguised as a belly dancer, Paris 1901 ("Oriental Dancing”).

Kaldas in the context of her cultural exploration of Egypt also recalls artistic performances in Egypt. She remembers the names of famous Egyptian singers who used to count as "heroes of Arab culture" ( $L C$ 132). Since the days of her child-

12 The English term "belly dance" is a misnomer resulting from the translation of the descriptive French term "danse du ventre." The Arabic term raks al sharki literally means Oriental dance (Rasmussen 177). Belly dance by now has become an umbrella term for different variants of Oriental dance involving belly dance components. In contrast to the derogatory treatment of belly dancers as symbols of Orientalism, belly dancing traditionally counted as an admired art in the Middle East. It was performed by women who also displayed other artistic skills such as singing and poetry writing (van Nieuwkerk 136). 
hood, however, Arab art has undergone a transition, she observes. This has resulted in a cultural blending which gives expression to the larger confrontation between the two worlds. "Today, Egyptian musicians [...] utilize the beat of Western music," she explains, "combining a duality of sound to create songs that can speak to a generation that struggles with the influence of Western culture" (LC 132). This cultural fusion can also be noticed with respect to the consumers of Egyptian art. Kaldas recalls the audience at the concert to have consisted of "Egyptians and nonEgyptians." What she values most about the cultural event is the "opportunity for a sharing of culture that offers the possibility of learning and influence" ( $L C$ 132). She puts this credo into practice by explaining the historical origins of the dervish dance and its spiritual roots to the reader. Despite the sharing of this rich cultural knowledge, though, Kaldas is aware of her own cultural distance to Egypt. "I cannot judge the authenticity of the performance we watched," she admits when reflecting on the event ( $L C 133$ ). This leads her to further reflect on the importance of authenticity in the context of cultural representation:

I wonder what happens when dervish dancing and music are performed in the United States? In what way does the performance transform? Does it become less authentic? The same question must be asked when Western music travels to other countries. What happens when an art form like jazz, which is deeply rooted in the political, historical, and cultural experiences of African Americans, gets transported to other locations? (LC 133)

Just like the dervishes lift themselves to a higher level of consciousness during their spiritual dance performances, these thoughts place the topic of culture on a more abstract level of reading. Different from the average American spectator, Kaldas does know about the cultural heritage of the dervishes. Yet, she knows that the performers are viewed from a different perspective when performing in a different cultural setting. The performance itself might not change in the first place, but its evaluation from the cultural outsider probably does. ${ }^{13}$ This, as she speculates, might then also alter the art itself. These reflections reveal the complexity underlying performed culture and its susceptibility to outside influences. Kaldas's own inability to determine the authenticity of the dance puts additional emphasis on this complexity. She demonstrates that it requires more than cultural knowledge to fully grasp the meaning of cultural performances. By directly relating this example to the larger trajectories of culture as traveling, Kaldas adds another theoretical level to her personal storytelling. She transfers the dervish performance to the American context of jazz music and thus forces the reader to question the meaning behind

13 Postcolonial dance scholars have interpreted the adoption of foreign movement elements by Oriental dancers as form of auto-exoticization (Maira 321). The formerly colonized are said to reproduce their own image through the perspective of the colonizer. 
popular cultural symbols and their origin. Furthermore, the example of art and its transplantation to a different location here also functions as a metaphor of Kaldas's own process of multi-cultural identity transformation. Just like her life in the U.S. has transformed her, her stay in Egypt alters her personality once more. This process of transformation also applies to the narrative that records this identity negotiation if it is read in different cultural settings.

These multi-layered elaborations on culture ranging from everyday-cultural habits in Egypt to cultural performances point to the larger structural meaning of the issue. Kaldas's understanding of culture as a concept is highly sophisticated and self-reflexive. By sharing her thoughts and experiences on culture and its tranformation, she forces her audience to read Arab society and the prominent image of the belly dancer through a much more complicated cognitive lens. Her method of employing the familiar binary of East and West, of Egyptian and American culture, facilitates this thought process. The reader can thus integrate his/her own cultural experience while simultaneously being urged to question familiar thought patterns and ethnocentric criteria of cultural interpretation. A similar mechanism can be identified in case of the race frame.

\section{The Race Frame}

I'm making circles again, moving towards destinations that become points of departure, holding two homes till it seems my only place of comfort is in transit. Moving through airports for the last two days: Roanoke, Detroit, Amsterdam, Cairo - I'm reminded of how large the world is, of the variety of those who live in it, of how in the creation of these airports and the ability to cross borders, we encapsulate it - how much of the world is held in a single airport. [...] Then my glance turns inward: we're an Egyptian-looking family speaking English, and I know the man is wondering who we are. (LC 8)

Just like culture is determined by different criteria that together form an important part of identity, ethnicity combines many different formative elements. Especially visual markers ${ }^{14}$ have always been important for the definition of ethnicity, which explains the close and often involuntary relationship of the concept to race. Even though race has a very negative connotation, it nevertheless remains part of the daily practice of defining oneself and defining others, especially in predominantly "Western societies" (Barker, Sage Dictionary 170). As the above journal entry by Pauline Kaldas points out, the complex entanglement of ethnicity and race from the view of the outsider becomes another major frame through which she makes her audience share her experiences.

14 In addition, Barker and Galasinski list a series of other typical "[m]arkers of ethnicity," such as "Personal reference," "Spatial reference" (126), and "Temporal reference" (127). 
The first information the reader gets about Kaldas's husband T.J. Anderson III in the opening sentence of the memoir is that he is an "African American poet and scholar" ( $L C$ 3). At the beginning, this statement might appear as a mere detail, just like Kaldas a few lines later describes her Arab American origin. Yet, this supposed detail of ethnic identity gains immense prominence for the family's stay in Egypt and for the reflection on this stay in the memoir. As it turns out, the fact that T.J. not only is African American but looks Arab American makes an important difference to his integration in Cairo. "T.J. discovered that his brown skin and African American features allowed him to blend in easily," Kaldas reports. "Egyptians told him that he had classic Egyptian features and insisted that his ancestry must be Egyptian" ( $L C$ 5). T.J.'s Egyptian-like complexion appears so obvious that he actually has trouble to convince others he is not Egyptian. This point is highlighted in his university environment. When Kaldas describes his first teaching experiences in the Middle East, the confusion about his racial background dominates the scene. His first task in the classroom thus becomes "proving his American identity," she explains ( $L C$ 21). "No one here believes he is not Egyptian, not only because he is African American with a similar complexion, but also because many Egyptians assume that all Americans are white and blond," she then adds ( $L C 21)$.

These very explicit statements on ethnic identity in connection with racial appearance seem quite awkward at first. Kaldas uses terms like "brown skin," "African American features," and "complexion" without hesitance. Since race and skin color meanwhile count as the products of social construction, one might as well judge Kaldas's statements as racist. This particularly applies to her emphasis on her husband's racial appearance. After all, it is not his language - he does not speak Arabic - or his habits that are categorized as Egyptian. Rather, the confusion of his ethnic identity, which nevertheless facilitates his cultural integration, is merely based on racial complexion. What makes the reader separate these explanations from the ones of a racist Orientalist taking a tour to Cairo is Kaldas's authorial agency as multi-ethnic Arab American herself. In addition, Kaldas does not theorize in these passages; she does not start out with abstract explanations as to which role race and ethnic appearance play in society. Rather, the importance of race for social acceptance which Kaldas stresses is solely based on the personal observation she makes concerning her husband. In light of her own struggle to feel at home in Egypt, one can even notice a slight feeling of envy between the lines since T.J. eventually faces no outside challenges when adjusting to Egyptian life. His familiar racial appearance causes natural trust in his work environment. Without actively taking part in a process of intercultural negotiation, this appearance "made it easier for students to respond to him, and it also encouraged them to rethink their images of America," Kaldas explains ( $L C$ 34).

What the author here calls "images" are in fact outright stereotypes of Egyptians toward America, such as the belief that Americans are mostly "white and blond." 
Blondness as the extreme opposite of dark hair and skin color turns out to be a more comprehensive social ideal in the eyes of Egyptians, as Kaldas soon learns. One day, her housekeeper asks her why she does not dye her hair blond because, supposedly, "that is what everyone in America does" ( $L C$ 34). But not only is America known as the home of white and blond people, it is furthermore perceived as the country which does not tolerate any other skin color. Kaldas also hints at these "images of America" when referring to her husband's students. Obviously, these images are not at all favorable for the American ear, and they are quite widespread in Egyptian society. The family learns about this negative look at America in several everyday-encounters in Cairo. In one of her journal entries, Kaldas remembers a scene in a pastry store "The new man in Tseppas who helped us said America was a racist country with no morals. And another man said everyone with black hair is not suspect in America. Mustafa [old pastry man] must have died before 9/11, his vision of America is still intact" (LC 24).

As this incident reveals, the image of America among Egyptians does not at all correspond to the ideal of the multicultural melting pot in which everyone is welcome to contribute the uniqueness of his/her own ethnic background in order to form something new. Instead, America is seen as a severely racist country. By alluding to the impact of $9 / 11$ in this context, Kaldas also illustrates how a major key event can suddenly alter or even destroy former images of a country and its people. Even the "vision" of America as open and plural society can thus quickly turn into a myth and be replaced by notions of hatred and racism. Kaldas in another passage makes this changed role of race in American society very elaborate:

The image of America as a land of wealth and opportunity has been shattered for many here. The longing to go to America has been replaced by an anger that comes from feeling betrayed. Arab Americans have faced discrimination in the United States for a long time, but those in the Middle East are often unaware of it. Now, after 9/11, they have heard of the random attacks against Arab Americans, and they feel that there is no place for them in this new land. Their belief in those American ideals has turned into bitterness. (LC 36)

This passage emphasizes the impact of mediated key events on the global image of the United States. Race here plays an elevated role, as Kaldas explains. She identifies $9 / 11$ as the major turning point that gave way to an unprecedented intensity of racism in the U.S. and also as the event which made this racism publicly visible around the world. Particularly in the Middle East where the U.S. still counted as attractive country for many prospective immigrants, despite certain political hostilities, the open racism against Arab Americans has put an end to any glorifications. The fact that euphoria and admiration on the part of Egyptians have thus been transformed into "bitterness" underlines the emotional significance of Kaldas's observations. Clearly, Egyptians are not depicted by her as the ones who have always seen 
the U.S. as enemy. Rather, their high degree of frustration is only possible because they previously cherished the core value of racial equality which Americans themselves lifke to identify with. Despite the cracks the racist aftermath of 9/11 has caused for the image of America as favorite place of settlement for many Arabs, it has not fully forfeited its attractiveness. Immigration thus continues to be a prominent issue, even in Kaldas's extended circle of family and friends. Several of the families she meets in Egypt think about moving to the U.S. for work purposes, as she learns. Others decided to emigrate to Canada, such as her relative Rami and his family. "He was the only one tho could talk of racism, teaching me the word in Arabic," Kaldas remembers ( $L C$ 62).

Her stay in Egypt obviously brings about further learning experiences that endow the word racism with further meaning. The constant confrontation with the issue of race from the part of other Egyptians makes her elaborate on the topic in broader political, historical, and theoretical terms. Kaldas witnesses the protests regarding the Palestine conflict in high schools and universities in April 2002. The uproar is also related to racial reservations on the part of the Egyptian protesters and their hostility toward foreigners from the West. As Kaldas notes, T.J. still manages to escape the conflict-laden atmosphere and is allowed to pass through the gates of the university without difficulty because he is again identified as Egyptian based on his appearance ( $L C$ 37). Palestine, for Kaldas, only marks one example that shows how torn world society is between racial, cultural, and ethnic divisions. "Today, a wall still exists between the Greek and Turkish sides of Cyprus and Israel is building a wall along the West Bank. Such walls have marked our history," Kaldas reflects, "creating divisions that limit our vision" ( $L C$ 131). Often, these divisions evolve around the question of how "blood, location, and language become signifiers of identity," she gloomily ponders ( $L C 131$ ). American history provides the prime example. Here, the "distinction between blacks and whites" was essential to slavery, the author analyzes, which in turn was the basis of inferior treatment ( $L C 132$ ). Similar conditions in the present affect the definition of Native Americans who have to prove their "Indian blood" in order to be recognized. "It seems we might divide ourselves into oblivion," Kaldas wearily concludes.

The way in which the author deals with the issue of racism again proves her commitment to functioning as a cultural interpreter. Based on the multiple vignettes she presents on racial appearance and racial stereotypes, she draws a larger bow to the overall social, political, and historical conditions surrounding racism and ethnicpolitical conflict on a global scale. The style eventually equals a historical inquiry more than a memoir. By specifically elaborating on the history of racism in the U.S., Kaldas immediately transfers her racial experiences from Egypt to the American context. The image of "walls" separating countries and peoples in various parts of the world, as well as the emphasis on dividing lines in a larger sense, are major tools of Kaldas's didactic technique. Based on her cultural authority, she points to 
the significance of these binaries while at the same time challenging them. By making her American readers look at their own country's history as evidence of racist practice, she sets the groundwork for a change of thinking.

Besides encouraging her readers to reflect on the internalized binary between black and white, between self and other, Kaldas also provides more concrete starting points for overbearing these binaries. She does so by employing the example and voice of her daughter Yasmine who "rejects the label some put on her," as Kaldas explains ( $L C$ 132). When others tell Yasmine that she is "half African American and half Egyptian," she reacts with fierce disagreement. "How can you be half anything?" Kaldas quotes the response of her daughter ( $L C$ 132). "She claims an identity made of two wholes so that she can be all Egyptian and all African American at the same time," she then adds. This insistence on wholeness within a state of division is even more explicitly emphasized in a poem by Yasmine entitled "Who I Am":

\author{
Dark faces, black hair are my relatives \\ with a whole bunch of Oklahoma in between. \\ Some beating drums \\ Some Pharaohs \\ and some American cheese \\ are who I am. (LC 147)
}

This poem wraps up the issue frame of race in Kaldas's narrative. Not only does she make her reader interpret Arab and Arab American identity from a different and less clear-cut racial perspective, she also designs an alternative image of identity that incorporates difference without causing conflict. Kaldas presents this somewhat idealistic solution in the naïve poem of her child. Exactly because it is a child speaking here, and not Kaldas herself, such otherwise racist descriptions as "Dark faces" and "black hair" can appear alongside the phrase "some American cheese" without raising suspicions of racism. For the reader now looking through the racial cognitive frame that Kaldas creates, these supposedly naïve words model an identity which is anything but trivial. It stands for a renewed concept of race that allows individuals who combine multiple ethnicities to follow the example of "Who I Am" and define themselves instead of constantly being defined by others. Unfortunately, however, there are other hurdles to overcome in order to eventually redefine the image of the Arab in the larger public discourse. As often in life, this obstacle involves the issue of money. 


\section{The Economy Frame}

Borders and walls not only divide ethnic groups and cultures, they also create fissures between different socio-economic groups. This phenomenon is global, yet, the faces of poverty and wealth look different in every country. Pauline Kaldas begins to concentrate on economic circumstances in Egypt at an early point in the memoir. In the course of her account, this focus forms one of the most visible and stable frames of her life narrative. Here, cultural, ethnic, and social differences culminate and result in class conflict.

The quilt format of Kaldas's narrative allows for the integration of many everyday-experiences without adhering to a strict thematic order. It is through these snapshots of supposedly unimportant details that the reader learns most about the world of Egypt through the mediative distance. One of these details is connected to the story around a family dinner in a large hotel in Cairo. Upon entering, the Kaldas family members have to go through metal detectors. Heightened security measures, however, are only one result of the larger social divide which Kaldas becomes aware of pretty quickly. "The discrepancy between rich and poor, with the rich marked by Western modernism, has become even more striking," she writes (LC 10). The Marriott as an emblem of this "Western modernism" comes to represent the microcosm of class division, as she explains in another instance. "However, the only ones who can afford this restaurant are the foreigners and the upper class, two groups of people who are perhaps quite similar. The upper class who frequent the Marriott are marked by their access to the West [...]" (LC 29). It is this upper and partly also middle class which "help to sustain the Western businesses that are quickly claiming their territory in Egypt," Kaldas furthermore explains ( $L C$ 29).

These detailed elaborations on the relation between everyday impressions and larger economic trajectories focus the attention of the reader on the issue of economics early on in the narrative. Kaldas illustrates the economic and class situation in Egypt from the perspective of a cultural insider of both worlds east and west of the Nile. The very fact that she is able to make these observations in privileged places such as an upscale hotel automatically identifies her as a member of the very upper class she writes about. This shifts her focus to her own living conditions. With her husband being a Fulbright fellow, the family is provided with a spacious apartment and several servants to clean the home and take care of other needs ( $L C$ 12). This reminds Kaldas of her middle-class childhood in Cairo. The family also had servants and other luxurious privileges. This possibility of hiring personnel, however, has changed dramatically since her childhood. In present-day Egypt, she observes, only the very wealthy can afford to have servants. "Even the language has changed. The word 'servant, which was used when I was a child, is now considered somewhat derogatory and instead the word 'worker' has taken its place," she 
acknowledges ( $L C$ 84-85). Kaldas reads this change of vocabulary as an indicator of a larger social division and an economic shift. "Class dictinctions often seem marked by those who provide the services and those who can pay for them. This creates a country of entrepreneurs who, regardless of whether they can read or write, find ways to tap into the marketplace" ( $L C 85)$.

Such detailed reflections on class especially dominate the chapter "April Reflections: Making Ends Meet" which is almost entirely devoted to the analysis of economic circumstances in Cairo. The fact that the family still has servants while staying in Cairo emphasizes Kaldas's own privileged status which reaches back to her childhood. This becomes even more obvious since the possibility of average Egyptians to have servants has become considerably smaller. Kaldas's comparative wealth therefore not only separates her from the majority of other Egyptians but also from extended family members. When describing the living conditions of her uncles and aunts in Egypt, Kaldas employs almost textbook-like economic criteria. Their living environment "can best be described as a working-class neighborhood. Here, it is rare to see anyone dressed in stylish Western clothing," she reveals (LC 55). Kaldas, however, knows that her privileged status is not the result of her own economic rise in Egyptian society but the unintended product of the fortunate circumstance of living in the very place where "Western clothing" is everyday apparel. "Arriving in Egypt, we became wealthy," Kaldas sarcastically identifies the moment of conversion from an American middle-class family to the upper class in Cairo who can undertake fancy dinner outings regularly ( $L C 109)$.

This fairly humorous take on her privileged status comes to be overshadowed by the economic reality Kaldas encounters outside the walls of luxurious hotels. Here, extreme poverty can be observed in the streets and at popular tourist getaways. The author again provides very vivid illustrations of these scenes. In "Snapshot 5," Kaldas presents a short poem describing a young man selling T-shirts in front of the Sphinx. "T-shirts, two for ten pounds, my mother make them last night," she quotes his broken English ( $L C$ 87). Even in one of the sections where Kaldas provides traditional recipes, the economic context enters the picture. When describing the preparation of ful, a traditional breakfast dish in Egypt, Kaldas highlights the social context of the meal. "Ful provides basic nourishment for the poor in Egypt," she describes, "many of whom can afford little else to feed their families" (LC 94). Exactly those who "can afford little" or hardly anything, Kaldas sees begging in the streets of Cairo. Especially children follow the obvious stranger, motivated by the hope to get some money. It is exactly this inescapable and immediate confrontation of rich and poor, of two separate worlds that clash, which seems to worsen the material poverty even more. This becomes strikingly evident in a scene Kaldas recalls from her home at AUC. When the plumber came to repair something, he brought his little son. The child would not move anymore after see- 
ing the interior. "Through his eyes, the apartment, magic carpets to ride, bouncing on clouds. We had created the moment of his poverty," Kaldas admits (LC 109).

These further instances in which Kaldas deals with poverty, wealth, and class differences bear testimony to the increasing importance the issue plays in the narrative. What drives her depiction is not the separated illumination of rich and poor living conditions but the friction that emerges at the intersection of both. Not only does poverty exist due to the lack or shortage of money. The feeling and the awareness ${ }^{15}$ of poverty are reinforced when confronted with the opposite extreme, namely, unattainable wealth and abundance. The story of the plumber's son powerfully illustrates this logic. As Kaldas's reaction to the boy reveals, she is deeply aware that the mere view of their wealth awakens a sense of poverty in him which did not exist before. This feeling of estrangement in light of so many material goods is furthermore accentuated by the Orientalist reference Kaldas makes to "magic carpets." Both, the magic carpet and the view of Kaldas as being extremely wealthy are creations of fantasy. Still, the visual depiction of wealth deepens the gap to poverty. This example makes the reader aware of how the material abundance that counts as average for Americans, is looked upon from a different perspective. Furthermore, this personal confrontation with poverty contributes significantly to Kaldas's questioning of her own class identity. She is reminded that much of the wealth she is able to enjoy is merely a result of the fact that her parents once decided to live in the West. Upon realizing this, she asks: "Where would I have been if I had stayed?" ( $L C 111)$. The preposition "where" in this question is a rhetorical one because it refers to class position and Kaldas knows well that the possibilities to achieve her current socio-economic status would have been very limited in Egypt.

This increasing attention to economic circumstances and class difference does not prevent Kaldas and others to take advantage of the monetary privileges Egypt has to offer. Instances of this privileged life are provided when Kaldas reports on her visits to major grocery stores in Cairo. She gives a very detailed depiction of what she finds in these shops. "The store shelves are loaded with Western products from soaps and shampoos to coffee makers and computers," she describes (LC 20). Even gummy bears and Harry Potter books are available for her daughters. She devotes an entire subchapter entitled "Western Products" to the issue of material goods and explains that "American products" started being available in the 1980s ( $L C$ 30). The label "Western Products" here not only refers to soap and toys from America. Rather, the overall market picture Kaldas depicts hardly leaves any category untouched - from "Western" wardrobe to "Western-based education," anything seems to be handily available in the Eastern marketplace (LC 32). Even

15 The story serves as a confirmation of Spivak's presumption that only contrast creates consciousness. This specifically applies to subaltern consciousness in the case of postcolonial literature (Huddart 133). 
America's most popular export model, i.e., the fast food industry, has successfully established itself in Egypt, as Kaldas acknowledges. Chains, such as Kentucky Fried Chicken, McDonalds, and Pizza Hut are competing for upper-class Egyptian customers ( $L C 29$ ). "These fast-food chains have become locations of status and money, buoys on the streets of Cairo that mark class differences reflecting an acceptance of American products," she explains. This heavy influence of Western capitalism also causes amazement on the part of American friends visiting Kaldas. When seeing the flood of familiar fast food signs, one of them exclaims: "I can't believe how Western everything is" ( $L C$ 50).

In contrast to her American friends, Kaldas witnesses this ongoing process of Westernization with mixed feelings. Having grown up in the country of burgers and fried chicken, she also knows about the downsides of large-span capitalism. Some of the shortcomings connected to this are of a very practical nature in that the abundance of Western products hurts the domestic industry. Kaldas reports on a law that was passed to restrict the import of foreign goods ( $L C 20$ ). This measure, however, seems to have little effect, she explains, because foreign products continue to be favored by those who can afford it. Kaldas then provides a thorough description of these economic trajectories:

Western products are perceived to be superior to anything made in Egypt and of course they're very expensive. The cost of living has gone way up, making the poor even poorer while the middle class scrambles even more to make ends meet. Yet, there is still a strong upper class. The upscale restaurants and hotels are crowded with Egyptians, wearing the latest styles and flashing their mobile phones like jewelry. ( $L C$ 21)

This influence of "Western products" is not limited to the aspect of class formation and interior market conditions. Furthermore, the economic penetration of the West is inherently intertwined with politics. The growth of Egypt as a fastfood nation plays a particular role in this context. "There are those who argue that these restaurants are the hand of American imperialism," Kaldas delineates the different fronts for the reader ( $L C$ 30). The concept of imperialism thereby opens up another theoreotical layer of Kaldas's economic analysis. The topic also concerns her as a teacher in the classroom. Here, the political implications of the term, however, do not seem to fall on fruitful ground. Kaldas recalls explaining the concept of imperialism to her American students at AUC. She urged them to not buy American products because this hurts the Egyptian economy. Their answer was not one that she favored: "Why should we buy inferior products?" they replied ( $L C 31$ ).

To Kaldas's own disappointment, she does not really have a convincing answer to this. Despite her awareness of the negative consequences the West's interference with the Egyptian economy, her American identity also makes her share the students' view in many ways. The judgement of the Egyptian economy as being "infe- 
rior," as they put it, therefore also shimmers through in Kaldas's own behavior. This becomes strikingly evident in her elaborations on the Egyptian school system. When trying to pay the monthly tuition fee for her daughter, Kaldas is constantly asked to pay a different amount whenever she shows up at the school. Most of the times, she is asked to pay more than originally advised. When interjecting, the secretary behind the counter simply states that paying less would be "fine" as well ( $L C$ 22). This lack of a consistent and transparent tuition fee system, one that does not differentiate between Western and Eastern school parents, tempts Kaldas to use the example of schools to provide a generalized summary of the Egyptian economy:

The Egyptian economy may be as mysterious to explain as how the pyramids were built. [...] I guess, it all goes along with having to give a tip to the man who slices your cheese and luncheon meat at the supermarket, and the salesperson who shows you merchandise in a shop, as well as the one who wraps your pastries, and of course the one who mysteriously appears from behind the Queen's Pyramid in Giza to give you a tour. (LC 22)

This generalized depiction of the Egyptian economy as based on randomness and bribery obviously is not a positive one. The derogatory manner in which she describes the situation is fostered by Kaldas's allusion to the pyramids. The pyramids have become the most prominent symbols of Orientalism throughout the centuries. Kaldas even reinforces the economic component of this Orientalist image that relies on the stereotypes of the rich oil sheikh and the somewhat oblique and hard-to-betrusted camel trader. Kaldas in another instance even provides a modern version of this character when explaining how taxi drivers estimate the "economic capabilities" of their customers before suggesting a price for their service. "In Egypt's economy, everything is negotiable," she states and links this to the emergence of a large informal sector ( $L C 85)$.

Obviously, the derogatory undertone in these lines makes it difficult to distinguish Kaldas from other Orientalists. She certainly is convinced that her familiarity with the U.S. economic system entitles her to make judgements about the inferiority of the Egyptian practice of trading. The sarcasm she employs highlights this sense of Western superiority. The American reader might thus be tempted to find confirmation for any pre-existing Orientalist stereotypes in Kaldas's words. Her non-American students at Cairo University, however, prevent her and the reader to fall into this Orientalist pitfall. They do so by holding the mirror to the face and flaws of the U.S. economy. When explaining the issue of homelessness in America to her students, Kaldas meets puzzled faces. "America is so rich," she recalls the reaction of her students. "How could anyone be homeless," they ask themselves while thinking of America as the country where people "live like people in Dallas, right?" ( $L C 28$ ). Kaldas becomes aware that the circumstances she is describing destroy the vision of America as "the golden land" ( $L C$ 28). Even more importantly, 
the students' reaction reminds her that the image she herself has of America is more of a vision than reality. She and her American readers are aware that the former economic treasures of America have mostly turned into visionary stereotypes. The homeless people Kaldas is talking about do exist and so does poverty in the U.S. The outrage of the Egyptian students when learning about these economic conditions leaves the reader no option to uphold the image of America as the Land of Plenty. In this respect, the U.S. cannot claim any superiority over Egypt. In fact, as Kaldas notes later in the book, homelessness is a problem which reveals deeper social shortcomings which the U.S. has no reason to be proud of. In a collective culture like Egypt, homelessness is prevented by the support of close-knit families who feel a high degree of responsibility toward their relatives. "So although there is poverty in Egypt, the focus on community and family rather than on the individual makes it rare to find someone who lives in isolation," she explains ( $L C 86)$.

Kaldas with her thorough insights into the Egyptian economy and its links to other social realms sets up another issue frame through which her audience can interpret Arab identity apart from pre-existing stereotypes. As a multi-ethnic interpreter, she is able to look at the class systems in Egypt and in the U.S. by contributing further knowledge on the causes and effects of wealth and poverty. Her method again heavily relies on binary contrasting which enables her to directly confront the American readership with common stereotypes of Egypt. At times, Kaldas in these instances in fact confirms certain Orientalist stereotypes due to the dominance of her American identity affiliation. In other cases, she distances herself from U.S. imperialism and hyper-materialism by pointing to its moral and social flaws. In both cases, the comparative model which Kaldas employs by drawing on the binary of East and West allows the Western reader to immediately identify with the economic problems thus depicted. Moreover, the mirror that Kaldas designs forces the reader to rethink the image of the rich oil sheik or the poor Arab begger. These stereotypes are overturned by Kaldas's image of the "New Middle East"16 which stands in total contrast to the Old Middle East as backward and uncivilized. In fact, the U.S. are ultimately characterized as uncivilized when it comes to preventing individuals from drowning in poverty. Kaldas therefore arrives at a model which does not place monetary wealth at the top of the hierarchy of human needs for achieving a good life. "Despite our wealth, we are so isolated in the United States. As hard as it is, it's good to have left America for a while, to turn our heads and look from a different direction," she explains her own learning process ( $L C$ 82).

16 The term "New Middle East" was introduced to the world in June 2006 in Tel Aviv by U.S. Secretary of State Condoleezza Rice (who was credited by the Western media for coining the term) in replacement of the older and more imposing term 'Greater Middle East"” (Nazemroaya). 
Although the U.S. within this economic issue frame slowly loses the status as economic hegemon, the legacy of imperialist practice remains highly visible. The very fact that Western and Eastern origin still marks the ultimate quality criteria for consumer goods is the most obvious characteristic of this lasting cultural and economic influence. Kaldas's constant reference to these criteria sustains the enduring division of two economic and cultural spheres. The long-term effect of this materialist bias is proven by Kaldas's personal vision of a successful and enjoyable life. "I've acquired the desire for the American dream and want that piece of land with a house and yard, to set down a claim and draw a boundary around what I can call my own," she explains toward the very end of the memoir ( $L C 150)$. The economic frame through which she analyzes Egypt and the U.S. therefore does not prevent her from giving in to the materialist impulse of the West, as she consciously acknowledges. Although Kaldas at this point is more than aware that the "American dream," including its promise of wealth, is just as much a fable as the Egyptian camel trader, she nevertheless adheres to it. Learning and mediating alternative perspectives of interpretation is thus not the same as actually changing one's perspective, as this example demonstrates. This lesson particularly holds true when approaching the issue of politics.

\section{The Political Frame}

Finally, here's something I don't think that we have learned, and that is what makes people become suicide bombers. The preconceptions we have, which is that it's a long process of people becoming brainwashed and then finally at the end of that process, when they become fervent fanatics, they become willing to become suicide bombers, turns out not to be right. In many cases, the distance between what we would consider to be a normal Westerner and somebody who's willing to blow themselves and their children up in an airplane is a matter of weeks, and we don't fully understand that. We don't understand the mechanism of that. (Chertoff et al.)

This excerpt from NPR's special on the 9/11 anniversary in September 2011 points to the lasting lack of knowledge in the West concerning the roots of terrorism in the East. It is this lack of knowledge that creates the fear and distrust toward the Middle East. The journey of Kaldas and her family is overshadowed by the climax of this fear. Her husband has accepted the Fulbright scholarship shortly before 9/11. All of a sudden, the "positive journey" turns into the culmination of the "uncertain," Kaldas remembers her feelings ( $L C$ 8). Friends and ultimately Kaldas herself start questioning their decision to go to Egypt due to the fear of terrorism. They nevertheless decide to leave for Egypt in January 2002. Traveling with them is the media footage that frames the image of the Arab around the world. This frame also comes 
to surround the family's experience in Cairo and eventually of her memoir. Kaldas is thus forced to engage with politics and in this position she also sheds light on the question how people "become suicide bombers."

At the beginning, Kaldas wonders if there is some mysterious power making the family always stay in the Middle East at the height of political unrest. Their first visit in 1990 was overshadowed by the Gulf War. Now, 9/11 has transformed the political world forever ( $L C$ 34-35). Despite the dominance of this event, Kaldas seems to hope that the flight over the Atlantic allows the family to escape the WOT somehow. It quickly turns out, though, that the international terrorist threat continues to haunt her. Everywhere she goes, whatever she does, terrorism follows her.

Everyone wants to talk about America and 9/11. This cab driver told me people are angry at the way the U.S. tries to dictate to other countries. People are fed up, he said, with the way the U.S. handles the Palestinian issues and how it wants everyone to accept America's right to defend itself but won't allow other countries, especially Palestine, to do the same. He argued that in response to the terrorist acts of 9/11, the U.S. destroyed a whole country, but it won't let Palestine do anything. (LC 25)

These words uttered by a cab driver in Cairo who takes her to a book fair is Kaldas's first intensive encounter with the effect of the WOT in Egypt. The driver, however, does not leave it at this political outburst. In addition, he provides Kaldas with the larger story of "how terrorism is born," as she recalls ( $L C 25)$. The story evolves around a young boy whose mother is selling goods on the sidewalk. One day, an officer walks by and simply destroys her goods. The mother is helpless and so is the child. Years later, the officer has been promoted but still keeps roaming the streets, destroying the goods of poor bargainers. At this particular time, however, the boy has grown into manhood and the story ends as follows: "When he saw the chief officer, he picked up a banana cutter and killed him. Because what he saw done to his mother, had stayed with him and opened a vein in his body" ( $L C 25)$.

This story narrated by the cab driver marks the center of her journey entry on February 8 and at the same time concludes the entry - nothing follows these tragic lines. The reader is left with the powerful image of the young boy growing into a violent killer due to the injustice he formerly experienced. One can only speculate how Kaldas reacted to the story. She does not reveal any feelings in this instance by leaving the story uncommented. Her implicit statement on its meaning is provided by the very fact that she does include this vignette in the memoir. Indeed, it provides an answer to the question the American radio commentators and self-declared terrorist experts raise on the origins of terrorism. It gives a shocking answer, yet, it leaves the evaluation of this answer to the reader. This interpretative silence amplifies the power of the story itself. Obviously, the logic of terrorism is based on revenge for previous injustice committed by the self-declared powerful. Those with- 
out power do not have a voice, like the little boy who could only passively witness the events. Later, he forcefully regains agency through violence. Kaldas offers another solution to this violent scenario by giving voice to the Arab cab driver. The scene marks one of the very few exceptions in which Kaldas employs direct speech, apart from the letters and stories written and thus formulated by family members.

Speaking on behalf of America is something which Kaldas is forced to do as her confrontation with the political world after 9/11 increases in Egypt. "And everywhere people ask me what is America like now after 9/11, and I'm not sure what to say except that there are good people in America - I have one foot on each continent and I can't seem to strike a balance," she describes her uneasiness (LC 26). Obviously, she is pushed to speak about the collective state of America in a way that she is not able to. Against her will, the mere fact that she is recognized as American forces her to function not only as a cultural and linguistic interpreter, but also as a political one. As she reveals in her chapter "Politics in Translation," she feels completely unprepared for this role because her knowledge of politics is limited. "I do not presume to understand international policy, and, like others, I am limited by what the media chooses to show me" ( $L C$ 35). This emphasis on expertise and detailed knowledge highlights Kaldas's self-definition as a scholar. As such, she prefers to make statements based on detailed knowledge and profound insight instead of speculating or generalizing without sufficient background. She thus clearly separates herself from the media and other actors participating in public political discourse.

Instead of adopting the role of the pseudo-experts ${ }^{17}$ found in the media, Kaldas thus retreats to her role as a personal storyteller and chooses to relate to political events only based on her own experience. One of these major key events is the 1967 War. Although Kaldas was only six years old at the time, she still remembers the sound of the Israeli planes flying over her head and the sad face of her mother when one of her brothers got killed ( $L C$ 36). Kaldas immediately transfers these memories to the present political situation in which families in Iraq and Afghanistan suffer the same feelings. The same holds true for the ongoing conflict in Palestine, which also leads to student protests at Cairo University and other institutions during the family's stay there. Kaldas in all these cases emphasizes the fact that these are not merely conflicts between Arab countries in the Middle East. These are conflicts in which the United States has been involved over decades and ultimately lost its reputation over a series of violent responses ( $L C$ 36). Nevertheless, this national image directly touches the lives of individuals. "The fear is that the anger against

17 The media coverage of the WOT has fostered the emergence of many so-called "pseudoexperts" who shape the public debate and frame fear (Debrix 3). Pseudo-experts often present themselves as semi-intellectual figures but actually lack official academic qualifications. Their expert status mostly relies on their repeated media presence (Debrix 46). 
U.S. foreign policy will turn into anger against individual Americans," she states ( $L C$ 37). Kaldas as a consequence senses the "rise of anti-American feelings" when some of her friends from America visit ( $L C$ 82). She feels relief when they manage to leave safely.

Despite her initial impulse to reject the role of a political translator, Kaldas in these thorough reflections on political events related to the Middle East does much more than simply tell her story. She conveys important background knowledge on the political history of Egypt and its neighboring countries which many of her readers might not be familiar with. These events are marked by violence and military conflict that puts them into the overall context of the WOT frame. By presenting the Egyptian view on U.S. foreign policy as related to these events, Kaldas not only recites television news but provides an alternative pattern of interpretation for her readers. As she learns, the hostility against U.S. policy is not based on blind hatred but on honest disappointment and personal suffering caused by the U.S. There is no oversimplified or reductionist view of U.S. politics on Kaldas's part. Instead, she elevates the emotional and normative level of the given political conflicts in allowing other Egyptians to voice their lack of trust in U.S. policymaking. The most intriguing example of this method is provided by another one of her daughter's letters: "Dear President Bush, I'm an American Egyptian," Yasmine writes. "I'm eight years old. I don't think you're acting well in what's going on with Israel and Palestine" ( $L C$ 90). These seemingly naïve words uttered by a child express the general opinion and critique Kaldas discovers among the Egyptian population. Just like Yasmine, many of them do not base their evaluations of U.S. politics on sophisticated political analyses but on personal feelings of "right and wrong." Despite the seeming infantility of this approach, it reflects Kaldas's own method of binary contrasting to convey knowledge abou the Other.

The role of the political interpreter does not stop with Kaldas's departure from Cairo. "Back in the United States, I am again asked to be a political translator, and I am no more comfortable with the role," she explains ( $L C$ 37). Next to fulfilling this role as a teacher in the classroom and in daily life, Kaldas continues her political function as a writer. The overall importance of political framing for the identity definition of Arabs and Muslims around the globe has occupied her in various journalistic publications in which she comments on her own experience as Arab living in the U.S. Despite the non-literary genre, Kaldas here never takes the position of a detached journalist, but always frames her writings as life narratives to explain the "politics that reach into our lives" (Kaldas, "Walking"). Her memoir can as well be interpreted as such an act of political translation from public to personal. The political frame drawn by Kaldas is much more diverse than the logic underlying the WOT. The latter remains visible but does not dominate the account. This effect, however, is not only achieved by conveying multi-ethnic knowledge on political events to dissolve American half-knowledge. In addition, Kaldas provides a thor- 
ough analysis of how this half-knowledge on the Middle East takes its origin in the global mass media.

\section{The Media Frame}

Kaldas from the beginning of her stay in Cairo pays close attention to the media environment surrounding the family in their new home. As she explains, their TV provides about five channels with only one of them broadcasting English and French programs ( $L C$ 20). In light of the enormous number of TV channels available in the U.S., this poses a clear contrast to the usual information environment Kaldas is used to. She does not see this as a large limitation, though, since the content of the broadcasts still proves enlightening in many ways:

Watching the news here has been an exercise in shifting perspectives. Every newscast, regardless of whether it is in Arabic, French, or English, begins with news of Palestine and Israel, first highlighting Israeli attacks and the number of Palestinians killed. The images of the violence are far more graphic than anything we get in the States. I'm constantly aware of the degree to which the media shapes our understanding of current events as well as our judgements of the actions of other countries. World News also received more coverage here, with special segments on news in Africa and in Asia. (LC 20)

This depiction of the media landscape in Egypt again relies on the direct comparison to the U.S. Without explicitly saying so, Kaldas reveals the news bias of the Egyptian media. In highlighting the cruelty done to Palestinians by Israelis, the media stir anti-Israeli sentiment. The pro-Israeli stance of the U.S. media is thus reversed. Kaldas, however, does not openly criticize this contortion. Instead, she draws attention to the overall political conflict frame that dominates the Egyptian news much more than U.S. broadcasting. The dominant role of visual information appears particularly striking to her, whereby the blatant depiction of violence connotes that ethical ${ }^{18}$ concerns are much more adhered to in the Western media than in

18 Ethics constitutes a separate field of research in Communication Studies which has been on the rise since the 1980s (Christians 19). Especially with respect to visual information, debates constantly arise in academic as well as political and public circles, as to whether existing statutes are being upheld and sufficient. The U.S. press is regulated by the Code of Ethics established by the National Press Photographers Association (NPPA). The code contains the following paragraph for the conduct of visual journalists, which is of special relevance for the coverage of war and political conflict: "4. Treat all subjects with respect and dignity. Give special consideration to vulnerable subjects and compassion to victims of crime or tragedy. Intrude on private moments of grief only when the public has an overriding and justifiable need to see" ("NPPA Code of Ethics"). In Egypt, a similar code 
Egypt. Most intriguingly, Kaldas observes that the media impact both the understanging of current events as well as their normative and emotional evaluation. This focus on the cognitive and the affective impact of news coverage overlaps with the very definition of framing. Kaldas alludes to the effect of this mechanism by pointing out that her "perspective" has shifted and broadened in Egypt since world events play a much more important role than in America. ${ }^{19}$ This comment hints at the common critique of American culture as self-isolated from the world which constitutes a dominant argument throughout her memoir.

When adopting the worldview of the Egyptian media, Kaldas increasingly starts using the media as explanatory variable to interpret different elements of Egyptian culture, politics, and history. One of these phenomena is Egyptian immigration to the U.S. At the outset, this process is mostly explained in relation to economic and political factors. This corresponds to the experience of her own family, who looked for better opportunities in the West while war and ongoing economic shortages worsened the living conditions in Egypt during the 1970s. Kaldas infers that this led to a large-scale Egyptian "brain drain" ( $L C$ 3). This explanation of immigration motivations is in line with sociological and cultural findings. What it leaves out, however, is the role the modern mass media have come to play in triggering the wish to escape to countries like the U.S. When reflecting on the impact of the media in her own life and the one of other Egyptians, Kaldas suddenly realizes this link.

With the advent of television and the increased number of movie theaters, Egyptians began to have access to American shows and movies. What they saw on the screen were people living in large homes with manicured lawns. It must have triggered images of the villas in their own country that had remained out of their grasp. Perhaps they thought that in America they would be more accessible. ( $L C 28$ )

of ethics exists. It states that "the news reporting process should be accurate, objective, fair and impartial" ("Media Landscape: Egypt"). Due to the fact that Egypt finds itself in a political transition phase from formerly authoritative rule, however, the regulatory measures and institutions enforcing the code are practically absent. In addition, there are a large number of government-owned or -controlled media outlets, which means that the parliament remains the only body to interfere in possible violations.

19 This observation is in line with findings derived from international agenda setting studies. As empirical studies have demonstrated, the size of a country, as well as additional key indicators, such as GDP and international economic ties, largely determine the degree to which international coverage outweighs news on domestic events. The smaller a country the more room international coverage gains. Large countries like the U.S. thus mostly concentrate on domestic news (Dearing and Rogers 93). 
Kaldas in this passage demonstrates what the image of the West looks like in the eye of the Middle East. As she indicates, this certainly impacted the degree to which Arabs were and still are attracted to move to America. She identifies the media as the force filling the gap between the "other" as unknown and the other as personal experience. ${ }^{20}$ Since people in Egypt have considerably fewer financial means to travel than Americans, they to an even larger extent rely on the images provided in the media to at least get a virtual impression of the country. As Kaldas furthermore explains, these images continue to be ruled by popular American entertainment shows and soap operas. These formats are responsible for that fact that the image of the U.S., despite its military prowess, is framed as "the place where streets are paved with gold" ( $L C 28$ ). To the American reader, this reveals that Egypt's media landscape is Americanized to a surprising degree. What the American reader knows very well from personal experience, though, is that the image of the Land of Opportunity might be desirable to foreigners but has largely died in reality. Kaldas tries to make people in Egypt aware of this gap between the media framing and reality by reminding them that "life is hard in America" ( $L C 28$ ).

Instead of assigning the responsibility for this distorted image of the U.S. to the Egyptian media alone, Kaldas's own framing analysis takes her to a different conclusion. In her view, it is the U.S. that largely controls its image in global news reporting. This particularly refers to the issues of race and ethnicity. "The influence of American media abroad produces a homogeneous image of the American population, the assumption being that everyone in the United States is white," she observes based on her observations and expectations of other Egyptians ( $L C$ 34). Just like T.J.'s Egyptian ethnicity is actually a "mistaken identity," as she clarifies, so is the public image of the U.S. a result of false presumptions spread by the media ( $L C$ 34). Anyone associated with the U.S. thus has to "explain his existence against the stereotypes that had traveled across the ocean" via the global media culture ( $L C$ 34). Similar to her husband whose only defense against stereotypification is "explanation," Kaldas counters media images by conveying cultural explanations, both in Egypt and the U.S. "Without that knowledge, we are left with stereotypes and 'around the world in eighty seconds' on the news," she insists ( $L C$ 37).

Kaldas in these lines further explores the causes and effects of global media framing. Above all, she identifies the U.S. media hegemony as the main source of reductionist views of American culture and society. This finding is in line with the

20 Starting in the late 1980s, scholars already collected considerable evidence that the mass media constitute a considerable pull factor in influencing migration (Fawcett 674). They do so in conveying images about other countries and places in a way that appears highly attractive to people who face difficult living conditions in their own home countries (Fawcett 675). With the spread of modern mass media in less developed countries, this effect has been strengthened. 
thesis of U.S. media imperialism which states that the export of U.S. entertainment formats as well as the dominance in the global market of news by far exceeds the one of Europe and other parts of the world (K. Schmidt 7; Sreberny 9489). ${ }^{21}$ By identifying images of wealth and whiteness as dominant media stereotypes, Kaldas even points to the very issue frames which have been found to dominate the media coverage after $9 / 11$. The entire cluster of these overlapping frames is responsible for the stereotypes surrounding the image of the American in Egypt. In turn, this finding also suggests to the reader that his/her own mediatic images of Egypt and the Arab world as a whole are based on selective windows of interpretation. Again, Kaldas does not judge these trajectories merely on normative grounds by making the U.S. responsible for the emergence of mediated stereotypes. Rather, she identifies the lack of detailed information and background knowledge as major reasons why media stereotypes can dominate the public opinion regarding other countries.

In order to emphasize the important role first-hand experience and knowledge play for the maintenance of previously mediated generalizations, Kaldas recalls a striking scene at a party with other American expatriates. The party is held on the rooftop of one of the AUC apartments, overlooking the entire city. In the distance, the tallest building carries the neon sign "Sport Cola" ( $L C$ 107). While looking out over the rooftops of Cairo, Barbara, another American friend, says to Kaldas: "Cairo is just like a big village" ( $L C$ 107). Kaldas is struck by this plain statement. "Jolted back," is how she describes her reaction. "To travel this distance, be here, live, and still see only what you imagined before you came" she shares her thoughts $(L C$ 107)? A poem follows the question mark:

\section{Rooftops clamoring for space}

Night air seeps through a maze

I'm tucked into a refrain of images (LC 107)

Obviously, Kaldas, despite her strong identification as American, still notices the large gap that separates her from other American expatriates. In contrast to her colleague, she is able to see beyond the stereotype of Cairo as the big village. This reference, as her reaction illustrates, ultimately sustains the inherently inferior image of Cairo as diametrical opposite to hyper-modern American cityscapes with flickering lights and skyscrapers. This reductionist frame obviously makes the

21 More than $60 \%$ of Western European TV broadcasts between 1998 and 2003 were of American origin. In addition, U.S. entertainment companies dominate more than $80 \%$ of overseas movie-box office sales and close to $50 \%$ of television programming. This makes media content one of the most successful export goods for the U.S. (K. Schmidt 4). As Katrin Schmidt in her comparative study also reveals, cultural proximity is a key factor for determining to which degree a country is likey to adopt American media formats (9). 
foreign eye overlook the details of the scenery which might oppose preconceived notions. The "Sport Cola" sign as emblem of Western capitalism thus indicates Cairo's susceptibility to Western capitalism and modernization. The more detailed look at the city hinted at by Kaldas reveals Cairo's identity as part of the world as "global village," where transnational and regional influences become blurred (McLuhan and Fiore 67). Barbara's comment still underlines that even travel and immediate cultural experience sometimes cannot dissolve the long-standing frames of interpretation spread in the global village of mass communication.

Kaldas's lasting interest in the sustainability of global media frames has additionally been underlined by an article she published in the Roanoke Times entitled "To Talk Cautiously in the World." Here, she continues her reflection on being confronted with mediated stereotypes. As her report shows, even ten years after $9 / 11$, these images continue to be dominated by political events abroad and by the WOT. Kaldas writes about waking up and hearing that Bin Laden is dead. In the newspaper, she reads about the killing of Gaddhafi's sons and children. "I fold the newspaper and put it in the recycling bin -- my attempt to push the news aside, to remove it from daily life," she infers (Kaldas, "Walking"). Yet, leaving the news behind is hardly possible, as she soon discovers. When she steps out of the house, young boys see her dark skin and yell "Osama bin Laden." Obviously, mediated frames that lastingly define the identity of Arabs cannot be escaped by throwing the news in the trash. Even worse, the news constantly get recycled in the course of current events. "But when an incident occurs that highlights Arabs in the media, people's assumptions shift, and I'm defined in relation to the day's news," Kaldas explains the trajectories of media agenda setting (Kaldas, "Walking").

Just like the preconceived image of her American friend Rebecca cannot be reframed by the immediate exposure to Cairo as more than a "village," so is the political conflict frame a global phenomenon. Kaldas in her memoir as well as in her journalistic writing puts great emphasis on unveiling the logic behind this mechanism. As was the case with the issue frames discussed above, she deals with the impact of the media framing of Arabs on multiple levels of abstraction. Although Kaldas based on her own experiences raises doubts that existing media frames can be replaced easily, her memoir serves as an attempt to achieve this shift of perspectives. Eventually, she thus demonstrates that the lasting image of the Egyptian belly dancer is just another example of the familiar TV Arab.

\section{Reframing the Egyptian Belly Dancer as Didactic Device}

I had never heard of America until my parents told me we were moving there. My world was home, family, school, outings to the pyramids, vacations in Alexandria. That was as far as my vision would stretch. Like many children, my understanding of place was bound by what I 
could see and where I could go. The plane that took me to America forced me to redraw that map, to recognize immediately and abruptly that the world's boundaries were far greater than what I had experienced. ( $L C 131)$

Letters from Cairo closes with a series of reflections on the identity shift that Kaldas has experienced - throughout her past, throughout her stay in Egypt, and throughout the composition of her memoir. Just like the plane taking her to the United States allowed her to cross boundaries and get to know a different world, the trip to her homeland allows her to broaden her horizon. With the writing of her memoir, she allows her readers to join her on this journey. This in turn enables her to shift the perspective of her audience and thus reframe previous images of the Arab and Arab American. For Kaldas herself, this reframing nevertheless takes her back to America - physically and mentally.

Despite Kaldas's learning process to overcome her own stereotypes of Egypt, her life in Cairo does not provide a real alternative for her. Increasingly, the cultural gap which separates her from the life of the Egyptians becomes unbridgeable. In her final journal entries in July 2002, she describes the growing uneasiness of life in Cairo and her longing to go home. Rather minor disturbances like the heat, pollution, and the lasting stomach pain of her children gradually become unbearable. "We've been eager to leave," she describes her excitement and relief shortly before their departure ( $L C$ 145). Even though she admits that Egypt has provided her with a "home" that she will now trade with her American "home," it becomes clear that the two homes by far do not mean the same to her ( $L C$ 146). The former represents a mere physical location to her, the latter stands for the place where she actually wants to stay. Learning about this difference has also been part of the process she has gone through, as she notes. Thinking back of the past months, Kaldas realizes how much "this experience has transformed us" ( $L C$ 146). Part of this transformation was a prolongued one, such as providing her children with a "larger vision of the world." In addition, her husband has successfully managed teaching in a foreign culture and has thus learned to cope with "the shifting perceptions of his identity," as she claims proudly ( $L C 146$ ). In contrast to these rather positive learning experiences of her family members, Kaldas looks at her own unanticipated identity transformation with mixed feelings, as her words convey:

All these years I've been haunted by loss. This return to homeland has finally freed me. Immigrants return to their native land to discover their original identities, to claim a right to their ethnicity, to embrace a homeland of at least a spiritual belonging. But I have come back this time to unexpectedly find myself laying claim to my present life in the United States, and with it the undefined future for myself and the generations to follow. [...] My Egyptian identity will dissipate, perhaps only a memory for the generations to come. (LC 148) 
Kaldas here draws a line to the insights derived from the immigrant literature she teaches in the classroom. At an earlier stage of the memoir, this reference to literary depictions of homeland return serves the purpose of foreshadowing the possible result of her own journey to Egypt. At the end of her account, it becomes clear that only part of the promise has been fulfilled. The sense of belonging Kaldas discovers is not bound to her homeland. Instead, the confrontation with Egyptian life has brought her American identity to the forefront of consciousness more than ever before. She realizes that besides all good intentions, she has never really gone anywere outside the U.S. to make a permanent home, she admits. This becomes particularly obvious to her when she compares her two journeys to Egypt. The first trip "allowed me to reclaim a sense of who I was, to own the knowledge of my cultural identity, and to create a unified identity rather than the fragmented one that had been thrust on me by my American experience," she states ( $L C 153)$. This second trip in 2002 follows up on this experience but in a different way than expected. It thus enabled her "to release the sense of loss that comes with the immigrant experience," Kaldas subsumes ( $L C 153$ ).

As a solution to this loss, Kaldas longs for "wholeness." To her, this state can only be achieved by overcoming the constant oscillation between two worlds, between two homes. "I have learned that at some point you must choose a place to claim as your home, a place to locate yourself even as your shadow travels, even as loss fills your body, and even as nostalgia tugs at your memory" (LC 154). These reflections on identity loss and regain powerfully solve the tension that Kaldas builds up at the beginning of the memoir regarding the result of her own identity struggle. Remarkably, the overcoming of loss as healing function here is described as the outcome of her trip, which made her change perspectives in a physical and mental way. The writing of the memoir then also contributes to this end because it similarly relies on perspective shifts and intensive reflection. This fully corresponds to the notion of identity as negotiated and established through the act of narration. In yet another sense, this identity transformation also carries over to the reader of the memoir whom Kaldas enables to look at Egypt and her people through previously unknown frames of interpretation.

The necessary credibility and authorial agency to achieve this effect of reframing is strongly reinforced at the very end of the memoir in the last journal entry. Here, Kaldas again self-identifies with America, leaving behind her Egyptian past. "And I look forward to the intellectual and artistic energy of the United States - that community that I have made myself a part of. I think I can let go of the past, and hold the thread of my present to pull me ahead" ( $L C 165)$. This unequivocal selfpositioning on the American end of the hyphen marks the destination of her identity transformation. For the reader, it highlights Kaldas's strong cultural bond to the U.S., which in turn manifests her role as a cultural agent. Her knowledge on both worlds allows her to install alternative issue frames in the minds of the audience. 
When recapitulating the range of issue frames found in Kaldas's memoir, a series of findings emerge that contribute to the expansion of contemporary ethnic and Arab American life writing studies. The following model gives an overview of the frames thus identified.

\section{Graph 6: Frame Model of Letters from Cairo}

Frame Levels:

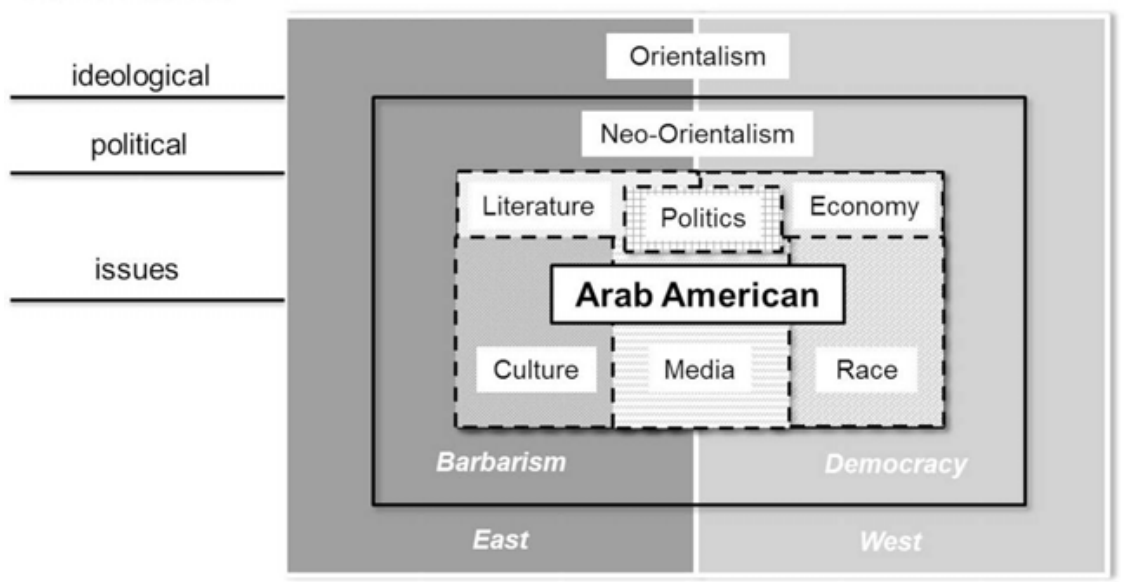

Kaldas develops a series of issue frames allowing for an alternative interpretative framework of Egyptian and Arab American identity. In contrast to Ansary's narrative, in which history stood out, the network of issue frames developed by Kaldas is more balanced. The most prominent issue frames are the ones of culture, race, and media. The strength of these frames does not necessarily emerge from the length of elaborations on these issues but from the diversity of topics covered. This is particularly striking with respect to the culture frame in which Kaldas provides a redefinition of various powerful cultural markers, e.g., food, everyday habits, internalized behavior and beliefs, and cultural performance. The issue frame of race fulfills a double function. On the one hand, the author's references to the racial implications of her Arab American identity are linked to her lasting efforts to underline her agency as a prerequisite for framing. On the other hand, the broader elaborations on race form an issue frame of itself that makes readers look through the perspective of the often discriminated racial Other. Again, the given issue frames overlap in certain instances. Kaldas's discussion of racial stereotypes in the context of the global media coverage provides an example of this.

The frames of literature and media require particular attention. Similar to Ansary's narrative in which the media frame was closely linked to his profession as a journalist, Kaldas designs a similar issue frame related to her occupation as a liter- 
ary scholar. At the core of both frames stands the effort of the authors to reveal the trajectories underlying the production and reception of texts and other media content while at the same time engaging in the task of writing. This self-reflexive mode reveals a high degree of abstraction and highly differs from the framing undertaken by the media themselves. As media analyses document, framing plays an enormous role in the production of almost any media content yet, the self-revelatory practice of introducing the media audience to its own framing techniques is highly unpopular. The given autobiographers take a much more transparent approach to their task of mediation by equipping their readers with the very knowledge they need in order to decode the framing mechanisms underlying their texts.

The juxtaposition of these issue frames reveals the wide range of interpretive options Kaldas creates for her readers to see Arab identity in a new context. When looking at these alternatives alongside the issue frames dominating the popular media coverage, additional particularities must be noted: 1) The religious frame that dominates the media coverage on the Middle East and also forms one of the most important issues in literary representations of the Orient, is not present in Letter from Cairo. 2) The same holds true for the issue frame of gender ${ }^{22}$ which also forms one of the most prominent frames in the media. The absence of this issue frame in Kaldas's memoir is particularly remarkable given the fact that contemporary criticism on Arab American life writing tends to reduce literary productions by women to this very aspect. Often, it does not seem to matter in these cases whether or not the theme actually occurs as a focus in the respective works. Critics thus seem to have transformed identity politics into a presupposed given by linking the gender and ethnic background of authors to certain themes. 3) Except for race, all issue frames constructed by Kaldas do not fit into the pattern of dominant media frames. This implies that she in fact does establish alternative frames on the issue level that allow the reader to reframe his/her image of the Arab.

With respect to the outer frames, especially on the political and ideological levels, the analysis has revealed that the WOT and other events within the political frame clearly play an important role in Kaldas's memoir. This is especially interesting when read alongside Ansary's autobiography. Whereas Afghanistan

22 Despite the mentioning of the belly dancer at the cultural performance, there are only two more specific references that catch the narrator's attention with respect to gender. One appears in regard to the family's housekeeper Nagah who struggles to support her family economically. This causes Kaldas to think of the collection Opening the Gates in which the authors deal with "invisible feminism" as defined by feminist acts who do not count as such in the public ( $L C 86)$. The other explicit reference to a gender stereotype occurs in the context of a visit to one of the hotels in Cairo frequented by expatriates. Here, Kaldas notices that there are no "veiled women swimming," yet, her own bathing suit as "loose dress" still catches other guests' attention (LC 106). 
counts as one of the epicenters of the "axis of evil," Egypt has not directly been involved in the WOT. Yet, political events and the issue of terrorism also largely frame the narrative of Kaldas. This is even more striking in light of the time gap between her stay in Cairo in 2002 and the publication of the book in 2007. This cornfirms the long-term impact of media framing as a crucial characteristic that differentiates the phenomenon from other media effects.

When discussing the sustainability of meta-frames, it is even more interesting to look at the impact of Orientalism in Kaldas's narrative. Throughout the memoir, the vocabulary of East versus West strongly evokes the Orientalist pattern of binary thinking. This is most prominent within the economic issue frame with "Western products" being one of the key concepts here. In addition, Orientalist schemata are confirmed and reproduced by Kaldas's behavior and by several explicit statements she makes about Egyptians. In these instances, she consciously displays a superior attitude based on her non-Oriental upbrining in the West, which she does not conceal or correct. Although this evocation of the binaries of East and West is less dominant than in Ansary's memoir, Kaldas with her constant invocation of dual positionality reinforces the binary thinking between Egypt and America by drawing a "distinct cultural line," as she admits toward the end of the book (LC 156).

This binary mode of thinking gets underscored when Kaldas determinedly locates herself on the American end of the hyphen, thus completely leaving the Orient in her past. In addition to the comparative method Kaldas employs as a didactic tool, this again speaks to the strong impact of Orientalism. As was the case with Ansary, Orientalism in this sense is not employed as instrument of hegemony but as a cognitive construct allowing author and reader to structure information and change perspectives. Nevertheless, it is remarkable that Kaldas, just like Ansary, after strongly insisting on her ability to take and teach multiple perspectives, has the need to position herself on only one side of the invisible hyphen. This side happens to be the American one for both authors, which in turn underscores their authenticity and credibility from the American perspective. Kaldas with her complex overlapping frame arrangement consequently does succeed in reframing the Ar$\mathrm{ab} /$ Muslim American in her memoir.

\subsection{Reception: The (Re-)Framed Egyptian Belly Dancer and Her Audience $\left(\mathrm{V}_{4}\right)$}

Scholars have engaged in life writing throughout the centuries around the world, which is why "academic life writing" by now is even considered to constitute a separate subgenre (Smith and Watson, Reading Autobiography 253). The academy as an institution and the academic profession are seen as focal points of socializa- 
tion in shaping the self (Smith and Watson, Reading Autobiography 254). Academic life writing is seen as a record of these trajectories acting on the self and on the academy. Kaldas due to her dominant self-definition as a scholar adds to the canon of academic autobiographies. Instead of turning the university into her major subject of investigation, she uses the academy and her academic knowledge as the starting points for her task to reframe the public image of Arabs. Academic life narrative here becomes a didactic tool in a much more complex manner than formerly revealed by autobiography scholars and by critics of ethnic memoir. Obviously, the activity of writing is an essential part of the academic discipline. What differentiates academic writing from life writing is not the author but the audience. Whereas academic writing targets a small elite audience within academic circles, memoir as part of popular culture aims at reaching the general public. The reception analysis reveals how the blending of the academic with the personal impacts the audience and whether the readers actually adopt a reframed image of the Arab.

\section{Letters from Cairo in the Marketplace}

Letters from Cairo stands in a series of other non-fictional and fictional works published by Pauline Kaldas. Among them are poetry and shorter pieces of prose published in book format and anthologies. In addition, Kaldas is known for her scholarly publications that mostly focus on stereotyping and multi-ethnic identity definition. Her academic work therefore shows close overlaps to the issues brought up in her autobiography (Kaldas, Home page). The memoir was published in April 2007 by Syracuse University Press. This was almost five years after the family's return from Egypt and six years after the event of 9/11. The impact of the WOT on the demand of books on the Arab world, however, still was at a high level at the time of publication. The ongoing political instability in the region and the lasting need of the public to learn about Arab and Middle Eastern culture continue this trend. The presses have reacted to the rising demand by establishing special series on Arab and Arab American issues. Syracuse is one of the precursors in this respect. The press maintains a special series ${ }^{23}$ on Arab American writing. As the press states on its homepage, the collection has the following objective:

23 Syracuse stands out in the publishing landscape due to its lasting interest in issues related to the Middle East. At the time of writing, the press sustains a total of nine special series which all show connections to "Middle East Studies." Additional series in other categories are related to Middle Eastern topics. The region has clearly become a major focus of the press, which serves as additional confirmation for the lasting market demand in this field (Syracuse, Home page). 
This series seeks to both present and celebrate Arab American literature in English in all its rich variety - fiction, drama, memoir, poetry, creative prose, and literary and cultural criticism. After more than a century of Arab immigration to the United States, Arab American literature remains largely obscure, and we hope to assist in redressing the balance. The writers we will publish will all write out of this multileveled texture of exile and diaspora -literature written in English by diaspora Arabs commands the unique perspective of an insider/outsider and commands the intensity and humanity of being nowhere and everywhere at home - Arabs influenced by America and Americans influenced by the Middle East.

This explicit focus on Arab American literature is quite unique when looking at the overall landscape of publishing houses. The possibility to introduce such a series obviously reflects the leading market position of the press which is characterized by a high degree of differentiation. The large number of books which have meanwhile become part of the series indicates the lasting demand on the topics described by the press in its mission statement. Some of the most influential works in the field of Arab American Studies - both scholarly and bellestristic - have thus been published by Syracuse. In addition to steering the interest of its special-interest readers with keywords such as "exile and diaspora," the press emphasizes the lasting lack of knowledge about Arab Americans on its homepage. Conveying this knowledge by means of literature constitutes a major aim of the press. This plays into the hands of framing processes that above all rely on cognitive information provision.

In order to achieve this knowledge building in the public, a large audience needs to be attracted by the respective publications. The size of this audience clearly needs to exceed the academic readership that is usually reached by scholarly writings. As the sales figures of Letters from Cairo provided by the press reveal, this goal has only been partially achieved, however. As of November 2011, a total of 487 copies were sold within a timespan of nearly five years since the book appeared on the market. Compared to the distribution range of Ansary's memoir, for example, this figure is considerably smaller. Letters from Cairo therefore clearly cannot count as a bestseller when compared to other titles in the Arab American Writing series of Syracuse Press.

Sales figures also, at least partially, reflect the marketing strategy of a press. Despite being part of the Arab American Writing series, Syracuse lists the book under "memoir" (Kuerbis). Obviously, the focus on memoir as non-fiction is not as prevalent as in the case of Ansary. This slight dominance of the personal over clearcut non-fiction also becomes visible when looking at the market appearance of the book. The front cover shows a painting of a human-looking figure in curved shape. In the right corner of the painting, a few houses can be seen. The reader can infer this to represent the silhouette of Cairo as the city mentioned in the title. The background is kept in darker blue. The figure spans over the entire front cover. No gender can be identified. The head of the figure can be interpreted to represent the 
moon. The figure clearly dominates the cover by its sheer size. A large part of the arms, hands, and the lower body actually expand beyond the frame of the cover. The reader thus has to use his/her imagination to envision the invisible part of the body. The title of the book is written in a font that reminds one of handwriting. The city name of Cairo is clearly emphasized in bold letters. Kaldas's name appears at the bottom in light blue color and small letters, hardly visible.

\section{Image 8: Book Cover of Letters from Cairo (back and front)}
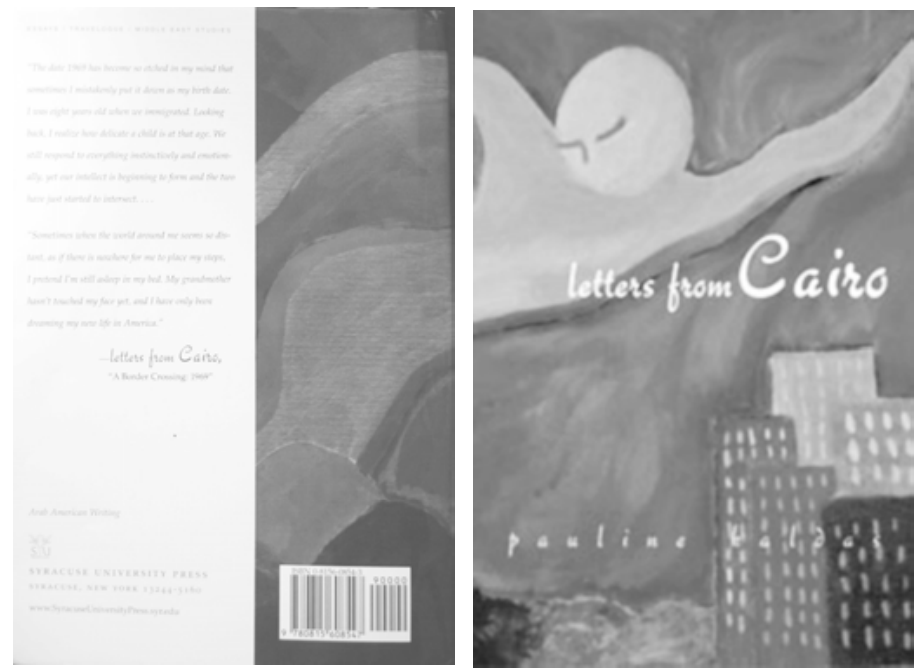

Source: Back and front cover of the memoir (" $L C$, Back Cover"; " $L C$, Front Cover").

The artistic and very playful design of the cover stands in total contrast to the photographic image shown on the cover of Ansary's memoir. The colors, the naïve shapes, the surreal figure - all of these features point to a world of imagination rather than of factual storytelling. To the reader unfamiliar with the content, the book could as well include a selection of art works or paintings. This openness of interpretation is reiterated by the fact that there is no hint to genre given on the cover. Except for the indication of an epistolary format based on the title of the book pointing to "Letters," there is no subline referring to life writing. To the spectator familiar with the interior of the book, the front cover represents a metaphor of the memoir at large, which, due to its combination of different forms of writing such as poetry and drawing, assembles an art work in itself.

The drawing on the front cover actually expands to the back part of the book. Here, the orange figure captures half of the page with only the lower body being visible. As the reader learns when looking at the inner cover, this semi-visibility of 
the body does carry symbolic meaning. The painting is entitled "Suspended Between" and was drawn by Kaldas herself. On the left part of the back cover, there are two longer quotes from Kaldas's chapter "A Border Crossing: 1969." The first quote highlights the year 1969 as the year of Kaldas's immigration to the U.S. The importance of childhood memories and the way in which memories are processed stand at the center of the excerpt. "We still respond to everything instinctively and emotionally, yet our intellect is beginning to form and the two have just started to intersect," the passage reads. These lines identify the topic of migration as one focus of the memoir. This connection between emotion and cognition promises the readers deeper insights into the complex workings of human relocation. The second quote on the back of the book also reflects the emotional tone of the first one. It describes childhood memory and alludes to a dreamlike life in America. Below the excerpts, one finds a direct reference to the Arab Amerian Writing series of Syracuse Uuniversity Press. Above the text, the categories "Essays/Travelogue/Middle East Studies" contain no particular reference to life writing. Different from Ansary's memoir, there are no further quotations from journalistic or scholarly reviews. The text thus remains uncommented and neither includes nor excludes any particular readers as target group.

The inner part of the book cover allows the reader to gain more detailed insights into the contents. An editorial review focuses on the reason of Kaldas's journey to Egypt and mentions some biographical background. In addition, the review identifies the major themes of the memoir, such as Arab American identity, homeland, reconciling past and present, place, family, and origin. Furthermore, Kaldas's combination of different genres is particularly stressed as accounting for "a richly detailed portrait of life in Cairo [...]." The second part of the editorial review clusters the given topics in broader categories ranging from "class issues and political activism to the impact of "Western culture." In quoting from Kaldas's self-description as a "cultural interpreter," her ability to shed light on the "complexities of Egyptian culture" is revealed. This rather analytical focus of the review is balanced by further elaborations on the emotional and entertaining impact of Kaldas's personal letters and the contributions of her children. In sum, as the last line states, the memoir thus offers a "unique lens for observing Middle Eastern societies."

This editorial review aims to create a well-struck balance between the thematic and thus rather analytical aspects of Kaldas's reflections and the emotional ones. The reference to themes such as politics and identity struggle, however, differs from the very playful cover painting. The themes thus identified to a high degree correspond to the issue frames found in the textual framing analysis. The same holds true for the influence of the Orientalist meta-frame, since the cultural impact of the "West" serves as major orientation in the review. In addition, the fact that Kaldas is praised for providing a unique lens for observing "Middle Eastern societies" underscores the reductionist impact of Orientalism. Although Kaldas writes on Egypt, her 
insights can be applied to other countries of the Middle East. The binary language of East and West found in the memoir also carries over to the editorial reviewer. He uses the binary as a short hand for awakening specific expectations in the reader. What clearly remains excluded from the picture is the WOT. Whereas 9/11 and its political consequences were visibly used as a marketing tool in Ansary's case, Kaldas's narrative, at least from the outside, upholds its rather non-violent and unpolitical appearance (Editorial Review). What rules the editorial review is Kaldas's ability to alternate between two perspectives in order to convey insider knowledge. This function is in line with the results of the frame analysis.

The right side of the inner cover shows a picture of the family sitting on horses in front of the pyramids in Cairo. Due to the touristy background, the image appears like a stereotypical family portrait from a vacation, one that the reader might expect to see in a family album. Below the picture is a very short biographical sketch of Kaldas that only mentions her university position and previous publications. Read alongside each other, all the given elements, i.e., the design, the excerpt, the editorial review, and the picture, all suggest a rather harmonious and emotional life reflection in which the WOT or other political issues have little room. As the textual frame analysis has demonstated, this innocent appearance of the book only partly holds true. It remains to be explored in how far this diversity of frames is reflected in the responses of the audience.

\section{The Journalistic Readership}

Similar to the meager critical attention paid to Ansary's memoir, Letters from Cairo has not been discussed by literary scholars. There are no analyses of Kaldas's work in the fields of American Literature or Arab American Studies. Journalistic reviews therefore provide the only hints as to how the book has been received by readers with a professional interest in the work. In contrast to Ansary, whose public popularity triggered fairly excessive media responses, the number of journalistic reviews on Kaldas's memoir is limited. The only comprehensive review, in addition to the editorial one cited on the book cover, can be found on "The Book Omnivore." The Omnivore is a blog-based portal offering comprehensive background information and reviews on a broad range of topics related to reading and writing. The site can be categorized under the larger umbrella of online book clubs ${ }^{24}$ which are enjoying

24 Online book clubs are the successors of televized book discussion shows which became popular especially at the end of the 1990s. Media analysts highlight the function of these book clubs as merging forces between the literary and the larger media market. Evelyn Alsultany illustrates this phenomenon: "A blending of the literary and the media could be observed when book clubs, such as Oprah Winfrey's, became popular. That show had a large impact on the audience and inspired both more reading and conversations, and also 
increasing popularity in the new media age. With their capacity to reach a diverse audience and encourage reading as an interactive activity, these sites also foster literary discourse as "social engagement" (Scharber 433). ${ }^{25}$ The review found on Kaldas's Letters, however, was not posted by one of the platform's members but originally appeared in the Roanoke Times in September $2007 .^{26}$

The review opens with a quite obvious link to the political circumstances surrounding a memoir from an Arab American author. "As the West struggles daily to comprehend the modern Middle East," reviewer Bertelsen acknowledges, "books like Pauline Kaldas's 'Letters from Cairo' are very welcome." The very first line of the review thus immediately draws attention to the binary frame of East and West. Without further preliminaries, the review assumes a predominantly political interpretation of the Middle East and the Middle Easterner. This is further illustrated by the short plot summary that follows the opening line of the review. The summary identifies 9/11 as the key departure point for Kaldas's journey to her Egyptian roots. In contrast to the editorial review found on the book cover, which did not mention the WOT frame at all, the perception of the journalistic reviewer here undoubtedly reflects the dominant media framing.

Besides the political frame, culture is identified by Bertelsen as dominating the memoir, both in terms of format and content. The mixture of different genres including "travel literature, memoir, multicultural literature, art, and Egyptian recipes" marks the quality of the book as welcome read for anybody interested in questions of culture in a broader sense (Bertelsen, Rev. of $L C$ ). Furthermore, the reviewer devotes particular attention to the aspect of food and the inclusion of recipes in the memoir. The notion of culture as it shimmers through the discussion of the book is not limited to culinary culture or traditional cultural performance. Instead,

popularized certain novels" (Personal interview). This insight also underlines the commercial aspect of media production as a result of public discourse which can never be cancelled out of the equation.

25 The study of online book clubs marks one of the few areas in which reception studies are significantly progressing. Cassandra Scharber, for example, studied the use of online book clubs by children and young adults. The results confirm that book clubs not only encourage reading as such but also function as a larger didactic tool to teach different modes of reading and responses to texts in the classroom (436).

26 The author of the review is the journalist Cynthia Bertelsen who occasionally works as a reviewer for regional newspapers. Bertelsen appears as a self-described "freelance indexer of medical and culinary books" in the New York Journal of Books website. She is currently working on a book on international foods (Bertelsen, "Reviewer Profile"). This link clearly situates Kaldas's memoir in the corner of food memoirs. Due to the multiplicity of themes which expand the frame of a cookbook memoir, this reductionist categorization hardly does justice to the book. 
the author also defines culture as a driving theme within the context of Egypt's history. As Bertelson states: “'Letters from Cairo' also tosses out tidbits about Egyptian and Arab culture and history." The word "tidbits" here gains a double meaning, since the author plays on cuisine language while at the same time pointing to the more serious historical issues appearing in the book. This minimization certainly prevents an overloading of audience members not interested in far-reaching historical analyses. Despite this culinary-laden definition of culture in Bertelsen's review, one can still sense the fairly high importance culture plays in the memoir.

A similar stress is put on the aspect of multi-ethnic identity negotiation in the review. Kaldas is described as "neither fully Egyptian nor fully American [...]." Her book is consequently viewed as the process of the author's coming to terms with her identity while sharing this process with the general audience. As the review highlights, personal and almost intimate insights and feelings are thus underscored by various forms of documentation. Bertelsen thus infers that following the memoir is "like reading a friend's personal journal." Obviously, the aspects of truth and authenticity here again become visible. The format of the book supports this authenticity that does not rely on the scholarly exploration of Egyptian American identity as based on dry facts. The excessive inclusion of personal documents, however, also raises critique. As Bertelsen notes in a discerning tone, "Kaldas's children's drawings and e-mails don't add much to the book and some passages pall." Other recurrent text modules, such as Kaldas's "reflections" on immigration, are highly welcomed by the reviewer. They "provide much to consider at a time when immigration issues dominate political discourse," Bertelsen concludes.

Especially this explicit relation between Kaldas's reflections and "political discourse" highlights that even the reception of supposedly personal and intimate literary accounts cannot be separated from larger debates in the public. Kaldas is not only assumed to play a role in this discourse; she can also be assumed to impact it, as the review suggests. Bertelsen's comment on the reflection triggered by the memoir thus also represents an urge to motivate the audience to take the narrative as impetus to adopt these thought processes. This finding also impacts the way in which Bertelsen categorizes Kaldas's memoir at large. As she states toward the end of her review, Kaldas's "attempt to explain the cultural fissures between Arabs and the West is a worthy addition to the literature." In the very last sentence that follows, the reviewer additionally clarifies the aspired effect of this act of cultural interpretation. "Kaldas's translation of Arab culture - through the prism of Egypt opens the way to understanding a people we simply must know better."

The latter lines strikingly underline a seemingly recurring pattern in the reception of Arab American life writing of the contemporary period. Letters from Cairo, despite its seemingly exclusive focus on personal and family matters, is read along the lines of the larger political and thus mediated discourse. As the theoretical underpinnings of discursive intervention state, this result can only be achieved through 
the transmission of alternative knowledge to fill blank spots in the cognitive mindmap of the audience and thus recategorize existing stereotypes based on more detailed information. It is this eagerness for knowledge gain on the Middle East and Kaldas's capability to provide it which Bertelsen alludes to. In this context, the review also highlights that it takes cultural authenticity to instill this alternative knowledge. Kaldas's role as a "translator" is only made possible by her selfpositioning on the American side of the hyphen, while her ethnic background endows her with the cultural authencity to look through the "prism of Egypt." Despite this seeming hybridity, however, Bertelsen does not deny the lasting binary structure of the world. Her mentioning of the fracture between "Arabs and the West" therefore once again points to the dominance of binary Orientalist thinking. As is the case in the narrative itself, though, the way in which this vocabulary is used here, does not correspond to Orientalism as suppressive practice. Rather, the dualism provides a necessary cognitive tool for the audience to cluster new information in the categories of East and West.

Clearly, the frame analysis of this single journalistic review can only serve as an indicator of how the journalistic audience at large might read Kaldas's memoir. Bertelson's reading signals the impact of the cultural, political, and racial frameworks found in Kaldas's work. The review also establishes the connection to cultural authority as basis to provide knowledge on these issues. Kaldas's identity as a scholar, which plays quite a dominant role in the narrative itself, does not get mentioned at all by the journalist. The same holds true for Kaldas's intensive elaboration on the media world. It therefore remains an act of speculation to assume that the reviewer's stressing of the larger discursive trajectories surrounding the memoir is a consequence of the media issue frame or whether this interpretation would have occurred without direct references to the media found in the book.

In sum, the shortage of critical reflections on Kaldas's memoir severely limits the conclusions one can draw concerning the reception of the book. This very shortcoming, however, also provides important insights concerning the position of memoirs within the larger competition of the media market. As the complex entanglement of overlapping frames as well as the political actuality of Kaldas's book underline, her memoir does not have to stand back behind Ansary's memoir. Both books provide important starting points to reframe common stereotypes about Muslims and Arabs in the public view. Yet, the fact that Ansary occupied the position of a public media figure even before the publication of his memoir obviously influenced the distribution of his book. His political and journalistic works are therefore read alongside his autobiography. The latter consequently received fairly high attention among journalistic reviewers. This does not hold true for Kaldas. Although her academic profession provides her with much credibility to reshape common frames of interpretation based on insider knowledge, her personal status remains that of a scholar who acts mostly unseen in academic circles. Consequent- 
ly, the tool of cross-media communication employed in Ansary's case seems to make an enormous difference when trying to bring individual life narratives by Arab Americans to public attention. As can be suspected, this logic is also reflected in the reception analysis of the larger consumer audience.

\section{The Consumer Audience}

The slender journalistic response to Kaldas's memoir and the rather small sales figures already indicate a limited overall response on the part of the consumer audience. When researching the audience reviews on the book, this hypothesis receives confirmation. Despite the positioning of the book in the Arab American Writers Series and the prestige of Syracuse University Press, the marketing efforts have not turned Letters into a widely-read publication. On popular discussion platforms, the memoir does receive some attention. On Goodreads, there are seven ratings to be found at the time of writing. The book is given an average rating of four out of five stars (Community Reviews of $L C$ ). No comprehensive reviews are published here.

The only more elaborate audience review on the memoir was posted by an Amazon customer in July 2007, shorty after the publication. Due to the limited length of the review, it can be quoted in full:

Dear Pauline,

I finished "Letters from Cairo" last night and just wanted to tell you how much I enjoyed it. Your rich language, deeply personal reflections, and thoughtful presentation of the meaning of family, place, and land of origin were delightful. Mostly I am grateful for your willingness to share your life with the literary world and for your ability to reconcil [sic] past and present as well as to find re-newed joy in making Virginia your home.

Thanks so much for the pleasure of reading your book! (Amstutz)

It is interesting to note that this reviewer does not address other readers as his audience but the author of the memoir. The fact that this review is written as a letter reflects the epistolary format of the memoir itself. The reviewer's appreciation of Kaldas's personal storytelling suggests that this is not an unintentional coincidence. Despite the fact that the reader obviously enjoyed the book, only limited findings can be drawn with respect to the adoption of textual frames. The mentioning of "family, place, and land" puts the personal identity struggle and the cultural frame of Kaldas's account into the center of attention. Another noteworthy aspect is that the reader specifically thinks of the "literary world" as target audience of the book. The broader public discourse does not get mentioned. This situates the memoir in the literary realm while non-fictional elements and its position in the media discourse are disregarded. As to the question of multi-ethnic readers as particular 
target audience, the name of the reviewer and the rather patriotic statement on Viriginia indicate that he does not have an immigrant background, though, this assumption is highly speculative and reductionist. Assuming that it does hold true, however, this finding corresponds to the impression that Kaldas primarily writes for the general American audience when reframing the Arab in the public eye.

When juxtaposing the results of the textual frame investigation with the limited findings derived from the reception analysis, the following comparative overview of frame resonance emerges:

Table 4: Frame Resonance Matrix of Letters from Cairo

\begin{tabular}{|c|c|c|c|c|}
\hline Frame Level & Frame & $\begin{array}{l}\text { Text } \\
\text { (Production/ } \\
\text { Medium) }\end{array}$ & $\begin{array}{l}\text { Journalistic } \\
\text { Audience } \\
\text { (Reception)* }\end{array}$ & $\begin{array}{l}\text { General } \\
\text { Audience } \\
\text { (Reception)* }\end{array}$ \\
\hline Ideological & Orientalism & .. & .. & \\
\hline Political & Neo-Orientalism & .. & •. & \\
\hline \multirow[t]{6}{*}{ Issue Level } & Literature & .. & - & - \\
\hline & Culture & $\cdots$ & $\cdots$ & • \\
\hline & Race & $\cdots$ & .. & - \\
\hline & Economy & $\bullet$ & & \\
\hline & Politics & .. & - & \\
\hline & Media & .. & - & \\
\hline
\end{tabular}

Legend: The number of dots marks the salience of the respective frame, as based on the close-reading analysis.

${ }^{*}=$ The dots in both audience columns are printed in grey to indicate that the limited number of reviews only allows for tentative conclusions concerning frame resonance.

The chart emphasizes that the multitude of different frames constituted by Kaldas in the memoir does not transfer to the audience. Despite the shortage of data on audience reception, the given textual evidence merely suggests the salience of the culture frame, whereby culture tends to be used as an umbrella term by the reviewers. These findings nevertheless allow for an important conclusion with respect to the impact of Kaldas's efforts to reframe the image of the Arab through the Egyptian American lens. Although the potential for this mediation effect is provided by the complexity of the memoir, the lack of audience reactions does not allow for a wider discursive impact outside literary circles. The thought-provoking impact mentioned up by the journalistic reviewer is thus not reflected in the wider audience. Still, the memoir is regarded as an important source of knowledge about the Middle East by those who read it. Although on a small scale, Kaldas at least in individual cases succeeds in reframing the image of the Arab apart from the dominant WOT frame. 



\title{
6. (Re-)Framing the Iraqi Terrorist in Howling in Mesopotamia
}

\begin{abstract}
PS from Diana: Before we conclude, I said, 'Salam, I just want to say one thing.' And I said, 'Fuck Saddam Hussein!' as loud as I could without disturbing the neighbours. [...] And Salam said, 'Everybody on the street is saying this like a mantra, 'Fuck Saddam! Fuck Saddam! Fuck Saddam [...]' (Well, maybe Salam didn't use the word 'mantra,' but you get the point.) I think we can't possibly understand what it's like to be Iraqi. It must be like being in a root cellar for thirty-five years, and now you are stumbling around in the light, blinking your eyes, wondering if what you see is real, or a dream. - Diana Moon (Pax 162)
\end{abstract}

There are two keywords that the world associates with Iraq: Saddam Hussein and war. This blog posting by Diana Moon, a fellow blogger of Salam Pax, ${ }^{1}$ demonstrates this reductionist and violent image of Iraq in a striking manner. In April 2003, the global public celebrated when American troops rolled into Baghdad, bringing the statue of the dictator down. The pictures circulated around the world.

1 Pax started his blog only shortly after the American troops landed in Iraq in 2003. Along with riverbend, he has become one of the most famous war bloggers. His work has come to count as prime example of new media life writing (Whitlock 201). Pax's vivid and emotional account accentuates the opportunities the new mediatic representation of life narrative offers with its focus on immediacy. Despite its origin in online writing, however, the blog was ultimately turned into a written autobiography entitled The Baghdad Blog. This marks an example of the transformation of new into old media. 
For the West, this was victory. ${ }^{2}$ For the Iraqis, it was liberation; the moment when they started "stumbling around in the light," as Moon puts it. Watching this moment on TV were thousands of Iraqis who had formerly escaped the darkness of the cellar by immigrating to the U.S. One of them is Haider Ala-Hamoudi. In his autobiographical reflection, Howling in Mesopotamia: An Iraqi-American Memoir (2008), he describes his journey to the home country of his parents. Similar to the one suddenly "stumbling around in light," he often wonders in his autobiography "if what you see is real" (Pax 162). For the reader, he thus reveals many facets of Iraq that have not been televised a million times before. Eventually, this constructs a more complex view of the "real" in which the Iraqi is more than a terrorist stereotype.

\subsection{Legal Agency $\left(\mathrm{V}_{1}\right)$}

\section{Author and Structure of Howling in Mesopotamia}

Haider Ala Hamoudi is a second-generation Iraqi American. He was born and raised in the United States as the son of Iraqi parents. As his short bio in the inlet of the book emphasizes, he "grew up speaking fluent Arabic and visiting Baghdad every year." Hamoudi attended MIT and graduated with a double major in Physics and in the Humanities with a concentration in Near Eastern Studies. Later, Hamoudi went to Columbia Law School and ultimately worked at several prestigious law firms in New York (Hamoudi, Home page). Today, he is an assistant professor of Law at Pittsburgh University. Interviews with him have appeared in a series of law journals and other publications. He also writes for newspapers and magazines such as Asia Times. He also is the author of a law blog called "Islamic Law in Our Times." The blog contains extensive contributions by Hamoudi on current issues related to law, religion, and economics ${ }^{3}$ in Iraq and the larger Middle East.

This short biographical sketch of Hamoudi reveals his initial professional distance to the literary realm. His occupational background is multi-faceted, whereby writing mostly takes place in the form of journalistic and scholarly publications. Both aspects also come into play when looking at the structure of Hamoudi's memoir. The book is divided into two major parts with the first one entitled "Dream and

2 Media studies on the coverage of the Iraq War meanwhile interpret the footage of the fall of Saddam's statue as a prime example of media inscenation. It was supposedly used for propaganda purposes to mobilize pro-war sentiment by the U.S. (Tumber and Palmer 110; Maass).

3 The blog also emphasizes Hamoudi's interest in the economic situation of Iraq. He frequently posts detailed entries on current economic developments that reveal in-depth background knowledge ("Rent Seeking"). 
Disillusionment" (Hamoudi, Howling in Mesopotamia 1) ${ }^{4}$ and the second "Marriage, Election, and Beyond" (HM 181). Within each chapter, the sub-structure is clustered according to the seasons of the year, starting with summer 2003 and ending with summer 2004. To each of these headings, Hamoudi adds a short subtitle; starting with "A Time of Hope," followed by "Concerns Mount," "Failure" in the spring of 2004, and concluding with "Hope and Despair" in summer 2004.

There are a total of 68 chapters that are enlisted in the extensive Table of Contents. The chapter names are all very short and to the point. In total, the chapter titles do not reveal a distinct thematic focus. The beginning is made by "Arrival" (HM 5). Some chapters have the names of places, such as "Baghdad" (HM 15) and "A Trip to Kirkuk" (HM 239). Especially with respect to the locations, it is important to notice that several of them refer to places that have become popular in the news coverage on the WOT, e.g., "Basra" (HM 82) and "Abu Ghraib" (HM 143). Other chapters merely signal an important keyword, such as "Gasoline" (HM 56), "Jogging" (HM 148) or "Work" (HM 234). Another specificity with respect to the geographic locations thus mentioned is that several Arabic terms are used, e.g., "Halabja" (HM 202) or "Ho-Hum" (HM 252). These terms stir the curiosity of the reader who is unfamiliar with Arabic and with Iraq.

The thorough and peculiar structure of Hamoudi's work reminds one of the outline of an academic research paper or of the overview of a non-fiction work. This stands in stark contrast to the chronological and diary-like chapter division. Despite the use of emotional terms such as hope and despair, the tone is rather neutral. Nothing indicates a very personal or affective narrative. The multitude of diverse and often unrelated chapter names also suggests that the account does not focus on one dominant issue frame, whereby the themes of the chapters mostly indicate a political and geographic context. This is underscored by the finding that many of the locations mentioned, as well as the political events appearing in the chapter overview, clearly relate to the war. A rather strong influence of the WOT can thus be inferred. Other events bear a more personal meaning, such as "Food" (HM 168) or "Wedding" (HM 267). These rather conventional topics appear slightly odd in this otherweise academic-seeming compilation. In fact, Hamoudi comes to manage both, the political as well as the personal, from the perspective of a distanced analyst. He derives this unique authorial voice from his position of a strong-minded and highly knowledgable multi-ethnic author who tells the story of present-day Iraq based on multi-ethnic agency.

4 All further references are to the same edition abbreviated by $H M$. 


\section{Arab Iraqi Authenticity}

The use of Arabic expressions in the table of contents highlights the Arabic background of the author. This is underlined by the subtitle of Hamoudi's book, an "Iraqi-American Memoir," which draws immediate attention to the mixed ethnic origin of the author. It is this dual identity that Hamoudi employs to open up his narrative. Before starting with the narration of his story, he provides a short but powerful introduction explaining the motives and background of his trip to Iraq:

On July 14, 2003, the forty-fifth anniversary of Iraq's independence from Great Britain, I left Kuwait on a C-130 transport plane bound for Baghdad, the city of my ancestors and a place I had not been, and to which I could not travel, for the previous thirteen years. Two nations could legitimately claim me as their native son. The first was the United States, where I was born and raised, whose influence was, obviously, very real and direct. The second was Iraq. Iraq occupied something of a hallowed place in my childhood home, a rose-colored enigma. (HM xi)

Hamoudi in these very first sentences builds up the foundation of his authorial agency that relies on cultural, historical, and political insider knowledge. The very mentioning of the anniversary of Iraq's independence from Britain constitutes a historical date that the average reader is not familiar with. This also positions the narrative that is about to unfold in a political frame that differs from the very personal and vacation-like first impression one gains of Kaldas as a narrator. Hamoudi underlines the close link to the political reality by mentioning his travel in a transport plane. Most importantly, the author assures his readers in this opening statement that the setting of his memoir is not a foreign place to him. Even though he was born and raised in the United States, he still considers himself Iraqi at the beginning of his journey. The hierarchy he sets up by calling the U.S. his "first" parent country, however, gives slight prevalence to his American identity.

The suggested balance between America and Iraq with respect to Hamoudi's multi-ethnic self-definition does not correspond to the political state of affairs. A friendly resolution of the opposition between Iraq as the "rose-colored enigma" and the U.S. has long been prevented by violent conflict, as Hamoudi reminds his reader a few lines later. "But these two countries - America, where I lived day by day, and my own images of Iraq, about which I dreamed every night - had long been at war," he states $(H M$ xi). Although Hamoudi in this sentence provides a realistic summary of the relation between the two countries, it can be noted that he, at this point, does not compare two personal realities with each other. Whereas America is the country he actually knows from daily life, Iraq is mostly present in images and dreams for him. With this evocation of popular images dominating over reality, 
Hamoudi positions himself in an equal position as his reader. Despite his mixed ethnic origin, he knows Iraq mostly from TV images and newspaper articles. The author then formulates what he perceives as his personal task, namely, to interfere with fictional media images by turning Iraq into a reality for his audience. "I wrote this memoir as an Iraqi and an American, to convey to Americans, as an American, what the lives of ordinary Iraqis are like, by living as closely as possible to Iraqis themselves, as an Iraqi, with neither an American force nor a protected zone between me and the people of Iraq," Hamoudi announces (HM xi).

These lines reinvoke the tenor already found in the thorough structure of Hamoudi's memoir. Similar to a research paper, he in this latter passage announces the purpose of his autobiographical endeavor in the form of a thesis statement that reveals the contribution he wants to make to public discourse. He wants to uncover a reality to the American public, a reality that does not focus on either American soldiers or Iraqi terrorists. Instead, he uses the somewhat derogatory-sounding term "ordinary ${ }^{5}$ Iraqis" in order to allude to the fact that there exists a life in Iraq which is detached from war and politics. The method pursued by Hamoudi strongly equals the one of an embedded journalist. By living among Iraqis, he seeks to occupy an insider position to convey his experience. This insider perspective is underlined by the closeness to the people, as he promises. It is this immediate and borderless contact to the Iraqi population that separates him from the thousands of American soldiers who also live in Iraq but not with the people of Iraq. It is this insider position that endows Hamoudi with a narrative authority journalists or American officials lack. The author, as his claims reveal, is very aware of this comparative advantage. He thus underlines that his ability to change pre-existig media images by presenting an alternative reality is based on the fact that he speaks from and for the perspective of both - Americans and Iraqis.

The explicit way in which Hamoudi establishes his multi-ethnic authenticity as an author appears remarkable compared to the memoirs of Ansary and Kaldas. The strong determination driving his endeavor and his self-declared courage to live as an American among Iraqis leave no doubt of his authorial agency. His Iraqi American heritage allows him to arrive at unique insights that others cannot provide, and Hamoudi displays extreme self-confidence in convincing his readers of this benefit. This declaration not only reveals something about the author himself but also about the audience he seeks to approach. He clearly formulates his authorial goal with an

5 The adjective "ordinary" also has a negative connotation in public opinion research. Here, the term is mostly used to conceptually separate average citizens from specific communication elites. The criteria for this division are connected to the cognitive capabilities of audience members who do not count as elite and the degree to which their opinion can be influenced through mediated discourse. The key question driving this vain of research is: "Are the ordinary people able to see beyond themselves [...]?" (Fortner 196). 
American audience in mind - not an Iraqi American or Arab American one. In other words, multi-ethnic identity struggle to him is not seen as the primary theme of his memoir. Rather, Hamoudi wants to reach those who lack this dual identity and also the knowledge about a country his family once called its home.

The manifestation of Iraqi American authenticity Hamoudi undertakes in the introduction speaks a powerful language. It again sheds light on the questions of truth and authenticity in autobiographical theory as a whole. Hamoudi nowhere raises doubts about the cloudiness of human memory and the subjectivity that goes along with this. Instead, he strongly confirms the reader that he/she will be presented with a truth-based reality, a reality originating in the empirical experiment of someone living in Iraq who knows both cultures. The explicit way in which Hamoudi builds up his multi-cultural agency also sheds light on the question of intentionality in ethnic life writing. The author at the outset does not regard life writing as a journey to himself or as any kind of psychological task to establish a new or transformed self. Rather, he has a clear and mostly political goal. Memoir for him seems to constitute an instrument to achieve this aim. This belief in the social impact of literature is especially remarkable for someone who otherwise regards positive law as his major subject of investigation. As he soon admits, this legal background does pose a professional challenge to him, yet, it also endows him with authorial agency.

\section{Legal Authority}

Whereas the first part of Hamoudi's introduction strongly focuses on his Arab American identity to substantiate his agency, the second part stresses his professional identity. The determination which marks the description of his autobiographical goal also characterizes the professional aim motivating his journey to Iraq. Hamoudi does convey his fear of getting killed and the mental burden of seeing a country ruined by political terror and war (HM xii). Yet, he in no instance bows to these circumstances. Rather, the depiction of constanly facing life and death situations underlines his courage. Instead of seeing his trip to Iraq as a journey to his roots, he makes it appear as an adventure. This undertaking itself, however, posed less of a challenge to him than the literary reflection on his experience, as he admits. "My task of recording my adventures has not been easy to accomplish," he explains ( $H M$ xii). The expression "recording" highlights Hamoudi's insistence on truth-telling as opposed to a personal and possibly diluted reconstruction of subjective memory. The reader soon learns that such a literary approach to memoir would not at all be in line with Hamoudi's professional identity.

In admitting that the literary production of memoir was difficult for him, the author makes no secret of the fact that literary writing is not his major occupation. In contrast to Kaldas for whom "writing" comes first, writing for Hamoudi is a means 
to achieve a business purpose, just like the trip to Iraq was motivated by a professional goal as a lawyer. Hamoudi clearly bases his authority to tell his story on his professional standing:

I am an attorney and a graduate from one of America's premier law schools, and served as a federal judicial clerk in New York before working for one of the largest law firms in New York as an associate. This combined with my Iraqi ethnicity, my Arabic language skills, and my Shi'i religious heritage qualified me more than almost anyone, I believed, to contribute to the rebuilding of Iraq's devastated legal culture. (HM xii)

This impressive overview of Hamoudi's attorney career reads more like a brief CV in an application than the introduction of a memoir. The author here unmistakably clarifies that it was not merely personal endeavor which brought him to Iraq. Instead, his legal career and his Iraqi American heritage served as suitable qualifications for pursuing a business which could hardly be realized by less-qualified lawyers. Similar to the multi-ethnic authority he reiterates, he obviously regards the different elements enlisted in his vita as a comparative business advantage. In addition to his reliance on professional and cultural knowledge, this advantage is also based on his religious background, as he furthermore reveals in this passage. This religious characteristic clearly stands out among the other criteria Hamoudi mentions, since it is unrelated to any kind of acquired capability or skill. Obviously, one can hardly plan on gaining this identity trait as one would when planning a career. However, the fact that he mentions it here hardly seems to present an accident.

In contrast to Sunni Muslims, the religious affiliation of Ansary, Shii ${ }^{6}$ Muslims originally opposed the idea that spiritual leadership after Muhammad should be given to an elected leader. They wanted religious guidance to be passed on directly to the Prophet's cousin Ali. To the present day, Shii Muslims oppose elected Muslim leaders and instead respect the authority of appointed Imams who, according to their view, were appointed by Muhammad or God himself (Campo 33). Whereas Sunnis make up the largest part of Muslims overall, Iraq counts among the few countries where Shiis have formed the majority in terms of demographic numbers, comprising about $60 \%$ of the population. In hardly any other country has the conflict between Sunnis and Shiis had such violent consequences as in Iraq where Shiis under the Hussein regime continued to be oppressed by the minority of Sunnis. After the fall of Hussein, Shiis for the first time were allowed to vote (Campo 277). When emphasizing his Shii identity as a benefit, Hamoudi therefore inherently links

6 There is a linguistic difference between the terms Shii and Shia that is often neglected in the press. Whereas shii refers to the religious belief exclusively, the term shia is derived from the Arabic word for "party" or "faction." The latter term thus has a more political connotation by referring to a collective with shared interests (Campo xxxiv). 
his professional task of participating in the rebuilding of Iraq's legal structure to a political project as well. He consequently aspires to support the previously suppressed Shii collective.

Hamoudi's claims for professional, cultural, and religious authority do not end with this biographical summary. Hamoudi adds another layer to his agenda, which allows the reader to learn more about his specific motivation to go to Iraq:

My ultimate goals were many and varied. Having been a commercial lawyer for the better part of a decade, I wanted to make money. Naively, I imagined investors pumping large streams of capital into this oil-rich and undeveloped land . [...] I thought I would be among the best qualified to handle such work. I would bridge the legal cultures, translate the issues of foreign investors in a way that an Iraqi attorney would understand them [...]. (HM xii-xiii)

In these lines, Hamoudi again builds on his professional and multi-cultural authority in explaining what brought him to Iraq. Whereas the intention to rebuild the legal structure of the country, which he mentions at the very beginning of the book, has more of an altruistic connotation, the given explanation reveals profit-making as another aim. The goal "to make money" indeed underlines the monetary aspect of Hamoudi's self-established comparative business advantage. It is remarkably honest how the author portrays this goal. He obviously does not envision readers to be offended who expect a less egoistic and more culture-related purpose in a narrative like this. Such a negative reaction would most likely be found in the case of an ethnic readership that shares a common concern about the future of Iraq. Yet, Hamoudi with his mission statement underlines that such an audience is not his primary target group. He is writing for an American audience, not an Arab American or other minority audience which might share experiences of multi-ethnic identity negotiation. This business-like mentality even gains an Orientalist twist with his depiction of Iraq as oil-rich but "underdeveloped" country. With this image of Iraq, he positions himself on the American end of the hyphen, perhaps unintentionally.

Toward the end of the introduction, this honesty with respect to his financial purposes seems to appear even too self-centered for Hamoudi himself. He thus relativizes his previously defined goal by returning to the importance of legal concerns. "Material impulses aside, my greatest desire was to participate in the development of a brave new legal world in Iraq - one that depended on the rule of law" ( $H M$ xiii), he clarifies. On the one hand, this announcement somewhat limits the stereotypical American materialism he displays. On the other hand, he also demonstrates a very American and thus Western approach in these lines. While it is certainly a welcome and not merely personal endeavor to bring professional expertise to Iraq in order to contribute to its recontrustruction, the vocabulary Hamoudi uses reinvokes Orientalist divisions linked to ideals of superiority. "Development" here stands in contrast to the idea of barbarism and backwardness - the common markers 
of the Orient. In addition, the adjective "brave" used with respect to the new legal structure carries a uniquely American connotation of heroism and success. The use of the term "rule of law" additionally underscores this ambivalent approach to the legal project. It derives from the binary opposition of legal order versus despotism and tyranny. No matter if this condition at the time of writing and maybe even today dominates the legal structure of Iraq, Hamoudi here assumes the position and authority of the cultural and legal superior to intervene in the country's affairs.

Although Hamoudi in the very last sentence of the introduction warns his readers that the euphoria with which he approached his task did not last long (HM xiii), one cannot escape the ambivalence emerging from these introductory pages. In addition to serving as an introduction to the narrative that follows, the opening above all represents an introduction to the cultural and professional status of the author. The legal authority which he ascribes to himself sets the stage for his journey and for the memoir. Given the questionable positioning of himself as cultural insider who nevertheless displays the cultural superiority of the American outsider, one wonders if his first goal, the presentation of another reality of Iraq beyond the images of terrorism, can actually be fulfilled.

\subsection{Reframing the IRAQI TERRORIST ( $\mathbf{V}_{2}$ AND $\left.\mathrm{V}_{3}\right)$}

\section{The Law Frame}

The heavy emphasis on Hamoudi's professional background as an experienced and prestigious lawyer, as well as his legal business purpose, leave a distinct mark on the memoir from the very beginning. Although he mentions the drafting of laws and the improvement of the Iraqi future as dreamlike goals, his self-constitution as "commercial lawyer" who is more interested in trade than in the general legal condition dominates (HM xiii). This stands in contrast to the explicit human angle which Hamoudi also introduces. When remembering the multitude of newspaper articles on civilian casualties in Iraq, he exclaims: "These were human beings in all their wonderful multifaceted complexity [...]“ (HM xii). Although this humanitarian focus at first seems to be irreconcilable with Hamoudi's other professional aim, the memoir takes an unexpected turn in this respect. The author by establishing a legal frame around his reflection retraces an important learning process that shows

the audience different approaches to the conception of $1 \mathrm{aw}^{7}$ itself and ultimately a new path of looking at Iraq.

7 The different definitions of the concept of "law" are exhaustive. With respect to the frame that Hamoudi creates in his memoir, this study follows the conception of law in more philosophical and anthropological terms. Law here refers to "a body of regularized pro- 
The way in which Hamoudi describes his arrival in Baghdad equals the beginning of an adventure movie. Just like planes "do not descend gradually" when landing in Baghdad, as he explains, his own arrival equals an abrupt descent from illusion to reality (HM 5). The airport and its surroundings display no civilian traces. Military bunkers, tents, tanks, and much armory is what Hamoudi sees at first. The situation clearly emphasizes that he has arrived in a city that is "Americanoccupied" (HM 5). More specifically, it is the American military which is in control of Baghdad and of the country at large. Hamoudi quickly learns in a very personal way what this dominance of the military and rule of guns means in daily life. When he asks a group of American soldiers when the airport will open for civilian traffic again, he is treated with neglect. Diverting the conversation to the favorite American topic of sports does not make any difference. On the contrary, the silly fact that the soldiers are from Florida and thus hostile to Hamoudi's Ohio home state team the Buckeyes - turns the conversation into a demonstration of U.S. occupational dominance. "They insisted that as an Iraqi, I knew nothing," he states (HM 7). As the conversation continues, they even address him as "Iraqi Buckeye" (HM 7).

This very first encounter in Baghdad indeed brings to light a different reality than the one Hamoudi previously had in mind. This reality, at the beginning, does not confront him with the "ordinary Iraqis" he seeks to meet. Rather, the Iraqi American travels to Iraq only to meet American soldiers. Most importantly, however, they do not respect him either as an American or an Iraqi American, but mostly as an "Iraqi." This reductionist view and the fact that their uniforms seem to endow them with any right to judge or even discriminate civilians makes them treat Hamoudi in a way that obviously puzzles him. The situation that "American soldiers were everywhere" worsens this unpleasant arrival ( $H M$ 9). Many places and buildings in the city can only be accessed by American soldiers, Iraqi food has been replaced by American dishes, and the American Forces use the recreational facilities of the former ruler Saddam Hussein. This initial description of the scenery in Baghdad strongly evokes images of the WOT. In sum, it indicates the absolute rule of military power which seems to have replaced the regime of Saddam.

How comprehensively the old and the new military regime rule the everyday life of the Iraqis, Hamoudi learns in his daily efforts to conduct his work. Baghdad traffic is almost insurmountable because the military blocks many roads due to security concerns. When riding in a cab one day, the radio broadcasts an interview with an American officer talking about this issue. When the latter explains that "the interest of Iraqis not wanting to sit in traffic jams" needs to be balanced against "the lives of American soldiers," Hamoudi's cab driver loses his patience (HM 16-17). "That man's mother is a whore," Abdullah shouts at the radio. "Bring this chaos to

cedures and normative standards that is considered justiciable - i.e., susceptible of being enforced by a judicial authority [...]" (de Sousa Santos 86). 
America and give them our heat and take away their air conditioners and how do you think they'll do? They'll start killing each other in the streets, worse than us," he adds furiously ( $H M$ 17). Hamoudi in response remarks that he understands these concerns of the Iraqis. Still, his response also reveals that he distances himself from the Iraqis who are suffering under the military regime of the U.S. "Taxi drivers, like most Iraqis, always seemed to be complaining about something. If it was not the Americans, the power cuts, gas lines, and the traffic, it was the brutality of the previous regime," he comments pejoratively (HM 17).

Hamoudi with this comment obviously exposes that he does not take the concerns of the "ordinary people" like his cab driver very seriously. To the contrary, the way in which he uses the word "complaining" has a connotation of 'get over it.' This somewhat callous reaction gains an even cruel connotation when recalling how much the people of Iraq previously suffered under the former regime that brought death and destruction to the country. This derogatory position consequently lacks honest concerns for the humanitarian issues of the people. What seems to count for Hamoudi is the fact that the rule of law has not been emplaced so far while his mind is still occupied with the idea of setting up his own "law firm that would assist in reconstruction and earn handsome returns," as he phrases it (HM 7). Surprisingly, however, this remains the only detailed reference to the author's legal project in the entire first chapter bearing the telling title "A Time of Hope" (HM 4). The remainder of the chapter deals with several other issues describing Hamoudi's efforts to settle in Baghdad. Yet, not much is heard of the successful commercial lawyer Hamoudi seeks to be.

Only toward the end of the first chapter and at the beginning of the second chapter entitled "Concerns Mount," Hamoudi finally reveals why there has been little recollection of business success and the constitution of the "rule of law." When meeting with one of his politically successful uncles, he finally realizes something he has been pushing aside so far: "This was not a place to make money. [...] My professional plans were not working and provided me with no satisfaction," he admits. "I needed to do something else" (HM 65). Given the previous determination and professional egotism with which Hamoudi approached his law firm establishment in Iraq, this acknowledgement of personal defeat seems quite surprising. The way in which he puts it, however, is in line with the overall tone Hamoudi keeps up throughout most of the narrative. He presents his insight merely as a cognitive conclusion that is not related to intense emotions. As a man of action, as he positions himself, he looks ahead and tries to find a new occupation. In order to do so, Hamoudi leaves the country for a while. This departure brings along another rather unsentimental testimony: "I could prattle on at length about the importance of being in Iraq to serve the country, about the essential goodness of the Iraqi people, and about the heart and the head, but after a good cappuccino [...] all of that seemed to be sentimental claptrap, capable of deferral," he states (HM 69). 
This confession reveals Hamoudi's initial dishonesty about believing in the "goodness of the Iraqi people." Almost ironically, then, it is this confession that brings him closer to the humanitarian side of the law business.

By chance, Hamoudi gets recommended to the International Human Rights Law Institute of DePaul University. The Institute had previously received a contract from the U.S. International Development Agency to help in building Iraqi law schools (HM 69). Hamoudi describes his new professional goal as follows: "I therefore embarked on an entirely different mission, of reconstruction and not of commercialism" (HM 70). This announcement further underlines that the altruistic purpose Hamoudi conveyed at the beginning was nomenclature. The lawyer in this instance still adheres to his monetary thinking by letting the reader know that the new position will only earn him half the salary he would make at a U.S. law firm. Yet, he also reveals a new emotional side by calling the new job more "satisfying" (HM 70). This turn from law as source of money-making to law as humanitarian instrument used to contribute to the reconstruction of Iraq marks an important turning point in Hamoudi's development and in the construction of the memoir. The legal frame constructed by him gains a different connotation from this point onwards. While first employing law as the hallmark of his authorial agency, as source of profit-making, and as counter-part of military rule, this new true concern about the legal management of Iraq ultimately changes the way in which Hamoudi perceives of the country.

An example of Hamoudi's newly awakened sense of humanitarianism is provided when he meets a group of lawyers working for an excavation project to disclose the crimes of Saddam Hussein. When he asks them if they can speak Arabic, he receives a discomforting but nevertheless striking answer. "What the fuck for?" they ask. "We believe in George W. Bush, we're serious Republicans, and we're here to do our part to take back Iraq. Rule of law, baby. Rule [...] of [...] Law [...]" (HM 75). Hamoudi is struck by this reply. It reminds him more of the "words of an ESPN sportscaster" than of anything a lawyer investigating crimes against humanity and promoting the rule of law would say (HM 75). Obviously, the author in this instance also demonstrates that his own understanding of "the rule of law" has considerably changed at this point. Formerly, he used the phrase as a pretext when really thinking about making money in Iraq. His honest renunciation of the way in which the American lawyers denigrate the rule of law reveals a different mindset.

Hamoudi thus seriously identifies with his new professional task and starts making himself familiar with different models of civil law systems in other countries (HM 78). Continuously, the humanitarian concerns he has been passively witnessing from the beginning move closer into the center of his attention. This is a point at which he, by means of using direct speech, increasingly allows "ordinary Iraqis" to raise their voice about law and justice. A striking example of this occurs when his elderly aunt asks him about the pictures from Abu Ghraib the family 
happens to see on television. To Hamoudi's surprise, she describes them as "shameful" (HM 143). The Arabic term for this, in Iraq, means a real insult. Hamoudi's uncle Nawfal then adds: "I never thought the Americans would do something like this. I did think from the beginning that they came for our oil. I didn't think they would respect our traditions, culture, and religion - but this? Your aunt is right, it's shameful" (HM 144).

The reaction of Hamoudi's relatives to the Abu Ghraib scandal and the general behavior of Americans he observes in Iraq trigger further changes in his consciousness and his perception of the "rule of law." He obviously arrived in Iraq thinking that the U.S. is the country that could convert Iraq from the rule of violence to the implementation of law and justice. Now, he realizes that the Americans are trampling down any humanitarian concerns by treating the prisoners in Abu Ghraib as well as the Iraqis in general as non-humans. ${ }^{8}$ The inescapability from these events becomes underlined by the fact that Abu Ghraib is not some distant place to Hamoudi, as it is for the American television audience. Abu Ghraib is right in the neighborhood of Baghdad airport, a place that Hamoudi often passes (HM 141). Obviously, this closeness to the Iraqi people and to mediated news events changes his personal belief in justice and rights in an unanticipated way. Other events he witnesses contribute to this transformation from the professional hardcore lawyer to the one who sees the human side of justice. The climax of the violation of legal guidelines by Americans occurs when Hamoudi wants to visit his brother in Baghdad. The brother only lives two houses down the street. Hamoudi does not think of this visit as a problem, yet, all his relatives warn him that walking or driving this short distance would be too dangerous. They tell him that if he gets mistaken for a Kurd by accident, he will get shot (HM 214). This incident finally lets him give up any belief in the rule of law and convinces him "of the sheer failure that Iraq had become." He concludes the reflection on this incident with the striking remark: "Human beings could not live here" (HM 215).

This realization of failure, only one instance of many experienced by Hamoudi throughout his memoir, has a multi-layered meaning. In the first place, Hamoudi notices the sheer impossibility to install the rule of justice as he previously defined it. Linked to that is his own failure to contribute to this process. Furthermore, Hamoudi's emphasis on the fact that "human beings" cannot live in Baghdad points to the overall change of perception he undergoes in the course of his journey. By openly sharing his thoughts on this process, he lets his reader develop a new angle

8 Studies on the specific news framing of the Abu Ghraib scandal in the American media reveal the finding that the media mostly disregarded the inhuman treatment committed by the American soldiers. Instead of evoking any empathy with the victims, the news rather concentrated on the reasons why the victims had ended up in prison in the first place (Bennett, Lawrence, and Livingston 110). 
of looking at Iraq. By constituting law as a cognitive framework to interpret the events and people in Iraq, Hamoudi at the same time teaches the different aspects of legal concerns. In the beginning, law represents a commercial enterprise, a necessary toolkit to settle contracts and expand businesses. When faced with the reality of Iraq, the humanitarian side of law becomes prevalent. Law gains an international dimension linked to the assumption that there are global human rights that constantly get neglected - both by fundamentalist sectarians in Iraq and by American soldiers. A legal framework provides the primary means to protect life and liberty. This legal frame gains increasing importance with Hamoudi's realization that these rights cannot be enforced as easily as he, in his ambitious and partly presumptious manner, thought before. This presumption still resonates in his comment that "human beings cannot live here," a statement that negates the fact that Iraqis are human beings who have to somehow manage living in Iraq, whereas he, an Arab American visitor, can leave the country upon his own volition.

The constitution of law as an important conceptual framework to look at Iraq occupies much room in Hamoudi's reflection. This finding is particularly noteworthy with respect to the dominant public stereotype of the Iraqi as terrorist. Hamoudi's legal lens reframes this stereotype since legal issues from the perspective of law professionals are hardly visible in the mainstream media framing of the Middle East. From a historical perspective, however, the law frame has a long Orientalist tradition which is more distinct than the current notion of barbarism connected to neo-Orientalistm in the WOT. The law scholar Teema Ruskola terms this phenomenon "Legal Orientalism" (179). ${ }^{9}$ This concept derives from the question of "who gets to decide who has 'law' and what the normative implications of its absence are" (Ruskola 181). Ruskola compares this legal kind of ethnocentrism to the realm of literature. In quoting Boaventura de Sousa Santos, ${ }^{10}$ he states: "As there is a literary canon that establishes what is and what is not literature, there is

9 Ruskola analyzes the issue of legal Orientalism in the context of China. The starting point of the analysis is the lasting claim that China lacks a "tradition of "law", (181). Ruskola traces the geneaology of Orientalism exerted by the U.S. by demonstrating that the nation has traditionally defined itself as lawful based on representing Western superior civilization (Ruskola 215). As the author reveals, the special purpose behind this practice was providing a justification for the legal exclusion of Chinese immigrants in the $19^{\text {th }}$ century (216). Another aspect of this legal version of Orientalism is the intentional inferiorization of China's legal system as "stagnant," whereas the U.S. value progress and dynamic the most (Ruskola 224). The study, however, also finds a tendency on the part of the Chinese to "self-Orientalize" by bowing to these Orientalist attacks from outside (224).

10 Boaventura de Sousa Santos is one of the leading international scholars on the relation between law and globalization. He counts as fierce critic of the "Western" legal domination and instead argues in favor of legal pluralism (de Sousa Santos 85). 
also a legal canon that establishes what is and what is not law" (181). Consequently, the definition of law and terms such as "Western" or "American law" must be put in quotation marks since they all represent merely cultural ideas (Ruskola 197). These concepts ultimately gain their legitimacy from the self-declared superiority of Western civilization (Ruskola 215). Especially Americans have historically tended to "self-Americanize" by representing themselves as inherently "legal" while denigrating other countries as lawless (Ruskola 228). Lawlessness in this context also has the connotation of lacking modernization which is another key element of Orientalist discourse (Ruskola 228). "The rule of law" thus poses a dilemma while there remains a human desire to enforce it (Ruskola 231). This urge also corresponds to the growing importance of human rights framing in the global media (Whitlock 67). ${ }^{11}$ Ultimately, the global debate revolves around the same problem: "So long as we insist that "real' law is a Western notion," Ruskola summarizes, "it will always be the West that holds the key to the truth about law" (234).

This thorough explanation of legal Orientalism formulated from the perspective of legal studies reflects the dilemma Hamoudi finds himself in. His own questioning of the rule of law, its implementation, and the problem of universalism make the reader think along the same lines. Just like the author cannot escape Orientalist judgement completely when separating himself from the Iraqi people, he nevertheless raises the question of who gets to decide who is human and "who has 'law,", as Ruskola puts it. Historically, this question has been answered in reference to power trajectories. In the Iraq Hamoudi sketches, this aspect holds true. His law school project is a keen example of this. Although the project's aim is to implement law for the protection of human rights as a universal value, the students participating in the program nevertheless learn "the principles of American law" (HM 185).

This paradox is characteristic of the entire law frame created in the memoir. While legal concerns are first presented as referring to mere de jure law and practical decision-making, the issue of law later gains a much broader ethical ${ }^{12}$ and normative meaning. This legal lens eventually works to the effect that the structural question of lawfulness cannot be separated from the view of Iraqis as individual citizens and subjects of this law. As the discussion of Legal Orientalism from a historical viewpoint also reveals, however, these legal concerns linked to the image of the Iraqis have to be read in an even larger cultural context. Law therefore serves as a means to "construct cultural identity" (Ruskola 184). This directly hints at the close relation of the law frame with the cultural frame established by Hamoudi.

11 The freedom of opinion and expression itself constitutes a universal right beyond national legal frameworks. It is formally granted in Article 19 of the Declaration of Human Rights (Hackett and Zhao 5).

12 Ethics in this context refers to a normative system which not so much rules what individuals shall or shall not do but rather how the "ethical subject" ermerges (Ruskola 225). 


\section{The Culture Frame}

'Yo, Iraqi Buckeye. Got a question. [...] That little fruit thing on a palm tree, what is that thing?' he [the U.S. soldier] asked. 'Harris, you never hear of a damn coconut?' another said. 'Ain't no coconut on the tree. There's hundreds of 'em up there,' Harris replied. 'Those are baby coconuts,' the other soldiers said. 'Actually,' I added, 'they are called dates, and they are a staple of the Iraqi diet.' 'They must really like 'em, right?' [...] 'It's like potatoes to an American, they eat them all the time,' I said. 'I got a different question, how do I tell some asshole to fuck off in Iraqi?' someone else asked. (HM 7-8)

This conversation marks the first encounter between Hamoudi and the U.S. soldiers. Obviously, the interest of the Americans in learning about Iraqi culture is fairly limited. The derogatory way in which they talk about Iraqis reflects the language of the superior power depicting inferior barbarians. Hamoudi takes up this reductionist viewpoint and subverts it by evoking the stereotype of the U.S. as potato culture. What at first seems to be a funny incident that proves his ability of cultural translation then quickly turns out to be a metaphor of colonial domination spanning the entire memoir. Hamoudi exposes this Orientalist trajectory not only by painting a detailed picture of what Iraqi culture looks like from his perspective, but also by establishing a cultural frame that unmasks the U.S. culture of neglect.

In contrast to the extensive cultural experiences Kaldas depicts in her memoir, a look at Hamoudi's table of contents already reveals that food, cultural performance, and religious holidays do not count as primary topics. This does not mean that these aspects are completely excluded from his account. In describing everyday life in Baghdad, the family's celebration of religious holidays (HM 218), and the cultural difficulties surrounding Hamoudi's relationship with his future wife Sara (HM 266), the reader does get a detailed picture of cultural customs in Iraq. These scenes in which Hamoudi exclusively focuses on Iraqi culture, however, are far less visible than the instances in which the primary attention rests on U.S. culture. This practice ends up shedding as much light on U.S. culture as on the Iraqi one. Contrary to common Orientalist stereotypes, the latter is depicted as superior, as various unpleasant experiences of Hamoudi with his fellow Americans suggest.

Hamoudi's first contact with highly armed U.S. military personnel introduces as series of similar encounters with American gun culture. Shortly after his arrival in Baghdad, he gets involved in a conversation with a representative of a large U.S. weapon company. The meeting happens in the middle of a multitude of guns and other armory surrounding them at the airport. Hamoudi is obviously disturbed by this gun-loaded atmosphere because guns are less visible in the U.S. His confusion worsens when the man mistakes him for an Iraqi immigrant to the U.S. "It didn't occur to me that he hadn't thought of me as an American," Hamoudi recalls, "and 
that "my country' would not be the United States" (HM 6). Despite the fact that this marks the story of ongoing cultural confusion for him, it also provides the starting point for his lasting confrontation with U.S. gun culture. Although he claims that guns in his home state Ohio do not play such an important role, he soon gets reminded that Ohio might not be the U.S. norm when it comes to gun affection. The outside view of U.S. culture therefore points to a different reality. For the Iraqis, the U.S. constitutes the epicenter of gun prowess. As Hamoudi's cab driver one day tells him: "I read an article about some place in Texas where everyone has guns and they shoot each other for fun. What would they do in this hell of fire?" (HM 17).

Obviously, this image of the U.S. as a gun-loving country is not only based on newspaper articles or TV footage. Rather, the conclusion made by Abdullah derivees from the daily confrontation with the U.S. military exerting its power with guns, street blockades, and rolling tanks. Hamoudi soon gets to learn how it feels to be exposed to this violence, even when there are no gun shots involved. When visiting the Shrines of Najaf, a holy site for Shiis, Hamoudi feels deeply humble. Having been raised in the Shii tradition, he takes pride in his religious knowledge of the Quran and recites prayers. Upon leaving the tombs, this sacred atmosphere all of a sudden becomes dimmed. An American tank is parked right on former burial ground. "Two soldiers sat on the roof, their legs idly dangling," Hamoudi recalls (HM 24). When he is about to give the Americans a gesture to move, his driver Abbas declines and lets him know he is not upset about the scene. In contrast to Hamoudi, Abbas is used to similar cultural and religious violations. "The Americans did not recognize their error and were in his eyes blameless," Hamoudi remembers the driver's reaction (HM 24).

This scene of a tank parking on sacred burial ground presents a powerful image of how the U.S. military power literally rolls over the cultural treasures of the Iraqi people. As the forgiving gesture of Abbas suggests, this cultural trespassing tends to be excused by the lack of cultural knowledge. This is also how Hamoudi seems to perceive of the cultural violence he observes when describing his visit to the Imam Ali mosque on his way to another martyr site in Kerbala. The mosque marks the burial ground of Prophet Muhammad's son in law. Hamoudi illustrates the emotional vigor dominating at these sites. "To a Westerner, no doubt the scene is disturbing, with frenzied crowds screaming the name of the Imams as they surround the tomb and seek to grasp its edges," he explains (HM 25). He then adds: "Those from nonwestern cultures more accustomed to such emotional displays are probably not so much disturbed as confused, as emotional urgency of this sort is not unusual in many cultures upon the recent death of a loved one" (HM 25). Hamoudi then gives a longer explanation of the meaning of the religious burial grounds and their relation to the division between Shiis and Sunnis (HM 25-26).

This comparison between the cultures of "non-Western" versus "Western" obviously transcends the single cultural contrast between Iraq and America. Hamoudi 
draws on the century-old cultural dichotomy of East and West to point to the differences he perceives. His longer digression on the religious history of Shiism underlines that he attributes the reason for cultural neglect to the lack of cultural knowledge. Slowly, however, this presumption of innocence starts fading in light of the repeated cultural offenses and imperialist superiority the Americans display. For Hamoudi, this goes along with further personal encounters with U.S. gun culture. One day, when arriving at Baghdad airport, an American representative of the Coalition Provisional Authority picks him up. The man is armed to the teeth. When they drive off, other American officers load their guns and tell Hamoudi. "Don't you worry [...] we'll blow the fucking heads off of any motherfucking Haji who looks funny at us" (HM 74). With the authority of the American gun expert, the man adds: "Fucking Hajis, don't know a fucking thing but a gun [...]" (HM 74). Apparently, it does not occur to the American authorities that Hamoudi himself is one of the "Hajis" they are talking about. As Hamoudi then admits, the only reason why he knows that Haji is a derogative term used to refer to Iraqis, is because he accidentally read a news report explaining it. It is still striking for him to see that this is exactly the kind of cultural encounter Iraqis have every day. Guns are all they can think of when seeing an American. Hamoudi's uncle summarizes this gundominated view of U.S. culture after almost getting shot by a U.S. soldier. The "Americans only know about their big guns. They think they will wave around their big guns and everything will be like they want. Can I get money for this? All they have are their big guns, any place they invade they destroy, except Germany and Japan, but those are very resourceful. The Americans are stupid" (HM 120).

This statement powerfully underlines in how far the image of the U.S. is ruled by gun-culture and related imperialist and materialist conduct. Hamoudi's repeated personal encounters with this culture and with its condemnation by the Iraqis begin to leave their mark on his cultural self-identification. This question of cultural and national affiliation, though, causes a conflict for him that he first tries to escape. It poses “The Question," as he entitles the chapter devoted to the issue (HM 32):

A day never passed in Iraq that I was not faced with one question from Iraqis and Americans alike - whether I considered myself an Iraqi or an American. [...] The question always struck me as absurd and entirely unbefitting this modern global era of multicultural families, dual citizenships, foreign residency, and immigration. The tendency to compartmentalize, to reduce, and to simplify seemed universal, but while it was easy and therefore appealing to the intellectually incurious, it was, for those of us raised as I was, utterly incongruous to the nature of our existence and upbringing. (HM 32)

At first, it seems that Hamoudi again elevates his own multi-cultural upbringing by claiming that compartmentalizing and categorizing cultures runs counter to his "intellectual advancement. Yet, as he admits in the paragraph that follows, "anti- 
thetical as it was to my own nature to even consider such a question, I had been given cause to reflect on it [...]" (HM 32). The rather impersonal and complicated way in which he constructs this sentence reflects his lasting attempt to push the issue of cultural affiliation aside. In rational terms, though, "the cause to reflect" is just too pervasive at this point. Hamoudi therefore has to answer "The Question" of cultural belonging - to himself and to others.

Surprisingly, this answer situates him on the Iraqi side of the hyphen. "I am clearly an Iraqi born in the United States because both my mother and father are Iraqi," he exclaims (HM 32). In line with his judicially-oriented mindset, this selfidentification relies on formal citizenship more than on emotional or cultural attachment. As he also explains, however, his self-identification is not a matter of law but one of parental lineage. This criterion evokes pride in the eyes of Iraqis. He then gives a cultural explanation for his identity affiliation. "If my behavior was ecxessively American, my language skills poor; my respect for my family and elders not high enough, I might be considered Americanized, or even American" (HM 32-33). He then explains the American perspective toward this understanding of cultural heritage. As he knows, Americans "regard such genetic determinism as arbitrary and inherently unjust" (HM 33). Still, his former and current experiences have also taught him that Americans are the ones who question his identity most frequently.

This first longer and very personal reflection on his cultural identity occurs at a point when Hamoudi has already witnessed much cultural neglect by his fellow Americans. After all the humiliation he has witnessed, he obviously seeks to distance himself from being American. Furthermore, he does not want to count as "Americanized" either, since this term to him signals the opposite of culturally appropriate behaviour. This view highlights his encompassing professional and personal belief in the relevance of laws and its normative implications. For him, culture is characterized by the adherence to cultural norms and values as well as by certain cultural knowledge, such as language skills, as he repeatedly emphasizes. This compartmentalized notion of culture becomes even more prevalent when he explains that Americans tend to raise the same question about his cultural identity as the Iraqis. Both parties want to know on which side he stands. Ironically, Hamoudi pretends he has "no answer" to this question. In fact, however, he implicitly provides one in the statement that follows right after this negation: "I speak fluent English, yet insist on speaking Arabic at any occasion where I can. I love Amerian football, yet find indoor soccer ludicrous and a perfect metaphor for what is wrong with America vis-à-vis the world: we can't just play a game like everyone else, we have to change it" (HM 34).

This passage strikingly illustrates that his claim of having "no answer" is a major understatement. Hamoudi does have a very detailed answer, one that is highly political. With his awkward allusion to football and soccer in this instance, he mocks America's obsession with sports and its role as major cultural fulfillment. At 
the same time, he draws an accurate picture of the culture America displays to the world and to the Iraqi people. It is one of cultural neglect and superiority, of militancy and dominance - of changing the rules. Iraq, however, becomes more than a game to Hamoudi because he is not eager to violently change the rules in the way his fellow American countrymen do. Cultural neglect and violence doe not correspond to the cultural norms he envisions. Hamoudi still humorously tries to avoid a definite answer to this cultural dilemma. "[I]n the words of Popeye the Sailor Man: Am I an American or an Iraqi? I yam what I yam and that's what I yam" (HM 35). Even Popeye, however, cannot help much in this case to resolve the tension. It thus becomes more and more visible that Hamoudi feels a growing distance to America in cultural terms. Two more key events add to this growing cultural detachment.

When walking through the streets of Baghdad, Hamoudi all of a sudden notices a crowd of people gathering around an assembly of Americans. When moving closer, he notices he is standing in a massive puddle of water. Very quickly, the intense smell of gasoline then reveals a different story. The scene was caused by American soldiers trying to take disciplinary action against blackmarket sellers of gasoline by destroying the vendors' containers. To Hamoudi, this incident is eyeopening. "I became witness to a sight I am not likely to forget as a near perfect metaphor of the incompetent colonial exercise in which the United States was engaged" (HM 58). Hamoudi's choice of words here explicitly hints at the imperialist and thus Orientalist practice under which the cultural and humanitarian disrespect of the Americans can be subsumed. It divides Americans and Iraqis into "colonials and colonized"13 (HM 38). There is no effort on the part of America to let anything but the language of cultural and political hegemony speak. This also finds reflection in the field of education which Hamoudi finally devotes his energy to.

Hamoudi in the context of his work to develop law education in Iraq also faces issues of gender division. A remarkable encounter with a U.S. advisor gives Hamoudi a lasting sense of how Americans handle this element of Iraqi culture. The official is in charge of developing a program for the advancement of girls' education. After getting a sketch of the project, Hamoudi voices his concern that the implementation might fail because it requires young Iraqi women to travel to Baghdad by themselves. Their families will most likely oppose this, he explains. The reaction of the female U.S. official, however, does away with any kind of cultural

13 Hamoudi uses this vocabulary in an earlier passage in which he explains the political power relations in Iraq and the influence of Islamism. As he states: "Among colonials and colonized alike, there were too many liars and cheats, too much chaos and disorder, too many promises broken and deadlines not kept to believe in much of anything that a current politician, American or Iraqi, had to say" (HM 38). Hamoudi here still keeps a high degree of distance between himself and both "colonizer and colonized." This lack of cultural attachment vanishes with his growing disappointment in the U.S. culture of neglect. 
sensitivity. Besides claiming to respect cultural peculiarities, she insists that in Iraq, "the culture was sexist and wrong," Hamoudi recalls (HM 34). The official "was going to make this program work, so that Iraqis would learn the ways of modernity," he adds (HM 34). How such a procedure is perceived by Iraqis, Hamoudi learns in another eye-opening conversation. An Iraqi professor in Basra who works in the field of women's education puts the matter in a nutshell: "The Americans have to understand something about this country if they are going to try to run it" (HM 98).

These experiences at the intersection of education and gender add another layer to the devastated picture of U.S. cultural neglect that Hamoudi highlights from a mirror perspective. Not only do Americans enforce their cultural prozalitation against all odds, they also lastingly resist learning about the culture of Iraq. The importance of cultural knowledge as prerequisite for political rule is highlighted by the professor in Basra. He reiterates Hamoudi's own claim to employ his bi-cultural knowledge in order to shed light on a country viewed as the home of uncultivated barbarian terrorists. When learning that Americans actually act as barbarians who are neither able nor willing to learn and respect cultural difference, Hamoudi's distance to America increases. He consequently shares the hostility towards Americans which he senses to flourish at accelerating pace (HM 154).

The growing distance to the U.S., however, does not ultimately settle his indetermination concerning his own cultural identity. This inner state of imbalance becomes reflected in the language Hamoudi uses. Sometimes he clearly positions himself among the Iraqis by including himself in the collective of "We Iraqis" (HM 180). At other times, he is drawn to his American identity affiliation again. Ultimately, he comes to realize that it is not so much a matter of making the right decision of cultural self-identification but one of being given the opportunity to decide at all: "Unlike many others, as an American who had lived most of his life in the United States, I had a choice," he recapitulates. At this stage of his narrative, his choice again falls on Iraq because "what mattered to me most was that I still believed [...]. I believed in this land rich with oil [...] the home of the gardens of Babylon [...] I believed [...] I still believed" (HM 166-67).

Hamoudi in this testimony to his belief in Iraq, which he reiterates by employing anaphora, acts against his rational thinking and the conviction of Iraq's likely failure. In political terms, this collapse is almost tangible, as Hamoudi lets the reader know. In cultural terms, however, he makes it very clear who fails to understand cultural difference on a very personal level - certainly not the Iraqis. The strengthening relationship to his future wife Sara provides another strong demonstration of the cultural ignorance on the part of Americans. While he is already struggling to avoid cultural taboos in the relationship itself, he finds it even harder to deal with the cultural reaction of his friends. In the chapter "Nuptial Preparations," he reveals the reason for his unease (HM 219): 
As open and accepting as my American upbringing was, as tolerant and kind as most of my American friends were, there was a tinge of cultural bigotry in American society that time had not erased. There was a sense that those of us from the Arab and Muslim world were in some unexpressed way inferior and silly, the kind of people who traded women at camel auctions [...]. (HM 220)

Hamoudi in this passage puts the mirror in front of the American reader to remind him/her of prevailing Orientalist stereotypes. Not only does the term "cultural bigotry" strongly oppose the otherwise celebtrated ideals of openness and cultural pluralism, he specifically relates this to the views surrounding Arabs and Muslims. It is this culture of cultural neglect that prevents even Hamoudi's closest friends from knowing his "own deep cultural identity," as he admits (HM 221).

In his criticism of American culture, Hamoudi also points to the double standards underlying it. This gap between image and reality becomes particularly visible in another conversation the author has with Iraqi business acquaintances. When they talk about the cultural norm that alcohol is permitted only "for men and whores," Hamoudi almost ironically points out that Americans would consider this statement to be "politically incorrect" (HM 223). One of the men then asks what that means. Hamoudi replies that it "means you have to show respect for all genders and ethnic groups and races. You can't categorize any of them." He then adds: "Westerners feel that stereotypes are wrong" (HM 223). Upon this politically correct defense of American political correctness, Hamoudi gets a simple but revealing answer: "They aren't wrong, they are usually true" (HM 223).

This explicit reflection on stereotypes in combination with political correctness forms a precise summary of the very complex culture frame Hamoudi constructs. This frame certainly has different connotations than the one established by Kaldas. Hamoudi, instead of focusing on cultural details in Iraq, pursues a more offensive strategy to convey cultural knowledge. By directly pointing to the constant violation of cultural code, Hamoudi exposes the prevailing Orientalist and colonialist attitude of the U.S. as imperial hegemon. He achieves this effect by directly confronting his readership with an outside view of U.S. culture. In the eyes of many Iraqis who get to voice their opinion in the memoir, this culture is one of moral and cultural neglect. The Americans' adherence to political correctness as a mere ideal ridicules this culture in a powerful way. At times, Hamoudi's judgement of these cultural offenses makes him distance himself from his American identity. At other times, he cannot resist his American socialization by treating the Iraqis as inferior and by displaying a high degree of cultural arrogance.

Due to the personal struggle Hamoudi faces with respect to the issue of culture, the very concept itself gains a more differentiated meaning for himself and thus also for his audience. One of the most striking findings within this cultural frame is that stereotypes are true, at least in the reality of the people living in both worlds - East 
and West. Hamoudi knows, however, that this reality is hardly ever conveyed in the immediate way that he aspires for his own narrative. Stereotypes are the result of second-hand information which he seeks to correct in his first-hand account. The strongest competitors in this battle for authentic information on Iraq are the media. Hamoudi thus pays close attention to the way in which they uphold the image of the Iraqi terrorist.

\section{The Media Frame}

\section{Image 9: Television Is Our World}

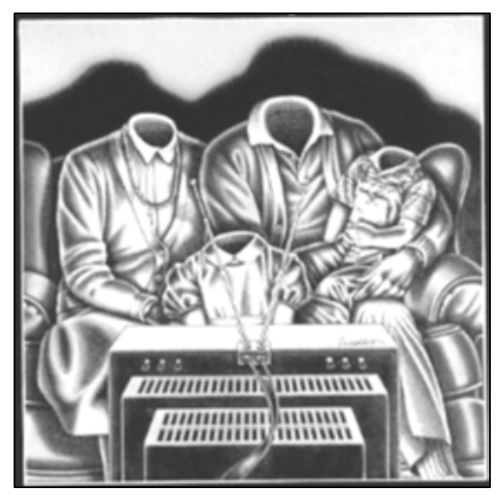

Source: The front cover of Amusing Ourselves to Death: Public Discourse in the Age of Television showing how television culture turns its audience into 'headless' victims of the media (Postman).

When thinking of American culture as based on military tanks and colonial hegemony, there is another supposed stereotype that, as Hamoudi is aware of, actually contains much truth - America as TV culture. This cultural transition to a brainless "Peek-a-Boo World"

(Postman 64) was strikingly illustrated by Neil Postman in Amusing Ourselves to Death: Public Discourse in the Age of Show Business, published in 1985. Postman in his critical reflection states that television "has gradually become our culture. [...] We have adjusted to what may have at one time been termed 'bizarre,' and the extent to which we have adjusted is a measure of the extent to which we have been changed" (79-80). Hamoudi during his time in Baghdad also experiences how this change of culture initiated by television and other media has impacted the discourse on Iraq. Since he grew up in the number one television country of America, he is familiar with the images of Shaheen's "TV Arab." Partly, these very images shaped his own view of Iraq long before his arrival there. As an Arab American living among Iraqis, however, he looks at the world and America through a different TV set. This causes him to keep a critical analytical eye on the mechanisms through which the media in both worlds, East and West, frame the image of the Iraqi.

To Hamoudi's initial surprise, his journey from America to Iraq not only takes him from one country to another, but also from one TV culture to another. He constantly catches his relatives sitting in front of the flickering screen for hours. 
Iraqis were addicted to hearing the news immediately after the fall of the regime. Both Ali [cousin] and my uncle Isam spent their time watching Arab satellite news channels as if they were highly-regarded films. I had never known anyone who could watch four to six consecutive hours of news programming every single day, but they seemed to enjoy it immensely. (HM 19)

By describing the exhaustive television consumption of his relatives, Hamoudi already points to a crucial difference separating the Iraqi television audience from the one in America. As he clarifies, Iraqis do not spend hours in front of the TV watching soap operas or other entertainment programs. Their seeming television addiction is not motivated by the mere need for entertainment, but by the eagerness to gain information. As Hamoudi explains, for the first time after the long-standing regime of Saddam Hussein, they are able to receive news channels that do not rely on the propaganda machinery of a dictator or the limited view of only one Arab news station (HM 19). The Iraqis highly appreciate to have escaped the propagandist news framing of the former regime, Hamoudi explains.

Still, the Iraqis as a consequence of their former negative media experience continue to read and watch between the lines. This also causes skepticism toward seemingly independent news stations such as Al-Jazeera. Here, they criticize the "panArabist bias" of the coverage (HM 19). In order to demonstrate this point, Hamoudi quotes from a moderated panel discussion on Al-Jazeera on the current state of domestic political affairs in Iraq. The Palestinian commentator calls the Iraqi resistance movement "the shining cause in our blighted Arab world that will lead us over the shackles of imperialism and Zionism and colonialism [...]" (HM 19). Hamoudi recalls the reaction of his uncle Abu Ahmed to this statement: "Who is this resistance killing," the uncle asks? He then quickly answers his own question: "Ten Iraqis for every American. Idiot" (HM 20). This scene reveals that colonial oppression, especially in the context of Zionism, is not a phenomenon that deserves the scholarly prefix of "post-" in the Middle East. Rather, colonialism is a very present experience for the Iraqi people. Hamoudi's description of his uncle's reaction also demonstrates that the television audience in Iraq does not approach this issue from a reductionist viewpoint. The reservations of the Iraqis against biased news reporting thus rely on a nuanced approach to pan-Arab political affairs, the Palestine conflict, and the role of the media therein. This observation reveals that the Iraqis themselves are highly aware of the role news framing plays in the shaping of their worldview. Hamoudi's detailed attention to the media coverage and its reception also underlines his media-theoretic knowledge of framing.

News in Iraq do not only stem from Arab sources, however. Abu Ahmed after his outburst instantly changes the channel to Fox News. After watching the program for a few minutes, he has to admit: "'I wish I knew English. I think the Americans and this O'Reilly fellow on this channel sometimes make much more sense than the 
Al-Jazeera people ever did, but I cannot understand what they are saying'" (HM 20). Abu Ahmed obviously has trust in American media outlets. This reaction symbolizes the new media freedom Iraq has achieved after the fall of the old regime. What prevents him and the majority of Iraqis from fully taking advantage of this is the lack of education. In fact, this shortcoming also is the result of Iraq's longlasting political and economic mismanagement.

The lack of education and foreign language skills, however, does not prevent the Iraqi media audience to look for comprehensive information and truthful reports in the media, Hamoudi in his more far-reaching analysis of media consumption in Iraq reveals. As his alertness to the issue of media production and reception in Iraq intensifies, he closely watches the way in which news media information is distributed and perceived in the country. These reflections pervade the entire narrative like a red thread. To further reinforce this mediatic lens for his readers, Hamoudi devotes an entire chapter to explaining the trajectories of news consumption in Iraq. The chapter bears the telling title "Truth and Rumors in Baghdad" (HM 45). As the conjunction "and" suggests, according to Hamoudi, the concepts of truth and rumors do not necessarily stand in contrast to each other. This assumption receives immediate confirmation when he explains how much the "truth" was distorted by the Iraqi media in the past. "In light of the lies told by official media sources over the past thirty-five years in Iraq, it should come as no surprise that Iraqis have been ingrained with a healthy skepticism concerning the accuracy of sources of information that are usually taken to be reliable in other parts of the world," he outlines (HM 45). This inherent discredit of news reports not only refers to government and military sources but also to American news media outlets. Truth is thus assumed to be lacking independent from the specific news producer. As Hamoudi explains, "Iraqis also rarely trusted any breaking story on television" (HM 45). This general mistrust in the media as a legacy of the Saddam regime is further complicated by the different religious and political factions in the media audience. Shiis do not trust Al-Jazeera because of its "pan-Arab and anti-Shii" stance, Hamoudi explains (HM 46). Also, they do not trust CNN or European outlets such BBC either because both function as a "mouthpiece" for the American and European governments (HM 46).

Hamoudi in the first part of this chapter provides a very detailed analysis of the reasons behind the Iraqi skepticism toward any kind of media content. As he clearly emphasizes, the distrust is not simply a consequence of homogeneous anti-Western sentiment in the Arab world. Rather, internal and international political divisions also influence the process of news production and news reception in Iraq. This aspect is hardly illuminated in the common coverage on Iraq. This knowledge, however, provides the precursor for understanding the importance Iraqis ascribe to the issue of truth within the larger social environment and the exchange of information. The author uses a very striking example to demonstrate this point. "Thus, to the ordinary Iraqi, the story on CNN about a soldier who helped rebuild a school in 
Kirkuk was clearly untrue because it was a news report, but a street rumor that the sunglasses of U.S. soldiers were designed to see through women's clothing was widely accepted, even to some degree among the educated who really should have known better" (HM 15).

Whereas Hamoudi's narrative voice in the analysis of the different news media outlets and their perception appears rather neutral, the above-mentioned elaboration on the Iraqi understanding of truth displays a sense of cultural superioty again. Although he reiterates his goal to provide an authentic image of the "ordinary Iraqi," he at the same time exposes the lack of education and its replacement by superstition and conspiracy theories in the general population. The spreading of "street rumors" therefore clearly contradicts Hamoudi's conception of truthful reporting. The tone in which he describes this Iraqi habit disregards the fact that the belief in rumors is also an attempt to fill the information gaps left by the media. Rather, the author emphasizes the cultural and social backwardness that goes along with the practice (HM 46). The unrealistic example of the glasses as screening instruments to see through women's clothing underscores this point even further. The man believing in this information is presented as unintelligent native who believes in rumors as a child believes in fairy tales. Hamoudi makes no attempt to balance the Western perspective he occupies in this instance and consequently does not show any sympathy toward the cultural appreciation of "rumors." To him the truth of news media clearly is truer than any rumor. This reveals an ethnocentrist attitude which Hamoudi seems to be highly unaware of in his depiction of the discursive landscape in Iraq. This cultural arrogance is underpinned in another media-related comment he drops. When visiting a movie theater in Baghdad, he mourns the "sad condition of the Iraqi arts" (HM 50). Such a judgement underscores the position of a Western visitor who is used to fine arts entertainment and a choice of dozens of news channels in the U.S. Given the war-like circumstances in Iraq, such a comment seems out of place.

The situational Orientalist arrogance with respect to the media environment in Iraq slowly gets embanked by the political reality Hamoudi is facing. Life and above all survival to a large degree depend on the media as only source of information, as he quickly learns. Several key events taking place in Iraq or related to Iraq demonstrate this important function of the media in the condition of war to him. The only way in which Hamoudi learns about these events is through the television coverage. An example of this is provided when the sons of Saddam Hussein are found dead. The author first hears about this in the streets, but the ultimate proof of the truthfulness of the information is affirmed when the dead bodies are displayed on television, as he recalls (HM 50). A similar importance of the media as Hamoudi's prime source of information appears in the context of the capture of 
Saddam Hussein. The coverage of the incident quickly focused on the announcement by chief administrator Paul Bremer "We got him" (HM 71). ${ }^{14}$

Hamoudi in the course of his account increasingly interlaces information he gained from the media with his own observations (HM 126). Just like the life of the Iraqis is very much determined by the information they receive from the news, Hamoudi's own survival in the war-struck country comes to depend on the news media. The climax of this appears in the chapter "Ashura" that deals with the bombings in March 2004 (HM 125). Ashura marks the most important religious celebration in honor of the martyrdom of Prophet Muhammad's grandson Hussein (HM 128; Packer 258). For the first time after Iraq's liberation, Shiis in the year of his visit were free to celebrate this event at the holy shrines in Kerbala. Due to security issues, Hamoudi can only watch the commemoration on TV, which he regrets deeply. As it turns out, however, the decision to watch the celebrations at home saves his life. On that day, celebrations in Ashura were replaced by bombings. More than 180 mostly Shiite pilgrims died when terrorists of the resistance movement carried out suicide killings in Baghdad and Kerbala (Packer 256). Al Qaeda was later blamed for the attacks that were directed against Sunnis and the occupational forces alike. "On television, all that we could see were bloody limbs, terrorized people running frantically, buildings falling apart [...]. We could make no sense of it," Hamoudi remembers his shock and frustration (HM 128). Following the event, Hamoudi describes the deeds of the terrorists in Iraq with more hatred in his voice than ever before (HM 128). Despite this emotional impact, the bombings also mark a turning point in Hamoudi's analysis of the media. His major target from now on is the American press.

Hamoudi's increasing skepticism of U.S. media coverage already becomes visible when his uncle tells him about the shooting incident with the American soldiers which the former was able to escape. The author interprets this violent act within the larger framework of the media coverage that obviously leaves out certain events while focusing on others. "The U.S. media, in their never-ending campaign to 'support the troops,' and the U.S. government, desperate to keep public support of the war high, had not reported on these matters [shooting of uncle] at all," he notes (HM 120). The Ashura bombing then directs Hamoudi's attention farther away from his analysis of Iraqi news and toward U.S. media framing. He continues

14 Although Hamoudi largely focuses on television as most popular media outlet in Iraq, his own media consumption also includes print sources. Since the selection of print media is limited, he also knows that this alternative news medium makes him dependent on a particular world view that depends on Western sources. He even admits that the International Herald Tribune effectively becomes a substitute for the New York Times for him. It provides him with all necessary political information and in addition serves as a mediator to keep him in touch with the "West," as he states (HM 163). 
to point out examples in which mechanisms of selectivity and distortion serve the U.S. media as a tool for propaganda purposes. While the Ashura bombings represent the ultimate sign of the political failure of the U.S., he knows that nobody on American television will see or hear this negative truth. "I was angry at the Americans, and the very thought of watching a single U.S. Army of CPA spokesman express regret," he describes his feelings of disgust about the coverage (HM 12829). Besides their constant claims of bringing democracy to Iraq, the U.S. has lastingly failed to guarantee security to the Iraqi people, Hamoudi clarifies. Yet, it is not an exclusively politically-oriented analysis he provides here but one related to the function of media framing as instrument of an occupational force. "Nothing good could come from this type of governance," he derives. "It was not governance at all, only its illusion to satisfy a discontented American public" (HM 129).

Hamoudi in his critical analysis of the U.S. media coverage on the Ashura bombings and on further critical events directly attacks the way in which the media serve as political instruments to justify the war in Iraq. Read from the background of his previous comments on the Iraqi media landscape, he indirectly equates the U.S. system of news production to the one of Iraq. While the Iraqi media in former times held their audience hostage to maintain the dicatatorship of Saddam Hussein, the U.S. and eventually the world audience are now taken captive in a similar vein to support the WOT. This investigation of the instrumentalist framing in both media systems highlights Hamoudi's knowledgable approach to the issue and also alarms the American media audience to critically reflect on its media practices. Further examples the author provides from the mechanisms underlying the U.S. media coverage make these critical insights even more unavoidable for the reader:

I heard the CNN spokespeople, I heard the experts explain how impossible it was going to be to protect so many people [...]. I could only think one thing - if it was the Olympics, if it was the anniversary of September 11, if it was the Oscars, if it was the Super Bowl, an event not one-tenth as important as the Ashura, America would have found a way. Whatever the problem, whatever the obstacles, the U.S. would make sure its people were protected. But when it came to Iraq, they sounded like Yassir Arafat. (HM 129)

This passage marks one of the most powerful strikes Hamoudi launches at the U.S. media system and its framing of the WOT. The daunting comparison to a figure like Yassir Arafat conveys the strong disappointment resonating in the author's voice. He compares the leader of a highly disputed political organization to the American media outlets to underline how neglectful but also violent the U.S. treats the concerns of the Iraqi people in compasrison to its own. The failure to protect the Iraqi people is therefore not the result of inability, as Hamoudi clarifies. Rather, it is the intentional disregard to take full advantage of the often-praised military and political capabilities existing in the land of unlimited opportunities. 
The concerted American coverage on Iraqi affairs as such is only one indicator of the U.S. media's attempts to frame the WOT, as Hamoudi furthermore explicates. This framing also relies on the intentional depiction of the Muslim as enemy within the larger context of the Middle East conflict in Palestine. In the case of the Ashura bombings, this focus on religious identity stereotypes again received confirmation, Hamoudi observes. While "Americans did not actually commit the crime," he clarifies that their media practice gained criminal traces (HM 129). The media after the bombings thus exclusively focused on the ones who were responsible for the bombings - namely Muslims, without any further differentiation. The American television audience therefore never learned about the fact that the majority of Muslims actually condemned the crime. Many of them univocally interjected that real Muslims would never commit such violent acts directed at fellow believers. The U.S. media, however, turn this argument around in their reporting:

CNN misunderstood the sentiment when expressed thus, seeming to think that the statements of witnesses that the perpetrators were not Muslims implied some sort of Jewish conspiracy rather than a simple statement that anyone who committed such an act was not moved to do it by the tenets of our religion. It was not, I was sure, the last misunderstanding I would hear relayed on American television. (HM 129-30)

Hamoudi by calling the broadcasting a "misunderstanding" allows for the possibility to attribute the distorted representation to a lack of knowledge on the part of the media. This already exposes an inherent incompetence of U.S. media in foreign affairs coverage. The fact that Hamoudi expects more misunderstandings to happen, in addition suggests that the flawed coverage he mentions from the past is the result of intentional distortion within the overall media framing of the WOT. Hamoudi strengthens this argument by referring to the impact of Zionism in the political framing of the Middle East and hints at the pro-Israeli bias ruling in the U.S. media.

The analysis Hamoudi provides of media framing does not end with his exposure of the WOT. Moreover, he stretches his analytical angle even further by locating the coverage he witneses within the framework of Orientalism, an interpretative pattern that has left a considerable mark on the history of $20^{\text {th }}$-century media reporting. Hamoudi reminds the reader of several key events that contributed to the framing of the Arab within the common enemy pattern, no matter if Muslims or Arabs actually were involved in any of these events. "Whether it was the Achille Lauro or September 11 [...], we found ourselves repeatedly on the defense, attempting to explain our religion and our culture on our own terms," he states (HM 134). Other terrorist acts that are in fact committed by Muslims pose a particular challenge to those who want to change this image. The other significant problem preventing this reframing process is the media and their selective but also sensational depiction of terrorism. "They [terrorists] made the news," Hamoudi summarizes the phenome- 
non while also pointing out that the average Muslim or Arab does not appear in the media (HM 134). In light of this reductionist presentation of Iraqis as terrorists, the ordinary - i.e., non-terrorist - Iraqi is mostly fed up with any type of news coverage. The reaction of Hamoudi's grandmother is symptomatic of this attempt to escape the stereotypical images about Arabs and Muslims in the media. "Please don't turn on the news," she advises Hamoudi (HM 136).

The detailed explanations Hamoudi devotes to the issue of the media powerfully underline his overall purpose of his memoir as an instrument to depict an alternative reality of Iraq for his readers. As in the case of Ansary and Kaldas, his strategy for achieving this aim does not rely on the simple narration of counter-stories. Hamoudi takes the position of the Iraqi looking at U.S. media framing from outside while at the same time taking the position of the American to highlight particularities of the Iraqi media world. The effect of this juxtaposition is that the Orientalist power-relation separating both countries is dissolved. The American reader is thus reminded that his/her stereotypes of Arabs are based on a similarly distorted media practice as employed in supposedly backward countries in the Middle East. Hamoudi in this context explicitly points to the importance of lasting stereotypes in the minds of Iraqis and Americans. When recalling a meeting of a finance committee, he notices that "Iraqis knew America from recycled sitcoms on bad satellite television only" (HM 79-80). One of the most important messages Hamoudi therefore provides by unfolding the logic of framing in front of his readership is that notions of the respective Other in the binary confrontation between East and West are always mediated but rarely immediate.

Due to the great importance of the media issue in Hamoudi's account, it comes as little surprise that a specific media event also forms a major cause of his nearing departure from Iraq. When he wakes up one morning in Baghdad and turns on $\mathrm{CNN}$, he believes to recognize pictures of the legal education office he works for in Mansour. The report states that three employees have been kidnapped and taken to Fallujah. After his initial shock, he slowly finds out that the coverage is actually spreading false information. The footage shows an office in "Mosul" not Mansour, as the reporters erroneously state. Hamoudi's assumption of this error is soon confirmed by Arab media outlets who give the correct information. Although Hamoudi feels relief after learning that his colleagues are not in danger, the incident is symptomatic of a larger problem in his eyes. The author knows that the confusion about the place names could only occur because of the ignorance and seclusion of American journalists. With a satirical undertone, Hamoudi thus infers that American "correspondents never left Army bases, but the Arabs tended to be better" (HM 197). This additional event underscoring the severe role the media play for the political development of the country is one of the last straws that ruin Hamoudi's initial motivation to come to Iraq. "This was it," he concludes (HM 198). He has 
almost no hope left that he can contribute to the reconstruction of the country and thus decides to leave soon.

The media frame created by Hamoudi ultimately changes his vision of the country as well as the angle from which the American audience looks at Iraq and at its own mediated stereotypes. The memoir serves as an instrument to compete with these essentialist notions by providing an alternative and more authentic picture of Iraq. How difficult this competition with the global network of mass media is, however, Hamoudi painfully learns throughout his stay. He finds himself caught in a vicious cycle of depending on and at the same time cursing the media's role in framing the Arab as terrorist. The disillusionment connected to this finding and the constant threat to his life eat up Hamoudi's energy. The only factor that for a long time prevents him from leaving early is his personal economic situation. Unfortunately, this initial privilege also erodes to the effect that the economic lens Hamoudi develops in his memoir triggers even more frustration.

\section{The Economy Frame}

In 1996, the political scientist Benjamin Barber published a book that would later be interpreted as prophecy of the current world order. The title reads Jihad ${ }^{15}$ versus McWorld (1992), whereby the author uses jihad as an umbrella term for tribalism and traditional culture in contrast to the corporate globalized part of the world ruled by large corporations (Barber 17). This provocative thesis is in line with the notion that the origin of colonialism largely relied on an economic enterprise. Linked to this stress on economic advancement and exploitation is the constructivist idea that modernism rests on a Western metaphor of progress and economic success. Hence, the binary division of the world into First and Third World countries still rests on economic indicators. Hardly anywhere could the clash of both worlds be more visible than in a country struck by the WOT. Especially for someone raised in the privileged environment of American materialism, this confrontation with a country in despair becomes a matter of personal division. As Hamoudi within the economic issue frame of the memoir reveals, McWorld is also starting to conquer Iraq, yet, this does not benefit his own class struggle in Iraq at all.

Hamoudi's self-appraisal of his outstanding education and professional career at the very outset of the memoir underlines that he belongs not only to an intellectual but also economic elite in the U.S. This status and his de-facto expatriate identity

15 Especially following the events of $9 / 11$, the term "jihad" has come to indicate religious fundamentalism and Islamic warfare. In general translation, however, jihad means "to struggle" or "strive" toward an overall goal (Campo 397). Barber in his book also uses the phrase in this broader context when referring to it as a form of identity politics and strategy to represent social diversity (9). 
when living in Iraq automatically identify him as a member of Iraq's social elite. In addition, it is his outspoken goal at the beginning of the memoir to make money in Iraq. Despite the geographical distance to the Iraqi people which he overcomes by living in Iraq, his elevated socio-economic status thus separates him from the "ordinary Iraqis." This also becomes reflected in the daily life Hamoudi pursues. He spends most of his leisure time in recreational facilities of the Iraqi Ba' ath ${ }^{16}$ elite and at the Hunting Club, a gathering place for American expatriates. The club has also become known as the favorite spare-time place of Saddam Hussein's sons (HM 28). The two brothers, who did not gain an education in the "decadent' West," 17 as Hamoudi emphasizes, are constantly ridiculed by the other club members for their lack of education and poor manners (HM 30). These stories on the special connection between money and education lead Hamoudi to more far-reaching thoughts on Iraqi's social structure. "I left the Hunting Club slightly more uneasy than I had been. Class was a distinction I never favored, and it bore me no pleasure to witness its strong presence. However, it would be a mistake to overstate the class-related problems in Iraq" (HM 31). Although Hamoudi upon this early encounter with economic-based social divisions in Iraq tries to downplay the importance of class in society and in his own life, the topic keeps occupying him to an increasing degree. Especially the Hunting Club hereby serves as a microcosm for Iraqi society at large:

The Hunting Club stories, however, revealed a deeper class-based fault within Iraqi society that is largely not discussed in media circles. In a society torn by divisions over religion, tribe, and ethnicity, class is not the premier distinction most Iraqis make with respect to one another, but it does exist. Families that are prominent and well-known tend to stay prominent and well-known. Individuals from families who are not prominent can graduate as a doctor from a top medical school or as a professor well respected in this field, but the opportunities for social advancement are considerably more limited. There is almost no chance for that graduate to join the Hunting Club, for example (HM 31).

16 The Ba'ath Party was the ruling political force in Iraq. The regime dominated the country from 1968 until the overtaking of the U.S. forces in 2003. Originally, the party had emerged as a revolutionary movement against European colonial suppression. Its major goal was the creation of pan-Arab unity. This aim is still reflected in the party's name which stands for "resurrection or renewal" (Campo 81). The official translation, however, is Arab Socialist Party. The faction claims to pursue secularist goals by denying the idea of religion as ultimate truth, though, the Ba'ath ideology equals the one of European fascism and communism.

17 This remark points to the correlation between an education "in the West" and the class status of diaspora members who return to their home countries. Various studies in Postcolonial and Cultural Studies investigate this phenomenon with increasing concern (Ansary, Interview with Menten). 
The author here provides insights into the dynamics of upward mobility in Iraq. He thoroughly traces how class generally stands behind in public discourse because issues of ethnicity and religion mostly dominate the picture. This also holds true for the Western media coverage on Iraq, where the domestic economic and social trajectories in the country are mostly neglected. Hamoudi's economic insights therefore indeed fill existing knowledge gaps of the audience. While the economic part of the American Dream is still dominated by the vision of rising 'from dishwasher to millionaire,' Hamoudi emphatically illustrates that this ideal is not universally valid and thus ethnocentric. As his example of medical school graduates from average family backgrounds demonstrates, an invisible glass cealing prevents many in Iraq from rising in society. Even a highly-advanced education thus cannot make up for a low-status family background. Hamoudi presents this system as faulty but at the same time reminds the American reader of similar trajectories persisting in the U.S. Here, class has historically been an unpopular topic because of the strong emphasis on the American Dream that supposedly can be achieved by anybody who is willing to work hard. Meanwhile, though, the economic downturn has brought class issues back to the consciousness of Americans. They are thus likely to identify with the situation described by Hamoudi. The importance of family background, however, also directly relates to Hamoudi's personal status. At this stage of his economic observations in Iraq, he is obtrusively quiet about his own elevated status as Iraqi American with an education in America who now enjoys upper-class privileges in Iraq. He does not seem to be aware of the fact that his life in Iraq and his self-constructed authority as an author largely rest on his class position. Slowly, this aspect reaches his consciousness.

Daily life in Iraq gradually reminds Hamoudi of how much his view of economic concerns is rooted in a Western conception of class and socio-demographic status. When he is asked about his tribal origin by another Iraqi, he fails to provide an answer. Although he is well aware that tribal origin to a large extent determines social status in Iraq, as he explains, he has never pursued his personal roots in this respect. To his parents, to him, and to most of his exilic Iraqi friends, the question of tribal affiliation is of no concern. "Growing up, it seemed to me that tribes existed, the uneducated and peasantry paid heed, and nobody else cared," Hamoudi summarizes (HM 38). This somewhat indifferent explanation highlights that the very question of tribal affiliation introduces a socio-demographic division because the educated elite obviously does not care about the issue. Hamoudi is aware that the Iraqis do not understand this carelessness. Still, he strongly adheres to a model of social identity that is shaped by money, not by tribal origin. This material conception of self is deeply ingrained in his upbringing as he reveals. His early childhood memories are linked to consumer experiences such as having a "Pepsi in a tall thin bottle" on his outings with one of his uncles (HM 61). The maintenance of this upper-class status in his present life enables him to purchase items that normal 
Iraqis cannot afford. This also leads to a somewhat idealistic trust in the financial orientation of others. Even when the economy in Iraq continues to decline and markets almost collapse, Hamoudi adheres to the belief that there are "people who will pay American money" for rebuilding Iraq (HM 63).

This fierce defense of materialism as opposed to the importance of nonmaterialistic identity features prevailing in Iraq causes a deep feeling of alienation on the part of Hamoudi. His worldview is so much dominated by the economic well-being of the U.S. that he can show little empathy for the material hardship he witnesses in Iraq. His depiction of the market situation in the country highlights this Western standpoint. When trying to buy a car, he gives a comprehensive account of the automobile market in Iraq in which both extremely cheap and luxurious models are available, as he explains. Especially the expensive models can only be afforded by a small group of upscale Iraqis. Although the cars lack amenities such as airconditioning, as the author ironically adds, they do display famous brand names such as Volkswagen on the outside, which is what matters most to the Iraqis. To Hamoudi, this is a sign of a more general class pattern found in Iraq; "an insufferable predisposition toward ostentation, at times verging on the vulgar," he infers (HM 97). To him, "such showiness" supposedly is of little importance, he clarifies, since security concerns matter most. In addition, the problem of choosing a suitable car does not even become relevant for him. As he learns, as a foreigner he is not allowed to own a car without a respective license anyway. "But in Iraq, a short explanation and a handsome bribe would cure the problem," he shares his solution to this problem (HM 97).

This inside view of the Iraqi car market based on his own experience allows the reader to gain a more detailed picture of the Iraqi economy which is hardly available from other sources. The derogative tone Hamoudi employs in this instance, however, also underlines his lasting economic socialization in the U.S. His exposure of bribery as the major way to bypass legal regulations in Iraq most likely derived from a truthful account of his experience. Still, it confirms Western images of disorder and dishonesty that have served Orientalists throughout the past as major arguments to explain the failure of Middle Eastern countries to thrive. Other scenes of bribery and intransparency underscore this inferior economic image Hamoudi designs. Ultimately, he uses the desperate state of the Iraqi economy to his own advantage and decides to "bribe [his] way through entirely" (HM 110).

Bribery and intransparency are not the only characteristics revealing his colonialist attitude when it comes to economic matters. When exploring a grocery store that supposedly "had everything," as he was told by Iraqis, he finds out that the selection would actually be "paltry" and "not impressive by Western standards" (HM 108). The same experience bothers him when trying to find a suitable gym. He goes to one of the most luxurious hotels in Baghdad that has a gym that supposedly has "everything." When he sees the inside of the place, though, he is disappointed 
again. Everything to him clearly looks different than expected. Yet, he also uses the experience to infer a larger finding about the state of the Iraqi economy. Whereas the outside facilities are lined by nice palm trees and luxurious accessories, the inside to him appears filthy and in need of caretaking. This leads him to the conclusion that the gym simply represents a "metaphor of Iraq" (HM 112).

All these depictions of the economic condition of Iraq open up an economic frame of interpretation for the reader which diverges from the common image of Iraq as the paradise for oil-importing countries. Yet, the way in which Hamoudi constructs this frame remains highly ambivalent. On the one hand, he draws an image of a country facing enormous economic hardship. On the other hand, this country is attempting to copy Western economic standards for those who can afford respective amenities and consequently denigrate everything else as inferior. Hamoudi, despite his constant claims to sympathize with the Iraqi people, is one of those who display this Western economic stance.

The chapter "Health Club" (HM 105) underlines this far-reaching economic and cultural fissure dividing Iraq. When Hamoudi discusses his wish to join a gym with his family, they regard this as an "odd form of leisure" (HM 105). The oddness, however, does not merely rest on the athletic activity itself but on the logic behind it. Hamoudi meets serious incomprehension. "I just want to make sure I understand what you are saying, Hauder," his uncle addresses him (HM 105). "You are going to eat nothing but meat, which costs money, and then spend more money to go running on a machine?" he asks (HM 105-06). Hamoudi tries to counter this interpretation by reminding his uncle that this is a "question of how you put it" (HM 106). For his uncle this interjection does not count. Rather, "it's a question of whether or not this is what rich people do when they have too much money. Spend money eating too much, and then spend money to lose weight that you gain from spending money. Can't you just eat less," he ironically asks (HM 106)? Hamoudi's other uncle Nawfal shares this critical stance by explaining that "paying to climb stairs that aren't even real on a silly machine makes no sense at all." Nawfal always thought "that in the West they did that to meet women (HM 106).

The Health Club episode marks one of the most obvious confrontations of the diverging views on money and materialism between America and Iraq in the memoir. This time, it is not Hamoudi who ridicules the Iraqis for their love of bribery, dishonesty, and economic inability. Instead, he finds himself in the position of defending himself for something as unimportant as a health club membership. Yet, as the questions and comments posed by his relatives strikingly underline, this scene is not about the health club itself but about the clash of economic cultures. In a society struck by war and economic suffering, existential needs such as food and safety represent the highest goods. The logic of spending money on too much food, which in return requires spending more money to fight the consequences, is simply inconceivable. Not only does it not make sense in logical terms to the Iraqis, it is 
also a sign of a fundamentally "Western" flaw of consumerism and saturation. Hamoudi realizes that the different perspectives are difficult to bridge when mentioning that his "American individualism and consumerism" can only be shared by one of his uncles who is a businessman and has experience in spending money "as he pleases." Among ordinary Iraqis, however, "money is a matter in which the community very much takes interest," Hamoudi knows (HM 106).

Although the author consequently is aware of the different cultural conceptions of money and class-status, he himself cannot resist following the American pattern of consumerism. It seems that only consumerism provides him with the necessary diversion he needs in order to be able to physically and mentally maintain his strength in Iraq. Increasingly, the economic frame through which he interprets his experience in Iraq dominates his perception. His frustration with the economic and political situation in Iraq thus worsens. When going to the airport, he notices a new Burger King restaurant and a duty free shop as ultimate symbol of Western capitalism (HM 141). After he realizes these exterior changes in the airport setting, he reflects on its interior transformation. "Other than this, nothing had changed, but I had changed," he reveals his proceeding movement from Iraq toward his American identity affiliation ( $H M$ 141). This transition is accompanied by a growing aspiration to be amongst fellow Americans. His favorite lunch destination becomes an exquisite Italian restaurant. What he treasures most about the place is not the food, though. As he explains, "I longed, even then, for the company of people who had been raised in the West" (HM 161). Western leisure activities like in superior restaurants and occasional visits to a hotel pool with fellow expatriates thus become his only pleasures in Iraq (HM 168).

The economic lens that finally comes to dominate Hamoudi's observations exposes the socio-demographic clash separating Iraq and America. Eventually, this dualism also irreversibly separates Hamoudi from other Iraqis. The author provides detailed economic insights into Iraq, yet these rational explanations cannot dissolve the strong opposites between American materialism and Iraq's more collective economic culture based on immaterial values. It is within this frame of interpretation where Hamoudi's American identity stands out most pervasively. In no other frame does the term West so often occur as in the context of the economic one. Contrary to other frames Hamoudi creates in his memoir, he does not even attempt to enforce a balance between both perspectives. He often ends up speaking from the Orientalist position of the Western economic hegemon. This in turn confirms the Iraqis' image of America as the colonizing power with political endeavors that have always been linked to economic ends (HM 120). Nevertheless, Hamoudi by allowing his Iraqi relatives to voice their criticism of American capitalism in direct speech reminds the reader of the often absurd characteristics materialism has gained in America. This economic obsession and the belief that everything can be purchased reflecs the image that Iraq holds of the U.S. as the Other. The statement of 
an Iraqi car dealer quoted by Hamoudi puts this mirror view and the Iraqi's attitude toward it in a nutshell: "I don't care what the Americans say, this country is not for sale" (HM 114).

The growing doubts about the Iraqi economy also force Hamoudi to question his ideal of bicultural identity. His economic orientation and superior class status have no place in Iraq. His affiliation with the Iraqi part of his identity gradually erodes. Another experience with his relatives fosters this growing retreat to his American identity. When his family members tell him they might have to leave their home behind due to security reasons, the first thing Hamoudi worries about is financial "compensation" from the government. "Still thinking like an American," his aunt simply responds in a frustrated manner (HM 214). She has given up the hope of countering the materialist impulse of someone who always worries about money first and saving one's life second. These immediate confrontations with this outside perspective on America serve as final indicators for Hamoudi that materialism is just one among too many cultural and social characteristics which separate him from Iraq. His somewhat nostalgic attachment to cultural customs in Iraq that he remembers from earlier visits does not change this. "My place was not here," he realizes when celebrating Eid in Baghdad with his family (HM 218). The place where he belongs is mostly defined in socio-cultural terms. He needs his American friends in order to feel comfortable as an American again. As opposed to the Iraqis, these friends conceive of him in ways that he can identify with. "They saw me as I chose to present myself to them, as an American (as they themselves were), certainly of differing ethnic origin and religion, but as a jetsetter, and a wellheeled child of the Ivy League, living in New York or Hong Kong with weekends in the Hamptons or Saigon" (HM 221).

This self-portrayal strikingly illustrates how much Hamoudi's identity and selfesteem are connected to his socio-economic status. What connects him most with his friends is his financial status which allows him to share a privileged life style. These characteristics might be stereotypical markers of American identity. Yet, as Hamoudi reveals, they are essential to his self-definition. With respect to his American friends, class status therefore bridges any ethnic or religious divide. In Iraq, however, it is exactly this class difference that ultimately distances himself from his ethnic heritage. In line wih this finding, the author's explanation of his decision to go back to America reads like a manifesto of the American work ethic:

Nobody would leave Iraq and the Islamic world to go to America to make a positive contribution to Iraq and the Islamic world. I'd given up. I did hope and expect that my future work would prove to be useful [...]. I just wanted to be happy and productive. I needed work that was important, not a tangential position on a project in which few showed interest. [...] I had to leave, I had to live. (HM 237-38) 
Hamoudi's notion of a happy life, as shown in this passage, is one in which meaning is mostly defined by productivity, success and material well-being. This highly individualist notion of happiness stands in sharp contrast to the more collective concerns dominating Middle Eastern culture. Here, visits to the opera, a round on the golf course, or outings to the museum are not considered "personal needs" mostly because these things are not even available. This not only holds true for Iraq itself but for many countries in the "Islamic world," as Hamoudi in a very universalizing manner reiterates. The American work ethic and its focus on productivity have no room in a country where happiness is defined in different terms. Hence, a life in Iraq, even for an American Iraqi, is not worth living.

This economic frame drawn by Hamoudi creates a novel interpretative pattern through which the American readership can gain insights about life in Iraq and about its own materialist culture. The identity conflict experienced by Hamoudi underlines the far-raching social and ethnic implications of economic issues. Class here functions as an identity trait capable of bridging and dividing ethnic identity affiliation. ${ }^{18}$ Similar to Kaldas whose economic analysis of Egypt underlined her American identity, Hamoudi also ends up on the American side of the hyphen. Both explicitly testify to the American Dream in a materialist and ideological way. Hamoudi, however, even more strongly reiterates the binary between East and West by actively provoking Orientalist stereotypes in his interpretation. It is this overbearing greatness and superiority of America as opposed to the inferiority of the rest of the world that Hamoudi alludes to in his epilogue.

From the time I was a child growing up in America, coaches and teachers, not to mention Hollywood movies, taught me that to give up, to surrender is a sign of weakness, and that with persistence and fortitude I could achieve anything I wanted. I fully adopted this outlook and found it, overall, a useful way to lead my life. But right now, I wish I had a touch of the Eastern fatalism. (HM 272)

18 This finding is in line with the theory of transnational class formation developed by Leslie Sklair in the field of sociology. The concept holds that a growing transnational capitalist class (TCC) has emerged that is made up of mobile professionals who function as agents in a network of transnational corporations (TNC). This group is assumed to be the engine of globalization (Sprague 500). Classical TCC members are diplomats, government ministers, aid officials, and representatives of international organizations such as the United Nations. They tend to publicly display their class status, which is why they are assumed to severely impact "images of the world and images for the world [...] a proliferation of interpretations of the world" (Friedman qtd. in Werbner 18). Hamoudi certainly displays many of the given characteristics. 
He utters these words while continuing his privileged life in New York. The experiences in Iraq merely constitute dark memories at this point. The temporal distance to his journey obviously also causes him to reflect on Iraq in much broader terms. He becomes partly aware of the enormous cultural arrogance of the U.S. teaching anybody that one can "achieve anything." War, desperation, and imperial powers enforcing their economic ideals on others do not appear in this picture. Hamoudi seems to appreciate this uniquely American ideal, which underlines his Americanness even further. Still, his words also reflect the finding that the American self-conception of heroism and greatness is an illusion after all as well as the cause of personal frustration. Living in a country like Iraq brings this sense of failure to light. "Eastern fatalism," a term which again evokes rather negative and violent images of the Middle East, might provide an alternative to the American concept. Hamoudi leaves his readers in doubt what he actually means by this. Nevertheless, he knows that it is lacking from his life since he has left the "Eastern" part of his self entirely behind. His focus now rests on living a "useful" life again at least in an American sense. This self-centered conclusion makes one doubt his claim to have achieved an "entirely bi-jural and bi-cultural" personality in Iraq (HM 272). At least the first part of this statement seems to be true, though. The professional experience in Iraq has obviously benefited his legal career. He now holds a well-acclaimed academic position. The memoir thus ends as it began: with the ambiguous assurance of Hamoudi's professional authority and a spark of hope that Iraq can be rescued (HM 272).

\section{Reframing the Iraqi Terrorist as Theory of Justice}

Reframing such a dominant and omnipresent image as the Iraqi terrorist does not constitute an easy task. The shift from euphoria to deep frustration that Hamoudi describes in his memoir points to the difficulty of this endeavor. Nevertheless, his closing lines are an appeal to keep up the endeavor. "Perhaps the readers of this memoir will indulge me in what might seem to them like belief in the fantastic mythologies of children, but like all Shi' a, when I think of all that has happened to Iraq, I cannot help uttering the words recited by us: quickly, quickly, Companion of the Times. Quickly. Quickly"19 (HM 273). This acknowledgement underlines the lasting urgency to act on behalf of Iraq. In addtition, the explicit addressing of his audience reaffirms his original intention to employ his memoir as an activist tool to reshape the public view of Iraq from the inside. The clear-cut table of contents in the memoir provided a roadmap for this task. The memoir in its entirety then reveals the detailed method of his authorial project. Although Hamoudi thus ultimate-

19 Hamoudi here quotes from a popular Shiite recitation that refers to the testimony of the companions to Prophet Muhammad known as Sahaba (Campo 162). 
ly fails to contribute to the recovery of Iraq as a lawyer, he does succeed in reframing the image of the Iraqi terrorist as the author of his memoir.

\section{Graph 7: Frame Model of Howling in Mesopotamia}

\section{Frame Levels:}

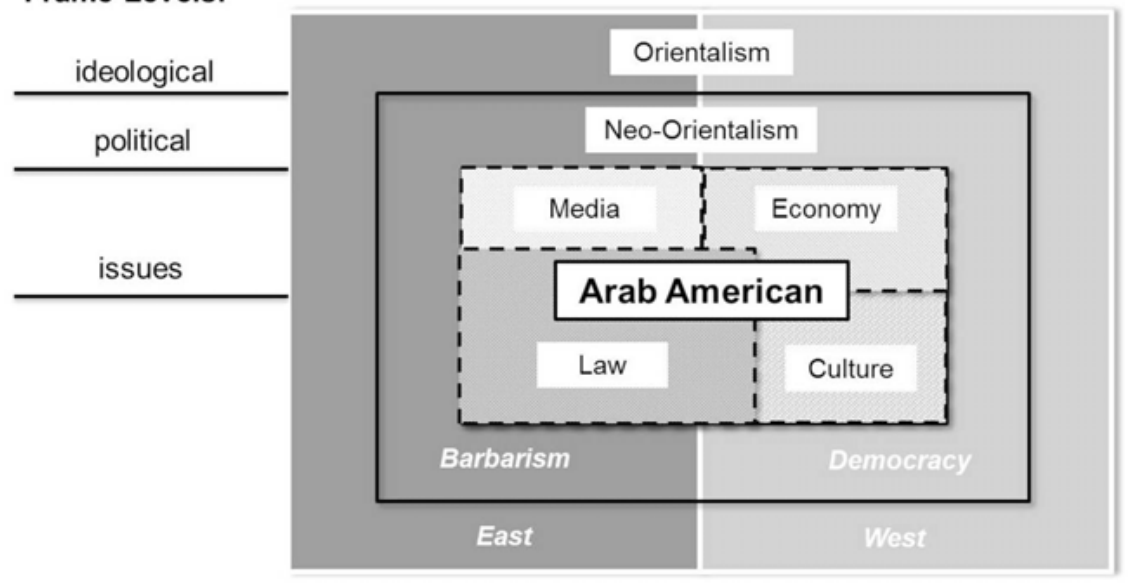

This graphical recapitulation again displays the four major issue frames found in the textual analysis of the memoir; namely, law, culture, media, and economy. Similar to the memoirs of Ansary and Kaldas, the most dominant issue frame shows a close relation to Hamoudi's occupation. His professional authority as a lawyer is built up at the beginning of the memoir and reiterated throughout. The issue frame of law as it further underlines Hamoudi's competence in the judicial field, is characterized by the conflict area between written law and normativity. This especially accounts for the overlapping of the law frame with the one of culture. Both issue frames are shaped by strong value judgements by the author. Hamoudi mostly concentrates on the moral misconduct of Americans to illustrate the cultural code existing in Iraq. This focus on America and the reversal of othering also differentiates Hamoudi's culture frame from the one found in Kaldas who mostly focuses on Egypt in her account. Whereas Kaldas develops her frames with a strong didactic focus, Hamoudi reframes based on a theory of justice. A remarkable emphasis on domestic U.S. practices is also found in the case of the media frame created in Howling in Mesopotamia. Hamoudi also demonstrates strong value judgements when exploring the Iraqi and the American media landscape. His most critical stance is found when he reveals the mechanisms of framing applied by the U.S. in support of the WOT. The economy frame as the fourth issue frame again forms around the topic of class divisions. This constitutes a parallel to Kaldas's narrative. When looking at this series of issue frames in comparison to the frames found in 
empirical framing studies on the Middle East media coverage, the peculiarity of Hamoudi's reframing efforts unfolds. None of the frames created in his memoir correspond to the ones ruling public media discourse. Hamoudi thus creates an entirely new interpretative pattern for the media audience to look at Iraq.

This autonomy on the level of issue frames is not confirmed in the case of the higher-level political and ideological frames. Especially in the context of the economic issue frame, the binary opposition between East and West dominates the account and Hamoudi's identity definition. This points to the reproduction of the neo-Orientalist and Orientalist framework as it circulates in the public media discourse. In contrast to the instrumentalization of Orientalism in the memoirs of Ansary and Kaldas, Hamoudi's position to Orientalism as imperialist practice is more ambivalent. At times, Hamoudi consciously employs Orientalist binaries as a conceptual tool to stress the differences between Iraq and the U.S. to thus convey insider knowledge. At other times, he does not distance his own position from an Orientalist stance and strongly embraces stereotypical notions of Western superiority without balancing them. This underlines his strong identity attachment to the U.S. concerning many of the issues he raises. Whereas this attitude is problematic from a post-colonial standpoint, it might endow him with additional agency on the part of the American reader whom he clearly addresses in the end. Overall, Hamoudi presents the least emotional and most scientific approach to his memoir. Both aspects are particularly interesting starting points for the investigation of resulting audience frames.

\subsection{RECEPTION: The (RE-)FRAMEd IRAQI TERRORIST AND HIS AUdiEnCE $\left(\mathrm{V}_{4}\right)$}

On December 6, 2011, Haider Ala Hamoudi posted an entry under the title "A Shii's Lament" on his blog. It was the day of the Ashura, the holy day of the Shii which brought so much blood and frustration to Iraq in 2004. In his memoir, Hamoudi creates a vivid picture of these events from the perspective of the Iraqi insider. Seven years later and back in the U.S., Hamoudi again decides to reveal his thoughts and feelings in the form of writing. In contrast to the other posts on the law blog, this entry represents a testimony to the American public and to the Arab collective. "I wish to give license to my heart and not my head, for just this day, just this once, so you know how we, the others in the Arab midst, feel," Hamoudi introduces the final lines of his blog entry. "Here's what I think today, or feel rather, straight from the heart": 
Tyranny or democracy, it's always the same in the Arab world. You won't accept us, you won't even make an effort to see the world through our eyes. You demand loyalty and offer no tolerance. You ask for support, and abandon us or are silent when our children our [sic] killed. When you come to accept the others, and all the others, [...] when some modicum of mutual respect, honor and tolerance reaches or even just perceptibly registers somehow in civil discourse, penetrates even one tenth of a millimeter, give us all a call, we'd love to join in. Until then, go fuck yourselves. ("Shii's Lament”)

This blog entry displays a much more emotional tone than the entire memoir. Still, the parallel in terms of authorial intent is obvious. Making others, especially the American audience, "see the world through our eyes," is what Hamoudi explicitly seeks to achieve with his inside perspective from Iraq. With Howling in Mesopotamia, the lawyer who rarely reveals his innermost feelings as forcefully as cited above chose the literary format of the memoir to achieve his discursive aim. His method largely rests on his profession as a lawyer, which also leads to a less literary and more scientific style, structure, and language. The memoir therefore in many respects differs from common conceptions of autobiography as the personal sharing of one's life story. Hamoudi establishes himself as a strong agent who focuses on facts, not on feelings. This helps him to constitute a series of issue frames that do not reflect the common cognitive framing pattern found in the media landscape. Since framing relies on both the affective and the cognitive component, the reception analysis promises to reveal particularly insightful results.

\section{Howling in Mesopotamia in the Marketplace}

When clicking on the "Selected Publications" button on Hamoudi's site at the Law School of the University of Pittsburgh, Howling in Mesopotamia stands at the top of the list. This is not because it is the most recent text by the author. Rather, the memoir remains the only book-length publication by Hamoudi so far. In addition, it is the only text that is unrelated to any kind of legal or journalistic contribution (Home page). The memoir was published by Beaufort Books in April 2008. This was almost four years after Hamoudi's return from Iraq. In line with his prophecy at the end of the memoir, the situation in Iraq indeed has not improved much since then. The year of publication, as many years before and after that, was characterized by rising civilian death tolls and the continuation of the WOT (Exoo 151). In addition, the Americans witnessed another type of war at the political homefront with the hot battle for the presidential office. The fight against terrorism - at home and abroad - again was one of the major issues in the presidential campaign. 


\section{Image 10: Book Cover of Howling in Mesopotamia}

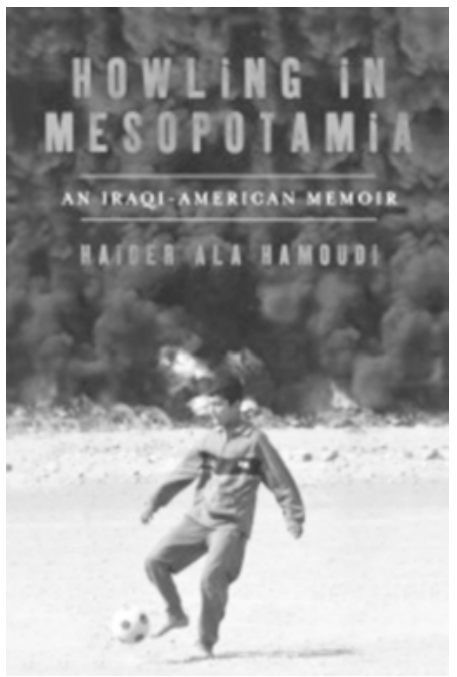

Source: Front cover of the memoir ("HM, Front

Cover").

Howling in Mesopotamia's appearance in the marketplace reflects the political circumstances and the dominance of the WOT frame surrounding Iraq. The cover shows an Iraqi boy dressed in an old jogging suit. Barefooted and alone, he plays with a soccer ball in a rocky desert landscape. Behind him in the background of the cover image, only a few yards away from the boy, black smoke covers almost two thirds of the picture. The smoke comes from glowing red and yellow flames suggesting the detonation of bombs. The title of the book is printed in red capital letters. The same red is used for the flames and the name of the author. Only the subtitle "An Iraqi-American Memoir" is printed in smaller white letters. The font reminds one of a newspaper article. This impresson also summarizes the entire look of the front cover which parallels the one of a political magazine or nonfiction book. The visual appearance therefore stands in contrast to the emotional and somewhat nostalgic title of the memoir. The term "Mesopotamia" 20 points to the setting of the memoir, whereby many readers might not immediately be able to establish this connection.

The orange-colored back cover does not contain a picture. There are no excerpts from the text or any biographical information. Instead, two reviews are printed in yellow font, both written by distinguished scholars as the names and respective titles reveal. The first one is by Kanan Makiya, a professor of Islamic and Middle Eastern Studies. He also is an Iraqi immigrant who has published several books on Iraq such as Republic of Fear. "Honest, delightful and touching" are the words Makiya uses to describe the memoir. In addition, he phrases the wish "that America and Iraq had encountered one another through many thousands of people like Haider Ala Hamoudi." Makiya obviously sees a balance between truthful facttelling and emotional elements. Most importantly, the memoir is depicted as a medium to facilitate the mutual encounter between America and Iraq. The focus on reciprocity suggests that the reviewer does not identify Americans as the only target audience of the book but also Iraqis and possibly diaspora members of both coun-

20 The area around Baghdad along with other ancient cities, such as Babylon, was formerly known as Mesopotamia (Campo 83-84). 
tries. Makiya also stresses the important role of Hamoudi as author and translator between the two worlds.

This aspect of cultural negotiation based on insider knowledge and truthful personal storytelling is emphasized even more by Cherif Bassiouni in the second review provided on the back of the memoir. Bassiouni is described as Distinguished Profesor of Law and President of the International Human Rights Law institute at DePaul University, the very institution that employed Hamoudi after his business idea in Iraq had failed. Bassiouni divides his short reflection into two parts dealing with the memoir itself and the author's background. "However narrow a witness's view of history may be, it is often more telling than volumes of facts and analysis by distant observers," Bassiouni writes before describing the historical moment in which Hamoudi went to Iraq. This contrasting of a supposedly "narrow" subjective account versus the recitation of facts at first seems to suggest an inherent difference between the two modes of writing. As it turns out, however, Bassiouni, underlined by his own scholarly agency, values the learning effect of personal storytelling even more. He explains this especially with the perspective shifts accounting for the revealing effect of the personal in opposition to the factual. Bassiouni in the remainder of the statement centers on Hamoudi's outstanding professional position and legal work which also granted him access to the political and religious Iraqi elite. This point strikingly reflects the focus on personal and socio-economic status the author himself continuously reiterates. Bassiouni in addition labels the memoir a "useful reader" which provides important insights into the present state of Iraq and its possible future.

Especially these final remarks reaffirm the peculiar status of the memoir which both reviews point to. Above all, they value the historical and political knowledge conveyed by Hamoudi. The comparison to a "reader" underlines this textbook-like function. With respect to the theory of ethnic life-writing, it is particularly noteworthy that none of these two reviews mention the aspect of bicultural identity struggle as major concern of the memoir. Consequently, the selection of reviews therefore does not reflect a marketing attempt to especially attract an ethnic-minority readership. The focus on historical, political, and cultural fact-telling clearly stands in the foreground. In sum, the appearance of the book is more journalistic than literary, more objective than personal. This general impression is strikingly underlined by the small subject description provided by the press on the backside of the cover which lists the title under "Current Events."

The left-hand side of the inner cover contains a quotation from the opening line of Hamoudi's memoir describing him as son of Iraq and the U.S. The citation is followed by a comment depicting the book as "groundbreaking memoir of hope and hardship." These emotional terms are further underlined by the mentioning of several key events appearing in the memoir. All of them are to varying degrees related to the WOT. The remaining lines, however, divert the attention away from this 
frame by inviting the reader to "experience a new side of the country that has featured so prominently in our nightly news." This explicit reference to the news stresses the role of the memoir as medium in the larger public discourse. The "new side" of Iraq confirms the reframing efforts of Hamoudi. As the comment further points out, this capacity is based on his bicultural identity. The memoir thus provides an answer to the question that seems to be most pressing for the marketing of the book - the open question of "What went wrong in Iraq?" that concludes the description. This directly points to the WOT frame surrounding the image of Iraq in the public. Above all, the country, according to this dominant interpretation, is a problem. Based on these lines, the reader is made to believe that Hamoudi provides answers to solving this problem. This impression is furthermore underscored on the other side of the book's inlet. It provides the biographical information on Hamoudi featururing his career as a lawyer and his journalistic contributions. The text is accompanied by a large photograph of the author in suit and tie. ${ }^{21}$ The image corresponds to the professional authority Hamoudi sets up in his story.

Some of the comments provided in the book inlet overlap with the editorial review provided by Beaufort Books online. Here, the focus rests more on the cultural knowledge Hamoudi provides. After again stressing the fact that his trip to Iraq made him leave "his comfortable life in the United States" in order to rebuild the legal structure of Iraq, the review centers on the cultural divide in his insider account (Rev. of Howling, Beaufort). As an example, the reviewer contrasts the warmth of Iraqi culture and hospitality with the bloodshed taking place in the streets of Baghdad. In highlighting the security concerns accompanying Hamoudi's stay in Iraq, the reviewer raises fear while at the same time celebrating Hamoudi as a heroic figure. The most outstanding characteristic of the life account is seen in the "intimacy" Hamoudi provides in his encounters with members of all ranks of society. Overall, so the editorial review closes, "Hamoudi's first-hand experiences [...] give the reader an inside view of life in Iraq that we don't see on CNN" (Beaufort).

The journalistic marketing of the book and the heavy emphasis on the professional and ethnic authority of the author position the book apart from other ethnic memoirs found in the entertainment section of the book store. In fact, Beaufort Press after originally listing the book under "Current Events" meanwhile categorizes Howling as "non-fiction" (Lucie). As was the case with West of Kabul and to a somewhat lesser extent also with Letters from Cairo, this non-fiction genre classification has important implications for the reception process. The readers approach the text in a different way than they would in the case of fictional or semi-fictional accounts. The most striking confirmation of Hamoudi's discursive impact beyond

21 As to the aspects of materialism and socio-economic status which Hamoudi clearly values, it is a curious detail to note that the inlet even displays the designer brand of the jacket Hamoudi is wearing in the picture. 
the literary realm is given by the reviewer's explicit reference to the media. The CNN coverage here is used as an umbrella concept to point to the dominant media frames that the memoir competes with. The media frames reproduced in the memoir resonate in this review. Hypothetically, one could assume that this issue frame is of particular relevance for the journalistic audience of Hamoudi.

\section{The Journalistic Readership}

In juxtaposition to the outstanding media presence of Tamim Ansary as opposed to the public invisibility of Pauline Kaldas, Haider Ala Hamoudi occupies the middle ground. In February 2008, about a month before the publication of the book, the Pittsburgh Post-Gazette published a longer article on the author under the title "The Catch 22 of Iraq: Pitt Law Professor's Book Recalls Trying Experiences in 'Mesopotamia" (Rouvalis). The article represents a symbiosis of a review and a portrait of the author, whereby the focus rests on Hamoudi's Iraqi love story with his future wife Sarah. In addition to this emotional angle, the article mostly centers on the contrast between Hamoudi's privileged life in America and the hardhip he endured in Iraq. In this context, the article also points out that the most visible cultural differences in the memoir are the American optimism and self-determination Hamoudi represents versus the fatalism and distrust spread by official American news and government sources (Rouvalis). Hamoudi, however, does not blame the American forces for their behavior, as the reviewer clarifies, because Hamoudi knows that demoralization causes the misconduct. In sum, the review draws an overly positive picture of the book which avoids many critical issues concerning U.S. foreign policy issues. Still, the impact of the media frame surrounding the American notion of Iraq is pointed to, although any form of intentional manipulation on the part of the U.S. is ruled out. This rosy picture also shimmers through the concluding sentence of the review which deals with Hamoudi's recent marriage to his Iraqi wife. "The couple has not experienced much anti-Iraqi sentiment - except an occasional anonymous rant sent to his blog," the author Rouvalis acknowledges.

The positive image drawn in this article not only serves as a marketing tool for Hamoudi's book, it also fosters the author's popularity on a larger scale. Hamoudi's blog, for example, which the article also alludes to, offers new posts almost on a daily basis. Hamoudi's authorial voice is thus permanently available for those who want to access it. In addition, he meanwhile counts as a welcome expert in public media outlets. In 2011, he commented on the possible release of post-mortem pictures of Osamah Bin Laden on $C B S$. He outspokenly opposed the publication of the pictures. The explanation for this decision was somewhat characteristic of the judicial and normative stance he displays in his memoir. "To show that we in the United States operate on a much higher plane," Hamoudi introduced his argument, "I 
like that idea of a global demonstration," he said (Jackson). This "global demonstration" eventually sought to show the moral and ethical superiority of the U.S. Despite this exemplary political issue, Hamoudi's expert status on questions of media ethics and law underline his personal concern for the workings and effects of media production displayed in the media frame of his book. His repeated media appearances contribute to his public status outside the field of law.

In how far the sales figures of Hamoudi's book have benefited from his media popularity remains speculation. At the time of writing, a total of 500 books have been sold. This figure is about twice as large as the number of books sold by Kaldas. Still, it only represents about one fifth of the total print run (Lucie). In light of these rather low sales figure, the journalistic responses to the memoir were quite numerous. Given the fact that Hamoudi does not count as a noteworthy author outside the realm of special interest law journals, this might indeed be a result of his general media visibility. In addition, the lasting impact of the WOT frame still dominates the American and global book market. Journalists are thus eager to provide their readers with new insights from troublesome Iraq.

A review by Publishers Weekly ${ }^{22}$ can be suspected to have had an effect on the outcome of the book's market position. It was published in August 2008 in the section "Nonfiction review." Similar to the way in which Hamoudi himself introduces his persona at the beginning of the memoir, the review first centers on the brevity and professional authority embodied by the author. Shortly after the fall of Saddam Hussein, Hamoudi "decided to leave his cushy home behind to aid in reconstructing Iraq, his parents' homeland," the reviewer explains. His journey to Iraq is furthermore depicted as a heroic "mission" of reconstruction and development. Hamoudi is described as participating in the installation of "a brave new legal world in Iraq“ (Rev. of HM, Publishers Weekly). The review also stresses Hamoudi's conversation with the American soldiers at the beginning of the book in which he admits his limited knowledge about the everyday-life of Iraqis and their picture of America prior to his trip. The memoir is presented to convey his explorations as a series of "punchy episodes, in which his ignorance and naivete are stripped away by small revelations and details [...]" (Rev. of HM, Publishers Weekly). After recalling some specific instances of these vignettes, the reviewer focuses on the balancing of hope and despair found in Hamoudi's autobiography. The review ultimately praises

22 Analyses on the causal relationship between reviews and sales figures show that reviews in well-known newspapers and magazines, such as the New York Times or Publishers Weekly, do have a considerable effect on the distribution of books (Greco, Rodríguez, and Wharton 49). For decades, Publishers Weekly was the leading review medium with an average of 8,300 reviews published in 2004 . Since then, the numbers are steadily declining whereas online reviews are increasing (Greco, Rodríguez, and Wharton 50). 
Hamoudi's story as an "illuminating guide" to get to know different facts of daily life in Iraq (Rev. of HM, Publishers Weekly).

Despite the very positive and optimistic tone drawn by the Publishers Weekly author to attract rather than scare the readership, several frames are reflected in this journalistic reception which overlap with the ones found in Hamoudi's text. Its strong emphasis on Hamoudi's authorial and professional agency is one example of this. The high degree of credibility deriving from this is linked to the importance the reviewer grants to the topic of legal development in Iraq. He eventually looks at the narrative through the legal frame. Another indication of frame resonance occurs with respect to the overall categorization of the book as "guide" to Iraq rather than a personal account. Similar to the textbook comparison found on the book cover, the reviewer appreciates the memoir as source of knowledge on daily affairs in Iraq which covers both perspectives - the American and the Iraqi one.

The didactic effect of Hamoudi's memoir is also highlighted in another journalistic review by the Midwest Book Review. The journalist here especially endorses Hamoudi's capacity to present "a different look at the Iraq conflict [...]" ("War in Iraq"). This conception clearly reflects the impact of the WOT frame found in the book. The reviewer does not limit the overall contribution of Hamoudi's work merely to the political realm. Rather, he praises Howling as a recommended complementation to the "current events shelves" of libraries. This classification again denotes the non-fiction status of the memoir, whereby the direct reference to current events specifically points to its role in the media discourse on Iraq. This journalistic review overall confirms the success of Hamoudi's authorial intention to draw a different picture of Iraq based on detailed insider knowledge. In the larger context of life writing theory, this also testifies to the importance of authorial intent and strategic framing as keys to life writing and reading.

The frame resonance found in these journalistic reviews hints at the effectiveness of Hamoudi's efforts to reframe the image of the Arab in the public. The size of the journalistic audience discussing the book remains limited, however. No further reviews have appeared in national newspapers or other bigger media outlets. The scholarly audience has not dealt with Hamoudi's memoir at all. Since the same held true for Ansary and Kaldas, this shortage of scholarly work on contemporary Arab American literature outside the field of fiction remains prevalent. Yet, this does not prevent the popular culture readership from participating in a lively discourse on the memoir. As it turns out, general readers are eager to share how the frames established by Hamoudi changed their perceptions of Iraq and its people. 


\section{The Consumer Audience}

Hamoudi's memoir steered a fairly high number of reactions on the part of the general audience. On Amazon, eight long and detailed customer reviews on the book appeared. The memoir receives an overall ranking of five stars on Amazon, an evaluation which suggests a very positive feedback. All reviews were posted in the year 2008, shortly after the book was released. This is an indicator that the immediate publicity around the memoir motivated respective consumer purchases. Since the readers' reflections on the book followed in immediate succession, they in a way speak to each other. The analysis of these voices reveals that Hamoudi's memoir indeed represents an outstanding example of how reframing through life writing can interfere with the public discourse.

One of the most striking parallels between all reviews on Howling is the audience's high appreciation of the author's narrative authority. The readers are well aware that Hamoudi did not just travel to Iraq as a private person exploring his roots. Rather, the comments strongly underline his professional agency as a "bilingual lawyer from a prominent Shi' a family," thus conceiving of him as a "privileged and highly educated man, idealistic and religious but also secular" (Littrell). This differentiates him from the vast majority of ethnic memoir writers, journalistic authors, and American professionals who seek adventures in the war zone to turn them into literary bestsellers. As one reviewer therefore notes, "Hamoudi is not just some ex-pat returning to his homeland [...] to reap the spoils of war" (Littrell). This perception again reflects the authority and multi-ethnic agency Hamoudi establishes from the outset of his story. His professional and intellectual status especially contributes to the way in which his memoir is read. The academic style the author employs in this context is almost ironically highlighted by the previous reviewer. In his discussion of the book, he repeatedly uses the academic title "Professor Hamoudi" when referring to the author (Littrell). In addition, "Hamoudi reveals himself (as one must in telling such a long and personal story) to be sincere, hardworking, intelligent, diplomatic," the reader acknowledges (Littrell).

All these references to Hamoudi's professional prestige underline how much credibility Hamoudi enjoys in the eyes of the audience. As a likely effect of his selfpositioning, they are thus willing to enter the autobiographical pact without doubting the author's authenticity. The previous review furthermore points to yet another aspect of this authority. The remark that it is an inherent obligation to display characteristics such as sincerity and intelligence when engaging in an autobiographical task like Hamoudi's signals how well-reflected the audience approaches the memoir. Different from the reading of a novel or of memoir as merely personal storytelling in the grey zone between fact and fiction, readers have clear expectations toward the honesty and sincerity represented by the author. This view is shared by 
other reviewers who describe the memoir as an "honest" (upe) ${ }^{23}$ and "real" (Littrell) account of life in Iraq.

The importance of honesty and authenticity is closely related to the format and style of the book, as the reception analysis also brings to light. Readers note that Hamoudi does not engage in mere prose writing but presents his experience in the form of "vignettes" (Adams), "observances," and "anecdotes" (McBride), as well as by allowing other Iraqis to voice their opinion (Carey). The reviewer upe from New York especially emphasizes that "this memoir is written without unnecessary drama, hyperbole, or an agenda - just keen, plain observation [...] (upe). Other readers acknowledge that this fact-based approach to memoir writing does not at all override a "whirlwind of emotions" (Carey). This emotional aspect is especially mentioned with respect to the romantic relationship which develops between Hamoudi and his future wife in Iraq (Littrell). ${ }^{24}$ The unusually intimate insights the author reveals in this context in the latter part of the memoir seem to balance the objective narrative style employed in other sections.

Overall, the "just-the-facts-style" dominating the memoir strongly resonates in the comments of the readers. It seems to underline the "power of Hamoudi's words," as one reader points out on the discussion platform curledup (Adams). This non-fiction perception of Hamoudi's autobiography is also summarized by the reviewer Carey: "The writing in this book is impeccable," he states before adding that it "almost seems too surreal to be true. Some parts read like a work of fiction. But make no mistake: this is a work of non-fiction through and through, even though the author probably wishes it was a fictional novel rather than the cold, hard truth" (Carey). This contrasting of truth versus fiction and the determined urge to categorize the memoir as non-fiction emphasizes how reflected the audience deals with the question of genre. Contrary to the practical elimination of Lejeune's authorial pact from contemporary autobiography theory, the readers make a clear differentiation between different literary genres. This ultimately guides their expectations and their reception experience.

Hamoudi's "disarming honesty" (Littrell) as a substantial requirement for framing successfully sets the stage for changing the conceptual framework around the stereotype of the Iraqi terrorist. One of the most dominant frames to achieve this

23 The user names of many online reviewers rarely correspond to real first or last names. They are thus often spelled in lower-case letters. The given citation in the case of the user "upe" and some reviewers that follow gives credit to this new media convention.

24 The reviewer presents long quotes from the memoir that particularly deal with the romantic relationship of Hamoudi and his future wife (Littrell). This detailed reference to the text is exemplary of several other customer reviews. Many of them are of considerable length, well-structured, and hardly contain any colloquial language. This indicates how well-reflected the literary audience outside the academy contributes to literary discourse. 
effect is the one of law, as the reviews further reveal (Community Reviews of $H M$ ). The readers identify Hamoudi's task to "educate the people of Iraq on the rule of law and help the nation transform itself to a democratic and just society" as the most important frame structuring the experience of the author (Carey). As is the case with the professional change Hamoudi undergoes in the text following the failure of his business, the readers acknowledge that his focus does not merely rest on the "practical and personal nature of his concerns" (Littrell) but on the larger goal of "rebuilding" (Carey). The reviewers contrast this engagement in reconstruction to any "personal gain" (Littrell). ${ }^{25}$ In addition, Hamoudi's legal conception of country development is put in sharp contrast to the military operation undertaken by the U.S. The judicial recovery of the country is thus perceived to underscore the ethical and normative concerns which gradually gain prominence in the course of the account. Hamoudi is described to depict these issues in a "genuinely human way [...]" (Littrell). These detailed elaborations on the importance of legal aspects confirm the resonance of the law frame in the audience.

Hamoudi's legal authority and his focus on humanitarian rights are closely connected to the cultural issue frame in the text. This also corresponds to the way in which the audience reads the memoir. The reviewers frequently point to Hamoudi's bicultural and Muslim identity which allows him to present a "heartfelt perspective of Iraq from the ground" (upe; Littrell). While on the one hand presenting unique insider knowledge from the other world of Iraq, Hamoudi on the other hand is seen as a "stranger in both worlds" (Adams). This special insider/outsider status, as the readers attest, allows for the necessary analytical distance to reflect on the Iraqi and the American perspective in an equally intriguing way (knotheadusc). His goal to shed light on average Iraqis who normally do not appear on television is especially appreciated by a reviewer who plays on the Hamoudi's own term of the "ordinary Iraqi" by stating that the book depicts the "ordinary person living in Iraq" (Fishel).

One of the most important insights connected to this portrayal of daily life is the economic situation in Iraq. The readers refer to the economic hardships Hamoudi

25 The reviewer in this context explicitly mentions Ahmed Chalabi as counter-example. Chalabi is described "as just another of those privileged exiled Iraqis [...] [who] promoted the invasion of Iraqi [sic] for personal gain" (Littrell). The Iraqi politician and famous opposition figure was once favored by the U.S. as possible successor of Sadam Hussein. He mostly fell out of favor because of financial misdemeanors and accusations according to which he used the Iraqi National Congress opposition movement to further his own ambitions. Chalabi now counts as a highly controversial figure ("Profile: Ahmed Chalabi"). The explicit reference to Chalabi by the reviewer sheds further light on the wellinformed background of many readers. In addition, the use of Chalabi as counter-example highlights that Hamoudi in the course of the narrative is able to overcome his own materialistic concerns in the eyes of the readers. 
reflects on but also to the U.S. culture of materialism the author draws attention to. The way in which Hamoudi describes his own struggle with "air conditioning failures" and the "lack of recreation" leaves a particularly vivid impression on the readership (Littrell). The reviewers do not interpret these difficulties as unavoidable for a spoiled upper-class lawyer who is not fit for ordinary Iraqi life. Rather, they see it as an indicator of the real life struggle endured by the Iraqis who have to cope with the poor state of the economy (Carey). In turn, this makes the American readers reflect on their own position. As one reviewer states: "Not long after getting into the book, one quickly appreciates what they have and takes for granted" (Jonathan). Although Hamoudi clearly remains rooted in the U.S. culture of materialism, his insider elaborations help the readers to shift their perspectives.

This direct transfer of Hamoudi's experiences to the situation of the U.S. points to a larger conceptual finding related to the culture frame. Obviously, the reviewers of Hamoudi's book do not belong to a multi-ethnic audience seeking shared cultural experiences and common identification as major motivations for their purchase of the book. Ethnicity only plays a role in their comments to the extent that Hamoudi's dual ethnicity allows for perspective shifts related to the specific issues he explores. This indeed allows the readers to self-identify with the author's observation, independent of ethnic background. Not only do the reviewers point out that they are able to learn about their own culture based on Hamoudi's memoir, they also closely examine how he achieves this effect. As the reviewer Fishel states: "The author uses superb analogies of American culture to explain Iraqi culture" (Fishel). Another reader adds that this technique allows Hamoudi to reveal "a number of unexpected cultural differences between Iraqis and Americans" (McBride).

Both comments underline the didactic result of the comparative method the author employs. Eventually, this focus on binary opposites facilitates the cultural learning process of the audience. In the first place, it allows the American readers to look at themselves through the eyes of the Iraqi. Furthermore, it makes the audience realize that its own lack of knowledge about Iraq is similarly reflected on the part of Iraqis. This fosters the empathy American readers build up for the position of the Other. Instead of conceiving of Iraqis as hostile to anything American, the readers learn that possible reservations are a result of the lack of knowledge about the U.S. The reviewer Brian Carey describes this positive impact on mutual understanding by explaining that conflicts mostly appear "with Iraqis who don't quite understand the American way of life and cannot understand why Americans speak and act the way they do." As the use of the pronoun "they" instead of 'we' demonstrates, it is not an inferior Orientalist stance the readers infer from the lack of cross-cultural knowledge in Iraq but the insight that this lack of knowledge exists on both sides.

The constant binary contrasting used by Hamoudi helps overcome seemingly insurmountable differences. Especially the law frame and related thoughts on human rights play a crucial role in this respect. The readers appreciate the way in 
which Hamoudi makes them see Iraqis as "people who are trying to make their way in life, just like everyone else" (knotheadusc). The Iraqi therefore not only loses the label 'terrorist' but is presented as human being sharing similar needs and concerns as the American. This insight also provokes the readers to think about the origin of stereotypes in public discourse. "Just like many Americans judge an entire group of people by their experiences with just a few," one reviewer states, "I could see that the Iraqis were also prone to making such judgements." Negative evaluations of the Other and possible conflicts ermerging from it are thus presented as a human tendency rather than the intentional project of backward barbarians (knotheadusc). This also explains the reviewer's ultimate tolerance for stereotyping. As he adds to his former statement, "I can't say that I'd fault them for that."

The idea of universal humanity based on global human and legal rights is even more forcefully underlined by another reviewer who puts the memoir's capacity to reframe in the context of the American credo of the freedom of opportunity:

'Howling in Mesopotamia: An Iraqi-American Memoir' will remind you that Iraqis are individuals just like everyone else in this world and even though the US government and media will many times make it sound like they are lesser people because of the harsh world that they live in, this book is a stark reminder that given the right opportunities they are no different than anyone else. (McKinnon)

This passage strikingly underscores the effect of the binary and often conflictual method of contrasting found in Hamoudi's narrative. It deconstructs otherness by pointing to the ways in which seeming differences are commonly reinforced and instrumentalized. This passage also identifies the agents who usually fill existing knowledge gaps about other countries and peoples with one-sided information. McKinnon mentions the government and the media as dominant actors shaping stereotypes of Iraq. This notion is in line with the position taken by Hamoudi. Its resonance in the review signals the importance of the media issue frame.

The political relevance of instrumentalist framing alluded to in the given review also reveals further findings in the context of the WOT. With no exception, the reviewers implicitly or explicitly acknowledge that their perception of Iraq before reading the memoir was dominated by the WOT frame as it is created and reinforced by the media. Titles such as "Rebuilding a War-Torn Nation" and detailed reflections on the desperate security state in Iraq demonstrate the omnipresence of the WOT frame in the audience reactions (Carey). Hamoudi's double perspective on the military culture, his legal authority, and his critical treatment of American gun culture, however, force the reader to think beyond this pattern (knotheadusc). The reviewers consequently display a critical treatment of the military presence in Iraq. In addition, they question the official media narrative of military control in 
Iraq by adopting Hamoudi's conclusion of Iraq as failure of U.S. foreign policy. The reviewer Carey in his detailed elaboration also emphasizes this trajectory:

[F]requent mention is made of the seemingly indifferent attitude of the Americans in Iraq and how they have done little to nothing to help transition the nation from dictatorship to democracy. In the minds of the Iraqi people, the American forces either do not care or do not know what to do. With people dying from gunfire on a daily basis, Iraqis don't feel much safer than they did under Saddam and they long for the day when the U.S. forces are gone and they can reclaim their land.

This passage signals the sudden erosion of the belief in Iraq as victorious military endeavor - an image that builds the center of the WOT frame in the media. This image is successfully turned upside down by the authority of an author who claims to have detailed political insights into both countries, America and Iraq. This effect therefore does not only rest on Hamoudi's national or ethnic background but on his ability to unveil the methods underlying media-created myths. This knowledge, which is independent of national, political, or ethnic self-identification, is what creates a powerful persuasive effect. Another reviewer thus points out that it does not matter for the reception of the book whether one is "for" or "against the initial invasion of Iraq." The book is a "must read" for anyone interested in Iraq, as he suggests (Fishel). How much he appreciates the contribution of Hamoudi for the political discourse on the WOT, the reviewer underlines with a powerful parallel to the Vietnam War. "When reading the book, keep in mind Robert McNamara's rationale for why we lost in Vietnam, in that we did not understand the history and culture of that Southeast Asian nation. History does repeat itself, but never in the same way," he concludes (Fishel).

The evocation of the trauma in Vietnam underlines the reframing effect of the memoir. Due to the provided cognitive framework, the readers are able to infer the knowledge they gained from the book to look at Iraq and the Iraqi people in different and less stereotypical contexts. Even more far-reaching historical and political inferences are thus facilitated. Some reviewers even explicitly describe this reframing effect in the context of the general media discourse. Carey states that Hamoudi provides "different images" of Iraq that are not directly related to the WOT. Another reviewer establishes the impact of the book on the public media discourse even more insistently: "I can only imagine what the world and US policy towards Iraq would be like if the public read this book, rather than relied on the common reporting, where everything is politicized as pro-war, anti-war, red vs. blue - and really understood the complexities on the ground, the practical realities, and history and dreams of the Iraqi people" (upe).

This reaction directly situates the memoir within the dominant media discourse and grants it a substantial influence on the WOT frame. Hamoudi's technique to 
unveil the framing processes of the media, however, reaches even further into the logic of public discourse theory. Based on the knowledge the readers gain on mediated stereotypes, many of them start questioning the larger trajectories of knowledge creation and distribution. As the reviews demonstrate, many readers are not uninformed about the situation in Iraq. "I feel like I've read 100s of news article [sic] and watched hours of news broadcasts on the war on Iraq, and after reading this memoir was amazed by what I didn't understand. I hadn't the faintest clue what life in Iraq, is, was, and could be," the reviewer recalls the knowledge gain derived from Hamoudi's memoir (upe). Another reader shares a similar experience: "While we can understand on the surface what's going on in Iraq by reading news accounts, we can't really get the sense, the feel, of what's going on deep inside the country. Reading this book will give you the inside view" (Hutcheson). Others point out that the book left them with "a new understanding and appreciation of the Iraqi people" (Littrell). The reviewer Carey concludes: "This book explains the current situation well, and it ranks as one of the best books I have read on this subject."

What combines all these testimonies on reframed images of the Iraqi is their focus on the aspect of learning in a very comprehensive sense. One of the review titles highlights this focus on cognitive knowledge gain in plain language: "A great way to understand what's really going on" (Hutcheson). Others point to the complexity of the situation in Iraq which Hamoudi is able to communicate in an intelligent and easy to read way (McBride). This complexity and his ability to convey it derive from his cultural and professional expert status. Knowledge and not publicity is what differentiates Hamoudi's narrative from the content of mainstream media coverage. A reviewer on Ibookreviews stresses the author's unique position in direct reference to the media: "Hamoudi offers an insight into the tragedy and transformation of Iraq that few others can provide with such intimacy and firsthand knowledge. Iraq isn't just a news story to Hamoudi. It is his life" (Hanania).

The sharing of complex knowledge in a well-structured format and not the simplified countering of stereotypes sets the basis for Hamoudi's success to reframe the Iraqi in the public eye. The binary oppositions he uses facilitate the cognititive processing on the part of the readers. Their realization that stereotypes are the result of lacking knowledge is a key finding of the reception analysis. Not only does this impact their thinking about the Other, it also changes the way in which they think about themselves - as individuals and as members of a national and global collective. The effect still is a binary but at the same time more complex image of Iraq and of the world. One reviewer summarizes the multi-layered impact of Hamoudi's memoir by stating that the relevance of the book exceeds "the situation in Iraq" and represents "a product of this transcultural, globalized world we live in" (upe).

As the comparison of the textual with the audience frames suggests, Hamoudi's efforts to reframe the public view of the Iraqi Arab/Muslim are largely successful. All the issue frames found in the textual analysis are reflected in the audience 
statements, sometimes with differing salience. Whereas the cultural frame in the memoir itself is less visible than the law frame, the audience stresses the knowledge gain on culture more. This finding does not stand in opposition to the text analysis, since the law frame has been found to overlap with the issue frame of culture to a large extent. This is fostered by the fact that many reviewers use the term 'culture' as an umbrella concept for different issues. With respect to the remaining issue frames, the reception analysis displays that the audience proves less susceptible to the adoption of the economic issue frame. The opposite holds true for the media frame. This issue frame strongly resonates through the audience reactions. In contrast to this dominance of the media frame in the general audience, the journalistic readership mostly neglects this issue in its discussion of the book.

Table 5: Frame Resonance Matrix of Howling in Mesopotamia

\begin{tabular}{|c|c|c|c|c|}
\hline Frame Level & Frame & $\begin{array}{l}\text { Text } \\
\text { (Production/ } \\
\text { Medium) }\end{array}$ & $\begin{array}{l}\text { Journalistic } \\
\text { Audience } \\
\text { (Reception) }\end{array}$ & $\begin{array}{l}\text { General } \\
\text { Audience } \\
\text { (Reception) }\end{array}$ \\
\hline Ideological & Orientalism & .. & • & • \\
\hline Political & Neo-Orientalism & $\cdots$ & .• & .• \\
\hline \multirow[t]{4}{*}{ Issue Level } & Law & $\cdots$ & $\cdots$ & .. \\
\hline & Culture & .• & .• & $\cdots$ \\
\hline & Media & $\cdots$ & • & $\cdots$ \\
\hline & Economy & .. & - & - \\
\hline
\end{tabular}

Legend: The number of dots marks the salience of the respective frame, as based on the close-reading analysis

With respect to the higher-level frames of Orientalism and Neo-Orientalism related to the political WOT, a striking finding emerges. Whereas Hamoudi does not use the vocabulary of East versus West as frequently as Ansary and Kaldas, he shows a decisive tendency to adopt the normative superiority of the imperial hegemon implied in Orientalism. Surprisingly, however, this normative view is not reflected in the audience. Rather, the readers welcome the didactic effect of the binary method because it seemingly facilitates the learning process on different Iraq-related issues. In total, the frames created by Hamoudi to some extent overlap with the ones created by Ansary and Kaldas. All of them create a cultural frame to give insights into the daily life and customs of Arabs and Muslims. This culture frame is missing from the mainstream media coverage. In direct comparison to other dominant media frames, Hamoudi is least susceptible to this framing influence. All of the issue frames he creates are largely missing from the public media discourse. 


\title{
7. (Re-)Mediating Orientalism
}

\begin{abstract}
If postcolonial studies is to survive in any meaningful way, it needs to absorb itself far more deeply with the contemporary world, and with the local circumstances within which colonial institutions and ideas are being moulded into the disparate cultural and socioeconomic practices which define our contemporary 'globality.' (Loomba qtd. in Lau and Mendes 256-57)
\end{abstract}

Ania Loomba wrote these lines in 1998. Since then, the world has transformed in unprecedented ways. Wars have erupted; natural disasters occurred; 9/11 has forever changed the definition of the word terrorism. These and other events continue to resonate in global discourse fostered by the accelerating speed of mass-mediated communication. Postcolonial literature and life writing in particular are usually not considered main actors in this discourse. As the analysis of contemporary Arab American life writing in this study demonstrates, this notion has to be revised. Autobiographies, even in classical print format, indeed constitute media which specifically address the major issues uniting and dividing the "contemporary world" Loomba mentions. They address "cultural and socioeconomic practices" as well as many other pressing issues by drawing on unique narrative registers. This allows the media audience to notice the "globality" of seemingly local or regional conflicts. As Loomba also urges her readers, it is high time for postcolonial, cultural, and Literary Studies alike to integrate this function into its theoretical horizon. 


\subsection{The (Re-)Framed Arab/Muslim}

The Arab American writer and literary scholar Gregory Orfalea in his memoir Angeleno Days takes a very clear position concerning the intention of writers. "It is not enough for many of us writers to reflect the world, to celebrate or damn it - we want to change it," he forcefully declares (233). Especially postcolonial theory with its political implications shares this view. By writing exhaustively on the topic of counter-discourse and the postcolonial quest for agency, scholars in this field have at length explored the possibilities of rewriting history from the perspective of the formerly suppressed in order to arrive at a less ethnocentric and more balanced stance. The question of how exactly this can be achieved, namely the question of method, though, has been addressed with less vigor. The prefixes "re-" and "counter-" have become most popular to connote the basic assumption that ethnic authors write in opposition to existing and lasting stereotypes. As the analysis of contemporary Arab American life writing from a Media Studies perspective suggests, the mere focus on counter-narration does not fully unveil the complex registers employed by authors to change collective identity definitions. Evelyn Alsultany therefore underlines the need to arrive at more comprehensive theoretical models. In an interview with the author, she explains: "Within broader Cultural Studies, theories are more sophisticated to account for how representations operate beyond assessing whether they are positive or negative. However, in Arab American Studies specifically, there is much work to do in this area." Framing as a novel theory of life writing and reading provides a tool to uncovering how authors mediate alternative schemata of interpretation.

\section{Frame Synthesis}

The analysis of the three life narratives by Ansary, Kaldas, and Hamoudi hints at the most obvious similarities and differences found in the respective works. In order to infer more substantial theoretical knowledge about the function of framing as theory of life writing and reading, a coherent synthesis of the framing analyses needs to be conducted. The starting point of this comparative analysis is the overall finding that all authors achieve the effect of constituting alternative interpretative frameworks to look at Arabs, Muslims, and ultimately at Arab Americans. In addition, all narratives also reflect existing frames circulating in the media discourse. Hence, literary reframing can never take place apart from the influence of general media framing. The process of (re-)framing is thus characterized by the reproduction of existing frames while partially complementing these frames with novel and more complex information. 
When systematically juxtaposing the frames created by the authors in the present analysis with the ones dominating in news media discourse, the following picture emerges:

\section{Table 6: Comparative Frame Matrix}

\begin{tabular}{|c|c|c|c|c|c|c|}
\hline Frame Level & Frame & Media & Ansary & Kaldas & Hamoudi & \\
\hline Ideological & Orientalism & .. & $\cdots$ & .. & .. & \\
\hline Political & Neo-Orientalism & $\cdots$ & .• & .. & $\cdots$ & $\downarrow$ \\
\hline \multirow[t]{5}{*}{ Issue Level } & Religion & $\cdots$ & .• & .• & & \multirow{3}{*}{$\begin{array}{c}\text { (Re-)Framing } \\
\vdots\end{array}$} \\
\hline & Race & $\cdots$ & $\cdot$ & $\cdots$ & & \\
\hline & Gender & .. & & & & \\
\hline & Media & & $\cdots$ & .• & $\cdots$ & \\
\hline & Culture & & • & $\cdots$ & .• & \\
\hline \multirow[t]{4}{*}{$\begin{array}{l}\text { Frequency, } \\
\text { salience }\end{array}$} & Economy & & & .* & .. & \multirow{4}{*}{$\begin{array}{c}\vdots \\
\text { Reframing } \\
\downarrow\end{array}$} \\
\hline & History & & $\cdots$ & & & \\
\hline & Law & & & & $\cdots$ & \\
\hline & Literature & & & .. & & \\
\hline
\end{tabular}

The comparative table depicts the most important findings of the frame analysis. On the level of issue frames, the chart highlights the limited number of issue frames dominating the media discourse on Arabs, namely religion, gender, and race. Except for the memoir of Hamoudi, all memoirs reproduce the majority of these media frames with varying salience. In Hamoudi's work, these issues do occur selectively as topics, yet, they are not dominant enough to account for interpretative frameworks. The most curious finding with respect to issue frames appears with respect to the gender frame. This frame constitutes one of the most dominant media frames, as the constant debates on veiling and the suppression of Middle Eastern women suggests (see Chapter 3.3). This focus on gender to a large degree also rules the scholarship on Arab American writing which heavily draws on feminist theory (Naber, "New Texts Out"). As the literary examples illustrate, however, gender here plays a subordinate role. None of the memoirs contains a gender issue frame. This also holds true for the frames constituted by Pauline Kaldas who is the only female author chosen in this study. Her work Letters from Cairo does contain shorter observations on gender topics. The number and elaborateness of these instances does not reveal a higher interest in the topic than displayed in the memoirs of her male colleagues. Ansary and Hamoudi thus deal with the topic of gender at least to an equal extent. This finding underscores the fundamental gap between artificial 
salience created for an issue by the media and the actual relevance of the issue derived from the personal experience of Arabs, Muslims, and Arab Americans.

The fact that the authors are quite resilient to the mass-mediated gender frame furthermore suggests that there are indeed frames that for specific reasons do not transfer to the audience or which are consciously rejected due to oversaturation. ${ }^{1}$ Other frames, in contrast, seem to be so pervasive in public discourse that authors automatically adopt and reproduce them. This, for example, applies to the issue frames of race and religion. This finding is largely in line with the hypothesis inferred from the theory of media framing, stating that anybody acting in the media environment is affected by existing media frames. The fact that Hamoudi is most resilient to this framing impact serves as a possible explanation why his narrative stirs such a vital discussion among audience members. Due to the large number of alternative frames created by the author, readers perceive his narrative to present a very different reality from the one they are used to from other literary writings and mainstream news media outlets.

The example of Hamoudi's successful reframing also illustrates the overall logic of (re-)framing as developed in the theoretical section of this study and applied in the analytical chapters. A number of frames identified in the memoirs have been found to overlap with those of the media environment. The model indicates this media influence in the form of the arrow pointing from the discursive environment inward to the narrative frames installed in the memoirs. This confirms the theoretical assumption that media frames act as perceptional constraints on authors. Instead of simply reiterating these frames, the authors use their personal and ethnic position to add information and thus alter pre-existing frames in the public. This limited influence on framing is indicated by the dashed arrow in the model. It illustrates the process of (re-)framing which is characterized by the efforts of reframing while at the same time being framed by external discourse.

The last six items in the frame column show the alternative issue frames found in the frame analysis. As with the previous issue frames, they are listed according to the frequency to which they occur in the memoirs and according to their salience. Obviously, the issues of culture and economy stand out as most important ones from the perspective of the authors. In the case of the cultural issue frame, life writing seems to successfully fill a knowledge gap on the part of the audience. This knowledge gap is a result of the lack of this frame in the media discourse on the Arab world, since cultural content in the era post 9/11 has mostly disappeared from

1 This would be in line with a finding derived from agenda setting studies which shows that a highly mediated topic after reaching the climax of its coverage experiences no more increase in salience in the media audience unless recurring events fuel the coverage anew. Expressed in graphical terms, this logic transfers to an S-shaped learning curve on the part of the media audience (Dearing and Rogers 65). 
the news coverage that dominated the WOT. The issue frame of economy is one that clearly demonstrates the potential of life narratives to reframe the public view in formerly neglected ways. Economic concerns and the detailed contrasting of economic systems of Arab countries and the U.S. do not play a role in the news media apart from natural resource concerns. ${ }^{2}$ Equally noteworthy instances of reframing can be found with respect to the issue frames of history, law, and literature. Obviously, these issues reflect the areas in which the given authors fully play out their professional expertise and thus succeed in opening up alternative interpretative frameworks that the media do not give credit to. Especially in the case of the literature frame in Kaldas's memoir, this also points to the multi-layered knowledge framing can convey. Kaldas reveals the means of her own writing as mechanism of a larger interpretative frame to view the Arab world and identity.

The complexity accompanying some issue frames fully unfolds when looking at the most multi-faceted issue frame found in the analysis - the media. As Table 6 suggests, the media issue frame is not only the most frequent one, for it appears in all of the life narratives, it is also one of the most salient ones. This finding marks one of the most crucial outcomes of this study because since it directly points to the close entanglement between life narrative and journalistic media production. Above all, the media issue frame highlights the strong impact media framing has on the individual consciousness of authors - both in terms of memory recollection and narrative constraints. Even more striking in this context is the high degree of consciousness with which the given authors reflect on this mediatic impact to ultimately turn it into an issue frame in their own life narratives. The effect in this case compares to the one of the literature frame in Letters from Cairo in the sense that the authors reveal the mechanisms of media framing while at the same time employing them. The reader, while learning about this issue, gains consciousness of his/her own susceptibility to media frames and is simultaneously offered alternative frameworks based on information that is missing from the media coverage.

As the matrix also indicates, all (re-)framing processes on the issue level take place under the larger roof of the ideological and political frame. In this respect, Table 7 speaks a clear language. All narratives can be characterized to reflect the Orientalist and neo-Orientalist frames to a varying extent. The presence of these frames is marked by the language use of binary contrasts between East and West and related dualisms. This reflection of the Orientalist and neo-Orientalist frame again speaks to the dominance of mass media framing as shaping literary production. As in the case of the dominant media frames on the issue level, the authors

2 The neglect of economic circumstances is also characteristic of Ethnic and Arab American Studies. The topic of class is especially missing from the analytical radar. Literary production and identity politics continue to be ruled by a middle-class bias that negates intra-group differences and undermines artificial homogeneity (Naber, "New Texts Out"). 
cannot detach themselves from these omnipresent binary structures resonating in their memory and in their daily life experiences.

This seemingly simplistic dualistic thinking, however, stands in juxtaposition to the complex and obviously successful reframing effects on the public's image of Arab/American/Muslim identity. The reception analysis of Hamoudi's memoir sheds even more light on this seeming paradox. Here, audience members explicitly identified binary thinking and the method of contrasting as valuable aid to their learning experience on the Middle East. This finding puts additional emphasis on the role of life writing as mediator in public discourse well beyond the limited confines of the literary market. Furthermore, the sophisticated way in which the audience reflects on this medium, by openly claiming to derive knowledge and not merely diversion from the reading experience, also underlines the urgent need to grant the audience more room in life writing research.

In addition to these audience-related aspects, the strong visibility of Orientalism opens up a larger and even more urgent debate on Orientalism and NeoOrientalism. Obviously, the Orientalism found in the narratives corresponds with but also differs from the common notion of Orientalism in many ways. In the autobiographies under investigation in this study, Orientalism is obviously characterized by the strong prevalence of binary and at times inferior thinking. This seeming essentialism stands in contrast to the non-essentialism of the overlapping frames which this study has brought to the surface. Based on the evidence at hand, it can thus be assumed that the very language of Orientalist thinking creates the necessary ground for the installment of more complex information. As an analysis of the current scholarly literature reveals, the authors of life narratives are not the only ones drawing on Orientalist divisions.

\section{Orientalism Is "Everywhere"}

In his study on Arab American life writing, Wail Hassan quotes a provocative but also challenging finding by Rudyard Kipling: "East is East, and West is West, and never the twain shall meet" ("Arab-American Autobiography" 31). The contemporary Arab American life narratives discussed in this study obviously pose a counterexample to this bleak outlook since they make the two worlds meet. Still, this does not dissolve the linguistic binary of East and West separating the two. As the recurrent use of this binary by the life writers suggests, this division structures the everyday life of Arabs and Muslims around the world. When taking a close look at the publications in the field of Postcolonial and Autobiography Studies, it turns out that Arab Americans are not alone with their binary thinking.

As Vladimir Braginsky in his thought-provoking study on Orientalism in Europe points out, the literature produced on the relations between East and West is 
"enormous" (511). The same holds true for the various contexts in which this linguistic binary appears in scholarly writing. Without attempting to provide a comprehensive list of these instances, the following enumeration conveys an impression of the different couplings in which East and West occur: "The West organizes knowledge" (Shohat and Stam 14), "Western neoliberalism" and the "Western hegemonic perspective" (Mignolo 8) and "Western ignorance" (Said, Orientalism 63), "modern (Western) epistemology" (Mignolo 9), "Western memory" (Mignolo 11), "Western intellectuals" (Foucault, Interview 69), "Western viewers" and "Western media" (Whitlock 30), "public and private spheres of the West" (Whitlock 31), "literate Western readership" (Whitlock 35) and the "liberal Western consumer" (Whitlock 47), "Western obsession" (Banerjee, "Between the Burqa" 301), "the Western eye" (Whitlock 59), "Western intervention" (Whitlock 101), "Western views" of autobiography (Golley, Reading Arab 76), "Western representationalist discourse" (Bhabha, Location 97), the "Western image of the harem" linked to the idea of "Western men" (Hamilton 176) and "Western women" (Hamilton 178) as seen by "non-Western women" (Hamilton 178).

This comprehensive list of formulations using the binary opposition between East and West could be continued to form a book-length collection of quotations. The given examples are, however, sufficient to derive some major findings. First of all, the fact that the West in the previous examples is mostly used without the opposite East implies that the West still dominates in defining the Other. Most authors do not seem to be aware of this Orienalist bias for they use the terms without quotation marks. This seems to be a minor detail, yet, this detail is symptomatic of the large body of literature found on the topic of Orientalism today. The overwhelming majority of writers uses the terms West/East, Orient/Occident and related terminologies without bothering to explain their "ambiguous usage" (Williams qtd. in Shohat and Stam 13). Edward Said himself provides a slightly more nuanced example of this ambivalence:

I suggested that studying the relationship between the "West" and its dominated cultural "others" is not just a way of understanding an unequal relationship between unequal interlocutors, but also a point of entry into studying the formation and meaning of Western cultural practices themselves. And the persistent disparity in power between the West and non-West must be taken into account if we are accurately to understand cultural forms [...]. (Culture and Imperialism 230)

Said's statement adds another example to the long list of binary vocabulary. By using quotation marks in some instances, Said does emphasize the problematic function of words such as "West." As the passage also demonstrates, however, this careful attention to binary vocabulary is not coherent and sometimes arbitrary. Even more striking is the fact that Said uses these prominent binaries while at the same 
time pointing to the good intention of cultural and postcolonial scholarship to unveil the dichotomy. Other examples of this counter-intuitive claim to unfold Orientalism while at the same time confirming its language are again manifold. Often, the binary terminology of West and East covers entire pages. A prime example of this paradox is provided by Whitlock who makes an explicit reference to framing in her discussion of women's autobiographies from Iraq: "These images, the titles, and the subtitles are designed to grab the Western eye with a glimpse of absolute difference, of the exotic. This is a way of positioning them for metropolitan markets [...] Here conventions are reversed: it is the Western eye of the viewer that is in an enclosed and framed interior space [...]" (Whitlock 59). The use of the dualism between East and West again dominates in these lines, which is particularly thought-provoking with respect to the critique of framing Whitlock applies. In the very instance of identifying Orientalism as frame of the narrative she analyzes, she also reproduces Orientalism in her own writing by evoking its characteristic language of othering (see Said, Culture and Imperialism 9; Shohat and Stam 13; Fritsch-El Alaoui 27).

These numerous examples illustrate that Orientalism as based on binary thinking not only characterizes the life narratives of multi-ethnic life writers but also of the ones who critically reflect on these works (Marrouchi "Counternarratives" 237). This underlines the powerful function of Orientalism as an ideology. One can therefore agree with Naber's conclusion that the influence of Orientalism is practically "everywhere" (Naber, "New Texts Out"). ${ }^{3}$ Instead of simply lamenting this state, as has been the major occupation of scholars for many decades, the question needs to be raised if these binaries actually serve a non-essentialist function. Obviously, the authors for the most part do not use Orientalist vocabulary to intentionally underline the inferiority of the Other. Instead, they apply respective terms for a particular purpose: to convey knowledge not stereotypes. In doing so, they not only reframe the image of the Arab and Muslim but also mediate Orientalism in a way that has not been explored so far.

\subsection{Mediated Orientalism}

There is a very revealing line found in the study of Esra Sandikcioglu on the metaphorical meaning of Orientalism behind the Gulf War. "It is very difficult, if not impossible, to see the world around us with different eyes, since we are literally

3 While deriving their major motivation from the intention to unveil the constructed nature of Orientalism, these works substantiate the effect of othering. As Arab American scholar Nadine Naber in an interview points out when looking back at her own upbringing in the San Francisco Bay area, she retrospectively notices that "the impact of Orientalism was everywhere" ("New Texts Out"). 
products of our cultures," he writes. The results of the present interdisciplinary study on contemporary Arab American life narratives confirm one part of this finding while shedding more light on the other. After all, the impact of Orientalism has proven to be strong. This is why it cannot be neglected in the analysis of literature dealing with the representation of Arabs and the Arab world. This highlights that "Orientalism Matters," maybe even more than it did before the current wave of Neo-Orientalism and the creation of new mediated stereotypes post 9/11 (Behdad 709). Leaving it at this short-sighted conclusion, however, would miss the avisaged aim and scope of this study. The framing analysis has revealed novel insights into the way in which Arab Americans adopt Orientalism. This demonstrates that "Orientalism matters" - but it matters in a different way than previously discussed.

\section{Orientalism Revisited}

The history of mediated stereotypes about Arabs and Muslims is inherently interwoven with Said's Orientalism as the founding manifesto of Postcolonial Studies (Aboul-Ela, "Is there an Arab" 730; El-Haj 539). Orientalism therefore not only represents a single theory but a "tradition" which shapes the mindset of researchers in innumerable academic disciplines (El-Haj 545). Due to this dominance of Orientalism and its various adaptations in present-day Cultural Studies (see Chapter 2.1), scholars hardly ever go back to the conceptual roots of the concept when employing Said's vocabulary. They simply use Orientalism like a household term. Media scholars, in contrast, have so far resisted the inflationary use of the concept. In their field, Orientalism is mostly absent from the methodological toolkit.

The frame analysis presented in this study suggests that neither the blind application of Orientalism as a catch word nor its complete negligence contribute to the advancement of life writing research. Instead, the prominent role which the concept still plays in contemporary discourse requires a reconsideration of Orientalism as overarching ideological frame. It is this critical engagement with seemingly established knowledge that counts as one of the most important effects achieved by the Arab American life narratives investigated in this study. This reframing effect is in line with Said's notion of the "heterodox in theory" that does not merely reproduce the given (Marrouchi, "Counternarratives" 254). When putting this call into practice, Orientalism turns out to be much more than a concept of "Knowledge and Power" (Said, Covering Islam 157).

The urgent need to reread many seemingly established facts about Orientalism is underlined by selective and often distorted views ruling in scholarly discourse. Scholars intentionally twist and turn Said's elaborations to justify their own theories. Orientalism, according to this common use of the concept, counts as a more or less fixed concept with a definite pre-defined and hardly ever re-defined meaning. 
This notion of Orientalism as stable concept, however, runs counter to the view Said himself represented. He argued in favor of the dynamic quality of Orientalism. Nadia El-Haj accounts for this dynamic aspect in her definition of Orientalism:

Orientalist discourse is an archive of systematic statements and bodies of knowledge, continuously drawn on and reformulated, that converges with broader prevailing philosophical tendencies at different moments in time [...], all the while retaining a powerful trace of itself as Europe reexperiences the Orient but never as something wholly new or alien. (545)

El-Haj in this redefinition of Orientalism raises two crucial issues that lay the groundwork for rethinking the concept in light of the present framing analysis. The first aspect is the significance of Orientalism as an umbrella term which summaryzes "bodies of knowledge." The use of the plural is crucial here since it underlines that various theoretical concepts and practical arguments in total account for Orientalism as phenomenon in public discourse. This categorizing function is linked to the time-dependence of Orientalism which El-Haj also points to. This is related to the second major claim of her definition, namely the dynamic quality of Orientalism. Since knowledge is bound to "different moments in time," Orientalism as a product of this knowledge creation needs to be re-read and reinterpreted continuously. It is this alternation between stability and change, between the familiar and the newly-emerging, which marks the lasting theoretical potential of Orientalism for contemporary discourse analysis.

What has prevented scholars from recognizing this potential is the normative meaning they associate with the term. This normative connotation is rooted in postcolonialism's fundamental neglect of binaries. As Jonathan Culler summarizes this deconstructivist approach in a discussion of Paul de Man's contribution to literary theory: "Deconstruction seeks to undo all oppositions that, in the name of unity, purity, order, and hierarchy, try to eliminate difference" (qtd. in Elbow 51). Postcolonial theory can therefore be characterized as "hostile to dialectics" (Huddart 58). This hostility toward dialectical thinking, however, did not start with the rise of Orientalism as a research object nor with the emergence of Postcolonial Studies. Rather, the deconstruction of dialectics is rooted in the philosophical origin of binary thinking as such.

Binary thinking was largely theorized by the German philosopher Georg Friedrich Wilhelm Hegel. His concept of dialectics is based on the idea that two terms standing in opposition to each other, such as master and slave, can be overcome by introducing a third term or "higher category" (Elbow 52; Morton, "Poststructuralist Formulations" 162). According to this notion, the goal is to dissolve the dichotomy to achieve unity without negating either one of the previous binary components. This process is commonly referred to as discursive method of thesis, antithesis, and synthesis (Elbow 52). Hegel's concept, however, despite its epistemological rele- 
vance, became the subject of harsh criticism. Aside from his valuable contributions, Hegel linked his insights to racist and Eurocentric ideology (Morton, "Poststructuralist Formulations" 162).

One of the harshest and most influential critics of binary thinking in postcolonial theory was Michel Foucault. While generally agreeing on the existence of the historical continuity suggested by Hegelian dialectics, he proclaimed to resolve it. As he states in his discussion of the French philosopher Gilles Deleuze:

The freeing of difference requires thought without contradiction, without dialectics, without negation; thought that accepts divergence; affirmative thought whose instrument is disjunction; thought of the multiple - of the nomadic and dispersed multiplicity that is not limited or confined by the constraints of the same; thought that does not conform to a pedagogical model (the fakery of prepared answers) but attacks insoluble problems - that is, a thought which addresses a multiplicity of exceptional points, which is displaced as we distinguish their conditions and which insists upon and subsists in the play of repetitions. ("Theatrum Philosophicum" 358)

This reflection by Foucault indicates a second strategy in response to the perceived problem of binary thinking. The first one is Hegel's suggestion to overcome binaries by synthesis. The second one established by Foucault replaces dialectical thinking by "multiplicity." Although Hegel's own strategy appears somewhat less radical when compared to this idea of total replacement by Foucault, both approaches are united by the ultimate goal of eliminating the dialectical state. Especially Foucault with his deconstructionist opposition to oppositional thinking fostered the overcoming of binary thinking as the major aim of Postcolonial Studies (Said, Orientalism 3; Ashcroft, Griffiths, and Tiffin 165; Varisco 254).

This philosophical synopsis detects the origins of anti-binary thinking and it underlines the two major methods that can be employed to eliminate binaries in discourse. The lasting antipathy against binaries, however, is not merely a philosophical legacy or a flaw of postcolonialism to deconstruct binaries for its own sake. Rather, the neglect of binaries on normative grounds is linked to the notion that binaries necessarily represent power structures (Merskin 158). Conceptually speaking, binaries are not imagined to stand alongside each other on a horizontal axis. Instead, the implied power relations situate binaries along a vertical axis where one party is always superior to the other. The one who gets to define this Other automatically is the one in power. This "Other Thinking" can therefore never take place without the Other (Mignolo 67). This concept ultimately leads to a tautology of othering. As Ning writes: "Since the Occident is already the 'other' to the Oriental, the 'Orient' in the eyes of Westerners is just an 'other' of this 'other'" (58). Hence, whoever gains the upper hand in the power struggle wins. This logic applies to colonial and to postcolonial discourse alike. Postcolonial Studies' main aim has 
always been to reveal the effects of this binary discourse on the basis of the "dynamics of Western ethnocentrism" (Whitlock 48). Just like colonialism relied on the colonizer dominating the colonial subject, Orientalism inherently relies on the notion of Occidental power. As Armstrong strikingly infers: "If the author in Orientalism wins, he becomes the 'us' that succeeds in defining 'them'" (114-15). The result is a "reverse polarization" that seeks to reformulate history and cultural relations from the view of the Other (Aboul-Ela, "Is there an Arab" 731).

This inherent understanding of binaries as power relation also applies to the contemporary discourse on Orientalism. The concept continues to be seen as a major problem as Nadine Naber points out in identifying "new Orientalist discourses that reify and legitimize imperial racism, military violence, and war" (Naber, "New Texts Out"). Orientalism, as this example shows, is used as a synonym of the most unequal binaries history has to offer, among them racism and imperialism. The deconstruction of these "new Orientalist discourses" has become the subject of contemporary scholars employing reformulated Orientalisms such as neoOrientalism, re-Orientalism and post-Orientalism (see Chapter 3.1). Orientalism of this new period is mostly used in the context of the U.S. actions against terrorism. A chapter title like the one of Ta called "Team America: The War on Terror and the Return of Orientalism" illustratively sums up the supposed relationship between the WOT and the renewed sense of Orientalism (136).

Although these supposed "re"-formulations of Orientalism claim to extend the explanatory capacity of classical Orientalim in unique and novel ways (Lau and Mendes 2), a close look at their theoretical potential makes one question this claim. Khair Tabish therefore ironically states that "Re-Orientalism is genetically modified Orientalism [...]" (154). He attributes this genetic modification to the critical finding that "certain aspects of colonial narratives are repeated again and again, consciously or not, with or without irony" (Khair 154). One of these cloned features is the lasting normative definition of Orientalism based on the inherent conviction that binaries are unequal and in need to be dissolved (Jacobson 312). Since this normative understanding dominates the scholarly discourse on the topic, one can call it 'mediated Orientalism' in the sense that it resonates through all major publications. This sheds light on the question of how far these "re-"formulations of Orientalism actually reach. Mediated Orientalist scholarship reproduces the core assumptions of Orientalism as they have axiomatically circulated in academic discourse throughout the decades. This new Orientalism, however, does not actually re-frame the old model in unique ways. By merely taking a normative approach to binaries, postcolonialism has thus successfully colonized Orientalism to an extent that any other definition is not even considered.

When looking at the empirical impact of postcolonialism's efforts to deconstruct binaries, this neglect of novel thinking raises questions. Have Orientalist binaries actually disappeared? In light of the given evidence, the answer is no. As 
the memoirs discussed in this study show, the experience of Arabs, Muslims, and Americans alike takes place along Orientalist binaries. One could claim, this is an unfortunate circumstance that should motivate postcolonial scholars even more in their efforts to fight binary thinking. The irony, however, is that the literature of these very scholars is charged with Orientalist binaries. One conclusion to draw from this would be to call Orientalist scholarship a failure. A more constructive approach that actually contributes to the furthering of Orientalist scholarship is to assume that binaries have a function that normative postcolonial scholars have overlooked thus far.

\section{Binaries Revisited}

Daniel Varisco in Reading Orientalism sums up postcolonialism's obsession with binaries by stating that the motto has always been to get "Beyond the Binary" (290). "Beyond" in this respect has always been defined as the elimination of binary structures. Often, this credo has produced "binary-blinded writers" as Varisco also provocatively puts it (264). For him, Said counts as major example of this group. The previous examination of binary vocabulary found in the majority of postcolonialist writing, however, points to the fact that this lack of eye-sight is by far more widespread among postcolonial scholars. When leaving behind the goal of eliminating binaries in the quest to get "beyond" the present status of research, one encounters that alternative definitions of binaries exist which extend Orientalist scholarship beyond its normative confines.

When searching for alternative approaches to the study of binaries, one that is positioned in-between conservative Orientalism and contemporary Postcolonial Studies, a third view emerges that looks back at an even longer philosophical tradition than the ones of Hegel and Foucault. This more inclusive approach originated at the time of Socrates and Plato and can also be found in the concepts of yin and yang propagated by Eastern philosophy (Elbow 52). This alternative tradition does not see binaries as fundamental cause of opposition and therefore denies "a dialectical either/or" in favor of embracing a "dialogic both/and" (Bakhtin qtd. in Elbow 52). Although this dialogical view clearly sets the focus on inclusiveness rather than exclusion, it is not synonymous with Foucault's elaborations on multiplicity. Multiplicity, according to this reformed reading of dialectics, is not preferred over binaries with the goal of their ultimate elimination. Rather, binaries are granted a valuable function for human thinking and discourse. Peter Elbow makes an outspoken claim for this revised notion: "Even though binary oppositions tempt people to oversimple, black/white thinking, binary oppositions also present us with uniquely valuable occasions for balance, irresolution, nonclosure, nonconsensus, nonwinning" (54). He thus argues for an "approach to binary oppositions that seems to go 
against the grain and require some conscious discipline: affirming both sides of a dichotomy as equally true or important, even if they are contradictory" (Elbow 54).

Going "against the grain" consequently means embracing instead of eliminating binaries. The cause of this appreciation, however, is not rooted in normative considerations only. As Elbow emphasizes, the scientific perspective differs from postcolonialism's focus on identity politics. Whereas Postcolonial Studies demonize binaries based on the negative socio-political consequences they supposedly have, the embracing of binaries and their function relies on a cognitive scientific standpoint. The affirmation of "both sides" is therefore only possibly if both sides are granted a separate and distinct place in the information grid of human cognition. This multiplicity achieved via binary differences allows for diversity without hierarchies. "Having three or more options is great," Peter Elbow states in his support of "framing issues in terms of more than two sides. Just so long as there's more than one! If we can see three or five sides, that's good - so long as that multiplicity isn't a cover for letting one side be the real winner" (Elbow 53).

This alternative approach to dialectics contributes important insights to the theoretical dimension of the present framing study. The crucial link is provided by the relation between binaries and human learning. A cognitive definition of binary discourse thus gives credit to the fact that the human mind functions in a dialectical mode (Elbow 53). These more abstract theoretical insights linked to human learning theory also have very specific implications for key concepts in Postcolonial Studies. As Esra Sandikcioglu points out, thinking in strict dialectics results in a reduction of the complex political reality to contrastive concepts such as "Self and Other." "thinking and evaluating in oppositions or dualisms" represents a set of strategies which are deeply rooted in "cultural, political, psychological and anthropological" practice (Krause qtd. in Sandikcioglu). Consequently, the cognitive process of dual thinking is necessary for identity creation as well as for political and social order (Wöhlert 64). As Lewis Sego puts it, “[o]ne's identity is established cognitively on the basis of contrast to others. If no others are perceived, identity is neither possible nor necessary" (qtd. in Sandikcioglu). This reformed view also results in a revision of border thinking. Borders become necessary means to differentiate the self from the other and to delineate the "universal" from the "particular" (Mignolo 19; Majaj, “Arab-American Ethnicity” 323).

4 Sandikcioglu draws on Morillas's cultural model that links Cultural and Cognitivie Studies. It depicts how people construct their own and others' sense of self by relying on public resources as well as on private experiences for self-construction. The concept of self in a given culture is an integral part of the model. "It includes the image-schemata, metaphoric and metonymic mappings, and script-like information with which a culture schematizes cognitive-culturally its members [...]" (Morillas qtd. in Sandikcioglu). 
This cognitive definition of binaries allows one to explore the full range of "Uses of Binary Thinking" (Elbow 51). Binaries as "formative binaries" lose their negative, destructive connotation and instead become the crucial preliminaries of human learning and understanding (Hinz). Expressed in the vocabulary of framing, the thinking in black and white opposites facilitates the categorization of incoming information into existing and newly emerging cognitive schemata. The reduction of information is key to this process. Such a rethinking of binaries, however, also shakens related core pillars of Literary and Cultural Studies. Here, the "Fear of Reductionism" has been entangled with the ultimate goal of eliminating essentialism (Slingerland 25). Binaries as preconditions for effective framing consequently also challenge the meaning of essentialism.

\section{Essentialism Revisited}

The vilification of Orientalism and the corresponding binary discourse must be seen within the larger context of Literary and Cultural Studies and their inherently antiessentialist objectives (see Chapter 2.1). Embracing and even calling for the intentional employment of binaries to underline difference, as this study suggests, counts as the "essential unpardonable sin" in the "postmodern intellectual milieu" (Varisco 251). The redefinition of Orientalism as a cognitive binary which embraces both the other and the self, however, cannot merely be neglected based on arguments of essentialism, relativism, or universalism. ${ }^{5}$ The very definition of binaries as facilitators of complexity and diversity excludes such a denial. Consequently, the notion of essentialism also needs to be studied from a new perspective. This perspective starts with the cognitive function of binaries and ends with the finding that essentialism facilitates comparison.

In contrast to the examples found in the memoirs discussed in this study which inherently rely on the accentuation of differences and oppositions, contemporary postcolonial discourse proscribes the labeling of other cultures and religions "as fundamentally different from ours" (Sandikcioglu). The separation of our culture and their culture as well as the focus on difference count as markers of essentialism. In how far this anti-essentialist bias rules the scholarly discussion is highlighted by Whitlock in her analysis of Islam in life narratives from the Middle East:

5 This understanding of Orientalism as a conscious act and an unconscious cognitive activity somewhat corresponds to Said's notion of "latent" and "manifest" Orientalism. Latent to Said refers to "almost unconscious" positivist assumptions of the East whereas manifest Orientalism comprises "stated views" and other forms of knowledge distribution (Orientalism 205; El-Haj 543). 
[L]ife narratives are constantly caught up in circuits of self-construction, where Islam is objectified as the obverse of Euro-Americans societies that self-identify as "the West," driving a constant creation and re-creation of imaginary boundaries between "we" and "others." "The West" can only be defined relationally. It is not a geographic location but a locus of symbolic and grounded power relations emanating from the United States and Europe; there is no ground for identifying an essential "Western" subject, and [...] the "other" can only be relational [...]. (7) ${ }^{6}$

Although Whitlock in this passage aims to make a claim against essentialism, she at the same time sets up an important argument for the recognition of essentialism as constructive theoretical concept in postcolonialism. The fact that "East" and "West" are "relational" presupposes the act of comparison. This comparison in life narrative does not take place along "symbolic" and mostly artificial boundaries, as Whitlock suggests. Rather, these borders are perceived as real by members of different cultures. As the importance of truth and authenticity in audience research furthermore reveals, the public's notion of the "real" has little to do with the academic discourse on reality as a constructed concept. The binary of East and West instead is understood as a social fact that forms the most important cognitive structure to define "a network of relationships" between individuals and cultures (Behdad 711).

When linking the important function of comparativism with the redefined meaning and value of binaries, the human need for essentialist thinking unfolds. Since binaries do not merely represent power structures but two separated entities that stand in contrast to each other, the act of comparison is needed to explore differences and commonalities in equal juxtaposition to each other. Certainly, this cognitive process cannot account for all details, which is why simplification is required to structure new information within known and emerging schemata. Essentialism, defined in cognitive terms as the reduction of complexity, fulfills this purpose. The feminist scholar Vicki Kirby summarizes this form of complexity within a seemingly reductionist pattern by stating that "essentialism is not an entity that can be identified and dissolved by saying yes or no to it" (qtd. in Yeğenoğlu, Colonial Fantasies 37).

This necessity for comparisons that precede value judgements sheds new light on the "how" of essentialism and ultimately leads to a redefinition of the "essence" itself (Kirby qtd. in Yeğenoğlu, Colonial Fantasies 37). This essence is the product of the comparative method. It derives the fact that human understanding and learning are rooted in comparative thinking. Such an altered notion of essentialism even-

6 Whitlock in these lines quotes from Seyla Benhabib's work The Claims of Culture: Equality and Diversity in the Global Era (2002). Benhabib is professor of political science at Yale University who specializes in democratic theory with a particular focus on cultural change and minority discourse. 
tually allows postcolonial scholarship to take a more realistic position; one that accepts "that things have a set of characteristics which make them what they are, and that the task of science and philosophy is their discovery and expression" ( $O x$ ford English Dictionary qtd. in Varisco 252). Contemporary philosophy already provides a rationale as to how this revised notion of essentialism can benefit humanities scholars in making new discoveries.

\section{From Normative Essentialism to Cognitive Comparativism}

The reception analysis of the chosen autobiographies above has illustrated that consumers of ethnic life writing pursue the goal of knowledge acquision as important result of their reading experience. Especially learning processes about other cultures rely on binary comparisons that require essentialist schemata. A contemporary thinker who provides the philosophical rationale for the integration of this comparativist mode of learning into Cultural Studies is Charles Taylor. In his essay "Comparison, History and Truth," he reminds his readers: "[A]re we not always engaged in some sort of comparison when trying to understand another culture?" (Philosophical Arguments 147). With his elaborations on the connection between binary thinking and multiculturalism, he builds the bridge from normative essentialism to cognitive comparativism.

The multitude of Orientalist vocabulary in contemporary postcolonial writing has mostly been perceived as the "problem of language" so far (Khair 150). The problem is rooted in the difficulty of writing about alterity while trying to avoid expressions of alterity in language. Taylor also starts his discussion of binary thinking on the basis of language. In his thought construct, however, the "problem of language" turns into an unavoidable necessity and even advantage. To him, one of the fundamental reasons why comparison is substantial for cultural learning is the origin of language in one's cultural surroundings. If culture can only be discussed in one's "own" language, this self-evidently leads to an ethnocentric bias. Yet, there is hardly any other option possible (Philosophical Arguments 147). ${ }^{7}$ To Taylor, language as internalized component of social interaction is the foundation of exploring cultural difference. It therefore reflects the larger trajectories of how knowledge and evaluation come into being more or less unconsciously.

When read alongside the cognitive preliminaries of comparison, the question of language and its relation to consciousness emerges. Taylor bases his reasoning on

7 Wang Ning in her critique of the dichotomy of Orientalism and Occidentalism points out that one of the major limitations of Orientalist criticism in Literary Studies remains that the majority of texts only exists in English (61). 
Hans-Georg Gadamer ${ }^{8}$ in stating that "much of our understanding is quite inarticulate; is in this sense a form of pre-understanding. It shapes our judgements without our being aware of it" (Philosophical Arguments 148-49). Instead of concluding that this form of "pre-understanding" automatically leads to an insurmountable selfpositioning along hierarchies, as postcolonialism claims, Taylor points to the value of the comparative mode in resolving the normative tension between Self and Other. He derives that "other-understanding is always in a sense comparative. That is because we make the other intelligible through our own understanding" (Philosophical Arguments 150). He then links this value of comparison to the concept of ethnocentrism by arguing that "the great leaps in other-understanding take place through (perhaps implicit) comparisons or contrasts. The hope that we can escape ethnocentrism reposes on the fact that these contrasts transcend and often incommode the previous home understanding" (Philosophical Arguments 150).

Taylor with his thoughts on the importance and inevitableness of comparativism in cultural learning provides the philosophical and scientific skeletal structure to assemble the core results of the present framing study. The mode in which the chosen authors pursue their autobiographical endeavor meets the very challenge of comparativism in a pragmatic and effective way. They demonstrate that essentialism and cultural other-thinking serve a cognitive purpose that does not "lock us into ethnocentric prisons" (C. Taylor, Philosophical Arguments 148-49). Taylor again refers to Gadamer in emphasizing this positive learning effect when stating that "the fortunate thing about human beings is that understanding can change. And one of the important sources of this learning can be meeting foreign cultures" (C. Taylor, Philosophical Arguments 148-49). In allowing the reader to meet the Other in a form not experienced through mainstream media consumption, contemporary Arab American and Muslim life writers open up the possibility of comprehensive comparison and contrasting between different issues separating the self from the cultural and ethnic Other. Only in provoking this constant cognitive contrasting does the formerly internalized half-knowledge derived from mainstream media sources become apparent. The temptation of taking the position of the colonial superior still remains as the attitude displayed by the life writers also suggests. Yet, information gain provides the key to preventing this scenario. Taylor sums up the trajectory of this mechanism in powerful words: "I meet this challenge [of ruling another culture] by altering and enlarging my understanding, remaking its forms and limits. This means that I articulate things that were purely implicit before, in order to put them into question" (Philosophical Arguments 149).

8 Gadamer was an influential proponent of critical hermeneutics in the $20^{\text {th }}$ century. He was especially concerned about questions of truth and matter which also play a key role in Taylor's work and ultimately in the present analysis of the role of life writing in contemporary discourse. 
These lines also demonstrate that the initial realization of cultural difference is the essential starting point for questioning truths about one's own culture. In other words, cultural commonalities between individuals and people cannot be encountered if difference is not acknowledged in the first place. The numerous accounts of the general and of the journalistic readership in reaction to the life narratives bear testimony to this finding. The respective identity change of the authors serves as a model for a cultural opening that emerges in the act of articulating difference and finally carries over to the reader. This again points to the strong impact of mediated discourse on human thinking and feeling. Instead of simply presupposing this influence, the empirical method of framing in conjunction with the philosophical insights provided by Taylor explains this link on an empirical basis. Mediated schemata thus frame the world and only the reframing of this worldview can lead to different thoughts, evaluations, and actions of the cultural Other.

This is why other-understanding changes self-understanding, and in particular prizes us loose from some of the most fixed contours of our former culture. The very questioning we are engaged in here is an instance of this. The sober and rational discourse which tries to understand other cultures has to become aware of itself as one among many possibilities in order properly to understand the others. (C. Taylor, Philosophical Arguments 149)

The life narratives analyzed in this study provide striking evidence for this effect. With their focus on "rational discourse" and knowledge transmission rather than on mere personal storytelling and ethnic identity negotiation, the authors trigger this process of self-understanding in unique and formerly unexplained ways. The constitution of alternative frames of interpretation fosters this process by not only offering the audience snapshots of details on various topics but by essentializing Orientalist difference to the effect that more complex thought patterns can be derived. This complexity within simplification and these details conveyed by essentialized contrasting provide the methodological power for reframing the Arab/Muslim.

\section{Mediated Orientalism}

The relationship between the media and Orientalism has always been interpreted along the same normative lines as Orientalism itself. Mediation has become a synonym for distortion, stereotyping, and essentialism (Shohat and Stam 59). Postcolonial media scholars like Ella Shohat and Robert Stam count as the strongest advocates to counter this shortcoming. In their work Unthinking Eurocentrism (2007), they approach the deconstruction of binary oppositions from an interdisciplinary 
angle to unveil the "universalization of Eurocentric ${ }^{9}$ norms" conducted by the media (3). Obviously, contemporary Arab American life narratives share the view that the media are crucial actors in manifesting stereotypes about Arabs. Their own use of Orientalist binaries, however, also underlines the function of mediation as act of communication which reconciles conflictual notions, reframes stereotypes, and ultimately contributes to the conveying of alternative Orientalisms that are not defined by the West.

The origin for the mediation of binaries between different cultures is rooted in the existential importance of binaries for self-creation. The different cultures emerging from this are surrounded by frames connected to a particular cognitive structure. Pamela Morgan establishes this link between binary discourse, selfcreation, and framing in the following passage by drawing on the works of Goffman and Lakoff:

[E]ach of these "frames" of self-presentation is a multi-element cognitive model with rich traditional linguistic and cultural components and associations, including presuppositions and entailments or inferences, through which a society views, understands, structures, and conducts itself and its activities. Because of this complexity, these cultural frames are often cognitively linked to each other by the intersection or overlap of some of the elements of their idealized cognitive models. (qtd. in Sandikcioglu)

The key terms mentioned in this paragraph provide the basic elements of a reformed notion of Orientalism. As the analysis has illustrated, Orientalist binaries build up a conceptual framework around different cultures. In order to communicate knowledge of the Orient beyond the notion of borders as conflict lines, ${ }^{10}$ mediation is required. Binary thinking and its respective vocabulary fosters this process: it does not hinder it, as postcolonial ideology has always claimed. It is precisely the dualism of East and West that allows for the "us and them" to find a proper voice. The authors of autobiographies do not engage in sophisticated scientific metadiscourses on the state of Orientalism today. When formulated in more unconventional terms, one can infer that these life writers put into practice a call by Spivak

9 Eurocentrism is commonly defined as the viewing of the West as the center of historical development (Childs and Fowler 75). Shohat and Stam more specifically see Eurocentrism as "an ideological substratum common to colonialist, imperialist, and racist discourse" that is not only buried in the past but "a form of vestigial thinking which permeates and structures contemporary practices and representations even after the formal end of colonialism" (2). In short, they view Orientalism as a present, not a historical concept.

10 Mignolo, who locates the "exercise of border thinking" inherently in "Western epistemology," suggests the use of the concept "gnosis" to avoid the negative and confrontative connotation of the term (9). 
who states that "one must learn to speak in such a way that the masses will not regard it as bullshit" ("Interview" 24). It is this language that the audience in its reading experience can share and that leads to "unlearning one's learning" (Spivak, "Interview" 24). The result is a reframed and more complex image of the Ar$\mathrm{ab} /$ Muslim that is mediated through Orientalism as "cognitive model" (Morillas qtd. in Sandikcioglu).

\section{Graph 8: Model of (Re-)Framed Arab/Muslim American Identity in Mediated Orientalism}

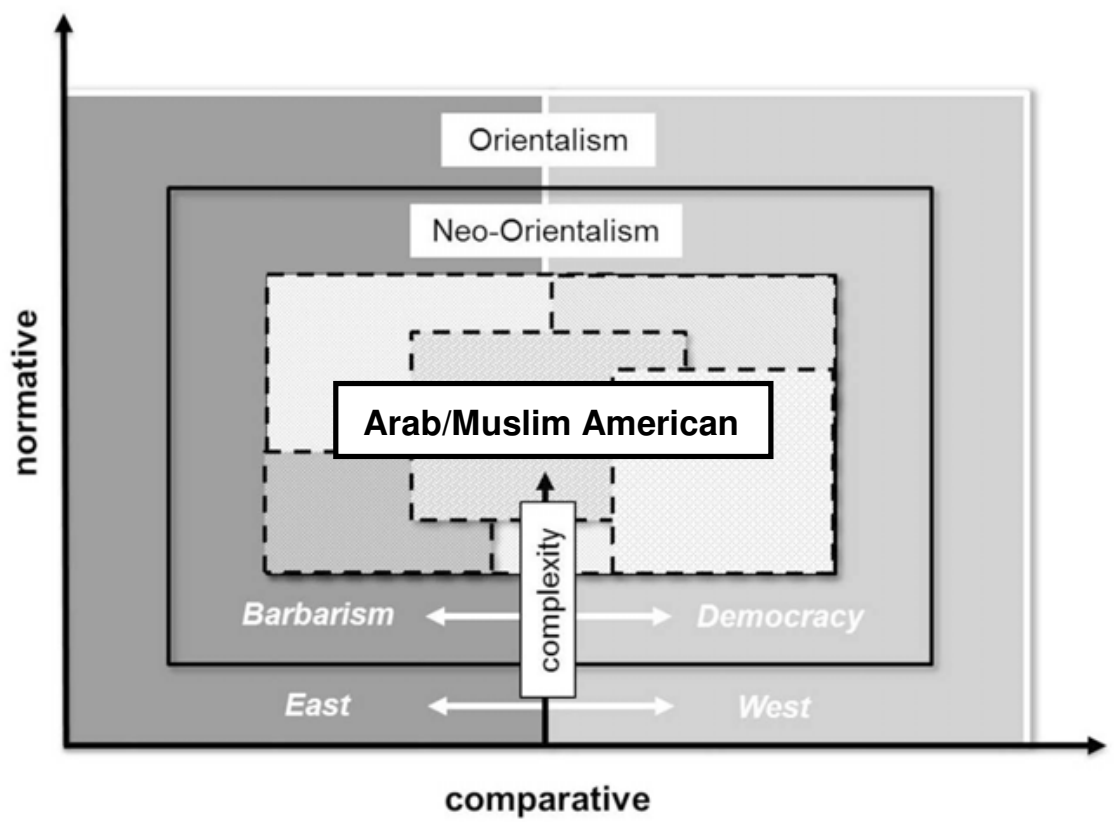

This (re-)mediated model of Orientalism demonstrates that Orientalism does not only take place along the vertical axis of normative judgement but also on the horizontal line of contrastation in which East and West build "contrasting pairs" that are necessary for learning about other cultures and ultimately for surmounting normative ethnocentric biases. As Hinz puts it in her study of the conditions for multiculturalism, "'binaries without hierarchies are possible" and horizontal thinking pro-

11 Hinz discusses the positive and even constitutive impact of binary thinking in the practical political context of multiculturalism. Similar to the notion of horizontal Orientalism, multiculturalism claims as its main feature a focus on pluralism of thought rather than hierarchical thinking. Hinz also makes a strong claim that this 'equality' of multicultural- 
vides the necessary condition for this. Consequently, single terms such as barbarism and democracy that constitute the neo-Orientalist frame, do not lose their affective connotation as either positive or negative. Their opposition, however, is necessary to charge them with new meaning.

Orientalism as a cognitive concept represents a step toward a reformulation of Orientalism from the other side. The act of mediation makes cognitive difference visible. This conceptual opening also results in the reversal of stereotypes concerning the epistemologies of East and West. Such an approach requires the examination of a "variant of Orientalist dualistic thinking [...] that sees the West as conceptually rigid and Eastern thought as open-ended and flexible" (Sandikcioglu). Only such a theoretical opening allows for a rethinking that Orientalism itself is not the reason for colonial practice. As Sandikcioglu as one of the few contemporary scholars who account for the existence of alternative Orientalisms suggests, such a rethinking "would have to start with a discussion of the culturally and geographically different notions of Orientalism held by the West resulting in a differentiation between what can tentatively be referred to as an Asian Orient with a background of Buddhism and Hinduism and an Islamic Orient."

The function of mediating Orientalism found in this study therefore has a dual meaning. The authors of the memoirs analyzed in this study obviously act within the larger ideological framework of Orientalism. Partly, they reflect the Orientalist ideology by taking a morally superior stance based on their American background. This notion of Orientalism as instrument of suppression corresponds to the normative condemnation of binary thinking in Postcolonial Studies (Merskin 158). By employing Orientalist binaries as tools of communication, however, they also mediate an alternative concept of Orientalism to the general and scientific public. This notion is cognitive in nature and differs from the Western view of Orientalism as normative power constellation. Taylor summarizes this constructive effect of mediation by means of a binary "language or mode of human understanding" which allows both sides, the "us and them," to be undistortedly described (Philosophical Arguments 155).

In sum, an "East-West synthesis"12 (Braginsky 515) is only possible through the evocation of the East/West dialectic. This mode of comparativism builds the basis for a reformulated model of Orientalism. This model is detached from the historical determinism suggested by Hegel. As Taylor points out, the focus on comparison is

ism cannot emerge without "dualistic" thinking since the thinking of the other always requires the thinking in opposites.

12 Ning in her work on Orientalism in Asian American literature uses the term dialogue with respect to the finding that Asian American studies are moving away from the binary opposition between Orient and Occident. This corresponds to the logic of a synthesis following the antithesis to both concepts (57). 
not necessarily linked to a unidirectional course of history but allows for the notion of "potentiality" (Philosophical Arguments 164). Ultimately, this potentiality derives from the fact that "the comparativist enterprise," as Taylor coins it, includes various actors from all sides of the lines dividing contemporary discourse (Philosophical Arguments 164). The hope thus rests on a "community of comparativists" who come from different cultural backgrounds to contribute their insights in different languages (C. Taylor, Philosophical Arguments 164). It is up to writers and scholars alike to form this collective and put the act of mediation into practice.

\section{Mediating Orientalism: Framing as Narrative Method}

When Said published his major work Orientalism and his progressive notions of the way in which the media influence the spread of Orientalist thought on a global level, he did not do so with a limited view only on the academic world. As a public intellectual and political activist for the Palestinian cause, scholarship to him always needed to fulfill the criterion of "wordliness" to meet the demands of political and social life ("Interview with Salusinszky" 76). The practical relevance of Said's work relied on its quality to help Arab Americans as part of a larger postcolonial collective to reflect and understand their own position (Shakir, Bint Arab 17). With respect to the practical impact of actually changing Orientalist power structures, his outlook was rather bleak. Said's pessimism was mostly caused by his awareness of the rising dominance of the media in comparison to literary and political activism. As he states in an interview: "We have not yet devised the means to deal with a television or film or even a script image, and to criticize the framework in which that image is represented, because it is given as reality, mediated so powerfully, and accepted almost subliminally," he laments ("Interview with Crary and Mariani" 43). ${ }^{13}$ The present study provides a more positive outlook to change the media reality through framing.

When read from the renewed perspective of comparativist Orientalism, new possibilities for the self-definition of Arab/Muslim Americans and other so-called minority groups emerge. Since it is not Orientalism itself which triggers possible negative evaluations of Arabs and Muslims but the lack of information within this cognitive binary, the struggle between two identities and between two cultures becomes a valuable source of agency (compare Leonard 83). Contrary to the previous practice of countering Orientalism, the latter can thus be strategically em-

13 Especially contemporary readings of Said approach the founder of Postcolonial Studies very critically with respect to the lack of trust he had in the potential to implement effective counter-narratives. This critical stance from within the postcolonial theory camp appears quite noteworthy given the almost unchallenged praise of his work in former periods (Aboul-Ela, "Is there an Arab" 730). 
ployed and mediated in life writing to make a positive impact on public discourse. The result is a renewed sense of literary activism based on the use of framing as literary instrument.

Framing in the political realm has long been accepted not only as a constraint but as an instrument of political and social activism. Framing as activist tool counters the popular critique spread by media critics who claim that framing cannot serve the "public good" if political decisions depend on it (Kern 298). If those who are affected by these political decisions, however, employ the same means of public opinion management, framing can indeed serve the public good by means of supporting collectives. This particularly holds true for Arab and Muslim American political activisits in the period post $9 / 11$ who have come to realize the potential of media framing as an effective force to counter media images through mobilization. They increasingly started to regard framing as "political and educational tool" to reclaim their agency (Buck). Mostly due to the separation of the disciplines and the limited view of life narratives as counter-stories, this practical relevance of framing has not been transferred to the literary arena. The present analysis, however, reveals that framing can be just as powerful to influence public discourse as other media formats. The first step to achieving this aim is not the avoidance or deconstruction of Orientalism but its instrumental and strategic use in order to systematically explore contrasts between East and West (compare Norris 203-04).

It needs to be reiterated that this concept of strategic Orientalism does not correspond to any of the given ideas on re-Orientalism, counter-Orientalism, or postOrientalism. Rather, the source of this Orientalist mode can be traced to the traditional opposition between East and West, as it was first formulated by Said. What differentiates the strategic use of this comparativist trope of Orientalism on the basis of framing from other uses of the term today is its focus on the cognitive and structural function of opposition. This logic does not negate the factor of normative judgement since comparativism will never be value-neutral (C. Taylor, Philosophical Arguments 163). It thus sees judgement and evaluation as the conclusion emerging from binary comparison. This opposes the constant accusation by (Re-)Orientalist critics who state that Orientalism has come to serve as "discursive strategy that is directly absorbed and re-cycled by the diaspora in a way that it attests to the separation of cultures" (Salgado 211, 204). Furthermore, this practice stands in contrast to the constant debates on Spivak's "strategic essentialism" as tool to political agency (Salgado 204). If essentialism is defined in cognitive and not normative terms of identity politics, it does serve a strategic function in the creation of a collective identity which is more complex than essentialist.

How these more complex frameworks of identity definition can be installed has also been demonstrated by the given authors. By mediating issues which do not count among the standard issues found in the dominant media discourse on Arabs and Muslims, they offer the very complexity necessary to alter public images. De- 
spite the issue frame of the media itself, one of the most outstanding examples is the economic issue frame established by Kaldas and Hamoudi. The strong impact of this frame on the audience relies on the fact that class counts as one of the most neglected issues in the literature on Arab Americans. ${ }^{14}$ The strategic employment of an economic frame fills this information gap. Another noteworthy example of an alternative frame with a high potential to change the public definition of Arabs and Muslims is the one of law, as established by Hamoudi. This frame facilitates the intervention of Arab American authors in the expanding discourse on civil and human rights. Without the strategic targeting of this frame "it will always be the West that holds the key to the truth about law," as Ruskola reminds his readers (234). By actively bringing attention to legal topics, the writer as an "unacknowledged legislator" fully uses his/her professional and multi-ethnic agency to interfere in this discourse (Shelley qtd. in Orfalea 191).

These are just two outstanding examples that illuminate how framing based on the strategic use of Orientalist comparativism can fully take advantage of its potential to interfere in mediated discourse. The examples provide evidence that the stage at which the main purpose of Arab American literature was mostly seen in a collective "defining discourse" has been overcome (Jarmakani qtd. in Cainkar 164). By now, a more sophisticated approach to identity definition in life writing should be taken. The achievement of agency does not lose its significance within this approach but should be seen as an effect of more complex literary instruments. Not the reiteration of existing frameworks of interpretation and their countering allow for this potential, but the embracing of alternative frames sheds light on facets of Arab/American/Muslim identity previously unacknowledged. Orfalea in his observation of the current status of Arab American writing notices this necessity of thematic shifting when urging Arab American authors to write on things which are "not strictly Arab American," as he puts it (224).

This expansion of the thematic scope presently limiting the production of Arab American writing and ultimately its reception in the public not only refers to Arab American authors themselves. Writers in the literary and media sphere can also adopt the method of reframing presented in this study instead of being lost in counter-discourse. "The avoidance of stereotyping is not just a matter of grinding a single scene to imaginative powder," Orfalea poetically phrases it (170). The most essential prerequisite to actively engage with stereotypes and not their avoidance is

14 This neglect of class issues is symptomatic of a large body of Cultural Studies literature. Class here played a major role during the Thatcherism of the 1980s in British Cultural Studies and later quickly ceased (Padley 15). In American Cultural Studies, class as a sociological concept has never been a considerable object of investigation except for the muckraking period. It remains to be seen whether the lasting economic difficulties faced by the United States at the beginning of the $21^{\text {st }}$ century change this trend. 
cultural and issue-related expertise to produce the authentic accounts the audience obviously demands. As suggested by the authors of the present Arab American life narratives, this also calls for immediate cultural experiences in the Middle East. Orfalea in this context again points to the close entanglement between literary and journalistic production when urging American authors to become familiar with the Arab world. "We need authors with the lust for experience and hunger for humanity [...]. We need authors to live in Cairo, Nablus, and Damascus," Orfalea tries to awaken the lust for immediate cultural encounter (185-86). ${ }^{15}$

These elaborations on the strategic use of Orientalist comparativism turn the world of postcolonial scholarship upside down. Orientalism thus loses its status as a merely "intellectual enterprise" and takes the shape of "practical orientalism" 16 (Haldrup, Koefoed, and Simonsen 173). As such, it meets the reality of contemporary globalized discourse on Arab Americans and other ethnic minorities on much more empirical grounds than the secluded intellectual theorizing of supposedly deconstructable binaries. Framing as narrative strategy does not provide a tool to write about Orientalism, Arab Americans and Muslims. Instead it offers a tool for Arab/Muslim Americans authors to negotiate and mediate the Orientalist reality of their lives. It is now up to Orientalist scholars to also take a closer look at this Orientalist reality without deconstructing it. Framing as an analytical instrument therefore also gains practical value for the scholarly audience.

\section{Mediating Orientalism: Framing as Analytical Method}

Obviously, the redefinition of a long-standing concept such as Orientalism poses a challenge to all those who derive their right of academic existence from the very assumption that Orientalism fosters the notion that the West is still "civilizing the world" (Khair 156). Even critics in postcolonism have meanwhile come to the conclusion that Western scholars are still the ones defining major scientific concepts and thus play a "constructive" role (Khair 156). The immediate postcolonial impulse to this critical finding is to work against it by insisting even more vividly on the essentialist tendency of Western scholarship. Again, this approach seeks to

15 Orfalea generally has a high acclaim of literature and values it even more than journalism. In the case of immediate cultural experience, he nevertheless sees the mobility of journalism triumphing over literary production. "On this account," Orfalea states, "our journalists may have a better start than our so-called serious novelists [...]" (185-6).

16 Haldrup, Koefoed, and Simonsen introduce the term "practical orientalism" to describe the function of Orientalism in Denmark. The interview-based analysis reveals that the borders between East and West are blurred in the everyday encounter of members from different cultural backgrounds who display practical Orientalism as a means to engage with each other (173). 
change the conditions of empirical reality before actually interfering in it. If taking the empirical reality as a given, one can see the lasting Western dominance in scientific discourse as a chance to arrive at new theoretical concepts and redefinitions of former Western biases. Framing provides a means to this.

According to the harsh critique of Hilfer, the lasting essentialist impulse of scholars is one of the greatest obstacles to path-breaking new theories in Postcolonial Studies:

Theory is most self-contradictory in its overt negations and covert resurrections of value. Theory thrills by its ruthless negations, using the methodological shortcuts examined in previous chapters. Other discourses are discredited for violating essential rules of thought by being essentialist - that is, centered, universalist, transcendent. These bad discourses are also ascriptively discredited by illegitimate origins: "white, bourgeois, androcentric Westerners" [...]. (Hilfer 69)

The interdisciplinary analysis of the workings of Orientalism in present-day culture and literature points to the fact that such an opening toward "other discourses" is not only necessary but possible in order to grasp the reality of Orientalist tropes working through discourse. Pragmatic essentialism must first and foremost embrace the positive potential of binary thinking as not only constitutive of power structures but of cultural knowledge. As Ashcroft and his colleagues state: "Just as the two geographical entities, the Occident and the Orient, in Said's terms, 'support and to an extent reflect each other', so all postcolonial societies realize their identity in difference rather than in essence" (165). Elizabeth Eide in her study on strategic essentialism hints at a similar trajectory when calling for a move away from "ethnification" to "culturalization" to leave behind the heavy thematic focus on ethnic identity in scientific discourse (69). The most radical shift of thinking on the basis of the comparative mode is suggested by Ruskola. From the philosophical insights of Taylor, he derives the need for "an ethics of comparison" (230). This ultimately provides the chance for scholarship to arrive at a new understanding of Orientalism which turns into "an ethics of Orientalism, rather an impossible morality of antiOrientalism" (Ruskola 225). ${ }^{17}$

17 Ruskola develops his argument for an ethics of Orientalism in the context of his discussion of legal Orientalism in which the rule of law is constantly defined by Western standards. He defends a very specific definition of ethics as "normative systems that are concerned, not with what a pre-given subject may or may not do, but rather with the construction of that subject. Instead of assuming an ethical subject and then regulating it, ethics regulates the conditions under which subjects emerge" (225). Although developed in a field outside Literary and Cultural Studies, this understanding underlines the interdisci- 
Such a reformed understanding of Orientalism as the consequence of autobiographical mediation marks a move from a focus on normativity to cognitivism, from essentialism to comparativism. Above all, knowledge relies on cognitive schemata produced and reproduced in everyday discourse. Framing as a theory of reading life narratives and ethnic literature provides a novel instrument for scholars to grasp the mechanisms underlying mediated discourse. The necessary condition for this is the acquisition of empirical as opposed to hermeneutical knowledge on the part of cultural and literary scholars. The opening toward cognitive science and social psychology is a promising starting point for such an interdisciplinary engagement. In addition, the overcoming of the constructionist bias to either ignore or deconstruct empirical reality in favor of purely abstract models is another fruitful path. Both of these theoretical advancements ultimately also constitute a strategy for scholars to reframe present-day postcolonial discourse and look at fictional and non-fictional writing as active participants in contemporary media discourse.

The evidence presented in this analysis strongly underlines that Orientalism continues to be one of the most encompassing ideologies in mediated discourse. It is a global cognitive mindmap allowing people to order and evaluate cultural knowledge. Alternative Orientalisms, such as the comparativist Orientalism modeled in this study on the basis of framing, allow those who mediate cultural knowledge and who analyze it in the academy to probe new strategies of communication without neglecting the respective other. Taylor thus suggests that "comparative understanding lets our own faith be too. It liberates our selves along with the other" (Philosophical Arguments 164). In a similar vein, Orientalism as cognitive concept opens up new forms of analytical engagement with multi-ethnic life narrative inside and outside the academy.

plinary importance of comparison as preceeding normative judgement, which in turn is a consequence of individual agency. 


\title{
8. Conclusion
}

\begin{abstract}
My subject is both simple and impossible: Why write? I seem to be facing the void of late. This has been one of those times in a writer's life that questions the most fundamental assumptions about life and oneself in particular, and it seems unavoidable that if this self-weeping is going on, then one can't help but consider the possibility that writing is useless. It won't help you eat, certainly, and it won't help you breathe, and it certainly won't stop the war in Iraq. Or Palestine. (Orfalea 226)
\end{abstract}

These lines from the chapter "Why Write?" in Gregory Orfalea's autobiography Angeleno Days reveals a fundamental struggle writers face. It is the question of meaning and thus also a question of effect. With respect to the writing of autobiography, this question has usually been answered in a twofold way by literary authors and scholars of life writing. In an era in which the self largely depends on narrative formation and performance, the act of writing first and foremost benefits the self. As Orfalea puts it, writing helps make discoveries that "can be as psychologically shaking as they can be healing" (231). With respect to the effects of autobiographical writing, this focus on the self and, in the case of ethnic writing, the focus on a particular collective, has always been interpreted as the major effect of life writing as agency-building and counter-discursive. But does agency stop a war? Does it stop the Palestine conflict? The answer Orfalea suggests is no. If one looks at literature not as a weapon of words but as a weapon of mediation, the answer can be more positive.

The reason why autobiographical writing has hardly been regarded to make an impact beyond the literary realm is because the literary has never truly looked beyond its limited theoretical confines. Especially with respect to literature as a medium, the framing analysis has demonstrated that a new theoretical angle to approach autobiography allows for new audience effects to be explored. This ap- 
proach takes the term discourse seriously and defines it within the media reality of today. The results reveal a detailed picture of how autobiography functions within the larger media discourse thereby also pointing to the possible potential it currently has and might have in the future. As the (re-)framing of the Arab/Muslim achieved by the authors in this study reveals, life writing is not unarmed in the battle for public opinion. An overview of the results structures the theoretical and practical implications that a reformed view of life writing as mediation brings about.

\section{Life Writing as Mediation: Arab Americans in the Theoretical Borderland}

Despite Orfalea's bleak outlook with respect to the effectiveness of writing in fighting wars, Arab Americans still seem to believe in the impact of literature. The number of fictional and non-fictional works continues to rise. Some of these new book releases become a subject of media debates due to the fame of the author or the timeliness of the issue. In a similar vein, the media increasingly become a topic in the writings of literary authors as a result of the constant mediatization of Arabs and Muslims. With respect to the academic analysis of these works, however, the bridge between the media and the literary realm has not been built so far. Literature continues to be read and analyzed as literature by literary theorists. The media continue to be seen as media and analyzed by media scientists. Only the overcoming of this artificial academic division recognizes the empirical reality that public discourse today almost exclusively takes place in a mediated environment. In result, the hegemony of media discourse can be regarded as a major source of potential for literary writing to make an impact on public discourse. This also unveils audience effects that have previously been neglected.

The interdisciplinary theory transfer from Media to Literary Studies has demonstrated that life narratives due to their specific characteristics do not stand in opposition to other media forms in public discourse. The key to installing this understanding is to leave the merely theoretical ground of the respective disciplines and look at autobiography from the viewpoint of production and reception. This fulfills the urge of Stanley Fish who draws attention to a "strategy of self-consciousness" in the disciplines (108). This consciousness needs to take into account the larger trajectories surrounding literary works. Such a move ultimately transforms the nature of literary criticism altogether, as Fish extrapolates. "Once you turn, for example, from actually performing literary criticism to examining the 'network of forces and factors' that underlie the performance, literary criticism is no longer what you are performing" (108-9). When putting this call into practice, it turns out that the supposed semi-fictional nature of life narratives does not explain why autobiography tends to be read as fact rather than fiction. What combines media content 
and life writing, and what distinguishes life writing from other forms of fictional writing from the angle of the audience - not from the position of the postcolonial critic - are the truth and authenticity of information. Said already acknowledged this finding in his discussion of scholarly life writing. The perceived authenticity of autobiography provides the key for the audience "to see the story within the story" ("Scholars, Media" 301). This crucial link of life writing as information medium grants it a position outside the literary market and inside mediated social discourse.

This definition of autobiography as a medium allows for further insights into the social function of contemporary autobiographical writing. One of the most farreaching findings is that truth and authenticity do matter, despite any constructivist assumptions dominating the scientific discourse. Hilfer thus urges literary theorists to not neglect this realist stance in her chapter "Get Real" in which she claims: "In becoming real, our chance of resisting the unreality that surrounds us becomes more possible" (73). Part of this "unreality" today is shaped by the emergence of new media. This in turn allows for new types of life writing. These "hybrid forms" that continue to emerge in "ongoing metamorphoses" no doubt blurr the lines between media and literature (Arida 5). These new media formats, however, should not make researchers blind out the fact that old media life writing still constitutes a powerful instrument of social discourse.

The conceptual link allowing one to see this parallel is the precise definition of discourse as based on knowledge exchange. This ultimately brings in a larger political dimension of life writing as medium; a dimension which autobiography theory so far has s only explored in the context of ethnic life writing. Here, "talking back discourse" has been seen as the major instrument of formerly colonized groups to reverse public identity definitions. Obviously, this assumption is based on political and normative grounds rather than on analytical discourse analysis. The latter in turn states that the biggest impact on public opinion is not achieved through counter-images but by providing affective and cognitive knowledge. Just like journalistic life narrative occupies a particular place in the literary realm, life narrative takes a particular position in the "economy of news" (Whitlock 137). Only factual and credible information can therefore achieve opinion changes by altering cognitive frames (Aruri 35; Hart 319). This new knowledge allows audience members to place stereotypes in a different cognitive context and thus also arrive at different normative evaluations toward issues and individuals.

This interdisciplinary link between cognitive and affective opinion influence is provided by the theory of framing which is a strategic, analytical, and effectsoriented theoretical model (Hart 315). The detailed theoretical transfer of the theory from Media to Autobiographical Studies reveals that framing fulfills the following functions: 1) It is a necessary mechanism to reduce complexity on the part of the author and thus structure information; 2) it allows the audience to process information in a structured manner; 3) as an effect, it alters the cognitive as well as the 
affective perception of issues and thus also impacts attitudes, behavior, and stereotypes; 4) as a strategy, it helps authors achieve certain discursive goals. This view of framing as partly unintentional process to structure information and as process of strategic communication is what marks the particular theoretical value of framing as a theory of literary production and reception. Frames can be detected in literary works as well as in the environment surrounding the production of these works. Autobiography and ethnic autobiography in particular can therefore never be "[1] ocated outside the frames sustained by the media networks," as Whitlock claims, since it is an inherent part of this framed environment (Whitlock 139).

The intradisciplinary model that regards life narratives as media also has implications for the status of ethnic life writing within the larger field of autobiography research. As the analysis demonstrates, there is no justified reason to treat ethnic life writing merely within the limited confines of Ethnic Studies (Whitlock 179). Rather, its structural features situate the genre within the overall market of autobiography and thus also as part of non-literary public discourse. This underlines the "great power" that lies in personal stories without reducing this power to the emotional component of autobiographical reflection (Sadaawi qtd. in Arida 5). Neither is the discursive potential solely based on a political or specifically postcolonial axiom. It rests on an analytical understanding of how public images of individual and collective identities can be affected. This investigative coherence marks the strength of (re-)framing as an analytical tool in life writing research.

In sum, life writing as mediation helps the genre of ethnic autobiography in particular to escape the theoretical borderland position it has been caught in. Ethnic life writing therefore serves as a special example of the practical and theoretical potential of life writing at large, not as an exotic exception. This redefinition of autobiography as a medium consequently contributes to life writing research at large and to a more realistic analytical position therein. "Outside Theory, in the real world, readers not only form relationships with literary works but discover possibilities for richer human relationships inscribed within them," Hilfer states (81). As the closereading analysis of contemporary Arab American and Arab Muslim life narratives has demonstrated, this realist-minded analytical model helps reveal the mechanisms through which autobiographers impact public discourse and thus (re-)frame the public image of the Arab/American/Muslim. It is now time for scholars in Cultural Studies to further explore discourse based on a changed scientific ideology.

\section{(De-)Orientalizing Orientalist Scholarship}

The goal of Orientalist criticism has essentially been to get rid of Orientalism by bringing to light and subverting the underlying power regime of the West without, however, falling into the trap of using knowledge as power in the form of reduc- 
tionist Occidentalism. The underlying assumption has always been that Orientalism is nothing but the incarnation of an evil system of suppression. When turning this worldview upside down by regarding the cognitive frame of Orientalism as an analytical category, the question remains in how far this affects the larger tropes of Orientalist scholarship. Are postcolonial scholars losing their academic right of existence? The answer is 'yes,' if they continue to indulge in endless discussions on "Occidentalocentrism," native informants, and counter-discourse (Varisco 265). The answer is 'no' if contemporary Cultural Studies successfully manage the process of redefining some retracted definitions of concepts that have become outdated if looked upon from a more empirical perspective. In short, Orientalist studies need to (de-)orientalize their own field by means of including framing and other interdisciplinary approaches in their methodological toolkit. The major critical issues arising from this study provide starting points to such a reformation.

The first point of criticism can be derived from the very lack of studies found on contemporary Arab American life writing and the limited scope of themes under scrutiny in the scarce criticism that does exist. Scholars have been preoccupied with detecting Orientalist stereotypes in any possible piece of cultural production - by Western and Eastern writers, as well as by critics in the academy. Directly following the events of 9/11, due to the global media-bashing of Arabs, scholars first critiqued a "neo-Orientalist establishment within the academy" (W. Hassan, "ArabAmerican Autobiography" 32). In line with this warning, they then developed a hyper-sensitivity to anything that might point to differences between East and West, thus also targeting the conceptual twin of Orientalism, namely, Occidentalism. Mignolo's chapter "Post-Occidental Reason: The Crisis of Occidentalism and the Emergenc(y)e of Border Thinking" strikingly illustrates this aversion (91). The last step of the obsession to chase Orientalism like a ghost haunting cultural production has caused critics to blame members of the Arab world for supposedly reiterating Orientalist stereotypes. The ping-pong debates on the "Native informant over here" (Khan 2023) and the "Native informant over there" (Khan 2026) are only the most outstanding examples underlining this paradox. These debates bundled in Lisa Lau's formulation of Re-Orientalism as almost inevitable reiteration of the binary between the "Western world" and the rest of the world (Lau, "Re-Orientalism" 574). As Baneerjee's study on Iranian life narrative shows, the thematic scope of this "re-Orientalist trend" is mostly limited to feminist issues and large media critique (302).

This short synopsis of Orientalism in the academy provides evidence that Orientalism is not a dead concept. It is highly vivid in the sense that almost no publication can live without elaborations on the return of Orientalism, neo-Orientalism, reOrientalism, and the like. Critics thus ironically infer that Orientalism has gained the status of a "conspiracy" (Marrouchi, "Counternarratives" 213). This conspiracy undergoes constant transformation in the sense that it is not limited to the Middle 
East anymore but refers to the construction of Otherness in any possible context. Despite the negative connotation of the term Orientalism as such, it is therefore very much in fashion to associate oneself with the "community" of "counterinterpreters" which now includes highly paid professors and other intellectuals from East and West of whom many have developed not only a passion for countering counter-narratives but have also turned the enterprise into a "Stardom Syndrom," as Dabashi critically remarks (7-8). This intellectual community meanwhile also includes scholars of Arab and Muslim descent who set out to reframe public images of the Arab but now find themselves torn between countering the discourse on Arabs and Muslims and countering the accusation of being "producers of counterdiscourse" (Cainkar 156). These former but officially not-so-called "Orientals" are probably fighting the most difficult battle against Orientalism (Behdad 710).

This head-buzzing back and forth between different concepts of Orientalism strongly underlines that scholars have always focused on Orientalism as power division without allowing for alternative interpretations of the concept. Braginsky calls attention to this shortcoming when stating that "it seems clear that making an absolute of the factor of power only prevents the scholar from reaching a more realistic understanding of the multidimensional process of West-East attractions and repulsions which progressively reveals both their need for one another and their self-definition through reflection in one another" (530). Especially his calling attention to the aspect of "realistic understanding" is noteworthy in this far-reaching critique of Braginsky since it directly points to key concepts of border thinking, truth, and authenticity. All these terms today count as conceptual enemies in postcolonial scholarship and in the humanities at large. As the comprehensive study of life narrative in the context of production and reception demonstrates, it is this social reality that counts most for the writers and readers of contemporary ethnic life narratives. This realistic approach also to a large extent determines the very meaning and impact of life writing in society. The scholarly detachment from this reality and the neglect of "real contrasts" in the lives and narratives between East and West thus also explains the missing embracement of contrast as a value.

As Braginsky in his critique also highlights, this one-sided approach to Orientalism prevents postcolonial scholarship from moving on to reveal novel insights into the actual relations of East and West. In other words, "Said's specious Homo orientalicus is for many critics a revolutionary dead end" (252). Gradually, these critics in the fields of Ethnic and Arab American Studies draw attention to the need of overcoming the Orientalist legacy to develop novel approaches. Nadine Naber, one of the most progressive voices within this movement, identifies the most important question occupying the field: "How can Arab American Studies scholars respond to Orientalism in ways that do not reinforce it, or encourage Arabbashing?" ("New Texts Out"). Naber in this context also criticizes that the preoccupation with Orientalist practices in the media and in scholarly criticism disregards 
"intra-Arab American relationships and differences," such as sexuality, gender, and class ("New Texts Out"). As Naber explains in an interview, her book Arab America: Gender, Cultural Politics and Activism is an effort to respond to this challenge. It suggests diasporic feminist critique as "de-Orientalizing theory and method" for analyzing the situation of Arab Americans from a new perspective ("New Texts Out"). Naber puts particular emphasis on the link between the academy and the social world by explicitly regarding "academic audiences" as well as Arab Americans and social movements as her audience ("New Texts Out").

A similar suggestion to the problem with an equally high emphasis on the role of the scholar in responding to the challenges of Orientalism was proposed by Dabashi. In his study Post-Orientalism: Knowledge and Power in Time of Terror (2009), he identifies what he calls an "epistemic endosmosis" as the recent stage of knowledge production about the Middle East (xvi). To him, both Said and Spivak as most prominent figures in postcolonial scholarship fail in tackling the underlying trajectories of Orientalist knowledge production by taking the idea of the West too seriously to weaken it. Dabashi sees the solution to this problem in a new form of "Post-Orientalism." As he emphasizes, this alternative Orientalism stresses the role of the intellectual not merely as critic but as "social category" represented mostly by exilic scholars (1). The core pillar of this thesis is an "altered interlocutor" to speak on behalf of a global collective (272-73). The ultimate purpose of this changed interlocutor lies in the breaking of the vicious cycle around counterdiscourse to arrive at "post-Orientalist knowledge production" (278). What is needed for this, as he argues, is a "politically pointed and powerful language that is not trapped in ciruitous discourse of merely talking back to the self-appointed interlocutors of the world" (278). Ultimately, Dabashi sees the potential of this postOrientalist discourse rooted in the normative agency of the postcolonial critic to produce and spread alternative knowledge in the period after 9/11 (280). In sum, he thus regards the intellectual as "paramount site for the cultivation of normative and moral agency with a sense of worldly presence" (xiii). ${ }^{1}$

Although these suggestions promise considerable potential for breaking the vicious cycle of counter-discourse analysis and its ceaseless reproduction, the study at hand reaches further in its critique of the present state of Cultural and Arab American Studies. Based on the findings at hand, the plea for an "altered interlocutor" and the embracing of new methodologies has certainly received confirmation by the results at hand. What this study denies, however, is that the potential of this altered

1 Although Dabashi regards his approach partly as a critique of Said's notion of Orientalism, his clinging to the normative agency of the academic as interlocutor nevertheless traps him in a similar tautology as Said. The latter has been criticized for his vision of scholars who "act in the interest of truth and justice and fairness and honesty" while at the same time challenging notions of absolute truth (Lewis et al. 306). 
intellectual is rooted in normative concerns or in a post-Orientalist stance. It is the very opposite of the constant struggle against Orientalism or the overcoming of Orientalism toward a post-something-era that this work argues for. It has demonstrated that the major shortcoming of present postcolonial scholarship can be found in the fact that Orientalist critics by constantly reinvoking the issue of counterdiscourse have limited their thematic scope ad infinitum to Orientalism. This has led to the paradox result that they themselves are the major actors in keeping the Orientalist/Occidentalist binary alive as the most dominant power mechanism circulating through the global academy. Instead of accepting and embracing the "real" differences found in the cultural material at hand, their spontaneous impulses immediately make them turn those differences into artificial boundaries symbolizing power relations. Not only is this approach highly ignorant of historical dynamics and findings derived from the empirical sciences which analyze discourse on less normative grounds. This resilience to alternative theories is also highly Orientalist in nature since it neglects alternative interpretations that do not necessarily originate in the Western academy. Rationality and enlightenment continue to be the buzzwords in this scholarly discourse which now also increasingly targets Middle Eastern writers. A telling example of this is provided by Banerjee who states that "In this brave new world in which re-Orientalist writers happily recreate the American neo-colonialist structures of popular culture, enlightenment is not quite what it used to be" ("Between the Burqa" 313).

Obviously, statements of this kind underscore instead of subvert the cultural presumption which postcolonialism seeks to tackle. This incremental finding that alarmingly many in Postcolonial and Cultural Studies seem to ignore successfully is again formulated to the point by Taylor. He identifies the tenacious clinging to the concept of equality in the Western academy as an "axiom" in the contemporary humanities. This axiom especially haunts Cultural Studies, as he states:

[W]hatever it is that has pushed modern western culture to study others, at least nominally in a spirit of equality (it is because they recognize this spirit as legitimate that orientalists feel calumnied by the attacks of such critics as Edward Said), is missing in many cultures. Our very valuing of this equality ${ }^{2}$ seems to mark our superiority of our culture over some others. (C. Taylor, Philosophical Arguments 156)

2 The finding that the value of equality itself is a Western invention is linked to a much larger debate on the definition of human rights and ethics towards a supposedly common goal of "Universal Personhood" (Ta 167). The critique of equality as Western axiom also highlights that the field of ethics at large continues to be dominated by the West (Christians 37). Scholars like Spivak clearly operate with Orientalist binaries when speaking of "Western ethics" (Spivak, "Interview" 27). 
Taylor in these lines unfolds the powerful logic of how a supposedly positive value such as equality can become the instrument of hegemony because its inherent goodness is derived from its definition by the West. Instead of constantly enforcing the normative value of equality on the social world, scholars in Postcolonial and Literary Studies alike have the opportunity to take the "social inequality" existing in the world as an empirical given. This inequality is not merely rooted in the intentional or unintentional ideological thinking of the unenlightened but in the fact that comparison naturally leads to judgements of one kind or another. Only this rethinking of the fundamental axioms of postcolonial scholarship really creates room for other concepts to emerge.

(De-)orientalizing Orientalist scholarship consequently has a double meaning when it comes to the effective development of Postcolonial Studies. On the one hand, Orientalist scholars should be deorientalized in the sense that axiomatic theoretical concepts such as Orientalism lose their imperial status as normative and ethical theory axioms. This should also lead to more thematic variety. On the other hand, Orientalist scholarship can consciously orientalize itself by "prizing otherness" based on alternative forms of Orientalism (Khair 150). Framing provides an analytical tool to performing this step in the sense that it allows for the structured investigation of difference as produced and circulated in the global literary and media discourse. It fulfills what critics of postcolonial scholarship have been calling for, namely, "negotiating similarity and difference" (Khair 155) without reinvoking "old-style Orientalism"3 (Schueller 481). Naber introduces the concept of a "DeOrientalizing Pedagogy" to move away from the same and highly abstract categories of analysis toward the study of the real-life circumstances of Arab Americans (Naber, "De-Orientalizing Pedagogy"). ${ }^{4}$ The key to offering a changed episteme thus does not lie in the normative agency of the scholar but in his/her analytical capacity to reveal mechanisms of knowledge production in the social world. As the life writers in this study have proven, this knowledge production can be facilitated

3 Malini Schueller in an article entitled "Orientalizing American Studies" from 2008 especially critiqued the continuous rise of Orientalism in the field post 9/11. By calling it "old-style Orientalism," Schueller explicitly targets the normative implications of Western scholarly dominance (481).

4 Naber especially values the meaning of the Arab spring movements as opening up new opportunities for scholars to teach about the Middle East (Naber, "De-Orientalizing Pedagogy"). This impact of political key events as "pedagogically crucial" was also demonstrated in the aftermath of $9 / 11$. The extremely derogatory and discriminatory coverage of Arabs in turn triggered a movement in favor of a more balanced representation of Arabs and other ethnic minorities at large. Merskin summarizes the positive side-effect of this defining moment: "Perhaps then, in an odd twist of fate, the experiences of Arab Americans after September 11 will ironically serve as a crucible of our times" (Merskin 173). 
by the reinforcement of binary oppositions. The denial of these differences on intellectual, political, and above all normative grounds does not correspond to this social reality. The major step toward (de-)Orientalizing Cultural Studies thus rests on the acknowledgement that Orientalism as cognitive structure is part of the social present. This will naturally eliminate some of the preoccupations currently preventing scholars from devoting themselves to more nuanced analyses. The Chinese scholar Wang Ning summarizes this claim: "Orientalism is - and does not simply represent - a considerable dimension of modern political-intellectual culture, and as such has less to do with the Orient than it does with 'our' world" (57).

\section{Marketing the Market of Mediated Lives}

\section{Image 11: The Media World as Market of Ideas}

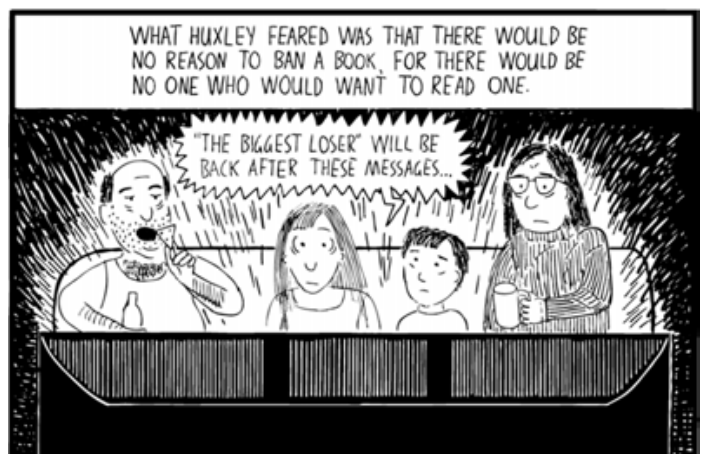

Source: Comic adaptation of Amusing Ourselves to Death (McMillen).

"Our" world is not only a synonym of the Western world anymore. Instead, the Eastern and the Western world are becoming increasingly unified by their common embracement of the media revolution. The comic adaptation of Postman's Amusing Ourselves to Death draws attention to the centrality media play in the life of the people. Several decades ago, the spread of TV culture triumphed over more traditional forms of media entertainment. Meanwhile, the internet has made an even more central impact on the social life of people around the world. The fear of cultural critics has always been that old forms of media might be pushed aside by newer ones, as the debate by Aldous Huxley and George Orwell in the comic demonstrates. The book counts as the "biggest loser" in this development. The reality of media consumption, however, has proven these gloomy scenarios wrong. The often-declared death of the book has not occurred. Instead, new forms of media entertainment such as television and film have complemented old media. This has also supported the marketing of print publications (Padley 107-08). The growing demand for the publications of Arab and Muslim authors in the recent period serves as another example of the fact that the book is not dead. In addition, this demonstrates that TV culture has not turned the media audience into brainless losers of the entertainment industry. As the present study reveals, media consumers still turn toward books to gain knowledge. Autobiographies as interlocutors of cultural and 
theoretical knowledge have considerable potential to meet this demand because of the high degree of authenticity granted to them. Orfalea underlines this unique potential for literary reframing in powerful words:

[I]t is truth evoked in moving language that gives us readers a twinge inside. [...] We readers live for that effect. The best imaginative fiction cannot, by definition, utilize stereotype, which is the antithesis of imagination. Stereotype causes the hungry reader a wince, rather than a twinge. Stereotyping involves a breakdown in the perception of the plentitude of existence. Simple laws of perception admit reality's diversity. The keen eye, ear, and heart of a storyteller will not allow for the reduction of the individual to a mathematical equation or one characteristic ([...] Jews are stingy, Arabs are wily, Blacks are slow [...]). (169)

Just like new media with their "moving language" have not replaced old media but complemented them, life narratives complement the media discourse in popular culture. They have distinctive features that still allow and even require them to be read as part of the global media market, not outside of it. Such an opening requires an altered mindset on the part of literary scholars to approach books as market commodities. The bourgeois thesis of Huxley and Postman that values the book as higher cultural good than the TV set is still reflected in the Literary and Cultural Studies departments around the world. This particularly holds true when it comes to postcolonial scholars whose major preoccupation has been attacking Arab American writers for marketing their works as native informants for the purpose of lining their pockets. It seems that also in this case, the normative paradigm of Orientalism has prevented the field from moving further. Capitalism has always been connected to the Occident and Orientalism thus forms a tool of economic exploitation by the West, as cultural critics like to argue (Mignolo 65; Braginsky 518). Questions to the role of ethnic life narrative in the book market have therefore either been denied completely or treated from an anti-capitalist standpoint which sees the market as place of cooptation. Huggan's provocative book title "Marketing the Margins" is only one example of this practice.

The condemnation of market trajectories has naturally led to the result that those supporting this market, namely, the general readership outside the Literary Studies departments, has mostly been excluded from the analytical picture. The audience is therefore, although mostly implicitly, regarded as "uninformed American readership" (Whitlock 165). In the Arab American context, the assumption is that readers enjoy the "one-sided jingoism" on Arabs spread by the American media (Cainkar 155). Instead of exploring the motives why readers consume the life narratives of particular ethnic groups, cultural critics continue to judge these motives in the first place. This partly causes that the primary audience of cultural literary critics still consists of "cultural literary critics" themselves (El-Haj 547). The study of popular culture therefore remains slightly unpopular among postcolonial scholars. Joli Jen- 
sen's critique of the "Fear of Trash" raised in 1988 therefore still holds true. Jensen states "that popular culture study is acceptable in academic life only when it becomes, via the jargon of 'high theory,' unrecognizable to its actual audiences" (97).

As this study of ethnic life writing based on a theory of production and reception has shown, the hostility toward the market would ultimately change with a less normative understanding of Orientalism and with the inclusion of more empirical methodology in the humanities. Instead of theoretically assuming that literature is written for general audiences, literary scholars should start studying these audiences with a more practical mindset. This would call into question some of the most resistant theoretical myths in the field and make room for new research topics. One of the myths related to ethnic life writing remains the lasting focus on identity negotiation and possible benefits ethnic audiences might derive from the reading experience. The present analysis clearly demonstrates that the audience of Arab American life narratives mostly consists of Americans with no multi-ethnic background and that, in addition, most authors explicitly focus on reaching this audience. "Especially in the post-9/11 context," Carol Bardenstein confirms, "a significant segment of Arab American authors are writing very consciously for a 'Western' audience" (Personal interview).

An important research path to pursue therefore is the study of different audience motivations for consuming ethnic life narratives. This in turn sets the basis for identifying audience effects in more differentiated ways. Previous analyses on ethnic readerships, their features as media consumers and their reading habits provide first starting points for such novel findings (Greco, Rodríguez, and Wharton 173). ${ }^{5}$ Arab Americans, however, have so far been absent from the range of ethnic groups appearing in these studies. Their inclusion would ultimately benefit the status of Arab American Studies in the academy at large. Furthermore, the inclusion of formerly neglected audiences and the detailed study of readers as media consumers would contribute to life writing studies at large, since especially audience re-

5 Greco, Rodriguez, and Wharton in their study entitled The Culture and Commerce of Publishing in the 21st Century provide a thorough data analysis of the relation between the book market and audience reception. With respect to the variables that highly impact book consumption, the authors identify ethnicity and gender to be decisive criteria. As they explain, the vast majority of data available on this subject focuses on Latinos and African Americans (173). The analysis largely draws on a study released by the National Endowments for the Arts (NEA) from 2007 that bears the revealing title "To Read or Not to Read: A Question of National Consequence.” The latter study also strongly highlights the impact of ethnicity on reading habits and purchase decisions (94). 
search is in need of further theorization in Autobiography Studies (Smith and Watson, Reading Autobiography 92). ${ }^{6}$

Such a theoretical and practical opening of life writing scholarship toward the market as major source of knowledge gain would naturally lead to an altered image of the intellectual as interlocutor between the social world and the iron tower. Nadine Naber with her longing to write for multiple audiences located outside the academy provides a promising example of this quest. Only very few scholars in the field of Postcolonial and Arab American Studies have so far successfully managed this step of overcoming the boundary between scholarship and popular culture. Tamim Ansary and Haider Ala Hamoudi, due to their public presence in the mass media, constitute such examples. With their writing and public advocacy they stimulate a dialogue on Arab and Muslim Americans inside and outside the academy that also helps Arab American cultural production to become a part of the Ethnic Studies canon (Aoudé 151). Such an inclusion fosters the further differentiation of Ethnic Studies and ideally allows Arab American Studies to develop as an acknowledged field in the academy (Salaita, "Ethnic Identity" 162). This recognition of Arab American Studies based on progressive theoretical approaches would invite more young scholars to contribute novel insights without having to fear the ideological battlefront of traditional Orientalist (counter-)arguments. Above all, these young critics are desperately needed to push the field (Orfalea 191). Eventually, this positive marketing of the market of life narrative within the realm of the academy might turn Said's vision of the public intellectual into academic reality.

The embracing of the media market and its opportunities for reframing collective images of the Arab/Muslim similarly applies to the side of Arab and Muslim writers themselves. So far, most of them have intentionally and unintentionally accepted the glass ceiling existing between the media market on the one hand and the literary and scholarly market on the other. Kaldas as someone who is not very prominent outside scholarly circles confirms this position. Her lack of media presence is at least one of the major reasons why her memoir has not become widely read in the public. This is not to argue that publicity guarantees market success. Nor does market success allow for any far-reaching claims concerning the content of respective literary works. Still, the mere sales figures are indicators of how much impact this literary content can potentially have on the readership. Academic writing in contrast to journalism and new media writing clearly reaches a more limited radius of audience members. This logic of academic seclusion only tends to be broken whenever the core pillars of academic integrity are violated and scandals sweep the field. Whitlock realizes this paradox in stating that only the hoax was

6 Smith and Watson in their brief discussion of the lack of audience studies in Reading Autobiography point out that the commercial success of a book remains one of the only indicators at hand to gain insights into audience reception (92). 
able to bring Arab American life narratives out of the "specialized academic journal and into the popular press" (Whitlock 119). This certainly should not count as an appeal to writers to sell untruthful accounts as personal memories. Rather, the sensitive reactions of the media audience in such cases point to the fact that there is a large potential to trigger public discourses by means of literary production.

The texts analyzed in this study and the respective audience responses have illustrated that this discursive impact can undoubtedly be achieved by life writing. The problem remains that the scope of audience members reached remains minimal compared to best-sellers in other fields. A number of only a few hundred copies sold certainly cannot count as major impact on what is considered public opinion. ${ }^{7}$ Nevertheless, the example of Ansary and the media popularity following the publication of his e-mail suggest that cross-media communication can indeed widen the circles of target audiences. Again, writers and scholars alike should not denigrate this media presence as the longing for personal fame merely. Rather, authors like Ansary should serve as models to merge the different forms of mediated discourse to a common end. Only this heightened presence of Arab Americans in various media markets will continue to satisfy the steady demand for more knowledge created and narrated by not about Arabs and Muslims. Since this demand naturally produces economic potential on the part of publishing houses, the number of presses issuing special series such as Syracuse can be expected to rise. Above all, the reading of life narrative therefore not only relies on an autobiographical pact but on an economic pact as well. The acknowledgement of this finding will also eliminate much of the "repressive publishing culture" that authors of Arab and Muslim descent previously faced as a consequence of the political impact of the Middle East conflict (185). In fact, many of the instances in which Arab American authors faced difficulties were caused by Orientalist hegemony played out by publishing houses. If the market forces the presses to learn more about the Orientalist dichotomy itself, normative arguments preventing Arab American voices to appear in the public would automatically be overruled by economic interest.

In sum, these repercussions on the importance of life narrative as part of the larger media market provoke the urgent need to accept that capitalism is not merely an evil legacy bequeathed by the Western colonizer. Capitalism is the economic and social reality in most countries around the world and this system therefore also rules the media market. Life narratives as part of this market are written to be read - not by literary scholars merely, but by the general audience. Every single audience

7 Alsultany emphasizes the decisive impact of life stories on the larger media audience while also pointing to the crucial disadvantage written autobiographies still have in comparison to other media material. "Life stories do impact public stereotypes in many ways," she states, but "stories in the media generally have a bigger impact than written autobiographies because more people watch than read" (Personal interview). 
member is part of the collective forming public opinion in the polls. The reaction of the market thus also determines who is allowed to have a voice in the larger public dialogue (Whitlock 10). The media market as stimulator and indicator of social discourse therefore does not limit but emphasize the value of life writing - in material and immaterial terms. Writers and especially scholars should develop a more market-oriented attitude toward the potential the media market has to offer. Instead of "Marketing the Margins" they should thus market the market of ideas arising from life narratives as consumer commodities.

\section{Outlook: The "All-American Muslim" Memoir?}

Ten years after 9/11, a new reality TV show, called "All-American Muslim," tackles stereotypes by following five families in Dearborn, Michigan. They focus on a cop, an expectant mother, a bride, an entrepreneur and a football coach. [...]

UNIDENTIFIED TEEN \#1: Our school, we're 95 percent Muslim.

UNIDENTIFIED TEEN \#2: When we play teams away from Dearborn, they start calling us names.

UNIDENTIFIED TEEN \#3: You f-in(ph) Arabs, terrorists.

UNIDENTIFIED TEEN \#4: You're the A-rabs, camel jockeys. (“Ali Calls”)

In December 2011, the "Talk of the Nation," not only on National Public Radio but across the country, focused on one topic: Arab American Muslims. This time, however, the debate did not target a new terrorist threat or female veiling. Instead, the nation talked about the "ordinary" Arab American who was now displayed weekly at prime time on public television. Not long after the "All-American Muslim" aired for the first time, the discourse on the new reality show inflamed. Above all, reality soaps were nothing new in the number one country of soap entertainment. Witnessing the reality of Arab American lives on television, though, was a new experience for the American audience. ${ }^{8}$

Many Arab Americans highly welcomed the new show. As the Arab American playwright and journalist Wahajat Ali stated on NPR's most famous talk spot: "I think it's refreshingly bland. It's honest, it's real, it's human. And it's nice to see a show where Muslims aren't terrorists, taxi cab drivers or potential terrorists, you

8 In connection with the "All-American Muslim," media critics also point to the lasting lack of detailed audience research, even in the field of Communication Research itself. "When we talk about the audience of 'All-American Muslim,"” Alsultany explicates, "we do not know who this audience is; there are no figures." Despite the lack of comprehensive audience data, though, Alsultany and other scholars in Arab American Studies share an educated guess about the likely audience. "Definitely, Arab American families are watching," she adds (Personal interview; cf. Bardenstein, Personal interview). 
know? They're just people" (“Ali Calls"). Others in turn criticized the homogeneity created by the selection of cast members. As a caller on the program who teaches at an Arab American high school near Detroit summarized the reaction of her students: "They feel that the show has sort of chosen very Westernized Muslims as opposed to more conservative ones that they feel are reflective of the community" ("Ali Calls"). ${ }^{9}$ The responses of the mainstream American media audience were even more divided and mostly framed in political terms. While many appreciated the insider view on Arab American life in the U.S., especially conservatives were outraged to see potential terrorists in their own living room on Sunday evening. As a consequence, one of America's largest retailers decided to ban ads of the show from its stores. The retailer thus bowed to the pressure of a conservative group claiming that the program advocates "propaganda that riskily hides the Islamic agenda's clear and present danger to American liberties and traditional values" (Associated Press, "Lowe's Threatened"). Despite this torn audience evaluation, media critics and journalists received the show mostly in positive terms. Their reviews praised it as "intimate and informative" and "deeply intriguing" (Wajahat).

This recent example of discourse on Arab American Muslims illustrates that Arab Americans themselves are becoming increasingly aware of the importance mediated lives have as tools of social and political activism. This realization of the potential of mediated discourse grants Arab Americans and Muslims new means of public engagement which were long concealed due to the long history of media bashing applied to TV Arabs. In employing the media's own logic of news management and agenda setting, Arab Americans thus gradually succeed in affecting "The Pictures in Our Heads" (McCombs 68). As Wajahat furthermore stated, "the fact that Muslims have their own reality TV show means, you know, the Muslim agenda is successful" ("Ali Calls").

9 This comment is a tidbit of the discussion that the reality show fueled among Arab Americans. At the center of this debate stood the critique that the show does not reflect an "authentic" view of the average Muslim American family but a minority within it. This debate is particularly interesting since it reflects earlier critiques of the otherrepresentation of the Middle East and Arabs as reductionist and homogenizing. Wajahat in this context points out: "[T] he five families on 'All-American Muslim' should not be asked to represent all Muslims, Arabs or Americans. Does Jersey Shore represent all Italians?" (Wajahat). In an interview on NPR, he furthermore states: "There's no such thing as the, quote, unquote, 'perfect Muslim' (“Ali Calls”). Overall, this underlines that every media representation will always be selective and reductionist in nature. Alsultany thus adds, "the show is not completely unscripted" (Personal interview).

10 The expression "pictures in our heads" which counts as a popular metaphor in communication research was first used by Walter Lippman in the early days of public opinion research dating back to the 1920s (Jasperson and El-Kikhia 135). 
Whether this positive effect of mediated lives on public opinion will be successful in the long run remains to be seen. Still, two important conclusions can already be drawn from the current discussion on the "All-American Muslim." This conclusion again allows for important insights for the further development of life writing research. The first finding is that the public debate continues to revolve around the oppositions between Muslims and Christians, between Arabs and Americans, between West and East. This binary Orientalist thought pattern continues to be the reality of the social and political world, whether cultural critics like it or not. Secondly, the audience's high appreciation of findings derived from the depiction of 'normal' Arab American life again highlights the strong impact the authentic confrontation with mediated lives has on cultural learning. As one critic put it, the show is "More Educational Than [sic] the Cast Will Admit" (Nededog). This learning benefit is not only fostered by the show itself but also to a large extent by the media discourse that surrounds it. Similar to crucial events like 9/11 and the Arab Spring, this issue-related discourse has triggered a "pedagogical shake-up" in the public (Cainkar 155). Evelyn Alsultany therefore granted the show a large "potential to make a difference" because it is "part of a system of meaning-making" (Personal interview). Many Arabs and Muslims have thus become able to express their views in public who otherwise do not count as prominent media guests. Wajahat counts as one of them, and he is particularly aware of the important function, public communication has for collective self-definition:

A "real Muslim" according to many is this anti-American, extremist, violent stereotype - an image often plastered over news headlines. This myth is unsurprising, perhaps, considering $60 \%$ of Americans say they don't know a Muslim. Furthermore, the No 1 source of information about Muslims for American is the media, and often, the images are negative. Yet, according to all the studies and evidence, the reality of American Muslims is that they are moderate, loyal to America, optimistic about America's future, in tune with American values, well-educated, and are the nation's most diverse religious community. (Wajahat)

Wajahat in these lines reveals that social science scholars with their studies on the benevolence of American Muslims are far less recognized than the mass mediated truth of the Muslim extremist. Besides this implicit critique by Wajahat, his words also build an immediate bridge to the life narratives analyzed in this study. Just like Ansary, Kaldas, and Hamoudi, he directly points to the differences existing between Americans and Arabs in order to convey knowledge and understanding of a reality that cannot be seen in other media. Wajahat summarizes this (re-)framing function by pointing to the information that is usually lacking from mainstream media coverage. "So what you do see is, you know, a terrorist stereotype. What you don't see is, you know, an educated, intelligent American-born Muslim woman who voluntarily chooses to wear the hijab. And even though she wears the hijab, she's opin- 
ionated, she works, she practices her Islam and, you know, she talks back to her husband" ("Ali Calls"). Ironically, it is America's TV culture that for so many decades vilified Arab and Muslims and now fosters the change of his image. This speaks to the value of Shaheen's prophecy that the power of the media to distort public images also provides the means to correct them. Carol Bardenstein thus calls the "All-American Muslim" show an "effective demystifier" (Personal interview). Life narratives as media follow this path. The "All-American Muslim" as offspring of America's dearest family member - the TV-set - provides an important starting point for this mass-mediated reframing of the Arab/Muslim. As Ali points out: "Reality TV is the current zeitgeist of popular culture. Unlike the euro, it is the predominant cultural currency, whose value is skyrocketing" (Wajahat).

It is now up to writers and scholars in Arab American Studies to take advantage of this zeitgeist and publicly interfere in public discourse - both on paper and on public television. They have the opportunity to fully explore the potential of life writing to mediate knowledge about Arab and Muslim lives. Framing offers a unique thereotical and practical instrument to link the media and the literary sphere by exposing the cognitive dimension of autobiographical writing and reading. Orientalism in this discourse cannot simply be countered or replaced since it allows Western and Eastern audiences alike to locate their own identities along necessary lines of interpretation. Only this - at least temporarily - fixed location of the self amidst a globalized world in constant flux allows for the possibility to comprehend and explore the Other beyond familiar frames of interpretation.

Orientalism as an analytical rather than normative concept ruling social reality makes room for novel possibilities of (re-)framing Arab and Muslim identity. This step is a beginning in autobiography research, and as Said described it in his chapter "Beginnings," "beginning is making or producing difference, but [...] difference which is the result of combining the already familiar with the fertile novelty of human work in language" (qtd. in El-Haj 550). It thereby matters little whether this difference is printed on pages or presented in flickering TV images. What matters most is the common message to be received by the American and global media audience. Arab Americans are Arabs because they are different from Americans in some ways. But they are Arab American because "[t]hey're American, too" (Salaita, "Ethnic Identity" 151). 


\section{Bibliography}

Abdelrazek, Amal Talaat. Contemporary Arab American Women Writers: Hyphenated Identities and Border Crossings. Youngstown: Cambria Press, 2007. Print.

Aboul-Ela, Hosam. "Edward Said's Out of Place: Criticism, Polemic, and Arab American Identity." MELUS 31.4 (2006): 15-32. Print.

---. "Is there an Arab (Yet) in this Field? Postcolonialism, Comparative Literature, and the Middle Eastern Horizon of Said's Discourse Analysis." MFS Modern Fiction Studies 56.4 (2010): 729-50. Print.

Adams, Deborah. Rev. of Howling in Mesopotamia: An Iraqi-American Memoir, by Haider Ala Hamoudi. Curledup. Web. 18 Aug. 2011.

Ahmed, Leila. Women and Gender in Islam: Historical Roots of a Modern Debate. New Haven: Yale UP, 1992. Print.

Ahmad, Muneer. "Homeland Insecurities: Racial Violence the Day after September 11." Social Text 20.3 (2002): 101-15. Print.

Altman, Alex. "Time Poll: Majority Oppose Mosque, Many Distrust Muslims." Time Magazine. 19 Aug. 2010. Web. 10 Oct. 2011.

Ajrouch, Kristine J. "Family and Ethnic Identity in an Arab-American Community." Suleiman, ed. 129-39. Print.

---. "Gender, Race, and Symbolic Boundaries: Contested Spaces of Identity among Arab American Adolescents." Sociological Perspectives 47.4 (2004): 371-91. Print.

Alasuutari, Pertti. "Introduction: Three Phases of Reception Studies." Rethinking the Media Audience: The New Agenda. Ed. Pertti Alasuutari. London: Sage, 1999. 1-21. Print.

"Ali Calls ‘All-American Muslim' a Welcome Relief." Talk of the Nation. NPR. 30 Nov. 2011. Web. 2 Dec. 2011.

Alkalima. University of California, Irvine, n.d. Web. 6 Nov. 2011.

Allen, Barbara, et al. "The Media and the Gulf War: Framing, Priming, and the Spiral of Silence." Polity 27.2 (1994): 255-84. Print.

Allen, Roger. "Four Meanings of an Arabic Word." Language Log. University of Pennsylvania. 19 June 2006. Web. 12 Dec. 2011. 
Alsultany, Evelyn. Personal interview. 23 Jan. 2012.

---. "The Prime-Time Plight of the Arab Muslim American after 9/11." Jamal and Naber 204-28. Print.

Altheide, David L. "Fear, Terrorism, and Popular Culture." Reframing 9/11: Film, Popular Culture and the "War on Terror." Ed. Jeff Birkenstein. New York: Continuum, 2010. 11-22. Print.

---. "The News Media, the Problem Frame, and the Production of Fear." The Sociological Quarterly 38.4 (1997). 647-68. Print.

"American Views on Arab and Muslim Americans." Arab American Institute. Zogby International, 2010. Web. 18 Sept.

Amstutz, Richard D. Rev. of Letters from Cairo, by Pauline Kaldas. Amazon 5 July 2007. Web. 18 Sept. 2011.

Andrews, Robert. Famous Lines: The Columbia Dictionary of Familiar Quotations. New York: Columbia UP, 1997. Print.

Angus, Ian. "Democracy and the Constitution of Audiences: A Comparative Media Theory Perspective." Viewing, Reading, Listening: Audiences and Cultural Reception. Ed. Jon Cruz. Boulder: Westview P, 1994. 233-52. Print.

Ansary, Tamim. Home page. Web. 22 Sept. 2011.

---. Interview with Alexis Menten. "West of Kabul, East of New York with Tamim Ansary." Asia Society, n.d. Web. 22 Sept. 2011.

---. Interview with Eren Güvercin."Militante Islamisten haben niemals das traditionelle islamische Leben erlebt." Heise Online. 1 Mar. 2010. Web. 22 Sept. 2011.

---. West of Kabul, East of New York: An Afghan American Story. New York: Picador, 2002. Print.

---. "Your Questions." E-mail to Silke Schmidt. 21 Mar. 2012.

Aoudé, Ibrahim. "Arab Americans and Ethnic Studies." Journal of Asian American Studies 9.2 (2006): 141-55. Print.

Appadurai, Arjun. Modernity at Large: Cultural Dimensions of Globalization. Minneapolis: U of Minnesota P, 2003. Print.

Arida, Holly. "Etching Our Own Image: Voices from within the Arab-American Art Movement." Etching Our Own Image: Voices from within the ArabAmerican Art Movement. Ed. Anan Ameri and Holly Arida. Newcastle, UK: Cambridge Scholars Publishing, 2007. 1-6. Print.

Armstrong, Paul B. "Being 'Out of Place': Edward W. Said and the Contradictions of Cultural Differences.” MLQ: Modern Language Quarterly 64.1 (2003): 97121. Print.

Arnold, Martin. "Racing against Attention Spans." The New York Times 25 Oct. 2001: E.3. Print.

Aruri, Naseer H. “AAUG: A Memoir.” Arab Studies Quarterly 29.3/4 (2007): 3346. Print.

Asayesh, Gelareh. "Stepping Westward.” The Washington Post 26 May 2002: T.15. 
---. "The Stolen Education." The American Scholar. Winter 2010. Web. 24 Nov. 2011.

Ashcroft, Bill, Gareth Griffiths, and Helen Tiffin. The Empire Writes Back: Theory and Practice in Post-Colonial Literatures. 2nd ed. London: Routledge, 2010. Print.

Ashmore, Richard D., Kay Deaux, and Tracey McLaughlin-Volpe. "An Organizing Framework for Collective Identity: Articulation and Significance of Multidimensionality." Psychological Bulletin 130.1 (2004): 80-114. Print.

Associated Press. "Lowe's Threatened with Boycott for Yanking Ads from Show about Muslims." Chicago Tribune. 12 Dec. 2011. Web. 14 Dec. 2011.

---. "Rights Group: Bias in West's Response to Arab Spring." NPR News. 22 Jan. 2012. Web. 23 Jan. 2012.

Audi, Ghada Q. "Challenges Facing the Arab American Community from a Legal Perspective.” American Studies Journal 52 (2008). Web. 22 Sept. 2011.

"Audiobook Cover West of Kabul." Blackstone Audio, n.d. Web. 12 Dec. 2011.

“Authenticity." Def. 2a. Merriam-Webster.com. Merriam-Webster, 2011. Web. 2 Dec. 2011.

Babin, Pierre, and Mercedes Iannone: "The Impact of Electronic Media on Faith." The New Era in Religious Communication. Ed. Pierre Babin and Mercedes Iannone. Minneapolis: Fortress P, 1991. 54-69. Print.

Bahramitash, Roksana. "The War on Terror, Feminist Orientalism and Orientalist Feminism: Case Studies of Two North American Bestsellers. Critique: Critical Middle Eastern Studies 14.2 (2005): 223-37. Print.

Bakalian, Anny P., and Mehdi Bozorgmehr. Backlash 9/11: Middle Eastern and Muslim Americans Respond. Berkeley: U of California P, 2009. Print.

Baker, John F. “Afghan Voices.” Rev. of West of Kabul, East of New York: An Afghan American Story, by Tamim Ansary. Publishers Weekly 248.41 (2001): 13. Print.

Baldwin, Elaine et al. Introducing Cultural Studies. London: Prentice Hall, 1999. Print.

Banerjee, Mita. "Between the Burqa and the Beauty Parlor: Re-Orientalism in Azar Nafisi's Reading Lolita in Tehran.” Living American Studies. Ed. Mita Banerjee et al. Heidelberg: Winter, 2010. 301-25.

---. “Arab Americans in Literature and the Media." American Studies Journal 52 (2008). Web. 08 Oct. 2010.

Barber, Benjamin R. Jihad versus McWorld: How Globalism and Tribalism Are Reshaping the World. New York: Ballatine Books, 1996. Web.

Bardenstein, Carol. "Beyond Univocal Baklava: Deconstructing Food-as-Ethnicity and the Ideology of Homeland in Diana Abu Jaber's The Language of Baklava." Journal of Arabic Literature 41 (2010): 160-79. Print.

---. Personal interview. 26 Jan. 2012. 
Barker, Chris. Cultural Studies: Theory and Practice. 3rd ed. Los Angeles: Sage, 2010. Print.

---. The Sage Dictionary of Cultural Studies. London: Sage, 2004. Print.

---, and Dariusz Galasiński. Cultural Studies and Discourse Analysis: A Dialogue on Language and Identity. London: Sage, 2001. Print.

Barnett, Brooke, and Amy Reynolds. Terrorism and the Press: An Uneasy Relationship. New York: Peter Lang, 2009. Print.

Baskin, Barbara. Rev. of West of Kabul, East of New York: An Afghan American Story, by Tamim Ansary. The Booklist 103.19-20 (2007): 112. Print.

Bayoumi, Mustafa. How Does It Feel to Be a Problem? Being Young and Arab in America. New York: Penguin, 2008. Print.

---, and Andrew Rubin. Introduction. The Edward Said Reader. Ed. Moustafa Bayoumi and Andrew Rubin. London: Granta Books, 2000. xi-xxxiv. Print.

Behdad, Ali. “Orientalism Matters.” MFS Modern Fiction Studies 56.4 (2010): 70928. Print.

Bennett, W. Lance. "The News about Foreign Policy." Taken by the Storm: The Media, Public Opinion, and U.S. Foreign Policy in the Gulf War. Ed. W. Lance Bennett and David L. Paletz. Chicago: U of Chicago P, 1994. 12-42. Print.

---, Regina G. Lawrence, and Steven Livingston. When the Press Fails: Political Power and the News Media from Iraq to Katrina. Chicago: U of Chicago P, 2007. Print.

Bernstein, Richard. "Edward W. Said, Literary Critic and Advocate for Palestinian Independence, Dies at 67." New York Times. 26 Sept. 2003. Web. 3 Oct. 2011.

Bertelsen, Cynthia. Rev. of Letters from Cairo, by Pauline Kaldas. The Book Omnivore 25 Aug. 2008. Web. 12 Sept.

---. Reviewer Profile. New York Journal of Books, n.d. 2 Nov. 2011.

Bhabha, Homi K. The Location of Culture. 1994. London: Routledge, 2010. Print.

---. "The Postcolonial and the Postmodern: The Question of Agency." The Cultural Studies Reader. 2nd ed. Ed. Simon During. London: Routledge, 1999. 189-208. Print.

"Binary." Merriam-Webster.com. Merriam-Webster, 2011. Web. 10 Oct. 2011.

Birkenstein, Jeff, Anna Froula, and Karen Randell. Introduction. Reframing 9/11: Film, Popular Culture and the "War on Terror." Ed. Jeff Birkenstein, Anna Froula, and Karen Randall. New York: Continuum, 2010. 1-8. Print.

Bissell, Elizabeth B. The Question of Literature: The Place of the Literary in Contemporary Theory. Manchester: Manchester UP, 2002. Print.

Blake, John. "Arab- and Persian-American Campaign: 'Check it Right' on Census." CNN. 1 Apr. 2010. Web. 2 Nov. 2011.

Boelhower, William. "The Making of Ethnic Autobiography in the United States." American Autobiography: Retrospect and Prospect. Ed. Paul J. Eakin. Madison: U of Wisconsin P, 1991. 123-41. Print. 
Bortolussi, Marisa, and Peter Dixon. Psychonarratology: Foundations for the Empirical Study of Literary Response. Cambridge: Cambridge UP, 2003. Print.

Bouzid, Ahmed. Framing the Struggle: Essays on the Middle East and the US Media. Lincoln: iUniverse, 2003. Print.

Braginsky, Vladimir I. "Rediscovering the 'Oriental' in the Orient and Europe: New Books on the East-West Cultural Interface: A Review Article." Bulletin of the School of Oriental and African Studies 60.3 (1997): 511-32. Print.

Buck, Leila. "Finding Our Voice: The Politics of the Personal in Arab American Theater." Etching Our Own Image: Voices from within the Arab-American Art Movement. Ed. Anan Ameri and Holly Arida. Newcastle, UK: Cambridge Scholars Publishing, 2007. 18-30. Print.

Burr, Vivien. Social Constructionism. 2nd ed. Hove: Routledge, 2003. Print.

Cainkar, Louise. Homeland Insecurity: The Arab American and Muslim American Experience after 9/11. New York: Russell Sage Foundation, 2009. Print.

Carey, Bryan. "Life in Post-Saddam Iraq." Rev. of Howling in Mesopotamia: An Iraqi-American Memoir, by Haider Ala Hamoudi. Epinions. 15 Apr. 2008. Web. 18 Sept. 2011.

Campbell, Duncan. "Reading Phonography, Inscribing Interdisciplinarity." Critical Studies: Cultural Studies, Interdisciplinarity, and Translation. Vol. 20. Ed. Stefan Herbrechter. Amsterdam: Rodopi, 1994. 131-45. Print.

Campo, Juan Eduardo. Encyclopedia of Islam. New York: Infobase Publishing, 2009. Print.

Cherkaoui, Tarek. "Orientalism, Pan-Arabism, and Military-Media Warfare: A Comparison between CNN and AlJazeera Coverage of the Iraq War." Diss. AUT University, 2010. Web. 12 Nov. 2011.

Chertoff, Michael et al. Interview with Neal Conan. "Drawing Lessons from 9/11, Ten Years Later. Talk of the Nation. Natl. Public Radio. WBUR, Aspen. 28 Jun. 2011. Web. 12 Oct. 2011.

Childs, Peter, and Roger Fowler. The Routledge Dictionary of Literary Terms. London: Routledge, 2006. Print.

Chong, Dennis, and James A. Druckman. "Framing Theory." Annual Review of Political Science 10 (2007): 103-26. Print.

Christians, Clifford. "Ethical and Normative Perspectives." Downing et al. 19-39. Print.

Clabough, Raven. "Did NYT Change Criteria for Bestselling List for Political Reasons?” New American. 22 Mar 2011. Web. 12 Feb. 2012.

Cole, Juan. “The Arab Spring: One Year Revisited.” Lecture. University of Michigan. Rackham Amphitheater, Ann Arbor. 9 Feb. 2012.

Coleman, Renita. "Framing the Pictures in Our Heads: Exploring the Framing and Agenda-Setting Effects of Visual Images." Doing News Framing Analysis: Empirical and Theoretical Perspectives. Ed. Paul D'Angelo and Jim A. Kuypers. New York: Routledge, 2010. 233-61. Print. 
"Common Concerns About Islamic Extremism: Muslim-Western Tensions Persist." Pew Research Center. 21 July 2011. Web. 12 Oct. 2011.

"Commodity." Def. 5. Merriam-Webster.com. Merriam-Webster, 2012. Web. 6 Feb. 2012.

Community Reviews of Howling in Mesopotamia: An Iraqi-American Memoir, by Haider Ala Hamoudi. Goodreads, n.d. 12 Sept. 2011.

Community Reviews of Letters from Cairo, by Pauline Kaldas. Goodreads, n.d. Web. 20 Sept. 2011.

Community Reviews of West of Kabul, East of New York: An Afghan American Story, by Tamim Ansary. Goodreads, n.d. Web. 18 Sept. 2011.

Condon, Stephanie. "Poll: 1 in 3 Think Muslim Americans More Sympathetic to Terrorists than Other Americans." Political Hotsheet. CBS News. 8 Sept. 2011. Web. 2 Oct. 2011.

Cruz, Jon, and Justin Lewis. Introduction. Viewing, Reading, Listening: Audiences and Cultural Reception. Ed. Jon Cruz and Justin Lewis. Boulder: Westview P, 1994. 1-18. Print.

Culler, Jonathan. "Critical Consequences." Deconstruction: Critical Concepts in Literary and Cultural Studies. Vol. 2. Ed. Jonathan Culler. London: Routledge, 2003. 35-70. Print.

Curiel, Jonathan. "The Voices of Arab Culture: Arts from Ancient, Diverse World Stir Interest in the West." San Francisco Chronicle 14 Apr. 2003: D-1. Print.

Dabashi, Hamid. Post-Orientalism: Knowledge and Power in Time of Terror. New Brunswick: Transaction Publishers, 2009. Print.

Dahinden, Urs. Framing: Eine Integrative Theorie der Massenkommunikation. Konstanz: UVK Universitätsverlag, 2006. Print.

Damrosch, David. What Is World Literature? Princeton: Princeton UP, 2003. Print.

Darznik, Jasmin. "The Perils and Seductions of Home: Return Narratives of the Iranian Diaspora.” MELUS 33.2 (2008): 55-71. Print.

---. "Veiled Bestsellers." Rev. of West of Kabul, East of New York: An Afghan American Story, by Tamim Ansary. The Women's Review of Books 24.6 (2007): 6-8. Print.

Davis, Helen. Understanding Stuart Hall. London: Sage, 2004. Print.

Dearing, James W., and Everett M. Rogers. Agenda-Setting. Thousand Oaks: Sage, 1996. Print.

Debrix, François. Tabloid Terror: War, Culture, and Geopolitics. Abingdon: Routledge, 2008. Print.

DeLong-Bas, Natana J. "Women of the Arab Spring: A Driving Force behind Change.” The Daily Star. 2 Nov. 2011. Web. 10 Dec. 2011.

"Demographics." Arab American Institute, n.d. Web. 12 Sept. 2011.

"Dichotomy." Def. 1. Merriam-Webster.com. Merriam-Webster, 2012. Web. 21 Jan. 2012. 
Dijck, José van. Mediated Memories in the Digital Age. Stanford: Stanford UP, 2007. Print.

"Discourse." Def. 5. Merriam-Webster.com. Merriam-Webster, 2011. Web. 10 Oct. 2011.

"Discourse Analysis." Merriam-Webster.com. Merriam-Webster, 2011. Web. 10 Oct. 2011.

Disha, Ilir, James C. Cavendish, and Ryan D. King. "Historical Events and Spaces of Hate: Hate Crimes against Arabs and Muslims in Post-9/11 America." Social Problems 58.1 (2011): 21-46. Print.

Dixon, Travis L. "A Social Cognitive Approach to Studying Racial Stereotyping in the Mass Media." Institute for Social Research, University of Michigan, 2010. Web. 1-7. 12 Sept. 2011.

Donges, Patrick, Martina Leonarz, and Werner A. Meier. "Theorien und Theoretische Perspektiven." Einführung in die Publizistikwissenschaft. 2nd ed. Ed. Heinz Bonfadelli, Otfried Jarren, and Gabriele Siegert. Bern: UTB, 2005. 103-46. Print.

Douglas, Kate. Contesting Childhood: Autobiography, Trauma, and Memory. Piscataway: Rutgers UP, 2010. Print.

Downey, Roger. "Between Two Worlds." Rev. of West of Kabul, East of New York: An Afghan American Story, by Tamim Ansary. Seattle Weekly 15 May 2002. Web. 12 Sept. 2011.

Downing, John D. H. et al., eds. The Sage Handbook of Media Studies. Thousand Oaks: Sage Publications. 2004. Print.

Druckman, James A. "On the Limits of Framing Effects: Who Can Frame?" The Journal of Politics 63.4 (2001): 1041-66. Print.

"Dualism.” Def. 3a. Merriam-Webster.com. Merriam-Webster, 2011. Web. 2 Nov. 2011.

Du Bois, W. E. B. The Souls of Black Folk. 1903. Rockville: Arc Manor, 2008. Print.

Eakin, Paul J. "Breaking Rules: The Consequences of Self-Narration." Biography 24.1 (2001): 113-27. Print.

---. Fictions in Autobiography: Studies in the Art of Self-Invention. Ann Arbor: UMI Dissertation Services, 1998. Print.

---. Foreword. On Autobiography, Ed. Paul John Eakin. Trans. Katherine Leary. Minneapolis: U of Minnesota P, 1989. vii-xxviii. Print.

---. How Our Lives Become Stories: Making Selves. Ithaca: Cornell UP, 1999.

---. Introduction. American Autobiography: Retrospect and Prospect. Ed. Paul J. Eakin. Madison: U of Wisconsin P, 1991. 3-22. Print.

---. Living Autobiographically: How We Create Identity in Narrative. Ithaca: Cornell UP, 2008. Print.

---. "What Are We Reading When We Read Autobiography?" Narrative 12.2 (2004). 121-32. Print. 
Eco, Umberto. The Role of the Reader: Explorations in the Semiotics of Texts. Bloomington: Indiana UP, 1984. Print.

Eder, Richard. "Straddling a Fault Line between Islam and the West." The New York Times 25 Apr. 2002: E.2:39. Print.

Edwards, Holly. "A Million and One Nights: Orientalism in America, 1870-1930."

Noble Dreams, Wicked Pleasures: Orientalism in America, 1870-1930. Ed.

Holly Edwards and Brian T. Allen. Princeton: Princeton UP, 2000. 11-57. Print.

Eide, Elizabeth. "Strategic Essentialism and Ethnification: Hand in Glove?" Nordicom Review 31.2 (2010): 63-78. Print.

Elbow, Peter. "The Uses of Binary Thinking." JAC 13.1 (1993): 51-78. Web. 11 Oct. 2011.

El-Haj, Nadia A. "Edward Said and the Political Present." American Ethnologist 32.4 (2005): 538-55. Print.

Elias, Marilyn. "USA's Muslims Under a Cloud.” USA Today 8 Sept. Web. 2006. 12 Sept. 2011.

Ellis, Carolyn. The Ethnographic I: A Methodological Novel about Autoethnography. Walnut Creek: Alta Mira Press, 2004. Print.

Ender, Evelyne. Architexts of Memory: Literature, Science and Autobiography. Ann Arbor: U of Michigan P, 2005. Print.

Entman, Robert M. "Framing: Toward Clarification of a Fractured Paradigm." Journal of Communication 43 (1993): 51-58. Print.

---. Projections of Power: Framing News, Public Opinion, and U.S. Foreign Policy. Chicago: U of Chicago P, 2004. Print.

Exoo, Calvin F. The Pen and the Sword: Press, War, and Terror in the $21^{\text {st }}$ Century. Thousand Oaks: Sage, 2010. Print.

Eyerman, Ron. The Assassination of Theo Van Gogh: From Social Drama to Cultural Trauma. Durham: Duke UP, 2008. Print.

Fadda-Conrey, Carol N. "Racially White but Culturally Colored: Defining Contemporary Arab-American Literature and Its Transnational Connections." Diss. Purdue University, 2006. Proquest. Web. 10 Sept. 2011.

---. "Arab American Literature in the Ethnic Borderland: Cultural Intersections in Diana Abu-Jaber's Crescent." MELUS 31.4 (2006): 187-205. Print.

Fawcett, James T. "Networks, Linkages, and Migration Systems." International Migration Review xxiii.3 (1989): 671-80. Print.

Fish, Stanley. "Being Interdisciplinary Is so Very Hard to Do." Rpt. Issues in Integrative Studies 9 (1991): 99-112. Print.

Fishel, J. "Must Read." Rev. of Howling in Mesopotamia: An Iraqi-American Memoir, by Haider Ala Hamoudi. Amazon 1 Apr. 2008. Print. 6 Dec. 2011.

Fluck, Winfried. "Theories of American Culture (and the Transnational Turn in American Studies)." REAL - Yearbook of Research in English and American Literature 23 (2007): 59-77. Print. 
Fortner, Robert. "Philosophical Foundations and Distortions in the Quest for Civitas." Key Concepts in Critical Cultural Studies. Ed. Linda Steiner and Clifford Christians. Urbana: U of Illinois P, 2010. 187-98. Print.

Foucault, Michel. Interview by Allessandro Fontana, and Pasquale Pasquino. "Truth and Power." The Foucault Reader. Ed. Paul Rabinow. New York Pantheon Books, 1994. 51-75. Print.

Foucault, Michel. "Theatrum Philosophicum." The Essential Works of Michel Foucault: Aesthetics, Method, and Epistemology. Ed. James D. Faubion. New York: New Press, 1998. 343-68. Print.

Fritsch-El Alaoui, Lalla K. "Arab, Arab-American, American: Hegemonic and Contrapuntal Representations.” Diss. Technische Universität Dresden, 2005. Web. 4 Apr. 2011.

Gamson, William et al. "Media Images and the Social Construction of Reality." Annual Review of Sociology 18 (1992): 373-93. Print.

Gelder, Ken. Popular Fiction: The Logics and Practices of a Literary Field. Million Park: Routledge, 2005. Print.

Ghareeb, Edmund. "Imbalance in the American Media." Split Vision: The Portrayal of Arabs in the American Media. Ed. Edmung Ghareeb. Washington: AmericanArab Affairs Council, 1983. 3-24. Print.

Ghosh, Bobby. “Arab-Americans: Detroit's Unlikely Saviors.” Time Magazine. 13 Nov. 2010. Web. 21 May 2011.

Gibson, Mark, and Alec McHoul. "Interdisciplinarity." A Companion to Cultural Studies. Ed. Toby Miller. Malden: Blackwell, 2001. 23-35. Print.

“Global Conflict Trends.” Center for Systemic Peace, 2012. Web. 8 Dec. 2011.

Goethals, George R. "A Century of Social Psychology: Individuals, Ideas, Investigations." The Sage Handbook of Social Psychology. Ed. Michael A. Hogg and Joel Cooper. London: Sage, 2003. Print.

Goffman, Erwin. Frame Analysis: An Essay on the Organization of Human Experience. New York: Harper and Row, 1974. Print.

---. The Presentation of Self in Everyday Life. Garden City: Doubleday, 1959. Print.

Golley, Nawar Al-Hassan. Introduction. Arab Women's Lives Retold: Exploring Identity Through Writing. Ed. Al-Hassan Golley. Syracuse: Syracuse UP, 2007. xxv-xxxiv. Print.

---. Reading Arab Women's Autobiographies: Shahrazad Tells Her Story. Austin: U of Texas P, 2003. Print.

Graham-Dixon, Andrew. Caravaggio: A Life Sacred and Profane. New York: W. W. Norton, 2010. Print.

Gray, Ann. "Audience and Reception Research in Retrospect: The Trouble with Audiences." Rethinking the Media Audience: The New Agenda. Ed. Pertti Alasuutari. London: Sage, 1999. 22-37. Print.

Greco, Albert N., Clara E. Rodriguez, and Robert M.Wharton. The Culture and Commerce of Publishing in the $21^{\text {st }}$ Century. Stanford: Stanford UP, 2007. Print. 
Grey, Stephen. Into the Viper's Nest: The First Pivotal Battle of the Afghan War. Minneapolis: Zenith Press, 2010. Print.

Guarnizo, Luis Eduardo, and Michael Peter Smith. "The Locations of Transnationalism.“ Transnationalism from Below. Ed. Michael Peter Smith and Luis Eduardo Guarnizo. New Brunswick: Transaction Papers, 1998. 3-31. Print.

Guest, Peter. "Arab Spring: EU Extends Sanctions As Pressure Builds On Syrian President." Huffington Post. 14 Nov. 2011. Web. 16 Nov. 2011.

Guindi, Fadwa E. "Veiling Resistance." Feminist Postcolonial Theory: A Reader. Ed. Reina Lewis. Edinburgh: Edinburgh UP, 2003. 586-609. Print.

Hackett, Robert A., and Yuezhi Zhao. "Media Globalization, Media Democratization: Challenges, Issues, and Paradoxes." Democratizing Global Media: One World, Many Struggles. Ed. Hackett and Zhao. Oxford: Rowman \& Littlefield Publishers, 2005. 1-33. Print.

Haddad, Yvonne Y. "Maintaining the Faith of the Fathers: Dilemmas of Religious Identity in the Christian and Muslim Arab-American Community." The Development of Arab-American Identity. Ed. Ernest N. McCarus. Ann Arbor: U of Michigan P, 1994. 61-84. Print.

---, Jane I. Smith, and Kathleen M. Moore. Muslim Women in America: The Challenge of Islamic Identity Today. New York: Oxford UP, 2006. Print.

Haldrup, Michael, Lasse Koefoed, and Kirsten Simonsen. "Practical Orientalism: Bodies, Everyday Life and the Construction of Otherness." Geografiska Annaler. Series B, Human Geography 88.2 (2006): 173-84. Print.

Hall, Stuart. "Encoding/Decoding." Media and Cultural Studies: Keyworks. Ed. Meenakshi Gigi Durham and Douglas M. Kellner. Malden: Blackwell, 2006. 163-78. Print.

---. "New Ethnicities." Stuart Hall: Critical Dialogues in Cultural Studies. Ed. David Morley and Kuan-Hsing Chen. New York: Routledge, 1996. 442-51. Print.

Hamid, Shadi. "Between Orientalism and Postmodernism: The Changing Nature of Western Feminist Thought towards the Middle East." HAWWA - Journal of Women of the Middle East and the Islamic World 4.1 (2006): 76-92. Print.

Hamilton, Marsha J. "The Arab Woman in U.S. Popular Culture: Sex and Stereotype." Food for Our Grandmothers: Writings by Arab-American and ArabCanadian Feminists. Ed. Joanna Kadi. Boston: South End Press, 1994. 173-80. Print.

Hamoudi, Haider Ala. Home page. University of Pittsburgh. Web. 10 Oct. 2011.

---. Howling in Mesopotamia: An Iraqi-American Memoir. New York: Beaufort Books, 2008. Print.

---. "Rent Seeking and Legal and Economic Malaise in Iraq and the Middle East." Weblog Entry. Islamic Law in Our Times. 31 Aug. 2011. Web. 12 Sept. 2011.

---. “A Shii's Lament." Weblog Entry. Islamic Law in Our Times. 6 Dec. 2011. Web. 12 Sept. 2011. 
Hanania, Ray. Rev. of Howling in Mesopotamia: An Iraqi-American Memoir, by Haider Ala Hamoudi. Ibookreviews. 19 Mar. 2008. Web. 2 Dec. 2011.

Haney-López, Ian. White by Law: The Legal Construction of Race. New York: New York UP, 2006. Print.

Hart, F. Elizabeth. "The Epistemology of Cognitive Literary Studies." Philosophy and Literature 23 (2001). 314-34. Print.

Hartsock, John C. A History of American Literary Journalism: The Emergence of a Modern Narrative Form. Hunt Valley: Sheridan Books, 2000. Print.

Hasan, Asma G. "American Muslim Women: Between Two Worlds." Muslims in America. Ed. Allen Verbrugge. Detroit: Greenhaven Press, 2005. 71-78. Print.

Hasan, Mahmudul. "The Orientalization of Gender." AJISS - The American Journal of Muslim Social Sciences 22.4 (2005): 26-56. Print.

Hassan, Salah D., and Marcy J. Knopf-Newman. Introduction. MELUS 31.4 (2006): 3-13. Print.

Hassan, Waïl S. "Arab-American Autobiography and the Reinvention of Identity: Two Egyptian Negotiations." Alif: Journal of Comparative Poetics 22 (2002): 7-35. Print.

---. Immigrant Narratives: Orientalism and Cultural Translation in Arab American and Arab British Literature. Oxford: Oxford UP, 2011. Print.

Hatem, Mervat F. "The Invisible American Half: Arab American Hybridity and Feminist Discourses in the 1990s." Talking Visions: Multicultural Feminism in a Transnational Age. Ed. Ella Shohat. Cambridge: MIT Press 1998. 369-90. Print.

Heffernan, Valerie. Provocation from the Periphery: Robert Walser Re-Examined. Würzburg: Königshausen und Neumann, 2007. Print.

Hewstone, Miles. "Contact and Categorization: Social Psychological Interventions to Change Intergroup Relations." Stereotypes and Stereotyping. Ed. C. Neil Macrae, Charles Stangor, and Miles Hewstone. New York: Guilford Press, 1996. 323-68. Print.

Hilfer, Tony. The New Hegemony in Literary Studies: Contradictions in Theory. Evanston: Northwestern UP, 2003. Print.

Hilton, Isabel. "Behind the Veil: Two Afghan Women Tell of Life under the Taliban, and an Afghan Man Recalls Life before." Rev. of West of Kabul, East of New York: An Afghan American Story, by Tamim Ansary. New York Time Book Review 28 Apr. 2002: 12-13. Print.

Hinz, Evelyn J. "What Is Multiculturalism? A 'Cognitive' Introduction.” Mosaic 29.3 (1996). Proquest. Web. 4 Sept. 2011.

Hollinger, David A. Postethnic America: Beyond Multiculturalism. New York: BasicBooks, 1995. Print.

Hopkins, Nicholas S., and Saad E. Ibrahim. Arab Society: Class, Gender, Power, and Development. 3rd ed. Cairo: American U in Cairo P, 1997. Print. 
Hornung, Alfred. "Out of Place: Extraterritorial Existence and Autobiography." ZAA - A Quarterly of Language, Literature and Culture 52.4 (2004): 367-77. Print.

Hospers, John. An Introduction to Philosophical Analysis. 3rd ed. London: Routledge, 1990. Print.

"Howling in Mesopotamia, Front Cover." Beaufort Books. Web. 21 Jan. 2012.

Huddart, David Paul. Postcolonial Theory and Autobiography. Oxford: Routledge, 2007. Print.

Huggan, Graham. The Postcolonial Exotic: Marketing the Margins. London: Routledge, 2001. Print.

Huntington, Samuel P. The Clash of Civilizations and the Remaking of World Order. New York: Simon and Schuster, 1996. Print.

Hutcheson, Susan. "A Great Way to Understand What's Really Going on." Rev. of Howling in Mesopotamia: An Iraqi-American Memoir, by Haider Ala Hamoudi. Amazon 31 Mar. 2008. Web. 6 Dec. 2011.

Inglehart, Ronald. "Evolutionary Modernization and Culture Change." Inaugural Lecture. University of Michigan. Rackham Amphitheater, Ann Arbor. 24 Jan. 2012.

---. Modernization and Postmodernization: Cultural, Economic and Political Change in 43 Societies. Princeton: Princeton UP, 1997. Print.

"Interdisciplinarity.” Merriam-Webster.com. Merriam-Webster, 2011. Web. 10 Oct. 2011.

Iser, Wolfgang. Prospecting: From Reader Response to Literary Anthropology. Baltimore: Johns Hopkins UP, 1989. Print.

Iyengar, Shanto, Adam Simon. "News Coverage of the Gulf Crisis and Public Opinion." Taken by the Storm: The Media, Public Opinion, and U.S. Foreign Policy in the Gulf War. Ed. W. Lance Bennett and David L. Paletz. Chicago: U of Chicago P, 1994. 167-85. Print.

Jackson, Mary Robb. "Bin Laden Photos to Be Kept Sealed. CBS Pittsburgh 4 May 2011. Print. 10 Dec. 2011.

Jacobson, Matthew F. Rev. of Post-Orientalism, by Hamid Dabashi. American Quarterly 54.2 (2002): 307-15. Print.

Jamal, Amaney A., and Nadine C. Naber, eds. Race and Arab Americans before and after 9/11: From Invisible Citizens to Visible Subjects. Syracuse: Syracuse UP, 2008. Print.

Jasperson, Amy E., and Mansour O. El-Kikhia. "CNN and Al Jazeera's Media Coverage of America's War in Afghanistan." Norris, Kern, and Just 113-32. Print.

Jensen, Joli. "Popular Culture: Asking the Right Questions" Key Concepts in Critical Cultural Studies. Ed. Linda Steiner and Clifford Christians. Urbana: U of Illinois P, 2010. 88-102. Print. 
Johnson-Cartee, Karen S. News Narratives and News Framing: Constructing Political Reality. Lanham: Rowman and Littlefield, 2005. Print.

Johnston, Alastair Iain. "Treating International Institutions as Social Environments. International Studies Quarterly 45.4 (2001). 487-515. Print.

Joseph, Suad. "Against the Grain of the Nation - The Arab-." Suleiman, ed. 257-71. Print.

Kahf, Mohja. E-Mails from Scheherazad. Gainesville: UP of Florida, 2003. Print. Khadduri, Majid, and Edmund Ghareeb. War in the Gulf, 1990-91: The IraqKuwait Conflict and Its Implications. New York: Oxford UP, 1997. Print.

Kaldas, Pauline. “Quote.” Saudi Aramco World, n.d. Web. 22 Sept. 2011.

---. Home page. Web. 18 Sept. 2011.

---. Letters from Cairo. Syracuse: Syracuse UP, 2007. Print.

---. "To Walk Cautiously in the World." The Roanoke Times 15 May 2011. Web. 24 Aug. 2011.

Karman, Tawakkul. "Women in the Arab Spring." University of Michigan. Rackham Auditorium, Ann Arbor. 14 Nov. 2011.

Kayyali, Randa A. The Arab Americans. Westport, CT: Greenwood Press, 2006. Print.

Kellner, Douglas. "Cultural Studies and Philosophy: An Intervention." A Companion to Cultural Studies. Ed. Toby Miller. Malden: Blackwell, 2001. 139-53. Print.

Kern, Montague, Marion Just, and Pippa Norris. "The Lessons of Framing Terrorism." Norris, Kern, and Just 281-302. Print.

Khair, Tabish. "Re-Orientalisms: Meditations on Exoticism and Transcendence, Otherness and the Self." Re-Orientalism and South Asian Identity Politics: The Oriental Other Within. Ed. Lisa Lau and Cristina Mendes. New York: Routledge, 2011. 144-58. Print.

Khalid, Asma. "Lifting The Veil: Muslim Women Explain Their Choice." NPR 21 Apr. 2011. Web. 12 Nov. 2011.

Khan, Shahnaz. "Reconfiguring the Native Informant: Positionality in the Global Age." Journal of Women in Culture and Society 30.4 (2005): 2017-35. Print.

Kindinger, Evangelia. “'Only Stones and Stories Remain': Greek American (Travel) Writing about Greece." COPAS 12 (2011). Web. 10 Nov. 2011.

knotheadusc. “One Man's Iraqi Heritage Meets His American Upbringing in Post Saddam Iraq." Rev. of Howling in Mesopotamia: An Iraqi-American Memoir, by Haider Ala Hamoudi. Epinions 29 May 2008. Web. 10 Sept. 2011.

Kramer, Martin. Ivory Towers on Sand The Failure of Middle Eastern Studies in America. Washington: The Washington Institute for Near Eastern Policy, 2001. Web. 12 Nov. 2011.

Kuerbis, Lisa Renee. "FW: Question: Pauline Kaldas - Letters from Cairo.” E-mail to Silke Schmidt. 26 Sept. 2011. 
Kuhn, Thomas A. The Structure of Scientific Revolutions. 3rd ed. Chicago: U of Chicago P, 1996. Print.

Kunczik, Michael, and Astrid Zipfel. Publizistik. 2nd ed. Köln: Böhlau, 2005. Print. Lakoff, George, and Mark Johnson. Philosophy in the Flesh: The Embodied Mind and Its Challenge to Western Thought. New York: Basic Books, 1999. Print.

Lambert, Miriam U. "American Muslim Women Can Be Both Devout and Liberated." Muslims in America. Ed. Allen Verbrugge. Detroit: Greenhaven Press, 2005. 91-95. Print.

Lau, Lisa. "Re-Orientalism: The Perpetration and Development of Orientalism by Orientals." Modern Asian Studies 43.2 (2009): 571-90. Print.

---, and Ana Cristina Mendes. "Introducing Re-Orientalism: A New Manifestation of Orientalism. Re-Orientalism and South Asian Identity Politics: The Oriental Other within. Ed. Lau and Mendes. New York: Routledge, 2011. 1-14. Print.

Lederhandler, Marty. "Iconic Images of 9/11." Omaha World Herold 11 Sept. 2001. Web. 12 Nov. 2011.

Leitch, Vincent B. Cultural Criticism, Literary Theory, Poststructuralism. New York: Columbia UP, 1992. Print.

Lejeune, Philippe. "The Autobiographical Pact.” On Autobiography, Ed. Paul John Eakin. Trans. Katherine Leary. Minneapolis: U of Minnesota P, 1989. 3-30. Print.

---, Annette Tomarken, and Edward Tomarken. "Autobiography in the Third Person.” New Literary History 9.1 (1977): 27-50. Print.

Lennon, Paul. Allusions in the Press: An Applied Linguistic Study. Berlin: Walter de Gruyter, 2004. Print.

Leonard, Karen I. Muslims in the United States: The State of Research. New York: Russell Sage Foundation, 2003. Print.

"Letters from Cairo, Back Cover." Personal photograph by author. 4 Feb. 2012.

"Letters from Cairo, Front Cover." Syracuse UP. Web. 2 Feb. 2012.

Lewis, Justin. "The Meaning of Things: Audiences, Ambiguity, and Power." Viewing, Reading, Listening: Audiences and Cultural Reception. Ed. Jon Cruz. Boulder: Westview Press, 1994. 19-32. Print.

--- et al. Shoot First and Ask Questions Later: Media Coverage of the 2003 Iraq War. New York: Peter Lang, 2006. Print.

Lindemann Nelson, Hilde. Damaged Identities, Narrative Repair. Ithaca, NY: Cornell UP, 2001. Print.

Little, Douglas. American Orientalism: The United States and the Middle East since 1945. Chapel Hill: U of North Carolina P, 2008. Print.

Littrell, Dennis. "Splendid Memoir - Honest, Charming, Intelligent and Real." Rev. of Howling in Mesopotamia: An Iraqi-American Memoir, by Haider Ala Hamoudi. Amazon 3 Apr. 2008. Web. 6 Dec. 2011.

Logan, Robert K. Understanding New Media: Extending Marshall McLuhan. New York: Peter Lang, 2010. Print. 
Lyon, David. "Airports as Data Filters: Converging Surveillance Systems after September 11th." Information, Communication and Ethics in Society 1 (2003): 13-20. Print.

Lucie, Sarah. "Re: Question: Haider Ala Hamoudi - Howling in Mesopotamia.” Email to Silke Schmidt. 29 Sept. 2011.

Ludescher, Tanyss. "From Nostalgia to Critique: An Overview of Arab American Literature." MELUS 31.4 (2006): 93-114. Print.

Maira, Sunaina. "Belly Dancing: Arab-Face, Orientalist Feminism, and U.S. Empire." American Quarterly 60.2 (2008): 317-345. Print.

---, and Magid Shihade. "Meeting Asian/Arab American Studies: Thinking Race, Empire, and Zionism in the U.S." Journal of Asian American Studies 9.2 (2006): 117-40. Print.

Majaj, Lisa S. "Arab-American Ethnicity: Locations, Coalitions and Cultural Negotiations." Suleiman, ed. 320-26. Print.

---. "Arab-American Literature Today." America and the Orient. Ed. Heike Schäfer. Heidelberg: Winter, 2006. 125-51. Print.

---. "Arab-American Literature: Origins and Developments." American Studies Journal 52 (2008). Web. 12 Aug. 2009.

---. "Arab-Americans and the Meanings of Race." Postcolonial Theory and the United States: Race, Ethnicity, and Literature. Ed. Amritjit Singh and Peter Schmidt. Jackson: UP, 2000. 320-37. Print.

---. "Arab-American Ethnicity: Locations, Coalitions and Cultural Negotiations." Suleiman, ed. 320-26. Print.

---. "Boundaries: Arab/American." Food for Our Grandmothers: Writings by Arab American and Arab Canadian Feminists. Ed. Joanna Kadi. Boston: South End Press, 1994. 65-84. Print.

---. "Geographies of Light: Poetry Reading and Discussion.” Department of American Culture. U of Michigan. Haven Hall, Ann Arbor, 7 Nov. 2011.

Man, Paul de. “Autobiography as De-Facement." MLN 94.5 (1979): 919-30. Print.

Manneh, Suzanne. "Arabs Organize to Get Counted in Census." New America Media 11 Mar. Web. 2010. 6 Nov. 2011.

“'Man Seeks God,' Finds Wayne Of Staten Island." NPR Morning Edition. 5 Dec. 2011. Web. 6 Dec. 2011.

Marcus, George E. "The Unbalanced Reciprocity between Cultural Studies and Anthropology." A Companion to Cultural Studies. Ed. Toby Miller. Malden: Blackwell, 2001. 169-87. Print.

Mardorossian, Carine. "Danticat and Caribbean Women Writers." Edwidge Danticat: A Reader's Guide. Ed. Martin Munro. Charlottesville: U of Virginia P. 2010. 39-51. Print.

Marrouchi, Mustapha. "Counternarratives, Recoveries, Refusals.” Boundary 225.2 (1998): 205-57. Print.

---. Edward Said at the Limits. Albany: State U of New York P, 2004. Print. 
Maass, Peter. "The Toppling: How the Media Inflated a Minor Moment in a Long War." The New Yorker 10 Jan. 10, 2011. Web. 10 Oct. 2011.

"Mass Medium." Merriam-Webster.com. Merriam-Webster, 2011. Web. 8 Oct. 2011.

McBride, S. "Quick and Fun Read on a Weighty Subject." Rev. of Howling in Mesopotamia: An Iraqi-American Memoir, by Haider Ala Hamoudi. Amazon 22 Oct. 2011. Web. 6 Dec. 2011.

McCombs, Maxwell. Setting the Agenda: The Mass Media and Public Opinion. Cambridge: Polity Press, 2004. Print.

McKinnon, Daniel. "Good Iraqi Memoir." Rev. of Howling in Mesopotamia: An Iraqi-American Memoir, by Haider Ala Hamoudi. Amazon 19 May 2008. Web. 6 Dec. 2011.

McLuhan, Marshall, and Quentin Fiore. The Medium Is the Massage. London: Penguin, 1967. Print.

McMillen, Stuart. "Amusing Ourselves to Death.” Comic. Recombinant Records 24 May 2009. Web. 11 Nov. 2011.

McQuail, Denis. McQuail's Mass Communication Theory. 5th ed. London: Sage Publications, 2005. Print.

Mearsheimer, John J., and Stephen M. Walt. The Israel Lobby and U.S. Foreign Policy. New York: Farrar, Straus, and Giroux, 2007. Print.

"Media Landscape: Egypt." European Journalism Centre 8 Nov. 2010. Web. 10 Oct. 2011.

"Mediate." Def. 2a. Merriam-Webster.com. Merriam-Webster, 2011. Web. 8 Oct. 2011.

"Mediation.” Merriam-Webster.com. Merriam-Webster, 2011. Web. 10 Oct. 2011.

"Medium." Def. 2a. Merriam-Webster.com. Merriam-Webster, 2011. Web. 10 Oct. 2011.

Mehta, Brinda J. Rituals of Memory: In Contemporary Arab Women's Writing. Syracuse: Syracuse UP, 2007. Print.

Merskin, Debra. "The Construction of Arabs as Enemies: Post-September 11 Discourse of George W. Bush.” Mass Communication and Society 7.2 (2004): 15775. Print.

Miall, David S. Literary Reading: Empirical and Theoretical Studies. New York: Lang, 2006. Print.

Mignolo, Walter D. Local Histories - Global Designs: Coloniality, Subaltern Knowledges, and Border Thinking. Princeton: Princeton UP, 2000. Print.

Moallem, Minoo. "Globalization and Gender.” Signs 26.4 (2001): 1265-68. Print.

Montopoli, Brian. "Obama Announces End of Iraq War, Troops to Return Home by Year End.” CBS News 21 Oct. Web. 2011. 12 Nov. 2011.

---. "Poll: Most Know Those with Anti-Muslim Feeling." Political Hotsheet. CBS News 15 Sept. 2010. Web. 12 Sept. 2011. 
Moore-Gilbert, Bart. Postcolonial Life-Writing: Culture, Politics and SelfRepresentation. London: Routledge, 2009. Print.

Morley, David. "Theoretical Orthodoxies: Textualism, Constructivism, and 'the New Ethnography' in Cultural Studies." Cultural Studies in Question. Ed. M. Ferguson and P. Golding. London: Sage. 1997. 121-37. Print.

Morton, Stephen. Gayatri Spivak: Ethics, Subalternity and the Critique of Postcolonial Reason. Cambridge: Polity Press, 2007. Print.

---. "Poststructuralist Formulations." The Routledge Companion to Postcolonial Studies. Ed. John McLeod. Oxfordshire: Routledge, 2007. 161-73. Print.

Naber, Nadine C. Introduction: Arab Americans and U.S. Racial Formations. Jamal and Naber 1-45. Print.

---. “Look, Mohammed the Terrorist Is Coming!": Cultural Racism, Nation-Based Racism, and the Intersectionality of Oppressions after 9/11." Jamal and Naber 267-304. Print.

---. “Arab San Francisco: On Gender, Cultural Citizenship, and Belonging.” Diss. U of California, Davis, 2002. Web. 10 Aug. 2011.

---. "De-Orientalizing Pedagogy.” Jadaliyya 2 May 2011. Web. 30 Sept. 2011.

---. "New Texts Out Now: Nadine Naber, 'Arab America: Gender, Cultural Politics, and Activism."” Interview. Jadaliyya 24 Aug. 2011. Web. 3 Oct. 2011.

Nacos, Brigitte L., and Oscar Torres-Reyna. "Framing Muslim-Americans before and after 9/11." Norris, Kern, and Just 133-57. Print.

Nafisi, Azar. Home page. Web. 22 Jan. 2012.

Nazemroaya, Mahdi Darius. "Plans for Redrawing the Middle East: The Project for a 'New Middle East'." Center for Research on Globalization 18 Nov. Web. 2006.

Nededog, Jethro. "TLC's 'All-American Muslim': More Educational than the Cast Will Admit." The Hollywood Reporter 29 July 2011. Web. 12 Dec. 2011.

Neisser, Ulric. "Self-Narratives: True and False." The Remembering Self: Construction and Accuracy in the Self-Narrative. Ed. Ulric Neisser and Robyn Fivush. Cambridge: Cambridge UP, 1994. 1-18. Print.

Nichols, John. Rev. of West of Kabul, East of New York: An Afghan American Story, by Tamim Ansary." Capital Times, 2002. Web. 12 Sept. 2011.

Nieuwkerk, Karin van. "Changing Images and Shifting Identities: Female Performers in Egypt." Moving History: A Dance History Reader. Ed. Ann Dils. Middletown: Wesleyan UP, 2001. 136-43. Print.

Ning, Wang. "Orientalism versus Occidentalism?" New Literary History 28.1 (1997): 57-67. Print.

Norris, Pippa, Montague Kern, and Marion Just, eds. Framing Terrorism: The News Media, the Government and the Public. New York: Routledge, 2003. Print.

---, Montague Kern, and Marion Just. Introduction: Framing Terrorism. Norris, Kern, and Just 3-23. Print. 
---, and Ronald Inglehart. "Public Opinion among Muslims and the West." Norris, Kern, and Just 203-28. Print.

"NPPA Code of Ethics." National Press Photographers Association, n.d. Web. 10.

Opp, K.-D. "Norms." International Encyclopedia of the Social and Behavioral

Sciences. Vol. 16. Ed. Neil J. Smelser and Paul B. Baltes. Oxford: Elsevier, 2001. 10714-20. Print.

Orfalea, Gregory. Angeleno Days: An Arab American Writer on Family, Place, and Politics. Tuscon: U of Arizona P, 2009. Print.

"Oriental Dancing, the Belly Dance." N.d. Web. 22 Feb. 2012.

Packer, George. The Assassins' Gate: America in Iraq. New York: Farrar, Straus, Giroux, 2005. Print.

Padley, Steve. Key Concepts in Contemporary Literature. Houndmills: Palgrave Macmillan, 2006. Print.

Palmer, A. "The Arab Image in Newspaper Political Cartoons." The US Media and the Middle East. Ed. Yahya Kamalipour. Westport, CT: Greenwood Press, 13950. Print.

Panagopoulos, Costas. "The Polls - Trends: Arab and Muslim Americans and Islam in the Aftermath of 9/11." Public Opinion Quarterly 70.4 (2006): 608-24. Print.

Parker, David: "Inhabiting Multiple Worlds: Auto/Biography in an (Anti-)Global Age.” Biography 28.1 (2005): v-xv. Print.

Paulson, William. "Literature, Complexity, Interdisciplinarity." Chaos and Order: Complex Dynamics in Literature and Science. Ed. Ann Katherine Hayles. Chicago: U of Chicago P. 37-53. Print.

Pax, Salam. The Baghdad Blog. London: Atlantic Books/The Guardian, 2003.

Payne, James Robert. Introduction. Multicultural Autobiography: American Lives.

Ed. James Robert Payne. Knoxville: U of Tennessee P, 1992. xi-xxix. Print.

Perrett, Roy W. "Autobiography and Self-Deception: Conjoining Philosophy, Literature, and Cognitive Psychology.” Mosaic 29. 4 (1996). Web. 14 Oct. 2010.

Popper, Karl R. Truth, Rationality, and the Growth of Scientific Knowledge. Frankfurt: Vittorio Klostermann, 1979. Print.

Postman, Neil. Amusing Ourselves to Death: Public Discourse in the Age of Show Business. New York: Penguin, 1985. Print.

Powell, Mark Allan. What Is Narrative Criticism? Minneapolis: Augsburg Fortress, 1990. Print.

"Profile: Ahmed Chalabi." BBC News 3 Oct. 2002. 10 Dec. $2011<$ http:// news.bbc.co.uk/2/hi/not_in_website/syndication/monitoring/media_reports/229 1649.stm>.

Pulcini, Theodore. "Trends in Research on Arab Americans." Journal of American Ethnic History 12.4 (1993). 27-60. Print.

Rajagopal, Arvind. "A Nation and Its Immigration: The USA after September 11." Media and Cultural Theory. Ed. James Curran and David Morley. London: Routledge, 2006. 75-85. Print. 
Rasmussen, Anne. "'An Evening in the Orient': The Middle Eastern Nightclub in America." Belly Dance: Orientalism, Transnationalism, and Harem Fantasy. Ed. Anthony Shay and Barbara Sellers-Young. Costa Mesa: Mazda Publishers, 2005. 172-206. Print.

"To Read or Not To Read A Question of National Consequence." Research Report \#47. National Endowment for the Arts. Washington: National Endowment for the Arts, 2007. Print.

"Report on Hate Crimes and Discrimination against Arab Americans." 2003-2007. Ed. Hussein Ibish. American-Arab Anti-Discrimination Committee Research Institute, 2008. Web. 2 Dec. 2011.

Rev. of America in an Arab Mirror: Images of America in Arabic Travel Literature, 1668 to 9/11 and Beyond, ed. by Kamal Abdel-Malek and Mouna El Kahla. Palgrave Macmillan. Mar. 2011. Web. 20 Nov. 2011.

Rev. of Howling in Mesopotamia: An Iraqi-American Memoir, by Haider Ala Hamoudi. Beaufort Books, n.d. Web. 12 Nov. 2011.

Rev. of Howling in Mesopotamia: An Iraqi-American Memoir, by Haider Ala Hamoudi. Nonfiction review. Publishers Weekly 31 Mar. 2008. Web. 6 Dec. 2011.

Reynolds, Dwight F., ed. Interpreting the Self: Autobiography in the Arabic Literary Tradition. Berkeley: U of California P, 2001. Print.

Rezsohazy, Rudolf. "Values, Sociology of." International Encyclopedia of the Social and Behavioral Sciences. Vol. 24. Ed. Neil J. Smelser and Paul B. Baltes. Oxford: Elsevier, 2001. 16153-58. Print.

Rotella, Mark. Rev. of West of Kabul, East of New York: An Afghan American Story, by Tamim Ansary. Publishers Weekly 249.12 (2002): 54. Print.

Rowan, Katherine E. "Effective Explanation of Uncertain and Complex Science." Communicating Uncertainty: Media Coverage of New and Controversial Science. Ed. Sharon M. Friedman, Sharon Dunwoody, and Carol L. Rogers. New York: IFA Press, 1999. 201-23. Print.

Ruigrok, Nel, and Wouter van Atteveldt. "Global Angling with a Local Angle: How U.S., British, and Dutch Newspapers Frame Global and Local Terrorist Attacks." The Harvard International Journal of Press/Politics 12.1 (2007): 68-90. Print.

Ruskola, Teema. "Legal Orientalism.” Michigan Law Review 101.1 (2002): 179234. Print.

Rustum, Mikhail Asad. "A Stranger in the West: The Trip of Mikhail Asad Rustum to America, 1885-1894." Trans. Kamal Abdel-Malek. America in an Arab Mirror: Images of America in Arabic Travel Literature, 1668 to 9/11 and Beyond. 2nd ed. Ed. Kamal Abdel-Malek and Mouna El Kahla. New York: Palgrave Macmillan, 2011. 3-5. Print. 
Rouvalis, Christina. "The Catch 22 of Iraq: Pitt Law Professor's Book Recalls Trying Experiences in 'Mesopotamia'." Pittsburgh Post-Gazette 27 Feb. 2008. Web. 10 Nov. 2011.

Ryan, Michael. "Framing the War Against Terrorism: U.S. Newspaper Editorials and Military Action in Afghanistan." Gazette: The International Journal for Communication Studies 66.5 (2004): 363-82. Print.

Sadowski, Yahya. "The New Orientalism and the Democracy Debate." Middle East Report 183 (1993): 14-21+40. Print.

Said, Edward W. Covering Islam: How the Media and the Experts Determine How We See the Rest of the World. Rev. New York: Vintage Books, 1997. Print.

---. Culture and Imperialism. New York: Vintage, 1994. Print.

---. "Invention, Memory, and Place." Critical Inquiry 26.2 (2000): 175-92. Print.

---. Orientalism. London: Penguin, 2003. Print.

---. Out of Place: A Memoir. New York: Vintage Books, 1999. Print.

---. The Question of Palestine. New York: Vintage Books, 1992. Print.

---. Interview with Jonathan Crary and Phil Mariani. "In the Shadow of the West." 1985. Power, Politics and Culture: Interviews with Edward W. Said. Ed. Gauri Viswanathan. London: Bloomsbury, 2005. 39-52. Print.

---. Interview with Imre Salusinszky. "Literary Theory at the Crossroads of Public Life." Power, Politics, and Culture: Interviews with Edward W. Said. Ed. Gauri Viswanathan. London: Bloomsbury, 2004. 69-93. Print.

---. "Scholars, Media, and the Middle East." Panel Discussion. Lewis et al. 1986. Power, Politics and Culture: Interviews with Edward W. Said. Ed. Gauri Viswanathan. London: Bloomsbury, 2005. 291-312. Print.

---. The World, the Text, and the Critic. Cambridge: Harvard UP, 1983.

Salaita, Steven. "Ethnic Identity and Imperative Patriotism: Arab Americans before and after 9/11." College Literature 32.2 (2005): 146-68. Print.

---. "Sand Niggers, Small Shops, and Uncle Sam: Cultural Negotiation in the Fiction of Joseph Geha and Diana Abu-Jaber." Criticism 43.4 (2001): 423-44.

Salgado, Minoli. "The New Cartographies of Re-Orientalism." The Journal of Commonwealth Literature 46.3 (2011): 199-218. Print.

Saliba, Therese. "Resisting Invisibility: Arab Americans in Academia and Activism." Suleiman, ed. 304-19. Print.

Samhan, Helen Hatab. "By the Numbers." Allied Media Corporation, n.d. Web. 2 Oct. 2011.

Sandikcioglu, Esra. Orientalism: The Ideology behind the Metaphorical Gulf War. Gerhard Mercator University, Duisburg, n.d. Web. 12 Sept. 2010.

Scharber, Cassandra. "Online Book Clubs: Bridges between Old and New Literacies Practices.” Journal of Adolescent \& Adult Literacy 52.5 (2009): 433-37. Print.

Schatz, Thomas, and Alisa Perren. "Hollywood.” Downing et al. 495-516. Print. 
Scheufele, Bertram. Frames - Framing - Framing-Effekte: Theoretische und Methodische Grundlegung des Framing-Ansatzes sowie Empirische Befunde zur Nachrichtenproduktion. Wiesbaden: Westdeutscher Verlag, 2003. Print.

---, and Dietram Scheufele. "Of Spreading Activation, Applicability, and Schemas: Conceptual Distinctions and Their Operational Implications for Measuring Frames and Framing Effects." Doing News Framing Analysis: Empirical and Theoretical Perspectives. Ed. Paul D’Angelo and Jim A. Kuypers. New York: Routledge, 2010. 110-34. Print.

Scheufele, Dietram A. "Framing as a Theory of Media Effects." Journal of Communication 49.1 (1999): 103-22. Print.

Schmidt, Katrin. Die Bedeutung der kulturellen Nähe für den Export US-Amerikanischer TV-Serien nach England, Deutschland und Südkorea. Norderstedt: GRIN Verlag, 2009. Print.

Schmidt, Siegfried J. "Literary Studies from Hermeneutics to Media Culture Studies." Contents of CLCWeb: Comparative Literature and Culture 12.1 (2010). Web. 10 Oct. 2011.

---. "The Logic of Observation: An Introduction to Constructivism." Canadian Review of Comparative Literature/Revue Canadienne de Litterature Comparee 19.3 (1992): 295-311. Print.

Schmidt, Silke. "(Re-)Framing the Arab as Political Project: Scholarly Agency in the Life Writing of Edward Said and Leila Ahmed." Unpublished manuscript, Philipps-Universität Marburg, 2011.

---. "Arabian Dance in the Promised Land: Hyphenating Identity in Contemporary Arab(-)American Women's Literature.” M.A. Johannes Gutenberg U, 2009.

Schneiders, Thorsten G. "Geschichte aus Islamischer Sicht." Rev. of Die Unbekannte Mitte der Welt: Globalgeschichte aus Islamischer Sicht, by Tamim Ansary. Drradio 30 Aug. 2010. Web. 24 Aug. 2011.

Schueller, Malini Johar. "Review: Orientalizing American Studies." American Quarterly 60.2 (2008): 481-89. Print.

Schulz, Volker. A Structuralist-Generative Model of Literary Narrative: The Theory and Practice of Analyzing Fiction. New York: Lang, 2005. Print.

Schweizer, Bernard. Introduction. Rebecca West Today: Contemporary Critical Approaches. Ed. Bernard Schweizer. Newark: U of Delaware P, 2006. 21-40. Print.

Seaman, Donna. Rev. of West of Kabul, East of New York: An Afghan American Story, by Tamim Ansary. The Booklist 98.14 (2002): 1186. Print.

Semetko, Holli A. "Media, Public Opinion, and Political Action." Downing et al. 351-74. Print.

Shaheen, Jack G. Arab and Muslim Stereotyping in American Popular Culture. Washington: Georgetown University, Center for Muslim-Christian Understanding, 1997. Print.

---. The TV Arab. Bowling Green: Bowling Green State U Popular P, 1984. 
Shakir, Evelyn. Bint Arab: Arab and Arab American Women in the United States. Westport, CT: Praeger, 1997. Print.

---. "Mother's Milk: Women in Arab-American Autobiography." MELUS 15.4 (1988): 39-50. Print.

Shereen, Faiza W. "The Diasporic Memoirist as Saidian Itinerant Intellectual: A Reading of Leila Ahmed's A Border Passage." Studies in the Humanities 30.1-2 (2003): 108-30. Print.

Shohat, Ella. Introduction. Talking Visions: Multicultural Feminism in a Transnational Age. Ed. Shohat. Cambridge: MIT Press, 1998. 1-64. Print.

---, and Robert Stam. Unthinking Eurocentrism: Multiculturalism and the Media. 1994. London: Routledge, 2007. Print.

Shryock, Andrew. "The Moral Analogies of Race: Arab American Identity, Color Politics, and the Limits of Racialized Citizenship.” Jamal and Naber 81-113. Print.

Silverman, Scott H. Rev. of West of Kabul, East of New York: An Afghan American Story, by Tamim Ansary." Library Journal 127.7 (2002): 108. Print.

Singh, Amritjit and Peter Schmidt, ed. Postcolonial Theory and the United States: Race, Ethnicity, and Literature. Jackson: UP Mississippi, 2000. Print.

Sirin, Selcuk R., and Michelle Fine. Muslim American Youth: Understanding Hyphenated Identities through Multiple Methods. New York: New York UP, 2008. Print.

Sklair, Leslie. The Transnational Capitalist Class. Oxford: Blackwell, 2001. Print.

Slingerland, Edward G. What Science Offers the Humanities: Integrating Body and Culture. Cambridge: Cambridge UP, 2008. Print.

Smith Rakoff, Joanna. "Out Through the Inbox." The Village Voice 47.14 (2002): 53. Print.

Smith, Sidonie: "Autobiographical Discourse in the Theaters of Politics." Biography 33.1 (2010): v-xxvi. Print.

---. Personal interview. 2 Feb. 2012.

---, and Julia Watson. De/Colonizing the Subject: The Politics of Gender in Women's Autobiography. Minneapolis: U of Minnesota P, 1992. Print.

---, and Julia Watson. Reading Autobiography: A Guide for Interpreting Life Narratives, 2002. Minneapolis: U of Minnesota P, 2010. Print.

---, and Julia Watson. "The Rumpled Bed of Autobiography." Biography 24.1 (2001): 1-14. Print.

Sollors, Werner. Introduction: The Invention of Ethnicity. The Invention of Ethnicity. Ed. Sollors. New York: Oxford University Press, 1991. ix-xx. Print.

Somers, Margaret R. "The Narrative Constitution of Identity: A Relational and Network Approach." Theory and Society 23.5 (1994): 605-49. Print.

Sousa Santos, Boaventura de. Toward a New Legal Common Sense: Law, Globalization, and Emancipation. Edinburgh: Reed Elsevier, 2002. Print. 
Sreberny, A. "Media Imperialism." International Encyclopedia of the Social and Behavioral Sciences. Vol. 14. Ed. Neil J. Smelser and Paul B. Baltes. Oxford: Elsevier, 2001. 9489-94. Print.

Spivak, Gayatri C. “Acting Bits/Identity Talk.” Critical Inquiry 18.4 (1992): 770803. Print.

---. An Interview with Gayatri Chakravorty Spivak. By Sara Danius and Stefan Jonsson. Boundary 220.2 (1993): 24-50. Print.

---. In Other Worlds: Essays in Cultural Politics. New York: Methuen, 1987. Print.

Spivey, Nancy Nelson. The Constructivist Metaphor: Reading, Writing, and the Making of Meaning. San Diego: Academic Press, 1997. Print.

Sprague, Jeb. "Transnational Capitalist Class in the Global Financial Crisis: A Discussion with Leslie Sklair." Globalizations 6.4 (2009): 499-507. Print.

Stark, Werner. The Sociology of Knowledge: Toward a Deeper Understanding of the History of Ideas. 2nd ed. New Brunswick: Transaction Publishers, 1991. Print.

Stein, Rebecca L. "The Ballad of the Sad Café, and the Post/Colonial Question." Postcolonial Studies and Beyond. Ed. Ania Loomba. Durham: Duke UP, 2005. 317-36. Print.

Steinberg, Marc W. "Tilting the Frame: Considerations on Collective Action Framing from a Discursive Turn." Theory and Society 27.6 (1998): 845-72. Print.

Steuter, Erin C. "Understanding the Media/Terrorism Relationship: An Analysis of Ideology and the News in Time Magazine." Political Communication and Persuasion 7 (1990): 257-78. Print.

Stephens, Simon. "Keynote Speech: Writing Black People." German Society for Contemporary Drama, Vienna. 4 Jun. 2009.

"Strategy." Def. 2a, b. Merriam-Webster.com. Merriam-Webster, 2011. Web. 20 Dec. 2011.

Stroumsa, Sarah. "The Beginnings of the Mu'tazila Reconsidered." Jerusalem Studies in Arabic and Islam 13 (1990): 265-93. Print.

Suleiman, Michael W. Introduction: The Arab Immigrant Experience. Suleiman, ed. 1-21. Print.

---, ed. Arabs in America: Building a New Future. Philadelphia: Temple UP, 1999. Print.

Syracuse University Press. Home page. Web. 2 Dec. 2011.

Ta, Lynn M. "Citizens Without Borders: American Identity and the Cultural Politics of Globalization." Diss. University of California, San Diego, 2007. Web. 4 Mar. 2011.

Tankard, James W. "The Empirical Approach to the Study of Media Framing." Framing Public Lives: Perspectives on Media and Our Understanding of the Social World. Ed. Stephen D. Reese, Oscar H. Gandy Jr., and August E. Grant. Mahwah: Lawrence Erlbaum Associates, 2001. 95-105. Print.

Taylor, Charles. Philosophical Arguments. Cambridge: Harvard UP, 1995. Print. 
---. "Two Theories of Modernity." The Hastings Center Report 25.2 (1995): 24-33. Print.

Taylor, Philip M. “'We Know Where You Are’: Psychological Operations Media During Enduring Freedom." War and the Media: Reporting Conflict 24/7. Ed. Daya Kishan Thussu and Des Freedman. London: Sage, 2003. Manchester: Manchester UP, 1992. 101-14. Print.

Tehranian, John. Whitewashed: America's Invisible Middle Eastern Minority. New York: New York UP, 2009. Print.

Tessler, Mark. "Transnational Communication among Arab Americans in Detroit: Dimensions, Determinants, and Attitudinal Consequences." American Studies Journal 52 (2008). Web. 6 June 2010.

“Testimony.” Def. 2a. Merriam-Webster.com. Merriam-Webster, 2011. Web. 8 Oct. 2011.

“Text of Ansary's E-Mail.” CNN. 26 Sept. 2001. Web. 22 Nov. 2011.

Thiel, C. "Normative Aspects of Social and Behavioral Science." International Encyclopedia of the Social and Behavioral Sciences. Vol. 16. Ed. Neil J. Smelser and Paul B. Baltes. Oxford: Elsevier, 2001. 10711-14. Print.

"Timeline: Milestones in Six Decades of Middle East Conflict." Reuters, n.d. Web. 8 Nov. 2011.

Tuastad, Dag. "Neo-Orientalism and the New Barbarism Thesis: Aspects of Symbolic Violence in the Middle East Conflict(s)." Third World Quarterly 24.4 (2003): 591-99. Print.

Tumber, Howard, and Jerry Palmer. Media at War: The Iraq Crisis. London: Sage, 2004. Print.

“Truth.” Def. 3a. Merriam-Webster.com. Merriam-Webster, 2011. Web. 12 Nov. 2011.

upe. Rev. of Howling. "An Honest, Heartfelt Perspective of Iraq from the Ground." Amazon 30 Mar. 2008. Web. 4 Dec. 2011.

Varisco, Daniel Martin. Reading Orientalism: Said and the Unsaid. Seattle: U of Washington P, 2007. Print.

Vinson, Pauline H. "Shahrazadian Gestures in Arab Women's Autobiographies: Political History, Personal Memory, and Oral, Matrilineal Narratives in the Works of Nawal El Saadawi and Leila Ahmed." Feminist Formations 20.1 (2008): 78-98. Print.

Wajahat, Ali. "The Reality of the 'All-American Muslim' Reality TV Show." The Guardian. 17 Nov. 2011. Web. 12 Dec. 2011.

"The War in Iraq Rages on - But the Rebuilding Has Already Begun." Rev. of Howling in Mesopotamia: An Iraqi-American Memoir, by Haider Ala Hamoudi. Midwest Book Review 8 June 2008. Web. 10 Dec. 2011.

Werbner, Pnina. "Global Pathways. Working Class Cosmopolitans and the Creation of Transnational Ethnic Worlds.” Social Anthropology 7.1 (1999): 17-35. Print.

“West of Kabul, Front Cover.” Macmillan. Web. 12 Oct. 2011. 
Whitlock, Gillian. Soft Weapons: Autobiography in Transit. Chicago: U of Chicago P, 2007. Print.

Whitney, D. Charles, Randall S. Sumpter, and Denis McQuail. "News Media Production: Individuals, Organizations, and Institutions.” Downing et al. 393-410. Print.

Wiegand, Krista E. "Islam as an Ethnicity? The Media's Impact on Misperceptions in the West." Islam and the West in the Mass Media: Fragmented Images in a Globalizing World. Ed. Kai Hafez. New York: Hampton P, 2000. 235-271. Print.

Willard-Traub, Margaret K. "Rhetorics of Gender and Ethnicity in Scholarly Memoir: Notes on a Material Genre." College English 65.5 (2003): 511-25.

---. "Scholarly Autobiography: An Alternative Intellectual Practice." Feminist Studies 33.1 (2007): 188-235. Print.

Williams, Raynold. Keywords: A Vocabulary of Culture and Society. Rev. ed. New York: Oxford UP, 1983. Print.

Williams, Rhys H., and Gira Vashi. "Hijab and American Muslim Women: Creating the Space for Autonomous Selves." Sociology of Religion 68.2 (2007) 26987. Print.

Winslow, Donald J. Life-Writing: Biography, Autobiography, and Related Forms. 2nd ed. Honolulu: U of Hawaii P, 1995. Print.

Wöhlert, Romy. "Civilization versus Barbarism: The Images of Arabs and Muslims and the National Self-Concepts in German and U.S. Print Media around 9/11." Diss., Universität Bielefeld, 2007. Web. 3 Apr. 2011.

Wong, Sau-Ling C. "Immigrant Autobiography: Some Questions of Definition and Approach." American Autobiography: Retrospect and Prospect. Ed. Paul J. Eakin. Madison: U of Wisconsin P, 1991. 142-70. Print.

Wrong, N. T. "Israeli David and Arab Goliath." Weblog Entry. N. T. Wrong. 13 Aug. 2008. Web. 10 Nov. 2011.

Yamani, Mai. Introduction. Feminism and Islam: Legal and Literary Perspectives. Ed. Mai Yamani. Rpt. 1996. Reading: Ithaca P, 1997. 1-27. Print.

Yeğenoğlu, Meyda. Colonial Fantasies: Towards a Feminist Reading of Orientalism. Cambridge: Cambridge UP, 1998. Print.

Yeğenoğlu, Meyda. "Veiled Fantasies: Cultural and Sexual Difference in the Discourse of Orientalism." Feminist Postcolonial Theory: A Reader. Ed. Reina Lewis. Edinburgh: Edinburgh UP, 2003. 542-66. Print.

Zepetnek, Steven Tötösy de. "Constructivism and Comparative Cultural Studies." CLCWeb: Comparative Literature and Culture. Purdue University Press. (2002): 1-12. Web. 12 Oct. 2011.

Zogby, James. Arab Voices: What They Are Saying to Us, and Why It Matters. New York: Palgrave Macmillan, 2010. Print.

Zogby, John. The Way We'll Be: The Zogby Report on the Transformation of the American Dream. New York: Random House, 2008. Print. 
